1

FORESTRY IN MINNESOTA

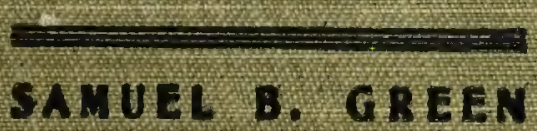




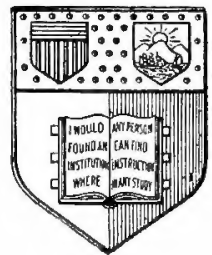

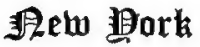

State College of Agriculture

At Cormell amibersity

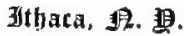

五íbrary 
Forestry in Minnesota.

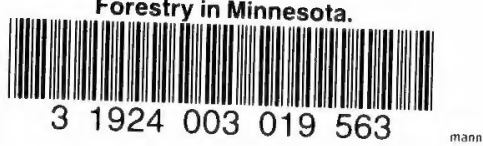




\section{Cornell University Library}

The original of this book is in the Cornell University Library.

There are no known copyright restrictions in the United States on the use of the text. 


\title{
FORESTRY IN MINNESOTA.
}

BY

\author{
SAMUEL B. GREEN, \\ PROFESSOR OF HORTICULTURE AND FORESTRY, \\ THE UNIVERSITY OF MINNESOTA.
}

PUBLISHED BY THE

GEOLOGICAL AND NATURAL HISTORY

SURVEY OF MINNESOTA.

I 902.

ST. PAUL, MINN.:

PIONEER PRESS COMPANY.

I902. 



\section{PREFACE TO FIRST EDITION.}

This book has been prepared especially for the classes in forestry in the School of Agriculture of the University of Minnesota. It is really a compilation of the lectures and mimeographed notes that I have found useful in my experience in teaching the elementary principles of forestry. The word forestry is here used in the broad sense in which it is often used in this section and includes much that, strictly speaking, would come under several allied heads. In the use of botanical names I have followed, so far as possible, those given by Dr. George B. Sudworth in his "Nomenclature of the Arborescent Flora of the United States," which has been adopted as the standard for the Agricultural Colleges and Experiment Stations. Otherwise the Index Kewensis has been followed. But where these names are different from those commonly used by horticulturists in current literature the more familiar term is also generally given in brackets.

I have received many lind suggestions and criticisms irom Dr. Otto Lugger, St. Anthony Park; Hon. L. R. Moyer, Montevideo; and Messrs. John S. Harris, La Crescent; Clarence Wedge, Albert Lea; F. H. Nutter, Minneapolis, and J. M. Underwood, Lake City. Professor Conway McMillan has furnished many specimens for drawings. My assistant, Mr. W. A. Wheeler, has given much careiul attention to the revision of the manuscript and has corrected many errors that would otherwise have crept in. I am especially indebted to all these parties who have aided me in this work, and I wish to extend my sincere thanks for their interest and kindness.

In the preparation of this book I have freely consulted the "Silva of North America" (Prof. C. S. Sargent); "Illustrated 
Flora of the United States" (Britton \& Brown); the publications of the Division of Forestry of the Department of Agriculture: "Bäume und Sträucher des Waldes" (Hempel \& Wilhelm); and Flora von Deutschland, Oesterreich u. d. Schweiz (Prof. Dr. Thome).

S. B. G.

University of Minnesota,

St. Anthony Park, July $29, \quad 1898$. 


\section{PREFACE TO SECOND EDITION.}

The first edition of 10.000 copies of "Forestry in Minnesota" was published by the Minnesota Forestry Association and has been received with much favor. It is now probably used in more than fourteen of the agricultural colleges as their chief text book on this important subject and it is also used in a number of normal and high schools in this and other states, either as a text book or as supplementary reading. The first edition is practically exhausted, but the demand for it continues to increase, and it is this demand, and the fact that it concerns a subject closely related to the development of this state, which has induced the Board of Regents to publish it as a portion of the report of the Geological and Natural History Survey of Minnesota.

This edition covers all the ground reached by the first edition, but it has been improved by the better classification and extension of the matter in Part $I$, and some additions and corrections to Part II. I think it greatly improved for the purposes of a text book. for which it is primarily intended.

Since the publication of the first edition the world of science and especially the state of Minnesota have lost two helpful men in the death of Dr. Otto Lugger and J. S. Harris, each of whom assisted in preparing the first edition of "Forestry in Minnesota." To me this is a personal bereavement, and I extend to their wives and children my most heartfelt sympathy and best wishes.

In this revision I have had the loyal and painstaking help of my assistant, Mr. T. L. Duncan, and the chapter on Forest Mensuration has been almost entirely prepared by him.

The drawings, with few exceptions, have been made under my direction by Miss M. M. Cheney. The half tone illustrations are mostly from photographs taken in the division of Horticulture and Forestry. Figure 32 is from a photograph 
loaned by Professor John Gifford, Figure 9 is from H. B. Ayres, Figure 32 from W. H. Rau. By permission of Houghton, Mifflin \& Co. the typical botanical figures of plates I4, I5, 2I, 22, $23,24,26,31,35,43,45,49,55$ and 63 have been redrawn from the "Silva of North America." The typical botanical figures of plates $1,6,7$, 10, 20 and 25 are redrawn from "Bäume und Sträucher des Waldes." Plate 52 is redrawn from Flora von Deutschland, Oesterreich u. d. Schweiz.

January 30, 1902.

SAMUEL B. GREEN. 


\section{CONTENTS.}

\section{PART I. \\ ELEMENTARY FORESTRY.}

Chapter I. The Tree.

Chapter II. The Forest.

Chapter III. Forest Influences.

Chapter IV. Tree Planting on Prairies.

Chapter V. Forest Regeneration and Treatment.

Chapter VI. Propagation.

Chapter VII. Nursery Practice.

Chapter VIII. Forest Protection.

Chapter IX. Rate of Increase.

Chapter X. Forest Mensuration.

Chapter XI. Forest Problems in Minnesota.

Chapter XII. Wood and its Uses.

Chapter XIII. Durability of Wood.

Chapter XIV. Forest Economics.

\section{PART II.}

\section{TREES OF MINNESOTA.}

Pinacere. Pine Family.

Pines, Larches, Spruces, Hemlock, Douglas Spruce, Firs. Arborvitæ and Junipers.

Juglandacee. Walnut Family.

Walnut, Butternut and Hickories.

Salicacere. Willow Family.

Willows and Poplars.

Betulacce. Birch Fanily.

Birches, Alders, Hornbeam and Blue Beech.

Fagacere. Oak Fanily.

Chestnut and Oaks. 
Clmacce. Elm Fanily.

Elms and Hackberry.

Moracea. Mulberry Family.

Nulberries.

Rosacere. Rose Family.

Wild Crab. Mountain Ashes, Serviceberries, Thorns, Wild Tlum and Wild Cherries.

\section{Leguminose. Pea Family.}

Honey Locust, Coffeetree and Locust.

Aceracca. Maple Family.

Maples and Boxelder.

Hippocastanacce. Buckcye Family:

Horse Chestnut and Ohio Buckeye.

Rhamnacer. Buckthom Family.

Buckthorn.

Tiliacece. Linden Family.

Basswoods.

Elaeagnacee. Oleaster Family.

Russian Olive.

Oleacer, Olive Family.

Ashes.

Catalpa.

Bignonacce. Bignonia Family.

Caprifoliacce. Honcysuckle Family.

Sheepberry.

PART III.

FOREST TREES OF THE UNITED STATES.

\section{GLOSSARY 。}

INDEX. 
PART I.

ELEMENTARY FORESTRY. 


$$
-
$$




\title{
CHAPTER I.
}

\author{
THE TREE.
}

A tree is a woody plant with a single stem more or less branched and taking on what is commonly known as the tree form.

The most evident parts of a tree are roots, stem or trunk, branches, buds, leaves, flowers, fruit and seed.

The Stem, Branches and Roots are made up of inner bark, outer bark, sapwood and heartwood. The outer bark, sap-

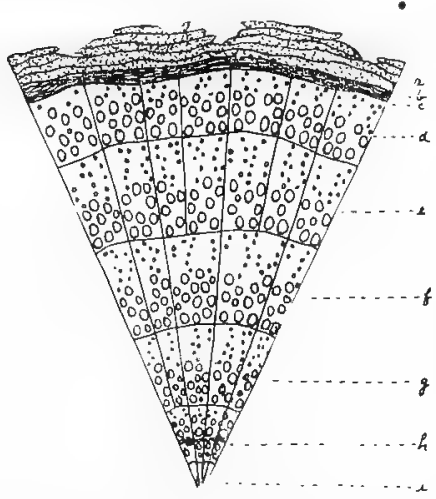

Figure I. Cross-section of Woody Stem-diagram showing $(a)$ outer bark, (b) inner bark or bast, (c) cambium, $(d, e, f, g$ and $h)$ annual rings of wood, and (i) pith. wood and heartwood are made up of concentric circles termed annual rings. During each period of growth two new rings are formed-one on the outside of the sapwood and another on the inside of the outer bark and as we seldom have more than one season of growth each year but one ring is formed on the wood in a year; so that by counting the rings of wood in the stem we can determine very closely the age of trees. In very rare cases we have two periods of growtli in one year, as in I894, when the drouth of midsummer ripened up the wood of the trees by the first of August and the rains of autumn started a new growth, and caused some trees and shrubs to Hower in October, but such occurrences are very uncommon and the extra rings formed 
are readily detected by their being smaller than adjoining rings and less distinctly defined. The age of trees could be told by the rings of the outer bark nearly as well as by those of the wood were it not for the fact that the outer layers of bark fall off as the tree grows older.

In some experiments the bark of rapidly growing branches was peeled back in the spring for a few inches, the wood covcred with tin-foil and the bark replaced. At the end of the season there was found a ring of wood outside of the tin-foil, thus showing where the annual growth of the tree was made.

The Bark covers the whole exterior surface of the trunk, branches and roots and serves as a protection. It is made up of two parts, the outer or corky layer which is dead bark and the inner or live bark. These vary much in appearance and thickness on different kinds of trees. For instance, on the White Birch the corky layer is pure white, very thin and tough, while on our White Pine it is very dark brown and often an inch or more in thicliness and quite brittle.

The Sapwood is the portion of the wood next to the bark. It varies much in thickness in different species and in trees of the same species; the most rapidly grown trees contain the largest amount. It is the most active portion of the wood in the growing tree, and contains considerable plant food and more water than the heartwood.

The Heartwood is the wood in the center of the trunk and is generally distinguished from the sapwood by its more compact structure and darker color, though in some cases it may be lighter colored than the sapwood. It is also harder and more valuable for fuel, shrinks less in drying, and is more duraWe in contact with the soil than the sapwood. There is very little movement of the sap in the heartwood.

The Roots furnish water and nourishment that the plant receives from the soil, but only the young roots have the power of taking up the soil water; the older roots are most useful in holding the tree in place. It is common to classify roots into surface roots and lap roots, depending on their shape and the depth they go in the ground. Some trees have nearly all surface roots, as the Birch and Spruce, others have nearly all tap roots, which often go to a great depth on dry land, as those of the Bur 
Oak, White Oak, Black Walnut and Butternut. Most of our trees have a combination of the two kinds, as the Maple. Hackberry and Ash. Seedling trees of most kinds have a decided tap root when young, but in many species it ceases to grow down ward when a few years old. This is true of the Red and Scarlet Oaks, which often have a tap root extending four feet in depth

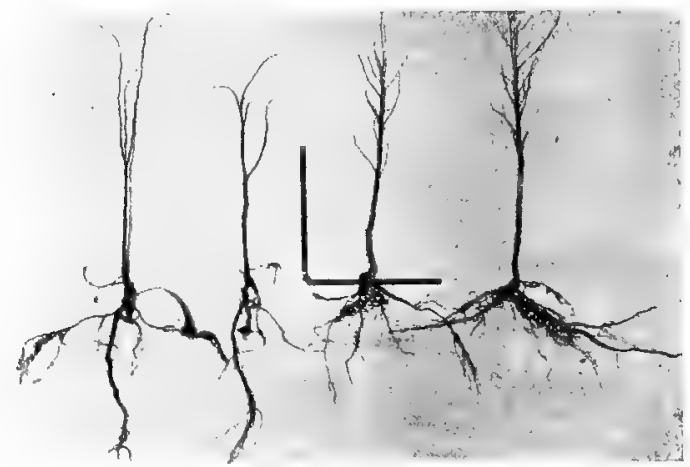

Figure 2. Characteristic Root Fiormation. On the left two Hackberry, on the right two white Birch, each 2-year seedlings from same seed bed. The first with a divided tap root, the second without tap root.

before the tree has attained a corresponding height above ground, but after about five years large lateral roots develop and the growth of the tap root nearly ceases.

Root growth is relatively less to the extent of ground occupied in moist and fertile soil than in dry and poor soil, but the roots are proportionately more branched. In wet seasons the root development is less for a given plant than in dry seasons, because the roots may get their needed food and water from a small area. Nursery trees grown on moist rich land have a more compact root system than those grown on poor land.

At the Minnesota Experiment Station a small Bur Oak growing on dry, gravelly soil had a tap root that was evidently 20 feet long, while on moist fertile clay land in the same section such trees probably seldom have tap roots more than six feet long.

Buds are placed regularly on the young branches and are 
said to be either alternate or opposite. When they occur on the stump or on roots they are not arranged in any regular order. There are two kinds of buds-flower buds, which develop into flowers and fruit; and leaf buds, which develop into leaves and branches. These can generally be distinguished from each other by their shape and size and by cutting through them and noting their construction. Flower buds are generally more liable to injury from climatic changes than leaf buds.

The Leaves of our trees vary much in size and shape. They are simple when compused of but one prece, as the leaves of the Oak, Maple and Birch, and compound when composed of more than one piece, as the leaves of the Locust, Ash and Black Walnut. Leaves are made up of a framework filled in with cellular tissue and covered with a thin skin. This skin has very many small pores in it called stomata, through which the plant takes in carbon dioxide from the air and gives off oxygen and water.

All our trees shed at least a part of their leaves each year. All the broad-leaved trees and the Tamarack shed their entire foliage yearly, while our so-called evergreen trees lose a part of their leaves each year. The length of time leaves remain on this latter class of trees varies from two or three years, in the case of White Pine growing in very severe locations in this section, to perhaps eight years, in the case of Red Cedar favorably located. The time that leaves remain on the branches of evergreens depends to some extent on the location and age of the individual tree.

The following table gives the approximate length of time that laves of conifers remain on trees in Minnesota: 


\section{LENGTH OF 'IIME THAT IEAVES OF CONIFERS REMAIN ON TREES IN MINNHSOTA.}

\begin{tabular}{|c|c|c|}
\hline- & $=$ & $\cdots$ \\
\hline Botanical Name. & Common Name. & Year of Falling. \\
\hline Pinus strobus .................. & White Pine.... & $2 d$ and $3 d$ \\
\hline Pinus flexilis ....... & Western White Pine. & 5 th and 6 th. \\
\hline Pinus resinosa ................... & Norway Pine.... . & 4 th and 5 th. \\
\hline Pinus divaricata .............. & Jack Pine ... & $2 d$ and $3 d$ \\
\hline Pinus ponderosa scopulor um..... & Bull Pine........... & 3 d and 4 th. \\
\hline Pinus sylvestris ................ & Scotch Pine ......... & $3 \mathrm{~d}$. \\
\hline Pinus lavicio austriaca.. & Austrian Pine....... & $4^{\text {th }}$ and 5 th. \\
\hline Plnus monlana pumila........... & Dwarf Pine.......... & sth, 6 th and 7 th. \\
\hline Larix laricina $\ldots \ldots \ldots \ldots \ldots \ldots$ & Tamarack .......... & Ist winter. \\
\hline Lavix europea ..... & European Karch.... & rst winter. \\
\hline Picea canadensis... & White Spruce ... & $4^{\text {th }}$ and $5^{\text {th }}$. \\
\hline Picea mariana ... ............. & Black Spruce.... & 4th and 5th. \\
\hline Picea pungens .................. & Blue Spruce......... & 6 th and 7 the. \\
\hline Picea engelmanni .............. & Engelmann Spruce.. & 5th and 6 th. \\
\hline Picea excelsa ................... & Norway Spruce.. & 5 th. \\
\hline Tsuga canadensis.. & Hemlock $\ldots . . . \ldots$. & $2 \mathrm{~d}$ and $3 \mathrm{~d}$ \\
\hline Pseudotsuga taxifola ............ & Douglas Spruce ...... & 5th. \\
\hline Abies balsamea.................. & Balsam Fir & 5 th. \\
\hline Abies concolor................... & White Fir .......... & sth. \\
\hline Thuja occidentalis ............. & Arborvitæ .. & $4^{\text {th }}$ and $5^{\text {th. }}$ \\
\hline Juniperus virginiana. & Red Cedar........... & $5^{\text {th }}$ and 6 th. \\
\hline Juniperus communis ........... & Dwarf Juniper....... & sth and 6 th. \\
\hline
\end{tabular}

Flowers are parts of the plant especially modified for the reproduction of the plant by seed. Both sexual organs may be located together in the same flower, as those of the Basswood, Mountain Ash and Cherry; or in separate flowers on the same plant, as those of the Birch, Oak and Black Walnut; or they may be separate on entirely different plants, as in the Willow, Poplar, Boxelder and Ash. 
The Fruit, botanically defined, is the seed-containing area, derived from a single flower. As used in nursery practice the term is generally applied to seeds having a fleshy covering or an adjoining fleshy part.

The Seed, botanically defined, is the ripened ovile, but as the term is used in nursery practice it often includes the ovary and other parts that may be attached to it. What is commonly callect the seed of Maple. Ash, Elm, Walnut and Basswood is really the fruit.

Distribution of Seeds. The seeds of plants are distributed in various ways, the most common of which are (I) by means of floats or wings which buoy the seeds up in the air or water, and (2) by animals. The seeds of Ash, Arborvite. Boxelder, Catalpa, Elm, Maple, Pine and Spruce have wings which allow them to be blown great distances by the wind, especially when they break loose from the upper branches of high trees during severe winds. The seeds of the Honey Locust are not shed from the pod until after it has fallen, and as the pod is ten inches or more long and spirally twisted it may be blown long distances on level ground or snow crust. The seeds of the poplars and willows have a cottony fonat attachment which buoys them up in the air. In the case of the Basswood, the parachutelike bract attached to the seed cluster aids in spreading the seeds by carrying them through the air or along the snow crust. The seeds of Mountain Ash, Wild Black Cherry, Hawthorn and others are largely distributed by wild animals which eat the fruit and allow the seeds to pass through the alimentary canal uninjured or carry off the fruit and spit out the seeds. Many seeds or seed vessels have bur-like or sticky coats by which they adhere to animals and are thus carried considerable distances. Very often bodies of water aid in the distribution of seeds, since all that are spread by the agency of the wind and most of those that have fleshy coverings will float on the surface of the water and may in this way be scattered.

Shapes of Trees. Different species of trees naturally develop different shapes. Some, like Spruces, Tamarack and Balsam, have a decided tendency to form a strong stem and to take on a conical form in preference to the development of a crown or head; while others, like the Basswood, Oaks, Maples and Boxelder, develop their crown in preference to their stem. 
The actual shape of trees depends on the space they have to wrow in, on the soil, situation, and on the age of the trees. Where trees have plenty of room to grow, and their natural development is not interfered with, their individual characteristics are most apparent.

\section{TREE GROWTH.}

Assimilation. Plants are made up of various tissues and these are formed of numerous cells. The naterial of which the cells are composed is largely carbon. This carbon is derived from the carbon dioxide of the air which enters into the leaves and under the action of light, air and water is there decomposed; the oxygen is given off and the carbon is retained, and, combined with water obtained from the roots, forms starch, sugar, gum and other plant foods.

This process of food making is called assimilation and can be carried on only in the green parts of the plant, and in these only when exposed to light and air. Hence, foliage, air and light at the top are essential prerequisites for tree growth, and, other conditions being favorable, the greater quantity and bettor development of foliage and the more light this foliage has at its disposal for its work, the more vigorously will the tree grow.

In general, therefore, the growth of wood may be reduced either by the removal of foliage, which reduces the working surface, or by shading, which somewhat checks the activity of the foliage by hindering light action.

Transpiration. The flow of sap in trees is not well understood. In a general way it may be said that the sapwood transmits the water from the roots to the lcaves. where a part enters into the assimilated sap and goes to build up the plant, and the remainder, which is by far the greater part, passes off as vapor. The amount thus transpired varies greatly with the species, age of the tree, amount of foliage at work, amount of light at its sisposil. clinatic conditions and the condition of tree growth The amount oi water transpired is so large in comparison to the amount retained in the tree that while an acre of forest may store in its trees I, OCo pounds of carbon, I5 or 20 pounds of mineral substances and 5.000 pounds of water in a year, it may 
have taken irom the soil and given off to the air from 500,000 to $1,500,000$ pounds of water, or from one-quarter to one-half as much as agricultural crops. It has been estimated that the leaves of deciduous trees transpire one-sixth to one-third as much water as an equal surface of water. Large deciduous trees undoubtedly give off as much as a barrel of water a day in dry summer weather. Coniferous trees transpire much less water than most deciduous trees, frecuently not over one-sixth as much.

Mineral Substances are taken up in small quantities and consist mostly of lime, magnesia and potash. They are carried to the leaves, where they are used (peihaps also on their passage through the tree), with a part of the water, in food preparation. The main part of the mineral substances taken up remains as the water transpires in the leaves and young twigs, and is returned to the soil when the leaves are shed, and when the tree is cut and the brush left to decompose and make humus.

The Soil of Woodlands is Improved from year to year if the leaves and litter are allowed to remain on the ground and fire is kept out, since the mineral matters taken up by the tree are largely returned to the soil in a more soluble form and the amount of humus is increased. For this reason there is little need of alternating woodland crops.

Almost any soil can furnish a sufficient quantity of mineral substances for the production of a crop of trees, provided it is moist and the leaf mould is not removed. Good soils will continue to furnish mineral matter in sufficient quantity, even if a portion of the leaf mould is carried away. If, however, this removal is continued annually for a long period, any but exceedingly fortile soils are likely to become exhausted, just as land on which field crops are grown cannot produce crops forever without manuring.

The Yearly Round of $\mathbf{L}$ ife in a Tree. In the spring the tree starts into growth and feeds on the plant food stored up the preceding year; the leaves unfold and commence furnishing plant food. These two sources of food push the wrowth along very rapidly in the spring and early summer. By the first of July the fond stored up the previous season is exhausted in many trees, and growth is entirely dependent upon the food fur- 
nished by the leaves. The growth at this time is generally much slower than in the spring, and as the capacity of the tree for building up plant food increases it commences to store up starch, sugar and other foods in its cells with which to start growth the following spring, and the cell walls become thicker and firmer. This maturing of the tree is termed the ripening of the reood, and when completed the tree is ready for winter. Our hardiest trees generally ripen their wood early in the autumn and then cease growing, although probably some food is being stored up so long as the leaves remain green on the trees.

Rest Period of Plants. With very fow exceptions all plants require an occasional rest period for their best development. Some species get it naturally by being dried and others by being frozen. And even when plants are kept under growing conditions the year round they have periods of rest and of excitement. During the rest period the plants undergo very few changes, and yet there is undoubtedly some growth during mild weather in winter, and, as evaporation must be going on most of the time from twigs and buds. water must be supplied from the roots.

The Amount of Water Lost by Trees in Winter. Aiter many careful experiments, A. L. Knisely, M. S., concludes that a Soft Maple standing 30 or 35 feet high with a trunk 15 to i8 inches in diameter near the ground, exposing from 750 to 800 square feet of bark surface, may lose daily by evaporation from 6 to 7 pounds of water when dormant. An apple tree 30 years old and 15 inches in diameter at the base, exposing from 800 to 1,000 square feet of bark surface, may lose daily while dormant from to to I3 pounds of water. These figures are from results obtained during winter weather in New York, where the relative humidity of the air is higher than in Minnesota, which would lessen evaporation. It is probable that during our winters here the evaporation from trees will greatly exceed that in New York, and that greater evaporation is nearly always responsible for some trees being tender here and hardy in New York and other places with similar conditions.

We know that in this section after a prolonged period of severely cold weather, the twigs of Soft Maple. Apple and some 
other trees have a decidedly shrivelled appearance, which disappears after a few days of mild weather. Soft Maple trees standing on dry land will sometimes in the spring appear to have been dried out and to have become partly or entirely dead. It is probable that during our coldest weather very little, if any, moisture can be suppl ed from the roots, which may account for this shrivelled condition.

Second Growth. Sometimes warm, moist weather in late autumin will cause trees to start a strong second growth in October, which draws on the stored plant food and perhaps exhausts it, and winter sets in before the tissues have again become hard and stnred with food. In such cases trees are liable to injury. No characteristic of hardiness is more important in plants than that of early maturity of wood.

One part of the tree may start into growth without regard to the conditions of the other parts. For instance, a branch brought into a warm room in winter without severing it from the tree will grow for some time. Sun scald is probably due to the bark on the side most exposed to the sun starting into growth very early, after which a sudden freeze destroys the young cellular tissue. 


\section{CHAPTER II.}

\section{THE FOREST.}

Forest is a Term variously applied in this country. As here used it applies to all collections of trees except such as are grown for fruit. It may, then, apply to a piece of land on which scedlings have only recently been planted, or to what is termed brush land, or to land heavily stocked with trees.

\section{TREE GROWTH AFFECTED BY LIGHT CONDITIONS.}

So Important is Sunlight to the Growth of Trees that it is sometimes said to be the purpose of trees to convert sunlight into wood. Practically all trees make their most rapid growth in full sunlight There is, however, quite a difference in the power of various trees to get along with small amounts of direct sunlight. It is the object of good forestry to grow as much good timber as possible upon the land, just as good agriculture consists in growing the largest amount of farm crops upon the land. An acre of land covered with trees of the same species, it is estimated, will lay on the same amount of woody fibre whether the stems are large or small, the amount of wood formed each year being in direct ratio to the amount of foliage covering the land that is in good active condition.

It is known that some trees will do very well in the shade of other trees. This gives a chance to grow trees in a sort of two-storied fashion, having the land nearly covered with the foliage of one set of trees which require the full exposure to sunlight, and underneath the land covered with the foliage of trees which will endure the shade of those above them, just as pumpkins can be grown under corn. On account of this peculiarity of trees, foresters have divided them into two classes, one of which is called light demanding and the 
other shade enduring. The words tolerant and intolerant are also used as distinguishing the peculiarity of trees in this respect, and they are perhaps better terms. 'Trees that are known as tolerant generally have a thicker mass of foliage than those that are intolerant of shade. 'This simply means that their lower leaves can withuand the shade of their upper leaves. While it is nnt an absolute rule that tolerant species have a thick mass of foliage and intolerant trees open foliage, yet it is so generally true that where the characteristics of a tree are known it serves as a very reliable indication. Most trees are much more tolerant of shade when young than when old. Among our tolerant trees may be mentioned the Spruce, Oak, Balsam, White Cedar, Red Cedar, Hornbeam and Hard Maple. Among our intolerant species are Poplars, Cottonwood, Willows, Soit Maplc and Birch. Of our native pines, the White Pine is mutch more tolerant than either the Jack or the Norway Pine, which are quite intolerant of shade and soon succumb if they are protected from the full sunlight.

Trees Protect One Another and are Mutually Helpful, and nuany trees that are guite hardy on the limits of their growth when grown in grovps, will fail if grown singly, as for instance the Fard Maple in exposed parts of Minnesota. Trees also interfere with onc another and struggle for light and soil conditions, and the weaker trees are destroyed. So true is this that where the land is thickly seeded with even-aged trees, they may all become weak and sickly because of hindering one another. (O) the other hand, this crowding of trees forces them to take on an 11pward growth and kills out the lower branches. Trees growing under such conditions nake long timber free from knots, which is therefore most valuable.

\section{SOIL CONDITIONS.}

Water Supply. Water is the most important clement in soils for tree growth, and the greatest attention nust be given to its conservation and distribution through the soil. 'Trees do not grow to best advantage in very wet or in very dry soil, although some can live and almost thrive under such unfavorable conditions. There is very litle land, except in the arid 
region, but that will support some form of tree growth. The soil best adapted to all kinds of trees is one that is moderately but evenly moist, porous, deep and well drained; yet with a subsoil compact enough to transmit the subsoil water from below upwards without its being so solid that it cannot be easily penetrated by the roots. It does not matter about its being stony if it has these qualities. On land that is very wet in this section, as the muskegs of northern Minnesota, which are covered with Tamarack and Spruce, the trees never get to be of large size. In the case of one Spruce grown on such land, 73 years was occupied in growing a tree $I^{1} / 8$ inches in diameter. and a Tamarack under similar conditions formed a diameter of only I I-Io inches in 48 years. We also find that growth is extremely slow on very dry land. On very open porous land the water sinks quickly out of reach of the roots, and where the soil is too compact it cannot be penetrated by the water or by the roots, so that on such soils trees generally suffer for moisture a part of the year.

Relation Between Trees and Soils. The growth of trees and the kinds growing on land are good thongh not infallible indexes to the value of the soil for agricultural purposes, For instance, land on which Black Walnut, Hard Maple, Hackberry or Hickory grow to large size is of good quality for grasses, grains and other agricultural crops, while Black Oak is generally abundant on dry, gravelly ridges and sandy soil. Where White Pine in this section is the prevailing tree the land is generally of good quality. Norway Pine will endure more drouth than the White Pine, ontorows it, and becomes the prevailing tree on drier land, while the Jack Pine is the most abundant on the very dry sandy lands of Northern Minnesota. In the more humid climate of the eastern states the White Pine grows on very sandy soils.

Mechanical Condition of $\mathbf{L}$ and in Forests. The agriculturist aims to keep the soil porous, yet moderately compact. that the roots may penetrate it easily and the subsoil waters may be readily transmitted upwards to the roots of plants. He aims to prevent the soil from becoming too compact and from the loss of water from evaporation by cultivating the surface soil, and to keep out standing water by drainage. The forest 
grower cannot rely upon such methods, because they are too expensive or entirely impracticable. He may indeed plow for his first planting and cultivate the young trees, but after a few years cultivation will become impossible and the effects of the first preparation will be lost. He must therefore attain his object in another way, that is, by mulching the soil. The shading is done at first by planting very closely, so that the ground may be protected as soon as possible from sun and wind. The shate should be maintained well throughout the life of the tree, even if more planting is necessary to accomplish it, and if in later life the trees get thin in the tops or die out, it may become necessary to plant underbrush to protect the land.

Undergrowth in Forests may be rather injurious in preventing the proper development of young trees, but it is gencrally very beneficial in retarding evaporation from the surface soil, in retaining the snow in the spring and in killing out grass and weeds.

Forest Floor is a term used to indicate the mulch on the ground in forests. This is made up of the fallen twigs and leaves which remain on the ground, where they slowly decay and form a cover of rich mould or humus. This protective covering serves a most useful purpose; it permits the rain and snow waters to penetrate the snil without at the same time making it too compact, thus keeping the soil granular so that the air can enter, and in the best condition for conducting water. while at the same time it prevents washing away of the land and too rapid or excessive evaporation from the surface: the humus is also an active agent in aiding dccomposition of the mineral strbstances in the soil.

Subsoil. Tree growth is less dependent on the condition of the surface soil and more dependent on the subsoil than is the growth of agricultural crops. For instance, in the case of drifting sand overlying a moist subsoil, it has been found that where pains are taken to get the young trees started they will often do well although such land is poorly adapted to agricultural crops. There are many acres of land in Minnesota and Wisconsin that have such conditions, and they should seldom be entircly cleared of trees.

Washing of Soils. The soils most likely to wash badiy 
are those that are fine grained without much adhesive power, such as fine sand and some kinds of clays. When, however, such soils have a forest growth on them they are protected from washing by the forest floor, tree roots and the humus in the soil. Soil which contains large quantities of humus does not wash much, since the particles of organic matter bind it together; thus we find that newly-cleared timber land which contains large amounts of humus may not wash much for a number of years after the clearing, and then commence to wash very badly. The washing away then is due to the humus having become used up and there being nothing left to bind the soil particles together. In such cases the application of organic matter will help very materially. For this purpose manu̧re, straw or other material may be applied, or crops like clover and the grasses, which leave considerable organic matter, may be grown on the land. Crops that leave very little lanmus in the ground, such as nursery stock, which is dug out by the roots, are most harminl in exhausting the humus in the soil, and land used for this purpose needs heavy manuring with stable manure and an occasional seeding down to grass or clover.

Alkali Soils. In the prairie portions and occasionally elsewhere in this scction, we have a kind of soil in which there is a superabundance of carbonate and sulphate of soda. This kind of soil scldom extends over large areas and generally occurs in places lower than the surrounding land. In some places the alkali occurs in such abundance as to coat the surface of the soil with a white crust. On such land very few agricultural crops or trces grow well. The leaves of the trees growing there generally talie on a yellowish color and the wood does not mature well in the autumn. Such land should be drained so that the surface water at least can run off. In this way the alkali can generally be washed out in a few years. It is seldom advisable to plant trees on these places, but if this seems desirable, as is sometimes the case on prairies, the best trees to plant are probably the Cottonwood and White Willow. 


\section{EFFECT OF SLOPE AND ASPECT ON TREE GROWTH.}

The slope of the land affords drainage and so affects the growth of trees, but trees will grow on any slope, even on precipices, if they can find room for their roots and the soil is somewhat moist. The direction of the slope usually has a very nuarked effect on the growth of vegetation. This is especially the case where high ranges of hills and other local conditions modify the climate.

A Northern Slope receives no full sunlight; the sun's rays fall obliquely in the morning or toward evening, according to the angle of elevation. The winds it receives in winter are colder than those received by the southern slope, but the few winds which strike it during the growing season are not strong, hot or very dry. As the vegetation is a little delayed on a northern slope, there is less danger from late spring frosts than on a sunnier aspect, and, as the snow melts slowly, there is a better chance for its waters to soak into the ground. In consequence of these facts trees are less liable to suffer from drouth on the same kind of land with a northern than with a southern exposure. The trees keep a more regular form and growth is more uniform and certain. It will generally be found that where timber is cut off from a northern slope growth renews itself very quickly, for tree seeds are most likely to grow undes the conditions found there.

An Eastern Slope receives the sun in the cool morning lours when the temperature and light are moderate. It is not exposed to our hot, dry winds nor to the intense heat of the sun. The soil retains its moisture fairly well and trees make a good growth. For trees it ranks next in value to a northern slope.

A Southern Slope receives the most direct rays of the sun, and the full force of our hot, dry winds and beating rains during the growing season. Consequently vegetation is more liable to injury by late spring frosts, because of starting earlier in the spring, than in any other location. The soil is most liable to crosion from beating summer rains and dries up most quickly after the spring rains. The trees grow irregular in form, the secds seldom start well on southern or western slopes. 
and when once cleared tree growth is often difficult to renew As proof of the importance of these conditions as affecting tres growth we have the commonly observed fact that the south and west sides of steep hills and mountains are more likely th be bare than any others. This can be very plainly seen on the bluffs along the Mississippi River in Minnesota.

A Western Slope receives the sun's rays obliquely, but in the warmest part of the day. and in this section gets the full force of our hot dry southwest winds. The effect of such an exposure on growth is about the same as the southern slope. 


\section{CHAPTER III.}

FOREST INFLUENCES.

Upon careful observation it will be found that a single large spreading trce growing in an open field appreciably affects climatic and sojl conditions in the following ways:

(I.) Daring the day the gromd under a trec is protected from the sun's rays and is therefore conler than soil not protected. As a result of this protection, the air under the tree is cooler than the air in the open, and, as it is constantly in circulation, tends to cool the air in the immediate vicinity of the tree on sunny days.

(2.) At night a trec returds the radiation of hout from the ground under it. This tends to equalize the temperature of not only the soil and air under the tree, but that in the near vicinity. Therefore, though a tree may reduce the temperature of the soil and air on sunny days or during a short period of warm weather, it may, on the other hand, increase the temperature at night or during a short period of cool weather. For example it may be noticed that vegetables growing near trees are frequently uninjured by autumn frosts which destroy those growing in the open.

(3.) A tree aids in retcining water in the surface soil to the leeward by breaking the force of the wind, and thus retarding evaporation, for it is known that evaporation increases with the rapidity of the air currents. It retains the water in the surface soil under the tree by shading the soil and thus retarding evaporation. The large amount of water which is transpired by a tree is largely drawn from the subsnil, and this increases the humidity of the surrounding air without drawing on the water of the surface soil. But some kinds of trees take up so much of the water from the soil as to preclude the growing of crops in such places near them. 
(4.) The leaves that fall to the ground form a mulch which prevents the drying out of the soil. They check the flow of water over the land, thus preventing the washing away or compacting of the snil by heavy rains, and giving the water a better chance to soak into the ground.

(5.) A tree protccis from the destructive force of severe winds. A single tree or group of trees may secm to have little effect on tormadoes, but large groups of trecs may possibly prevent their formation or greatly lessen their violence. Protection from severe winds may greatly affect the growing of plants, since on account of the winds many plants that may be successfully grown when protected by shelter belts cannot be grown on the open prairie. This protection, when present, serves to lessen the fuel necessary to warm dwelling houses and also lessens the food eaten by animals. It also keeps the surface soil in fields from being blown away.

In these five principal ways a single tree affects the conditions of clinate and soil in its immediate vicinity. To be sure, some of them are not so very evident where a single tree grows in an open field, but where trees are growing in groups or on large tracts of land all of these factors are important in modifying clinate and soil conditions, and will be referred to at greater length.

\section{INFLUENCE OF FORESTS ON WATER SUPPLIES.}

It is very evident that the proper disposition of water upon the land is the most important factor in the growing of crops, and it is equally evident that nature's changeful and wasteful ways of supplying water to crops are not the best ways of so doing, for we know that not only in the arid regions, but in general wherever irrigation is used, crops are produced in greatest abundance and certainty. This once recognized, then the proper distribution of the available water supplies becomes a question of immediate interest. Human effort can, to a limited extent. direct the laws of nature that influence climate and soil conditions, and it becomes necessary that we have a clear understanding of the forces that are at work in nature in order that we may know where we may or may not expect to be successful in directing them. In order that we may better understand this 
subject, I quote the following extract on forest influences from the report of the Forestry Division of the U. S. Department of Agriculture for 1889 , with a few changes in the nature of abbreviations:

"The water capital of the earth may be regarded as consisting of two parts, the fixed capital and the circulating capital. The first is represented not only in the waters on the earth but also by that amount of water which remains suspended in the atmosphere, being part of the original atmospheric water-masses which, after the rest had fallen to the cooled earth, remained in suspension and is never precipitated.

"The circulating water capital is that part which is evaporated from water surfaces, from the soil, from vegetation, and which, after having temporarily been held by the atmosphere in quantities locally varying according to the variations in temperature, is returned again to the earth by precipitation in the form of rain, snow and dew. There it is evaporated again, either immediately or after having percolated through the soil and been retained for a shorter or longer time before being returned to the surface, or, without such percolation, it runs through open channels to the rivers and seas, continually returning in part into the atmosphere by evaporation. Practically, then, the total amount of water capital remains constant; only one part of it-the circulating capital-changes in varying quantities its location, and is of interest to us more with reference to its local distribution and the channels by which it becomes available for human use and vegetation than with reference to its practically unchanged total quantity.

"As to the amount of this circulating water capital we have no knowledge; hardly an approximate estimate of the amount circulating in any given locality is possible with our present means of measurement; for it appears that so unevenly is the precipitation distributed that two rain gauges almost side by side will indicate varying amounts, and much of the moisture which is condensed and precipitated in dews escapes our observation, or at least our measurements, entirely. Thus it occurs that while the amount of water calculated to be discharged annually by the river Rhone into the sea appears to correspond to a rainfall of 44 inches, the records give only a precipitation over its watershed of 27.6 inches. 
"We must therefore enter into our discussions acknowledging ignorance of one of the most important factors, at least as to its numerical or quantitive value.

"The distribution of the circulating water capital is infuenced by various agencies. "The main factor which sets the capital afloat is the sun, which, by its heat and the air currents caused by it, and by the rotation of the eartli, produces the evaporation which fills the atmosphere with vapor. Anything, therefore. that influences the intensity of insolation, the action of the sun, or obstructs the passage of winds, must influence the local distribution of the water capital. The great cosmic influences which produce the variability of all climatic conditions, and therefore also of the circtilating water capital, are the position of the earth's axis to the sun, by which the angle and therefore the heat value of the sun's rays vary in different parts of the earth and at different times of the year; the distribution of land and water areas, which produces a difference of insolation because the water has less heat capacity than the land, and which also influences the direction of air and sea currents; the configuration of the earth, by which the density of the atmosphere is made unequal, and in consequence of which differences of insolation and of air temperature are induced. Thus we have not only climatic zones, but also continental climates and mountain climates in opposition to coast climates and plain or valley climates.

"While this classification of cosmic climates satisfies the climatologist, there are many local climates to be found within the range of the cosmic, and the local climatic conditions are those which affect human life and human occupations most sensibly.

"The same causes, different only in degree, which modify the cosmic climates, making a classification of the same possible, effect further modifications and give rise to local climates; these causes are different in the degree of insolation, obstruction to air currents, presence of water surfaces, or moisture-laden, air strata.

"Among the factors which thus modify the cosmic climate and help to produce a local climate differing from other local climates, the soil cover, and especially the presence of forest areas, is claimed as one that, under certain conditions, is potent: 
and this factor, being under the control of human agency more than any other possible modifier of climate, must therefore be of greatest interest to us. It is clear, from what has been stated so far, that the influences of the forest, if any, will be due mainly to its action as a cover protecting the soil and air against insolation and against winds. That the nature of a cover, its density. thickness, and its proper position has everything to do with the amount of protection it affords, everybody will admit. A mos(quito net is a cover, so is a linen sheet or a woolen blanket, yet the protection they afford is different in degree and may become practically none. It will also be conceded that it makes a great difference whether the cover be placed before or behind the wind. Just so with the influence of the forest; it makes all the difference whether we have to do with a deciduous or coniferous, a dense or an open, a young low or an old high growth, and what position it occupies with reference to other climatic elements, especially to prevailing winds and water surfaces. In the following discussions, when the word forest is used, unless differently stated, a dense growth of timber is meant.

"The question of forest infuences on water supplies can be considered under three heads, namely-influence upon precipitation or distribution of atmospheric water; influences upon conservation of available water supplies; influence upon the distribution or 'run-off' of these supplies.

\section{INFLUENCE UPON PRECIPITATION.}

"Whether forest areas are, or are not, capable of appreciably increasing precipitation within their limits or on neighboring rround is still a matter of dispute, and the complexity of the elements which must enter into the discussion has so far baflled solution based upon definite and strictly scientific observatirm. Yet new evidence is accumulating all the time which apparently shows that under certan conditions forest areas obtain larger precipitations than open grounds, that is, they may increase at least the amount of precipitation over their own inmediate and near lying areas.

In Minnesota popular opinion inclines to the belief that there is a close connection betw:en the existence of forests and the rainfall of this scction, and that with the disappearance of 
our forests will come a much more rigorous climate and a decrease in rainfall. But the records of the weather bureau do not show that there is any connection between the two or that there has been any apparent change in the general climate or amount of rainfall due to the removal of our forests. The flow of water in most of our rivers, and in many cases the flow of water from springs, and the height of the water table in the land, have been most seriously affected by the removal of our forests and should be regarded as the ways by which our water supply is to suffer most severely from deforestation.]

\section{DISPOSAL OF WATER SUPPLIES.}

"Given a certain amount of precipitation in rain or snow over a certain area, the disposal of the water after it has fallen, and the influence of the forest cover on its disposal, require our attention. For the sake of convenience we can divide the elements which need consideration in this discussion into elements of dissipation, elements of conservation, elements of distribution.

"The difference in effect between the first two classes of elements will give us an idea of the amount of available water supply or run-off resulting from precipitation, while the third class bears upon the methods of distributing the available water supply.

\section{ELEMENTS OF DISSIPATION}

"Elements of dissipation are those which diminish the available water supplies; they are represented in the quantity of water which is prevented by interception from reaching the ground, in the quantity dissipated by evaporation, in the quantity used by plants in their growth, and in that used by transpiration during the process of growing.

Interception. The amount of rainfall and snow which is prevented by a forest from reaching the soil varies considerably according to the nature of the precipitation and to the kind of trees which form the forest, as well as the density and age of the growth.

"A light drizzling rain of short duration may be almost entirely intercepted by the foliage and at once returned to the atmosphere by evaporation; if, however, the rain continues, 
although fine, the water will run off at last from the foliage and along the trunks.

"Altogether for the rainfall conditions of Austria, Prussia and Switzerland, where measurements have been made, a dense forest growth will on the average intercept 23 per cent of the precipitation; but if allowance be made for the water running down the trunks, this loss is reduced to not more than I2 per cent.

"The amount of interception in the open growths which characterize many of our western forest areas would be considerably smaller, especially as the rains usually fall with great force, and much of the precipitation is in the form of snow. Although branches and foliage catch a goodly amount of this, the winds usually shake it down, and consegitently but very little snow is lost to the ground by interception of the foliage.

"There is also a certain amount of water intercepted by the soil cover and held back by the soil itself, which must be saturated before any of it can run off or drain away. This amount, which is eventually dissipated by evaporation and transpiration, depends, of course, upon the nature of the soil and its cover: especially upon their capacity to absorb and retain water.

"The water capacity of litter depends upon its nature and of course its thickness to a certain degree, but is much greater than that of soils.

"Altogether an appreciable amount of the precipitation does not run off or drain through the forest cover, but is retained by it; yet, while this is apparently a loss, we shall see further on that this moisture retained in the upper strata fulfills an important office in checking a much greater loss due to evaporation, and thus become an element of conservation."

Evaporation. The loss by evaporation after the water has reached the ground depends in the first place upon the amount of direct insolation of the soil, and hence its temperature, which again influences the temperature of the air. The nature of the soil cover, the relative amount of moisture in the atmosphere and the circulation of the air are also factors determining the rate of evaporation. The importance of evaporation as an element of dissipation may be learned from the experiments of Prof. T. Russell, Jr., of the U. S. Signal Service, made in I888. We learn from these that the evaporation on the western plains 
and plateaus may, during the year, amount to from 50 to 80 inches, nay, in spots, 100 inches, while the rainfall (diminishing in reverse ratio) over this area is from 30 to 12 inches and less.

"Thus, in Denver, where the maximum annual precipitation may reach 20 inches, the evaporation during one year was 69 inches. This deficiency of 49 inches naturally must be supplied by waters coming from the mountains, where the precipitation is large and the evaporation low. (On Pike's Peak alone there may be 45.6 minus 26.8 or 18.8 inches to spare.)"

Evaporation from the soil is dependent upon its covering, and this is important, as the soil in forests is always covered with dead branches, leaves, etc. In some experiments which were carried on in Germany during the months of July and August, 1883 , to determine the amount of evaporation from different soils, it was found that from 1,000 square centimeters of bare ground 5,730 grams of water were evaporated, and that from the same area of similar soil covered with two inches of straw 575 grams were evaporated. This shows that the naked soil evaporated more than ten times as much as the covered soil. It is evident then that the soil covering has an important function in preventing evaporation.

Wind-breaking Power of Forests. If the loss by evapuration from an open field be compared with that of a forestcovered ground, as a matter of course it will be found to be less in the latter case, for the shade not only reduces the influence of the sun upon the soil, but also keeps the air under its cover relatively moister, therefore less capable of absorbing moisture from the soil by evaporation. In addition, the circulation of the air is impeded between the trunks, and this infuence upon available water supply, the wind-breaking power of the forest. must be considered as among the most important factors of water preservation. Especially is this the case on the Western plains and on those Western mountain ranges bearing only a scattered tree growth, and where, therefore, the influence of shade is but nominal.

The evaporation under the influence of the wind is dependent not only on the temperature and dryness of the same, but also on its velocity, which being impeded, the rate of evaporation is reduced. 
Interesting experiments for the purpose of ascertaining the changes in the rate of evaporation effected by the velocity of the wind were made by Prof. T. Russell, Jr., of the Signal Service, in 1887. The result of these experiments (made with Piche's hygrometers whirled around on an arm 28 feet in length, the results of which were compared with those from a tin dish containing 40 cubic centimeters of water exposed under shelter) show that, with the temperature of the air at 84 degrees and a relative humidity of 50 per cent, evaporation at 5 miles an hour was 2.2 times greater than in a calm; at ro miles, 3.8; at I5 miles, 4.9 ; at 20 miles, 5.7 ; at 25 miles, 6.I, and at 30 miles the wind would evaporate 6.3 times as much water as a calm atmosplere of the same temperature and humidity.

Now, if it is considered that the average velocity of the winds which conslantly sweep the Western subarid and arid plains is from 10 to 15 miles, not rarely attaining a maximum of 50 and more miles, the cause of the aridity is not far to seek, and the function of the timber belt or even simple windbreak can be readily appreciated.

Professor King has found in experiments made in Wisconsin that the influence of even a thin stand of woodland on the rate of evaporation was considerable. In one experiment made in the month of May the instruments were so placed as to measure the evaporation to the leeward of a scant hedgerow six tn eight feet high, having in it a few trees twelve feet high and many open gaps. It was found that at 300 feet from the hedge the evaporation was 30.1 per cent greater than at 20 feet, and at I 50 feet it was 7.2 per cent less than at 300 feet. The experiment was made during a moist north wind. It is sufficiently evident, therefore, that even a thin hedgerow exerts an influence that can readily be measured. In fact the presence or absence of protecting belts of trees under the conditions often existing on our prairies may make a difference between a good and a poor crop. All who are acquainted with our prairie sections know that great damage is often done to wheat, corn and other crops by the hot southwest winds which we are likely to have during the growing months. In Kansas and Nebraska during the summer of 1894 immense tracts of corn, fully tasselled out, were killed by such winds. At the same time it was noticed that where corn was protected by trees or slopes of land, or where 
the humidity of the wind was increased by passing over bodies of water or clover fields, the injury was greatly lessened.

What the possibilities of evaporation from hot and dry winds may be can be learned from statements regarding the "Fœhn," which is the hot wind of Switzerland, corresponding to the "chinook" of our western country.

The change in temperature from the normal, experienced under the influence of the Fohn, has been noted as from 28 degrees to 3 I degrees Fahr.. and a reduction of relative humidity of 58 per cent. A Fochn of twelve hours' duration has been known to "eat up" entirely a snow cover $2 \mathrm{I} / 2$ feet deep.

In Denver a chinook has been known to induce a rise in temperature of 57 degrees Fahr. in twenty-four hours (of which 36 degrees in five minutes), while the relative humidity sank from Ioo to 21 per cent.

The degree of forest influence upon rate of evaporation by breaking the force of winds is dependent upon the extcnt and density of the forest, and especially on the height of the trees; for according to an elementary law of mechanics the influence which breaks the force of the wind is felt at a considerable elevation above the trees. This can be practically demonstrated by passing along a timber plantation on the wind-swept plains. Even a thin stand of young trees not higher than five feet will absolutely calm the air within a considerable distance and height beyond the shelter.

Professor King found that an oak grove i2 to I5 feet high exerted an appreciable effect in a gentle breeze at a distance of 300 feet. In a strong wind the effect of such a grove would be felt at a much greater distance to the leeward.

At the Dominion Experiment Station in Assiniboia Dr. Saunders found on one occasion that windbreaks exerted an appreciable influence at from 50 to 80 feet to leeward for every foot in height, but this was during a very severe wind. It may probably be laid down as a general rule that windbreaks will exert an appreciable influence for at least one rod for every foot in height.

It may not be necessary to state that the damage done to crops by the cold, dry winter winds is mainly due to rapid evaporation, and that plants are liable to suffer as much by winter drouth as by summer drouth. 
This is certain-that since summer and winter drouth, that is. rapid evaporation due to continuous dry winds, is the bane of the farmer on the plains, rationally disposed timber belts will do much to increase available water supply by reducing evaporation.

Evvaporation, of course, goes on much less rapidly within than without the forest. How great this difference is in this section we have no exact figures to tell, but it is certain that it is much more than in Bavaria, where the following result was obtained: In an experiment which was carried on to cletermine the amount evaporated from April to October"it was found that from a certain area without the forest 40.8 centimeters were evaporated, within pine wood $r 5.9$ centimeters and within decidnous woods 6.2 centimeters. This shows that the evaporation was six and one-half times as great in the open field as in decidnons woods.

Transpiration. Another factor by which forests dissipate water supplies and which has been referred to (page 17) is transpiration. The quantity of water so used is as variable as the amount of precipitation, and in fact within certain limits depends largely upon it; that is to say, a plant will transpire in proportion to the amount of water which is at its disposal. Transpiration is also dependent on the stage of development of the plant, on the nature of its leaves and amount of foliage, on temperature. humidity and circulation of the air, on intensity of the sunlight, and on temperature and structure of the soil and on other metcorological conditions. Rain and dew reduce transpiration; wind increases it.

The amount of transpiration depends considerably upon the thickness of the leaves; therefore the suriace of the foliage is not a reliable neasure, but should be compared with the weight.

In some European experiments carried on during the period of vegetation, the amount of water transpired by the different species per pound of dry matter in the leaves was as follows: 
Prounds of Water.

Birch and Linden................600 to 700

Ash ............................. 500 to 600

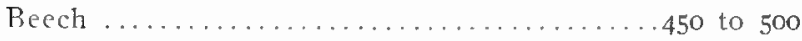

Maple .........................400 to 450

Oak ...........................200 to 300

Spruce and Scotch Pine................ 50 to 70

Fir .............................. 30 to 40

Black Pine ................................................ 40

Average, deciduous trees............... 470

Average, evergreen trees............... 43

This shows that there is a great difference in the amounts of water transpired from deciduous trees and evergreen trees. In this case the deciduous trees transpired about eleven times as much as the evergreens.

"The variability of transpiration from day to day is of wide range; a birch standing in the open and found to have 200,000 leaves was calculated to have transpired on hot summer days 700 to 900 pounds, while on other days its exhalations were probably not more than 18 to 20 pounds.

But while trees transpire large amounts of water, our agricultural crops and other low vegetation transpire much larger amounts to the same areas. A small factor in the dissipation of water supplies is the amount of water that is retained in the plant itself. As before mentioned this may amount annually to about 5,000 pounds per acre. The water in fresh cut woods forms a large part of their weight. In hard woods, such as Ash, Oak, Elm and Birch, it forms 38 to 45 per cent, and in soft woods 45 to 55 per cent or more.

\section{ELEMENTS OF CONSERVATION OF WATER SUPPLIES.}

In discussing the elements of dissipation as to the degree of their effect under forest cover as compared with the same elements at work in the open field, we have seen that the shade, the low temperature, the relative humidity, the absence of strong air currents and the protective and water-holding capacity of the forest floor are all factors in the conservation of the water supplies. We have also seen that the quantity of water lost by evaporation, the greatest source of dissipation, may be more 
than six times as great in the open as in the forest. The only other conservative effect of forests on water supplies is their effect in retarding the melting of the snows. This acts as an important function in the prevention of freshets by giving the snow a longer time to melt, so that the snow water has a better chance to sink into the ground. It is of course more evident in evergreen than in deciduous forests. On the grounds of the Minnesota Experiment Station, where the woodland consists of a low growth of Oak, the snow is often retained in the woods a week longer than in the open. This often allows the snow water from the fields to almost wholly run off before it has begun to flow from the woods. Then again the daily flow of snow water from the woods is much shorter than from the open fields during spring weather, when we have warm days and cold nights, for it begins later in the morning and stops earlier in the afternoon. Under the dense shade and mulch of the cedar swamps of northern Minnesota the snow and ice often remain until the beginning of summer. The Indians claim there has never been a time when they could not find ice for their sick in the cedar swamps of that section. This retarding effect on the melting of snows in the spring and in preventing the run-off is of far greater importance in the case of streams that rise in the high mountains than in Minnesota and Wisconsin, where the land is more nearly level. Where streams have their sources in mountains, as those of Colorado and other Rocky Mountain States, the cutting away of the forests causes a heavy flow of water carly in the spring and little water in the summer, when it is most needed for irrigation purposes. This has become so evident that the Chamber of Commerce of Denver, Colorado, recently petitioned the President of the United States to reserve such land in forests and administer it at public expense, and in their petition used in part the following language:

"The streams upon which the irrigation system of Colorado depends are fed by the springs, rivulets and melting snows of the mountains, which in turn are nourished and protected by the native forests. Where the forests have been destroyed and the mountain slopes laid bare most unfavorable conditions prevail. The springs and the rivulets have disappeared, the winter snow melts prematurely, and the flow of the streams, formerly 
equable and continuous, has become fitful and uncertain. Floods and drouth alternating clearly indicate that the natural physical conditions of the region have been unduly disturbed. In winter and early spring, when heavy masses of snow have been accumulated on treeless precipitous slopes, snow and land slides frequently occur with disastrous result to life and property."

\section{THE DISTRIBUTION OF WATER.}

The distribution or "run-off" of the water is often a more important factor in its economy than the quantity available. It is influenced by the surface conditions of the soil cover, by the porosity and structure of the soil and by the slope. There are two kinds of run-off, the surface run-off and the underground run-off or percolation. The former is likely to do injury by eroding the soil, while the latter is generally beneficial to vegetation in the formation of springs and in raising the water level in the soil. It is evident that the less surface drainage and the more underground drainage the greater the springwater supply and vice versa. We are, therefore, interested in determining the factors that increase underground drainage and reduce the surface flow.

It is plain that whatever retards the flow of water over the land aids it in sinking into the soil. We find this exemplified in swamps, where the soft, rough ground retards the surface flow, and in forests, where the foliage checks the water in its descent to the ground and the forest floor retards the surface run-off. Theoretically such a cover should promote the flow of springs and maintain the height of water in wells, and in practice we find that this is often the case. In some cases springs had entirely disappeared after the clearing of near-by forests, but have commenced their regular flow since the trees have been allowed to grow again. Springs in turn influence the flow of water in rivers, so that forests about the headwaters of streams often have a most potent effect in maintaining their flow. There is in fact no influence of the forest that is of greater importance in the distribution of water supplies than its effect in retarding the run-oft, even though its effect in preventing evaporation is very important. 


\section{FOREST INFLUENCES ON WIND AND HAIL STORMS.}

We have seen that the wind-breaking power of the forest is a very important factor in retarding evaporation, and in preventing the drifting of sandy soil and snow. In the forest the air may be rather still while in the open a piercing gale may be blowing; in consequence there are no blizzards in a wooded country. Tornadoes of great force have occasionally broken down wide areas of timber in this section, but instances are very rare in which they have continued for long distances through forests, and it is probably true that forests have a tendency to prevent their formation and perhaps entirely break up those of lesser violence. M. Becquerel is said to have found by careful study that in some parts of central France hail storms show a marked disinclination to enter forests, and yet occasionally they do so, but nothing of this sort has been noticed here.

\section{FOREST INFLUENCES ON FOGS AND CLOUDS.}

The influence of forests on fogs and clouds has frequently been mentioned. The fog seems to linger in the woods after it has cleared off elsewhere. Trees act also as condensers and gatherers of dew, hoar-frost and ice; the latter phenomenon is especially remarkable in the so-called ice storms, where the accumulation of ice on the trees is so great as to break them down. The load of ice on some large trees is probably a ton or more. In this case the tree acts simply as an inorganic body.

\section{IMPROVEMENT OF LAND ON WHICH TREES GROW.}

As has been shown, trees add large amounts of soluble mineral matters to the soil through the fall and decay of their leaves. In the same way they add large amounts of humus to the land, which helps to keep the soil porous and yet makes it more retentive of moisture and gases. The roots of trees often penetrate deep into the soil and bring up plant food that would not be reached by agricultural crops. A part of this is returned to the surface soil by the yearly fall of the leaves and in the twigs and branches that are left on the ground when the tree is cut down. The roots deepen the soil, and by their decay furnish plant food to the soil and leave channels through which 
water and air may cnter the subsoil. It has been estimated that after a sandy soil in New England is so exhausted that it will produce nothing but red mosses it may be renewed to its pristine vigor and productiveness by the growth of trees on it for thirty ycars.

\section{WHY THE PRAIRIES ARE TREELESS.}

This question has been answered in many ways, but often, it would seem, by persons not arguainted with the principles of forestry. It seems that the best way of getting a clear understanding of this matter is to consider two extremes of tree growth. Eastern Minnesota has a rainfall of perhaps 26 to 35 inches and a comparatively moist air, and at least during a part of the year is well adapted to the growth of the hardier kinds of trees. Here we find the White Pine, Basswood, Oak, Elm, Poplar and other trees attaining large size. Western Dakota has a very light rainfall, mostly in the spring, and a very high rate of evaporation. Trees can scarcely be made to grow in this section without irrigation, and the low vegetation, the grasses, which require a less amount of water, replace the trees. It is evident that between locations having such extremes of tree growth there must be a place where the trees give way to the lower forms of vegetation. Such a meridianal zone is found in central Minnesota, and though it has probably changed with fluctuating rainfall its general location has remained practically the same for many years. The location of this zone was probably gradually driven eastward, for many years previous to settlement, by the practice of the Indians of burning over prairies in order to furnish good pasturage for the buffalo. Of late years, since the prairie fires have been largely prevented, the tree line has moved westward and gained a little on the prairies. When left to itseli the western linit of this tree zone would not make very great progress westward, but with man's assistance in cultivation and various other ways it may be extended much farther towards the arid regions than if left to natural conditions. So we find that, while great sections of the interior of this country are treeless on account of lack of water, trees planted on them and properly cared for may often grow thriftily. But trees planted on our prairies always require more care to make them 
do well than those planted in sections of greater rainfall, and we should not expect them to grow as large as in the timbered sections without irrigation.

\section{RAINFALL AND HEIGHT OF WATER TABLE IN THE LAND.}

A few years ago it was argued by many friends of tree planting that it was practicable by the planting of trees to increase the rainfall and prevent evaporation in the great continental plain sufficiently to materially change the climate. The large rainfall and the good crops produced for a number of years in the drier portions of this area after considerable planting had been done seemed to endorse all that the most enthusiastic of tree planters claimed. But it must be very evident to any careful student of the subject that such small plantings as were made, even had they been maintained, could scarcely have had any appreciable effect on the general climate of so vast a territory. It is very evident, too, from a study of the annual rainfall, that it has fluctuated greatly in this section, and that we have perhaps not recorded the least or the greatest amount for any one year.

There are some facts that seem to show plainly that there must have been a time when the water level of our lakes was much lower than it is now or than it was during the very dry years from 1890 to 1895 , when the rainfall in most cases produced no flow in the streams. There is a lake near Devils Lake, N. D., where in 1890 the old overland trail leading west terminated abruptly on one side of the lake and was taken up again in the continuation of its direction on the opposite side. The trail is clear and distinct, showing it to have been of comparatively recent use. It is a reasonable inference that when this trail was in use this lake was dry. There are places near the shores of Devils Lake where upright stumps are standing submerged in water. The same phenomenon has been noticed in other places. These are almost certain indications of a time or times when the beds of these lakes, where the stumps are, were out of water or very neatly so for a sufficient length of time for the trees to grow. The climate must have been very dry, and the great continental plain, or at least portions of it, must have bordered pretty closely upon a desert, and the "Great American Desert" may have been a reality. It would seem, then, 
that the knowledge we are gaining of the unknown past, as well as the records of more recent years, point to the recurrence of great fluctuations in the annual rainfall of this section, and it seems probable that such changes follow series of years, and that the recedence of our lakes may be followed by periods of higher water.

But the influence of the cultivation of the soil on water supplies must be taken into account in this connection, for it is undoubtedly true that man has changed the conditions of the soil sufficiently to greatly influence the run-off. The breaking up of large areas of prairie sod, with its low rate of evaporation, and the planting of such land to agricultural crops with a relatively high rate of evaporation, has resulted in a loss of soil water. Then the cultivated soil takes up more water than the sod-bound prairie slopes, so that it does not have so good an opportunity to collect in lakes and swamps, which often supplied the water of wells. And further, the straightening and cleaning out of water courses, and the draining of swamps in the effort to get arable land, has had a similar effect on subsoil water supplies.

\section{HOT WINDS.}

The hot winds of the plains which so often cause serious injury to farm crops in Kansas, Nebraska and the Dakotas have been ascribed to the arid "staked" plains, whence, taking a northeasterly direction, they draw all the moisture from the vegetation with which they come in contact. The view has also been presented that they have their origin on the Pacific Coast, ascend the Rocky Mountains, lose their moisture and descend on the eastern slopes. But all theories that ascribe their origin to a distant source are inadequate to explain their phenomena. For instance, all who are acquainted with these winds know that they blow only during very dry weather, when the earth is heated very hot, that a good rain speedily brings them to an end, and that they blow only during the daytime, commencing about $9 \mathrm{~A}$. M. and continuing until sundown. This daily movement is often constant for several weeks, showing that there is evidently some connection between them and the course of the sun. For these reasons and others which would require too 
much space to give here, the best authorities unite in attributing them to local origin.

Mr. George C. Curtiss describes the process of the production of a typical hot wind as follows: "The necessary conditions are those of the 'warm wave, namely, a diminishing pressure to the northward, producing southerly winds which initially elevate the temperature above the normal. A cloudless sky favors an intense insolation, as a result of which the dry ground is soon raised to an extreme temperature, and the air is heated from it by radiation, reflection and conduction. The resulting diminution of density due to the rise of temperature furnishes impetus to previously existing horizontal currents, and by io o'clock in the morning the hot wind is fully developed. Hundreds of miles of hot dry earth contribute to maintain and feed the current, and, gathering strength as the sun mounts higher, the hot wind sweeps over the defenseless prairie. Neither hills nor forests rise in its path to break its power or dispute its sway, and, with no enemy save the tardy raincloud, the fetid blast sucks out the life-sap of the growing grain. It will be readily seen then that each of the states, Kansas, Nebraska and North and South Dakota, develops its own hot winds and cannot charge them to the account of its neighbors."

The local origin of these winds at once suggests the desirability of frequent windbreaks on the prairie farms, as offering the most practical way of breaking them up. Irrigation of large areas will also undoubtedly do much to prevent them. 


\section{CHAPTER IV.}

\section{TREE PLANTING ON PRAIRIES.}

The subject of tree planting in this section naturally divides itself under the two heads of prairie planting and forest planting. The former relates to the limited planting of trees on our prairies for ornament, protection and use. and the latter to the care and management of timber lands and the planting of trees for profit from their growth. Our people are very generally impressed with the importance of prairie planting for protection and ornament, but are too prone to regard the care and management of timber lands for the production of timber crops as a matter of little concern and very impracticable. (The subject of the regeneration of forests is treated in the chapter on Forest Planting and Treatment.)

\section{PRAIRIE PLANTING.}

- Whatever the ulterior object of prairie planting, the subject of protection to the buildings, their occupants and the cattle in the field should always be first considered. Our crops in this section are most liable to injury from the southwest wind of summer, which dries them out, and the northwest wind of winter, which blows the snow from the land, causing it to lose the snow water. It also causes a loss of evaporation, which goes on even in winter from the bare ground, and from exposed crops, causing them to winter-kill. The same winds are also the most uncomfortable to the occupants of farm buildings, and are most likely to cause dust storms, which should be especially guarded against.

Windbreak is a general name given to anything that gives protection from wind. On the prairies it is often applied to a single row of trees planted for protection.

Shelterbelt is a term more often used to signify several or a large number of rows of trees, but the term is often used interchangeably with windbreak.

Grove is a term that refers to comparatively large bodies of trees which may be planted for shelter, fuel or other purposes. 
Protection to Buildings may be furnished by a few rows of a grove of trees. It is generally best to locate the buildings in a grove, or grow one up around them, so that protection may be afforded from every quarter to the best advantage. The garden should also be included in the grove or shelterbelt about the buildings.

\section{Distance of the Trees from the Buildings and Roadways.}

Of whatever the protection consists, it should not be close to the buildings or to any paths which are used in winter, for the snow drifts which always form to the leeward of such protection may become a great nuisance under such circumstances during winters of great snowfall. The windbreak had better be placed about one hundred feet back from the buildings, and if shade is wanted it can be obtained from scattered trees near the buildings, which will not drift the snow. The same rule applies to the planting of trees on the north side of a roadway. The drifts of snow which wouldobe formed to the leeward of a windbreak so planted would take longer to thaw in the spring, and would keep the road muddy and in poor condition after those that were not protected had become dry and firm. A row of trees is very appropriate by the side of a street or roadway and affords a pleas. ant shade, and if not planted too closely together will not drift the snow sufficiently to be an objection.

Protection to Crops by Windbreaks. The objection to windbreaks close to driveways may also be made against their use in fields, for they often keep the land for a short distance to leeward wet and in unfit condition to work after the rest of the field has become dry. This is an objection where spring grains are grown, but to winter grains it is an advantage. On the other hand, the protection of a windbreak may give a much needed or beneficial covering of snow to crops on the leeward side. The protection from dust storms and drying winds has already been mentioned. The important question is how to get the advantages without the disadvantages. In many sections the disadvantage of having the snow linger on the field near the windbreak may be overcome by leaving a strip of land near it in permanent meadow, or use it for a rotation that does not take in crops that require very early planting. But even with springplanted grains it is more than probable that windbreaks properly 
planted are an advantage when their benefits are considered for a series of years. It ofttimes happens that low windbreaks are more beneficial than high windbreaks in holding the snow on the land, for the high windbreaks often form a great drift that may remain late in the spring, while the low windbreak nowhere forms a large drift, but spreads the snow for long distances. Professor Budd says that in parts of the great continental plain of Russia, where the climatic changes are much the same as in this section, the use of low windbreaks in wheat fields is very common.

Height of Windbreak. From the preceding paragraph it will be seen that low windbreaks may often serve a better purpose than high ones in protecting fields. Exactly what is meant by a low windbreak may be an open question, but for the purposes of this discussion a low windbreak may be considered one under twenty feet in height. In Russia and at the experiment station at Indian Head, Manitoba, windbreaks of Artemisia tobolksiana, which seldom grows more than eight feet high, are often used. About farm buildings windbreaks cannot be too high, and for this purpose the largest, longest-lived trees should be used.

Kinds of Trees for a Windbreak. In too many instances too many tree planters on the prairies have put out exclusively quick-growing, short-lived trees, such as the Cottonwood and Lombardy Poplar, and after fifteen or twenty years they have found their trees dying and nothing coming on to take their places. The quick-growing kinds are very desirable as a protection for the near future, but they are often short lived and should never be planted alone. Among them should be planted a sufficient number of long-lived and perhaps slower-growing kinds, to afford protection in later years, when the short-lived kinds have died out. 'The soil and location have much to do in determining the longevity of varieties; for instance, the Cottonwood and Lombardy Poplar are generally short-lived trees when planted in this section, but when planted in locations where their roots reach the permanent water level their period of life may be considerably lengthened, and they may then even be regarded as long-lived trees.

In starting a grove or windbreak on the prairie in this section, there is probably no better tree to begin with than the 
White Willow. It is quick-growing, rather long-lived in most situations, makes good summer fuel and renews itself very rapidly from the stump. The Grcen Ash would probably rank next

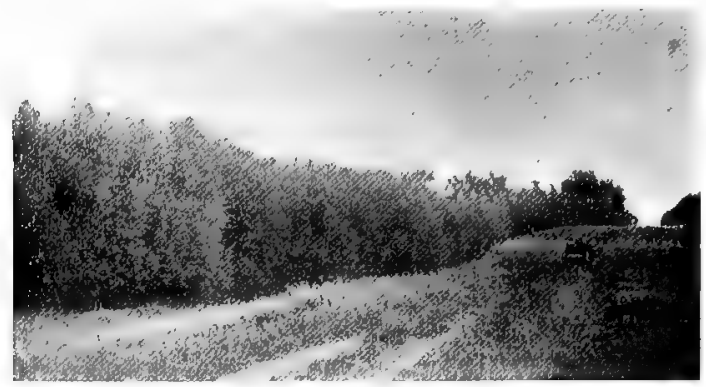

Figure 3. A young White Willow windbreak on dry prairie at Coteau Farm. Grown entirely by mulching after being well started.

as a pioneer tree. The White Elm is also very valuable for this purpose, but generally should follow the White Willow. The Cottonwood may sometimes, though very seldom, be the best to use, but on average prairie land it would be better if the White Willow or Green Ash were always planted instead.

After a good windbreak has been secured it is safe to plant out the hardy coniferous evergreens and such trees as the Mountain Ash, European White Birch and other similar ornamental trees. Wind protection is beneficial to all trees and necessary for many of our best ornamental kinds and often makes the difference between success and failure in growing them.

Distance Apart. In the planting of groves we should aim to get the land shaded by the trees as soon as practicable, and to keep it covered with a canopy of leaves. The United States government recommended the planting of trees four feet apart each way, with the idea that when so planted they would quickly shade the ground and consequently keep out grass and retard evaporation. Some successful plantings have been made on this plan, but when planted so closely together the branches grow into the rows after a few years and cultivation must be discontinued. In this section, where we have so much very 
bright sunshiny weather that grass can grow under foliage that would kill it out in a more humid climate, we find that trees planted four feet apart each way seldom afford sufficient shade to kill the grass under them for many years. This is especially true of such trees as the Cottonwood, Lombardy Poplar and White Elm when planted alone, as they have open foliage that does not fumish a dense shade. Among tree planters who have had a large experience in prairie planting there has been a tendency of late years to plant two feet apart in rows eight feet apart, and some of our most successful planters prefer even more room than this between the rows. When plantings are made $2 \times 8$ feet the same number of trees are required for an acre as when planted $4 \times 4$ feet, but the former distance has the advanttage over the latter in that the space between the rows can be cultivated for perhaps ten years or more, by which time must trees will have formed a dense shade and be able to take care of themselves. Where a much greater distance than eight feet is allowed between the rows we generally fail to get forest conditions for many years, and to that extent fall short of an important requisite in prairie planting. The distances given here might need to be modified to stit different varieties and local climatic conditions.

Clear Plantings. Most of the plantings on our prairies consist wholly of one kind. In some cases good results are thus obtained, but they are seldom as satisfactory as plantings made up of several different kinds. One of the greatest drawbacks to plantings made up entirely of one kind is the fact that drouth, insects or fungous disease may destroy the whole planting at one time, while in a judiciously mixed planting this could hardly occur.

Mixed Plantings, when properly made, have the following advantages: (I) They make possible the growing of species that form a protection in the least possible time, and still have coming on in the same grove longer-lived and better kinds to take their places. (2) Many kinds that are somewhat tender are helped very much by being grown among the hardier kinds until well established. In this case the protecting trees are called nurse trees. The Scotch Pine is seldom a success when standing alone on our Western prairies, but when partially protected by some decidtious tree it stands very well. The same 
is gencrally true of Hard Maple in this section and of Catalpa and Black WValnut in Southern Minnesota. (3) In good mixed plantings the ground is more likely to be properly shaded and protected from winds than it would be in clear plantings of such thinly-leafed species as the Cottonwood or White Elm, which do well and afford good sliade when mixed with Green Ash

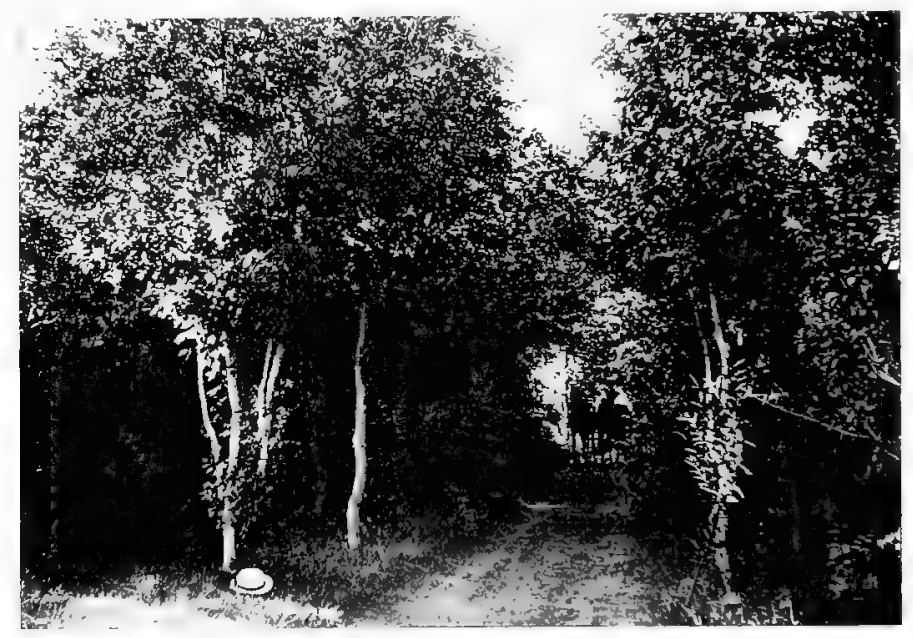

Figure 4. A good tree claim. Planted by Mr. Gardner, of Lyons county. Located on high prairie. Soil very dry. Ilas planted about jo acres in trees.

or Boxelder. (4) Nixed plantings are most interesting and ornamental. (5) They attract more birds by their better protection and the greater varicty of food offered. (6) While the chance of injury to some of the species by climatic changes, diseases and insects is increased, the possibility of total loss from any or all of these causes is reduced to the minimum.

The Most Important Constituent of a Prairie Grove of mixed trees in this section should be some well-known durable kind, as the Elm. Ash or Boxelder, of which there should be a sufficient number to completely shade the ground when the others are gone. On the outsicle, especially on the north and west, it is often a good plan to put at least? few rows of White 
Willow or possibly Cottonwood to furnish a quick protection. The rest of the grove should consist of hardy sorts, and may include some of the evergreens and such fruit-bearing trees or shrubs as the Wild Plum, Wild Black Cherry, Russian Mulberry and Juneberty. These latter furnish food for the birds and may often be a help in supplying the home table. The plan of planting with a view of providing some food tor birds is not mere sentiment, for they protect our gardens from many insects, and if we furnish an abundance of Russian Mulberry they will not trespass much on our strawberies or raspluerries. It is the author's opinion that in all our prairie planting we should pay more attention to using our native fruits and Russian Mulberry as plants of secondary importance.

L,ist of Trees for Mixed Plantings. Some suggestions may be found in the following lists, but several other trees might often be used to give a variety or a tasteful display.

For Porous Moist Soils in Southern Minnesota. White Elm, Black Walnut, Green Ash and Hard Maple in equal quantities with a scattering of the fruit plants. The Hackberry may wholly or in part take the place of the White Elm, and the Boxelder the place of the Green Ash. The White Willow, Basswood and Soft Maple would also do well in such a location. One of the main kinds might be replaced by the White or Norway Spruce, Douglas Fir or White Pine. In fact such land as this will grow any of the trees adapted to this section.

For High Prairie Soils in Southern Minnesota. Green Ash, Boxelder, White Elm and White Willow in equal quantities, with scattering of fruit plants. Basswood might be used to a limited extent, and White Spruce, Red Cedar, Norway Pine, White Pine or Scotch Pine might be used in the place of one of the main kinds.

For Moist, Porous Prairie Soils in Northern Minnesota. White Willow, White Elm, Boxelder, Basswood and Green Ash in equal quantities, with a scattering of fruit plants. In some localities it might be best to use Cottonwood on the outside of the grove. Hackberry might take the place of part of the White Elm and White Spruce, Arborvite, Norway Pine, Red Cedar, and some other conifers might be used to a limited extelit. 
For High Prairie Soils in Northern Minnesota. Cottonwood, White Willow, Boxelder and White Elm in equal quantities, with a scaftering of fruit plants. White Spruce and native Red Cedar might also be used in a small way.

Lists of trees commonly planted, arranged in the order of their hardiness: Deciduous trees-Green Ash, White Willow, White Ëlm, Boxelder, Basswood, White Poplar, Hackberry, Solt Maple, Canoe Birch and Yellow Locust. Evergreen treesRed Cedar, Dwarf Mountain Pine, Jack Pine, Bull Pine, White Spruce, Austrian Pine, Scotch Pine, Douglas Spruce, Norway Pine, Norway Spruce and White Pine.

size of Trees. In the case of deciduous trees it is generally best to start with one year old thrifty seedlings, although trees two ycars old may often be used to advantage. The Oak, Valnut and similar trees are better started from seeds where they are to remain, and the White Willow should be started from cuttings. Seedling Elm, Ash and Cottonwood may often be pulled from some river bank or lake shore, or bought of nursery men at a very low figure, or they may be raised from seeds. White Willow cuttings can generally be obtained from some neighbor or from nurseries. In the case of conifers, transplanted seedlings should be used. Whatever the source of any stock that is to be planted, it should be thrifty and vigorous and not weak or diseased.

Methods of Planting. The methods uscil in prairie planting are nuch the same as for transplanting in the nursery. In every case much pains should be taken to have the soil in the best condition. It is generally better to delay planting for a year than to attempt it in poorly prepared soil. Tree plantings have been made on our prairics by sowing tree seeds broadcast in atumn after first carefully preparing the soil, but the plan is seldom successful. A start can, however, be made from seeds by planting the seeds in hills either alone or with corn or beans. In the latter case the tree seedlings often do very well and do not interfere witl the growth of the crop. The seedlings are cultivated in the spring after the crop is removed and as they are in rows this is a very simple matter. The common and generally most successful plan with trees that can be easily transplanted is to start with seedlings and plant in rows. The simplest and easiest way of doing this is to furrow one way, mark out the 
other way and plant the trees in the furrows at the intersections. If Black Walnut or any of the oaks are wanted in a mixed planting it is generally best to plant the other species first and put in the nuts or acorns afterwards. Where it is desirable to plant seedlings or cuttings to fill vacancies, a pointed stick or spade may be used to make the hole. Whatever method is used in planting, it is most important that the soil be packed firmly around the roots, so they will not dry out. If the soil is dry it cannot be made too solid around the roots. If cuttings are used they should be made about $\mathrm{I}_{4}$ inches long, and in planting be pushed into the loose soil in a slanting position, leaving only one bud above the surface, as recommended in the planting of cuttings.

Cultivation should be commenced shortly after planting and be repeated often enough to kecp the top three inches of soil loose, so as to form a dust blanket to retard evaporation during dry weather. The soil should never be allowed to become baked hard after a rain, but the crust should be broken up with a horse cultivator as soon after a rain as it can be worked. Cultivation should be discontinued after the first of August, in order to encourage early ripening of the wood. The weeds that grow after this time of year will do no harm.

One of the best tools for early cultivation of small seedlings is Breed's Weeder, which may be worked both ways and cleans out the weeds to perfection. The ordinary corn cultivator is also a good implement for this purpose. Later cultivation should consist of working the soil with a one-horse cultivator or plow. If the horse implements are properly used there will be no necessity of hand hoeing, for the few weeds that grow in the rows of trees will do no injury to them. Some planters sow oats among the young trees for protection when cultivation ceases, but if field mice are abundant it may be best not to do so. Late in autumn of the first year or two after planting some soil should be turned towards the trees with a plow, to protect them.

Thinning. In growing prairie groves we should always aim to have the tops of the trees just touch one another without serious crowding, but still have the soil shaded and protected from wind. In orcler to bring this about, the grove must be thinned occasionally, for although the trees would thin them- 
selves if left alone it would be at the cxpense of growth and perhaps cause serious injury. T'rees that are crowded together may suffer more from drouth than those that have plenty of room for their roots. This is especially true of tender trees on dry land. If the trees begin to crowd one another the poorest should be removed, but this should be done carefully and never to such an extent as to let in the sunlight, which would encourage the growth of grass, weeds and side branches. Thinning may be done at any time, but if the wood taken out is to be used for fence posts or poles it would be better to cut in winter and peel at once to aid it in curing.

The Blowing Out of Small Seedlings planted in prairie soil is not uncommon where they are in very exposed situations. The movement of the young seedlings by the wind keeps the soil loose around them, which the severe winds blow away. Occasionally by such means the roots may be left three or four inches out of the ground the first season. In such very severe locations it is often a good plan to mulch the soil with straw or similar material until the seedlings are well established, after which they may be cultivated, or the mulching process may be continned until they will take care of themselves.

\section{The Proper Location of the Buildings on a Farm} is a very important matter and seldom receives the attention which its importance demands. The position of the buildings determines the location of the drives and of the shelterbelts if any are to be planted. There are many factors which should enter into the study of this question, among the first of which is the lay of the land. Good drainage and good water are the first requisites for the location of a home, after which come convenience and beauty. It is very desirable that the first location be made just right, since when other improvements and buildings have been commenced it can seldom be clanged without much extra expense. In the case of most of our farms the subject of plans is conspicuous by its absence, as small cramped grounds about inconveniently arranged buildings bear abundant evidence.

In figure 5 is shown four plans suggestive of the proper location of the shelter belts about farm buildings located on level prairies, and varying according to the location of the main highway. Five acres in the form of a rectangle, 25 rods wide and 32 
rods long. are included in the land about the buildings, and this has a shelter belt five rods wide on the north and west sides. and on the south side two rows of trees ten feet apart, with the

NORTH.
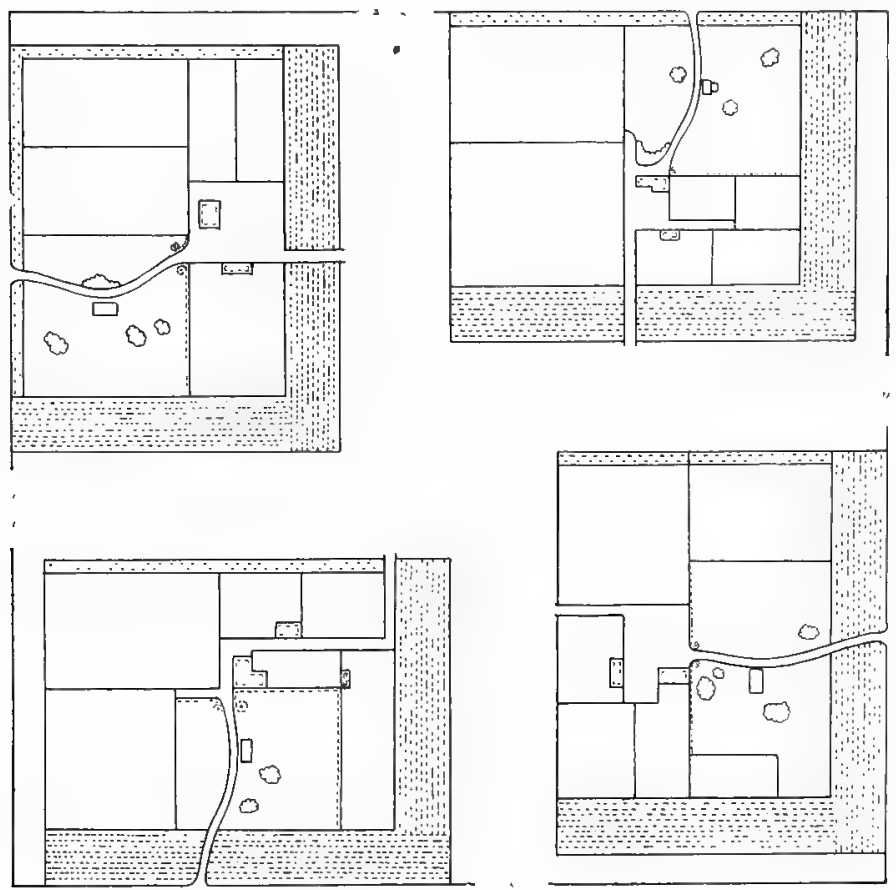

Figure 5. Suggestion for laying out the grounds about the buildings on prairie farms, showing arrangements adapted to a highway located on four different sides. Size $30 \times 37$ rods, enclosing five acres, exclusive of shelterbelt on north and west sides five tads wide. Rows of trees indicated. See figure (6) for further details and suggestions.

trees one rod apart in the rows. Within this enclosure are all the farm buildings, orchard, fruit and vegetable garden, barnyards, etc. The house should be within Ioo feet of the road, and the stock buildings at least 100 feet from the house and garden. About the buildings and garden some supplementary wind- 
breaks and ornamental trees and shrubs will be necded for inind protection and for beautifying the place. This arrangement gives plenty of room for the buildings, barnyards, garden and orchard, and, while all the land enclosed may not be needed for these purposes, the remainder is well adapted to the growing

NORTH.

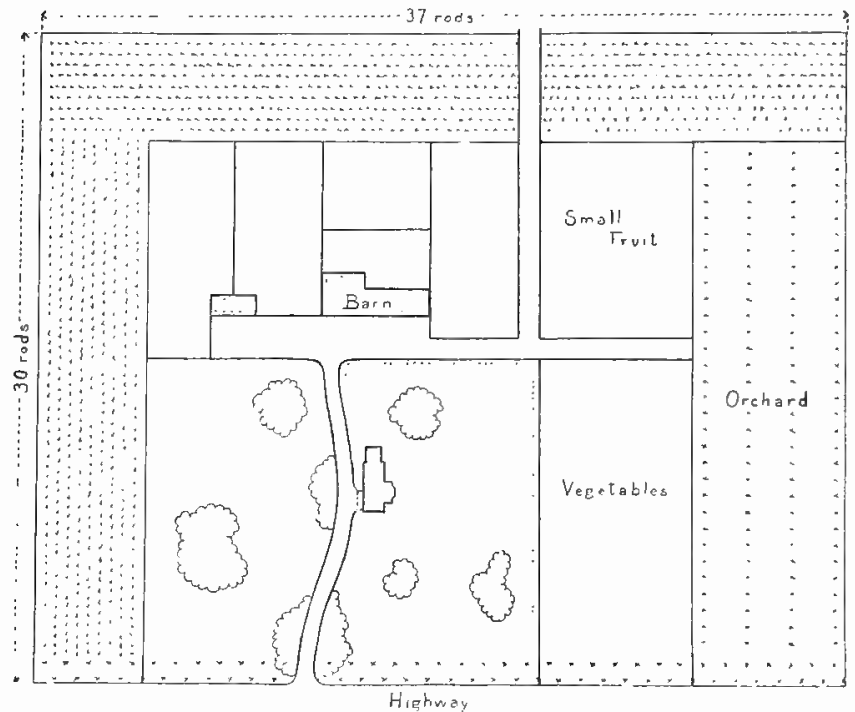

Figure 6. Suggestion in detail for laying out the grounds about the huildings on a prairie farm. Highway on south, size $30 \times 37$ rods enclosing five acres; windbreak on north and west five rods wide. Two rows of trees next to highway. Rows of trees indicated.

of general farm crops. The plans arc only suggestive and no attempt is made to work out details, and there are comparatively few farms that they would fit exactly. For instance, while it is desirable to have the buildings centrally located, their position must fiequently be pushed to one side on account of a swamp or lowland which is not suitable for them, or their position may be determined by a beautiful natural grove. Figure 6 shows a plan for a south front drawn on a larger scale. It may often be desirable to change the shape of the land enclosed, but 
in the great majority of prairie farms a plan similar to this would work out to good advantage and the area enclosed by windbreaks could often be increased to ten acres to good advantage.

A rule that should be carefully followed in all tree plantings is that the view from the most commonly used rooms of anything that is suggestive of pleasant associations or that is especially interesting or entertaining should not be cut off. Under this head would be included the view, from the livingroom windows, of the traveled wagon rnad or perhaps of the railroad, of the neighboring houses or perhaps a nearby lake, and of the important fields on the farm, especially those where stock is pastured. 'l'hese views can generally be secured without seriously impairing the value of the windbreaks, by cutting small openings in then or perhaps by simply shortening the trees, so that they will not interfere with the line of sight. 


\section{CHAPTER V.}

\section{FOREST REGENERATION AND TREATMENT.}

The timber lands of Minnesota should, as a rule, be managed so as to get the greatest cash returns from them, for that only is practical forestry which has this fundamental feature always in view. Our virgin forests have contained, and those remaining now contain, a large percentage of trees past their prime and losing in value each year they stand. Such forest products should be worked up as soon as a good market is found for them. In virgin forests there is no increase, the annual growth being just balanced by the annual decay under normal conuitions.

The Cultivation of Trees on timber lands in this section has never received much attention, and the only data as to the rate of increase that we have to follow are what can be obtained from the native forests, and these are for this reason only approximately correct. In European countries and elsewhere it has been proved by long experience that nore timber is grown per acre, and that the growth is much more rapid, on land where some attention is given to systematic forestry than on that which is left to itself, and it will seem reasonable to believe this. when we consider that much of the energy of trees may be expended in fierce competition with neighbors, which may weaken them all and perhaps bring about unhealthy conditions, and that natural forest land is generally unevenly stocked with trees, many of which are rotten or otherwise defective, and often with those that are not the most profitable kinds to grow. In the cultivated forests unnecessary crowding is prevented by judicious thinning, and the land is kept evenly and completely stocked with the most profitable kinds.

Succession of Tree Growth is an expresion sometimes used as though there were a natural rotation of trees on the land. There is nothing of the sort. Sometimes hard woods will follow pine, or the pine the hard woods, where the two were mixed at 


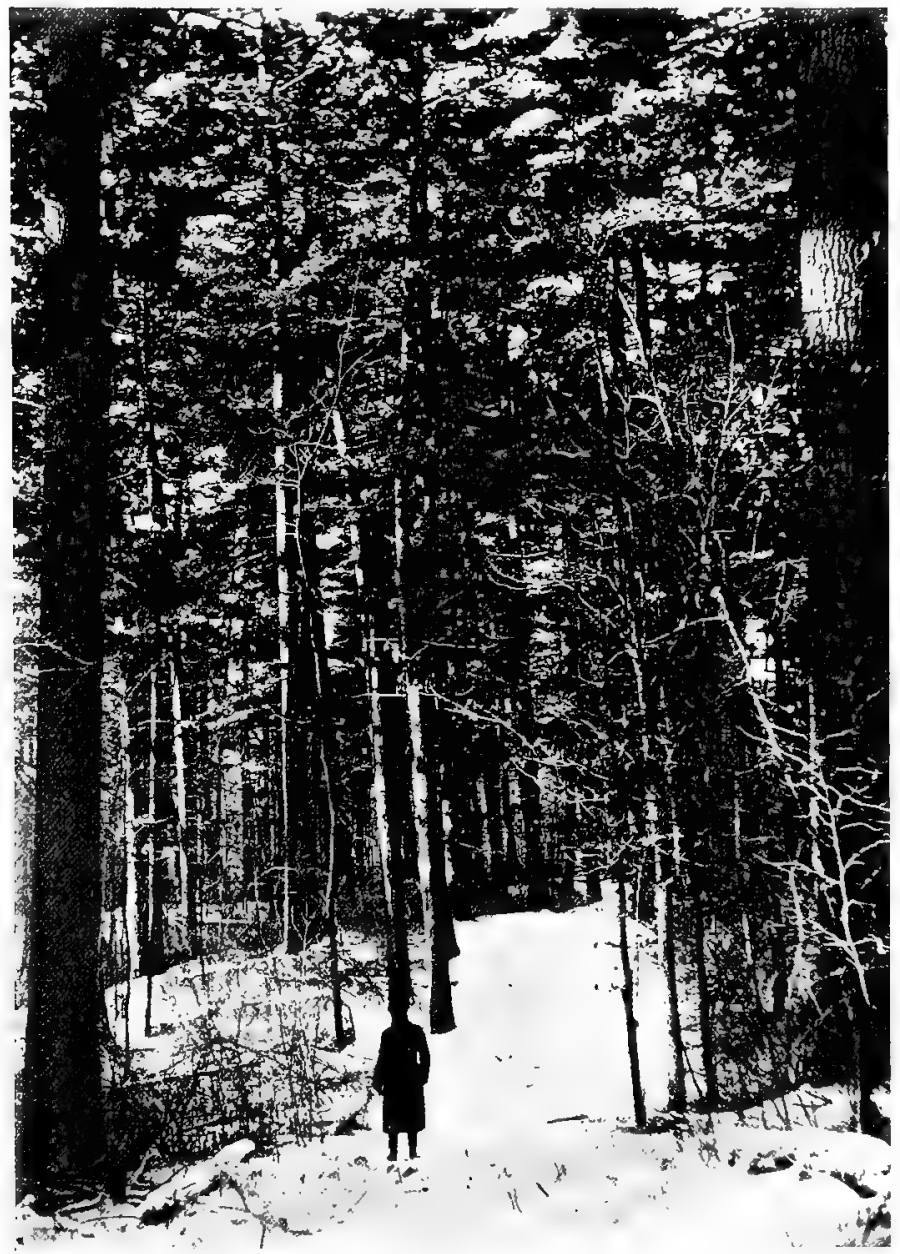

Figure 7 . Virgin Forest.

White and Red Pine mixed. Near Mille Lacs. Good Natural Regeneration. 
the time of cutting and there was a young growth of one or the other kind which had a chance to grow when its competitor was removed. Where land is severely burned after being cut over, the trees that show first are generally the kinds with seeds that float long distances in the wind, such as Poplar and Birch, or those having fruits especially liked by birds, such as the Bird Cherry, which is very widely distributed. These show first on account of getting started first. The pine and the other trees may come in later owing to their being seeded later or owing to the later advent of conditions favorable to their germination and growth. It may happen in the case of burnt-over pine land that pine seed is distributed over it the first year after it is burned, but owing to there being no protection from the sun the young seedlings of White and Norway Pine which are very delicate, are destroyed. After a young growth of Poplars has appeared the pine seed may find just the right conditions for growth for a few years and finally get ahead of the poplars and crowd them out, while in the meantime it is being much improved by the presence of the poplars, which grow rapidly and force the pines to make a tall growth. On the other hand. however, the poplars, birches and other trees and shrubs and even wecds may sometimes make so strong a growth as to kill out the young pine seedlings if they are not sufficiently well established at the time the mature growth is cut.

Regeneration is a term commonly used in forestry to signify the renewal of forest trees upon the land. It is a convenient term and well worthy of general introduction into the forest literature of this country. The different forms of regeneration may be referred to as (I) regeneration by natural seeding, (2) regeneration by artificial seeding, (3) regeneration by spronts and suckers, (4) regeneration by planting scedings, (5) regencration by planting cuttings. The method of regeneration best adapted for one section may not be at all fitted for another under different conditions, and often it is best to combine two or more of the different forms of regeneration.

Regeneration by Seed. Where natural regeneration by seed can be easily brought about, it is generally the best practice. This is especially true in sections where timber is comparatively cheap, as is generally the case in this country. It may be greatly assisted by stirring the surface of the soil in good seed 
years, and in other ways bringing about conditions conducive to the germination and growth of the seeds. Where it is practicable to use it, a disk harrow is an admirable implement for breaking up the forest floor so as to allow the germination of seeds. Where a disk harrow cannot be used to advantage, and it can seldom be so used on new land in this country, it is a good plan to use a drag made by tying together several oak branches or small logs. Good seed years do not occur very often in our most desirable specics, and it is very important to take advantage of these good years when they do come. $\Lambda t$ such times it is often a good practice to make extra cuttings in order to let in light and air, as well as to stir the soil and so make it possible to secure a good catch of the seed.

'The methods adopted to secure natural regeneration by seed may be divided into three systems, cach of which may be best adapted to some special conditions. These are known (I) as the Selection Method, (2) as the Strip Method and (3) as the Group Method.

The Selection Method refers to the cutting of the mature trees and to the removal of inferior trees to make room for the better kinds. In this system much care should be exercised to prevent the growth of grass, which gencrally comes in when the cutting is done more rapidly than the seeding trees can seed the bare land. On the other hand it is just as important to exercise care that the young seedlings which have started have sufficient light so that they can make a good growth and not be shaded out by the older trees. The removal of a single tree often lets in so very little light that seedlings cannot get a good start. On this account the group method is probably best adapted for general use.

Strip Method is a term that is applied to the system where the trees are removed in narrow strips across which the remaining older trees can easily scatter their seed. The best width of strips will depend on the species and the local conditions. Some who advocate this method claim that the strips should not be wider than the height of the trees, while others would allow strips three or four times the height in the case of the elm, maples and pine, and in the case of birch even eight times may not be too much. Such strips should generally begin on the side opposite from the prevailing winds at seeding time, so the 
seed will be blown onto the denuded land. In the case of hillsides the strips should generally extend along near the summits, and successive strips shotid be on the lower sides to prevent washing of the soil. The strips may extend on one or two sides, and in shape should often be adapted to the contour of the land.

The Group Method is a system of cutting strips successively on the insicle of certain groups. This may be termed a

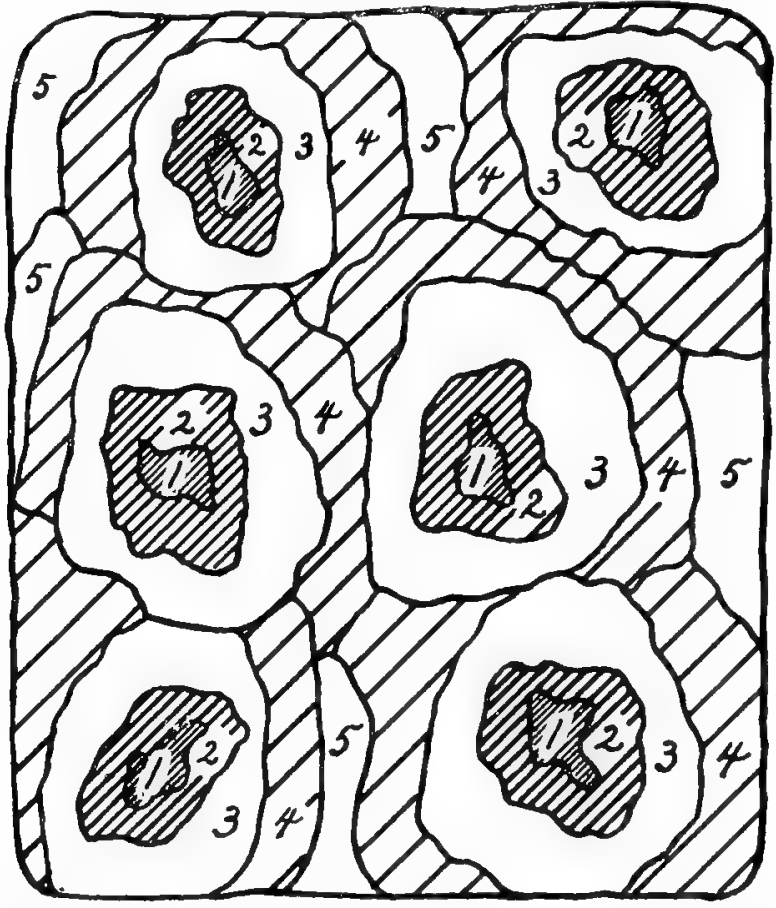

Figure 8. Diagram illustrating the system followed in the group method of cutting. Cuttings are begun at points marked $x_{\text {, and are }}$ gradually cxtcnded by successive cuttings as indicated by figures $2,3,4$ ind 5. After Schlich.

natural method, and for general use, especially in mixed woods and where the land and conditions are quite valuable, it is much 
the best. It gives a chance to adapt the method of cutting to the different species and to the different conditions which may be found in the forest. For instance, a tamarack swamp, dry knoll covered with oak, a steep hillside, and level, rich, rocky land, each covered with the trees peculiar to it, would very likely all be included in almost any forest tract of any considerable size in the northern states, and each portion shonld receive special treatment. We can begin with one group or several, and we can start our regeneration in each group perhaps where there is already a good growth of young trees. In fact this systen gives us a chance to begin regeneration where the greatest necessity or the best chance for it already exists.

The size of the opening will depend here as in the strip method on the species grown and their conditions. Generally the first openings will be from one-fourth to one-half acre or more, and the strips takien around it should in width not greatly exceed the height of the trees in the strip next to be cut.

Of course the regeneration in any case should be managed with the same care that should be given to any well managed forest to bring about the predominance of the most valuable kinds under the best light and soil conditions.

Regeneration by Artificial Seeding. Occasionally it may be desirable to sow seed in woodlands. This is especially so in the case of some of our nut trees such as black walnut, butternut and oaks, which readily renew themselves by such means. In the case of pine and Spruce. however, success is quite uncertain under such treatment. Perhaps it is most certain with pine and spruce where it is practicable to furrow out with the nlow. as for instance it might be on some of the sandy lands of Minnesota where furrows might be run between the trees or the land loosened in patches with a hoe. In this case the standing trees afford the proper shade conditions for the seedlings. In the case of clear fields, it is quite a simple matter to sow the seed in furrows. Where the moss is thick on the surface of the soil, it is a good plan to cut it off in squares, or long strips may be sown after preparation. The seed will seldom grow if it is sown in deep or thick moss. Where seed is sown broadcast over ordinary forest land the seedlings are liable to be killed out by the weeds, which generally come in quickly as soon as the sinlight is allowed upon the soil. Pine and many other seeds are 
sometimes sown in clear fields with oats, when the straw protects from the sun in summer and the stubble holds the snow and acts as winter protection. Seed of ash, maple, elm and some other trees may sometimes be sown in the hills with corn to advantage in prairie planting, and willow chttings may also be used in the same way or with beans.

Natural Reseeding of the land is then almost the only practical means of restocking the land in this section, which should receive attention here, as other methods are too expensive. It generally takes place in this section, and the only reason why it is not more successful is the frequent destruction of the young seedlings by fires. The small crooked branching pine and other seeding trees that are always left by lumbermen in their operations here, and generally considered worthless, perform a very important work in producing seed, and it is a pity that there are not more such trees left to produce seed for our cut-over lands. When such trees escape the first burning after the land is cut over, they often remain for twenty years doing their blessed work of distributing seed each year, and when the conditions exist for germination and growth the sced grows and lives. Sometimes where such trees are not left by lumbermen, or where they have been destroyed by fire, it has taken twenty years to get the land properly resceded to White Pine by the slow process of seeding from trees at a distance of half a mile or more.

The Covering of Tree Seeds in Woodland, whether the seeds are sown naturally or artificially, can often be best accomplished by stirring up the soil with a strong harrow or a brush drag made of the branches of an oak or other tree having strong wood. This may sometimes be done most advantageously before the seeds fall, and at other times after they have fallen. Where the soil is made loose and the forest floor is broken up before the seeds fall, they are generally sufficiently covered by wind and rain. They may sometimes be covered most satisfactorily by driving a flock of sheep over the land aiter the seed has fallen, the foct of the sheep pressing the seed into the ground.

Regeneration by Planting Seedlings. This form of regeneration is practiced to a considerable extent in sections where timber is high in price. It is often the most economical 
way of securing a stock of coniferous trees upon the land. Under the conditions which frequently prevail on our cut-over land there is very little chance for natural or artificial regeneration of desirable kinds by seed, owing to the fact that all the seed-producing trees were cut when the land was logged, or have since been clestroyed by fire and the ground covered by a

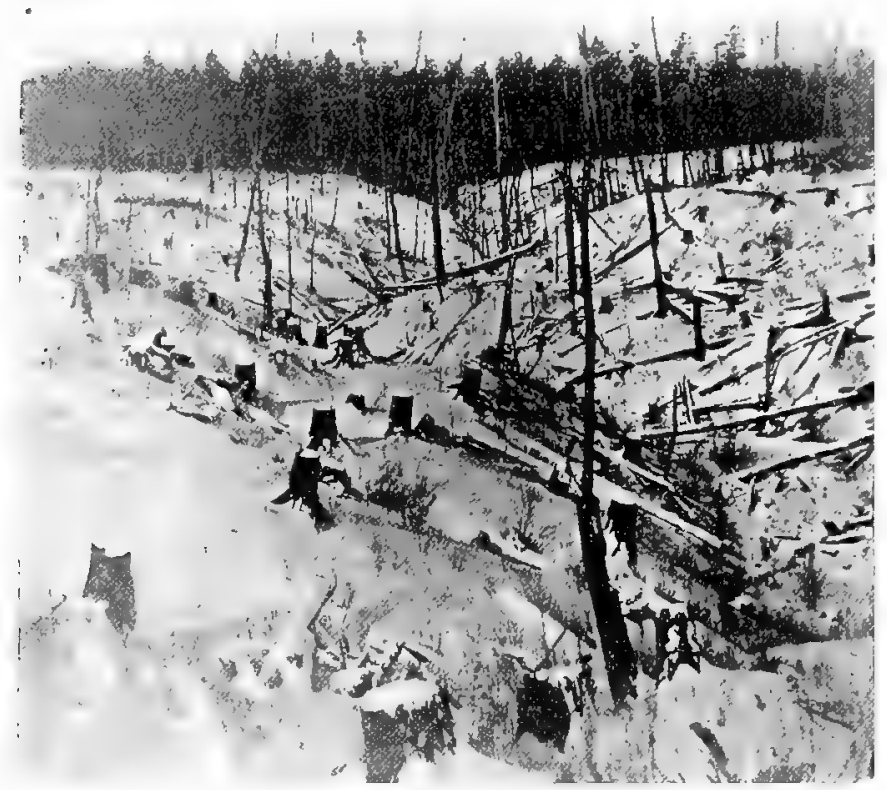

Figure 9. Old pine cuttings after being once burned over.

growth of weeds and inferior trees; but seedling pines can often be set out at intervals of perhaps ten feet apart each way where they would be sufficicntly crowded by the weeds, poplar and other fast growing trees, so that they would take on an upright form quite free from side branches until their tops interlaced, after which they would crowd one another. Such planting can be done here at an expense of about five dollars per acre. It is necessary for the success of such work that weeds be prevented from smothering the trees, which they are liable to do 
until the seedlings get well started, and to prevent this it may be necessary to cut back the crowding plants every summer.

It is quite common in European forests to see patches of land, perhaps four feet square. at twenty-foot intervals, which have been stripped of their mossy cover and sown to seed. These afford a sort of nursery throughout the forest, from which seedlings may be transplanted and on which a number of seedling plants are left and form a good forest cover.

Mound Planting is a term which signifies the planting of trees on mounds or on the surface of the land. This is sometimes done on wet lands for the purpose of getting the roots above standing water, and it is a practice which can be followed in the case of several trees that do well upon rather moist soil, although they may die if put at once into standing water when young.

Regeneration by Cuttings. There are few trees that can be grown in general practice from cuttings, but it is the best way to start willows, since seedlings of them are generally quite difficult to obtain. Some species of the poplar can also be grown to best advantage in this way.

Regeneration by Sprouts and Suckers. Some trees, such as the willow, poplars, oaks, chestnuts and maples renew themselves very readily by sprouts and suckers. Land that is managed on this plan for renewal is termed coppice. With the exception of the willow and possibly one or two other trees, the growth from coppice is not so large as that from seedlings, and it is seldom employed for other purposes than the production of firewood. In order to get the best growth in this way, the trees should be cut close to the ground when they are dormant, and the stumps left highest in the center, so they will tend to shed water and not rot. The advantage of cutting close to the ground is that the sprouts that come out from the trunk soon get roots of their own, which makes them more durable than when they depend entirely upon the old stump roots and they are much less liable to be broken off in high winds.

Pollarding consists in cutting back the side branches of a trce, or cutting off the main stem at a few feet from the ground. The branches may be cut off close to the main stem or at a short distance from it, the latter method being preferable. New 
shoots spring from the cuts, and these are again cut when of suitable size. What has been said in regard to the season and manner of cutting in the previous paragraphs is practically true here. This process is mostly used in the case of willows and poplars to obtain material for basket work, small poles, fuel, etc.

Time of Rotation is a term used to indicate the age to which trees are grown. The length of this time will depend on the species and on the conditions. For some species not less than eighty years should be allowed for full maturity, while still others may be successfully worked on a thirty-year rotation period. It is not used in the same sense as in ordinary agricultural operations, where it signifies frequent changes of the crop for several years with a view to getting the most out of the soil. Since trees do not impoverish the soil, but improve it, there is no necessity for any such method of rotation in forestry as there is in agriculture.

Pruning of Forest Trees is generally an expensive operation and little is required if trees are properly crowded when young, so that they take on an upright form free from side branches. If they are not crowded when young, many side branches are formed, which generally die out when the trees get large enough to shade all the ground. In some cases these dead branches drop quickly to the ground, and in others they remain for years, producing knots and irregularity in the wood formed in the meantime and should be removed. Trees grown in the open retain their lower branches more or less throughout life and they produce in consequence timber of inferior value as compared with trees grown in crowded woods.

Large wounds made by cutting off green branches should be covered. It is often desirable to remove dead branches and it is the practice to do so in some of the plantings of Wnite Pine that have been made in New England. It is said that the lumber there is so greatly improved by so doing that the operation is a paying one. But under ideal conditions for the development of timber trees very little is gained by pruning.

The Young Growth is Often Injured in ordinary lumbering operations by the felling of the trees, which bend them to the ground and often break them. Where special care is desired to protect the young growth it may be desirable to lop off the 
branches before felling. This is practiced to some extent where forests are very valuable.

The Small Dead Twigs on such trees as spruce, and also the shrubbery which mav surround them, are often a very va1uable protection against sun-scald. This also protects from drying winds, which would otherwise, perhaps, sweep through the forests and do them injury. Forest trees seldom do best where they are subject to a strong draft of wind around the trunks. While, under some conditions, it may be desirable to remove the dead branches from trees, yet even if it is decided to do this in the interior of the forest, it is generally best to leave the borders without such pruning in order to protect it from drafts.

Forest Weed is a term used to signify any growth that may occur in forests which crowds the other growth, and so prevents it from developing to the best advantage. It may apply to raspberry bushes, hazel brush, poplars and other similar materials which often come in our forests in the early growth of the plantation; or even to large inferior trees which are in the way of the proper development of the better species. But a tree may at one period of its growth be of much value in a forest in producing shade and acting as a nurse tree, while later on in its growth, after its usefulness has been completed, it may be regarded as a weed.

Thinning is the most inportant part of the forester's art in securing good timber and in reseeding the land. The ideal condition in the life of timber trees is to secure a natural crop of seedlings so crowded when young as to increase very rapidly in height and produce slender trunks free from side branches. When this crowding has gone far enough the less valuable and weaker trees should be removed to give the better trees sufficient room for their crowns to develop. These remaining trees in the course of a few years will again crowd one another too severely, and this process of removing poorer trees must then be repeated. Then when the final stand of trees is approaching maturity, thinning should be commenced to let in light and air to produce the conditions under which seedlings develop to best advantage.

Ifeavy thinning should be practiced only after very careful 
consideration. It is seldom desirable, as it lets in ton much sunlight and may encourage a growth of grass. Where natural regeneration is practiced, only such openings should be made as will be shortly covered with valuable species.

\section{Important Principles that Should be Remembered:} (I) That increase of wood is proportional to leaf surface and therefore the lands should be kept as nearly as possible covered with a canopy of leaves, which should be on trees that are valuable for their timber. (2) That leaves need light; therefore partly shaded branches form but little and imperfect wood, and those that are very heavily shaded die out; crowding prevents the formation of branches on trees and is important in secturing the best timber. The amount of waste in branchwood varies greatly, it being very much in trees that are entirely open grown, and very little in trees that have been severely crowded. But as over-crowding causes decay it is important to do the thinning as soon as the tree has taken on a proper form. Crowding on one side causes crooks, and these can be prevented by cutting off the crowding tree or branch.

Waste in Forests occurs, as has been partially stated, in branchwood, crooks, rot, and in growing of the kinds of trees that are not marketable. The kinds that are marketable depend largely on the demand. In considering this subject it is best to be conservative and to select linds that are of stable value, and not likely to go out of fashion. Since crowding is best done by small trees among the large timber trees, they should be of a kind that are marketable when small.

Much waste in timber is caused by cutting trees when small. The amount of waste in the shafts of straight trees, excluding trunks, branches and bark, may vary from eighty-one per cent in a tree eight inches in diameter and ninety feet high, to six per cent in a tree forty inches in diameter on the stump and one hundred feet high. It will thus be seen that there is great loss from cutting trees when small, especially if they are growing rapidly.

Improvement Cuttings is a term used to signify an improvement of forests by cutting out inferior and crowding trees. This is a very important matter in getting almost any forest tract into a condition where it can be managed to best 
advantage under the group, strip or other systems. Generally it will at first consist in removing the dead, rotten and mature trees and those of inferior species, and so give better opportunity for the more valuable kinds. This is a matter that calls for much good judgment. Care should be exercised not to make openings so large but what they will shortly be occupied by seedlings of valuable trees. Where large openings are made they are apt to become covered with grass, which is a great detriment to any forest growth and always indicates that the cutting has been done too rapidly for best results.

The $\mathbf{A x}$ and Saw, then, as will be seen from the foregoing paragraphs, furnish the most important means when used judiciously in securing the best growth of timber in forests of this section and the proper succession of growth on forest land.

The Farm Woodlot is a customary feature on many farms in the northeastern states. As a rule it occupies land that is of very little value for any other purpose. It is generally not managed at all, but left to look after itself, and often it is pastured. It is expected to furnish firewood, posts and poles and an occasional stick of dimension stuff. Too often the best is cut and the poorest left to grow. Under such rough treatment the woodlot becomes stocked with an inferior growth that is of little value except for firewood, and it does not produce as much of that as it might under a different system of management.

Improving the Woodlot. The general rules laid down for the management of forests will apply here. The cattle should be kept out, so as to give the young seedlings a chance to grow. Improvement cuttings should be introduced with a view of getting rid of the crooked and mature trees and those of inferior species and of encouraging a growth of young seedlings of valuable kinds. 


\title{
CHAPTER VI.
}

\author{
PROPAGATION.
}

Trees are Grown from Seeds or by Division. The latter term includes increase by cuttings, layers, buds and grafts. Plants grown from seeds are generally more vigorous and longer lived than those of the same species propagated in any other way. Trees should be grown from seeds when it is practicable to do so, but willows and some other trees are apparent exceptions to this rule and seem to do as well when grown from cuttings as when grown from seeds. Varieties do not generally perpetuate their peculiar characteristics when grown from seeds, and must therefore be propagated by some method of division.

The Most Desirable Trees from Which to Propagate are those of good form and healthy growth; the latter is the one most important requisite, especially if new plants are to be grown by any method of division. It is not so essential in selecting seeds, as even weak plants may produce good seedlings, but unhealthy cuttings, layers or grafts are of very uncertain growth. In general, it is best that the stock trees be healthy throughout, but a tree may have a rotten trunk due to some injury and still have perfectly healthy branches and be a desirable tree from which to propagate.

\section{SEEDS.}

Sources of Seeds. In growing trees from seeds the source of the seeds is very important. It may be given as a safe general rule that seeds are most desirable which come from trees grown in as severe a climate as that in which the seeds are to be sown. It has been found that trees of Boxelder and Red Cedar grown from seeds gathered in Missouri are not nearly so hardy in this section as those from seeds grown' in our own state. It has also been found that seeds from the western slopes of the Rocky Mountains, where the climate is very humid, produce trees which are not so well adapted to withstanding the condi- 
tions of this section as trees grown from seeds from the eastern slopes, where the stimmers are very dry and hot and the winters very dry and cold. Our climate is especially trying to trees, and it is necessary to exercise much more care in the selection of tree seeds here than it is in the more favored climate of the castern and western coast states.

There are Conditions Under Which Every Species of Tree Thrives Best and makes its greatest growth, but the trees produced under these conditions are not always the hardiest. As we reach the limits of their growth, trees have a tendency on account of drouth or cold to become smaller, more compact in form and to fruit younger; e. g., the Boxelder is a large tree in Kansas and Missouri, but as it gets towards the Manitoba line we find it becomes dwarfed and more bushy in habit. Towards the southern limit of its range the tree becomes more open in habit and more liable to disease. The Scotch Pine seeds imported into this country are generally saved from the small scrubby trees that are found in the higher altitudes of the mountains of Europe, because such trees produce the most seeds and they are most easily gathered from them, while seeds are seldom gathered from the large timber trees of this species, and it is very likely that this poor seed stock is responsible for much of the scrubby appearance of many Scotch Pine plantations in this section.

Trees Have a Strong Tendency to Perpetuate Qualities which have been developed in them by climate and soil conditions. Hence, even though an essential point in considering the value of any tree is its hardiness, the question of size is important and should be taken into account, as we generally wish to grow trees of as large size as practicable. We may conclude, then, that since trees from a very cold climate generally lack in hardiness, and those from a very severe climate may lack in size, it is best to procure seeds from the best trees grown near by or from those grown under similar climatic conditions elsewhere. It is not generally necessary to limit this range very closely, as a hundred miles north or south of a given point will seldom make much difference in hardiness, unless the climatic conditions are very dissimilar.

The Place Where the Trees that we are to Set Out are Grown is not of so great importance as the source of the seeds 
from which they are grown; e. g., seedlings of Red Cedar grown in Missouri from seeds of native Minnesota trees would be safer to plant here than seedlings raised in Minnesota from the seeds of native Missouri trees.

Seedling Variations. In our common trees varjations are not sufficiently marked but that we think of the trees as coming true from seeds, and yet careful observation will show to any one that each seedling plant is different from neighboring plants of the same species. Sometimes a seedling will occur that possesses especially pleasing or curious characteristics that are very marked and desirable. In such cases the seedling is generally propagated by some method of bud-division and makes a new variety. In this way have originated such highly-esteemed kinds as Wier's Cut-leaf Maple, which was a chance seedling of the Soft Maple, the Weeping American Elm, Cut-leaf Birch, Weeping Mountain Ash, Pyramidal Arborvite, and a host of other kinds that are propagated by bud-division by nurserymen. The person who is on the lookout for these or other variations will have no trouble in finding many that may perhaps be worth naming and propagating.

Gathering Seeds. All kinds of seeds should be gathered when ripe. In some cases it is best to pick them from the trees even before they are quite ripe, after which they will ripen if kept dry. Unripe seeds do not keep as well as perfectly ripe seeds. Most kinds of tree seeds are most cheaply gathered from the ground. In some cases this method can be greatly facilitated by cleaning up the land under the trees so it will be smooth and ever. Seeds of some species can often be swept up at little expense from under trees growing along the highway.

Germination of Seeds. There are many conditions which affect the germination of seeds:

(I) Seeds which are thoroughly ripened before they are gathered produce the best plants. Very immature seeds will very often grow, but the tendency with them is to produce weak plants. (2) Freshly gathered seeds, as a rule, are preferable to old seeds for sowing, and seeds that have never been allowed to become very dry are more likely to grow than those which have been severely dried. This is especially true of most of the kinds of seeds that ripen in early summer, the most of which lose their 
vitality very quickly when stored.

(3) Some seeds, such as those of the Plum, Cherry and Black Walnut, require severe freezing when moist in order to germinate. (4) Seeds that are covered with water will not generally grow. This is true at least of our northern tree seeds. (5) The seeds of some trees germinate at a temperature near freezing, while others requre a much higher temperature. (6) After seeds of some plants have become very dry, scalding may aid them in germinating, while with others scalding is injurious. It is sometimes desirable to soak seeds for one or two days in tepid water, and then mix with sand and freeze before sowing. Lindley records that seeds found in raspberry jam grew after passing through the heat necessary to boil syrup (240 degrees Fahr.) and that seeds of Acacia and Lophantha grew after being boiled five minutes, but our common tree seeds will not stand such treatment.

Stratification, as the term is used in this connection, refers to the storing of seeds mixed with layers of earth, leaves or other material. It is customary to apply the term solely to seeds that are mixed in this way and kept frozen over winter. It is the common practice with the seeds of such trees as the Black Walnut, Hickory, Basswood, Plum, Cherry and Mountain Ash. Where only small quantities are to be cared for they are generally mixed in boxes and the boxes buried in well drained soil out of doors, but where large quantities are to be handled they may be mixed with soil on the surface of the ground and left until spring; such a pile is termed a pit. One of the best materials with which to cover seed pits is inverted grass sod. It is a good plan to have the material that is mixed with the seed so fine that it will easily go through a screen and leave the seeds separated for sowing.

Wintering Acorns and Other Nuts in Large Quantities. On account of the great liability to injury where a large amount of nuts are stored in heaps, and on account of the impracticability many times of stratifying them with sand, the following plan is resorted to in some sections:

A house is made, preferably with a sandy floor, so as to secure good drainage, and is covered with sod roof and sides, so as to keep out most of the frost. This may be of any size, but perhaps 20 feet in width and any length would be very convenicnt. The 
nuts are spread over the ground about 18 inches thick, and are kept stirred until frozen in winter. As soon as they thaw out, they are turned once a day. In this way they are prevented from molding, and from the other injuries that are so common to nuts stored in large quantities. It would be desirable to keep the temperature from ever going much below freezing.

Seeds May be Classified Into Three Grotups: (r) Those that ripen in spring and early summer, (2) deciduous tree seeds that ripen in autumn, and (3) coniferous tree seeds.

Seeds that Ripen in Spring and Early Summer should be gathered as soon as ripe, and, with the exception of the Red Elm, sown within a few days or weeks, as they retain their vitality but a short time. (Red Elm seed will not grow until the following spring). In raising seedlings of this class it is important to have land that will retain its moisture during the summer months or else that which can be conveniently irrigated, since these seeds must often be sown during very hot, dry weather, and as they cannot be covered deeply they are very liable to fail with any but the best conditions. The thousands of seedlings of Cottonwood, Elm and Soft Maple that spring up on the sand bars along our rivers and lake shores show what are the best conditions for these seeds to germinate.

Cottonwood Seedings can be grown by scattering the branches bearing unopened seed pods along rows in moist soll and covering the seed lightly when it falls, but they are of so uncertain growth that most of our nurserymen depend upon the sand bars and lake shores for their supply.

E1m, Soft Maple and Mulberry seeds generally grow well on any good moist soil. They should be sown thickly in drills eight inches wide and three feet apart, or in narrow drills. Elm seeds should be covered with about one-half inch of soil, Mulberry with about one-fourth inch and Soft Maple with about one inch. If the weather is dry the soil over the seeds should be well packed, and if the weather continues dry the rows should be watered. Watering, however, is seldom necessary on retentive soil if the soil has been properly packed. With proper conditions seeds so planted will start quickly and grow rapidly; the Elm will grow from six to eighteen inches and the Soft Maple twelve to twenty-four inches high before the first autumn. Such 
seedlings are large enough for permanent setting in forest plantations or windbreaks. They may be allowed to grow in the seed bed another year without injury, but should be transplanted before the growth of the third season begins.

Seeds of Deciduous Trees that Ripen in Autumn may be sown to advantage in the autumn; provided, ( $\mathrm{I}$ ) the soil is not of such a nature as to become too solidly packed over them before spring; (2) they are not liable to dry up or wash out; or (3) they are not subject to injuries from rodents, insects or other animals. In many locations some or all of these possible injuries may make spring sowing most desirable with most kinds of seeds. Our most successful nurserymen, however, prefer to sow in autumn, and try to bring about the conditions that make it successful.

In the Matter of Storing Seeds it is difficult to lay down any exact rule to follow, and here, as in all other similar matters, consiclerable must be left to good judgment. As a rule, however, it is perfectly safe to winter over all of the seeds of hardy plants which ripen in autumn, by burying them in sand out of doors.

Tree Seeds that Ripen in Autumn may be divided into four classes, which require different methods of treatment to grow them, viz., dry seeds, seeds with fleshy coverings, nut seeds and leguminous tree seeds.

- Dry Seeds, like those of the Ash, Birch, Hard Maple and Boxelder, are very certain to grow when sown in the spring in drills as soon as the soil can be easily worked, in the same way as recommended for Soft Maple and Elm. If not sown unti] spring they will have to be kept over winter, and when only a small quantity is to be kept over this is best done by spreading the seeds on the surface of the hard ground, covering with an inverted box and digging a ditch around it to carry off the water, or the seeds may be mixed with sand and kept in a dry, cool place. Large quantities may be kept on dry ground under a shed. These seeds will stand considerable drying, but if allowed to become very dry, hot, or moist, their vitality may be injured or destroyed.

Seeds with Fleshy Coverings, as those of the Cherry and Plum, should be kept fron getting dry before planting. The best way to handle them is to separate them from the pulp, mix with 
moist sand ont of doors, and keep them moist until planted. It is generally safe to sow such seeds in the autumn on good land, but some growers prefer to sow them in the spring. This class of seeds requires to be frozen before germinating. If allowed to get dry before being frozen, they should be mixed with moist sand for a few days until plump, or they may be soaked in water. but care must be taken that they do not get water soaked. Sonnetimes the dry, hard shells of such seeds seem to be waterproof. In this case, if the seeds are of special value, it is a good plan to file a hole through the shell, so as to let the seed become moist. Most seeds of this class grow the first year if properly handled. but some of them-for example, the Red Cedar and the Wild Thorn-even with the best management, will remain dormant in the ground for one year before growing.

Nut Seeds, as those of the Oak, Hickory and Walnut, should be handled as recommended for seeds with fleshy coverings, but are more sensitive about being severely dried. As they do not transplant readily, it is very desirable to plant them where they are to remain permanently. They should be covered abont two inches deep.

Seeds of Leguminous Trees, as those of the Black Locust. Honey Locust and Coffeetree, will stand severe drying for a long time and still grow, provided they are treated with hot water just before planting. In this case the hot water should be poured over the seeds shortly before they are sown, and be allowed to stand until cool. when it will be iound that some of the seeds have swollen up; these should be picked out, and the remainder be treated again with hot water, and the process repeated until all have swollen. Seedlings of this class generally transplant readily, and are managed in the same way that is here recommended for the Ashes and Maples.

Seeds of Coniferous Trees, such as Pine, Spruce, Tamarack and Arborvite, are dry and winged, but the Red Cedar has a lleshy, berry-like covering surrounding its seed. The seeds that grow in cones are most easily gathered before being shed irom the cones. The cones should be gathered before they open. and then dried, after which those of most species will open, and the seeds can be threshed out. Cones of a few trees, as those of the Jack Pine, will not open without artificial heat. These 
can be opened by gently heating them over a stove or in an oven to a temperature of from Ioo to I50 degrees Fahr. Seeds of this class grow readily when sown, but must be very carefully stored or they will lose their vitality. They should be kept similarly to the seed of the Ash and Boxelder, but are more liable to injury than these kinds from too much moisture or heat, and for this reason some careful growers prefer to always keep them mixed with dry sand in a cool shed.

The seeds of the Red Cedar hang on the tree all winter, and must be picked by hand. They should be soaked in strong lye for twenty-four hours, the fleshy covering removed by rubbing them against a fine sieve, and then stratified in sand, where they will be frozen during the winter. Even with this treatment they will seldom grow until the sccond year.

Raising Coniferous Trees from Seed. The land selected for sowing the seed should have a light, porous surface soil, preferably underlaid with a moist subsoil that will not dry out easily. It should be so located as to have good circulation of air over it, that the plants may dry oft quickly after rains, and it must be so shaded as to keep off about one-half of the sunlight. This latter permits a play of light and shade over the bed all day, and is about the condition under which we find nature raising such seedlings where trees partially shade the ground and protect them from the constant rays of the sun. In practice we aim to secure these conditions as follows: A piece of well drained, rather sandy soil, in an airy place, is selected, and laid out in beds four feet wide. In May the seeds are sown rather thickly (about three good seeds to a square inch), either broadcast or in rows, and covered with about one-fourth inch of sandy loam and then with about one-fourth inch of clear sand. Some of the smaller seeds, like those of White Spruce, should not be covered more than one-fourth inch. Before the seedlings break the ground, a framework, six feet above the beds, is made, and covered with laths, laid about one and one-half inches apart, running north and south, or with sufficient brush to shut out about one-half the sunlight. If the bed is very much exposed to the winds it should have similar protection on all sides. In such a place as this, or in woollands where these conditions can be fulfilled, evergreens can be raised with much certainty, while if planted in the open ground most kinds are sure to fail. 
The most common cause of failure with those who try to raise evergreens is what is known as "damping off," which occurs only while the plants are growing rapidly the first year. In such a case the seeds start well, and the seedlings grow vigorously for a short time, or until we have a spell of damp weather, and then die off with great rapidity. It seems that the sunlight and the mud that has been spattered on the plants so weaken them that they are liable to disease. For this reason we shade the bed, and cover with sand, which will not allow the mud to be spattered over the seedlings, and in very moist warm weather we occasionally apply dry sand to dry off the plants.

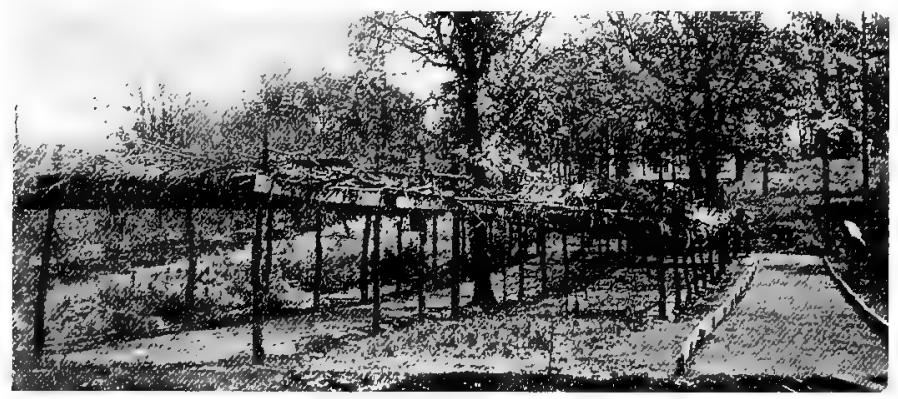

Figure Io, Evergreen seed bed shaded with a screen of old brush olaced on a frame.

For most kinds of conifers the shade is required for at least two years.

Coniferous tree seedlings grow very slowly when young, seldom making a growth of more than two or thrce inches the first year. The most rapid growing of our pines seldom produce a growth of more than sixteen inches in four years, and should not be moved to their permanent place until about this time. They should, however, be transplanted from the seed bed to a temporary place when two years old, to prevent crowding and to facilitate root growth.

On the approach of winter the beds of coniferous seedlings should be covered with about three inches of straw or leaves, evergreen branches, or other material that will afford protection from the sun and from alternate freezing and thawing. 
This should be removed in the spring after all danger from drying cold winds has passed.

Depth to Cover Seeds. Most of oni tree seeds should, in good soil, be covered from one-half to three-quarters of an inch; but this is rather too much for such small seeds as the Birch, Alder and Cottonwood, while the Black Walnut, Native Plum, Acorns and other large seeds and seeds of Boxelder, Ash, Soft Maple and Basswood may often be covered two inches to advantage if the soil is somewhat dry. It is a good rule not to cover any tree seeds deeper than is necessary to secure permanent moisture, and on wet or heavy land only a very thin covering is desirable. If the land is very heavy, it is a good plan not only to cover lightly but to sow more thickly than ustral, as a large number of seeds may be able to push up through the surface soil when a few would fail to do this.

The Amount of Seeds of Deciduous Trees to Sow on a given area depends very much on the kind and quality of the seeds and the soil in which they are to be sown. As a rule, thick is better than thin sowing. The seeds of Boxelder, Ash and Maple should be sown at the rate of about one good seed to the square inch; EIm and Birch should be sown twice as thick. Plums and cherries sown in drills should be allowed about one inch of row for each good seed. Black Walnut, Butternut, Hickory and similar seeds should preferably be planted three or four in a place, and all but one seedling cut out when nicely started. If sown in drills they should be placed from three to six inches apart. Rather thick seeding does not seem to be any hindrance to the making of a good growth by seedlings of most of our broad-leaved trees the first year, but if left thick in the seed bed the second year they are often seriously stunted. On this account such seedlings should be transplanted or thinned out before the beginning of the second year. In nursery planting it is a good plan to sow in freshly stirred land, as the seeds are far more likely to get a good start in it than in soil that has remained untilled long enough to become crusty and lumpy. Then, if the seeds are planted immediately after cultivation has been given, and while the soil is still moist, they have at least as good a chance as the weeds to start, while otherwise the weeds are soon ahead of the seedlings.

It is important to keep the soil loose and mellow between 
the seedlings, and to keep the weeds very carefully removed until at least the middle of July, after which they may sometimes be left to advantage to afford winter protection; but in the case of very small seedlings this protection is best given by a light mulch, put on in autumn and taken off in spring, and the weeds should be kept out.

If the seeds of Red Cedar, the Thorn, Mountain Ash, and other seeds that require a long tim $\approx$ to start, are sown in the spring, and do not germinate, it is a good plan to cover the bed with about an inch or two of hay or leaves, keep out weeds, and let this mulch remain until the following spring, when the seeds will probably be in condition to grow, and the mulch should then be removed.

TABLE SHOWING THE APPROXIMA'TE HEIGH'TS OF ONE-YEAR OLD SEEDLINGS GROWN ON GOOD AVERAGE, SOIL, IN MINNESOTA.

\begin{tabular}{|c|c|c|}
\hline BOTANICAL NAMES. & COMMON NAMES. & $\begin{array}{l}\text { Height in } \\
\text { Inches. }\end{array}$ \\
\hline Pinus strobus....... & White Pine ............. & 3 \\
\hline Pinus flexilis ....... & Western White Pine. & 3 \\
\hline 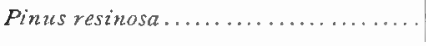 & Red Pine................. & 3 \\
\hline Pinus divaricala .. & Jack Pine .. ...... & 3 \\
\hline Pinus ponderosa scopulorum ..... & Rock Pine ............... & 3 \\
\hline Pinus sylvestris.............. & Scotch Pine ............. & 3 \\
\hline Pinus laricio aus/riaca... & Anstrian Pine ........ & 3 \\
\hline Larix Iaricina ... & Tamarack............... & 3 \\
\hline Larix europea....... & European $I_{\star}$ arch $\ldots . . . .$. & 3 \\
\hline Pirea canadensis............ & White spruce $\quad \ldots \ldots \ldots$ & 2 \\
\hline Picea mariana ............ & Black spruce............ & 2 \\
\hline Picea pungens ........... & Blue spruce.............. & 3 \\
\hline Picea engelmanni........... & Engelmann Spruce....... & 3 \\
\hline Picea excelsa............ & Norway Spruce ........... & 2 \\
\hline 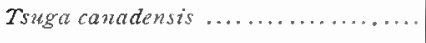 & Hemlock $\ldots \ldots \ldots \ldots \ldots$ & 3 \\
\hline Pseudolsuga taxifolia........ & Douglas spruce...$\ldots \ldots$.... & 4 \\
\hline Abies balsampa. . . & Balsam Fir.............. & 3 \\
\hline 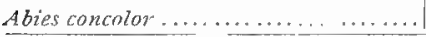 & White Fir ............. & 2 \\
\hline
\end{tabular}


TABLE SIOWING TIIE APPROXIMATE HEIGHTS OF UNE-YEAR OLD SEFDLINGS GRUWN ON GOOD AVERAGE SOIL,

IN MINNESOTA. (Contmued.)

\begin{tabular}{|c|c|c|}
\hline MOTANICAL NAMES. & COMMON NAMES. & $\begin{array}{l}\text { Height in } \\
\text { Inches. }\end{array}$ \\
\hline Thuja occidenlalis.... & Arborvitit & 2 \\
\hline Junperus z'turintana & Red Cedat........ & 3 \\
\hline Juniperts commanis & Common Juniper ......... & 2 \\
\hline Juglans nigra ...... & Black Walnut............ & 12 \\
\hline Juglans cinerea...... & Butternut .. ............ & $1 \stackrel{2}{2}$ \\
\hline Hicoria ovakt $\ldots \ldots \ldots \ldots$. & Shellbark Hickory & 8 \\
\hline Hicoria minima............ & Bitternut Hickory ........ & 4 \\
\hline Salir nigua $\ldots \ldots \ldots \ldots \ldots \ldots$ & Black Willow ........... I & 10 \\
\hline Saltix amygdalotdes ......... & Peachleaf willow ........ & 10 \\
\hline Salix alba........... & White Willow............ & 10 \\
\hline Salix lucida .................. & Shining Willow........ & 6 \\
\hline Popnlus tremuloides.... & Aspen ................ & 10 \\
\hline Populus grandidenta..... & Largetooth Poplar........ & $1: 3$ \\
\hline Populus balsamifera ................ & Balsain Poplar . ......... & 10 \\
\hline 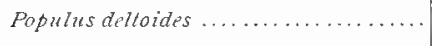 & Cottonwood $\ldots \ldots \ldots \ldots$ & 16 \\
\hline Berula papyrifera $\ldots \ldots \ldots \ldots$ & Canoe Birch.... & $4-8$ \\
\hline 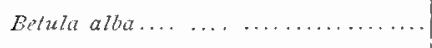 & European White Birch .. & $6-10$ \\
\hline Betula lutea ........... & Yellow Birch............. & $4-8$ \\
\hline Ostrya virginiana $\ldots \ldots \ldots \ldots \ldots \ldots$ & Hop Hornbeam . .... & $4-6$ \\
\hline Carpmus rarollniana...... & Blue Beach.............. & $4-i$ \\
\hline Sucreus alba ...... & White oak. . ........ & $1-8$ \\
\hline Quercus macrocarpa ....... & Bur Oak $\quad \ldots \quad \ldots \ldots$. & $4-8$ \\
\hline Quencusvubia $\ldots \ldots . .$. & ked oak.......... & $6-12$ \\
\hline Querus coccinea ............ & scarlet oak ....... & $6-12$ \\
\hline Ulmues amestrani. ................. & White Flm ............. & $6-12$ \\
\hline Immus acemosa. & Cork Ell1,.......... & $1 ;-10$ \\
\hline I'mun pubsocms........ & Slippery Elm ......... & $10-20$ \\
\hline Cellis meadintals.............. & Hackletry .......... & $8-10$ \\
\hline Morus rwbia .... & Red Mulberry......... & $6-10$ \\
\hline
\end{tabular}


TABI, SHOWVING TIIE APPROXIMATE HEIGHTS OF UNE-YEAR OI,D SFFDLINGS GROWN ON GOOD AVERAGE SOIL IN MINNESOTA. (Continued.)

\begin{tabular}{|c|c|c|}
\hline BOTANICAL NAMES. & COMMON NAMES. & $\begin{array}{l}\text { Height in } \\
\text { Inches. }\end{array}$ \\
\hline Morus albutartasica... & Russian Mulberry & $6-12$ \\
\hline Pyntus iormis .... & Wild Crah .... & $4-8$ \\
\hline Plvas americana ............ & American Mountain Ash. & $x$ \\
\hline Pyrus sambucifolia ............... & Elderleaf Mountain Ash. & $4-8$ \\
\hline Amelanchir canadensis... & Juneherry ........... & 8 \\
\hline Crataegus tomenlosa & Black Thorn ............. & $4-8$ \\
\hline Prunus americant. & Wild Plum ............. & 15 \\
\hline Prunus penns.luzanica.. & wild Red Cherry ........ & 12 \\
\hline 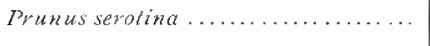 & Wild Black Cherry........ & 12 \\
\hline Prunus z'inginiana. & Choke cherry... & 12 \\
\hline Gleditsia triacanthos .......... & Honey Locust ............ & $8-12$ \\
\hline Grmnocladus dioicus.... & Coffeetree ............' & $8-12$ \\
\hline Robinia pseudacacia....... & L,ocust ................ & 24 \\
\hline Acer sacchartm............... & Sugat Maple ............ & 12 \\
\hline Acer platanoides....................... & Norway Maple............ & 12 \\
\hline Acer nubrum ........... & Red Maple...... & 10 \\
\hline Acer saccharinum. & Soft Maple........... & 24 \\
\hline Acer pennsylvanicum................ & Striped Maple............. & 4 \\
\hline Acer lavtaricum.............. & 'Tartarian Maple .......... & 4 \\
\hline 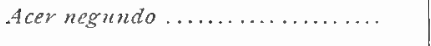 & Boxelder ..... ... & 12 \\
\hline Esculus hippocastanum .... & Horse Chestnut ........... & 6 \\
\hline . Esculus glabra ............. & Ohio Buckeye....... & $4-6$ \\
\hline Rhanmus cathanticus... & Buckthorn $\ldots . . . . .$. & $6-12$ \\
\hline Tilia antericana............. & Basswood $\ldots \ldots \ldots \ldots \ldots$ & $6-12$ \\
\hline Elaeagnus augusiffolia .... & Russian Olive...... & 12 \\
\hline 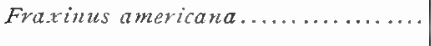 & White Ash $\ldots . . . . .$. & 12 \\
\hline Fraxinus lanceolata......... & Green Ash ........... & 12 \\
\hline Fraxinus nigra .... & Black Ash... . & 8 \\
\hline Catalpa speciosa ... & Hardy Catalpa........... & 24 \\
\hline Viburnum leniago ................. & Black Haw ............ & +6 \\
\hline
\end{tabular}




\section{CUTTINGS.}

Cuttings are pieces of the branches or roots which have the power of growing and forming new plants when placed in moist sand, soil or other material. For example, the pieces of the twigs on branches of many kinds of willows and poplars, when taken while the tree is dormant, will root when placed in moist soil, but there are few other trees that grow as readily from cuttings as these. Cuttings of the roots of many kinds of trees, as the White Poplar, Wild Plum, Yellow Locust, and many others that sprout from the roots, will grow if treated about the same way as branch cuttings.

In growing trees from cuttings the source of the cuttings is not of so great importance as the source of the seed from which the stock trees were grown, for the qualities of individual trees are probably not permanently or greatly changed by climate. For instance, trees grown from the cuttings of Russian Poplars would be as hardy in Minnesota if the cuttings came from St. Louis, where they had been growing for years, as they would be if imported direct from Siberia. However, owing to a longer growing season at St. Louis, the wood might be of a more open texture, and perhaps might not resist cold as well as Minnesotagrown wood; but after one season's growth in Minnesota it would probably be as hardy. The same would hold true of plants propagated by any method of division. With the exception of Willows and Poplars, very few of our ornamental trees grow readily from cuttings. The best time to make cuttings is in the fall, as soon as the leaves will strip easily from the twigs. Most of the willows and poplars will grow readily from cuttings made in the spring, and even those made in summer will generally grow if planted in moist soil. For this purpose the smaller branches with the leaves removed should be used. They may also be rooted from growing twigs with the leaves left on, provided the cut surfaces are placed in water, as they would be if stuck in the soil of a swamp or treated the same as cuttings of geraniums. These latter ways, however, are not to be depended upon for general propagation purposes.

The Form and Size of Cuttings is a matter tpon which there is great difference of opinion. Cuttings of the Willow from onc bud each and only an inch or two long up to those a 
foot or more in diameter and ten or twelve feet in length can generally be made to grow, but probably the most convenient size for general planting is one-half inch in diameter and twelve inches in length. They are generally tied in bunches of 100 or 200 each for convenience in handling, and care should be taken to keep all the butt ends one way to facilitate planting. Very

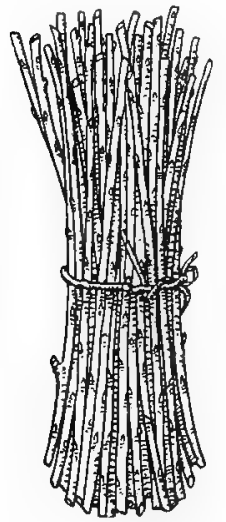

Figure II. A bunch of willow cuttings. large cuttings are liable to decay in the center, and are not best to use, although they often make a very rapid growth. Poles of willows and poplars are sometimes laid in furrows where they will generally sprout wherever the bark is laid bare and often make good trees.

In Planting Cuttings of ordinary size it is a good plan to have the soil loose, and then. after marking off the rows, the cuttings can be pushed into the land the proper depth. If not desirable to plow all the land, it may be loosened just where the rows are :o come. Where a subsoil plow can be obtained, it can be made very useful for this purpose.

Cuttings should be planted at an angle of about forty-five degrees, leaving only one bud above the surface of the ground and the soil should be packed firmly around

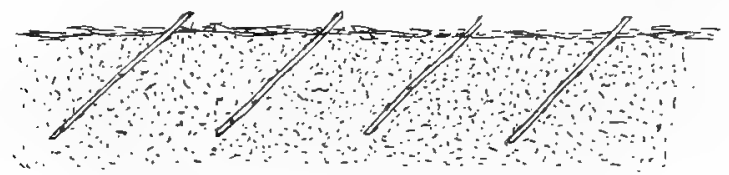

Figure I2. Planted cuttings, showing angle and depth at which to plant cuttings.

them. Those set in a slanting position settle with the soil and remain firm, while those set vertically mav become loosened by the settling of the soil near them, leaving too much of them exposed above the surface, unless very great care is exercised in planting. The rows in the nursery should be about four feet apart, and the cuttings about six inches apart in the rows, though 
a much less distance may sometimes be sufficient. In packing the soil over the cuttings great pains should be taken to get it very solid around the lower end, and if the soil is very dry, the firmest pressure of the full weight of a man over the base of each cutting is not too great; in fact, when the soil is dry it cannot be made too firm over the cutting. When the soil is moist, however, only enough pressure should be used to bring the particles in close contact and close up the air spaces.

The Cultivation of Cuttings should commence shortly after they are planted, and the top soil should be kept loosened to the depth of about three inches, which, while not disturbing the solid soil around the base of the cuttings, prevents evaporation from the soil.

Time of Planting Cuttings. Spring cuttings may be planted at once where they are to grow. Autumn cuttings may be planted out at once, provided the land is not wet, but when planted at this season they should be covered with soil turned toward them with a plow. In the spring this covering should be raked off before the buds swell. The ground being warm in autumn often causes attumn-planted cuttings of some kinds to root before cold weather sets in, and if made up before the first of October they may thus score quite a gain over spring-planted cuttings. If not desirable to plant in the autumn, the bundles of cuttings may be kept over winter, buried in moist soil, preferably that which is somewhat sandy, where there is no standing water; but much care should be taken to keep them from dry-

- ing out. To this end the bundles should be buried so as not to touch each other, and have two or three inches of soil packed in between them. If they are kept in a cellar, moist sawdust will be found to be good material to keep them in.

The amount of growth made by cuttings varies much, according to the kind of plant, size of cuttings, soil, etc. The most of our willows will make a growth of three or four feet, on good soil, in one season, from ordinary cuttings.

The Solar Pit. There are many trees that will not grow from cuttings unless they have their roots started a little before planting. This is most casily accomplished by means of what is called the "solar pit," which owes its success to the fact that cuttings root first at the warmer end. It is made and used as fol- 
lows: The bundles of cuttings are hecled in as recommended. In the spring, they are taken out, and buried close together, with the butt ends uppermost, in a warm sunny spot, and coverer] with about six incles of soil. A hotbed frame, with sash, is then put over the spot, to warm the soil. Sometimes, instead of

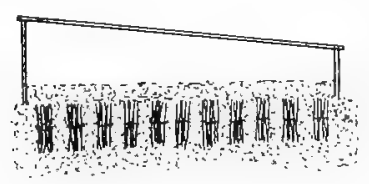

Figure 13. The solar pit, showing bundles of cuttings in place under glass. using sash, the soil over the cuttings is covered with a foot or more of fermenting manure. In cither case the soil is warmed. and the formation of roots encouraged. In using the solar pit the rooting process should not be carried so far as to permit roots to show plainly, as they are liable to be broken off in planting out; but the cuttings should be planted out as soon as they show signs of healing over on the butt end. 'This healingover process is called callousing, and in many plants necessarily precedes the formation of roots.

\section{LAYERS.}

I ayers are portions of the branches of trees, shrubs or vines which are covered with earth without being separated from the parent plant and there take root and grow. These are cut off from the main plant in autumn or spring, and form new plants. Almost all trees and other plants can be rooted in this way, but, while some root very easily, others require so long a time to do so as to make it impracticable with them.

The growing of trees from layers is seldom practiced in this country, but in some European nurseries it is a common means by which to increase special varieties of trees. For this purpose what is commonly known as mound layering is often used. This consists simply of drawing the soil up around the sprouts that come from the stump of a tree, covering the base of them about a foot in depth. It may be done at any time of the year after the sprouts are two or more feet high, but preferably in the spring. After the sprouts have become well rooted they may be removed in spring or autumn and treated the same as seedlings. Layering is sometimes practiced in European forests to fill up vacancies, and a similar method is often employed in nurseries. 
GRAFTAGE.

Graftage refers to the growing of one plant on the stem, root or branch of another plant. There are several forms of graftage, which are generally known as grafting, budding and inarching. It is a common practice to use graftage in the growing of the different varieties of fruit trees, and it is also used to some cxtent in the growing of some of the varieties of ornamental trees that cannot be grown from seed. Trees that are grown by any form of graftage are seldom as long-lived as those grown on their own roots, and these methods should be avoided when it is practicable to do so. These methods are not much used in common practicc, and consequently are not discussed at length here.

Inarching is a rather unusual way of growing plants. It works on the principle that when the growing stems, branches and roots of the same or closely allied plants are held closely together for some time they become united. Such unions of roots are frequently found in woodlands; in some cases the roots of the same trees, and in others the roots of different trees, become grown together. Occasionally also trees are found grown together by their branches or stems. Inarching is sometimes used for growing the Cutleaf Birch, in which case the sprouts from a stump of a Cutleaf Birch, or the twigs from a small tree laid on the ground, are tied to small Birch seedlings, which have been grown in pots and plunged to their rims in the ground near the tree. In doing this the bark is removed for about two inches at the point of contact of the twig and seedling, which are then tied firmly together. It should be done by the middle of June, but will often be successful if done even a month later. They should be kept together until the leaves fall, and then the branches from the parent tree should be cut away. leaving the secdlings with the twigs grown fast to them. These should be carcfully heeled-in over winter, and in the spring the secdlings should be cut off just above the union, so as to throw all their strength into the adopted twig of the Cutleaf Birch. This method may also be used to replace lost branches on trees or vines. 


\section{CHAPTER VII.}

NURSERY PRACTICE.

Nursery. This term is applied to a plot of land used for raising plants that are intended for planting elsewhere for their final growth.

Soil and Cultivation. The best soil for a general nursery is a deep, rich, reasonably level, retentive upland. It is customary to grow most of the nursery crops in rows, so that they may be readily cultivated. The land should be plowed deeply when the crop is planted, and the surface soil kept loose and fine during all the early part of the growing season, or until about the middle of July. If the land that has to be used for a nursery is rather shallow, it should be gradually deeperied by plowing from year to year, and, if inclined to dry out, the addition of large quantities of organic matter, together with constant cultivation, will do much to remedy these defects.

The cultivation of a nursery or young forest plantation, provided the latter is planted in rows, should consist in keeping the land stirred to the depth of three inches, thus giving a dust blanket, which will protect from drouth. After the first of August much cultivation is likely to encourage a late autumn growth, which should be avoided; but a moderate quantity of buckwheat or oats may be sown then, and be allowed to grow the remainder of the season, to serve as a winter protection-to hold snows, and prevent the heaving out of the young seedlings by frost.

\section{GRADES OF NURSERY STOCK.}

Nursery stock of different kinds has come to be known by such convenient names as seedlings, transplants, street trees, forest-pulled seedlings, etc. 
Seedlings are young plants, grown from sced, that have never been transplanted, and are generally designated by their size or

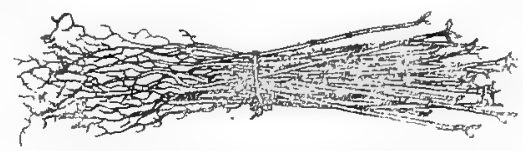

Figure 14. A bunch of fircen Asle Secedlings.

age. They form the cheapest class of nursery stock, and are used largely for starting windbreaks.

Transplants are scedlings that have been at least once transplanted, and are designated by the size and number of times they have been moved. They are higher in price than secdlings, but with some kinds of trees they are much more likely to grow, and may be well worth the extra price. Evergrcens, especially pines, will seldom do well unless once transplanted before being set in a permanent place.

Street Trees include the trees of large size which are used for street, shade and ornamental purposes. To be of the best quality they should have been transplanted two or more times and have received some attention in the way of pruning so as to give them a good form. Such trees vary much in quality and price, but the best are necessarily rather expensive.

Forest-pulled Deciduous Trees of small size can often be obtained at a very low price, and may be as desirable as those that are nursery grown.

Forest-pulled Evergreen Seedlings may also be desirable, but too often they have poor roots, or have been so injured by poor handling that they are generally worthless.

Forest-pulled Shade Trees sometimes grow very' well, but they are always inferior to good nursery-grown trees. They are greatly improved by having their roots shortened two years before they are to be removed, and when so treated grow very well.

TRANSPLANTING.

Transplanting is Simply the Removal of the Plant. It may be to some permanent place, as a park, lawn, or street, or it may be done for the purpose of improving the root system, 
and to give the tree more room to grow. By shortening the long roots the root system is made more compact and better able to withstand subsequent removal. This may be done by transplanting, or by cutting around the tree with a spade or tree digger. It is especially desirable to do this to trees that are not casily moved on account of their long branching roots, such as the Birch, or to those that have tap roots, like the Oak and Walnut. It is on account of their having had their roots shortened so they can all be moved with the tree that nursery-grown trees are generally superior to others.

In Transplanting it is Important to take up a sufficient amount of roots to support the plant, and as a rule the more roots the better the conditions for growth. Very long roots

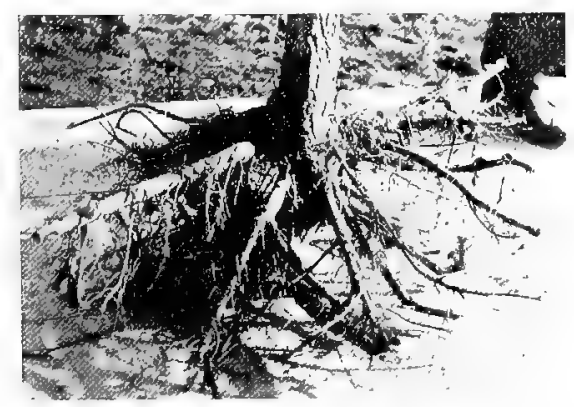

Figure 15. Extra good roots on a forestgrown Elm, used as a strect tree.

should be shortened unless the tree is removed to a permanent place, in which case all the good roots should be left on the tree. All bruised or broken roots should be cut off in either case, and the top of the tree shortened to correspond. In transplanting trees they should be set one or two inches lower than they formerly stood, and the roots should be spread out in the holes without crowding. It is customary to plant many kinds of small trees in furrows made with a plow.

Very Large Trees (those over six inches in diameter) are sometimes successfully planted in winter, by taking them up with a ball of earth. This is done by digging a trench around the tree, late in the autumn, deep enough to cut most of the 
roots, but far enough away from the tree to leave a large ball of earth. The trench is then filled in with a mulch of some kind, and when the ground is frozen the tree is moved, with the ball of earth attached, to the hole which has been previously prepared and kept free from frost.

After Trees Have Been Moved, or had their roots shortened.in some other way, they should generally not be transplanted again for at least one or two years, during which time they will have overcome the injuries done to their root system. The time which should thus elapse will vary with the kind of tree, and also with the amount of injury done. Where the injury is severe a much longer time will be required for recovery than where it is slight.

Time to Transplant. Planting of trees should always be done when they are dormant, or just as they start into growth in the spring, which is generally from the middle to last of April. If for any reason it is desirable to risk the moving of trees late in the spring, after the leaves have started, they should be cut back severely, all the leaves removed, and great pains be taken to secure all the roots and to prevent their drying out. Very hardy deciduous trees, as the Elm, Cottonwood, Boxelder and Ash, can often be successfully moved in the fall, if the ground is moist at the time of removal, but great care must be taken to work the soil in very compactly between the roots, so that there will be no large air spaces among them. If the trees are large, it is a good plan to stake them, so they cannot be blown about by the wind. The more tender trees should not be transplanted in this section in autumn, and even the hardiest kinds should never be moved at this season unless the soil is moist.

Transplanting Evergreens. When seedling evergreens are two years old they should be transplanted, and this should be done about once in three years afterwards, until they are moved to their permanent places. As evergreens are very sensitive to being moved, this requires more care than with most deciduous trees. The most important point is to not all $\mathrm{w}$ the roots to have even the appearance of being dry. They may be transplanted in the spring, as soon as the ground works easily and the roots have white tips, and they may be safely transplanted even up to the time that the new growth shows about an inch, but at 
this late time more care must be taken in doing the work than when it is done earlier. Evergreens can sometimes be moved successfully in August, or even in the autumn, if they are to be carried only a short distance and the conditions of the weather and land are favorable; but this is not a time for general planting, and it is seldom advisable to do it at this season.

The Very General Error is Current that June is the best time to plant out evergreens. They may be transplanted at this season successfully if the conditions are just right in every particular, but they are much more liable to failure than when the work is done earlier in the season. At whatever time of the year evergreens are to be moved, the work should be done in such a manner as to protect the roots from having even the appearance of being dry, for if dried ever so little the probabilities of their living are much lessened. The kind of treatment that would be considered all right for apple trees might be fatal to evergreens, as they are much more susceptible to injury from drying.

In addition to the above precautions to be taken when moving evergreens, it is desirable to shorten back the limbs about one-third, to compensate for the loss of roots. Of course this shortening should not be done in such a way as to disfigure the tree, but, when the roots are in any way severely mutilated, the whole top makes more of a draft on them for moisture than the roots can supply. This pruning is not so necessary in the case of young seedling evergreens or nursery-grown trees that have been recently transplanted, for when they are moved their root systems are not seriously injured.

Very Small Evergreens and Other Sma11 P1ants are often set in trenches made with a spade, as shown in figure I6. For this method the soil must be loose, and yet sufficiently compact so that it can be cut with a spade and not crumble before the plants can be set out. The beds are made about six feet wide, and a board of this length and six inches wide should be used. The soil is thrown out with a spade $(A)$ to the depth of about six inches, but no wider than necessary to just take in the roots. The plants are then placed in position by hand, and a little soil pushed against them to hold them in place. $(B)$ The trench is then half filled and the soil firmly compacted by the feet. The remainder of the soil is then put in and leveled off, the 
board is changed to the other side of the row first planted and the planting is continued in the same way. ( $C$ and $D)$ Such close planting as this is only desirable when it is intended to give special care to the plants, as by shading or watering. Plants should not remain more than two or three years in so close a bed before they are transplanted. When it is desirable to set out small seedlings in rows, instead of beds, a tight line may be used in place of the board.

Heeling in. This term is applied to the temporary covering of the roots of trees with earth to keep them from drying out after they are dug and until they are planted. If they are to be kept for only a few days, comparatively little care is needed in

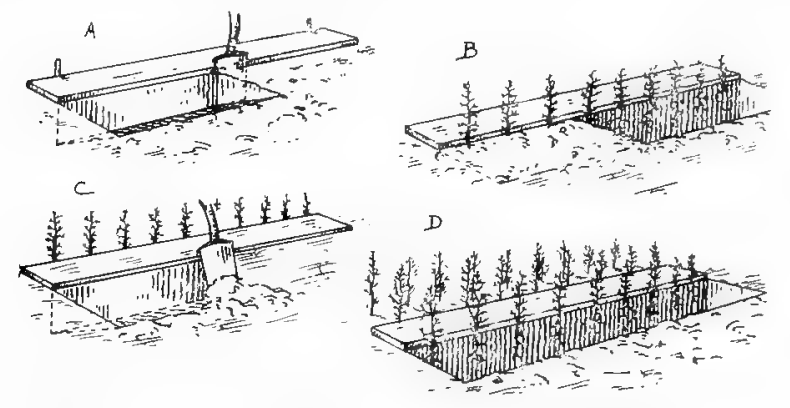

Figure 16. Successive steps in plant'ng young evergreen or other very small seedlings. (a) Board in place and trench partly opened. (b) Seedlings in place and partly covered. (c) New trench partly opened. (d) New trench with seedlings in place.

covering; but if they are to be kept for several weeks, or over winter, especially if the weather is dry, great care must be taken to work the fine soil in among the roots and to pack it solid. A good way of doing this is as follows: Select a dry, mellow piece of ground, and dig a trench just large enough to take in the roots of the trees when laid close together in a single row. Place the trees or seedlings in this trench. in an upright position, a few at a time, and cover the roots firmly and deeply with soil taken from close in front of the first trench, thus making a trench for the next row. In this section, if Maples, Cherries and other trees not of the greatest hardiness are to remain heeled in all winter, it is a good plan to bend the tops down and cover with 
earth. This is only necessary for winter protection. The neglect to properly heel in nursery stock as soon as it is received is undoubtedly a frequent cause of failure.

Trees and cuttings will sometimes get so dry in shipment that the bark shrivels. In such cases the best treatment is to

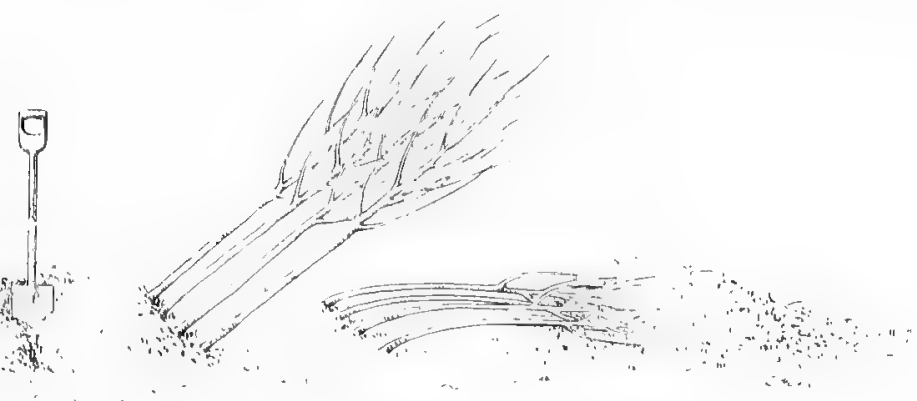

Higure 17. Heeling-in. Various stages of the operation: Row of trees wilh roots cuvered; row bent down and the tops covered.

bury them entirely for a few days, which will often enable them to recover. Soaking in water will answer the same purpose, but unless very carcfully done is likely to injure the wood.

\section{PRUNING.}

Pruning should be avoided as much as possible, and yet be thre sufficiently to secure the effect desired. If it is begun early in the life of a tree no large branches need ever be removed, the most desirable pruning being the directing of the growth by pinching off the burls that wonld develop into undesirable branches; but this is impracticable on a large scale, and for this reason, in ordinary practice, it is often necessary to do more cxtensive pruning.

The Purpose in Pruning Trees is to give them forms that are desirable for the purpose intended. For example, a tree for the lawn or windbreak may be most desirable when covered with branches even down to the ground, while street trees should have a trunk free from branches for eight or ten feet from the ground. Many of the evergreens, and some other trees userl for 
ornament, naturally take on so regular and desirable a form that it is not necessary to prune them, except perhaps to pinch or cut off an extra leading shoot that is likely to make a forked top, while the White Elm, Soft Maple, and others need occasional pruning to remove or shorten awkward branches, at least while the tree is young and growing rapidly.

The Proper Time for Pruning is determined by the effect of the operation upon the health of the tree. Dead branches may be safely removed at any season. The removal of live branches during the growing season lessens the leaf surince, and hence checks growth. Pruning when the tree is dormant results in a more vigorous growth in the remaining branches. Wounds made by pruning just as trees are starting into growth do not heal over as readily as those made earlier in the spring, or during the period of active growth in June. Wounds made in atutumn or early winter generally heal over well, but are more likely to cause bad injuries than if made at the close of the winter. These considerations and practical experience have brought about the following conclusions as to the best time for pruning:

Large Branches are Most Safely Removed during the latter part of winter, before growth starts. Small branches may be safely removed at this time, or during the growing season, preferably about the middle of June; but such very hardy trees as the Elm, Ash, Boxelder, White Willow and Cottonwood - may be safely pruned at any time in autumn, winter or spring. while the Mountain Ash, Apple, Plum and Wild Cherry are liable to injury if pruned at any but the most favorable seasons.

Among the Directions to be Followed in Good Pruning are the following:

(I) Do not cut off a single branch unless you have a good idea of what you wish to accomplish and the probable effect of so doing on the tree; better not prune at all than to do it without considering the consequences.

(2) Avoid doing very much pruning at one time, especially on small street trees, which, if they have all their branches removed from the trunlis to their final height, are likely to make too much growth at the top for the trunk to support well in high winds. A better way is to remove a part of the lower branches and 
shorten back in summer those that are to be removed later; by such treatment a large part of the strength of the tree goes into the top without increasing the size of the lower branches, which may be removed in a year or two without injury to the tree.

(3) After pruning paint the wounds with good white lead paint, to keep the wood from decaying and the injuries from thus becoming permanent. This is not so necessary on very hardy trces as on those that are somewhat tender.

(4) Where branches rub together it is generally best to remove one of them.

(5) Where bad crotches are being formed by the development of two leaders, severely check the growth of one of them by shortening it, thus throwing more sap into the other and making it the leading shoot.

(6) Prevent the formation of long side branches by shortening those that are liable to become too long. This is especially desirable with the Soft Maple, which has a tendency to form long branches that are likely to break off unless occasionally prined.

(7) Where trees have lost their leaders, prune so as to develop one of the side branches into a leading shoot. This the tree always attempts to do itself, but a little judicious pruning will greatly aid it.

(8) Every species of tree and shrub has its own natural form, and in pruning do not try to make all of them of one shape. Study the natural form of each kind of tree, and encourage the development of this form.

(9) When trees are full of frost the wood cracks very easily; therefore do not prune in very cold weather, for bad wounds may then be easily formed.

Treatment of Crooked Trees. It is common to have some trees in the nursery that are of vigorous, healthy growth, but so crooked as to be nearly worthless. The proper treatment for most of our shade trees when in this condition in the nursery, if anything is to be made of them. is to cut them off at the surface of the ground, early in the spring, and then select one of the good, strong sprouts that come from the roots of each tree, train it into a straight stem, and cut away the others. Treated in this way well-formed trees may soon be grown. Such treatment may also be desirable with small street trees that have their stems 
hopclessly injured. However, trees that to the novice may seem hopelessly crooked may only have crooks in them that will be outgrown in a few years.

\section{STREET TREES.}

Success with Street Trees'is perhaps more dependent on gnod soil about the roots than on any other one factor. If the land is so very sandy or gravelly as to be subject to drouth, at least two cubic yards (two full two-horse loads) should be taken from where each tree is to be planted and the same amount of good clay or loam substituted for it. If in subsequent years the trees outgrow the limits of the material supplied, more of it should be added, and if this consists largely of stable manure, so much the better, provided it does not come into contact with the roots of the trees. It is important to do this work thoroughly, for one tree well planted is better than a dozen poorly set out.

Kinds of Trees. The best trees for street planting in this section are the White Elm, Hackberry, Green Ash, Basswood, Boxelder and Soft Maple. All of these trees do well in good soil, and with the exception of the Soft Maple they all do well in rather inferior land. Evergreens may sometimes be used to advantage along narrow drives, but they are seldom desirable as street trees. The trees planted should be about two to four inches in diameter near the ground, eight or ten feet high, and of thrifty growth. Much larger trees are sometimes set out, but it is not advisable, as a rule, to plant those that are over four inches in diameter. Smaller trees are often planted and do well if properly cared for, but need more attention in directing their growth than those that are larger. But small, thrifty trees are much better for street planting than large stunted trees. In all cases it is more important to have plenty of good roots than a large top, as a top can soon be developed if the roots are good.

Distance Apart. The distance between trees depends on the kind planted and the quality of the land. On rich land in this section the trees named should be put forty feet apart, in fairly good soil about thirty feet, and in poor soil twenty feet apart. This gives sufficient room for good development, but where a quick effect is wanted it is a good plan to set the trees 
much thicker than this, and use Cottonwood. Willow or similar fast-growing trees to alternate with one of the kinds named as desirable, with the expectation of cutting out the less valuable when it shall have commenced to crowd the more desirable kinds.

Planting. Provided the soil is in the proper condition, the next consideration is the proper planting of the tree. The preparation for this should consist in digging a hole of sufficient size to take in the roots without crowding. If the subsoil is very solid clay, it should be thoroughly loosened up. and where practicable it is a good plan to dig a trench to the loose soil over a water pipe or sewer, for by this means the roots get into loose soil, and drainage is secure, which is often much needed on such land. Sometimes a very stiff hardpan can be broken up to advantage by cxploding a small dynamite cartridge in a deep hole made with a crowbar.

Before setting the tree, it should have all broken and dead roots cut off. It should then be set an inch or two deeper than it had been growing, the discoloration above the roots indicating the depth at which it had stood. If, however, good drainage cannot be secured, the tree can be planted less deeply, and then have a mound made around it. Fill in about the roots slowly, being careful (should the tree have a great number of fibrous roots) to work the earth well in among them and under the butt of the tree. Fine soil, free from large stones, should be used for this purpose. Pack the soil in firmly, if reasonably dry, with the heels, or, better still, with a rammer, making it as solid as possible around the roots. The object in doing this is to leave no air spaces about them. It is not a good plan to put water into the hole before the tree is set, but it may be put in when the roots are just covered and allowed to soak away before the remaining soil is put in. As a rule, however, little is gained by watering if the trees have not leafed out and the moist soil is packed firmly around the roots. Water is most needed after growth starts.

Mulching. Newly planted street trees are much helped by a mulch of straw, hay or well-rotted manure. The latter is best, as it also furnishes plant food, but hot manure is liable to injure the trunk if piled against it. These materials prevent the soil 
from drying out, and this is especially beneficial if the trees are artificially watered.

Watering should be done thoroughly or not at all. One good watering should keep the ground moist for two or three weeks, in the driest weather we have, if the land is heavily mulched when the water is applied. For a good watering in a dry time about one barrel of water should be given to each street or lawn tree. A hollow should be made around the tree and covered with mulch before the water is applied. This same amount of water might be applied at the rate of one or two pailfuls a day, and not be of the least benefit to the tree, if applied to the bare surface of the ground.

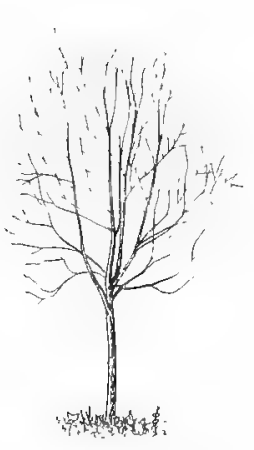

Fignire 18. Soft Maple not pruned since it was planted out. Liable to break in its crotches at any time. A bad form.

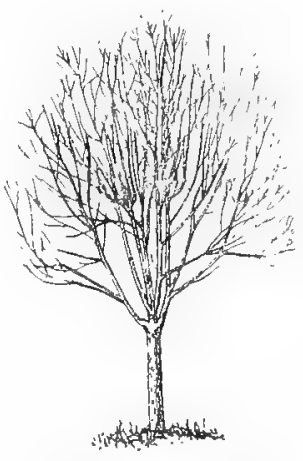

Figure 19. Soft Maple once pruned showing close head that is not liable to break down. A good form.

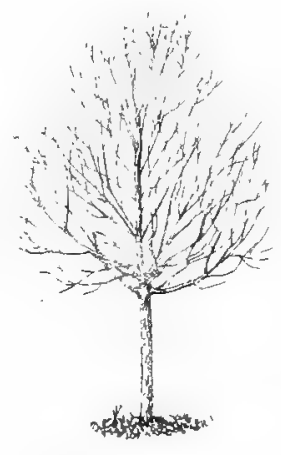

Higure 20. Soft Maple several times pruned preserving a main central axis. A good form.

The Pruning of Street Trees at the time they are set out is an important matter. If the trees are very tall and slender, it is a good plan to cut them off at about ten feet from the ground, and trim off all side branches, as shown in figure $2 \mathrm{I}$. For trees that have been pulled from the woods this is generally the best treatment, while for nursery-grown trees that have had plenty of room to develop a good top it may sometimes be best to trim so as to leave part of the top. If the trees are trimmed to bare poles before planting, some little pruning will be 
recuired cach season for a number of years to devclop good tops, while if they had well formed tops in the nursery and were shortened back at planting time much less
attention will be necessary.
In a row of Elms or other trees there
will often be found peculiar individual
shapes. Some of the trees will take
on desirable forms, while others will be
spreading and awkward, and perhaps have
a tendency to crack in the branches. In
some cases a little extra pruning will bring
such unfortunates into shape, but often they
are incorrigible, and are best replaced by
other trees with better forms.

Protection should always be given street trces as soon as they are set out, and this should consist of something that will protect them from stun-scald, gnawing of horses and whittling by thoughtless boys. A good temporary cover is afforded by wrapping the trunk with gunny sacking or similar Figure 2r. Elm street material, but a more desirable protection is tree properly trimmed afforded by a slatted wooden frame or box for planting out. for each tree, 


\title{
CHAPTER VIII. \\ FOREST PROTECTION.
}

\author{
INJURIES TO TREES.
}

The causes of injury to tree growth are many and various. some affecting principally the cultivated trees in windbreaks and shelterbelts, and others affecting the forest plantations and large areas of timber. Some injure or destroy the trees or tree seeds, and others do damage to the land on which they grow.

Saw-Flies and Tent-Caterpillars. At present perhaps the most serious injuries to cultivated trees in this section result from the neglect to take precautions against leaf-eating insects. such as saw-flies and tent-caterpillars. These injuries may be

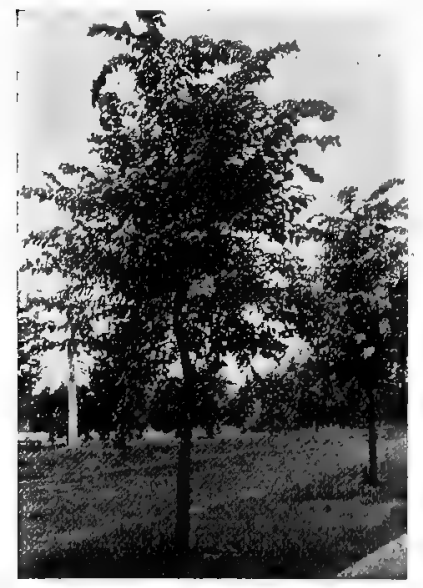

Figure 22. Elm tree that has been planted five years and was pruned to a bare pole when set out. largely prevented by the use of Paris Green, in a liquid form, applied by means of a force pump, using the solutions from a barrel carried in a wagon or on a stone boat. An ordinary spraying nozzle should be used, with a sufficient length of hose to reach up into the tree. In order to reacl the tops of the trees it may be necessary to have a raised platform on the wagon, and to attach the nozzle to the end of a long bamboo pole. In most prairie groves this is practicable, but with very high trees it is very difficult if not entirely impracticable, 
Borers and Lice. These sometimes cause scrious injury, but it is seldom practicable to combat them successfully. It is generally better to avoid them by planting the kinds that are least subject to injury from their attacks. Where lice are injurjous, kerosene emulsion or strong tobacco water are good remcdies. In the case of small trees that can be easily inclosed in a tent, the best remedy is tobacco smoke.

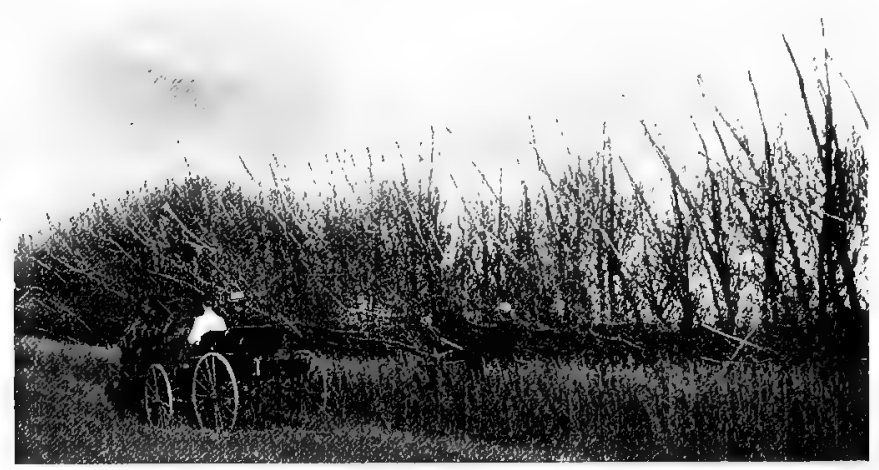

Figure 23. White Willow windbreak seriously injured iby successive attacks of saw-fly larve. A common source of injury to willows.

Mice and Rabbits. Seedlings and small trees of some kinds are liable to injury from rodents, such as mice and rabbits, which gnaw the bark near the surface of the ground, and perhaps girdle the tree. They are most likely to do this when the ground is covered with snow, for this furnishes them with a protection under which they can do their mischief without fear of being molested. In the case of small seedlings sucl injuries may be largely prevented by plowing a furrow or setting boards on edge around the seed bed. If, after each snowfall, the snow is trodden down so as to make a solid path between the seedlings and the grass or woodland whence the mice come, they will be kept out, as they will not try to work through the solid snow. Seedlings that are badly girdled in winter should be cut off at the surface of the ground, to encourage sprouts from the roots. To prevent the gnawing of larger trees. paint the truṇks with a cement or lịme wash made rather 
thick and containing Paris Green in the proportion of one tablespoonful of Paris Green to a pailful of the wash. If skim milk is user in mixing the wash, instead of water, the material sticks better. Trees that are gnawed badly may often be saved by coating the injured surface with grafting wax, blue clay, or other similar material, soon after the damage is done, so as to prevent the seasoning of the wood, and thus give it a chance to heal over. Where the injury is clnse to the ground it should be covered with earth.

The Pocket Gopher. Trees are sometimes injured by pocket gophers eating the roots. Trapping or poisoning may be resorted to, or bisulphide of carbon may be used to suffocate them in their burrows.

Birds. Most of our birds are helpful in various ways, such as distributing seeds and in destroying injurious insects, and such small injurious animals as mice and gophers. They also add to the beauty of our woods and fields, and to our pleasure and recreation. But some kinds are provokingly injurious by cating the seeds we wish to gather, or by digging up newly-sown seeds. Where they are troublesome on seed beds, they may be kept away by covering the bed with wire netting, which will also serve to keep away other animals. If only birds are troublesome, mosquito netting may be used, or the seeds may be given a light coating of red lead and dried in land plaster or flour before sowing.

The sap-sucker does considerable injury to some trees by making holes in the bark for the purpose of securing insects which go there to feed on the sap. They are sometimes so very injurious that it is necessary to destroy them. The Apple, Boxclder, Maple, and most other trees, are subject to their injuries.

Cattle. The pasturing of cows, horses, sheep and other animals in the woodlands is generally a poor practice, as these animals browse off many of the young seedlings, especially those of deciduous trees, such as the Oak, Basswood, Cherry and others, though they scldom eat coniferous trees. They also com. pact the ground, and destroy many small seedlings by their continued tramping, especially when present in large numbers. This is especially true of sheep on the Western forest reserves. Deer, moose, elk and other similar animals are likewise injurious in 
forests, and when abundant may do much damage, though on account of their comparatively small number they do but slight injury.

Severe Winters. These may injurc many kinds of young seedlings, which when two or three years old will be perfectly hardy. Seedlings of such kinds should be dug at the end of the first season's growth, and be heeled in over winter, or protected by a mulch or earth covering in winter.

Altenate Freezing and Thawing. Secdlings are often thrown out of the ground by alternate freczing and thawing, and

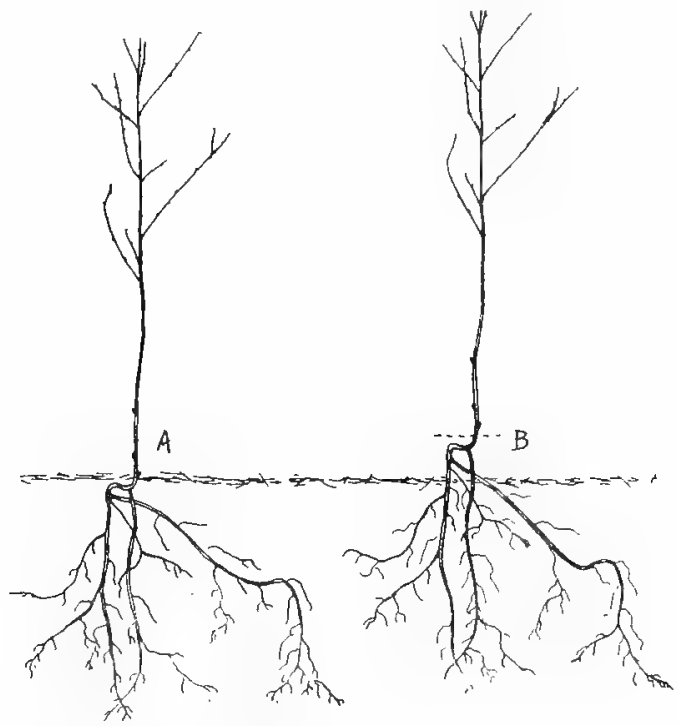

Figure 24. Heaving out by Frost. (a) Tree in natural position. (b) Drawn up by alternate freezing and thawing.

in this way have their roots broken. This is most likely to happen where the ground is bare; if covered with leaves or grass, or shaded in other ways, this seldom happens. The best preventive is to mulch the surface soil with leaves or other similar material, but as mice generally like to live in such places poison should be used. It should be placed under the mulch, in tin 
cans laid on their sides, so they may be readily found in spring and will not be liable to poison the birds. When seedlings are thrown out of the ground by frost they should be pushed back and have the earth pressed against them as soon as the ground is thawed in the spring.

Late Spring Frosts are common in the low lands of this section. They injure the trees by killing the new spring growth after it has started several inches. A large number of trees are scrinusly injured in this way, and are classed as frost tender trees, and those that are not liable to this injury are termed frost hardy trees. Among conifers the spruces and balsams are much injured by late spring frosts, while our pines and the Tamarack, Red Cedar and Arborvite are seldom if ever injured in this way. Deciduous trees recover from such injuries more quickly than evergreens. Among the deciduous trees most liable to injury from this cause are the Ash, Mulberry, Oak, Maple, Basswood, Black Walnut, Butternut and Boxelder, though they do not all suffer in the same degree. Among those that are not sensitive to late frosts are the Elm, Willow, Poplar, Birch, Hackberry, Wild Black Cherry and Mountain Ash.

On account of this liability to injury from late frosts, it is customary to study the probability of damage from this cause in given locations, and to plant accordingly. It will often be found that in certain low spots there is greater liability to late frosts, while there is very little injury from this cause on the higher lands. It is customary among European foresters to protect young seedlings of some kinds, particularly Beech, from late frosts until they get up off the ground. For this purpose Birch twenty or more feet high are encouraged at intervals of thirty or forty feet, and the frost tender plants, such as Beech and Spruce, are set out between. The result of this arrangement is that the Birch, which is frost hardy, quite successfully protects the frost tender trees below it. After the frost tender trees are well off the ground, as ten or fifteen feet high, there is comparatively little danger from this source of injury, and the Birch is removed.

Sleet Storms occasionally do much damage by breaking the limbs. Little can be done to relieve the trees, but preventive measures may be taken. If no large crotches are allowed to form in trees, and growth liept as near as possible to one cenfral shaft, or the longer branches shortened so as they will not 
exert too great a leverage, the losses may be reduced to a minimum. Trees having brittle wood or weak crotches, as the Soft Maple, are much more liable to this injury than those with tough wood, as the willows, oaks and elms, and need more pruning on this account. Evergreens are likely to be broken

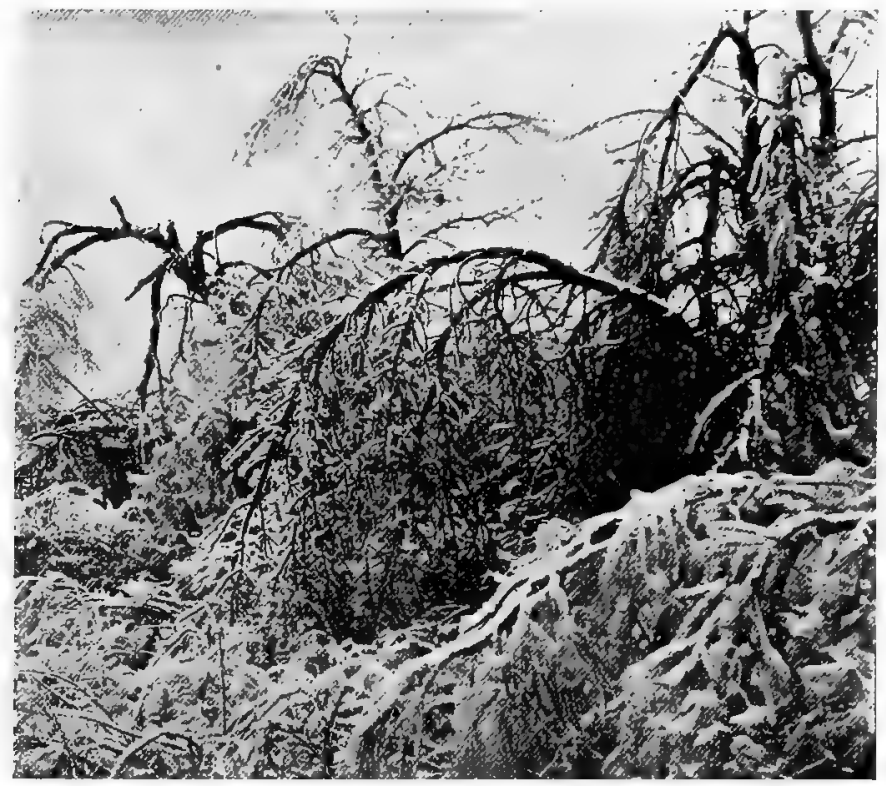

Figure 25. Trees heavily loaded with ice after a sleet storm.

by heavy snows that freeze on the leaves. This may be prevented on lawn and shade trees by shaking the snow off from them before it freezes.

Frost Cracks are a rather infrequent injury caused by the cracking of trees from center to outside, due to uneven contraction in very cold weather. It is generally accompanied by a loud report. Such cracks are often eight or ten feet long, and occasionally longer. They generally close up again when the wood thaws out, and during the following summer grow over. 
only to burst open again the next winter. This alternate bursting open and growing over may continue for many years, until very conspicuous ancl peculiar wounds are formed. In such cracks insects and rot-producing fungi find favorable lodging places, and as a result trees are seriously injured, and are liable to decay in the trunk. There are no practical remedics for such injuries.

Wind. Injuries from wind are common where thinning is done to a great extent at one time about shallow rooted trees.

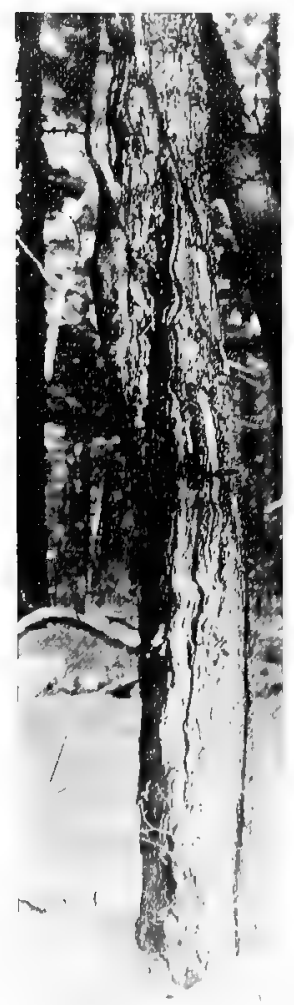

Figure 26. Old Frost Cracks in Sugar Maple. such as Spruce growing on moist soil. These injuries can be avoided only by thinning gradually. In many such cases, on timber lands, thinning is impracticable, and it is then best to cut all the merchantable timber. for if left it is sure to be blown down.

On our prairies, where the soil is light and easily moved by the wind, it is not uncommon to have young secdling trees seriously injured by the blowing away of the soil around the roots, which often leaves them uncovered for three or more inches. This injury ustually takes place in the spring, and may be almost entirely prevented by seeding the land to oats about the mid die of July, at the time of the last cultivation. Sown at this season the oats form a good sod that serves to loold the soil in place until spring, when it is easily broken up by cultivation, but cven then the roots prevent the blowing away of the soil. Occasional strips of grass are also a preventive of this injury, ol mulching may be resorted to.

Snow Crust. The scttling of a snow crust that has formed on the top of decp snow drifts may cause injury to young trees by stripping off their branches and breaking the stems. It 
may be prevented by breaking up the crust or by thinly scattering over the snow some sand, ashes or other material that will absorb the sun's heat and cause the crust to melt before the snow underneath melts. This injury seldom occurs except under drifts, and a little good judgment in selecting the location and arranging the windbreak so as to prevent drifts may obviate this source of injury.

Drouth. Injuries from drouth nay be prevented to a great extent by constant cultivation, but where this cannot be clone mulching is a good substitute. Attention to thinning at the proper time so as not to get the soil filled with roots will also

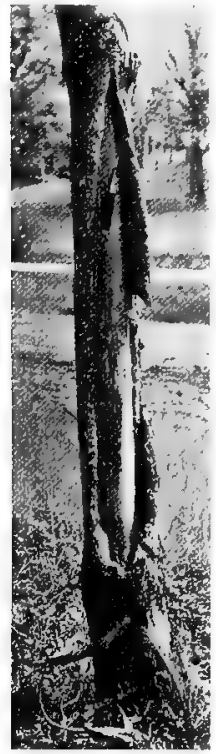

Figure 2\%. Trunk of Soft Maple badly sunscalded.

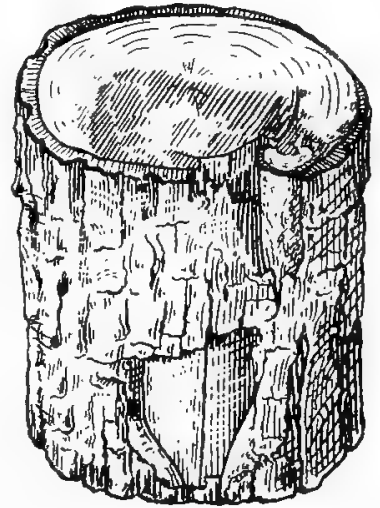

Figure 28. Section of Trunk of Sun-scalded Basswood. Showing dead bark and amount of wood decayed. The top and roots of the tree from which this section was cut were perfectly healthy at the time when the trunk broke off at the sun-scald.

help to prevent injury from drouth. Willow windbreaks can be grown without any cultivation, after being once well established, in the driest portion of Minnesota, if they are kept mulched with straw or litter for six feet on each side. Mulching also prevents injury from severe freezing of the roots. 
Sun-scald. Nearly all of our cultivated trees may be injured by sun-scald. This occurs, almost without exception, on the southwest side of unprotected trees of Hard and Soft Maple, Basswood, Boxelder, Black Walnut, etc. Oaks and all other trees are occasionally affected. It never occurs when the trees are sufficiently close together to shade their trunks, and for this reason the growth of shrubs and low branching trees should be encouraged on the south and west sides of groves where they do not crowd the principal kinds. Street trees liable to this injury may be protected by burlap sacking, straw, or other similar material. When injuries from sun-scald occur, the loose bark should be cut off down to the live growth and the wood coated with paint, to prevent its seasoning, or the wound wrapped in cloth. Trees inclined to the northeast are most liable to sunscald, because the rays of the sun strike the trunk more nearly perpendicular.

Broken Branches and Decay. Large wounds are sometimes formed by the breaking down of a branch, or by decay, which may have started in a wound made by pruning. In such cases the broken and decayed wood should be cleared away, and the exposed surfaces treated with a very heavy coat of white lead paint, grafting wax, or other material that will keep out water and disease. If the wound is very large, or forms a hole in which water is likely to stand, it should be cleaned and painted as recommended, and then covered with a sheet of zinc, carefully tacked on, and the joints closed with grafting wax to keep out water.

Fungus Diseases are quite common sources of injury to trees of all kinds, including those of our forests. They attack the foliage, trunk and roots. Occasionally very serious losses occur here from those that cause the trunks to rot. They are generally most numerous in sections where there is not much of a circulation of air. This subject is too large for a detailed account of any of them here, and only one is referred to, which, although not very common, is occasionally quite injurious. This is known as the toadstool root fungus, Agaricus melleus. This fungus lives upon the roots of pines, spruces, firs, etc., and occasionally kills them. At one stage of its growth it lives on the decaying wood of oaks and similar trees. 


\section{FOREST FIRES.}

Forest Fires are the one great cause of injuries to forests in this section. All other causes of injury are very slight in comparison to it, and could this one cause be removed it is more than probable that the natural renewal of our timber lands would be sufficient to maintain the timber industries of Minnesota for very many years to come.

Fires in this state have destroyed large areas of pine log timber before it could be made accessible to market. It is undonbt-

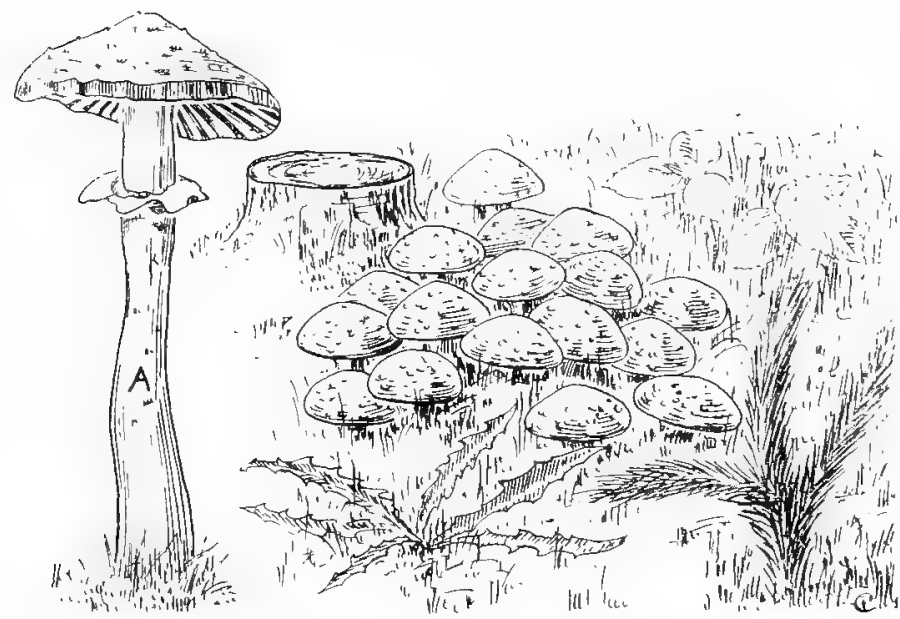

Figure 29. Agaricus melleus, a fungus that is occasionally very injurious to trees by destroying their roots. (a) A fruiting portion of the fungus

celly true that in this section of the country more pine timber has been destroyed by fire than the lumbermen have ever cut.

On account of this great danger to pine timber, and on account of high taxes, the lumbermen have been discouraged from holding their pine lands for a second growth, but prefer to cut every tree that can be made into salable lumber and then abandon the land. But even under such conditions it occasionally hapuens that the land is not burned over, or only slightly burned, for a number of years, when it will generally produce a 
good second cutting. Some land in this state that was first cut in the early days of the logging industry, when it was customary to cut nothing but that which would make a ten-inch $\log$, have been logged two or three times since, and with a good profit.

Since fires render most of the cut-over lands in this state cntirely non-productive, and since the annual increase on the trees that should grow on such land is at least 185 feet board measure per acre, it is plain that the loss to the people of the state on the $6,000,000$ or more acres of cut-over lands is very large.

Forest fires not only destroy a very great amount of property each year, but they nccasionally cause great loss of life. In the Hinckley fire of 1894 (which was entirely the result of ignorance and neglect) there is known to have been 424 lives lost, besides a large amount of property, and occasionally in other y'erars settlers have had to flee for thcir lives, and leave their houses and crops to be burned.

It is impossible for fires to run over any forest land without doing great injury. The amount of damage done by them is difficult to estimate, and varies much according to the time of year, the age and condition of the trees, the soil and the severity of the fire.

Forest fires are sometimes grouped into the three following classes: (I) Underground Fires, that do not show much on the surface, but which destroy the roots of trees and greatly injure the soil. (2) Surface Fires, which burn the leaves and grass in the woods, and do much damage by destroying the forest floor and killing the young seedlings. (3) Crown Fires, which run in the crowns of the trees, and when once started are almost irresistible. The latter is one of the worst forms, and is generally accompanied by surface, and often by underground, fires.

The Killing of Mature Trees by any of thes lluree linds of fires entails but a slight loss comparatively to the timber, providing it is accessible to market, as the trees can be cut the following winter. But fires that kill the mature growth generally do great damage by killing the young growth and destroying the forest floor. Timber that is allowed to stand more than nne or two years after being killed by fire generally suffers much 
from insects and fungus diseases. This is most evident in the case of White Pine, Birch, Foplar and similar soft woods, but cven hard woods are injured by insects if allowed to stand long after being killed.

The Killing of Half-Grown Trees by forest fires callses a loss that amonnts not only to the value of the timber trees bnt to the value of the seeding and shading trees and the forest floor. The value of the trees alone in this case is not a fair standard by which to measure the loss, since at this stage of their growth they are making their most rapid increase, and their value should be computed as the amount upon which the increase is paying a good interest. For instance, the Division of Forestry of the Minnesota Experiment Station found land that was well stocked with young White Pine (six inches in diameter and fifty feet high) that could be bought for about one dollar per acre, and yet the annual increase on the trees wouls! pay five per cent on a valuation of $\$ 100,000$ for the next twenty years. The reason why such a state of affairs exists is that there is such great danger from fire that the investment fails to command the money of careful investors.

The Destruction of the Forest Floor by fire greatly lessens the probability of an immediate renewal of valuable tree growth upon the land, and therefore is one of the greatest injuries to forests. The value of the forest floor can hardly be estimated, but the expense that would be necessary after a fire to produce conditions as favorable to the seeding of our timber lands as those found in unburned forests would probably be not less than twenty-five dollars per acre.

Light Fires, which repeatedly run over the ground, and which by the casual obscrver are thought to be of no importance, often destroy the seeds in the surface soil and the young tree seedlings, besides injuring the forest floor, and unless such fires are prevented it is impossible to secure a good growth of timber on any land. The fires that burn over the land shortly after it has been logged, and which feed on the tops and other waste parts of the trees, generally destroy a large number of young seedling trees, perhaps all of them, so that in order to secure a new growth seeds must be brought from a distance. Owing to the great heat developed by such fires in dry weather, 
they are unusually destructive, and leave very little humus in the top soil. For this reason land that has been burned over in this way is a long time in recovering from its injuries. Besides the injuries already cited, all forest fires kill or drive out much of the game in our forests.

Spring Fires are very injurious to trees, and especially ten. der seedlings, for trees in the spring of the year are full of sap, and can cndure but little heat.

Summer and Autumn Fires generally run deep into the ground, and if the soil is very dry and of a peaty nature burn off

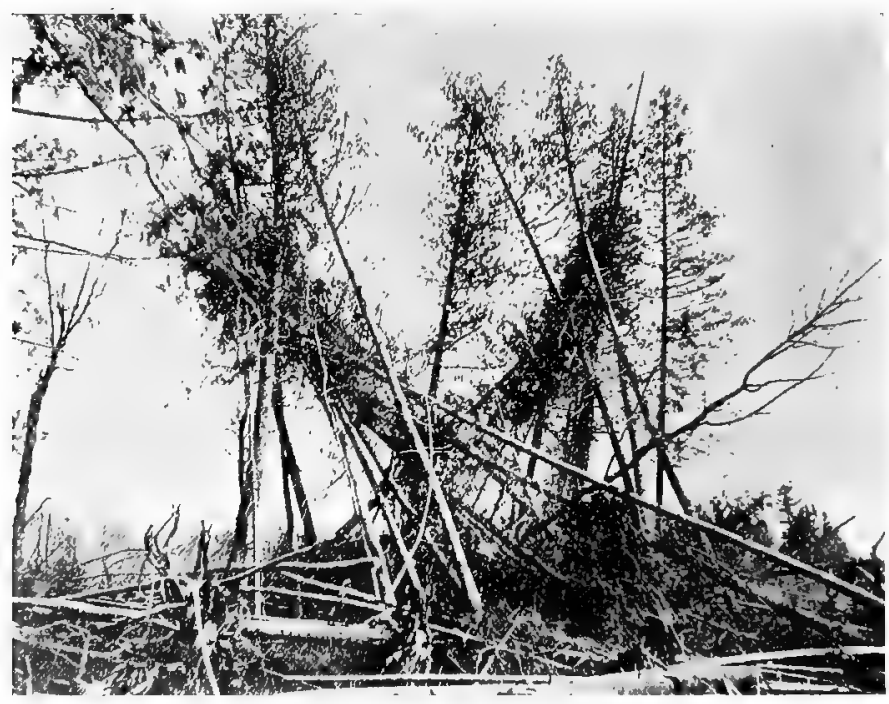

Figure 30. A Fire Fall. Roots burned off and trees blown down in great confusion.

the roots of the trces. The result of this is that the trees are blown down in great confusion, and form what are known as "fire falls." Where a thick growth falls it forms an almost impassable barrier, which remains in this state until decay and repeated fires, extending over a long series of years, finally destroy the trees, and perhaps get the land into condition for a new growth. 
Causes of Forest Fires. The only natural causes of forest fircs are friction and lightning, both of which occasionally start fires in dead trees, but as such fires are most likely to be set during a rain they seldom do much damage. Practically all the injurious forest fires that have devastated the forested part of this section have resulted indirectly either from a lack of appreciation of the damage done by them or from carelessness and ignorance. In the disastrous Hinckley fire of 1894 the damage was done by a large fire formed by the combination of several small fires that were allowed to smoulder in the swamps near Hinckley for a week or more, which when fanned by a dry hot wind attained an irresistible energy. If we had had a fire law that could have been properly enforced at that time, or if the people near Hinckley had been aware of their danger, that great fire, with its attendant great loss of life and property, need not have occurred.

Fires Often Escape from Settlers when they are clearing land, and are sometimes started by them to make pasture for their stock. The careless use of fire by the hunters, prospectors and others who camp in the forest and leave their camp fires unextinguished is another common cause of fires. Railroads set many fires, and should be required to more rigidly conform to the law requiring them to use spark arresters and to keep their right of way free from combustible material.

The moral effect of a properly enforced forest fire law is not only very great in restraining the careless, but especially in cducating law-abiding citizens in the idea that there is value in young seedlings and timber trees.

The Prevention of Forest Fires will be most certainly accomplished by educating our people to an appreciation of the amount of damage done by them. In some counties in this state it is impossible to enforce the law against setting forest fires, owing to the belief that fires are a good thing for their sections in destroying tree growth and bringing the land into condition to be easily taken up by settlers. There is some truth in this claim, but, since the fires destroy all increase on the land they sweep over, a large amount of it is thereby rendered entirely unproductive long before settlers are ready for it, while in the meantime it might be producing a crop of valuable timber. 
Then again, it is the greatest injustice to allow one person to burn the property of another, which right is practically claimed by those who advocate the unrestricted use of fire.

With a Desire in the Minds of People to keep out forest fires, there are many precautions that could be taken that would lessen the chances of their starting, and when started would aid in controlling them. The first thing is a good fire law, such as now stands in Minnesota, which recognizes the fact that the state and county should protect forest property from fire for the same reason that a town or city urotects the property of its citizens from fire. This law puts one-third the expense of enforcing it on the state and the other two-thirds on the county. The chief reasons why a part of this burden should be borne by the state and not by the counties alone are that fires spread from one county to another, and the state must be organized to extinguish such fires when they have once started, since it is the only competent authority that can do this. Then again, the State of Minnesota owns, or will own, when surveys have been completed, about $3,000,000$ acres of land scattered through the forested area, besides possibly nearly as great an area that has been bid in by the state for delinquent taxes. A large part of the land the state owns has a valuable growth of trees on ir. much of which is liable to injury or destruction by fire at any time, and the state can well afford to provide protection for it.

Firebreaks, in the shape of clean earth roads, plowed strips, ctc, are effective against ordinary forest fires. Very often by clearing up and widening the course of a brook a vely efficient firebreak may be made which will supplement other firebreaks. It is stated on good authority that fairly satisfactory and very cheap firebreaks may be made in rough stump land by fencing off a strip about three rods wide and pasturing it with sheep which will kill out all the brush in the course of a year or two. "Ihe sheep do this most effectually if the land is rather over stocked, and they receive a little grain to make up for their lack of pasturage. Figure 3I shows a firebreak or lane on Le Grande Dune in France.

The Burning of Trash leit on the ground at the time of logging is recommended by some of our best woodmen as a means of doing away with one of the sources of our worst forest fires. This trash can be burned early in the spring, or at other 


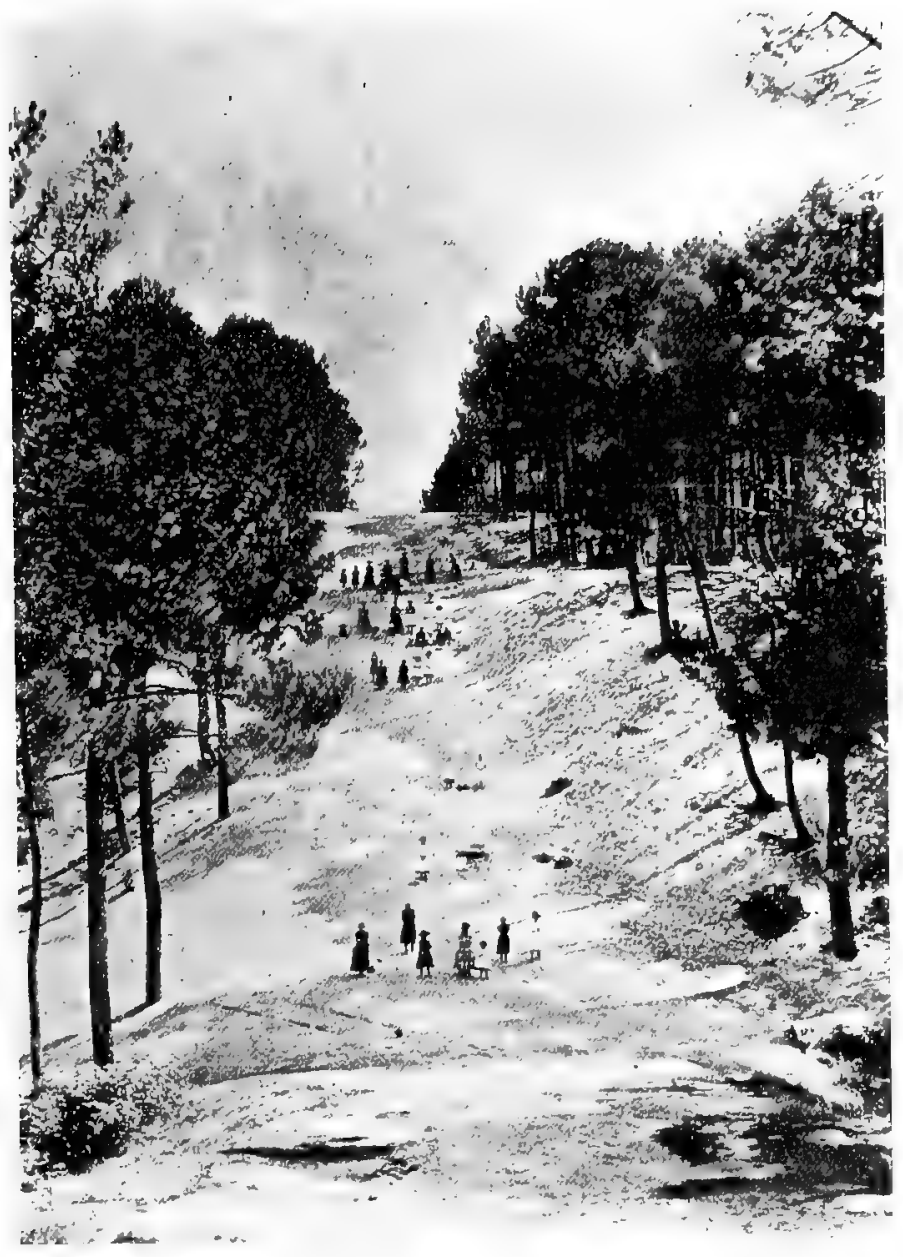

Figure 31. Firebreak on a great sand dune in France, which has been successfully covered with Pine. 
times when the ground is wet and fire is not likely to get beyond control. On the other hand, it is well known that there are many seedlings on such land that would be seriously injured or destroyed by such treatment. It is also known that under the trash left after logging are generally found about the best conditions for pine seeds to start and for the seedlings to grow, so that some of our best authorities condemn the practice. It would seem, however, that on account of the great liability of fires starting in such trash, prudence would generally advocate the burning of it while it could be controlled, but this should be done so as to cause as little injury as possible to new growth, and especial care should be taken to save seeding trees. The cost of such work has been urged against it, but this has often been overestimated, and it secms evident that it is entirely praclicable.

The Methods of Fighting Surface Fires are various, and their use depends on the conditions under which the work must be done. Where possible the plowing of a firebreak a rod or more wide is most satisfactory, but th's is seldom practicable within our wooded areas. Back Firing is generally the most successful method of making a firebreak. When this is to be practiced, a convenient place to fight fire should be chosen, at some distance ahead of the main fire, where the back fire should be started, after every precaution has been taken to prevent its getting beyond control. Where a supply of water can be obtained, surface fires can be most easily put out by applying it through a common sprinkling pot, with a good rose sprinkler on it. This is especially effective where fire is running through grass, and those who have never tried it will generally be surprised at the effectiveness of this method. Where the fire is burning sevcral inches of leaves a small strip should be cleaned of them before applying the water. Gunny sacks or similar material, wet in water, make very effective weapons with which to fight fire. Where the soil is sandy, sand is often the best material obtainable for putting out fires.

Underground Fires, such as occur in bogs and other soils containing a large amount of organic matter, when once started, are often very hard to subdue, owing to their great depth, and, where not looked after, sometimes burn for a year or more unless we have very heavy rains. They often cause great injury 
by burning out all organic matter from the soil and leaving it in poor shape for crops, though a rather severe but not excessive firing of bogs may do much to clear the land of roots and put it in shape for a good hay meadow. Then, too, they often so reduce the level of the land by burning out the organic matter as to make it wet and of no value for agricultural crops. If such fires are attacked soon after they sectire a foothold in the soil they are seldom very difficult to put out. Where not deep in the ground or of very great extent the burning peat may be , dug out and watered, but this is often impracticable on account of the heat. In this latter case a ditch should be dug around the fire as close to it as practicable and of sufficient depth to reach standing water or the subsoil. The fire should then be carefully watched to see that it does not get beyond the ditch. It is seldom that sufficient water can be put on a large bog fire to put it out, on account of the great amount of water that dry peat will absorb and the protective covering of ashes and peat usually found over a bog fire.

\section{NOT ABLE FOREST FIRES,}

Among the worst forest fires which have occurred on this continent are the following:

Miramichi Fire of $\mathbf{1 8 2 5}$. This occurred near Newcastle, on the Miramichi river, in New Brunswick. In nine hours it had destroyed a belt of forest eighty miles long and twenty-five miles wide, and almost every living thing was killed on that amount of territory; even the fish were destroyed in the smaller lakes and streams. It is estimated that the loss from this fire, not including the value of the timber burned, was $\$ 300,000$. One hundred and sixty persons lost their lives, and nearly $\mathrm{r}, 000$ head of stock were killed.

The Peshtigo Fire accurred in Octobcr, I871. This burned an area of over 2,000 square miles in Wisconsin. Between 1,100 and $I, 500$ persons lost their lives, and property to the amount of many millions of dollars was destroyed.

Very serious fires have occurred in Michigan from time to time, in one of which, in about $187 \mathrm{I}$, a strip of territory forty miles wide and I 80 miles long, extending across the central part of the state from Lake Michigan to Lake Huron, was devastated. 
More than ten million dollars worth of timber was burned, and several hundred persons perished.

The Hinckley Fire occurred Sept. I, r894, and was the most destructive fire of recent years. Hinckley, Minnesota, and several other towns were destroyed, about 500 lives were lost, and more than 2,000 persons were left destitute. It is estimated that the loss in property amounted to about $\$ 25,000,000$. The loss of life from this fire would have been much more than stated had it not been for the fact that the railroad companies ran special trains to carry the settlers away from the flames. This fire was wholly unnecessary, and could easily have been put out in its earlier stages. For two weeks previous to the breaking out of this fire into an uncontrollable mass of flame small fires had been raging in swamps about Hinckley, and filled the town with dense smoke, and it was only when these became united under the direction of a hot south wind that it passed beyond control. Had the present forest fire law of Minnesota been in force at that time this fire would undoubtedly have been prevented.

Forest and Pasture. When forests are used as pasture, the cattle will eat the foliage of many species, provided it is within their reach. They also trample on the young seedlings, and destroy them in this way. As a result, all good foresters are opposed to the pasturing of cattle in woodlands. Especially is this the case where the trees are of the broad-leaved species, which are preferred by cattle. However, in the case of well established forests, in which there is no special desire for a rencwal of growth from seed, no great injury can come from moderate pasturing. Cattle are rigidly excluded from most European forests, but in some of the more remote districts, where timber is still quite cheap, it is customary to pasture forests. Of course, where the range is large and not fully stocked, the injury is much less than where the range is crowded. This combination of forest and pasture has led to the use of several methods of protecting young seedlings against cattle, among the first of which might be mentioned the planting of seedling conifers between the buttresses of old stumps, where it would be very unlikely that the cattle would step on them. It is also practiced to protect the seedlings by driving two strong stakes 
in the ground near them, and occasionally over a considerable acreage the cattle and deer may be fenced out until the trces are so large that they will not injure them. Under some conditions the eating off of the leaves from the sides of the trunk of saplings would prove a desirable pruning. It is very certain that while forests and pastures cannot often be very well combined together, yet it is possible to combine then under some conditions. It is quite common to see the new growth of spruce and fir in European forests protected from the browsing of decr by covering the tips of the young shoots with a little coal tar

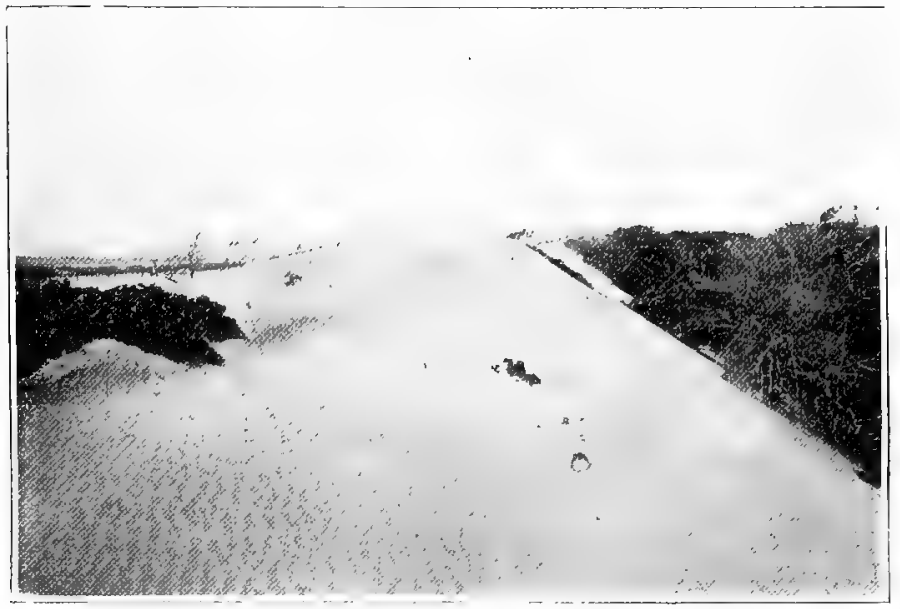

Figure 32. Sand dune near Seven Mile Beach, New Jersey.

or common cotton batting. The cotton batting seems to be very disagreeable to the deer, and to afford about as good protection as the coal tar. It is, however, rather more difficult to put on.

Sand Dunes. In a few places in this state, and in various parts of this country, notably along portions of the seashore and along the shores of the Great Lakes, there are quite considerable sand dunes. By this is meant the drifting sands which are easily blown about after the vegetation which has held them in 
place has been broken. Along the shore of New Jersey, at Seven Mile Beach, there is a dune which is traveling inward at the rate of perhaps fifteen fect per year, and is destroying quite a growth of forest trees. This dune is thirty or forty feet high, -as high as the trees, -and as the prevailing strong winds are from the east, its tendency is always inland. There are other notable sand dunes at Provincetown, on Cape Cod, Mass., which have been fixed in place by judicjous planting.

In some parts of Europe, notably in Gascony, France, dunes have destroyed an immense amount of territory in former ages. Whole villages have at times been gradually wiped out by the cncroaching dunes. The sand is so fine and so easily moved by the wind that there is very little chance for any vegetation to grow on it, and it is only in recent times that methods have been successfully adopted to hold it in place.

The Most Improved Way of Checking Sand Dunes is to first make a windbreak of boards or poles which may be pulled up as the sand drifts up onto them. These are used temporarily to afford an opportunity of getting vegetable growth started. As a rule the vegetable growth which has been most successfully used for fixing sand dunes is that of plants that grow naturally in such places. Such species are generally those that throw out long crecping stems at or just below the surface of the ground, and also such as are capable of healthy growth even when half buried by encroaching sand. We have a number of native species that are adapted to this purpose, among which are the Sand Reed, the Sand Cherry, several varieties of Willows, and Quack Grass. Where these once gain a foothold upon a sand dune they hold it better than would be possible by artificial means. In protecting such land it is generally best to dig up clumps of these grasses, or use long willow cuttings, and set them in place in a wet time.

In some sections along the Great Lakes the sand is now held in place by the natural covering of weeds and shrubs, but should this be removed and the land broken up there would be much trouble in getting it again fixed in place. Such is the case along the southern shore of Lake Michigan. 


\section{CHAPTER IX. \\ RATE OF INCREASE IN TIMBER.}

The Rate of Increase on Timber Trees varies according to the kind and age of the trees and the conditions under which they are growing. Most of the pine trees cut for log timber in this state have been upwards of roo years old, and some of the White and Norway Pine that has been cut was over 300 years old. Perhaps the largest White Pine ever cut in this state was scaled by $\mathrm{H}$. B. Ayres. The tree was 253 years old, measured forty-eight inches in diameter on the stump, and yielded 4,050 feet board measure of $\log$ timber. The most rapidly grown trees recorded in this state were: Norway Pine roo years old, thirty inches on the stump, yielding $\mathrm{I}, 050$ feet board measure; White Pine, I06 years old, twenty-seven inches on the stump, yielding $\mathrm{I}, 050$ feet board measure, and White Pine ros years old, thirty-two inches on the stump, yielding 1,450 board measure. The largest recorded acre yield of White Pine in Minnesota was near Carlton. The full yield of this acre was III,050 feet board measure, and after deducting for rot and crooks 94,264 feet of sound timber remained. The average yield of White Pine is much below this, and large areas have been cut that did not yield over 5,000 feet board measure per acre.

Marketable White and Norway Pine may be grown in abott thirty years under the best conditions in this section, and at this age will probably be about eight inches in diameter and forty feet high. But such trees are then growing very fast, and as the approximate increase in volume of the tree is as the square of the proportionate increase in diameter and the waste in working greatly decreases with the size of the trees, the cutting of them at such an early age would be at a loss of future profits. Such trees have very little, if any, heart wood, and yet this kind of timber is being grown and marketed in many of the Eastern States. In fact, there is very little heart to any of the pine now cut in the New England States, as it is practically all young 
second growth, and is generally marketed about as soon as it attains sufficient size to be salable, without regard to the fact that it is then making its most rapid growth.

From careful observation, the Experiment Station of the University of Minnesota estimates that on land adapted to the White Pine, with a thick growth of this kind of trees eight inches in diameter, the annual increase should be about fifty cubic feet, or 500 feet board measure, per acre. In some cases this rate of increase has been more than doubled, but under ordinary good conditions not over one-third as much increase need be expected.

The Thickness of the Annual Rings on trees varies with the conditions under which the trees make their growth, and is therefore a good index to these conditions. Trees that are crowded so that they make a very rapid upward growth form very thin rings, and when this upward growth ceases owing to the removal or suppression of surrounding trees much thicker rings are formed. Trees that are grown in the open produce throughoit their lives thick annual rings, which vary in thickness according to varying climatic conditions. Those of the White Pine vary in thickness from one-sixteenth of an inch or less in trees that are severely crowded to one-third of an inch in open-grown trees in good soil. Willows sometimes have antulual rings three-fourths of an inch wide.

The Life History of a Mature Tree in virgin forest may often be determined by a study of the anuual rings, in connection with the environment of the tree. The Division of Forestry of the Minnesota Experiment Station has made several studies of this kind, among which are the following:

Figure 33 shows a section of a White Pine which made its growth under varying conditions. This tree started into growth muler Birch and Aspen, and when from twenty to twenty-five years old was nearly suppressed by them. Overcoming them when thirty years old it pushed upward rapidly until about its fifticth year. It was then set free by fire, which checked its upward growth for about twenty-five years, when, owing to the crowding of surrounding trees, it began to again increase rapidly in height. Whon eighty-four years old fire killed the surrounding trees and set this one entircly free, in which condition 
it remained until it was cut eighteen years later. When cut it measured fifty-five feet high, thirteen inches through at the base and contained 29.95 cubic feet of timber. During the last ten years it had made an average annual increase of 1.5 cubic feet.

This study brought out the following facts: (I) While rapid upward growth is being made the lateral accretions are slight. (2) Large accretions accompany full leafage.

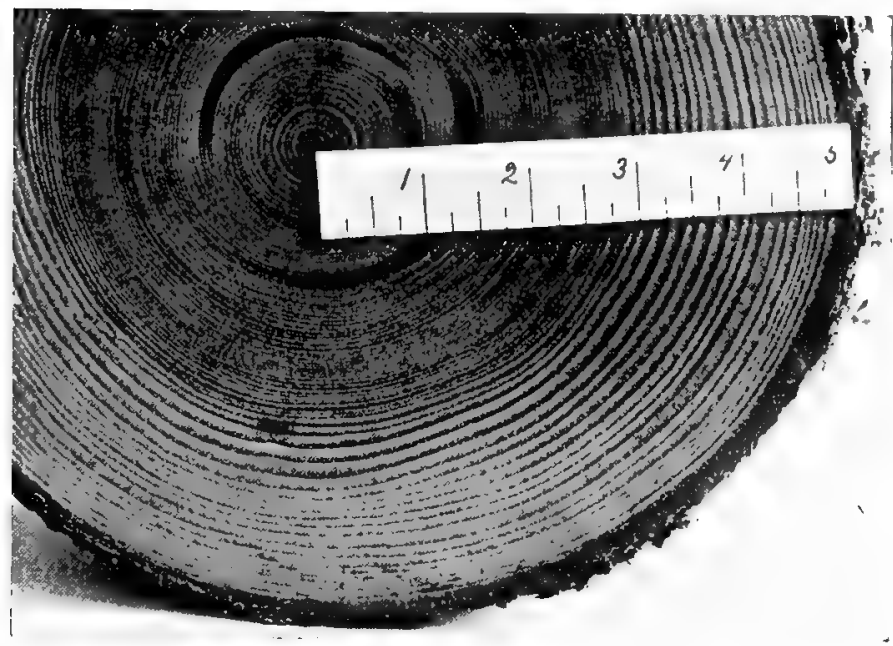

Figure 33. White Pine crowded and then open grown.

After the surrounding growth is killed, the tree begins to strengthen the portion which receives the greatest strain by wind, that is, the lower part of the trunk. (4) In approaching the top of the tree the accretions are found to diminish as each live branch is passed.

Figure 34 shows a section of a White Pine that was entirely open grown. This tree was cut when fifty-six years old, and measured eighteen inches in diameter on the stump, eight inches at twenty-five feet above. the stump and forty-eight feet in height. The volume of the stem when cut was 28.85 cubic feet; the 
accretion during the last ten years was 12.52 feet, which is equivalent to mean annual increment of 1.25 feet.

As the live branches of this tree occupied the whole trunk, the timber was very knotty. A proper crowding would have kept it from forming large branches on the lower trunk, stimulated its upward growth, and prevented so large an increment during the early life of the tree. But if, as with the former tree,

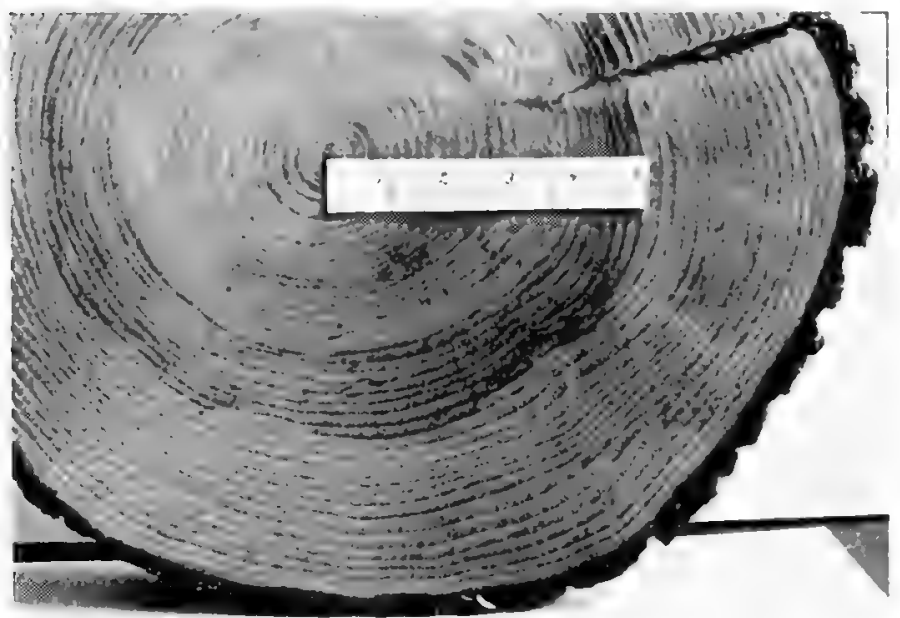

Figure 34. Cross section of White Pine open grown.

it liad been first crowded and then set free, the best timber in the least time would have been secured.

The Profit from an Investment in Land lhat is stocked with only very small conifernus secdlings is altogether too small and too remote to prove an attraction to investors at present, cven were the danger from fire entirely eliminated. But there is considerable land that is now stocked with a good growth of young pine of fair size that could be bought and managed at a good profit if the danger from fire could be greatly reduced. This land in many cases would not have to be held more than ten or fiftcen ycars to secure a good profit on the investment, 
after which the profit might be made nearly continuous. The rapid growing deciduous trees, such as the Poplar, Willow. White and Yellow Birch, Soft Maple, Ash, Red and White Elm, Hackberry, Basswood, Locust, Black Walnut and Tamarack, may sometimes be planted and grown at a profit on waste land

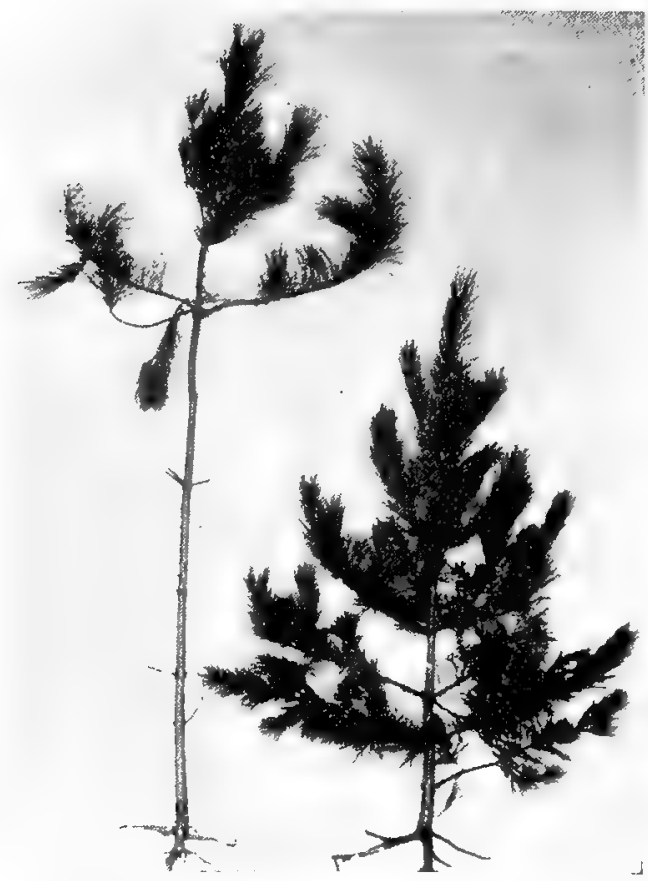

Figure 35. Crowded and open grown Norway Pine. Crowded trees form the most good timber in the shortest time. Open grown trees have many side branches, and consequently form poor timber.

that is adapted to them. and should there be a stock of young trees of these kinds already on the land it can perhaps be soon made to yield a revenue in the shape of posts and fuel, and later of timber. Even the slower growing deciduous trees, such as the Red, White and Bur Oak, Hard Maple and Rock Elm, 
increase very rapidly in good soil, and could often be made to yield a good profit if properly managed. However, most of the hard-wood lands of this section are of such good quality that they secm destined to be generally cleared for agriculture instead of being kept for timber.

Willow for Fuel. From a number of careful estimates it seens quite probable that good soil planted in White Willow will produce at the rate of from four to six cords of firewood per acre per year. If, then, ten acres were taken for this purpose. and one acre cut over clean each year, such amount of land would yield about fifty cords of fuel per annum, worth probably from two dollars to three dollars per cord in our prairie sections.

In starting such a woodlot it would be desirable to set the cuttings two feet apart in rows eight feet apart, since at this distance, if cultivated, they will soon cover the land, and until the land is fully shaded cultivation seems to be necessary in order to keep down the weeds and to protect from drouth. After the land is well shaded no further cultivation will be necessary.

At the end of five or six years some thinning should be done on all the land, and in this thinning probably at least half the trees should be removed. The remainder will soon fill up the vacancies, and in the course of three or four years more it should be again thinned out, and this should be repeated as often as they crowd one another until the trees on the land remain about twelve feet apart each way, after which the land should be treated as coppice, and since this tree renews itself very quickly and vigorously from sprouts, and continues to do so for a long period of years, it is probable that such a plantation will last indefinitely.

Willow wood makes good summer fuel, and as a fence post, when the bark is removed and the wood well cured, it is quite satisfactory, and will last in the soil abont seven years. It is also good for poles when peeled and dried.

The Common Cottonwood on very rich soil will probably yield from five to seven cords of firewood per acre per year. 
DIAMETER GROWTH OF SOME MINNESOTA TREES.

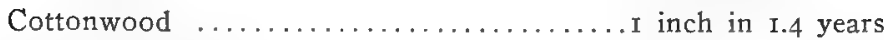
Norway Spruce ..................... inch in 2.5 years Silver Maple ....................... inch in 2.7 vears White Willow ..................... inch in 2.8 years

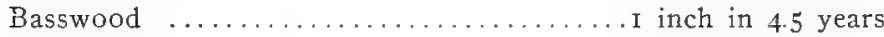
Sugar Maple ..................... inch in 6.6 years

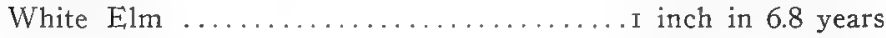

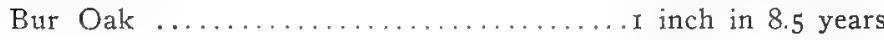

The height growth of Silver Maple and White Willow is about two feet per year, Norway Spruce one foot per year. Bur Oak averaging thirty feet in height makes an average growth of about .55 feet per year, while the rate of height growth of the first twenty feet of marketable cordwood is about one foot in I.5 years. The height growth of Cottonwood varies from two to eight feet per year. A fifteen-year-old Cottonwood will often grow in height three feet per year. Black Spruce has shown a diameter growth of one inch in 14.7 years, and a height growth of one foot in 2.3 years. 


\section{CHAPTER X.}

FOREST MENSURATION.

\section{MEASUREMENT OF SINGLE TREES.}

\section{Trees which are to be Cut May be Considered in Two} Classes, in the first of which fall all those which contain timber material, and in the second those which are too small to be of value for timber. The material of the first class is in the main part available for timber, and in part for firewood, while the stump, smaller limbs and leaves are waste; the material of the second class may be used in part for firewood, fence posts, etc. For timber purposes the cubic contents of the wood only is considered, while for firewood the bark is included in the calculation, so that we may measure part of the tree without bark and part with bark on. For timber usually only the main portion of the trunk is considered, especially in coniferous woods, but for firewood all limbs that will make a stick of cordwood must be included. In this discussion we will consider only the trunks of trees, as the volume of the limbs must be determined separately, but in the same way.

The Volume of a Standing Tree can be gotten at only roughly, as there is no geometric figure which exactly represents the shape of the trunk, the latter varying much under different conditions of growth. The volume of a paraboloid, the geometric figure which approaches nearest to the form of a tree, is equal to the product of the basal cross-sectional area by one-half the height. The basal area of a tree is taken at breast height, to avoid the excessive swelling near the ground. Breast height is usually considered as four feet three inches above the ground, at which point the diameter is measured by a pair of calipers in inches, and the area in square feet of the corresponding circle is found in a prepared table of such areas. The height of the tree may be deternined by triangulation, in which various instruments are used, as the transit, the altimeter, or a mirror 
liypsometer. A simple geometrical method is illustrated in the figure. A measuring rod is set up at a convenient distance from the tree $A B$, the eye of the observer is at $S$, and the lines of sight to the top and bottom of the tree intersect the rod at a and $b$. Then, by measuring the distances from the observer to the rod and to the tree the height is given by the formula $\mathrm{H}=\frac{\mathrm{ab} \times \mathrm{SC}}{\mathrm{SD}}$.

Now, considering the tree as a paraboloid, its basal area times one-half the height will give approximately the volume.

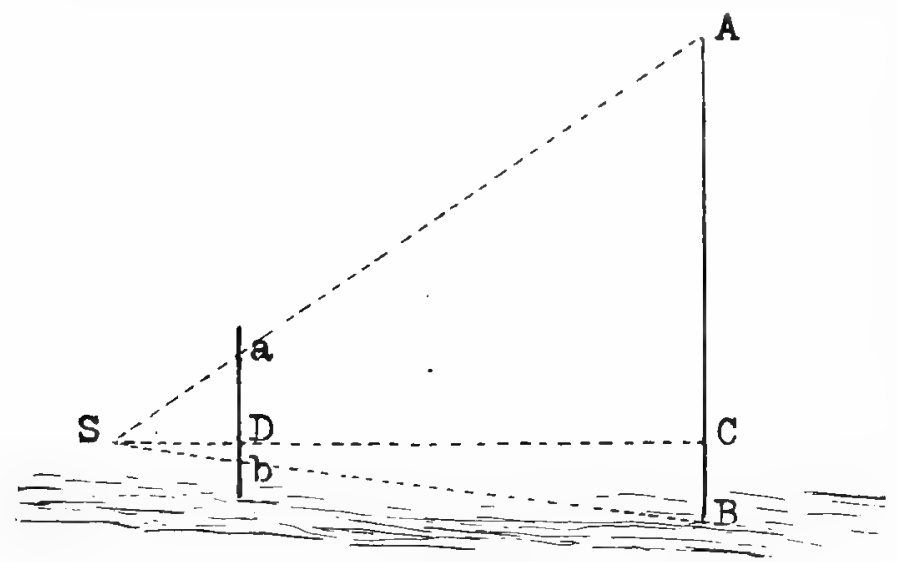

Figure 36 . Measuring the height of a tree by. a simple geometrical methed.

For example: A white pine has a diameter at breast height of I8.7 inches, and the height of the tree is eighty-four feet; what is the volume? By reference to the table of areas of circles the area corresponding to a diameter of 18.7 inches is found to be r.9072 square feet. Multiplying this by one-half the height, the approximate volume of the tree is found-1.9072 $\times 42=80.1024$ cubic feet.

The Volume of a Standing Tree may be obtained by Employing a Form Factor which has been previously determined for that Darticular species by the felling and accurate measurement of a great many sample trees of approxi- 
mately the same dimensions and grown under the same conditions. The form factor is expressed as a decimal, and is the ratio of the mean volume of the sample trees to the volume of a cylinder with the same diameter as the diameter of the mean sample tree at breast height, and whose length is equal to the height of the tree. For example: A tamarack measures 6.9 inches in diameter, breast high, and the height of the tree is fifty-one teet. Its volume by accurate measurement of the felled trec is $7.2 \mathrm{I}$ cubic feet, and the volume of a cylinder with a diameter of 6.9 inches and a length of fifty-one feet is 13.24 cubic feet. The form factor, or factor of shape, is therefore $7.21 \div 13.24=54$, and if this tamarack represents the mean of a large number of trees of approximately the same dimensions, the factor may be applied to all of them, or to all trees of the same size and grown under the same conditions. In the same way factors are determined

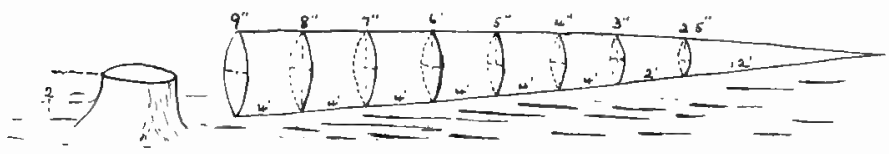

Figure 37. Determining the volume of a felled tree

for all sizes, and tabulated for future use. In application the volume of a tree 6.9 inches in diameter, breast high, and fiftyone feet high would be found thus: Volume of cylinder $X$ form factor equals volume of tree, or $13.24 \times .54=7.21$. This method gives a much closer approximation than could be obtained by using a geometric figure supposed to represent the shape of the tree.

The Volume of a Felled Tree may be determined more accurately. It is considered in sections, or log lengths, and the volume of each section is found by multiplying the middle crosssectional area by the length. The degree of accuracy of this method depends on the length of the sections; the shorter they are the more accurate the result. The last section at the top, when small, may be treated as a cone whose volume is equal to the basal area times one-third its length; or when large and tapering off suddenly it may be considered as a paraboloid whose volume is equal to the basal area times one-half its length. The 
sum of the volumes of all the sections will be the volume of the tree trunk.

For example: A tree is felled at two feet above ground, and calipered at the stump and every four feet along the trunk down to three inches in diameter, and also at two feet above the last measurement. The remaining distance to the top of the tree is twelve feet. (See Figure 37.)

By reference to the table of areas of circles on page 136 the areas at each point calipered are found:

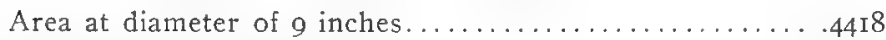

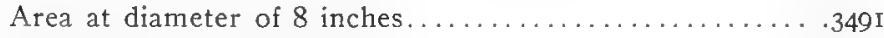

Area at diameter of 7 inches......................2673 Area at diameter of 6 inches..................... I963 Area at diameter of 5 inches.................... 364

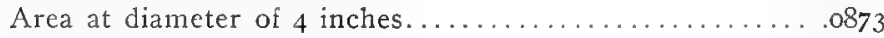
Area at diameter of 3 inches.................. O49 I

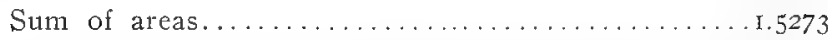

It will be noticed that these areas are taken at the middle of a four-foot section, so multiplying the sum by four, the volume of the trunk, from the ground to a height of 28 feet, is found to be 6.1092 cubic feet. Treating the top length of twelve feet as a cone, its voltume is one-third times the basal area into the height, - . $0341 \times 12 \div 3=\mathrm{I}_{3} 64 \mathrm{cubic}$ feet, - which added to the volume of the lower portion gives total volume of the tree 6.2456 cubic feet. 
AREAS OF CIRCI,ES.

\begin{tabular}{|c|c|c|c|c|c|c|c|c|c|c|c|}
\hline 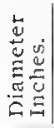 & 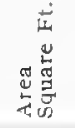 & 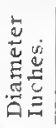 & 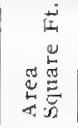 & 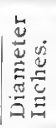 & 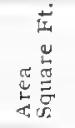 & 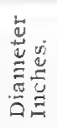 & 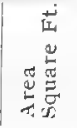 & 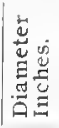 & 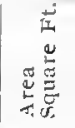 & 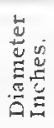 & 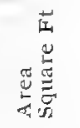 \\
\hline 0.0 & 00 & 5.7 & 772 & 11.4 & 0.7089 & 17 & 5949 & 22.8 & 2.8352 & 28.5 & 4.430 \\
\hline & 001 & & 835 & 11.5 & 0.7214 & 17 & 136 & 22 & 2.8602 & 28.6 & \\
\hline 2 & .0002 & 5.9 & 899 & 11.6 & 7340 & 17 & & 23.0 & 2.8852 & 2 & \\
\hline .3 & 0005 & 6.0 & 1968 & 11.7 & $746 \%$ & 17.4 & 1. 6513 & 23.1 & 2.9103 & 28.8 & \\
\hline 4 & .0009 & 6.1 & .2029 & 11.8 & 0.7595 & 17.5 & 16703 & 23.2 & 29856 & 28.9 & \\
\hline 5 & & 6.2 & 1.2096 & 11.9 & 0.7724 & 17.6 & 1. 6894 & 23.5 & 2.9610 & 290 & .580 \\
\hline 6 & 920 & 6.3 & 0.2164 & 12.0 & 0.7854 & 17.7 & 1. .087 & 23.4 & 29864 & 咆 1 & 4.6186 \\
\hline & $(027$ & 6.4 & 0.2234 & 12.1 & 0.7986 & 17.8 & 17280 & 23.5 & $3.01 \geq 0$ & 29.2 & 46504 \\
\hline 8 & $0: 35$ & & .8304 & 12.2 & 0.8118 & 17.9 & 1. 7475 & $23 . t i$ & 3.0377 & 29 & 4.68 \\
\hline & 044 & & .2876 & 12.3 & 2522 & 18 & 1.7671 & 23.7 & 6635 & & 4 \\
\hline & 0 & & .2448 & 12 & $38 \%$ & & 1.78 & 23.8 & 0844 & & 1464 \\
\hline & 0.0067 & 6. & $25 \div 2$ & 12.5 & 523 & & & 8.9 & 1154 & 29 & \\
\hline & 0.0079 & 6.9 & 0.2597 & 12.6 & 0.8660 & 18.3 & .8265 & 24.0 & 8.1416 & 29.7 & \\
\hline & & 7.0 & $0.26 \% 3$ & 12.7 & 0.8798 & 18.4 & 1.8465 & 24.1 & 3.1679 & 29.8 & \\
\hline-4 & & 7.1 & 0.2750 & 12.8 & 0.8987 & 18.5 & 1.8666 & 24.2 & 3.1942 & 29 & 3760 \\
\hline & & 7.2 & $0 \quad 28: 8$ & 12.9 & $0.90 \pi 7$ & 18. & 1.8869 & 24.3 & 3.2207 & & 9087 \\
\hline & & 73 & $0.290 i$ & 13.0 & 0.9218 & 18 & 072 & 24.4 & 3.2471 & & 9415 \\
\hline & & & .2987 & & 360 & & & 24.5 & 2748 & & \\
\hline & & 7. & 068 & & 3504 & & & & 8006 & & 5 \\
\hline 9 & & & .3151 & & 1384 & & & & $32 \pi 5$ & & 5 \\
\hline & 218 & 7.7 & .3234 & 1 i & 0.9794 & & 1. 9897 & 24.8 & 8545 & 30 & 6737 \\
\hline & 0.0940 & 7.8 & 0.3319 & 13.5 & 0.9941 & & 2.0206 & 24.9 & 3.3816 & 30. & 1071 \\
\hline & .0264 & 7.9 & 0.3404 & 13.6 & 1.0089 & 19.3 & 2.0316 & .0 & 3.4088 & 30 & 405 \\
\hline & & 8.0 & 0.3491 & 13.7 & $1.02 \%$ & 19 & 2.0527 & 25.1 & 3.4361 & 30 & \\
\hline & & 8. & 0.3579 & 13 & & & & 25.2 & 3. 4 & & \\
\hline & & 8. & & & & & & & & & \\
\hline & & 8. & & & 1.0 & & & & & & \\
\hline & & & & & 1.0843 & & & 25.5 & & & \\
\hline & 0.0428 & 8.5 & .3941 & & 1.099 & 1 & 599 & 25.6 & 3.57 & & \\
\hline & 0.0459 & 8.6 & $\begin{array}{l}0.4034 \\
0.4109\end{array}$ & & $\begin{array}{l}1.1153 \\
1.1309\end{array}$ & 20.0 & 2.1817 & 25.7 & $\begin{array}{l}3.6024 \\
36305\end{array}$ & & 7 \\
\hline & 00524 & 8.8 & $0.4 * 4$ & 14.5 & 1.1.67 & 20.2 & 2.2256 & 25.4 & 3.6587 & 37 & 7.466 \\
\hline & $\begin{array}{lll}0 & 0559\end{array}$ & 89 & & 14.6 & 1.16 & & $2.247 \pi$ & 26.0 & 3.6 & 38 & 7.8758 \\
\hline & & & & & & & & & 3.71 & 3 & 8. .958 \\
\hline & & 9.1 & & & & & & & 39 & 4 & 206 \\
\hline & & 9.2 & & & 1.2108 & 0.6 & 2.3146 & .3 & 25 & 4 & 684 \\
\hline & 0. & 9.3 & 18 & & 1.2272 & 0.7 & $2.33 \% 1$ & 26.4 & .8013 & 4 & 9.6211 \\
\hline & 0.0747 & 9.4 & 0.4 & & 1. 2437 & 20.8 & 2.3597 & 26.5 & 3.8301 & 4 & 10.0847 \\
\hline & & 9.8 & 23 & & $1.260 \%$ & 209 & 2.3825 & 6.6 & 3.8591 & 44 & 10.5592 \\
\hline 3 & & 9.1 & & & 1. & 2 L & 2.4 & & 3.8482 & 45 & $044 \%$ \\
\hline & & 9. & & & & & & 26.8 & 3.9 & & 5410 \\
\hline & & 9. & & & & & & & & & \\
\hline & & & & & & & & & & & \\
\hline & & 10.0 & & & & & & & & & \\
\hline & & 10.1 & & & & & & 7.2 & & & \\
\hline & & 10.2 & 0.5675 & & & & .5447 & 27.83 & & & \\
\hline & & 10.3 & 0.0681 & & $\begin{array}{l}1.846 n \\
1.4188\end{array}$ & 21.8 & $\begin{array}{l}251784 \\
25091\end{array}$ & 27.4 & & 53 & 8007 \\
\hline & & 105 & & & & 21.9 & $2 t$ & 27.6 & 4. 1548 & 54 & 15.9043 \\
\hline & & 10.6 & 0.6 & & & 22.0 & 2.63 & 27.7 & 4.1850 & 55 & 16.4988 \\
\hline & & 10.7 & & & 1.4 & 22.1 & 2. fif & 278 & 4.2152 & 56 & 17.1042 \\
\hline & & 10.8 & & & 1.4 & 22.2 & 2.6 & 279 & 4.2456 & 57 & 17.7206 \\
\hline & & & & & 1.50 & 22.3 & 2.71 & 28.0 & 4.2761 & 58 & 18.3478 \\
\hline & & & & & 152 & 22.4 & 279 & 28.1 & $4.306 \%$ & 59 & 18.9859 \\
\hline & & 11 & & & 1.53 & 22. & 2.76 & 28.2 & 4.3374 & $6 u$ & 19.6850 \\
\hline & & 11.5 & & & & 20. & 2.18 & 28.3 & 4.3681 & & \\
\hline & & & & & & 20.7 & 2.81 & & 4.34 & & \\
\hline
\end{tabular}


MEASUREMENT OF GROWING STOCK.

\section{The Growing Stock of a Forest, or Volume of Stand-} ing Timber, is equal to the sum of the volumes of all the trees. Where the tract is small caliper all the trees, or if the tract is large caliper all the trees on a small sample area selected as typical of the whole. If each species is in uniform stand, separation into species classes will be sufficient, but where much difference exists between individuals of the same species, due to conditions of growth, diameter and height classes in each species should be formed, and the volume of each class computed by itself. From the diameters obtained by calipering at breast height the average basal area is determined in eacli class, and trees of corresponding diameters in each class are felled and measured accurately. The volume of a sample tree, or the mean volume of several sample trees, times the number of trees, gives the volume of that class, and the sum of the volumes of the different classes is the total volume of timber on the tract. The more sample trees that are measured the more accurate will be the results, as trees vary so much in shape that quite different volumes may be obtained for two trees of the same diameter and height.
A Sample Acre of Jack Pine Shows the Following Stand:
Diameter, Breast Height.
2 inches....................... I
3 inches....................... 6
4 inches......................... 6
5 inches..................... I6
6 inches........................ 33
7 inches...................... 40
8 inches........................... 60
9 inches...................... 56
Io inches......................... 46
II inches.......................... 29
I 2 inches..................... II
$\mathrm{r}_{3}$ inches....................... 9
I4 inches........................ 2
I5 inches........................ 2
Basal A reg. .0218 .2946 .5238 2. 1824 6.4779 I0.6920 20.9460 24.7408 25.0884 29. I 400 8.6394 8.2962 2. 1380 2.4544 
Putting all these trees in one class, and dividing the total basal area by the number of trees, the mean basal area is found to be 4468 , which would correspond to a diameter, at breast height, of nine inches. Selecting a tree nine inches in diameter, it is felled and measured accurately, and the volume found to be II.63 cubic feet. This volume of the sample tree is multiplied by the number of trees, 317 , for the total volume on the acre3.686.7 I cubic feet. Greater accuracy may be attained by taking a sample tree for each diameter size, and a forest may be measured in miniature by felling and measuring a proportionate numper of each diameter, say one per cent of each.

The volume of a sample tree, or of sample trees, is often found by applying the factor of shape, which has been previously determined for that particular species and locality.

The Conversion of Cubic Feet Total Volume of Standing Timber into Feet Board Measure may be done roughly by considering $I, 000$ cubic feet as the equivalent of from 4,000 to 7,000 feet board measure, according to the size of the trees, young growths giving much less than old growths.

The Conversion of Cubic Feet Firewood into Cords is accomplished by the use of the factors which experience has shown to be practically accurate. A cord of wood piled up occupies 128 cubic feet of space, but on account of the shape of the sticks much of this is air space, and the actual wood content much less than I28 cubic feet. In Germany a cord has been found to contain 83.2 cubic feet of wood. In Saxony Dr. Schenck says that eighty-six cubic feet make a cord of ordinary firewood, and that 25.73 cubic feet of branch stuff will pile up to a cord. At the Minnesota Experiment Station, by actual measurement of round, straight sticks, a cord has been found to contain as high as I02 cubic fect. This factor of 102 cubic feet may apply very well to straight, well-trimmed spruce, tamarack, etc., free from knots and limbs, but will be too high for oak and similar wood, which is inclined to be more crooked, and does not pile so closely. A cord of small oak averaging 3.4 inches in diameter and ranging from $\mathrm{T} .5$ to 7.5 inches, consisting of 274 four-foot sticks, measured 69.67 cubic feet. Averaging these two extremes, 85.85 cubic feet is found in a cord of mixed wood, corresponding very nearly to the figure given by Dr. Schenck. 
RATE OF GROWTH.

The Accretion of a Tree is the Increase in Wood Content as the Result of its Activity During the Growing Periods. The rate of growth is indicated by the increase in diameter, in height, or in mass, and may be considered as annual or as periodic. The diameter accretion is equal to twice the thickness of the annual rings for the desired period, measured on the average radius. The current annual increase in diameter is taken as the average of several years back, as five or ten years. It is determined by counting off the required number of rings from the bark in, and measuring their thickness. Twice that thickness divided by the number of years in the period will give the current annual diameter increase.

The Height Accretion is Determined by counting and measuring the annual cones which appear in a longitudinal section, or by measuring the length of $\log$ between two cross sections which was grown in the time indicated by the difference in the number of annual rings at the two sections.

For example: A $\log$ is fourteen feet long. The lower end shows I78 annual rings and the upper end I5o annual rings. The difference in the number of these rings is 28 , or twentyeight years were required to grow the fourteen feet in length between the two cuts. The number of annual rings at any cross section indicates the lifetime of that portion of the tree above the section.

Mass Accretion is the Increase in Volume of the Growing Tree. The volume increase of standing trees can only be arrived at approximately, and is based on the measurement of the volumes of trees of different ages; the difference will be the increase for the period. The increase in volume is often calculated as simple interest, but where the mass of the tree is considered as capital, interest is computed as compound.

The Rate of Mass Accretion of a Standing Tree May be Determined in the following manner: In mature trees the height growth per year is inconsiderable, and may be disregarded for short periods of time. The present and past volumes, then, vary as their respective basal areas. Taking twice the width of the rings for the period desired from the present 
diameter will give approximately the former diameter of the tree. From this diameter obtain the area at that time, and compute percentage of growth from the difference between that and the present area.

For example: By cutting into the trunk of a tree, or by removing a core of wood with an accretion borer, and measuring the thickness of the annual rings for ten years, we find it to be .5 inch, and the present diameter of the tree inside bark is twenty inches.

Increase in diameter for ten years............ $5 \times 2=\mathrm{I}$ inch Diameter of tree ten years ago...........20-I $=\mathrm{I} 9$ inches Present cross-sectional area with diameter 20 inches .............................. 8 I7 square feet Area ten years ago, with diameter I9 inches... 1.9689 square fect

Increase in area for ten years.........2128 square foot Per cont increase...............21 $28 \times 100 \div 10 \times 1.9689=1 \%$

The Determination of the Rate of Mass Accretion of a Standing Tree with compound interest is a more difficult matter, but Pressler, an eminent German forester, calculated tables for average thrifty trees and for very thrifty trees, the use of which renders the work of computation very simple. The width of rings for the desired period is measured, and the diameter divided by twice the width of these rings. This gives relative diameter, opposite which, in Pressler's tables (see page I4I) will be found a number which is to be divided by the number of years in the period. The result will be the per cent of accretion with compound interest. For example: A Cottonwood sixteen inches in diameter shows a growth of 2.2 inches on the radius for the last ten years. The diameter increase would then be 4.4 inches, and by dividing the diameter by the diameter increase, 3.6 is found to be the relative diameter. In Pressler's tables, opposite 3.6 is found the number $8 \mathrm{I}$ in the column of average thrifty trees. Divide $8 \mathrm{r}$ by ten (the number of years), and obtain the rate of increase with compound interest, 8. I per cent. 
PRESSLER'S TABLE.

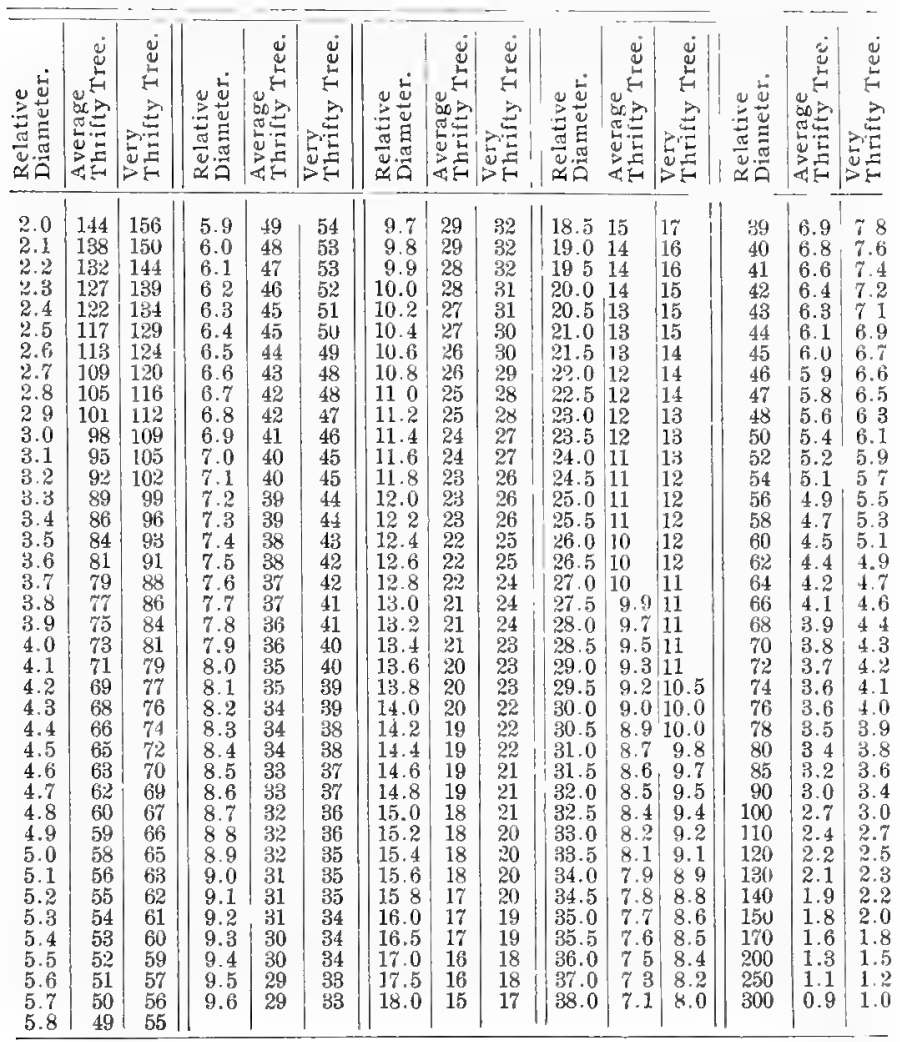

In Determining the Accretion of a Felled Tree the volume is computed from actual measurements. By a few trials the top is cut off where the section contains as many rings as there are years in the period for which the accretion is desired, and the height of the tree at that time measured. The difference in volumes past and present gives periodic accretion. The diameter for both the past and present tree may be taken at the middle of the topless stem, and volumes found by multiplying 


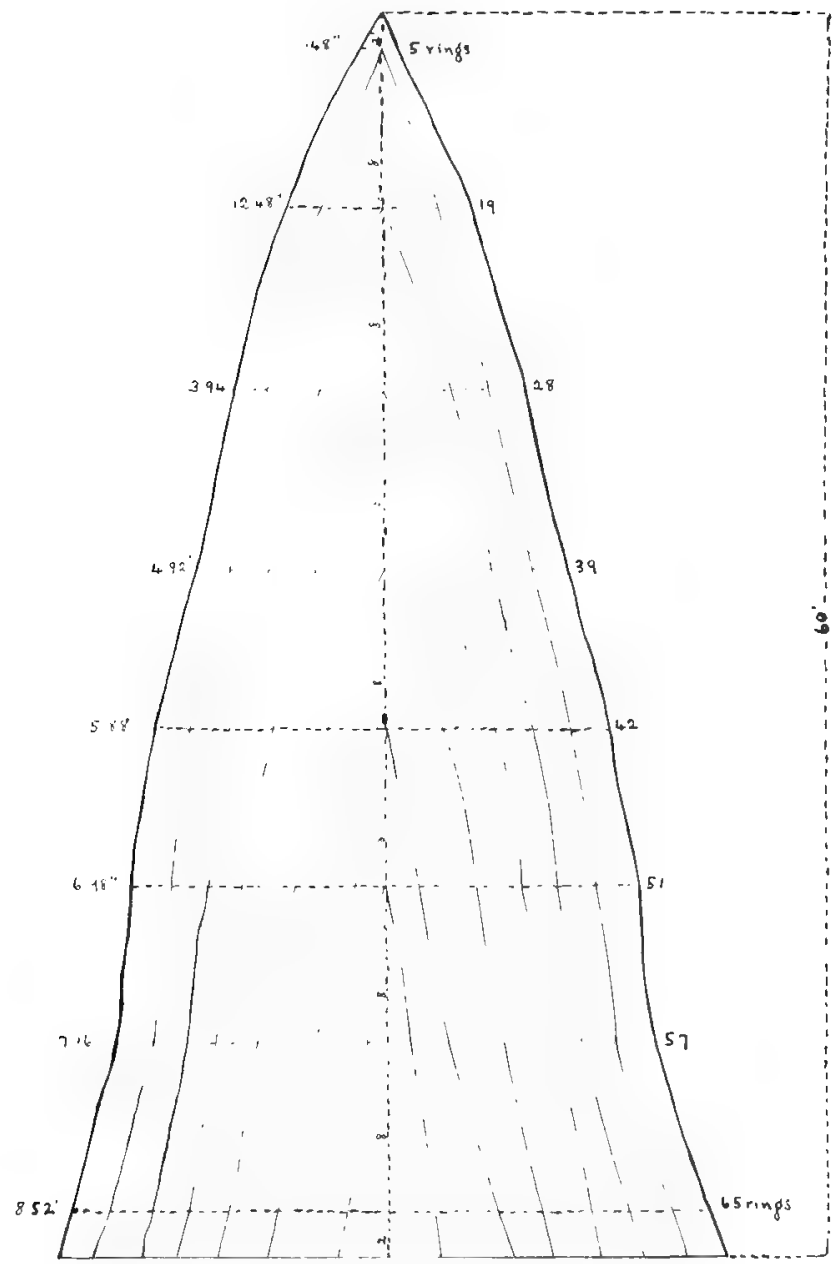

Figure 28 . The progressive volume of a tree. 
their respective cross-sectional areas at that point by the length of the topless trunk.

A more careful stem analysis of a tree affords detailed measurements from which the volume at any time during its lifetime may be determined very accurately. The following table of measurements of a pine will furnish data for the calculation of its volume at different ages, and its progressive development is graphically illustrated in Figure 38 :

\begin{tabular}{|c|c|c|c|c|c|c|c|c|c|c|}
\hline \multirow{2}{*}{ 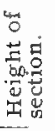 } & \multirow{2}{*}{ 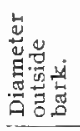 } & \multirow{2}{*}{ 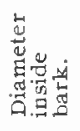 } & \multirow[b]{2}{*}{ Age. } & \multicolumn{7}{|c|}{ Accretion in inches during past } \\
\hline & & & & $\begin{array}{c}10 \\
\text { years. }\end{array}$ & $\begin{array}{c}20 \\
\text { years. }\end{array}$ & $\begin{array}{c}30 \\
\text { years. }\end{array}$ & $\begin{array}{c}40 \\
\text { years. }\end{array}$ & $\begin{array}{c}50 \\
\text { years. }\end{array}$ & yours. & y0 $\begin{array}{c}\text { i0 } \\
\text { years. }\end{array}$ \\
\hline $\begin{array}{l}2 \\
10 \\
18 \\
26 \\
34 \\
42 \\
50 \\
58 \\
60\end{array}$ & $\begin{array}{r}9.3 \\
7.8 \\
7.1 \\
6.3 \\
5.7 \\
4.4 \\
3.0 \\
.5 \\
\text { Top }\end{array}$ & $\begin{array}{l}8.52 \\
7.16 \\
6.98 \\
5.88 \\
4.92 \\
3.94 \\
2.48 \\
.48\end{array}$ & $\begin{array}{r}65 \\
57 \\
51 \\
42 \\
39 \\
28 \\
19 \\
5\end{array}$ & $\begin{array}{l}.54 \\
.50 \\
.57 \\
.42 \\
.44 \\
.48 \\
.56 \\
.24\end{array}$ & $\begin{array}{r}1.10 \\
.94 \\
1.07 \\
.99 \\
1.03 \\
1.24 \\
1.24\end{array}$ & $\begin{array}{l}1.60 \\
1.34 \\
1.58 \\
1.51 \\
1.71 \\
1.97\end{array}$ & $\begin{array}{l}2.16 \\
1.92 \\
2.30 \\
.59 \\
2.46\end{array}$ & $\begin{array}{l}2.80 \\
2.68 \\
3.37 \\
2.94\end{array}$ & $\begin{array}{l}3.70 \\
2.70 \\
3.49\end{array}$ & 4.96 \\
\hline
\end{tabular}

The Accretion of a Forest for a given number of years is found by multiplying the accretion of the sample tree for that period by the number of trees per acre and the number of acres in the tract. If the trees are arranged in diameter classes, the accretion of each class is determined, and the sum of accretions of all the classes taken as the accretion of the forest.

The Working Plan of a forest contemplates the economic management of the growing crop, so that there may be cut each year not to exceed the amount of the annual accretion; or, if worked on the rotation plan, so that there may be cut at any one time not more than the accretion for the period of rotation, thus leaving the capital stock unimpaired. The methods of measurement described are used in outlining this plan.

The Estimation of Standing Timber is usually a matter of personal experience on the part of the estimator. No measurements are taken of trees, but the estimate is made by men of long experience in the woods. Sometimes their figures are very close, but more often they fall short of the actual stand of timber. Buying and selling timber lands is based on this method of determining the possible crop, both parties sending out their 
own estimators. The number of trees on typical areas, as an acre in each forty, may be counted, and the sizes estimated. Often all timber trees on a forty-acre lot are counted, and the number of logs per $\mathrm{r}, 000$ feet board measure estimated.

For an inexperienced person a good method would be to caliper all trees on typical areas of the tract, and then compute the stand from the cross-sectional area and the average length of timber stick, which could be estimated very closely after a little practice. The greatest difficulty in this work lies in the selection of typical areas and sample trees. All forestry measurements and estimates are only approximations, and it is often found necessary to modify working plans to meet new information and changed conditions.

\section{MEASUREMENT OF LOGS AND LUMBER.}

Logs are Measured in Feet Board Measure by taking the length and diameter at the small end, and by reference to a table the corresponding number of feet board measure is found. This is not usually accurate, but seems to be sufficiently so to satisfy both buyer and seller in this state. Lumber is measured in square feet of surface of a board one inch in thickness, commonly called board measure, or B. M., for short.

Scaling Logs in Minnesota is a Simple Matter. It is done after they are cut from the tree and marked, wherever convenient,-in the woods, on skidways, on cars, on the river, or elsewhere. For straight, sound logs no experience is necessary, but for defective logs the scaler's judgment is depended upon to make proper deduction, so as to get out good lumber. Private scalers may be employed by those interested, but, to avoid possible litigation over sales, it is advisable to have the surveyor general of logs and lumber for the district appoint an official scaler to do the work. The scalers enter in a book carried for the purpose the number of logs scaled, the length, the feet $B$. M., the number of each $\log$ if numbered, the section, township and range where cut, and the markings. These books are kept on file in the surveyor general's office for future reference. There are seven lumber districts provided for by law in Minnesota, but in only five has it been found necessary to open offices, namely, at Stillwater, Minneapolis, Wabasha, Duluth and Crookston. 
The Minnesota law provides that Scribner's rule be the only legal rule for the survey of logs in this state, and that every log shall be surveyed by the largest number of even feet which it contains in length over ten feet and under twenty-four feet, and all logs of twenty-four feet or more shall be surveyed as two $\log _{5}$ or more. As to what Scribner's rule is the law does not say, and yet requires it to be posted in the offices of the surveyors general of logs and lumber. The following table is a copy of Scribner's rule as used here:

SCRIBNER'S RUI,F.

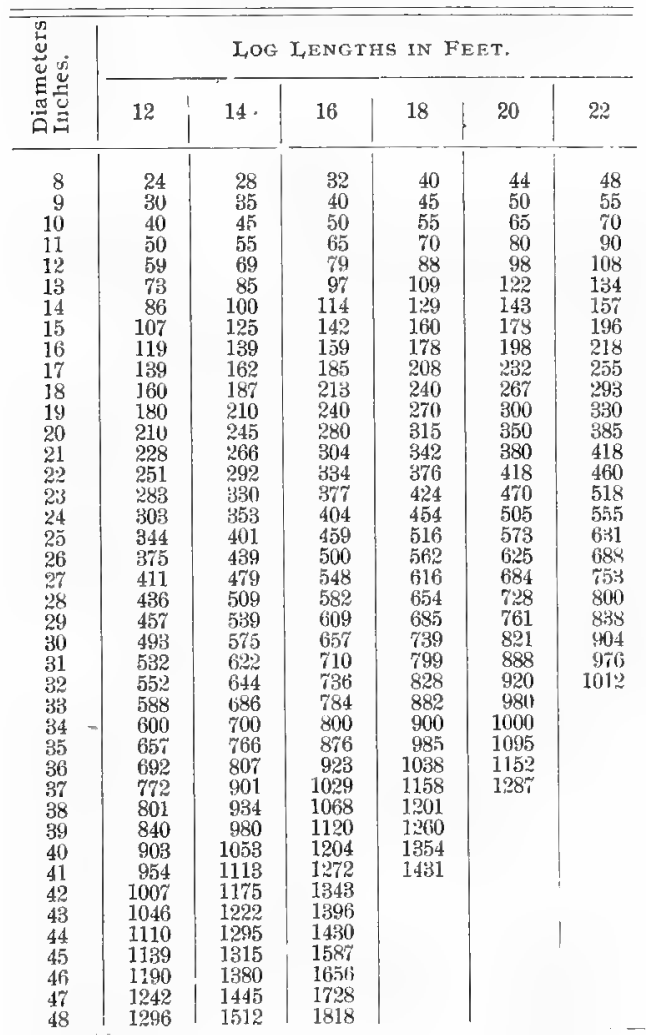




\section{The Number of Feet B. M. which May be Obtained} from a Log varies with the management of the cutting, the width of kerf, the width of boards, whether one or two inch boards, or some of both are cut from the same log. Usually the cut exceeds the scale. Take, for cxample, a log sixteen inches in diameter at the small end, eighteen inches at the middle, twenty inches at the large end, and twelve feet long. Such a log contains about $2 \mathbf{I} .2$ cubic feet. The official scale gives IIg feet B. M., which is equal to 9.9 cubic feet. The actual cut should give I55.75 feet B. M., or thirteen cubic feet of lumber, the slab would be about 5.3 cubic feet, and the keri (sawdust) about 2.9 cubic feet. From this it would appear that the Minnesota official scale gives the seller 46.7 per cent of his $\log$, while the mill turns out 6r.3 per cent in lumber, 13.7 per cent in sawdust and 25 per cent in slab. The producer loses 53.3 per cent of the scaled log; but that is not all his loss. In marking logs to be cut the tndercutter allows at least three inches over the required length to cover loss in checking; that is, a log scaled at twelve foot length would really measure twelve feet and three inches, or more.

The Percentage of the Logs, on which the seller or producer gets returns varies with different sizes and shapes. The following table will serve as a comparison:

\begin{tabular}{|c|c|c|c|c|c|}
\hline \multirow{2}{*}{$\begin{array}{c}\text { Diameters } \\
\text { Inches. }\end{array}$} & \multirow{2}{*}{$\begin{array}{l}\text { Irengths } \\
\text { Feet. }\end{array}$} & \multicolumn{2}{|c|}{ Scale } & \multirow{2}{*}{$\begin{array}{l}\text { Volume } \\
\text { C. F. }\end{array}$} & \multirow{2}{*}{$\begin{array}{l}\text { Per cent } \\
\text { of Actua } \\
\text { Volume } \\
\text { Scaled. }\end{array}$} \\
\hline & & B. M. & C. F. & & \\
\hline $2[-22$ & 16 & 304 & 25.3 & 40.3 & 62.8 \\
\hline $18-19$ & 22 & 293 & 24.4 & 41.1 & 59.4 \\
\hline $18-21$ & 16 & 213 & 17.9 & 332 & 53.9 \\
\hline $16-18$ & 16 & 159 & 13.3 & 25.2 & 52.8 \\
\hline $15-22$ & 16 & 142 & 11.8 & 29.9 & 39.5 \\
\hline $1-16$ & 14 & 125 & 10.6 & 18.3 & 579 \\
\hline $16-30$ & 12 & 119 & 9.9 & 21.2 & 467 \\
\hline $14-1 K$ & 12 & 86 & 7.2 & 16.8 & $42 \div$ \\
\hline $14-15$ & 12 & 86 & 7.2 & 13.8 & 52.2 \\
\hline $10-14$ & 20 & 85 & 5.4 & 15.7 & 34.4 \\
\hline $11-13$ & 16 & 6ล็ & 5.4 & 12.6 & 429 \\
\hline $11-12$ & 16 & 65 & 5.4 & 11.5 & 47.0 \\
\hline $11-15$ & 12 & 50 & 4.2 & 11.1 & 37.8 \\
\hline $10-12$ & 16 & 50 & 4.2 & 10.6 & 39.6 \\
\hline $8-10$ & 16 & 32 & 2.8 & 7.1 & $3 \pi .8$ \\
\hline $6-3$ & 16 & 16 & 1.3 & 4.9 & $2 \%$ \\
\hline $9-11$ & 10 & 40 & 3.3 & 8.7 & 38.1 \\
\hline $8-11$ & 16 & 82 & 2.7 & 7.9 & 33.8 \\
\hline $8-1: 3$ & in & 32 & 2.7 & 8.7 & 30.6 \\
\hline$x-1 ; 3$ & 16 & 32 & 2.7 & 9.6 & 27.8 \\
\hline$x-12$ & 12 & 24 & 2.0 & 65 & 304 \\
\hline $8-10$ & 12 & 24 & 2.0 & 5.3 & 37.7 \\
\hline$(1-11$ & 12 & 80 & 2.5 & $6 . \overline{5}$ & $38 \div$ \\
\hline
\end{tabular}


In practice these discrepancies are equalized as the result of the ordinary trade relations, and are not liable to work serious injustice under present conditions, and are here stated only to call attention to our crude methods of measuring timber.

\section{INSTRUMENTS USED IN FOREST MENSURATION.}

The Equipment of a Forester, while not extensive. must be complete for the work in hand. He surveys the land, lays out roads and ditches, cuts down trees and saws them into logs, measures diameters of logs and growing trees, takes heights of trees, determines rates of growth, estimates and measures timber and cordwood, and maps and plats his work. Where there has been a survey of land by the government, as in this state, he will not be called upon to make one, as maps sufficiently reliable for his purpose may be had from official records; but to meet all the requirements of his position the forester should be an expert surveyor, and provided with all the necessary instruments for the work, including drawing instruments, tables, stationery. etc., for office work, in mapping and platting his field observations. The work of forestry mensuration is concerned mainly with taking diameters and heights of trees, determining the areas on which they stand and the rate of growth.

For Measuring Land Areas the ordinary steel tape, graduated on one side in feet, tenths and hundredths, and on the other side in links for convenience in computing acreage, is used -the roo-foot length being preferred. For the same purpose a steel chain is also used, and with the chain or tape should be a set of marking pins and ranging poles. In laying out small rectangular areas, as a sample acre, a cross-staff head, an angle mirror, or an angle prism is used; but for more extended surveys and for road and ditch work a transit and level would be advisable, while for the location of lost corners the magnetic compass might have to be resorted to.

For the Rough Land Measurement of a Valuation Survey a Steel Chain, Thirty-three Feet Long, is used. This short chain is attached to a stout leather belt about the waist of the tallyman, whose hands are then free to carry the tallyboard holding notebook or tally blanks, and to work with a lead pencil. A small magnetic compass by which the tallyman directs his course is fixed on one corner of the tallyboard. 
The Diameters of Trees and Logs are taken with a pair of wooden calipers of convenicnt size for the timber of the district. A limb or scale bar, graduated in inches and tenths. has a fixed arm standing out at right angles at one end, while a second arm is movable along the bar so that the trunk of a tree may be inclosed between them and the diameter read directly from the scale. The fixed arm is held in place by a

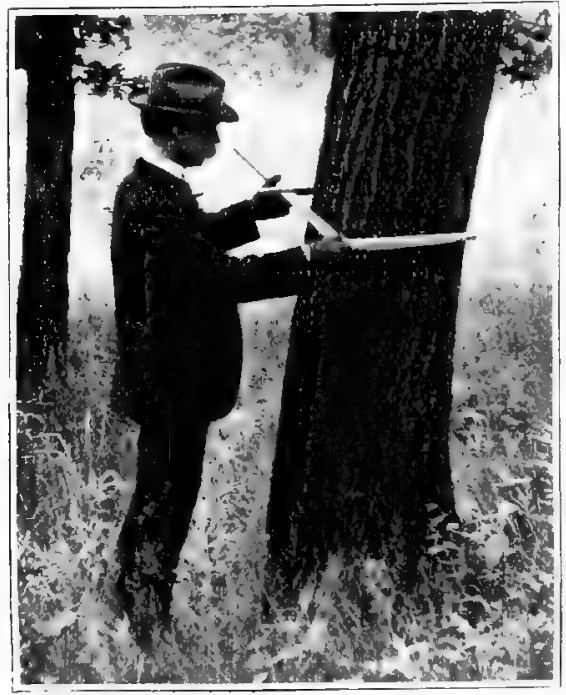

Figure 39. Calipering a tree.

screw so that it may be removed for packing and transportation, or so that a broken part may be replaced. The other arm has an adjustable plate which keeps it at right angles to the scale bar when pressed against the tree. Sometimes the circumference of the tree is measured with a steel tape, one side of which is graduated to give diameters of circles whose circumferences are read from the other side.

The Heights of Trees ate determincd by means of a most convenient and useful little instrument, called Faustman's mirror hypsometer. The distance of the observer from the tree is 
measured with a steel tape, and the instrument adjusted to that distance by the slide and vertical scale. The top and bottom of the tree are then sighted and the readings of the marginal scale where the plumb line crosses it added to or subtracted from each other, according as the eye of the observer is above or below the level of the tree. This instrument may also be used

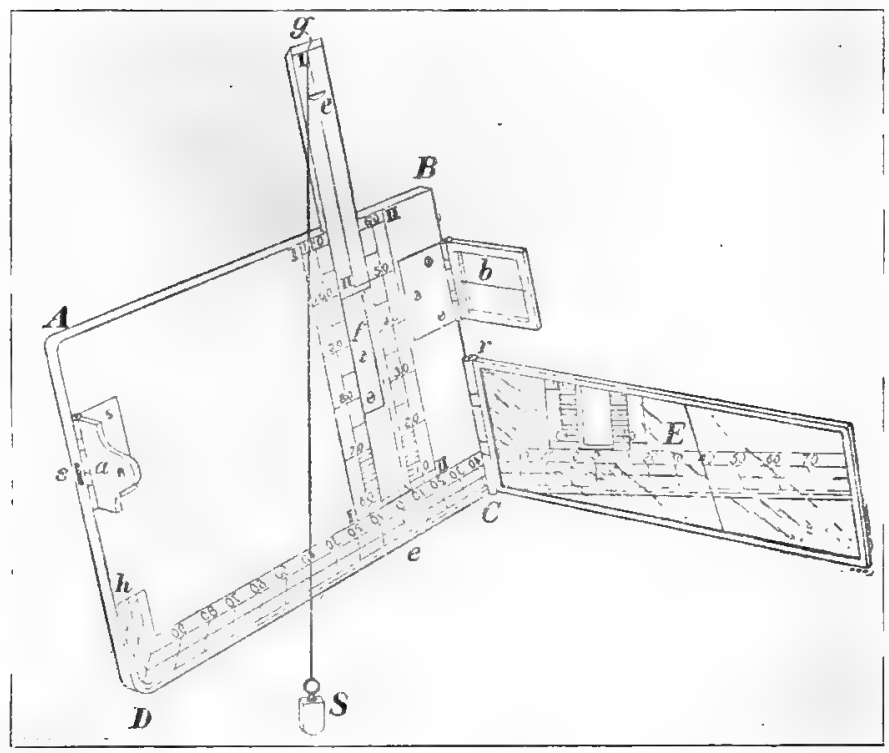

Figure 40. Faustman's mirror hypsometer. ( $A B C D$.) Frame of instrument, $(E)$ mirror in which scale is reflected, $(a)$ ey epiece, $(b)$ cross-wire on which object is sighted, $\left(g_{c}\right)$ slide and vertical scale for distance of observer from tree, (f) spring to hold slide in place, (h) marginal scale which gives height of tree.

in taking levels and grades, and may be mounted on a jacob staff or tripod, but is more often used in the hand. Another instrument, called "Baummesser" by the Germans, mounted on a tripod, is used to take heights, and by means of a stadia attachment the diameter at any point on the trunk of the tree may also be measured. After some practice with one of them a 
person may become sufficiently expert at estimating the heights of trees to get along without an instrument.

The Rate of Growth of a Standing Tree is determined by removing from the trunk a small cylinder of wood with a hollow auger, called an accretion borer. On this section of wood the annual rings are counted, and their width measured with a pocket rule graduated in inches and tenths, or in millimeters.

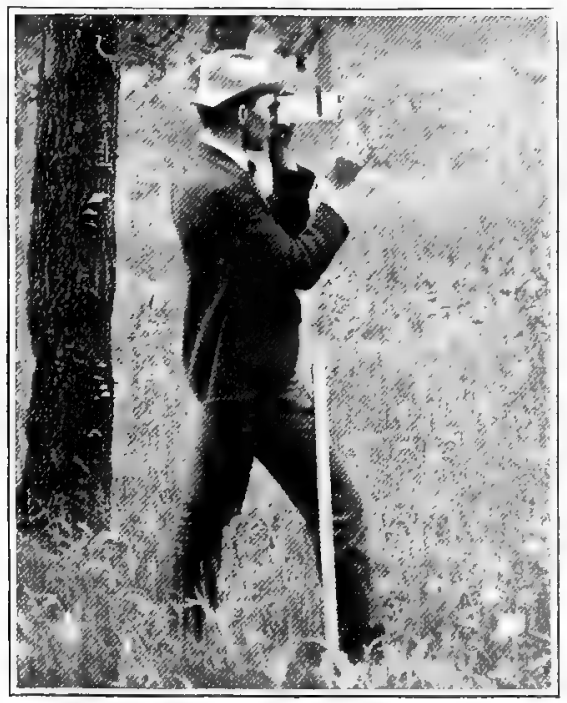

Figure $4 \mathrm{I}$. The mirror hypsometer in use.

Where the growth has been slow, and the rings are close, a pocket lens may be necessary to enable one to count them. When a fuller determination of the rate of growth is desirable, trees are felled with an ax, or with a saw, and cut into logs. A small saw is casier to carry around, but a longer, heavier saw does much faster work. The common logging saw of the Minnesota woods is six feet in length. In making an examination of the end of a log the rough graining of the saw must often be smoothed away before the rings can be counted readily, and this 


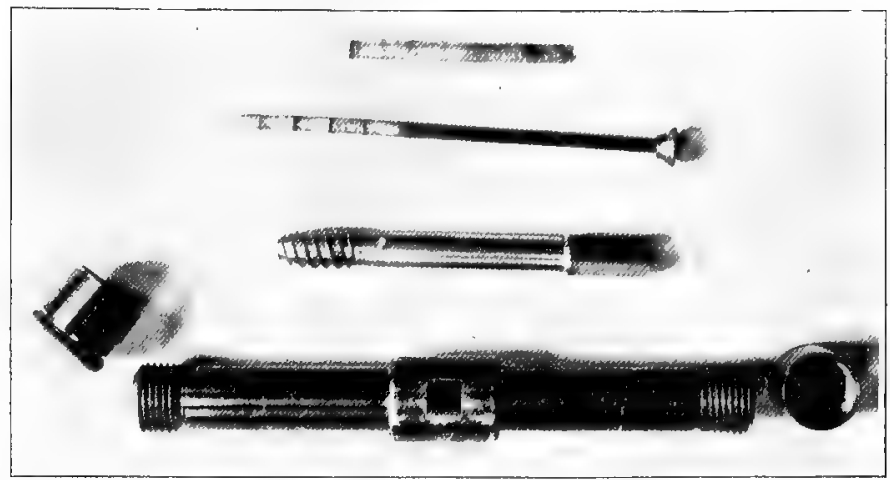

Figure 42. The accretion borer, showing handle, hollow auger, withdrawing pin and a core of wood extracted. The handle is hollow, with screw caps, so that the other parts may be carried inside when not in use.

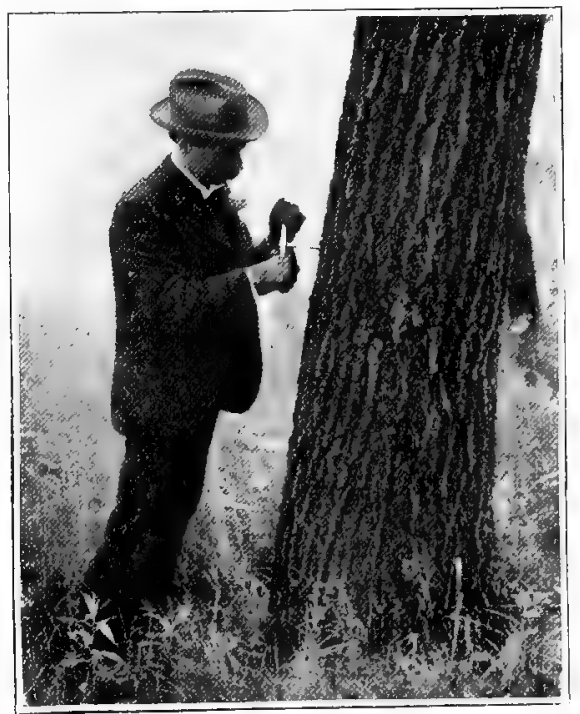

Figure 43. Using the accretion borer on the trunk of a tree. 
is well accomplished with a sharp knife, cutting a broad $V$ notch from the center to the circumference.

Miscellaneous Instruments used by the forester. For marking logs, blazing trecs, cutting away limbs, etc, a hand $\mathrm{ax}$ is a desirable addition to the equipment. It should be small, so as tn be conveniently carried in the pocket or in the belt, and shoul have a leather guard to protect the edge when not in use. As saws and axes will not keep sharp long, if used, a grindstone, whetstones, files and saw sets should be provided. In calipering trees on a small area across which it is necessary to make sevcral trips, the surveyor avoids repetitions by marking the bark of each tree, as he calipcrs it, with a metal scratcher carried in one hand. Sonetimes a pair of climbers are used to get into the top of a tree for the purpose of measuring upper limbs and diameters. The number of feet board measure in logs is ascertained by means of the ordinary $\log$ rule, Minnesota standard, used by scalers, and a board rule measures the lumber as it comes from the sawmill.

A Camping Outfit is necessary where the work of the forcster is done in the depths of the forest, far from habitations and railroads, and perhaps a wagon and a team of horses or pack horses should be provided for moving camp and hauling supplies. If the area to be worked over is great, the chief of the party should have a good saddle horse, so that he may get over the country quickly, and lay out work for his subordinates who operate on foot. 


\section{CHAPTER XI.}

\section{FOREST PROBLEMS IN MINNESOTA.}

The object of this chapter is to give general suggestions which may be applied to a variety of conditions, and not to prescribe exact treatment for any special forest problem. It has seemed that certain methods of treatment could be best given in this way.

I. A. has a swamp covered with thrifty Black Spruce, in all about seventy-five acres. Iast year he got 500 Christmas trees from it, which he sold at eight cents cach. There is also some Tamarack and Pine on the higher land. For what trees can this land be used for greatest profit? How long does it take to grow Christmas trees?

Answer: If the Black Spruce are thrifty, it is a very sure indication that the soil is not overly wet during the summer, and that it is in very good shape for Tamarack or other more valuable tree. The Black Spruce is a very slow grower, and it is doubtful if it should be encouraged under any condition. Our native White Spruce grows much faster, and this would be much the most profitable of any of our native trees for paper pulp; but some studies by the Minnesota Experiment Station seem to show that the Norway Spruce could be grown at even greate: profit for paper pulp. This tree is fully as rapid a grower as the White Spruce, nearly as hardy, and the seed of it is much more casily obtained. If it is thought desirable to use this land for pulp wood, a small bed of spruce seedlings should be made up near by, in which should be sown White or Norway Spruce seed, and when the seedlings are three or four years old they should be transplanted to the swamp. It would take at least fifteen years to grow Black Spruce to a height of six feet for Christmas trees, while the Norway Spruce could probably be grown to the same height under same conditions in ten years. About 1,800 Christmas trees can be grown on one acre of land to a height of six feet and with a spread of five feet. Spruce may be grown closer together than most other trees for this purpose, because the shaded branches are not easily killed out. 
2. B. has a Tamarack swamp of 800 acres, from which he has cut all the timber big enough for ties. There is practically no demand for the smaller post timber at present, and he asks what he shonld do with it, and if it will pay him to hold it. The land scems to be well stocked with young trees of various ages, some of which have been somewhat broken down in getting out the larger tie timber.

Ansucr: Probably the best treatment would be to let it alone. If the land is quite wet there is very little chance of fire doing much damage to it. If, however, it is liable to be dried out it would be a good plan to take some precautions to protect it from fire, if it can be done without too much expense.

The Tamarack grows very rapidly, and there is perhaps no tree that will pay better than this, providing the taxes are not too high. While there may be no demand at present for the smaller stuff for fence posts, yet within a few years such a demand is inevitable, as the nore accessible Tamarack is now being rapidly sought after for such purposes, and is being shipped in large quantities to the prairie farms. Such a Tamarack swamp, if carefully looked after, is capable of continuing itself indefinitely and producing a fairly good annual revenue. The advisability of perpetuating such a swamp in Tamarack would depend largely on the demand for hay land, for which purposes such land is generally well adapter.

3. A. has 500 acres of dry, sandy land. The soil blows badly, and is too light for grain. Clover does very well on this land when protected with snow in winter, but is liable to kill out in open winters. The subsoil is clay.

Answer: Such land should never have becn cleared for agricultural purposes, and the sooner it can be got into tree growth again the better for the soil. The land should be seeded down with rye or other crop, or possibly with clover, until something of a sod is formed. In this sod Jack Pine might be planted, or it is very probable that Jack Pine would come well from seed sown in furrows made in the sod. After the Jack Pine is well cstablished, about 500 Norway or White Pine per acre could be planted to advantage. This should receive only a moderate crowding by the Jack Pine, and should be protected from too much crowding until it can take care of itself. This number of 
trees would be enough to make a well stocked acre at nuturity. Since the land has a heavy subsoil, the chances are that there would be a good tree growth, as trees are more influenced by subsoil than by the surface. If such land is very accessible, it would probably pay better to grow green crops on the soil, and by careful rotation use it for agricultural purposes, for which it may be fairly well adapted if carefully managed.

4. B. has 600 acres of Jack Pine, four to twelve inches in diameter. The soil is typical of Jack Pine land, being very sandy and unfit for agriculture. What is the best treatment of it?

Answer: Such land is only fit for timber growth, and Jack Pine is probably the most profitable tree that can be grown upon it if it can be sold as fuel. The aim should be to keep out fires, and to cut the trees on the selection plan, removing the larger ones when they attain a diameter of ten inches. It may, however, be best to cut clean on certain parts at each cutting, but the cuttings in such cases should not be so large but what the trees near by will seed the land. This tree has wonderful regenerative power, and soon covers the soil with a new growth. It is rather impatient of shade, and the young seedlings do not do well under the old trees. It often happens that the cones on Jack Pines remain upon the trees unopened for a long time, and often fire sweeps over the land which scorches them, causing them to open and shed their seeds. As fire is to be avoided on such land, in order to protect the young growth, it may be best to gather the cones, and after roasting then slightly so that the scales open, scatter the cones broadcast over the cut-over portions. If timber is wanted, it would be worth while to try to secure a stand of Norway Pine seedlings.

5. A. has a dry, sandy prairie, the soil of which blows badly when it is broken up. The trees blow out, and it is of very little value for agricultural purposes. Can it be used for forestry? The subsoil is fairly good, and there is standing water at a depth of about ten feet.

Answer: Under such conditions trees should do well after they have once become established. The difficulty is in getting the land stocked. By seeding the land down to clover, with oats, in the spring of the year, the oats would come up quickly, and prevent the blowing out of the soil early in the spring, and the 
clover would come along and probably make a good showing the next year. After the oats and clover have started, about onehalf the land can be planted in strips, not nore than sixteen feet wide and twenty-four feet apart. If these strips are planted with almost any of our hardy trees, they should do well. For this purpose the White Willow would be very desirable, but seedlings of Boxelder, Green Ash or Norway Pine should also do well. The strips of land in oats and clover will afford sufficient protection to the planted strips to protect them from wind injury. After these strips are established and two or three years old the intervening spaces may be broken up and planted without danger of any further wind injury.

6. A, has a piece of burned-over timber land on which there are scarcely any seed-bearing trees of value; the valuable pines have all been destroyed by successive burnings. Most of the land is perhaps two miles from any seed-producing White Pine, which was the most profitable tree on this land, and is undoubtedly now the most profitable tree that this soil can produce. He would like to have it restocked with White Pine. How should he go to work to do it?

Aliswer: Since the seed-bearing trees are so far distant from the land there is no use depending upon them for restocking the soil with their seedlings, and the Poplar, Birch and Bird Cherry will undoubtedly soon reign supreme here, if they do not already. The best treatment is probably to gather White Pine seedlings that are under one foot in height from the nearby forest, if they can be obtained easily, and set them out, about twenty feet apart each way, amongst the brush now found on the land, taking care to make a little clearing, as it were, where each tree is planted. The tendency will be for the worthless trees now growing on the land to smother out the pines before they get started, and it will be necessary each summer for several years to go over the land and cut away those trees that are crowding the young pines too severely. After these young pines have become established it is probable that they will be able to take care of themselves in competition with the inferior species, and then the crowding which they receive from the latter will be a good thing for them, as it will cause them to take on an upright growth. Plantings of this kind will probably cost somewhere about five dollars per 
acre, and if the work is carefully done in the spring, just before the growth of young pine starts, there should be scarce any failures. In setting out the seedlings it is important that they be kept in water or in damp moss from the time they are pulled out until they are put into the soil again. They must not ever be allowed to appear dry.

7. B. has land in Northern Minnesota covered with a mixed growth of pine and poplar. The poplar is about twelve inches thick, and overtops the pine, which varies from four to eight inches in diameter and from twenty to forty feet high. What treatment would be best to securc an even stand of White Pine?

Answer: While the poplar is hardly marketable at present, yet it should be removed even if the material taken out hardly pays for the expense of so doing. This should be done in order to give the pine a chance to shoot upward. After the poplar is renoved the pine will probably stand for several years without serious crowding, when it shotld be thinned to obtain best results.

8. A. has 2,000 acres of burned-over land in Northern Minnesota. This has quite a number of crooked and branching seeding trees, probably sufficient to seed the land, but the soil is so covered with raspberries, grass and poplar that the pine has very little chance to grow.

Answcr: The best way for giving a chance for the pine seed to grow is to drag the land in good seed years as well as can be with a drag made of oak branches or logs. This will tear up a good deal of grass or bushes, and make a loose surface soil in which the pines can take root; but the next year the weeds will again start, and will destroy the pine unless they are held in check in some way. This is probably best done by going over the land in Junc and July, and cutting off some of the weeds where the pines have seeded thickest. This practice should be followed at least two years, after which but little attention of this sort will be needed, as the pines will probably be able to take care of themselves from then on. If the land can be used for sheep pasture for one or two years, most of the weeds and bushes will be destroyed, and the land will be left in improved shape for the treatment outlined in dragging the land to get it into good shape for a seed bed. In fact, without any further treat- 
ment the pine will probably come in unless the land is very heavily pastured.

9. A. has 2,000 acres of land in Northern Minnesota without any seeding trees. How can he secure a stand of pine upon the land?

Answer: In such a case the best way is probably to set out pine seedlings, pulled from the woods, setting them about twenty feet apart each way. This will require about 400 plants per acre. If the work is done early in the spring there should be no great trouble about securing a good stand. These trees will be crowded by weeds on the land, which may help them to take an upright growth, but they should be watched, and the weeds kept in check, if they are liable to overcome them. After a few years the pine will be improved by the crowding of poplar and hazel brush, which is generally found upon such soil.

ro. A. has a half section of moderately good land, covered witl 1 an even-aged growth of White and Norway Pine. He would like to maintain a stand of pine on this tract, not that he thinks it especially profitable, but that it would prove an interesting experiment.

Answer: Even-aged pine is very difficult of renewal without clean cutting, and it is quite out of the question to handle such tracts to advantage on the selection system. There is practically no such thing as even-aged pine over large areas in this state. It is probable that this land could be best renewed by the group or strip methods. The land should be burned over clean after cutting, care being taken to protect any good groups of seedlings that may occur. A stand of young seedlings should be secured on each piece of land cut over before further cutting is done. If grass or brush is coming in too fast, it will probably be a good plan to go over the land with a log-drag in August of the first good seeding year after cutting, so as to loosen the soil, that the seed may have a good chance to start. Grass and weeds often prevent the growth of pine seed, or even kill out the young seedlings after they are started.

II. A. would like to have a good shelterbelt about the buildings on his prairie farm, in central Minnesota, and would like if it could be made to furmish fence posts and fuel. He could use ten acres for this purpose. 
Answer: He will probably come nearest to accomplishing this if he makes a solid planting of White Willow, as recommended on page Izo.

I2. C. has a farm on rolling prairie. It is all tuder cultivation or used for pasture. He feels the necessity of having a home supply of fence posts and light fuel. Thinks of putting his wood lot on the rich bottom land. The soil is a sandy drift. some ridges being more sandy than others, and in a few places are bare from washing.

Answer: Since the bottom land resists drouth better than the high land, it would be better to keep it for agricultural purposes, and to place the trees on the ridges, where the soil is too bare to yield a return from agriculture. $\mathrm{He}$ could probably plant White Willow in these locations to good advantage, and get what he needs in fence posts and a considerable amount of summer fuel. It is probable that on such land there would be a yield of about three cords per acre of fuel wood per year, much of which material could be used for posts. These trees should be cultivated until they cover the land well. They should begin to yield some fuel within six years from the time cuttings are planted, if they are set two feet apart in rows eight feet apart.

I3. A farmer living on the open prairie in the southwestern part of Minnesota wants a windbreak and wood lot; more particularly desires a windbreak for buildings and a shelter for stock. Does not think of raising firewood or his own fence posts. Can a windbreak be worked to advantage as a wood lot in such a case?

Answer: Under such conditions the windbreak should be made somewhat wider than recommended on page 50, so as to include as much area as to give the wood desired. In cutting under such conditions it would be desirable to cut not more than one-half of any portion of the windbreak at one time, so that its value as a windbreak would not be impaired at any time. Working in such a way would require a rotation period of about ten years. It would probably be best to plant this largely with White Willow, but if the soil is heavy or somewhat inclined to be moist it would be a good plan to put in some Soft Maple and Boxelder. 
I4. What kinds of trees are best adapted to use for live fence posts? Should the wires be nailed directly to the tree, or on blocks of wood which are fastened to the tree?

Answer: Probably the best tree for a live fence post is one of the willows or other hardy tree. Where the White Willow is used for this purpose there is no special objection to nailing the wire directly to the tree, except that the tree will soon grow over the wire, and it cannot then be removed. If it is thought that the wire might be removed within a few years, it would be much the better plan to nail it onto blocks of wood which are nailed to the tree. Willow trees which are used in this way as live fence posts may be cut off about a foot above the top wire and allowed to reproduce themselves. Such trees, if properly managed, will often produce a large amount of firewood, as well as afford good fence posts.

15. We have thirty acres of rather wet land which we do not expect to use for many years cxcept as pasture. Would it pay to grow some White Willows on a portion of it, and would they interfere with its value as pasture?

Answer: If the land is not heavily pastured, it might be a good plan to grow a few groups of willow on it, as they will furnish some protection to the stock, and do not interfere materially with the pasturage value of the land. Scattered trees might also be grown, as they would not seriously interfere with the growth of grass under them where the land is moist; but it would not be desiralsle to encourage a very thick growth on the land, since it is much more valuable for pasturage than it would probably be for growing wood.

I6. B. has come into possession of fifty acres of bluff land along the Mississippi river, in Southern Minnesota. The lond is of goos quality, but too much broken for agriculture, and when used as pasture it washes badly. The southern slopes are nearly bare of trees, but the other slopes are well covered with White Oak, Hard Maple, Basswood and Eim, with some Hackberry, Wild Black Cherry, Black Walnut and Butternut. It has been pastured for twenty years, and consequently there are no young trees coming on. He desires to preserve it as a wood lot, since it has become of litlle value for pasture.

Anszer: The first thing to do is to kecp out the cattle, as 
they destroy all the young seedlings that start, and prevent any natural regeneration. In good seed years it might pay to loosen the soil, where it could be done easily, in portions that are not especially liable to erosion, so as to give the seeds that fall a good chance to grow. It would also be well to gather Black Walnuts and Acorns, and plant them in especially favorable locations. Improvement cuttings should also be made where needed.

I7. A. has five acres of overflow lands along the Mississippi river. This is about four feet above the low water mark. It is, however, so liable to freshets in the spring that it would not be safe to use it for agricultural purposes, and it is not desirable for pasture or meadow. It is now covered with a heavy growth of White Maple and Cottonwood, and some White and Red E, m. What is the best way of managing it?

Answer: It would seem quite probable that the White Maple will become the most valuable wood of any now on the land, and it should be encouraged by cutting out the Cottonwood wherever it crowds, and also the White and Red Elm. The aim should be to have a good stand of White Maple, as it seems probable that this will produce by far the most profit. This tree makes a very rapid growth on good soil, and the wood is used for a variety of purposes. If the maples do not thickly cover the ground, there may be some chance for good pasturage under the trees; but under the best conditions there would be no opportunity for pasturage. This land would possibly yield about 500 feet board measure per acre per year if well stocked. Such land will probably be used for meadow when the country is better settled, but this is perhaps no objection to using it for growing maple for the next twenty years.

I8. A. has a piece of gravelly land. It was originally covered with a growth of Bur, White, Red and Scarlet Oak, but was cut 'over about thirty years ago, and at present has a rather thin stand of stunted trees, many of which are sprouts from Bur Oaks. It is burned over every year. The land is of very little value for agricultural purposes.

Answer: On such land the increase is very little, and there will be no profit in holding it for tree growth if it is taxed at a high rate. If, however, the rate of taxation is low, it is quite likely that the trees will yield a fairly good return. It should be 
the aim of the owner to keep out fires, and so encourage the growth of underbrush and leaf mold, as this protects from drying out in summer, which is important on such land. The large trees that are decaying had better be cut out. and the younger growth favored by occasional thinnings, where too much crowded.

19. A. has a meadow which is subject to overflow in the spring of the year. The stream which runs through it is liable to sudden rises, and has made many channels for itself, and is continually making new channels. The land affords fairly good pasturage, but the cutting of new channels by the river is a source of great annoyance and loss. Is there any way that this can be prevented by planting trees?

Answer: Such streams may be permanently straightened out by planting willows across the cuts made, so as to confine the waters to a straight course. By this treatment a stream soon clears out a deeper main channel for itself, and the old high water channels gradually fill up with the sediment from the water which sets back into them from the river at times of freshet. The banks of the stream should also be protected from washing by planting willows on them. For this purpose willow cuttings of large size should preferably be used. They should be not less than two inches in diameter and six feet long, and be put at least three feet in the ground where exposed to erosion.

20. A. has forty acres near Minneapolis, covered mostly with a heavy stand of Sugar Maple, twenty-five years old, and two or three acres of Tamarack, Elm, Basswood and Oak. What treatment would be more profitable than to clear up for pasture or other purposes?

Answer: Such land as this is probably much more valuable for agricultural purposes than for forestry, unless it is stony or on steep hillsides, for the tree growth indicates a strong, valuable soil, and its being located near a large city should enhance its value for dairying or similar purposes.

2I. Some neglected lowlands have become partially covered with Cottonwoods and Willows, some of which are a foot or more in diameter. These trees are in irregular patches, covering perhaps two-thirds of the tract. The lowest places are quite wet and boggy. What income might be derived from a careful management of the growing wood? 
Answer: Very little profit can come from it in its present condition, except as it may be useful for pasturage. If, on further consideration, it is decided that it will be more valuable for lorestry purposes than for pasturage, it would probably be best to encourage a growth of White Maple, the seeds of which could be sown in furrows or in patches in June. The Cottonwood should be kept out as much as possible, as, since it is well adapted to this class of soil, it is liable to drive out everything else, and there is very little profit from the growing of it.

22. B. has forty acres of land covered with Maple, White Oak, Birch, Hackberry and Eilm. He cuts his fuel from it, and makes sugar from the Maple each year, and finds it fairly profitable. There are, however, no young trees coming on, the ground being entirely bare, and it looks as though in the course of time the old trees would ripen up, and there would be nothing to take their places. The land is so rough that it would not be profitable for agriculture nor especially desirable for pasturage.

Answer: The reason why there is no young growth coming on is probably because the land is closely pastured, since the foliage of the Maple, Elm, Birch and Oak is readily eaten by stock. The first thing to do is to keep out the cattle, so that the young seedlings may have a chance to become established. If the leaf canopy is rather thin, so that the light has encouraged the growth of grass under the trees, it would be a good plan to break up the soil just before the seed falls in good years. Possibly furrows could be made through the woodland with a plow, but if too rough for this, then it can be broken up by the dragging of several logs tied together over the land. It would be a good plan to keep out everything but the Sugar Maples, since these will undoubtedly be the most profitable, both for sugar and for fuel. As these seedlings come on, they should be encouraged to cover the land, by letting in a little light occasionally, if neces sary. This may be done by removing some of the old trees that are past their prime. After the young trees are seven or eight feet high no harn would come from the pasturing of stock among them for a few years, unless the land was so heavily pastured that the treading of the stock about the roots was injurious. If treated in this way there should be no trouble about securing a good stand of young Maples to come on and take the place of those which are maturing. 


\section{CHAPTER XII.}

THE USES OF WOOD.

Wood Serves so Many Purposes and enters so largely into human activities that it may indeed claim to be the most useful of all natural products, excepting only food. Iron is looked upon as the most useful of metals. Wood is not a metal, but in its usefulness it may be placed above iron, which it is replacing in many cases where the latter was formerly used exclusively. Iron and wood have displaced and replaced each other in public favor time and time again. so that their respective claims to supremacy have not yet been decided. For instance, in the manufacture of bicycles, wood rims were first used, and then gave way to iron and steel on account of their lighter appearance and strength. Now, with better methods of construction, wood is again in use, and giving general satisfaction. However, each has its place, and the two often work to better advantage in combination. Experiments have shown that in tensile strength hickory exceeds iron and steel of the same length and weight, and hickory and long-leaf pine resist greater endwise compression than wrought iron. The elasticity of wood enables it to yield to greater stress than metals without receiving permanent distortion, and in like manner it will resist high temperatures without warping, holding its shape until consumed or broken down by mere weight.

In Comparison with Iron, Wood is lighter, easier to work and handle, at present cheaper, and in many cases stronger and more durable. These facts, coupled with its abundance and ready adaptability, have brought it into such extensive use that the future depletion of the supply has become a matter of some concern to thoughtful people. Even now, in many parts, the local supply has already been exhausted (due much to extravagance and carelessness), and the inhabitants are dependent upon other regions to furnish their wood material, at an increased cost. Treeless regions, formerly uninhabited, are now teeming 
with thriving, industrious populations, whose standard of living demands the consumption of large quantities of wond, drawn from limited forest areas. The present supply is rapidly disappearing.

To give the reader a comprehensive view of the manifold utility of wood, and to impress upon him the importance of maintaining a permanent source of supply of this essential material, we may group its uses into general classes, as an enumeration in detail would be too bulky for this volume, and, by sheer weight, fail of its purpose. In a general way, wood is thought of as useful for lumber and fuel. As firewood it heats our houses, cooks our meals, makes steam for driving the engines which run our flour mills, factories, light and power plants, street cars, laundries, etc. Different woods have their own fuel value, as indicated in another chapter; the supply of different kinds varies in localities; the price varies; so that we cannot say that one kind should be used more than another. Poor material must often be taken where none other is available. In Minnesota there is in the wooded regions a considerable variety of fuel woods. The most common are, for the hard woods (or, more properly speaking, broad-leaved trees), Maple, Oak, Elm, Ash, Aspen, Birch, Cottonwood and Basswood; and of the conifers (or narrowleaved trees), Pine, Tamarack, Spruce and Balsam Fir.

As lumber, we may convert wood into a yet more extensive variety of channels of usefulness, included under the heads of general building, construction and wood working.

In Carpentry rough material is used in framework, as sills, studding, plates, joists, rafters; in sheathing, roofing, shingles, laths; while finished lumber is put into siding, floors, doors, window frames and sash, blinds, stairways, stationary furniture and fixtures, columns, moldings, turned and carved work (solid and veneer). All kinds of wood are used for this work, according to the purpose and the taste of the builder, but Pine in larger quantities than any other, on account of its cheapness, ease of working and general utility.

For Railways, wharves, piers, bridges, piling, etc., heavy material is used; that is, large pieces. For railroad ties, bridges, pavements and culverts all kinds of wood may be used, but those best adapted to withstand the usage of the position are most desired. 
In Shipbuilding ribs, rib franes, kecls and outside planking ake Oak or other hard wood, with trenails of Locust; while for inside planking Pine is used, and interiors and decks finished to taste and usage with any wood.

In Joinery, which includes furniture making, cabinet and box work, packing cases and crates, all kinds of wood are utilized.

In the Making of Cars, wagons and carriages the framework is usually of Oak and Ash, with covering of Pine and fancy woods, while the running gear takes Hickory, Oak, Elm, Ash. Locust,- -butt cuts being especially valuable.

In Cooperage, barrels, casks, tubs, kegs, pails, churns and tanks (staves, heads and hoops) are made of every description of wood, but for vessels designed to hold the finer grades of wet goods, as liquors and wines, White Oak only is desired.

\section{In the Manufacture of Farm and Household Machinery} and implements, mostly hard woods of tough, durable qualities. as Oak, Ash, Hickory and Fim, are in demand. For woodenware (turned, carved and split-ware goods), again, all kinds of wood find a place. For baskets and wickerware, Willows and other pliable growths are used, while sounding boards of pianos and organs are almost always of spruce. In machine building; cogs, gears and pulleys are often made of hard wood, while frames of a stationary nature are of Pine.

Timber for Mining Purposes is in great demand in all mining regions, and enormous quantities of it are required, so that the mines are among the largest consumers. In this state some of the deep mines use as much as eighty miles of log timher per year, besides lagging. In mining, usually, the wood of the district is used for props, lagging, etc. 'The same may be said fencing-the most convenient wood is taken.

Telegraph Poles require sticks that are free from large knots, and which are durable in contact with the ground. Cedar is much used for this purpose. Flagstaffs and masts call for long, slencler, yet resistant, material.

In Lumbering a considerable cuantity nf timber is used in roads, skidways, booms, piling, etc., and a much larger quantity of the skidway and roadway naterial than is necessary is left to rot on the ground after a season's work. 
Wood Pulp and Distillation Products. One of the most important industries connected with forests is their use for paper pulp. For this purpose all kinds of wood may be used, but on account of its superior quality and the ease of working little is used in this country at present besides Spruce. Many experiments have been made with Poplar, and it also is used to some extent, but Spruce is very much preferred on account of its better fiber. Paper pulp is made in two ways: First, chemical; second, mechanical. Chemical pulp is made by treating the tissues of the wood with chemicals which dissolve out the lignin substances until only the cellulose or pulp is left. There are sevcral processes used, one of which is by boiling the wood in Glauber salts for seven hours, after which the pulp is washed clean and bleached with chloride of lime until quite white. This process is more expensive than the sulphite process, in which sulphurous acid is used, but is said to give a better product. All kinds of wood may be converted into chemical pulp, but very dark colored and very resinous kinds are usually avoided. Ordinary paper ptulp is made by grinding Spruce wood on large stones, against which it is pressed by hydraulic power. For the manufacture of very tough paper and of leather board it is customary to boil the wood a long time before it is ground. Wood that is cooked a long time before grinding makes a dark colored but very tough product. In the mantufacture of ordinary printing paper the wood is put at once upon the stone, and the pulp from it is rolled into paper. It is customary to mix a certain per cent of chemically prepared paper pulp with ordinary wood pulp in order to improve its strength. Wood pulp is not only manufactured into paper, but boards, buckets, car wheels, and a thoulsand other things, are made from it. Its use is almost unlimited.

By the Destructive Distillation of Wood (all kinds of wood, all sizes,--logs, refuse, sawdust) we obtain charcoal, vinegar, alcohol, creosote, gas, tar; pyroligeneous, oxalic, acetic and other acids; acetone, paraffin, naphthalin; lampblack and other products. From the bark of Oak, Hemlock, Chestnut and other trees the tannic acid used in tanning leather is obtained.

As we have digressed slightly by including bark under the term "wood," we may go farther, and take in also the sap from which is obtained turpentine, resin, gums and rubber, sugar, liquors, medicines; the pith, which gives us food and fiber for 
clothing and other purposes; the fruit and leaves, which are also used for food, medicinal and chemical extracts.

Wood is Made up of Cells which vary in form and in arrangement in different species. The cells are arranged in the form of irregular concentric cones, so that a cross section of a tree shows a series of concentric rings. For ordinary purposes, however, a log may be considered as being made up of a series of concentric cylinders, each cylinder representing one year's growth. If each ring is examined closely, it will be noticed that it is made up of an inner, softer, lighter-colored portion and an outer portion that is firmer and darker colored. The inner portion was formed in the early part of the season, when growth was rapid; this portion is termed the spring wood. The outer portion, where the cells are packed firmly together, grew in the summer, when the growth was slow, and this is termed the summer wood. Since the latter portion is very heavy and firm. it to a large extent determines the weight and strength of the wood.

Wood a Structure. On account of the peculiar arrangement in its structure, wood should not be regarded as a homogeneous mass, but rather as a mechanical structure, the arrango ments of the units of which in each case should be carefully considered in estimating its strength and its value for various purposes.

Methods of Sawing. In sawing wood the relation of the saw cut to the annual rings is an important matter, and its reference in relation to then has given rise to the names crosscut, tangential and quarter-sawing.

Cross-Cut Sawing simply refers to cutting across the grain. This method of sawing is seldom adopted other than for purposes of division, but occasionally it is used for making thin veneers, which are used in finishing panels and the like.

"Through and Through," or regular sawing, refers to the ordinary way of sawing lumber, in which most of the cuts are tangential to the annual rings.

Quarter-Sawing is sawing that is done perpendicularly to the annual rings of the wood. Wood thus sawed presents an evenness of grain not to be found in wond tangentially sawed. When cut nearly or quite on the radius the beautiful silver grain of some woods is thus shown to the best advantage. 
Quarter-sawed lumber presents a more durable surface and warps and shrinks less than that tangentially sawed. If these points alone are the chief considerations, any wood is considered quarter-sawed that presents the edge of its annual rings to its surface at an angle of not less than forty-five degrees. This is done in various ways.

Figure 44 illustrates one method of quarter sawing such woods as Yellow Pine, which are so sawed solely to increase their strength and wearing qualities. Slabs are taken off the four sides, then a cant $A$. B. is removed by cutting to within two or three inches of the heart. This cant is thrown back on the deck. Then the mill goes on sawing right through the heart $\mathrm{C}$, taking off four to six boards, as the case may be, which are run

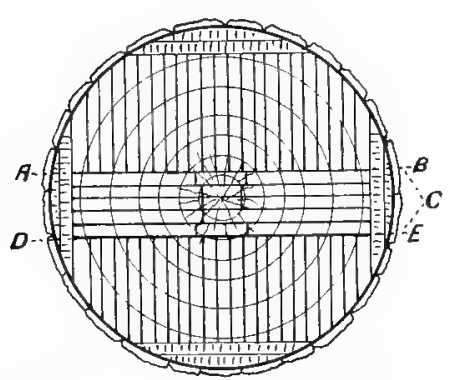

Figute 44. Common method of quarter sawing Yellow Pine for flooring.

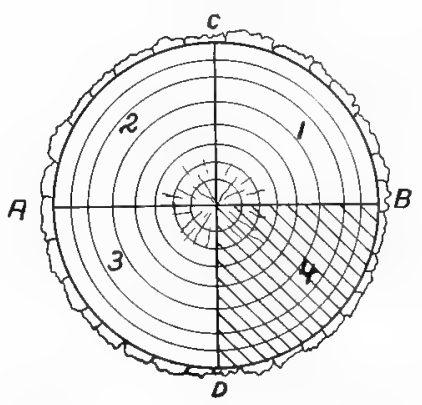

Fijgure 45 Showing method of quarter sawing to bring out the figure of the wood to best advantage. The $\log$ is first quartered, $1,2,3$ and 4 , and each quarter is sawed as indicated by lines in 4 .

through the edger and have the heart cut out. This leaves two cants of the same thickness. The one on the deck A. B. is put back on top of the one D. E. on the carriage and both are cut up together. Practically all of the stock thus made, except the boards taken off in slabbing, is edged grained, and if oak about half of it would show a fair figure.

If Quarter Sawing is Done for the Purpose of Bringing out the Silver Grain of the wood, as is necessary in the case of White Oak for best effects, then the saw cut should always be made towards the heart and on the line of the silver rays. This is a much more wasteful process than the former 
method, and requires very different management. The more nearly perfect the quarter-sawing is done the more waste there is, and so it is the object of practical men to avoid the extremes of perfect quarter-sawing (at great expense in labor and material) and through-and-through sawing (which is cheapest and most economical of material). In ordinary quarter-sawing of this kind there is a waste of twenty to thirty per cent in material as compared with through-and-through sawing. This waste is found in the feather edged pieces and bevelled edges which have to be cut off, and in the very narrow strips of no value. Small logs waste much more than large logs in quarter-sawing. Most sawyers place the minimum sized log that should be used for quarter-sawing at twenty-six inches in diameter. It is very important to have quarter-sawed lumber wide, as narrow stock is of comparatively little value. In ordinary sawing there are always a few cuts made parallel to the silver rays which have the desired quarter-sawed figure.

In practice, several methods of sawing are used to bring out the silver grain. The most common is to quarter the logs, and then saw each quarter, as shown by the lines in Figure 45 .

\section{FUEL VALUE OF WOODS.*}

"The Relative Fuel Values here given are obtained by deducting the percentage of ash from the specific gravity, and are based on the hypothesis that the real value of the combustible material in all woods is the same.

'It appears from Mr. Sharples' experiments that resinous woods give upwards of twelve per cent more heat from equal weights burned than non-resinous woods; the heat produced by burning a kilogram of dry non-resinous wood being about 4,000 units, while the heat produced by burning a kilogram of dry resinous wood is about 4,500 units, a unit being the quantity of heat required to raise one kilogram of water one degree centigrade.

"Count Rumford first propounded the theory that the value of equal weights of wood for fucl was the same, without reference to specific distinctions; that is, that a pound of wood, whatever

*This article on the fuel value of woods is taken from the "Report of the "Tenth Census," by Prof. C. S. Sargent. 
the variety, would always produce the same amount of heat. Marcus Bull, experimenting in 1826 upon the fuel value of different woods, found a variation of only eleven per cent between the different species tested. Rumford's theory must be regarded as nearly correct, if woods are separated into resinous and nonresinous classes. The specific gravity gives a direct means of comparing heat values of equal volumes of wood of different resinous and non-resinous species. In burning wood, however. various circumstances affect its value; few fire places are constructed to fully utilize the fuel value of resinous woods, and carbon escapes unconsumed in the form of smoke. Pine, there. fore, which although capable of yielding more heat $\dagger$ than Oak or Hickory, may in practice yield considerably less, the Pine losing both carbon and hydrogen in the form of smoke, while Hickory or Oak, burning with a smokeless flame, is practically entirely consumed. The ash in a wood, being non-combustible, influences its fucl value in proportion to its amount. The state of dryness of wood also has much influence upon its fuel valuc, though to a less degrce than is generally supposed. The water in green wood prevents its rapid combustion, evaporation reducing the temperature below the point of ignition. Green wood may often contain as much as fifty per cent of water, and this water must evaporate during combustion; but as half a kilogram of ordinary wood will give 2,000 units of heat, while half a kilogram of water requires only 268.5 units to evaporate it, I,73I.5 units remain available for generating heat in wood containing even a maximum amount of water.

"A factor in the general value of wood as fuel is the ease with which it can be seasoned; Beech, for example, a very dense wood of high fuel value when dried, is generally considered of little value as fuel, on account of the rapidity with which it decays when cut and the consequent loss of carbon by decomposition."

iFrom a given weight. 
TABI, OF TREES ARRANGED IN ORDER OF THE WEIGHT OF DRY WOOD. $\dagger$

\begin{tabular}{|c|c|c|c|}
\hline BOTANICAL NAMES. & COMMON NAMES. & $\begin{array}{l}\text { Approxi- } \\
\text { mate rela- } \\
\text { tive fuel } \\
\text { value. }\end{array}$ & $\begin{array}{l}\text { Specific } \\
\text { gravity of } \\
\text { absolutely } \\
\text { dry wood. }\end{array}$ \\
\hline Crataegus coccinea ............ & White Thorn........ & 85.85 & 0.8618 \\
\hline Hicoria ovala ................ & Shelibark Hickory.... & 83.11 & 0.8372 \\
\hline oslrya vinginiana............ & Hop Hornbeam..... & 82.43 & 0.8284 \\
\hline Amelanchier almufolia......... & Service-berry . & $\ldots \ldots \ldots$ & $0.826 \%$ \\
\hline Amelanchier canadensis ...... & Juneberry ........... & 77.95 & $0.78: 38$ \\
\hline Crataegus tomentosa........... & Black Thorn ......... & 7549 & 0.7585 \\
\hline Hicoria minima $\ldots . . . \ldots . .$. & Bitternut Hickory .... & 74.74 & 0.7552 \\
\hline 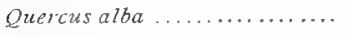 & White Oak ....... & 74.39 & 0.7470 \\
\hline Quercus macrocarpa.......... & Bur Oak............ & 74.06 & 0.7453 \\
\hline Robinia pseudacacia ......... & Locust. .............. & 72.96 & 0.7333 \\
\hline Prumus americana ........... & wild Plum .......... & 73.00 & 0.7313 \\
\hline Viburnum lenlago ........... & Black Haw........... & 72.82 & 0.7303 \\
\hline Celtis occidentalis.............. & Hack berry ........... & 72.08 & 0.7287 \\
\hline Carpinus caroliniana ....... & Blue Beech........... & 72.26 & 0.7296 \\
\hline tlonus racemosa.............. & Cork Elm .......... & 72.20 & 0.7268 \\
\hline Crataegus crus-galli......... & Cockspur Thorn ...... & 71.54 & $0 . \approx 194$ \\
\hline Fraxinus lanceolala.......... & Green Ash ........... & 70.71 & $0.711 i$ \\
\hline Quercus coccinea ............. & Scarlet Oak .......... & 70.82 & 0.7095 \\
\hline Pyras coronaria ............ & wild Crab........... & 70.11 & 0.7048 \\
\hline Ulmus pubescons............. & Slippery E1m ......... & 68.98 & 0.6956 \\
\hline Prunus virginiana........... & Choke Cherry......... & 69.16 & 0.6951 \\
\hline Gymnocladus diotcus......... & Coffee Tree .......... & 68.88 & 0.6934 \\
\hline Acer saccharum.............. & Sugar Maple ......... & 68.75 & 0.6916 \\
\hline Acer platanoides ............. & Norway Maple........ & $\ldots \ldots \ldots \ldots$ & $0.6800^{*}$ \\
\hline Gledilsia triacanthos .......... & Honey Locust ........ & 66.86 & 0.6740 \\
\hline Quercas rubra............... & Red oak & 66.04 & 0.6621 \\
\hline
\end{tabular}

in this table the figures relating to North Anerican species have been taken directly from or calculated from data in Sargent's Silva of North America and the report of the Tenth Census, and those relating to European species are from various European sources.

* Air dried. 
TAPI,E OF TREES ARRANGED IN ORDER OF THE WEIGHT OF DRY WOOD. (Continued.)

\begin{tabular}{|c|c|c|c|}
\hline BOTANICAL NAMES. & COMMON NAMES. & $\begin{array}{l}\text { Approxi- } \\
\text { mate rela- } \\
\text { tive fuel } \\
\text { value. }\end{array}$ & $\begin{array}{c}\text { Specific } \\
\text { gravity of } \\
\text { absolutely } \\
\text { dry wood, }\end{array}$ \\
\hline Betula lutea ......... & Yellow Bitch.. & 65.34 & 0.6553 \\
\hline Fraxinus americana... & White Ash ........ & 65.16 & 0.6543 \\
\hline Ulmus americana.... & White $\mathrm{E} 1 \mathrm{~m}, \ldots \ldots \ldots$ & 64.54 & 0.6506 \\
\hline Betula alba............ & European White Birch & . . . & $0.6400^{*}$ \\
\hline Fraxinus nigra........ & Black Ash & 62.72 & 0.6318 \\
\hline Lavix laricina ........ & Tamarack. & 6216 & 0.6318 \\
\hline Fraxinus pennsylvanica...... & Red Ash......... & 6199 & 0.6215 \\
\hline Acer rubrum......... & Red Maple. & 61.65 & 0.6178 \\
\hline Juglans nigra........ & Black Walnut... & 60.91 & 0.6115 \\
\hline Belula papyrifera... & Canoe Birch......... & 5940 & 0.5955 \\
\hline Pyrus sambucifolia.... & Elderleaf Mount'nAsh & 58.08 & 0.5928 \\
\hline Morus rubra ......... & Red Mulberry...... & 58.56 & 0.5898 \\
\hline Prunus seroting..... & Wild Black Cherry .... & 58.14 & $0.58 * 2$ \\
\hline Betula nigra ............. & River Birch $\ldots . . . \ldots$. & 57.42 & 0.5762 \\
\hline Pinus laricio austriaca.. & Austrian Pine ......... & & $0.5700^{*}$ \\
\hline Pyrus americana ....... & American Mount'n Ash & 54.08 & 0.5451 \\
\hline Acer spicatum......... & Mountain Maple... & i3. 07 & 0.5830 \\
\hline Acer saccharinum...... & Silver Maple ...... & 52.52 & 0.5269 \\
\hline Pinus syluestris...... & Scotch Pine....... & & $0.5200 *$ \\
\hline Pseudotsuga taxifolia.... & Douglas Spruce... & 51.53 & $0.515 \pi$ \\
\hline Prunus pennsylvanica....... & Wild Red Cherry .. & 5008 & 0.5023 \\
\hline Juniperus virginiana ......... & Red Juniper....... & 49.11 & 0.4926 \\
\hline Pinus resinosa....... & Red Pine....... & 48.41 & 0.4854 \\
\hline Populus alba............ & White Poplar ....... & n......... & $0.4800^{*}$ \\
\hline Pinus divaricala .............. & Jack Pine ............ & 47.50 & 0.4761 \\
\hline Pinus ponderosa ............. & Bull Pine.......... & 46.99 & 0.4715 \\
\hline Picea excelsa.................. & Norway Spruce ....... & $\ldots \ldots \ldots$ & $0.4700^{*}$ \\
\hline Populus grandidenta. & Largetooth Poplar. & 46.11 & 0.4632 \\
\hline
\end{tabular}

*Air dried. 
TABLE OF TREES ARRANGED IN ORDER OF THE WEIGHT OF DRY WOOD. (Continued.)

\begin{tabular}{|c|c|c|c|}
\hline BOTANICAL NAMES. & COMMON NAMES. & $\begin{array}{l}\text { Approxi- } \\
\text { mate rela- } \\
\text { tive fuel } \\
\text { valne. }\end{array}$ & $\begin{array}{l}\text { Specific } \\
\text { gravity of } \\
\text { absolutely } \\
\text { dry wood. }\end{array}$ \\
\hline 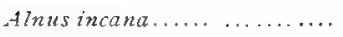 & Speckled Alder ....... & 45.88 & 0.4607 \\
\hline Picea maviana...... & Black Spruce... & 45.71 & 0.4584 \\
\hline -Esculus glabra.... & Ohio Buckeye ..... & 45.03 & 0.4542 \\
\hline Tilia americana..... & Basswood & 45.00 & 0.4525 \\
\hline Castanea dentata.... & Chestnut ........... & 44.95 & 0.4504 \\
\hline Salix amygdaloides... & Peachleaf willow .... & 44.68 & $0450 \%$ \\
\hline Salix alba..... & White Willow......... & & $04500^{*}$ \\
\hline Pupulus nigra........ & Black Poplar... ... & & $0.4500^{*}$ \\
\hline Salix nigra........ & Black willow ........ & ... & $0.4456^{*}$ \\
\hline Pinus flexilis. & Western White Pine. & 43.42 & 0.4358 \\
\hline Acernegundo & Boxelder ........ & 42.82 & 0.4858 \\
\hline Tsuga canadensis............. & Hemlock .......... & 42.20 & 0.4239 \\
\hline Catalpa speciosa. & Hardy Catalpa.. & 41.48 & 04165 \\
\hline Populus balsamifera candicans & Balm of Gilead........ & 41.42 & 0.4161 \\
\hline Juglans cinere....... & Butternut ............. & 40.66 & 0.4086 \\
\hline Picea canadensis..... & White Spruce.... & 40.88 & 0.4051 \\
\hline Populus tremuloides.. & Aspen ............... & 40.10 & $0.403 ?$ \\
\hline Populus angustifolia ... & Narrowleaf Cottonw'd & 38.81 & 0.3912 \\
\hline Populus delloides ..... & Cottonwood ........... & 38.52 & 0.3889 \\
\hline Pinus strobuts........ & White Pine ... & 38.47 & 0.3854 \\
\hline Abies balsamea ...... & Balsam Fir...... & 38.02 & 0.3819 \\
\hline Picea parrvana.. ............ & Blue Spruce ........ & 37.26 & 0.3740 \\
\hline Abies concolor .................. & White Fir........... & $\$ 6.07$ & 0.3638 \\
\hline Populus balsamifera........... & Balsam Poplar........ & 36.11 & 0.3635 \\
\hline Picea engelmanni... ......... & Fingelmann Spruce.. & 33.38 & 0.3449 \\
\hline Thuja occidentalis..... & Arborvitie ............ & 31.68 & 0.3164 \\
\hline
\end{tabular}

*Air dried. 


\section{CHAPTER XIII.}

\section{DURABILITY OF WOOD.}

Decay in Wood is due to the breaking down of the tissues by fungi. In some cases the fungus destroys the woody cells; in others it uses up the starch found in the cells and merely leaves a blue stain (bluing of lumber). Some kinds of fungi attack only conifers, others only hard woods; some are confined to one species while others may affect several species, but probably no one of them attacks all kinds of wood. Figure 46 shows the discoloration of wood by a shelf fungus. The wood contains the fungus plant, which, when ready to produce its spores, sends out a shelf-like body on the side of the wood. These shelves contain

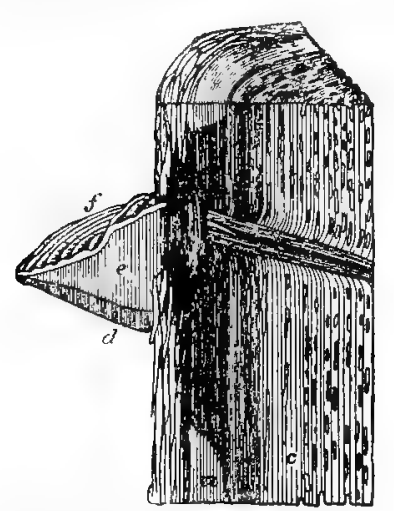

Figure 46. "Shelf" fungus on the stem of a Pine (Hartig). (a) Sound wood; (b) resinous wood;

(c) partly decayed wood or punk;

(d) layer of living spore tubes;

(e) old spore tubes filled up;

(f) fluted upper surface of the fruit-

ing body of the fungus which gets

its food through a great number of

fine threads (the mycelium), its vegetative tissues penetrating the wood and causing it to decay. the spores and may be found on many old decayed trees or stumps. Various odors are produced in the wood by some of these fungi; they may be pleasant, as those found sometimes in the Oak, or unpleasant, as those infesting some of the Poplars. By studying both the favorable and the unfavorable conditions for the growth of the rot-producing fungi we may learn the best methods of increasing the durability of our woods, and thus avoid unnecessary waste.

The soil and conditions under which wood is grown affect its durability. Coniferous woods with narrow annual rings are most durable, especially when grown on comparatively poor soils, in dense

forests, and at high altitudes. On the contrary, the hard woods 
with wicle annual rings are most durable, and are grown on the low lands and in isolated positions. The wood of most broadleafed trees produced in the open is more durable than that from the dense forest.

Sound Mature Trees Yield More Durable Timber than either young or very old trees. A tree is considered mature when it ceases growing vigorously, which condition is indicated by the flattening out of the crown, by dead branches in the crown, and by changes in the color of the bark. It is not indicated by size, since this varies in the same species according to circumstances. A small tree poorly situated for growth may be as old or older than a larger tree growing under better conditions.

Intense Coloration of the Heartwood is a measure of durability in timber, and faintly colored heartwood resembles sapwood in its properties, only surpassing it in dryness. The tannin or coloring matter of heartwood is antiseptic. Where heartwood does not change its color or is lighter than the sapwood the protecting substances are generally absent, and the wood is therefore liable to decay. This is plainly shown in the hollow trunks of wiliow and basswood.

Sapwood Contains More Ready-Made Food in forms acceptable to a great number of kinds of fungi than the heartwood. This largely accounts for the fact that sapwood is much more liable to decay than heartwood. This is especially true in the case of Cedar and Pine, where the heartwood is protected by resinous substances. But when the sapwood is well seasoned and heavier than the heartwood it lasts as long. Wood that has been once attacked by fungi becomes predisposed to further decay.

The Time of Cutting Timber affects its durability only as the weather at the time of cutting affects the curing process. Wood cut in summer is generally affected by decay-producing fungi, rapid fermenting of sap, and by bad checking, owing to very rapid curing on the outside. As the cracks thus made go deep into the wood they may increase the danger from fungi. Where summer-felled wood is worked up at once and protected by kiln-drying, it lasts as long as that cut at any other season.

Early winter is probably the best time to cut timber as regards durability, since it then seasons slowly at a time when 
the rot-producing fungi are not active, so that it can cure over on the outside before summer. Many kinds of fungi and beetles find a very favorable place just under the bark of logs. These can be avoided, the curing of the timber hastened and its durability greatly increased by removing the bark soon after felling. When trees are cut in full leaf it is advantageous to let them lie at full length until the leaves are thoroughly wilted (two or three weeks) before cutting to size. With conifers this is a good practice at any season, and while not practical, yet theoretically all winter-cut trees should be left to leaf out in the spring before being worked. In this way most of the sap is evaporated, but in the care of timber that is to go at once into the water these precautions are not so important.

Heat (6o Degrees to Ioo Degrees Fahr.), Moisture and Air in moderate quantities produce conditions under which wood quickly decays. It is on this account that fence posts rot off near the surface of the ground, where about such conditions of heat and moisture are usually found during several months of the year. For the same reason what is known as dry rot destroys green floor joists or other timbers where they are tightly inclosed, as under a house without ventilation, since moisture is always present in such places, and the timber cannot dry out. Perfectly dry wood or that submerged in water will last indefinitely, and there seems to be no difference in different kinds of wood under these conditions. Pieces of pine wood in good condition have been found in Illinois buried to a depth of sixty feet that must have been there for many centuries. Nearly sound pine logs are occasionally found in the woods of this state, where they have a thick moss covering that has kept them moist and prevented their decay for hundreds of years. The remains of timbers in the piles of the lake dwellers, which must have stood in place two thousand years, are still intact. In these instances the wood was kept moist, and never came in contact with the air. It is very evident, too, that wood which is kept in a dry place does not decay, since it may be found in an unimpaired state of preservation in some of our very oldest buildings.

In the following table is shown approximately the time fence posts will last in Minnesola. This table is based on practical experience in this state: 
TABLE, SHOWING RANGE OF DURABILITY OF FENCE POSTS IN MINNESOTA. (Air dry.)

Red Cedar ............................. 30 years

White Cedar (quartered 6 -inch face) ............. 10-15 years

White Oak (6-inch round)................. 8 years

Red and Black Oak...................... 4 years

Tamarack (Redwood).................... 9 years

Elm ............................. 6-7 years

Ash, Beech, Maple..................... 4 years

Black Walnut ......................... 7-10 years

White Willow, 6 inches in diameter, pecled and dried. 6-7 years

Curing is one of the most important processes in its effect on the durability of wood. Well cured wood resists decay far better than fresh wood, because it contains an insufficient amount of water for the growth of fungi. Green wood covered with paint before it is dry is often destroyed by dry rot, since this fungus finds abundant moisture under the paint and the protection which was intended for the wood really protects its enemy, the fungus. Paint and other wood-protecting compounds are efficient only when they are applied to dry material, which they preserve by protecting them from moisture. But fence posts or other timber to be used in moist places, if well cured, will, even if not protected, last much longer than fresh cut timber. The amount of moisture in wood, then, is the most important factor in influencing its durability.

Timber is Best Cured Under Cover, where it is protected from the sun and the full force of the wind, but has a good circulation of air. If piled in the open, it is a good plan to shade it. When piling green or wet timber, place lath or other strips of wood of uniform size under each log, post or tie. In piling sawed lumber the lath should be placed at the ends, as in this position they in a measure prevent checking on the ends.

From twelve to eighteen months is generally sufficient to cure wood for ordinary use, while for special work ten or more years may occasionally be required. If green or wet timber is closely piled in warm weather it is likely 10 rot. The best method of curing timber without resorting to the use of expensive apparatus is to work it up at once and soak it in water for from one to three weeks to remove the sap from the outside of the wood. 
It will then season more quickly and be more durable than when dried without soaking. Sometimes it is absolutely necessary to thus water season large timbers, as it is impossible to get the sap out of them by atmospheric seasoning. Large checks or cracks in the ends of logs or other timber of large dimension may be avoided or greatly lessened by painting the ends with linseed oil mixed with ground charcoal or other material to give it consistency. Covering with cloth or tarred paper also lessens check. ing.

Good Coatings for Wood consist of oily or resinous substances that are easily applied in a smooth coat and dry readily, yet do not have any tendency to crack or peel off. They should be applied to the whole exposed surface.

Coal Tar is one of the best materials for covering wood to increase its durability. It is best applied hot, especially if mixed with oil of turpentine, as it then penetrates more deeply. A mixture of three parts coal tar and one part unsalted grease, to prevent the tar from drying too quickly so it may penetrate the wood better, is recommended. One barrel of coal tar will cover from two to three hundred posts if it is properly applied.

Oil Paints are next in value. Boiled linseed oil is uscd with lead, pulverized charcoal, or other similar material, to give it substance. Soaking the dry wood in crude petroleum is also recommended.

Iime Whitewash is a good preventive of decay in wood and, although not as good for this purpose as coal tar, it is very desirable. As with all other preservatives that are applied to the surface, the wood should be very dry before it is applied, and the wash should be applied evenly over all the exposed parts. It is on account of the lime that washes out of the mortar that the shingles on a roof just below the chimney last longer than on other parts of the roof. But if whitewash is to be applied to shingles it should be applied before they are laid by dipping.

Charring those parts of posts or timbers which come in contact with the ground is a good preventive, provided a thick layer of charcoal is formed and the work so carefully done as not to cause the timber to crack, since deep cracking exposes the interior to decay. If not carefully done the timber may be seriously weakened. 
Antiseptics. The impregnating of timber with sulphate of copper (blue stone), sulphate of iron (green copperas), chloride of zinc, creosote, salts of mercury, or other similar material, has the effect, when properly done, of greatly increasing its durability. Such antiseptic substances have the power of destroying the rot-producing fungi. The materials are often applied to fresh logs. If dry timber is to be treated, it is first boiled or steamed to open the cells. A hollow cap connected with a force pump is placed over one end, and the liquid forced through the cap into the wood, which results in forcing out the sap at the opposite end and replacing it with the antiseptic, but the more common method is that described below as the treatment given in impregnating railroad ties in Europe. All the antiseptics mentioned have been used to some extent for this purpose, but for various reasons chloride of zinc is now most generally used. Railroad longer than those not so treated. Impregnation also to some extent renders wood fire-proof.

Iron Railroad Ties. A few years ago it was thought probable that iron railroad ties would come into general use in Europe, owing to the scarcity of Oak ties. They have, however, been found to give a very unyielding road bed, and are not generally liked, and are seldom used for more than a short distance at railroad stations. The disposition now is to substitute impregnated Beech ties for iron, and the successful impregnation of this wood, causing it to become quite durable, has had a large effect in doing away with iron ties.

The Impregnation of Beech Wood for railway ties is a large industry in Europe. Without impregnation Beech is one of the least durable of woods, but by modern impregnation methods it can be made to last at least fifteen years in any soil, and it is customary for concerns engaged in this business to warrant the durability of their impregnated ties for twelve years. Pine and Oak ties are not impregnated.

The process commonly followed in many parts of Germany is about as follows: A large boiler-like tank is provided, which is about six feet in diameter and forty to one hundred feet long. This is made with heads that can be securely and tightly bolted on. It also has a small track for the cars which carry the ties. Before treatment the ties are mortised to receive the rail plates. After the tank is filled with cars loaded with ties the steam is 
turned on for one to three hours, with a pressure of about twen ty-five pounds. This treatment softens the wood and dissolves the sap. The air is then pumped out of the tank, which removes the sap from the ties and leaves a vacuum. When this has been completed and the vacuum made, the impregnating material is added under a pressure of about $\mathrm{I} 20$ pounds. This forces the impregnating material into the cells of the wood. The preservative material used is made up one-third of a three per cent soltution of chloride of zinc and two-thirds of dead oil (creosote oil). Cliloride of zinc was formerly used alone, but it was found that it washed out after a few years, where the wood was laid in contact with the ground, and thus the wood was liable to decay; but by the addition of dead oil, which is itself a good antiseptic, the cells of the wood were effectually sealed over and water prevented from entering, and thus the chloride of zinc was protected and the process made more permanent. ' 1 he cost of this treatment in Hessen, Germany, is estimated at about twenty-two cents per tie.

Among the other processes for the preservation of wood are the following:

Kyanizing Process. In this the ties are steeped in a solution of bichloride of mercury (corrosive sublimate), in the proportion of about one part bichloride to one hundred parts, by weight, of water. The time required for this process is about one whole day for each inch in thickness. This material is an active poison, and must be handled carefully. It has given excellent satisfaction in the preservation of timber which comes in contact with the soil, but soon corrodes metal in contact with it.

Boucherie Process. In this process the timber is impregnated with a one per cent solution of sulphate of copper, either by pressure in a closed vessel, or by applying it to the end of the tie or $\log$ and forcing it through. This is an excellent antiseptic, and is said to have doubled the life of the Pine ties in Europe.

Creosoting. This process is very extensively used, and has given excellent satisfaction. The material is what is known as dead oil, of coal tar, and is obtained by distilling coal. Naphthaline is its principal preservative. A similar oil, known as wood creosote oil, is obtained by the distillation of Pine wood, but is said to be much more soluble than the dead oil, and on 
this account more liable to wash nut of the wond when in contact with the soil.

Zinc Tannin Process. In this process the chloride of zinc is protected from being washed out of the ties by coagulated albumen. The process is as follows: The ties are impregnated with chloride of zinc mixed with a small percentage of dissolved glue. They are then subjected to heavy pressure, after which the solution is drawn off and a tannin solution added at a pressure of 100 pounds. This material combines with the glue, and forms a leathery, waterproof substance which permanently closes the pores or outer cells of the wood, excluding moisture and retaining the zinc.

Burnettizing. In this process the timber is impregnated with chloride of zinc, the operation being similar to that of creosoting. It has a wonderful preservative effect upon the timber, the only objection to it being that the solution is liable to be washed out of the ties. This is overcome in the modern treatment of the ties in Germany by using a certain per cent of dead oil with it, as previously noted in describing the method of impregnating railroad ties.

Fire-Proof Wood. It has been known for many years that wood could be made fire proof by filling it with certain chemicals in much the same way that railway ties are impregnated. The most common chemical used for this purpose was phosphate of ammonia, and it is perhaps the best material for this purpose that has ever been used, but it is so expensive that the use of it is quite impracticable. The next best material that has been used for this purpose is sulphate of ammonia, but like phosphate of ammonia this somewhat injures the flexibility of the fiber and corrodes metal, and in addition deadens the color and causes the wood to be more hydroscopic. These chemicals, either alone or combined, have given some very good results, but have not been entirely satisfactory. They have been used in fire-proofing warships, where great results have sometimes been realized, as, notably, in the war between Chinapand Japan, where this treatment is said to have given Japan a great advantage in the greatest naval battle of that war. If a fire-proofing process were discovered that combined the merits of cheapness without injuriously affecting the qualities of the wood, it would be much sought after, and 
its application would be almost endless. In order to be effective such a process must not only be cheap, but must not prevent the wood from holding paint varnish and glue well, nor injure its fiber, nor corrode metal in contact with it nor tools used in working it, neither must it increase its tendency to absorb moisture 


\section{CHAPTER XIV.}

FOREST ECONOMICS.

Alarm About Destruction of Forests! Hor many years the attention of the people of this country has been drawn to the possibility of a depletion of our forests and a timber famine in the near future. But increased transportation facilities have made new sources of timber easily accessible to us, which fact, together with the use of inferior kinds of trees for lumber, has kept the predicted timber famine from materializing, until now our people have become skeptical on this point, and look upon these predictions as very premature. To any one who carefully studies the subject, however, it will be very evident that our supply of White Pine, that most generally useful of all our timber trees, is fast decreasing, and that it cannot be many years before this will be apparent by the advance of prices for this kind of timber. Most of the land of good quality in Minnesota seems destined to be eventually used for farming purposes, but there will always remain a large area of stony or very sandy land that will be unfit for profitable agriculture, and which will produce more reventue when used for the production of timber than when used for any other crop. There is also a large amount of land that will not be needed for farming purposes for many years, and this should grow timber until needed for agriculture. Besides this, with the increased value of fuel, Iumber and other forest products, there will come a better appreciation of the importance of farm wood lots as a source of fuel, poles, lumber, etc., for farm use, and a more general disposition to save some land for this purpose.

Price of Fuel. At present in the greater part of our forested area north of St. Paul the timber is greatly in the way of settlers, and the price of fucl is simply the cost of gathering it, no charge whatever being made for the wood itself. This state of things exists because not only in the forests but more especially in the great area of cut-over timber lands in that section there is such an immense amount of dead and down limber that 
it is seriously in the way and far in excess of the fuel demands of the settlers on those lands for a score of years to come. There seems to be something incongruous in the fact that while onehalf of our state is prairie, and sadly in want of fuel and other forest supplies, the other half has such a superabundance of these products that they are going to waste, and only a small portion is considered worth marketing.

Value of Forest Industries of Minnesota. The marketing of the products of the virgin forest in Minnesota has added greatly to the wealth and prosperity of the state, and under proper management this source of wealth would continue indefinitely. The value of the forests of Minnesota is most easily seen by showing the number of men employed. According to the report of the Bureau of Labor, there were employed in logging, in the year $1899-1900,15,886$ men and 8,285 horses. The average time of the men was about twenty weeks. They were employed in 329 camps, and cut I,II2,000,000 feet board measure. The total wages was $\$ 2,988,900$, besides board, or about $\$ 4,180,000$, including board.

In the wood-working industries, the following men were employed in the year I900:

Sash and door manufacturers................. I, 186

Sawmills, shingle and lath mills................ 9,179

Planing mills .......................... 1,707

Rattan and willow works........................ 48

Paper mills .............................. $\quad 229$

Lumber yards ................................ 276

Wood-working shops ...................... 830

Furniture and fixtures..................... 1,405

Cooperage ............................ $\quad 772$

Box manufacturing .................... 356

Total ............................. 15.988

Making a total in the wood-working and lumbering industries, besides carpenters and builders, of 31,874 men employes.

Possibilities of Yield of Our Forest Area. The best authorities agree that the normal annual increase on our I2,000, 000 acres of forest area should be about 2,000,000,000 feet board 
measure, or a mean annual increase of 185 feet board measure per acre. If this were true, it would leave a wide margin to our prescnt annual timber cut without impairing our normal growing stock. In other words, this great lumber industry, of so much value to the state, would be continued indefinitely under normal conditions. But there is practically no timber land in this state under normal conditions, and there is little or no increase on the far greater part of our cut-over timber lands. On this account the continuance of our lumber industry is not hoped for by those engaged in it. In other words, we are working our timber resources as though they were a mine which can never be restocked.

The timber lands of all civilized countries have passed through about the same wasteful conditions as those which now prevail here. While this does not justify the present deplorable situation here, it shows us that the trouble we are suffering from is a common one, that will right itself with increased population and proper education. Previous to 1700 the forests of Germany were in much the same condition as those here at present, and a square mile of forest land could be bought for the present price of one of the oaks planted at that time. Our people are simply uninformed as to the possibilities of our forest land under proper conditions.

\section{Iike Any Other Business, Forestry Requires Capital.} This is partly in land and partly in the growing crops of wood. Capital in wood may often exceed that in land. Income from forests comes as timber, fuel, bark, and in items of smaller importance, such as grazing, fruit, medicinal plants, hunting, etc.

Forests Should be so Managed as to yield an annual increase, as in this way the conditions for most successful marketing are best met. Under uch conditions, too, a certain amount of experienced help can be expected to become located conveniently near, as they will have steady work, while if the products are harvested at irregular intervals new help must be engaged at each harvest, which is extremely undesirable.

In Considering the Returns from the Forest the following terms should be clearly understood: (I) Normal growing stock, (2) normal income. (3) capital stock, and (4) actual income. These are defined in the following paragraphs: 
Norma1 Growing. Stock. Since the annual valuable increase of wood is in proportion to the amount of leaf surface on trees of the right kind, size and form, it follows that there nust always be a certain number of trees of a certain size in order to obtain normal annual growth. This material represents invested capital, and the highest annual income is dependent upon having a normal growing stock upon the land. As a matter of fact, this is an ideal thing, and is seldom, if ever, exactly attained. The amount of normal growing stock which there will be upon one acre will depend upon the species, its age and conditions, and must be determined in the working plan of the forest tract after a careful study of its conditions.

The Normal Income is the crop of wood that a given tract of forest will produce per year under normal conditions. This will, of course, vary with the species and conditions. It may be harvested by selecting only the large trees from all over the area, or by cutting clean over a certain portion of it, as shown in chapter $\mathrm{X}$. It is very plain that, if the increase per year is a given amount, it may be harvested by either method without infringing on the normal growing stock of the whole area. For some conditions the selection method is preferred, while for others, such as for even stands of Spruce, which are liable to blow down when thinned, it might be better to cut clean, and keep the trees in even age groups. In this latter case the tract should be divided into as many parts as there are years in the rotation, and the timber from one part cut each year. This would mean the planting or seeding of a like amount each year.

Capita1 Growing Stock. This represents the actual amount of trees on the land which is producing wood growth of value. The nearer this approaches to the normal growing stock the better the condition of the forest and the larger its returns.

Actual Income represents the annual return which a given forest tract is producing.

Increasing Value of Forests. In countries where forestry has reached a high degree of development a piece of land is regarded as being in forest as soon as it is stocked with trees, even if the seedlings are not yet over two inches high and are hardly to be seen at a short distance. Such a piece of land should have increased value and should be regarded as earning a rate of interest. It is so regarded in many of the European 
states, and money lenders there consider this matter as important when placing a loan; for while the increase on such land cannot be gathered at all for perhaps sixteen or twenty years, and then only a small amount, yet a certain increase in woody tissue is being stored up each year which will later on be harvested. It should be regarded as being worth at any time a certain proportion of its total value at. maturity, which perhaps will not come for twenty years, but if a forest is reasonably protected from fire, it is almost as sure to earn a certain increment as that the conditions on the earth will remain as they are for eighty years. And if a forest is twenty years old, it may be in such condition that it would be wasteful to try to derive any income from it for perhaps twenty years more, yet it is worth perhaps one-third of what it will be worth twenty years hence. Thus, if at forty years it will yield ninety cords of paper pulp per acre, worth five dollars per cord, it should at twenty years be worth about \$r 40, after allowing for compound interest at six per cent.

Unproductive Forest Land. In almost every range of forest there will be some land that is quite unproductive. This will generally consist of ledgy land, or that which is elevated above the tree line, or perhaps may consist of extended swamps. But on this account it should not be thought worthless, but should be allowed to produce what growth it can, especially where it is valuable in protecting the sources of streams, and in the case of elevated mountain sides the scrubby growth of no value for timber may be very valuable in preventing land slips or snow slides. Of course, in the case of individuals having small holdings such considerations do not apply, but they are important and should be encouraged in any comprehensive forestry scheme.

European.Systems of Forest Management have been frequently referred to as being applicable to our conditions, but, while we can learn much of value from the history and practice of European forest administration, our conditions are so very different from those existing in Europe that much discretion must be exercised in adapting their methods to our conditions. The chief difference between their conditions and ours is in the higher price of their timber and their cheaper hand labor, which makes possible very different methods than could be profitably used here. The conditions in the remote parts of Russia are much more like those in this country than are, perhaps, to be 
found elsewhere in Europe, and there is still in those sections a great waste of forest products, and large losses occur there annually from forest fires. But in the most accessible parts of Russia, and in Sweden, Norway, and in the larger portion of Germany and France, there is a profitable market for all we term waste forest products, such as the smaller top logs, the branches, twigs, leaves, stumps, underbrush, and even the roots of trees. In this country such material encumbers the ground, and greatly increases the danger of forest fires, which is by far the greatest source of injury to growing timber.

Taxes on Timber Iands. The taxes on timber lands are generally excessive in this country, and entirely out of proportion to the value of the land, and it is largely on this account that owners of timber lands do not care to hold them. This, as a matter of state policy, is unwise, for the reason that it prevents the development of economic forestry. In most European countries where forestry is well developed it is customary to levy a small tax on the land and to tax the products only when they are harvested. Such a tax system is almost unknown in this country, but it is much more just for forest property than our ordinary taxing methods. It would seem that forest property ought to be regarded in a special class for the purposes of taxation, for the reason that as a matter of state policy it should be encouraged, and the ordinary methods of taxation retard its best development.

Income Game Preserves. Most of the European forests are used as game preserves, as well as for forestry purposes. It is well known, however, that the presence of large game in the forest is generally a great disadvantage, and that much injury may come from its presence there, and the rental of about twenty-five cents per acre, which is the price generally paid for the use of forest preserves, is not sufficient to cover the loss.

The German forestry service generally think it desirable to have game in the forests for other considerations than that of its rental value, and chiefly from the fact that it adds interest to the iorest, and in this way attracts the attention of parties who otherwise would not be so much interested in it. There is a great deal of sentiment attached to the presence of this game among the foresters themselves, and it is said that were it not for this sentiment Germany could never keep as fine a body of men in 
its forestry scrvice as it now has. In the renting of land as a game preserve, it is customary to limit the number of deer, etc., that shall be killed in any one season. It is customary to make an estimate of the game of the forest ranges each year. In the case of deer this is done by feeding them in paddocks during the winter.

Government Supervision of Forests in Germany. It is the policy of the government in most of the German provinces

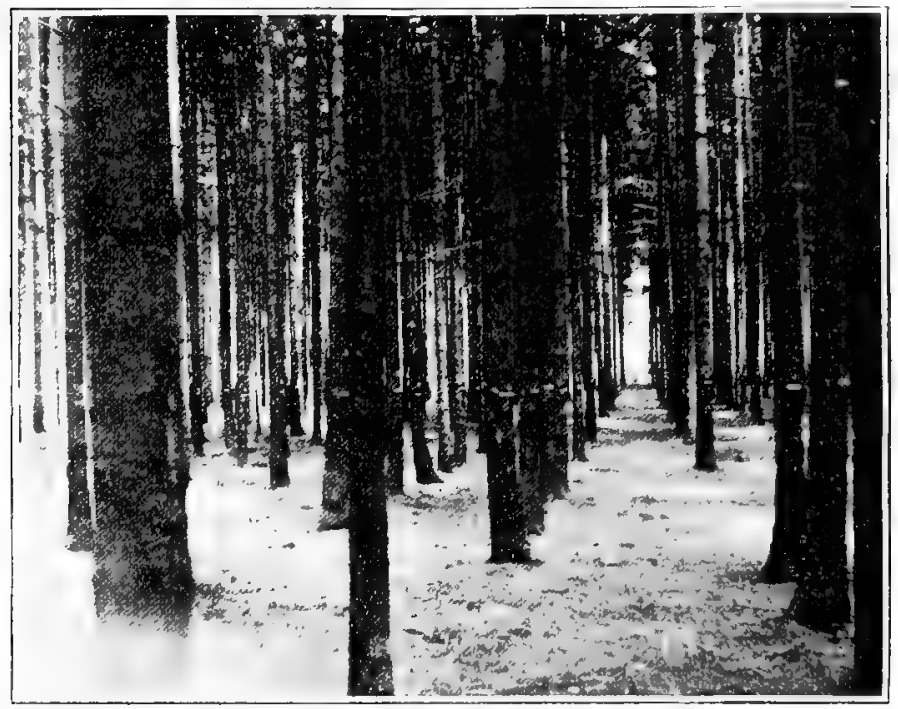

Figure. A fine young growth of Norway Spruce (Picea excelsa) in the forest garden of the "Giessen Forestry School" in Hessen, Germany.

not to interfere more than is necessary in the management of private woodlands, although the custom varies in the different provinces. On this account, where the land is not much broken, there are few requirements in regard to maintaining forests; but where the land is much broken, as is the case in the Bavarian Alps and the Black Forest, it is sometimes customary to require private owners to deposit the cost of replanting their land when they cut their timber, and if they do not attend to the 
replanting within a certain period it is done by the government. It is the very general settled policy' of the provincial governments to keep in forest about the same area that is now devoted to this purpose, and since the water powers in the valleys are dependent for the regularity of their supply upon the forests that are upon the mountain sides, the government reasons that the exercise of some supervision in this matter is necessary for the well being of all. Where forests are owned by municipalities. the municipal authorities can generally hire their own superintendent, but in some provinces the government generally manages to have laws passed that will make it most convenient for municipalities to employ the government superintendent. In the case of municipal forests the governments generally allow the cutting of only the increase each year. If this matter was left entirely to the will of the people they would frequently sacrifice the future for present gains. This supervision may be likened very much to that which is exercised in this state in preventing cities and towns from acquiring an indebtedness beyond a certain percentage of their taxable valuation. However, in case there is a pressing need for some public improvement, as for instance a schoolhouse, the government may allow extra cuttings for this special purpose, but in after years the annual cuttings must be lessened until the capital growing stock of wood on the land is made good.

Forest Reservations and National Parks. Many of the forest reservations in this country are in need of immediate attention. Much of the virgin timber on them has passed its prime and is decaying, and the constant liability to forest fires makes the young growth very unsafe. The increased demand for timber and the high price for the same has encouraged lumbermen in trying to have the timber on such reservations thrown onto the market. When cut in the ordinary manner there is practically nothing leit, and the end of the tree growth is reached. If this were to be managed in a proper way the mature trees would be cut as soon as there was a demand for lumber, and those trees should be left which are still growing thriftily. In some cases there is talk of utilizing some of these reservations as national parks, and in America too often the park idea means simply a piece of land from which nothing is removed. The best plan for managing these large tracts of timber would proba- 
bly be to use them as examples of good forestry, as well as for parks, as the one purpose need not in the least interfere with the other. It is quite customary in many parts of Europe to have woodland resorts carried on in this way. The carrying out of such a plan means practically the establishment of a business, which at the outset will employ a large number of men in harvesting the mature trees, which will generally be from one-third to one-half of that which is standing. This business, however, will not cease to be productive when the mature trees are cut, but will go on indefinitely producing a certain amount of annual growth which can be harvested. Putting a reservation onto this basis would have the effect of building up the country permanently, and would undoubtedly lead to the establishment of summer resorts in the most favored localities in them, which would also add to their prosperity. The government can well afford to do this, owing to the fact that it is perpetual and pays no taxes, while perhaps it would be extremely unwise for individuals to engage in such an enterprise, owing to the fact that taxes are too high and the profits are too long delayed. On many of the Indian reservations such an arrangement as this would result in great benefit to the tribes located there, for it would assure them in the continuance of their reservations as homes, and at the same time bring them in close contact with the whites, and give them regular employment and regular income. Such parks would be admirable army posts for cavalry, which could be used to prevent trespass.

Minnesota State Forest Reserves. The legislature of Minnesota passed an act in 1899 which created the "Minnesota State Forestry Board." This consists of nine members, two of whom are members ex-oficio, and the balance are appointed by the governor when recommended to him by the regents of the university and by the various agricultural and kindred societies of the state. The special purpose of this board is to act as trus1ce for the state in the management of any lands that may be donated to it for loresty purposes. It has also power to publish in a propular manner bulletins from time to time. Any person or corporation may donate to the state through this board any waste land it may have. The land is to be managed on forestry principles. At least once in five years the accumulated income 
from each tract that has been deeded is to be divided by the State Forestry Board as follows: One-third shall be divided between the state, county and town where the land is situated (one-half of said one-third going to the state, one-fourth to the county and one-fourth to the town) and two-thirds of the income shall be paid to such public educational institution in the state as may be designated in the deed of conveyance. Provision is made that, where the growth of towns, the building of railroads, the development of water powers, or other improvements may demand the alicnation of the land by the state, the forestry board may sell the same and divide the proceeds as directed for the income. Otherwise the land is to be held in perpetuity for forestry purposes.

It was thought that under the terms of this act a large amount of waste land would be donated, but the unprecedented land boom of the last two years has led to some disappointment in this regard.

An Act for the Prevention and Suppression of Forest Fires in Minnesota. 'This act, which was passed by the legislature of Minnesota in I895. makes a systematic division of the state in such a way that every section of it is in charge of a forest fire warden. It provides for the appointment of a chief fire warden, who shall have supervision of all fire wardens. Supervisors of towns, mayors of cities and presidents of village councils are constituted fire wardens in their respective towns, cities and villages. The chief fire warden has power to appoint as fire wardens other persons, as he may deem necessary, to protect unorganized territory. One-third of the expense is borne by the state and two-thirds by the counties. Under this act penalties are prescribed as follows:

The following are liable to a penalty not exceeding $\$ 100$, or imprisonment not exceeding three years:

Any person refusing, without sufficient cause, to assist fire wardens in extinguishing forest or prairie fires.

Any fire warden who neglects to perform his duties.

Any person who willfully, negligently or carelessly sets on fire, or causes to be set on fire, any woods, prairies or other combustible material, thereby causing injury to another. 
Any person who shall kindle a fire on or dangerously near to forest or prairie land, and leave it unquenched, or who shall be a party thereto.

Any person who shall tuse other than incombustible fire wads for firearms, or carry a naked torch, firebrand, or other exposed light, in or dangerously near to forest land.

Any person who shall willfully or heedlessly deface, destroy or remove any warning placard posted under the requirements of this act.

Any railroad company willfully neglecting to provide efficient spark arresters on its engines, or to keep its right of way to the width of roo feet cleared of combustible material, or which shall fail to comply with other provisions of section 12 of the above mentioned act.

The following are liable to a penalty of not less than $\$ 5.00$ nor more than $\$ 50.00$ :

Any railroad employe who willfully violates the provisions of section 12 of this act, in regard to depositing live coals or hot ashes near woodland, and to reporting fires.

Any owner of threshing or other portable steam engine who neglects to have efficient spark arresters, or who shall deposit live coals or hot ashes without extinguishing the same.

The following are liable to a penalty not exceeding $\$ 500$, or imprisonment in the state prison not over ten years, or both:

Any person who maliciously sets or causes to be set on fire any woods, prairie or other combustible material whereby the property of another is destroyed and life sacrificed.

The effect of this law has been very beneficial, and has prevented much loss of property by fire; but the area to be covered is very large, much of it is very sparsely populated, and the funds available are very meager for best results, so that, although it has been very ably enforced, and some convictions made under it, yet it should be amended in several respects to make it effective.

State Bounty for Tree Planting. It is provided by the laws of the State of Minnesota that any person who shall plant, cultivate and keep in a growing, thrifty condition one acre and 
not more than ten acres of prairie land with any kind of forest trees except Black Locust, to be planted not more than eight feet apart each way, and maintained at that distance by replanting each year such as may have died out, shall be entitled to $\$ 2.50$ per acre for a period of six years. Provided that not more than $\$ 20,000$ shall be expended in any one year for this purpose.

This law has no doubt been productive of much good in encouraging the planting of forest trees on the prairies. 

PART II.

TREES OF MINNESOTA. 



\section{TREES OF MINNESOTA.}

\section{PINACEAE. PINE FAMILY.}

Trees or shrubs with resinous juice. Leaves commonly needle-shaped or awl-shaped, and mostly evergreen. Flowers monoecious or sometimes dioecious, in catkins or cones, destitute of calyx and corolla. The pollen grains have lateral air sacs which buoy them up in the air, and they are occasionally carried hundreds of miles by the wind. Fruit either a woody cone with distinct scales, as in the pines, spruces, Arborvitze and Larch, or a somewhat berry-like cone with fleshy coherent scales, as in the Red Cedar.

\section{Genus PINUS.}

Leaves of two kinds; the primary ones, linear or scale like, deciduous; the secondary forming the ordinary foliage evergreen, from slender buds, in clusters of two, three or five together, each cluster surrounded by a sheath of thin membranous scales. Flowers appear in the spring, monoecious; the staminate in scaly catkins clustered at the base of the new growth; the pistillate in scaly catkins borne on the twigs of the preceding season, becoming scaly cones at maturity. Each scale is in the axil of a bract, and bears a pair of ovules adhering to its inner face, which peel off as the scale expands at maturity. Fruit a woody cone, maturing in the autumn of the second year. Cotyledons three to twelve, linear. We have only three native species in this state.

Pinus strobus. White Pine. Weymouth Pine.

Leaves soft, in clusters of five, about three to four inches long, falling at the end of the second or during the third season; sheath 


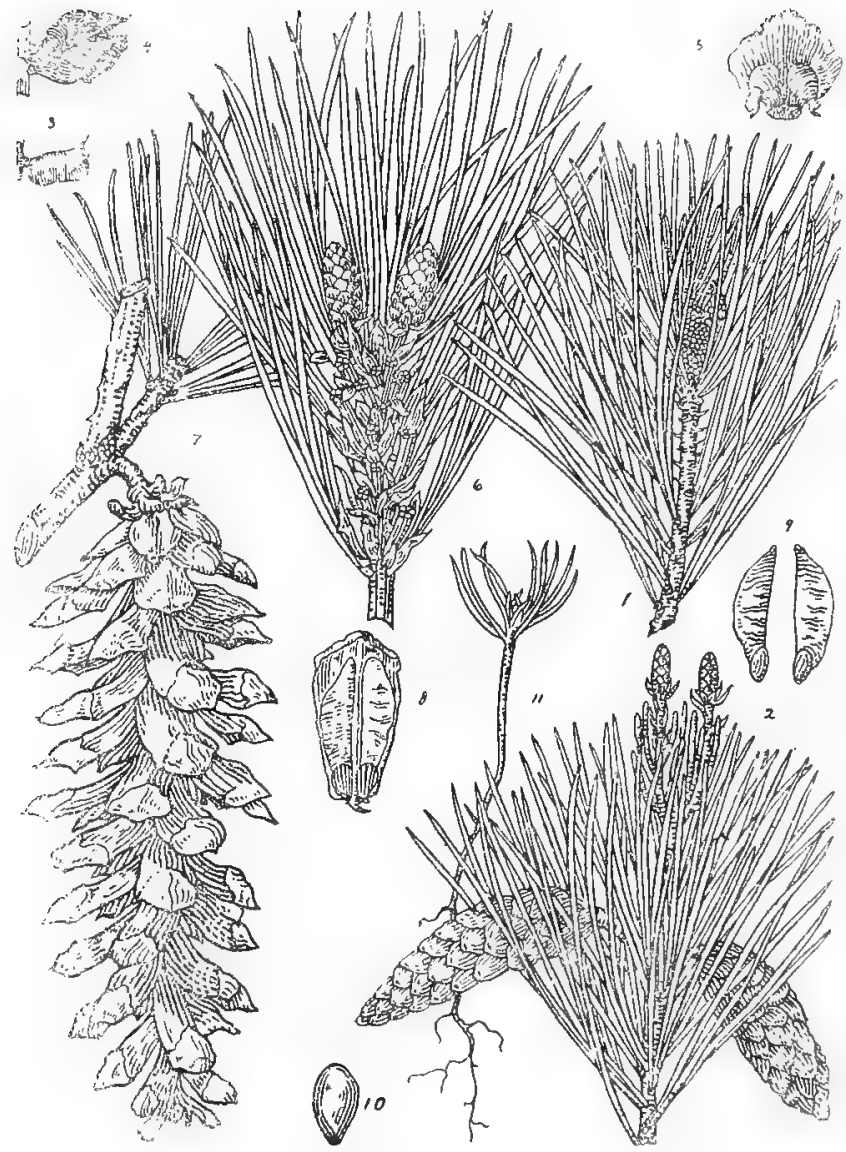

I'late I. Pinus sprobus. White Pine.

I. Branch bearing staminate flowers, one-half natural size. 2. Branch bearing pistillate flowers and young cones, one-half natural size. 3. An. ther, side view, enlarged. 4 and 5 . Scales of pistillate flower, side and top views, enlarged. 6. Autumn branch bearing young cones, one-half natural size. 7. Fruting branch bearing open cone, one-half natural size. 8. Scale of conc with seeds attached. one-half natural size. g. Seeds with wings attacherl, one-half natural size, rc. Seeds, enlarged, rt. Seedling plant. 
early deciduous. Sterile catkins five or six together. Cones solitary, four to six inches long, slender, cylindrical, terminal, pendulous, falling after shedding their seeds; scales thin and pointless, seeds nearly one-quarter of an inch long with eight to ten cotyledons. A magnificent tree, and the tallest one of the Eastern States. In good locations in this state it sometimes attains a height of over I60 feet and a diameter of four feet. One acre was scaled near Carlton, Minn., which yielded over 94,000 feet board measure of sound timber. The White Pine is generally found in this section on rather clayey land. On poor land the Norway and Jack Pine generally crowd it out.

Distribution.-Canada and the Northeastern States and southward along the Alleghanies to Georgia, the valley of the St. Lawrence and around the Great Lakes. In Minnesota it is common through the northern half of the state, excepting west of Red Lake, and south to the northern edge of Chisago county. It is found occasionally south of this limit, as at St. Cloud, Taylors Falls, Cannon River, Mantorville, Rochester, St. Charles, and at various points in Houston and Fillmore counties. In the western and southwestern portions of the state it is not found.

Propagation.-By seeds, as recommended for evergreens. The young seedlings will not bear as much sunlight as the Norway, Jack or the Bull Pine, and will bear considerable shade.

Properties of Wood-Very soft, light, weak, compact, straight grained, very resinous, easily worked, of a delicate pinkish brown color, with lighter colored sapwood. One of its points of considerable value is the small degree to which it shrinks and swells owing to change in the atmosphere. Not durable in contact with the soil, although the heartwood stands fairly well. Specific gravity, 0.3854 ; weight of a cubic foot, 24.02 pounds.

Uses.-The White Pine is one of the fastest growing and perhaps the most graceful of evergreens for ornamental planting. It grows rapidly when in retentive soil of a loose open texture, but is liable to kill out in wet, compact or very sandy soils. It should not be planted in very exposed situations, but should follow the planting of the more hardy deciduous trees in such places; it is liable to be killed by drying winds in the early spring on our Western prairies. It is not as hardy as the Scotch Pine, nor will it make as fast a growth when young, but is longer lived 
than the Scotch Pine, and in fifteen years will make a much larger and more ornamental tree. Within and near its range it is very valuable for ornamental purposes.

The White Pine yields the most useful timber of the American forests, it being especially valuable for sash, doors, blinds, shingles, etc., and for a general-purpose timber in building and woodworking. It is largely used in cooperage, railroad ties, pulp, matches and excelsior making. From the bark is obtained the compound syrup of White Pine now largely used in the United States as an expectorant.

\section{Pinus flexilis. Limber Pine. Western White Pine}

Leaves five in a sheath, somewhat rigid, sharp pointed and densely crowded on the branchlets, falling during fifth and sixth years. Cones cylindrical, taperıng, three to five inches long, light brown; scales thick, one and one-quarter inches broad; seeds one-third to one-half inch long, with six to nine cotyledons. A handseme tree, about fifty feet high, resembling the common White Pine, but of closer, stiffer habit and darker foliage.

Distribution.-Mountain ranges from Alberta to Western Texas, New Mexico, Arizona and California.

Propagation.-By seeds.

Properties of Wood.-Light, soft, close grained, compact; color, light clear yellow, turning red on exposure; sapwood nearly white. Specific gravity, 0.4358; weight of a cubic foot, 27.16 pounds.

Uses.--The Western White Pine is a handsome tree that is little known in cultivation, but promises to be of some value for ornamental planting, and is doing very well at the Minnesota Experiment Station, where it has been growing nine years.

Pinus resinosa. Red Pine. Norway Pine.

Leaves five to six inches long, nearly cylindrical; in pairs from long close sheaths, falling during fourth and fifth seasons. Cone ovoid conical, with rounded base, about two inches long, falling after shedding the seeds; scales of cone slightly thickened at the end without any priclily points; seeds one-eighth of an inch long, with from six to eight cotyledons. A very handsome, rapidgrowing, robust trec, with a straight, uniform trunk covered with 


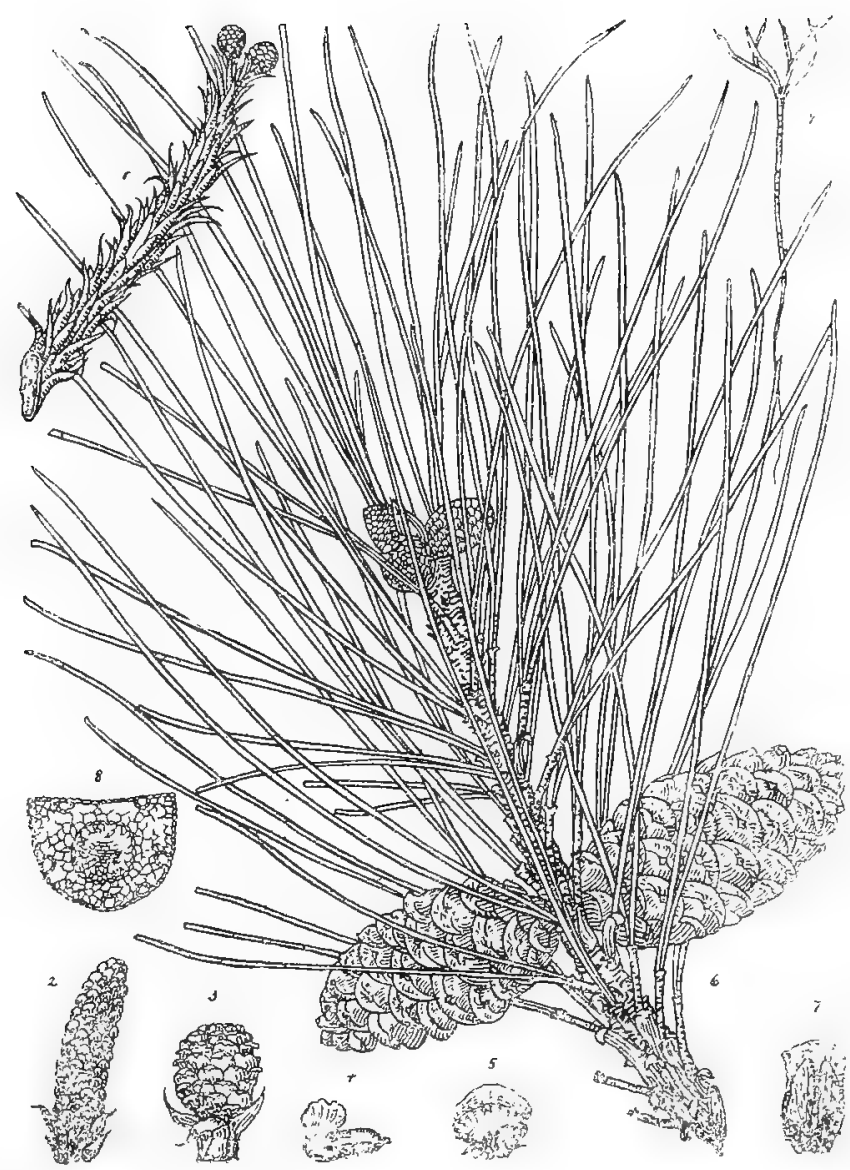

Plate 2. Pinus resinosa. Red Pine.

r. Branch bearing pistillate flowers, one-half natural size. 2. Staminate flower, natural size. 3. Pistillate flower, natural size. 4. Anther, open, enJarged. 5. Scale of pistillate flower, enlarged. 6. Branch bearing ripened cones and young cones. 7. Scale of cone with seeds attached, one-half natural size. 8. Cross section of neredle. 9. Seedling plant, one-half natural size. 
a pretty reddish gray, soft, flaky bark; commonly grows about eighty feet in height and two feet in diameter, but occasionally reaches a height of 150 feet. Wrongly called Norway Pine, for this species is not found in Norway or any other part of Europe.

Distribution.-Found in northern United States and Canada, southward as far as Pennsylvania, but reaches its greatest development in the northern part of Michigan, Wisconsin and Minnesota, where it forms large forests even on sandy or dry soil, often interspersed with Jack Pine when young. In Minnesota its range is about the same as that of White Pine, but does not extend as far south.

Propagation.-By seeds, as recummended for evergreens. The seeds of this pine are very scarce, and difficult to obtain on account of the few produced in the cones and the ravages of the squirrels. These animals are so fond of the seeds that they often cut into the cones before the seeds are mature and take the larger part.

Propagation.-By seeds, as recommended for evergreens. The secds of this pine are very scarce, and difficult to obtain on crack in drying: yellowish white sapwood and reddish heartwood, conspicuously grained; not durable in contact with the ground. Specific gravity, 0.4854; weight of a cubic foot, 30.25 pounds.

Uses.-As an ornamental tree and for windbreaks the Red Pine will stand much more hard usage than the White Pine, especially on light soil. It has a robust, vigorous appearance, and would undoubtedly be more commonly planted if young plants of it could be more cheaply obtained. Within and near its range it makes a very fine ornamental tree, and is very valuable for windbreaks. The principal value of this timber is for framing, flooring, wainscoting, car sills and ship building. In many ways it is used to take the place of White Pine. In fact, Red Pine, while inferior for general use, is frequently mixed with White Pine in lumber yards. While its specific name, resinosa, would seem to infer the presence of a large amount of resin in this tree, it in fact contains comparatively little, and is seldom used for the purpose of obtaining resin. 
Pinus divaricata. (P. banksiana.) Jack Pine. Northern Scrub Pine. Gray Pine.

Leaves in twos, short, from three-quarters to one and onehalf inches long, acute, rigid, thick, more or less curved and twisted, falling the second or third season; inner side channeled; margins very minutely serrate, sheaths short; buds very resinous. Cones ovoid acuminate, about two inches long, often curved, laterally located on branchlets, often in pairs. They are generally opened by the sun, but where they are in the shade they will remain on the trees unopened for several years until they become deeply covered with moss and sometimes until overgrown and imbedded in the wood and bark. The seeds are about one-eighth of an inch long, with four to five cotyledons. Those from the old cones seem to grow as readily as fresh seeds when sown. A very pronounced peculiarity of this tree is its habit of forming several whorls of branches on the new growth. This is especially noticeable when the trees are young and growing rapidly, when as many as six whorls of branches may be seen on a year's growth. This tree, under favorable conditions, will occasionally attain a height of 125 feet and a diameter of two feet. However it is seldom over seventy feet high and eight to twelve inches in diameter, and generally where it occurs in pine forests it is only forty or fifty feet high.

Distribution.-It is distributed from northern New England and the valley of the St. Lawrence westward along our northern frontier to the Rocky Mountains and north to the Arctic circle; found growing in sandy land and land that has been recently severely burned. It covers large areas of poor, sandy lands in Minnesota. In this state it probably has about the same range as Norway Pine.

Propagation.-By seeds. The cones may be obtained at any season of the year and kept out of doors until spring, when they can be opened by the application of a little heat. The seeds from the old cones seem to have as much vitality as those from young cones. In the woods the cones of Jack Pine often remain closed until a fire sweeping over the land causes them to open, and allows the seeds to fall in the loose ashes, where they soon start into growth. On account of this peculiarity it is sometimes called the Fire Pine. The seedlings are very hardy, and grow 
喿
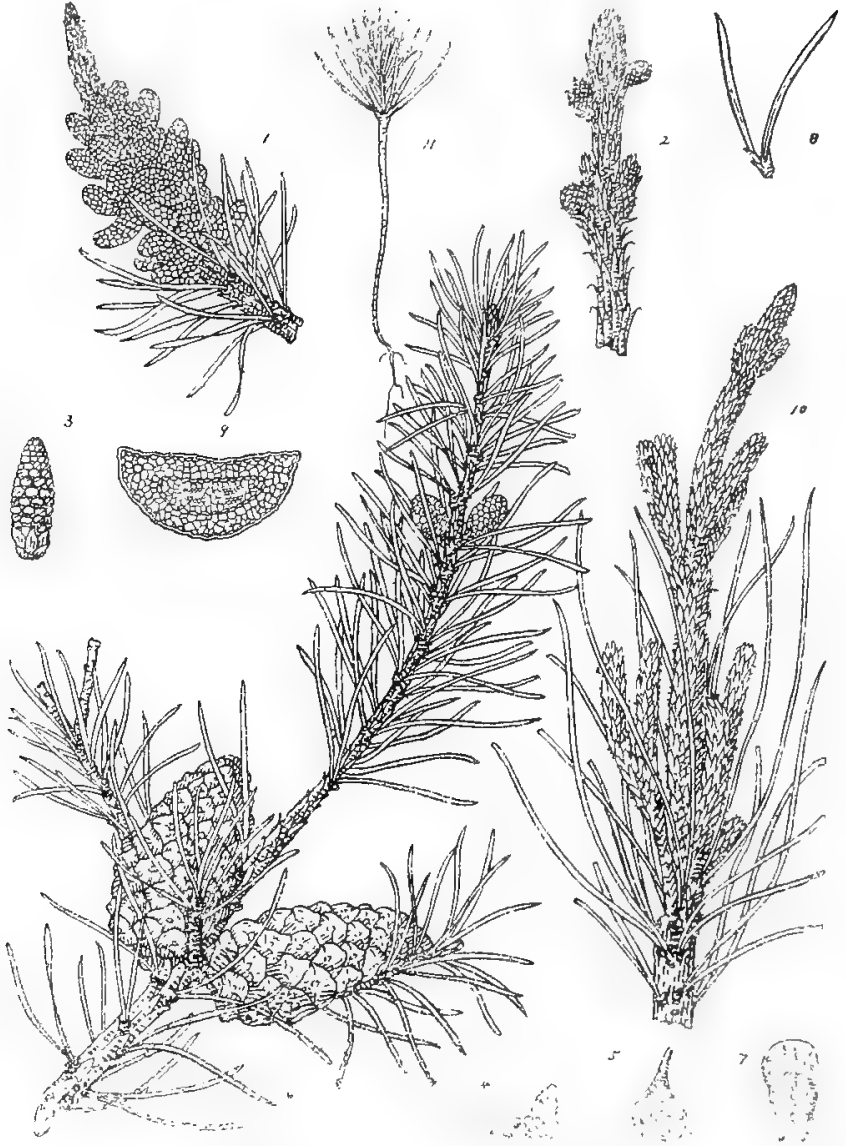

Plate 3. Pinus divaricata. Jack Pine.

I. Branch bearing staminate flowers, one-half natural size. 2. Branch bearing pistillate flowers, cue-half natural size, 3. Staminate flower, natural size, 4. Anther, open, enlarged. 5. Scale of pistillate flower, enlarged. 6. Branch bearing ripened cones and young cones, one-half nat. ural size. 7. Scale of cone with seeds attached, one-half natural size. 8. Fascicle of needles, one-half natural size. 9. Cross section of needle. ro. New growth showing several whorls of branches, one-half natural size. II. Seedling, one-half natural size. 
without shade. It is one of the first evergreens to start on the abandoned dry pine land in some sections of this state.

Properties of Wood.-Light, soft, not strong, resinous; light yellowish brown in colnr with thick whitish sapwood. Specific gravity, $0.476 \mathrm{r}$; weight of a cubic foot, 29.67 pounds.

Uses.-The Jack Pine is not a pretty tree, and is seldom used in ornamental planting. It is, however, the hardiest native evergreen tree we have and is especially adapted to dry, loose soil, where it has a wondrous power of withstanding drouth. It is of rapid growth when young, which, together with its great hardiness, has led to its being planted on some of the sandiest dry lands of the West. In the timbered portion of Minnesota it often acts as a nurse tree for the Red Pine, but too often is liable to crowd it out. The larger trees are generally sawed into lumber and pass as Red Pine, but they seldom attain a size large enough to be profitably used for this purpose, but much of it is used for fencing, farm buildings, railroad ties and as fuel.

Pinus ponderosa scopulorum. Rock Pine. Bull Pine. Heavy-wooded Pine. Western Yellow Pine.

Leaves three to six inches long, rigid, generally in threes, but occasionally in twos, falling during third and fourth seasons. Cones two to three inches long, grayish, with stout prickles. Tree 80 to 100 feet high. The species, Pinus ponderosa, of which this is an important variety, is the most magnificent and widely spread of Western Pines, attaining a height of 200 to 300 feet and a thickness of twelve to fifteen feet, and having much larger cones and longer needles than this variety.

Distribution.-The Rock Pine is found throughout the Rocky Mountain region. It inhabits even the dry sand hills of Western Nebraska and Montana, and is perhaps the hardiest Western Pine.

Propagation.-By seeds, which are large, easily obtained, and grow with the greatest certainty if given ordinary treatment.

Properties of $W$ ood.-The wood varies greatly in quality and value. It is heavy, hard, strong, brittle and compact, neither coarse grained nor durable; color, light red, with very thick light colored sapwood. Specific gravity, 0.4619; weight of a cubic foot, 28.78 pounds. 


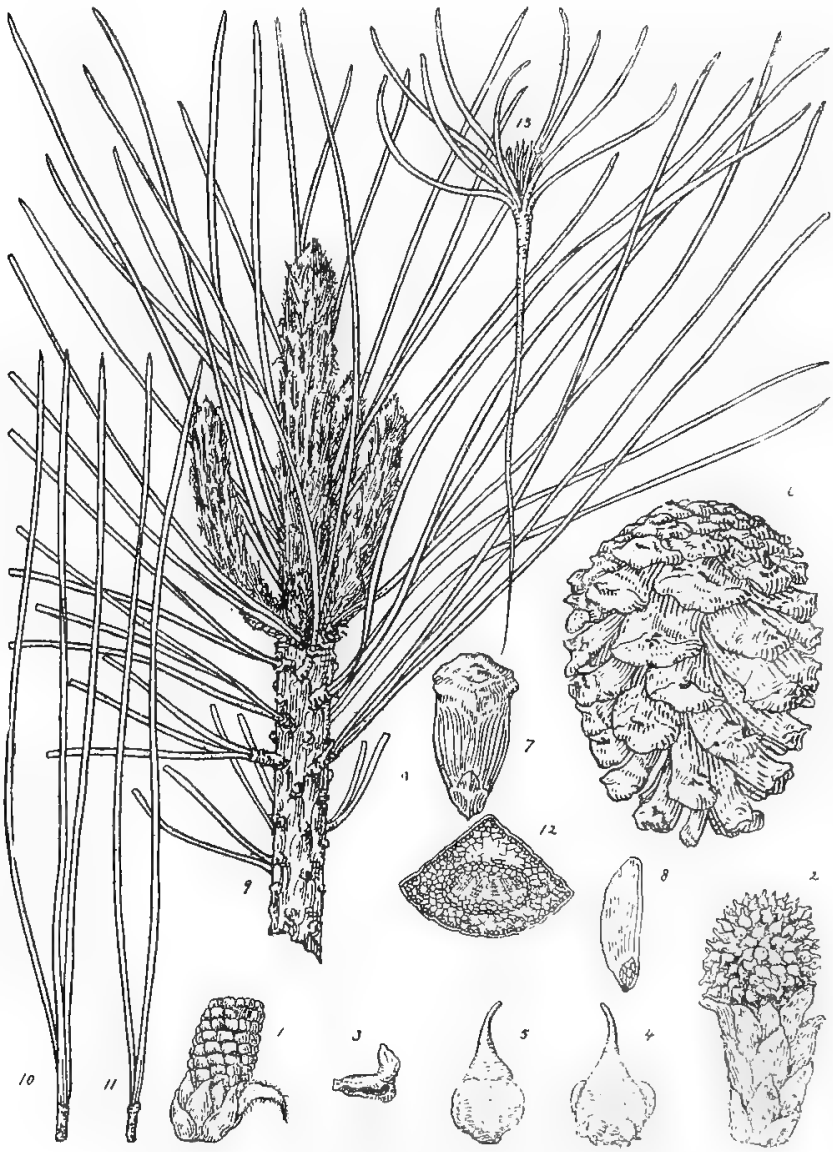

Plate 4. Pinus ponderosa scopulorum. Rock Pine.

I. End of branch bearing staminate flower, enlarged. 2. End of branch bearing pistillate flower, enlarged. 3. Anther, open. 4. Scalc of pistillate flower attached to bract, front view, enlarged. 5. Scale of pistillate flower attached to bract, rear view, enlarged. 6. Cone, one-half natural size. 7. Scale of cone, rear view, one-half natural size. 8. Seed attached to wing. 9. Branch showing young growth, one-half natural size, yo. Fascicle of three needles, one-half natural size. II. Fascicle of two needles, one-half natural size. 12. Cross section of needle from three-leaf fascicle. 13. Seedling, one-half natural size. 
Uses.-The Rock Pine has the power of withstanding great extremes of drouth and temperature, and promises to be of great value for planting on our Western plains. It is of rapid growth, and while it has a somewhat coarse appearance its sturdy form is far from being unsightly. It is perhaps rather more difficult to transplant than the Scotch Pine, probably on account of its deep tap root when young. The wood is largely manufactured into lumber, and used for railway ties, fuel, etc.

Pinus sylvestris. Scotch Pine. Scotch Fir. Deal Wood.

Leaves two in a sheath, one and one-half to two inches long, and of a glaucous hue, falling during third season; sheaths small, persistent, nearly black. Cones about two inches long, tapering towards the apex, solitary or in clusters of two or three; scales of cones tipped with a deciduous point. Trees rather inclined to grow crooked, and to not keep a straight shaft as in the case of the Norway and Austrian Pines. In this region where it is cultivated it seldom grows over ten inches in diameter, and forms round topped trees spreading twenty-five to thirty feet. There are several cultivated varieties, the most of which are of little value.

Distribution.-It is the common timber pine of northern Europe and Asia.

Propagation.-Easily grown from seeds if properly managed, but requires shade when very small. Most of the seeds of this pine that are commonly sold are gathered in Europe from a dwarf scrubby form that is found on dry poor land. There are probably very few seeds sold from the large timber trees, as they are most cheaply gathered from the dwarf form. This may be a reason why the tree is generally so dwarf with us, although it varies much in size when grown in different soils.

Propertics of Wood.-Yellowish white, soft, light, close grained and easily worked. Specific gravity, air dried, 0.52.

Uses.-The Scotch Pine is one of the hardiest of evergreens, of very rapid close growth when young, but often rather open in habit when old. It generally reaches its maturity when about twenty years old, and seldom lasts much longer when on dry soil. It has been planted more largely than any other evergreen on our prairies, and perhaps is as good as any for pioneer plantings. 


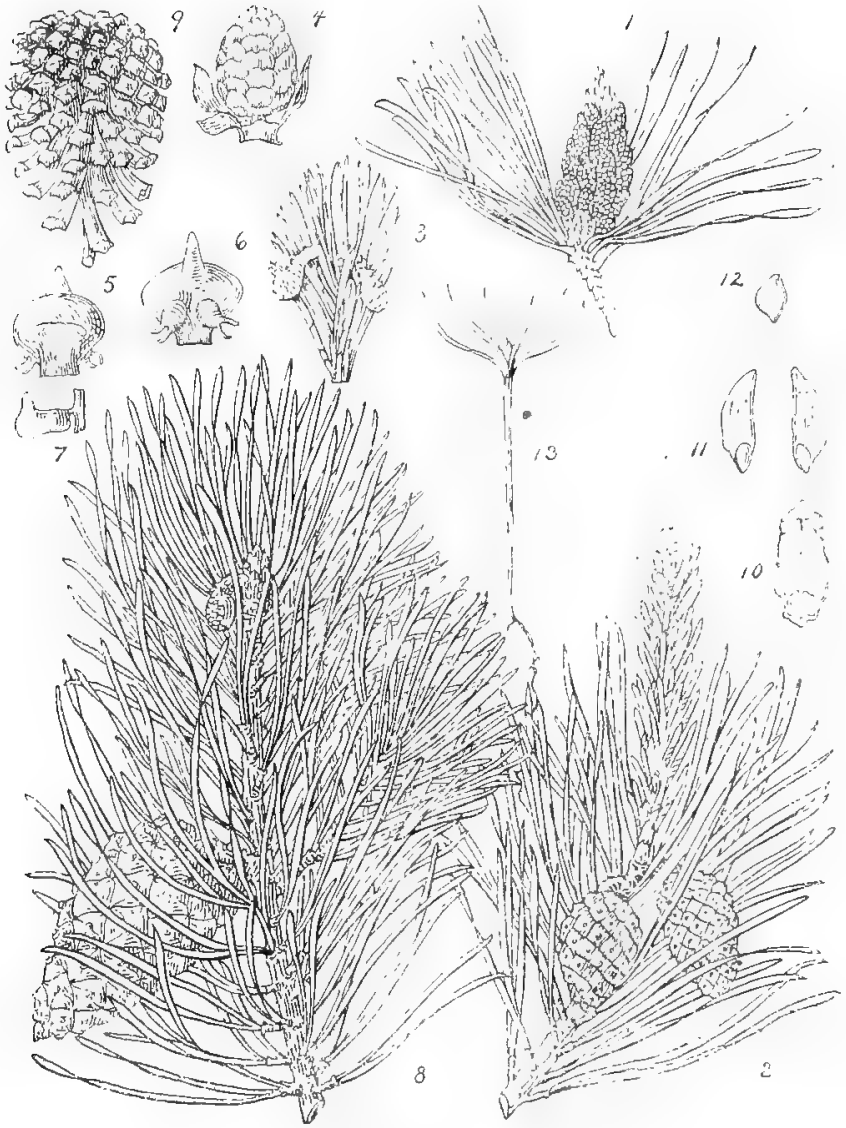

Plate 5. Pinus sylvestris. Scotch Pine.

I Branch bearing staminate flowers, one-half natural size. 2. Branch bearing pistillate fowers and young cones, one-half natural size. 3. Branch bearing pistillate flowers after pollination, one-half natural size. 4. Unopened pistillate flower, enlarged. 5. Scale of pistillate flower, rear view, etularged. 6. Seale of pistillate flower, front view, enlarged. 7. Anther, enlarged. 8. Branch bearing ripe cone and young cone, one-half natural size. 9. An open cone, one-half natural size. Io. Seale of cone, one-half natural size. Ir. Seeds with wings attached, I?. Seed, natural size. r3. Seedling, one-half natural size, 
The wood of this tree is valuable for interior finishing, and is largely used in Europe, where it is the common timber pine. The celebrated pine of Norway and the Baltic countries is of th:s species. What has been termed the best form of this, and known as Riga Pine, has been partially tried in this country, but thus far its superiority has not been demonstrated.

"This pine yields a considerable portion of the common European turpentine. In Germany a fibrous substance is prepared from the leaves of this and other species of Pinus and Abies, called fir-wool, and a volatile oil is distilled from them called fir-wool oil, which is considerably used as a remedy for rheumatism, chronic catarrh, chronic skin diseases, etc.; in fact, generally for the same purposes as the oil of turpentine. The leaves are made into wadding and clothing (designated as firwool from their origin), which are supposed to have some merit in the treatment of rheumatic affections."

Pinus 1aricio austriaca. Austrian Pine. Black Pine.

Leaves two in a sheath, dark green, slender but rigid, four to six inches long, falling during fourth and fifth seasons. Cones two and one-half to three inches long, conical, not beaked. Tree much more regular in outline than the Scotch Pine, the branches coming out in a very regular, candelabra-like fashion. There are a few cultivated varieties.

Distribution.-Native of southern and central Europe.

Propagation.-By seeds, seedlings require shading when young.

Properties of Wood.-Light, solt, durable, very rich in turpentine. Specific gravity, air dried, 0.57 .

Uses.-The Austrian Pine is very desirable for planting in this section, rather longer lived and perhaps hardier than the Scotch Pine, and of a much darker color, resembling most closely the Norway Pine.

Pinus montana pumila. ( $P . m u g h u s$, Dwarf Pine. Dwarf Mountain Pine.

Leaves dark green. crowded, stiff, twisted, about two inches long, falling during fifth, sixth and seventh years. Cones usually in pairs, nearly two inches long, tapering, with slight points to 


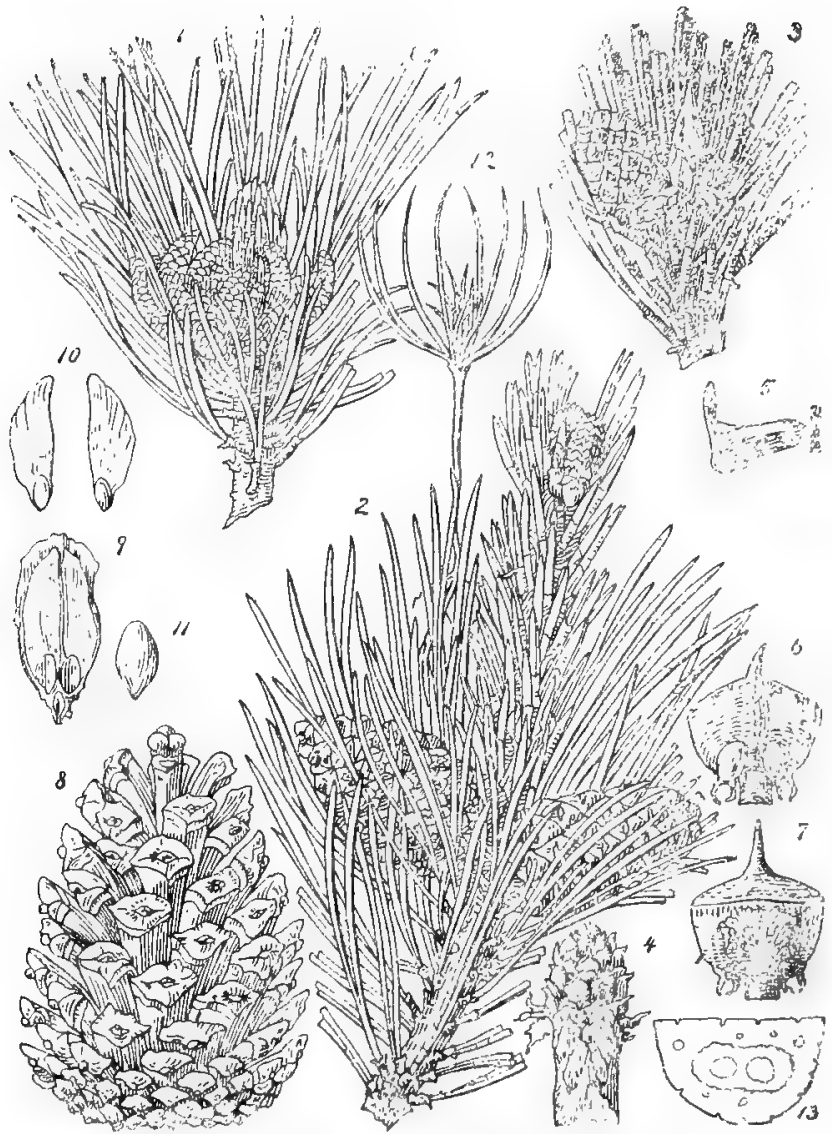

Plate 6. Pints laricio austriaca. Austrian Pine.

I. Branch bearing staminate flowers, one-half natural size, 2. Branch bearing pistillate flowers and young cones, one-half natural size, 3. Find of branch bearing bud and young cone, one-half natural size. 4. Pistillate flower, natural size. 5. Anther, en'arged. 6 and 7. Scales of pistillate flower, front and rear views, enlarged. 8. Open cone, one-half natural size, 9. Scale of cone, one-half natural size. 10. Seeds with wings attached, one-half natural size. Ix. Seed, natural size. Iz. Seedling, one. half natural size. I3. Cross section of needle. 
the scales. A densely branched shrub, or possibly a small tree, two to ten feet high.

Distribution.-Mountains of central Europe.

Propagation,-Easily grown from seeds.

Uses.-The Dwarf Pine is one of the hardiest of Pines. It is of pretty, close shrubby form and takes kindly to pruning, which often greatly improves it. The plants from seed vary quite a little in habit, some being dwarf and spreading while others are

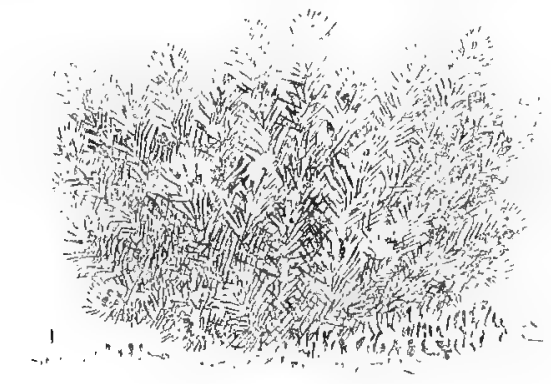

Figure 48. Pinus montana pumila. Dwarf Pine.

quite erect and tree-like. It is valuable for single specimens in lawn planting, for the edges of evergreen groups and for low hedges.

\section{Genus IARIX.}

A genus of large, deciduous, cone-bearing trees. Leaves needle-shaped, soft, deciduous, clustered, except on young shoots, where they are spirally arranged; leaf clusters developed in early spring from lateral, scaly, globular buds, which are scattered along the shoots of the season.

Propagation.-The seeds germinate readily in moist sandy soil, and the seedlings are easily raised in the manner described for evergreens. They should be transplanted very early in the spring, and if this is done at the right time the seedlings will start readily, but if moved after the plants have started they are very likely to fail. 
Larix 1aricina. (L. americanct.) Tamarack. American Larch. Hackmatack.

Leaves one-half to three-quarters of an inch long, slender and thread-like, light bluish green, deciduous. Cones one-half to one inch long, ovoid. A slender, graceful tree, thirty to one hundred feet high, with close or at length sightly scaly bark.

Distribution.--Northeastern United States, north of Pennsylvania, nearly or quite to the Arctic regions and west nearly to Central Minnesota; rare farther south than Ramsey and Hennepin counties in Minnesota. It covers vast areas of swamp land in the northern part of this state with a short stunted growth. It fails to reach large size in very wet land, while on land that is not excessively wet it grows soo feet high and sixteen inches through at the stump. In one instance a stunted Tamarack, growing on excessively wet land, had been forty-eight years in attaining a diameter of one and one-tenth inches, while on land well adapted to it a tree had grown to the height of forty-four and one-quarter feet, with a diameter of eleven inches in thirtyeight years.

Properties of Wood--Heavy, hard, strong, rather coarse grained, compact, durable in contact with the soil; color light brown; sapwood nearly white. Specific gravity, 0.6236 ; weight of a cubic foot, 38.86 pounds.

Uses.-The Tamarack may occasionally be used for variety in lawn planting on moist soil, and is well adapted to planting along lake shores and around sloughs; but on dry soil it is of little value, and we have many far more valuable trees for moist soils. The lumber is largely used in ship building, canoe making, for fence posts, telegraph poles, railway ties, etc. The inner bark of European Larch is used in medicine, and it is probable that the bark of our American species has similar medicinal properties. Two varieties varying in color of heartwood, the red and the white Tamarack, are commonly distinguished. The difference is probably one of age only. The red hearted trees, having the more heartwood, make the more durable lumber. This tree grows fast, and readily renews itself from seed. For these reasons, good Tamarack swamps, properly managed, should prove profitable investments. 


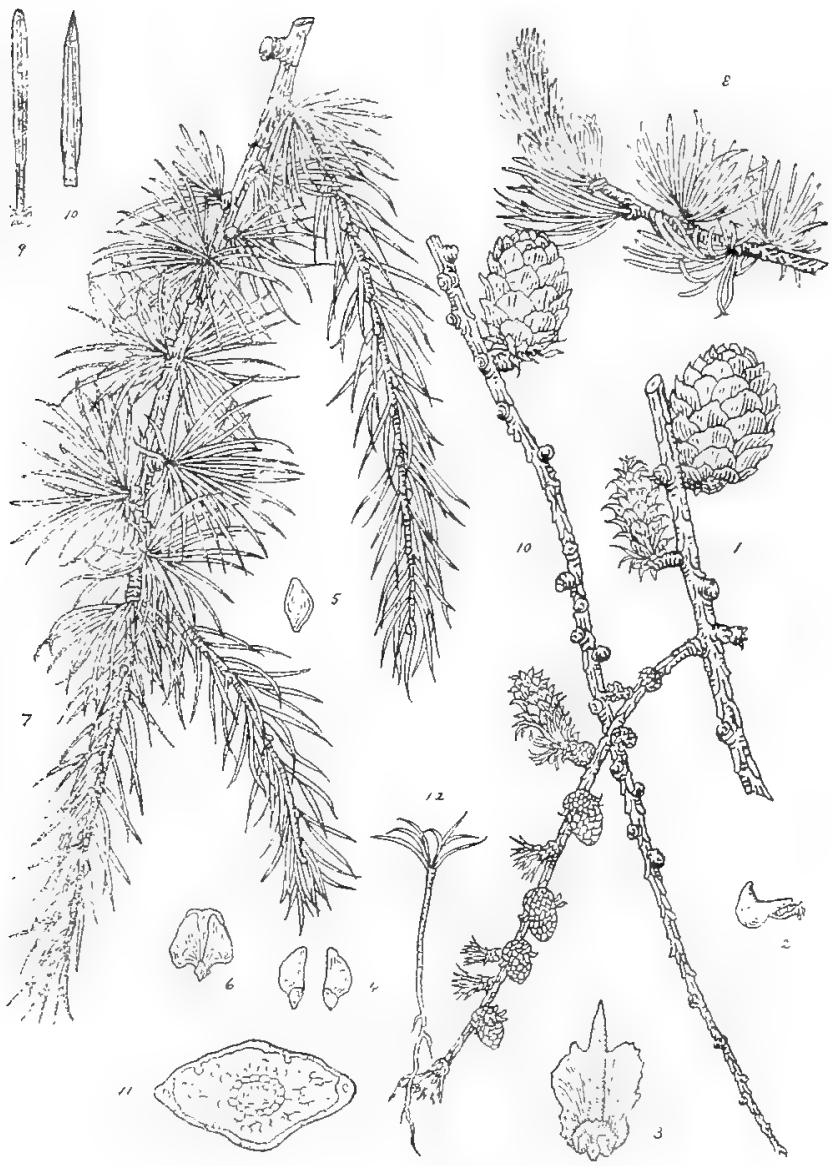

Plate 7. Larix europea. European Larch.

I. Branch-bearing staminate and pistillate flowers and a mature cone. one-half natural size, 2. Anther, enlarged. 3. Scale of pistillate flower, enlarged. 4. Seeds with wings attached, one-half natural size. 5. Seed, natural size. 6. Scale of cone, one-half ratural size. 7. Branches showing arrangement of leaves on new and old growth. 8. Branch showing tip of new growth in spring. 9. A leaf from fascicle on old growth. 10. A leaf from new growth. II. Winter branch showing persistent cone. I2. Seedling. 


\section{Larix europea. European Larch.}

Leaves longer than those of the Tamarack, and of a brighter green color. Cones longer than those of the Tamarack. A large and important timber tree.

Distribution.-Native of northern and central Europe, on moist mountain sides.

Propertics of Wood.-Hard, strong, tough, very durable in contact with the soil. Specific gravity, 0.62 .

Uses. - The European Larch has been largely planted in the Fastern States in small timber plantations, for windbreaks and ornament. It is superior to our native Larch for these purposes, but has not succeeded well on our Western prairies, probably on account of the dry climate. On moist soil in somewhat sheltered locations it often does well, and becomes a graceful, pretty tree. Very large and successful plantations of this tree have been made in Scotland and other European countries, but in some parts of Germany the Japanese Larch is preferred, as it is not so much infested with insects. The lumber is used for posts, telegraph poles, piles, beams and joists and in ship building. The bark is used in tanning leather. One tree, grown at Owatonna, Minnesota, attained a height of about fifty feet and a diameter of fifteen inches in thirty years, but so rapid a growth is uncommon here.

\section{Genus PICEA.}

Leaves evergreen, scattered, not grouped in sheaths, jointed on a persistent base, needle shaped, generally four-angled, short, pointing every way, and all of one kind. Flowers appear, in spring, monoecious; the staminate catkins in the axils of the leaves of the preceding year; the pistillate catkins terminal ovoid or oblong. Fruit a cone, maturing the first year, pendulous with thin tough scales that open when ripe and dry, to liberate the two, winged seeds, found at the base of each scale. Trees tall and pyramidal or conical in form.

\section{Picea canadensis. $\left(P, a l b \alpha_{0}\right)$ White Spruce.}

Leaves slender, one-half to one inch long, varying in color from light glaucous to dark green, falling during fourth and fifth seasons. Cones oblong, one to two inches in length, deciduous 


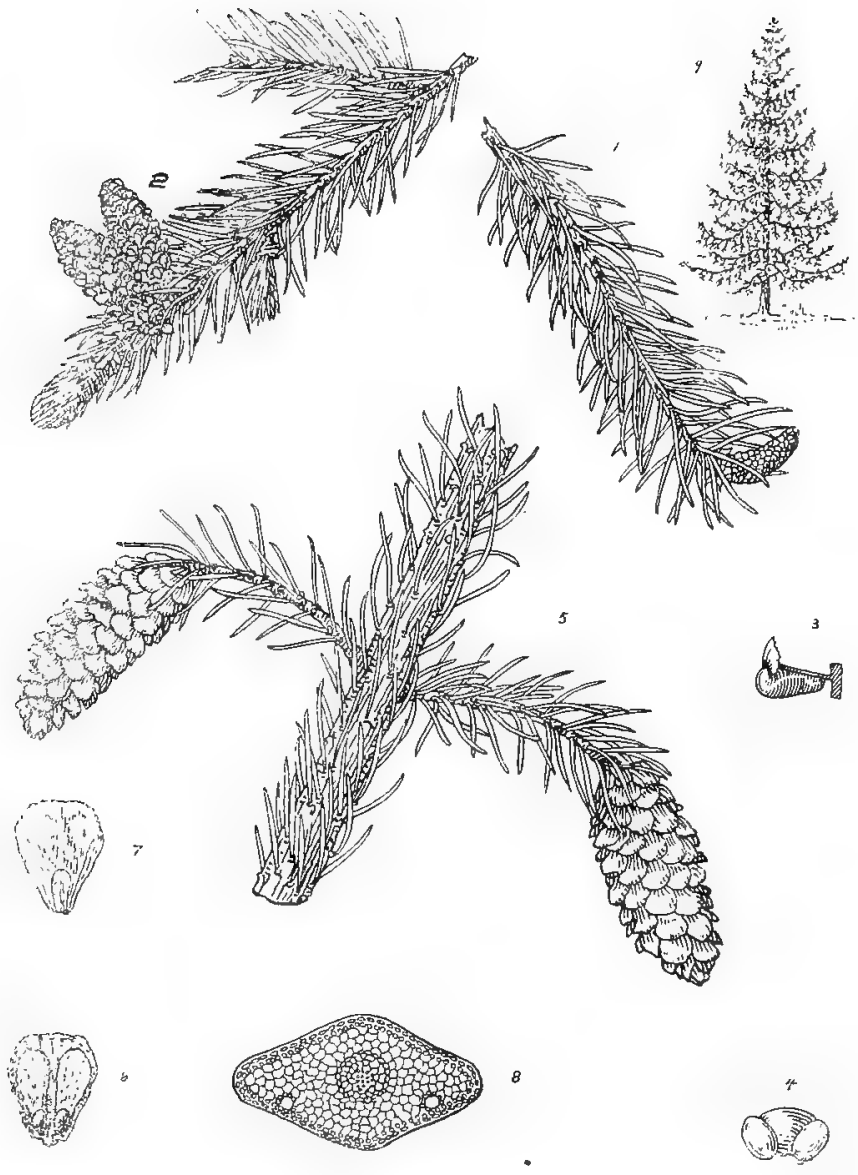

Plate 8. Picea canadensis. White Spruce.

I. Branch bearing staminate flower, one-half riatural size. 2. Branch tearing pistillate flower, one-half natural size. 3. Anther, side view, enlarged. 4. Pollen grain, showing air sacs, enlarged. 5. Branch bearing ripened cones, one-half natural size. 6. Scale of cone with seeds attached, natural size. 7. Scale of cone, rear view, natural size. 8. Cross section of needle, enlarged. 9. General view of tree. 
in autumn or winter of first year; scales thin, with entire margins, not rigid; seeds small, with thin wings. A graceful tree of pyramidal habit and horizontal branches, sometimes attaining a height of over Ioo fect, with a diameter of two feet. There are several varieties of value for ornamental planting.

Distribution.-In the United States it is found in Northern Maine and westward in certain localities to Montana. It is also found in Newfoundland and Labrador, westward to the Rocky Mountains and nortl to Alaska. It reaches its best development growing in moist soil. It is found more or less throughout Northeastern Minnesota, but is especially abundant near the northern boundary.

Propagation.--The species is grown from seeds and the varieties by grafting. The seeds of the White Spruce are often infested by a weevil, which fact, together with their small size and the difficulty in gathering them, makes them high in price and often difficult to obtain. On account of the ease with which Norway Spruce seeds are obtained they are preferably sold by nurserymen.

Properties of Wood-Light, soft, compact, straight grained, of only moderate strength, nearly odorless; color, light yellow; sapwood hardly distinguishable. Specific gravity, 0.405I; weight of a cubic foot, 25.25 pounds.

Uses.-The White Spruce is one of the best evergreens for planting in this section, generally rather slow in growth, but forming pretty conical trees. The wood is largely used for general construction, spars, canoe and boat building, oars, paddles, tripods, step ladders, baseball bats, flooring, sounding boards for musical instruments, paper pulp, nail kegs, casks, lime and cement barrels, butter tubs and pails, excelsior and charcoal. It is not distinguished from Black Spruce in commerce. Spruce chewing gum is, in part, the product of this tree.

Picea mariana. ( $I$. nigru.) Black Spruce. Double Spruce.

Leaves deep green, short, about one-half inch in length, scattered thickly over the branches, falling during the fourth and fifth seasons. Cones ovoid, oblong, one to one and three-quarter inches long, persistent; scales very thin, rigid, with an 

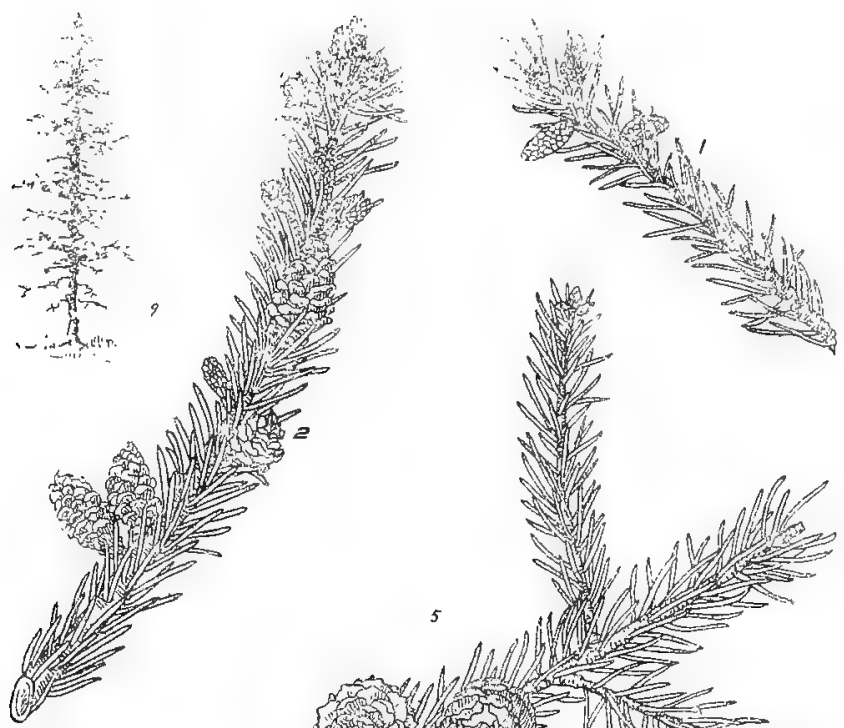

5
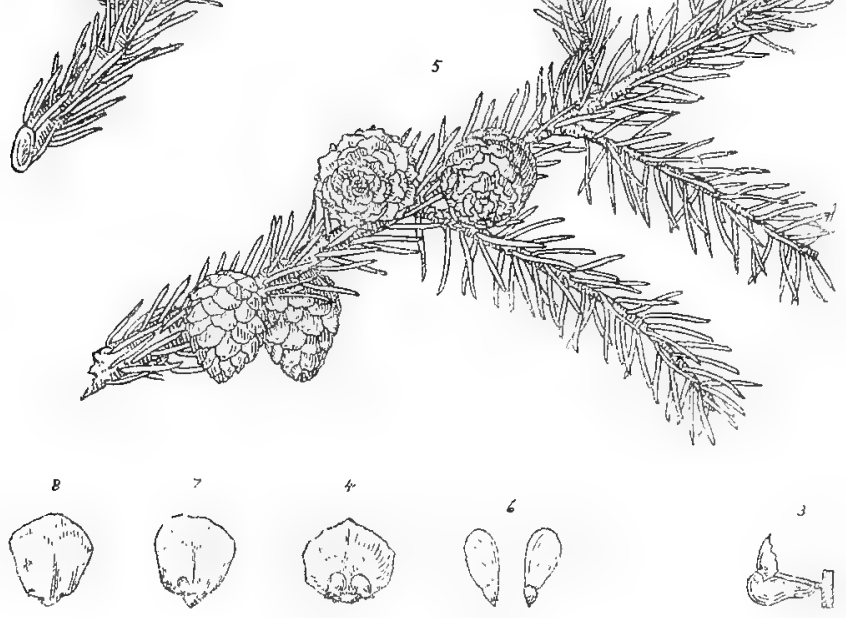

Plate 9. Picea mariana. Black Spruce.

r. Branch bearing staminate flowers, one-half natural size. 2. Branch kearing pistillate flowers, one-half natural size. 3. Anther, enlarged. 4. Scale of pistillate flower, enlarged. 5. Branch bearing ripened cones, onehalf natural size. 6. Seeds, enlarged. 7. Scalc, front view, natural size. 8. Scale, rear view, natural size. 9. General view of tree as found in the muskegs of northern Minnesota. 
uneven margin; seeds small, with rigid wings. In Maine and elsewhere a large tree, forming valuable forests. In this section occasionally a large tree, but generally small, and seldom cut for timber.

Distribution.-Northern United States, Canada and northward, forming large forests in some sections. In Minnesota it is found in the Wlite Pine belt, though most common in the extreme northern portions. Generally found in swamps known as musliegs, on which the trees, with their roots half submerged, make a very slow growth. One specimen, the rings of which showed it to be seventy-three years old, was only one and one-eighth inches in diameter.

Propagation.-By seeds. When plants are desired they may be easily gathered from the woods in this state.

Propertics of Wood.-Light, soft, strong, compact and satiny; color, reddish with nearly white sapwood. Specific gravity, 0.458 ; weight of a cubic foot, 28.57 pounds.

Uses.-The Black Spruce is a poor ornamental tree, as it soon loses its lower branches, which with its dead persistent cones and dark-colored bark makes it appear unsightly. It is also a short-lived tree on dry land in this section. Most of the Christmas trees in our market of recent years have been of this kind, although the Balsam Fir is also used. The wood is used here to some extent and elsewhere in large quantities for paper pulp, for which purpose it is highly esteemed. In the eastern range of this tree its wood is largely used for flooring, masts, spars, general house and ship building, sounding boards for instruments, and for any other purpose where a light, stiff wood is needed. The gum which this tree exudes is valued as chewing gum, and the gathering of it is quite an industry in some sections. The essence of spruce is made by boiling the young branches in water and evaporating the decoction. It is used in the manufacture of spruce beer, which is a pleasant and wholesome beverage, and it is sometimes useful on long sea voyages as a preventive of scurvy. 


\section{Picea parryana. ( $\Gamma$. pungens.) Colorado Blue Spruce.} Silver Spruce. White Spruce. Blue Spruce.

Leaves about one inch long, rather broad, rigid, stout, pointed, tustrally incurved, falling during sixth and seventh years; branchlets smooth and shining. Cones light brown in color, very priclily, three to five inches long, cylindrical, with more or less elongated thin truncate wavy scales; seeds small but larger than those of $P$. engclmanni. A large tree, of strictly conical growth and spreading branches. The seedlings vary greatly in color, from a bright glaucous blue to dark green. The form having light colored foliage has become known as Picka pungens glauca.

Distribution.-Valley of the Wind river south through the mountain ranges of Wyoming, Colorado and Utah.

Propagation.--The species by seeds and the varieties by grafting on the same or other species.

Properties of Wood.-Soft, weak, light, close grained, satiny; color, very light brown, or often nearly white; sapwood hardly distinguishable. Specific gravity, 0.374; weight of a cubic foot, 23.3 pounds.

Uses.-The Colorado Blue Spruce is a handsome ornamental tree that is now very popular with tree planters in this section and elsewhere in the Northern States. It is very ornamental when young, but its later development is often not so pretty, and if not growing rapidly when older it has a rather ragged appearance; of slower growth than the white or Norway Spruce, very hardy and well worthy of trial in a small way. The wood is used within its range for fuel and timber, although it is nowhere very abundant. A hedge of this tree may be grown so close that even a dog cannot get through, as the sharp-pointed leaves are excecdingly pungent.

Picea engelmanni. Engelmann Spruce. Mountain Spruce. White Spruce.

Leaves three-quarters to one inch long, pointed, but not as prickly as $P$. parrayana; branchlets pubescent. Cones solitary, one and one-half to two inches long; scales rhombic, the upper ends appearing as though broken off: seeds smaller than those of $P$. parrayana. In form and color of foliage this species resembles 
P. parrayana, but makes a larger tree, often growing Ioo feet in height. In some nurseries it is customary to tell the Colorado Blue Spruce from the Engelmann Spruce by grasping the top of the young tree with the hand, when, if it pricks only a little, the tree is set down as Engelmann Spruce, while if the pricking is unendurable, it is called Colorado Blue Spruce. This method of determining the species generally gives correct results, but a certain way is to examine the bark of the new growth between the needles which, if slightly downy, indicates the Engelmann Spruce, and if smooth and shining, the Colorado Blue Spruce.

Distribution,-Northern New Mexico, Arizona, Colorado, northward to British Columbia, in the mountains at high elevations.

Propagation.-By seeds.

Properties of Wood.-Very light, soft, weak, very close straight grained, compact, satiny; color, pale yellow, tinged with red; sapwood hardly distinguishable. Specific gravity, 0.3449; weight of a cubic foot, 2 T.49 pounds.

Uses.-The Engelmann Spruce is a valuable ornamental and timber tree, resembling the Blue Spruce, but it has been tried to only a limited extent. It is the most valuable timber tree of the central Rocky Mountain region, where it forms extensive forests. In Colorado it is manufactured into lumber, and is largely used for fuel, charcoal, etc. The bark is rich in tannin, and in Utah is sometimes used for tanning leather.

\section{Picea exce1sa. Norway Spruce.}

Leaves long, deep green in color, falling during the fifth season. Cones cylindrical, large, five to seven inches long, light colored, often very conspicuous in the tops of the trees. A fine, large conical tree, with stout branches and generally pendulous branchlets. There are numerous horticultural varieties, some of the dwarf forms growing only three to five feet high.

Distribution.-Native of Northern Europe and Asia.

Propagation.-Easily grown from seeds, which are used in large quantities. The varieties are propagated by grafting on the species.

Propertics of Whood.-Light, strong and fine grained. Specific gravity, air dried, 0.47 . 


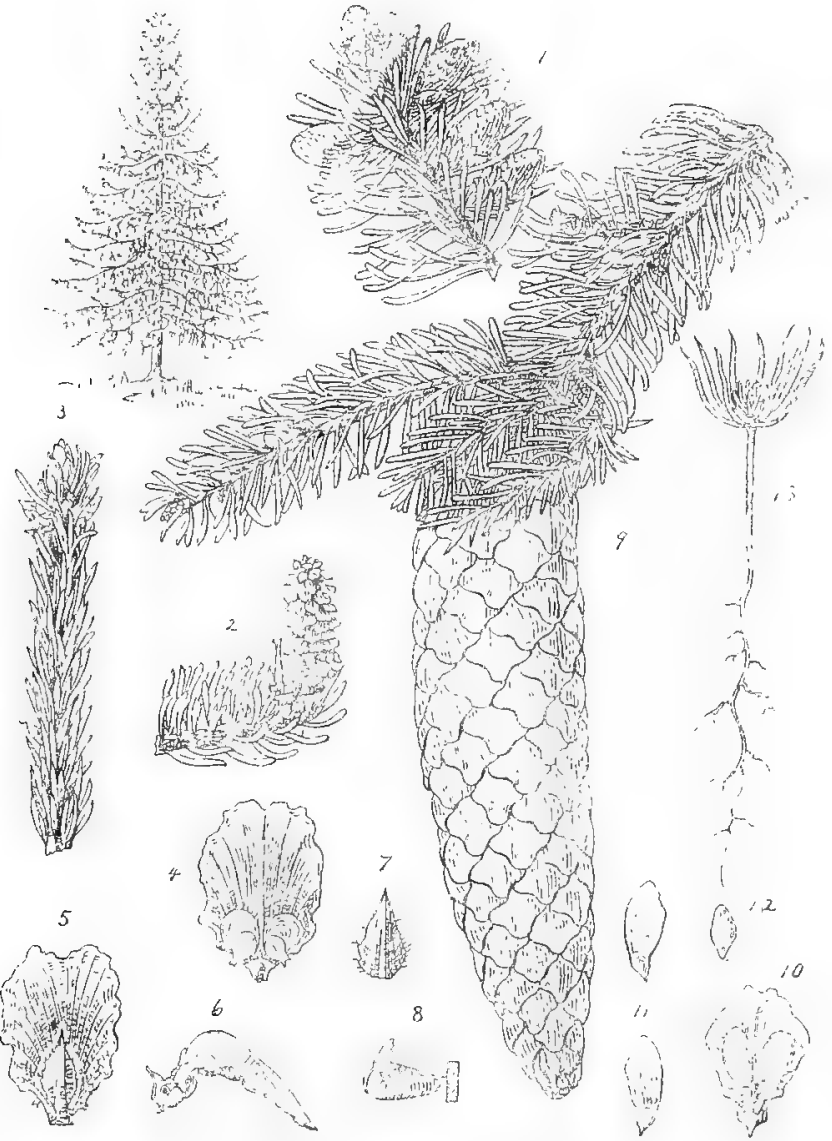

Plate Io, Picea excelsa. Norway Spruce.

x. Branch bearing staminate flowers, one-half natural size. 2. Branch bearing pistillate flower, one-half natural size. 3. Winter branch, showing buds, one-half natural size. A. Scale of pistillate flower, front view, enlarged. 5. Scale of pistillate flower, rear view, enlarged. 6. Scale of pistillate flower, side view, enlarged, 7. Bract of pistillate flower, enlarged. 8. Anther, side view, enlarged. 9. Fruiting branch, one-half natural size. Io. Scale of cone with saeds attached, one-half natural size. Ir. Seeds with wings attached. 12. Seed, natural size. 13. Seedling, one-half natural size. 14. General view of tree showing drocping branches and pyramidal form. 
Uses.-The Norway Spruce has been largely planted in the more Eastern States, and is a general favorite, as it grows more rapidly than any of our native spruces and is very graceful and stately in form. There are many plantings of this tree in Minnesota, and they are holding on well; yet the White Spruce is a safer tree for general planting, and generally grows nearly as fast. Since it is more difficult to obtain the seed of the White Spruce, it is probable that the Norway Spruce will continue to be planted. The wood of Norway Spruce is much used in Europe, and is largely grown there for paper pulp, fuel and timber. The young branches are used in making the essence of spruce, as described under Black Spruce. The bark is used to a considerable extent in E,urope for tanning purposes.

\section{Genus TSUGA.}

A genus of but a single species in our section.

\section{Tsuga canadensis. Hemlock.}

Leaves linear, flat, one-half inch long, obtuse, whitened beneath, short petioled and diverging from the sides of the branchlet so as to make it appear flattened, falling during second and third years. Cones small, scarcely longer than the leaves, pendent from the tips of the branches of the preceding year, persistent, with inconspicuous bracts; seeds quite small, with thin wings, maturing the first year. A large, graceful tree. There are several horticultural varieties in cultivation.

Distribution.-From Nova Scotia west to Minnesota, south as far as Delaware and along the mountains to Alabama. Scarcely found in Minnesota, though common near its eastern borders, in Wisconsin. A few specimens are said to have been found near Cloquet, and perhaps occasionally elsewhere near the eastern boundary.

Propagation.-The species by sceds and the varieties by grafting on the species.

Properties of Wood-Light, soft, brittle, coarse grained and not very easily worked; color, very light red or brown, with still lighter colored sapwood. Specific gravity, 0.4239; weight of a cubic foot, 26.42 pounds. 
Uses.-The Hemlock is unsafe for general planting in this section, as it is very liable to injury from cold winds and drouth, but in extreme Fiastern Minnesota, on moist soil and in protected locations, it has proved desirable for ornamental planting. The wood of the Hemlock is used for framing and general construction purposes where fine finish is not needed, wood work, furniture, picture moldings, ties, fencing and charcoal. It is loose, and warps badly when exposed to the air, but stands fairly well in contact with the ground. The bark is used in immense quantities for tanning leather, and is largely obtained for this purpose in Wisconsin.

\section{Genus PSEUDOTSUGA.}

A genus of a single species midway between the firs and hemlock. Leaves somewhat two-ranked by a twist at the base. Cones upright, maturing the first season.

Pseudotsuga taxifolia. (P. douglusii.) Douglas Spruce. Red Fir. Douglas Fir.

Leaves linear, distinctly petioled, mostly blunt or rounded, nearly an inch long on old trees, but a little longer on young thrifty trees, falling during fifth season; in color generally a rich dark green, but some specimens occur on which the foliage is a light glaucous blue. Cones two to four inches long, cylindrical; bracts toothed, protruding above the scales, and giving a fringed appearance to the cones; seeds triangular, reddish on the upper side, flat, and white on the lower side. A gigantic tree, sometimes 200 to 300 feet in height. When young it is seldom very symmetrical in form, and is likely to produce heavy limbs unless severely crowded.

Distribution.-Throughout the Rocky Mountains and the mountains of California, reaching its greatest height in Oregon. Propagation.-One of the easiest conifers to grow from seeds, which may be readily obtained from the Rocky Mountain region.

Propertics of Wood.-Hard, strong, durable, varying greatly with age and conditions of density, quality and amount of sapwood; difficult to work; color varying from light red to yellow; sapwood nearly white. Specific gravity, 0.5157; weight of a cubic foot, 32.23 pounds. 


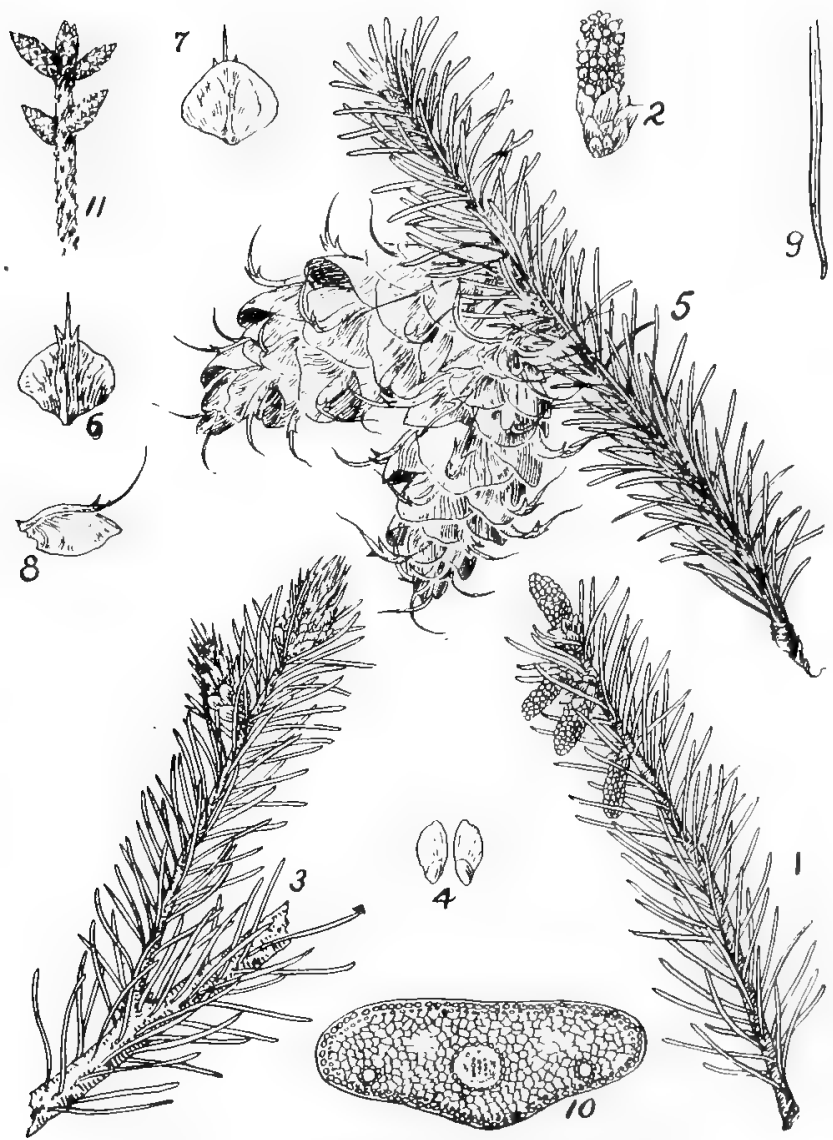

Plate I. Pseudolsuga tarifolia. Douglas Spruce.

I. Lranch bearing staminate flowers, one-half natural size. 2. Stam inate flower, enlarged, 3. Branch bearing pistillate flowers, one-half natural sıze. 4. Seeds with wings attached, one-half natural size. 5. Fruiting branch, one-half natural size, 6. Cone-scale, lower side, showing bract, one-half natural size. 7. Cone-scale, upper side, showing seed scars, onehalf natural size. 8 . Scale of cone, side view, showing bract, one-half natural size, 9. Needle, natural size. 10. Cross section of necdle, I1. IVinter buds. 


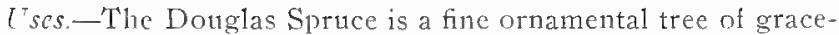
ful proportions, good color, rapid growth and wonderful hardiness. Probably one of the most valuable evergreens for general planting in Minnesota, and apparently destined to partly supersede the White and Norway Spruce for this purpose. It is also the most promising foreign tree for sowing on the cut-over timber lands of this section, and should be largely experimented with for this purpose. Two varieties are distinguished by lumbermen, the Red and the Yellow Fir, the former is coarse grained and dark colored, and considered less valuable than the latter. Both kinds are largely manufactured into lumber, and used for all kinds of construction, railway ties, piles, etc.

\section{Genus ABIES.}

Trees of pyramidal habit. Leaves sessile, flat, with the midrib prominent on the lower surface, appearing two-ranked by a twist near the base, giving the horizontal branches a flat appearance. Cones erect on the upper side of the branches, maturing the first year, when the scales fall, leaving the naked axes standing erect on the branches.

\section{Abies balsamea. Balsam Fir. Balsam.}

Leaves narrow, linear, one-half to three-quarters of an inch long, dark green above, whitened on the under side, falling during the fifth season. Cones cylindrical, two to four inches long, and one inch thick, violet colored; bracts shorter than the scales and tipped with a slender point. The branches grow out usually in whorls of about five each, with great regularity, and diminishing in length from below upwards, forming a symmetrical pyramidal top. This is a very striking habit, and gives to the Balsam Fir swamps a characteristic aspect. Tree slender, sometimes eighty feet high.

Distribution.--Northeastern United States and Canada, southward to Virginia, westward beyond the Mississippi and far north to Hudson Bay and northwest to Rocky Mountains; growing in swamps and cold damp woods. In Minnesota almost confined to the northeastern half of the state, extending south to Chisago and Isanti counties. 


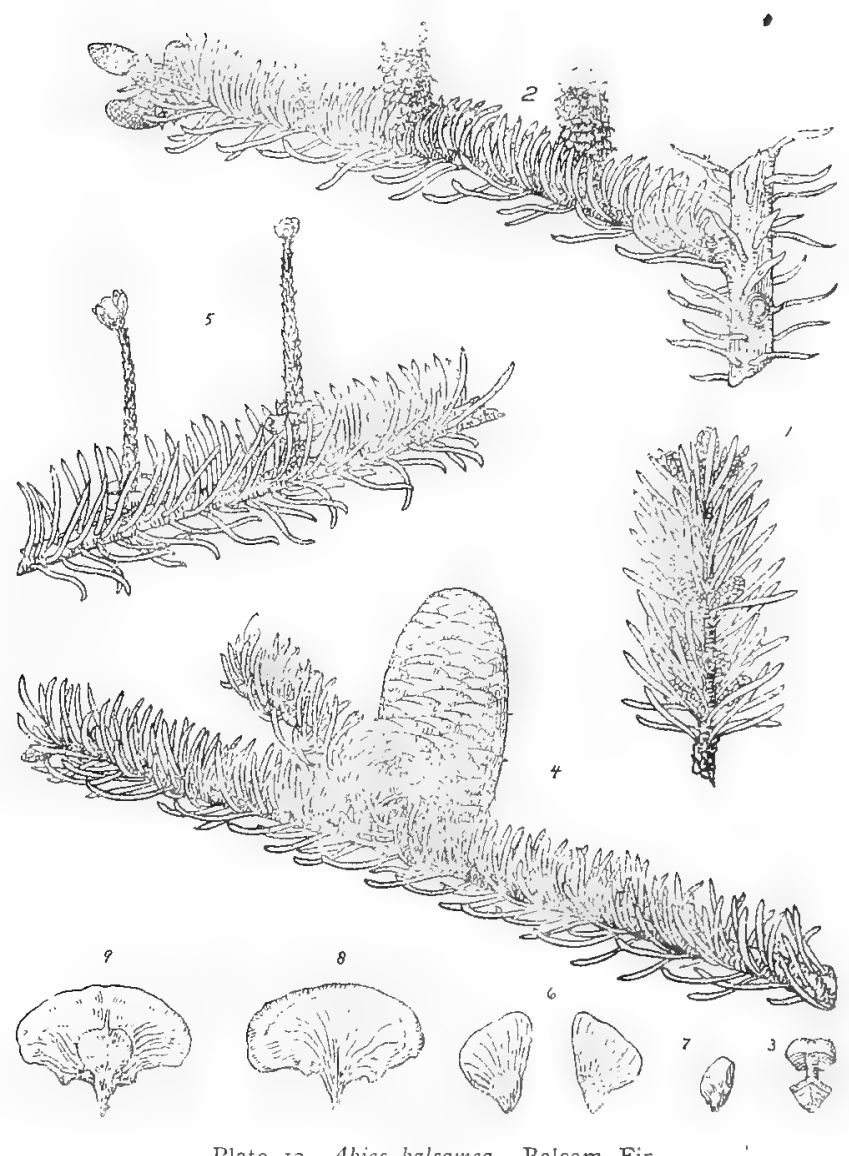

Plate i2. Abies balsamea. Balsam Fir.

I. Branch bearing staminate flowers, one-lalf natural size. 2. Branch bearing pistillate flowers, onc-half natural size. 3. Anther, open, rear view, enlarged. 4. Branch bearing mature cone, one-half natural size, 5. Branch bearing axes of cones atter scales have fallen, one-half natural size. 6 . Seeds with wings attached, natural size. 7. Seed, enlarged. 8. Scale of cone, upper view, natural size. 9. Scale of cone, lower view, natural size. 
Propagation.-The species by seeds, horticultural varieties by grafting.

Properties of Wood-Very soft, light, weak, not durable, with distinct coarse grain, color whitish with a slightly reddish tint toward the heart. Specific gravity, 0.3819: weight of a cubic foot, 23.8 pounds.

Uses.-The Balsam Fir is very striking and very pretty when young. On moist, retentive soil it holds on well in this section but is poorly adapted for general planting, and should be used sparingly, if at all. The wood is of very little value, and is seldom sawed into lumber, but is used for laths, shingles, boxes. packing and pulp making. It furnishes Canada Balsam, which is an aromatic oil-like resin of considerable commercial importance. It is obtained by puncturing the vescicles (blisters) formed under the bark of the stem and branches, which contain from a few drops to a half teaspoonful each. This is used in the arts and medicinally in chronic bronchial and catarrhal affections. The smaller branches exhale a delightful odor, and are preferred by campers in the woods for beds.

\section{Abies concolor. White Fir. Silver Fir.}

Leaves mostly obtuse, pale green, one to two and one-half inches long, with two resin ducts close to the epidermis of the lower surface. Cones oblong, cylindrical, three to five inches long, one to one and three-quarter inches in diameter, pale green or sometimes dull purple. A large tree.

Distribution.-From Arizona to Southern Colorado, Utah, California and Oregon.

Propagation.-By seeds.

Propertics of Wood.--Very light, soft, coarse grained, compact, not strong; color very light brown or nearly white, with somewhat darker sapwood. Specific gravity, 0.3638; weight of a cubic foot, 22.67 pounds.

Uses.-The White Fir is justly gaining in popularity as an ornamental evergreen. When young it often-spreads out on the ground, and seems slow to make an upward growth, but after a few years it takes on a good broad conical form. Its rather long leaves of a pale green color, and its light bark and good form give it a very pretty appearance. It has stood for more than ten 
years on the grounds of the Minnesota Experiment Station without serious injury, and has made pretty specimens about six feet high and nearly as broad. It undoubtedly prefers a moist soil, though it has done very well on gond retentive upland. The wood is of very little value, but is used within its range for cheap packing cases, etc.

\section{Genus THUJA.}

Flowers mostly monoecious, on different branches in small terminal catkins, opening in May; anther cells, two to four. Scales of the pistillate flowers, eight to twelve. Ovules, two to four. Fruit an erect, dry, loose cone, from one-third to one-half of an inch long, maturing in the autumn of the first season, but remaining on the branch until the appearance of the new growth the following spring. Seeds oval, about one-eighth of an inch wide, and winged all round. Leaves evergreen, small, awl or scale shaped, closely imbricated and appressed so as to make a flat two-edged branchlet. On the leading shoots the leaves are often one-quarter of an inch long. A small genus of evergreen trees and shrubs. Only one species, the Arborvita, comes within our range.

\section{Thuja occidentalis. Arborvitæ. White Cedar.}

A tree fifty or sixty feet high, seldom two feet in diameter, but occasionally much larger than this. There are many varieties, the most of which are characterized by some peculiar habit of the branches or by peculiar coloring of the leaves.

Distribution.-From the valley of the St. Lawrence to northern Pennsylvania and North Carolina, and from the Atlantic to Central Minnesota. A very common tree in cold swamps and along river banks and lake shores where the soil is moist. In Minnesota very common in the northeastern portion, west to Roseau county and south to the sonth shore of Mille Lacs and the mouth of Snake river. It also occurs occasionally as far south as the southeastern portion of Winona county. In some sections, as along the Mississippi river, in the northern part of Aitkin county, it covers large areas with an almost impenetrable growth, which are known as cedar swamps. Not found in the western or southwestern parts of this state. 

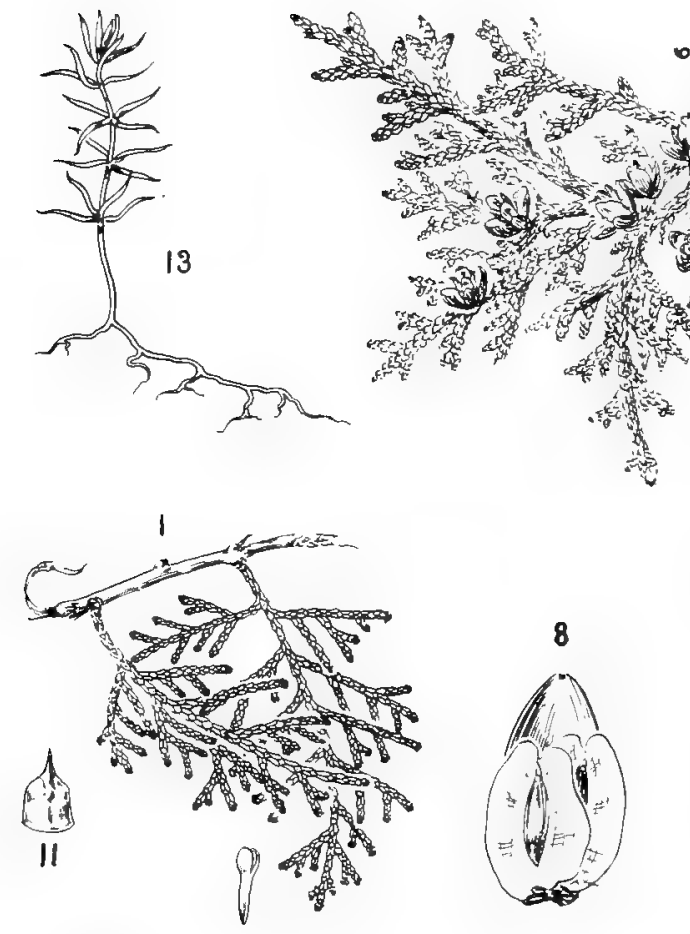

12

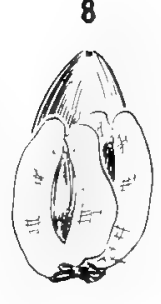

9
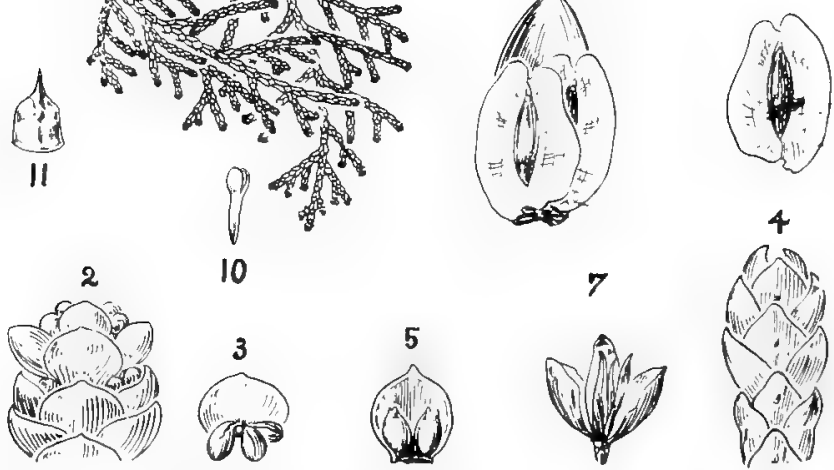

Plate 13. Thuja occidentalis. Arborvitae.

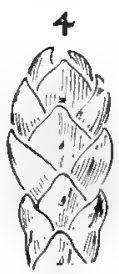

I. Flowering branch, one-half natural size. 2. Staminate Hower, enlarged. 3. Stamens, enlarged. 4. Pistillate flower, enlarged. 5. Scale of pistillate flower, enlarged. 6. Fruiting branch, one-half natural size. 7. Cone. 8. Scale with seed attached, natural size. 9. Longitudinal section of seed. 10. Embryo, II. A leaf, natural size, I2. Cross section of a branch, reduced. I3. Seedling, reduced. 
Propagation.-The seeds of the Arborvite grow readily, but the seedlings must be protected from the full sunlight for the first year. The many varieties are propagated from cuttings in a cool greenhouse or frame, and root very slowly.

Properties of Wood.--Very light, soft, close and often spirally grained, very durable in contact with the snil, light yellowish brown in color, turning darker on exposure; sapwood thin and nearly white. Specific gravity, $0.3 \mathrm{~T} 64$; weight of a cubic foot, I9.72 pounds.

Uses.-The Arborvite is a popular plant for evergreen hedges, as it forms a close compact top when pruned, and is of a bright green color. It stands well in this section when growing on good retentive land, but suffers from a deficiency of moisture in the soil and occasionally from severe winds in winter, and on this account does best in somewhat sheltered locations. The wood is largely used for telegraph poles and cross arms for same, fence posts, shingles, paving blocks and for the siding of light weight boats and canoes, also for tubs, pails, tanks and dash churns. The thick layers of the sapwood, which are easily separated, are manufactured by the Canadian Indians into baskets and are used to strengthen birch bark canoes. The fresh branches often serve the purpose of brooms. A decoction or tincture of the young branches of this tree is used for intermittent fevers, coughs, scurvy, rheumatism, etc., and externally to remove warts. It is also used in homeopathic practice.

\section{Varictics.-}

Thuja occidentalis wareana. ( $T$. sibivich) Siberian Arborvitæ.

This is of a dark rich green color and compact habit. It is one of the best kinds for favorable locations, but not so hardy as the species or variety next described.

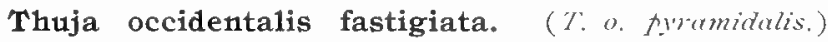
Pyramida1 Arborvitæ.

Branches and leaves very distinct, fine and handsome. Form upright, regular, pyramidal or almost columnar. Valuable for variety, probably as hardy as the species and hardier than most of the varieties. 


\section{Thuja occidentalis aurea. Douglas Golden Arbor- vitæ.}

In habit like the species, but with a bright yellow color to the leaves; conspicuous and pretty; rather more tender than the species and occasionally sunscalds severely.

\section{Genus JUNIPERUS.}

A large genus of evergrcen trees and shrubs. Flowers naked, dioecious, axillary or terminal. Fruit a fleshy cone, in some species resembling a berry or drupe more than a true cone.

Juniperus virginiana. Red Juniper. Red Cedar. Sarin.

Leaves small, evergreen, opposite, scale-like and awl-shaped. the former sort minute, the latter about one-half inch long and spreading. Flowers dioecious, or very rarely monoecious; the small solitary catkins upon lateral twigs appearing in this section in May. Fruit a small dark colored fleshy berry-like cone with a light bluish bloom, maturing late in the fall of the first year. Fruit, leaves and wood are aromatic and resinous.

Distribution.-It is the most widely distributed conifer of North America. It ranges from the Atlantic to the Rocky Mountains and from Northern Minnesota to Florida. In Western Louisiana and Texas it makes a tree sometimes eighty feet high and three or more feet in diameter, but it is usually very" much smaller. In this section it is nowhere abundant, rarely thirty feet high, and generally short and bushy. In the north of its range it grows on dry land, while in the south it is often found in swamps, but it is not particular about soil.

Propagation.-By seeds. For planting the berries should be gathered in autumn, then bruised and mixed with an equal or greater bulk of wet wood ashes or strong lye. In three weeks the ashes or lye will have cut the resinous gum so that the seeds can be washed clean. They should then be stratified over winter, and be sown in the spring, as recommended for coniferous seeds in general. The bed should be covered with mulch for the first season, as the seeds do not usually start until the second year. There are a number of varieties which may be propagated by cuttings of the young wood or by layers. 


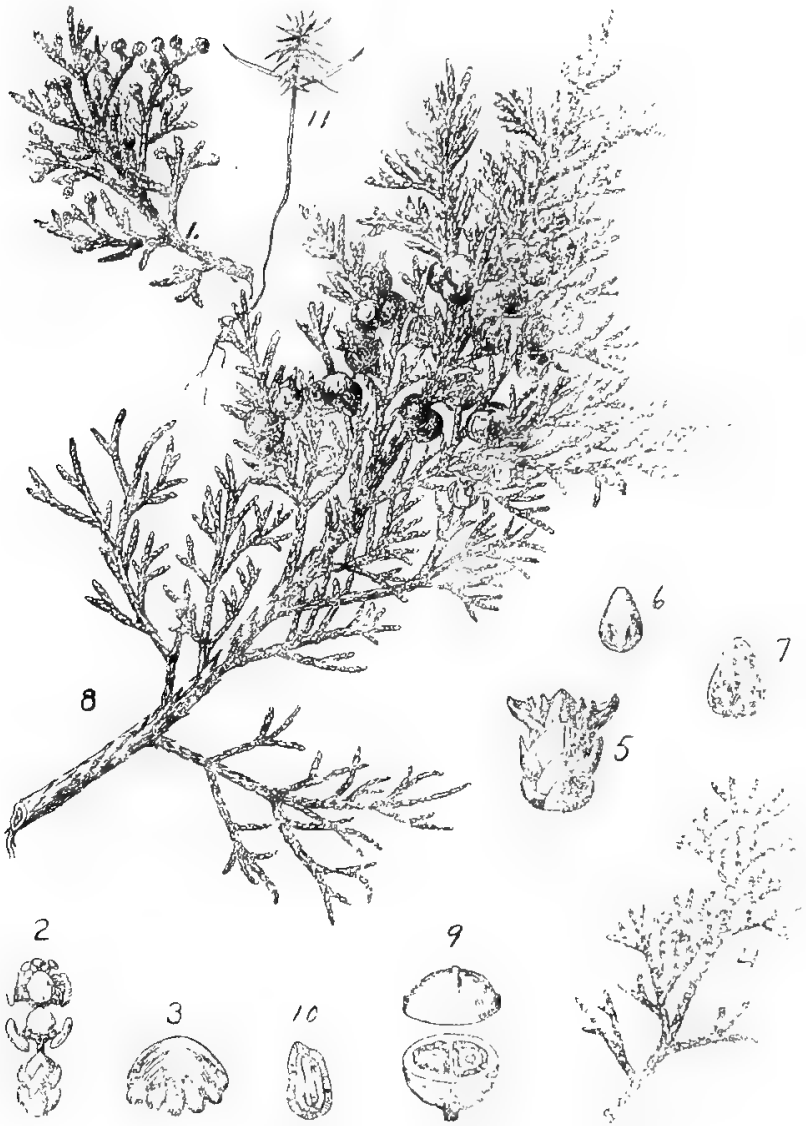

Plate r4. Juniperus virginiana. Red Cedar.

1. Flowering branch of staminate tree, one-lialf natural size. 2. Staminate flower, enlarged. 3. Stanen, enlarged. 4. Flowering branch of pistillate tree, one-half natural size. 5. Pistıllate flower, enlarged. 6. A seed, unlarged. 7. Scale of pistillate flower, enlarged. 8. Fruting branch, onehalf natural size. 9. Transverse sections of irut, enlaryed. Io. Longitudinal section of seed, cnlarged, II, Secdling, one-half natural size, 
Properties of Wood.-Light, soft, close grained, but brittle and not strong, dull red, with thin, nearly white, sapwood, very iragrant, easily worked and extremely durable in contact with the soil. Specific gravity, 0.4926; weight of a cubic foot, 30.7 poinds.

Uses.-The Red Cedar is a valuable ornamental tree for this section, of rather slow growth except when young, but very hardy and durable. It makes an excellent low windbreak or hedge, and bears close pruning without injury. The leaves generally turn brown by the latter part of winter. The wood is used where great durability in contact with the soil is required, as for telegraph poles and fence posts, for interior finishing, cabinet making and for lining chests and closets in which woolens are preserved against the attacks of moths. It is almost the only wood

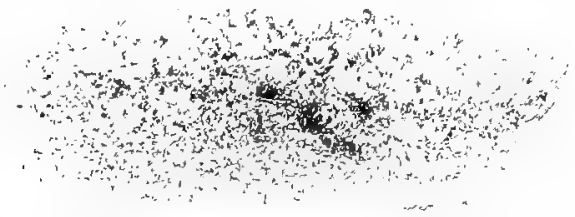

Figure 49. Common Juniper.

used in the manufacture of lead pencils, and is the most highly esteemed of any wond for the manufacture of pails, tubs, brush and tnol handles, faucets. A decoction of the fruit and leaves is occasionally used medicinally and an infusion of the berries as a diuretic and in homeopathic remedies. Oil of Red Cedar is distilled from the leaves and wood, and is used principally in perfumery.

Juniperus communis. Dwarf Juniper. Common Juniper. Trailing Juniper.

Leaves in whorls of three, pointed at the base, linear, lanceolate, pointed, dark green on the lower side, channelled and glatcous white on the upper side, one-third to one-half inch long, spreading at nearly right angles to the branches, have a strong, unpleasant, slightly astringent taste, during winter turn to a rich bronze color on the lower surface and remain on tree for five or six years. Flowers open late in spring. Fruit during the first 
year does not enlarge, but resembles the flower bud, and does not ripen until the autumn of the third season, when it becomes fleshy and berry-like. Sometimes a low, crooked tree, but in our range, and commonly elsewhere in the United States, a low spreading shrub, often forming dense mats three or four feet high. In Southern Illinois it frequently attains a height of twenty-five feet and forms trunks eight to ten inches in diameter. The foliage of the tree form is smaller than that of the dwarf.

Distribution.-The common Juniper is the most widely distributed tree of the northern hemisphere. In North America it ranges from Labrador and Greenland to Pennsylvania on the east, across the continent to Alaska and Northern California, and along the Rocky Mountains to Northern Nebraska, Western Texas and Arizona. In the old world it is widely spread over Northern and Central Europe and Asia. In Minnesota often found along the bluffs of rivers.

Propagation.-By seeds, as for Red Cedar.

Properties of Wood.-Hard, close-grained, light brown with whitish sapwood, susceptible of a fine polish, very durable in contact with the soil.

Uses.-The great hardiness and pretty dwarf habit of the common Juniper make it desirable in some situations for ornamental planting. It readily yields itself to shearing. Many fine specimens may be seen in the parks of St. Paul and Minneapolis, and elsewhere. In India the wood and twigs are burned for incense, and on the high Himalayan passes are used for fuel. The fruit is gathered in Europe in large quantities for flavoring gin, and is occasionally used in medicine.

Varictics.-There are many varieties that are used in ornamental planting in this country and in Europe, some of which are distinguished by the color of the foliage, and others by the habit of growth, which may be columnar or pyramidal or dwarf and compact. Some of these varieties in English and Dutch gardens are trained into the shapes of globes, bowls, animals and other fantastic forms. The Swedish Juniper, one of the most distinct varietics, has erect branches, which form a narrow pyramidal head. 


\section{JUGLANDACEAE. WALNUT FAMILY.}

Trees with alternate, pinnately-compound leaves, no stipules. Flowers monoecious; the staminate in catkins with or without an irregular calyx and several stamens; the pistillate solitary or in clusters of two to five, their common peduncle terminating the shoot of the season; calyx, three to five lobed; stigmas, sessile, two-lobed, persistent. Ovary one-celled or incompletely two to four-celled, with a single ovule erect from its base; ripens into a large fruit, the bony inner part of which forms the shell of the nut and the fleshy outer part, the husk. Seed four-lobed, filled with fleshy oily embryo and large crumpled or corrugated cotyledons.

\section{Genus JUGLANS.}

Leaves odd-pinnate with numerous serrate leaflets; petioles long, grooved on the upper side, gradually enlarged towards the base. In falling, the leaves expose large, conspicuous, elevated, obcordate, five-lobed scars. Flowers monoecious, opening in late spring after the leaves; the staminate in catkins, solitary or in pairs from the wood of the preceding year, each with eight to forty stamens on very short filaments and a three to six-lobed calyx; the pistillate solitary or several in a cluster on a branch of the season; calyx four-toothed, bearing in its sinuses four small petals; stigmas two, somewhat club-shaped and fringed. Fruit large, drupaceous, marked at the apex with the remnant of the style and covered with a fibrous, spongy, somewhat fleshy, indehiscent epicarp (shuck) and a rough, irregularly furrowed endocarp (shell); embryo edible. Trees with sweet, watery juice, furrowed, scaly, resinous, aromatic bark and pith that separates into thin transverse layers. To this genus belong our native Black Walnut and Butternut, and the English Walnut (J. regia) of commerce, which has been long in cultivation, and is probably a native of Asia Minor. The Japanese use in large quantities a walnut belonging to this genus. The species here described have long tap roots and but few lateral roots. For this reason they do not transplant easily except when very young, or unless the tap roots are cut when the seedlings are small. In the latter case 
lateral roots are produced which may be saved in transplanting. It is desirable to plant the nuts where the trees are to remain.

\section{Juglans nigra. Black Walnut.}

Leaves twelve to twenty-four inches long, leaflets in seven to eleven pairs, ovate-lanceolate, lower surface and petioles minutely glandular pubescent, aromatic when bruised. Fruit odoriferous, spongy, usually globose, but occasionally oval, solitary or in pairs, one and one-half to two inches in diameter, with a rough dotted surface not as deeply furrowed as the Butternut. A large tree, sometimes too feet high and four to six feet or more in diameter. When growing in the open it develops a round head and casts a dense shade.

Distribution.-From Western Massachusetts to Southern Minnesota and Eastern Kansas, south to Western Florida and the valley of the San Antonio river in Texas. In Minnesota formerly a common tree along the creek and river bottoms of the southern part of the state, and in a few locations is still rather abundant.

Propagation.-By seeds, which should be gathered in autumn, kept stratified with moist leaves or sand over winter, and sown in the spring. Also grown to some extent by planting the seeds in attumn where the trees are to remain. The varieties are grown by grafting. Old trees may be top grafted like apple trees.

Propertics of IVood.-Heavy, hard, strong, rather coarse grained, easily worked, and very durable in contact with the soil. Color a rich, dark brown, with a thin, light sapwood. The finished wood has a satiny surface, and will take a beautiful polish. Specific gravity, 0.6II5; weight of a cubic foot, 38. II pounds.

Uses.-The Black Walnut is frequently used for ornamental planting in the parks of the United States and Europe. In this section, however, we reach the northern limit of its range, and find that it is not generally satisfactory when planted in the open, but often does well in protected locations and on deep alluvial soils. It can sometimes be used to advantage in timber plantings in the southern half of Minnesota when surrounded by some hardier tree to protect it from the wind. It is liable to sun-scald when the trunk is exposed in this section. Many large plantations of this tree have been made in Iowa, Southern Minnesota 


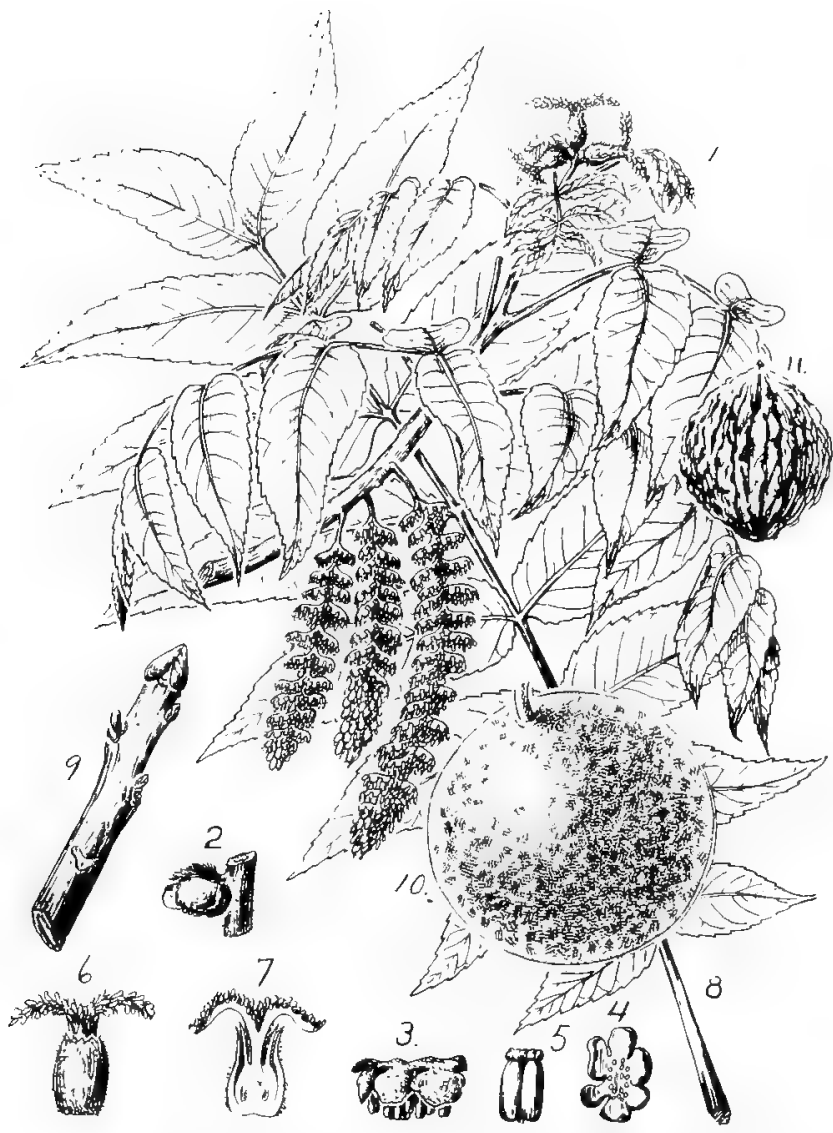

Plate 15. Juglans nigra. Black Walnut.

I. Flowering branch, one-half natural size. 2. Staminate flower before anthesis, enlarged. 3. Staminate flower, enlarged. 4. Perianth of staminate flower, displayed, enlarged. 5. Stamen, enlarged. 6. Pistillate flow. er, natural size. 7. Longitudinal section of pistillate flower, natural size. 8. Leaf, reduced. 9. Winter branchlet, one-half natural size. ro. Mature fruit, one-half natural size. II. Walnut with husk removed, one-half natural size. 
and elsewhere. In good locations the young trees grow rapidly, and soon make good, durable fence posts or nut-bearing trees. It is one of the most valuable woods found in America, and is largely used in cabinet making, interior finishing, flooring, gun stocks, furniture, saw handles, veneering, and formerly in boat building and for fence rails and posts, for which it was highly esteemed. It is used in the making of school apparatus, artists' goods, billiard tables, carpet sweepers, clock cases, butter and lunch plates. This timber is now very scarce. The nuts are much sought for, and find ready sale. They are oily, and have a sweet, pleasant taste, but become rancid with age. The husks are used for dyeing, and the leaves are supposed to possess medical properties. It was formerly believed that this tree could be grown at a profit for its valuable timber, but it has been found that the wood does not take on its dark, rich, even color until very old, but remains for many years a mixture of yellow and brown; hence its cultivation for timber has not proved so profitable as was expected. It will, however, make board timber in about twenty-five years.

\section{Juglans cinerea. Butternut.}

Leaves fifteen to thirty inches long; leaflets eleven to nineteen, oblong, lanceolate, pubescent, especially underneath; petioles and branchlets clammy pubescent. Fruit two to three inches long, very clammy pubescent, of a rather pleasant odor when fresh, oblong, pointed, two-celled at the base; nut shell deeply and irregularly furrowed with rough, ragged ridges; embryo very rich in oil and of a delicious flavor. A tree occasionally Ioo feet high and three feet in diameter in forests, but generally much smaller. Where it grows in the open it forms an immense spreading top. .

Distribution.-From the valley of the St. Lawrence river to Eastern Dakota, southward to Northern Georgia and Northeastern Arkansas. Not common south of the Ohio river. In Minnesota common in the southern part except far southwest, extends north to Aitkin county, where trees have been found two fect or more in diameter.

Propagation.-Same as for Black Walnut.

Properties of Wood.-Light, soft, not strong, rather coarse grained, easily worked, with a satiny surface capable of receiving 


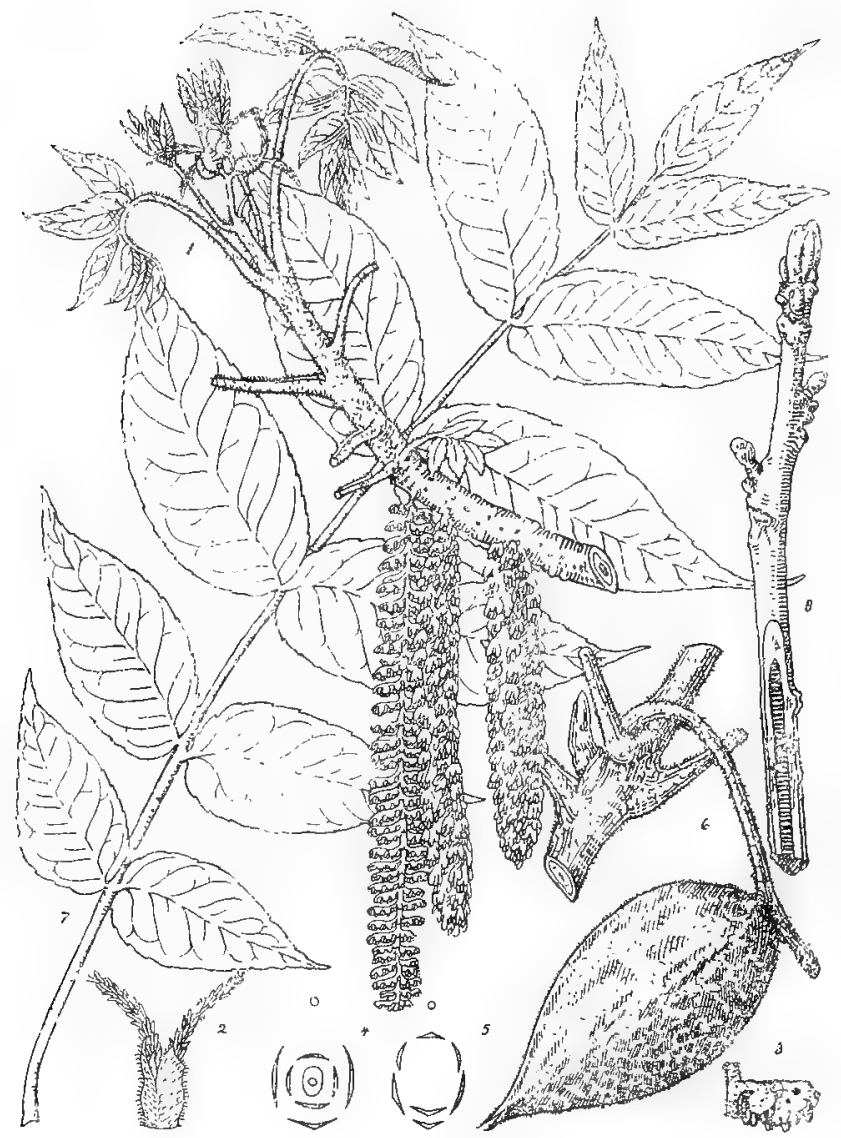

Plate i6. Juglans cinerea. Butternut.

r. Flowering branch, one-half natural size. 2. Pistillate flower, enlarged. 3. Staminate flower, enlarged. 4. Diagram of pistillate flower. 5. J)iagram of staminate flower. 6. Fruiting branch, one-half natural size. $\%$ Leaf, reduced. 8. Winter branch, one-half natural size. 
a beautiful polish, light brown turning darker with exposure; sapwood thin and light colored. Specific gravity, 0.4086; weight of a cubic foot, 25.46 pounds.

Uses.-The Butternut is occasionally used for ornamental planting in the parks of this country, but is seldom a safe tree to depend on in Minnesota when growing in the open. In protected locations it may be used as a shade tree, but is more valuable in timber plantings. It is found farther north than the Black Walnut, and is somewhat hardier, but is more easily injured by drouth. The wood is not so valuable as that of the Black Walnut, but is nevertheless very desirable for interior finishing, cabinet making and furniture and tool handles. The nuts, which ripen in October, contain a large amount of oil, are delicious when fresh, and are generally preferred to the nuts of the Black Walnut, but like them they become rancid with age. The unripe nuts are sometimes gathered early in June, when they are tender, and after removing the clammy pubescent by scalding and rubbing with a coarse cloth make excellent pickles. The inner bark is white, but becomes light yellow and ultimately dark brown upon exposure to the air. It possesses mild cathartic properties, that from the root being especially valued as a safe cathartic. The acrid leaves have been used as a substitute for Spanish flies, Sugar of excellent quality has been made from the sap, and a dye for coloring cloth a yellow or orange color is obtained from the green husks of the fruit and from the bark, and formed the butternut color commonly used in the early history of this country.

\section{Genus HICORIA.}

Leaves alternate, odd-pinnate, with few leaflets. Flowers monoecious, apetalous; the staminate in clustered lateral catkins, each cluster on a terminal peduncle; the pistillate two to six together on a terminal peduncle; stigmas two to four, large. Fruit a smooth or angled nut, covered with a four-valved husk, which generally separates at maturity. The leaves of most, if not all, the hickories are aromatic and astringent, and the bark is astringent and bitter. The bark has been successfully used in the treatment of dyspepsia and intermittent fevers and in homeopathic practice. The Indians used an oil made from the nuts. 
Hicoria ovata. (c'try't allut) Shagbark Hickory.

Shellbark Hickory:

Leaves eight to fourteen inches long; leaflets five (rarely seven), obovate to oblong-lanceolate, ciliate; fruit globose, depressed at the apex; nut pale or nearly white, more or less flattened, four-angled, thin or thick shelled, covered with thick husk; meat highly flavored. Bark of old trees is very shaggy. separating into wide, rough strips, and often falling away in large pieces. A sturdy, beautiful tree, often seventy to ninety feet high in forests; in the open forming an inversely conical top, with pendulous branches.

Distribution.-From Maine and the valley of the St. Lawrence river westward along the southern region of the Great Lakes to Central Minnesota and Kansas, south to Western Florida, Northern Alabama and Eastern Texas. In Minnesota common in a few counties in the extreme southeastern portion of the state.

Propagation.-By seeds sown in attumn or stratified over winter in moist leaves or sand and sown in the spring; also, by root sprouts. Grafted only with much difficulty.

Properties of Wood.-Heavy, very hard, strong, tough, close grained and flexible, not durable when exposed to moisture. It is light colored, with thin nearly white sapwood. Specific gravity, 0.8372 ; weight of a cubic foot, 52 .I7 pounds.

Lses.-The Shagbark IIickory is often very ornamental, and is used to some extent in park planting. It is also planted for the nuts, which find a ready sale. These vary greatly in size, thickness of shell and in quality, and none but the best should be planted for fruit. The tree is of exceedingly slow growth, and is not of sufficient hardiness to warrant planting it in any but a few very favorable locations in Southern Minnesota. The wood is largely used for ax and tool handles, plane blocks, wood screws, mallets, skewers, baskets, fuel and in the manufacture of agricultural implements, carriages and wagons, gymnasium apparatus, connecting rods for pumping machinery, etc. The second growth hickory is tougher, and on this account most desirable for these purposes. Hickory is also used in ship and boat building, hoops for barrels, tubs and pails, and oxbows are made from the sapwood. 


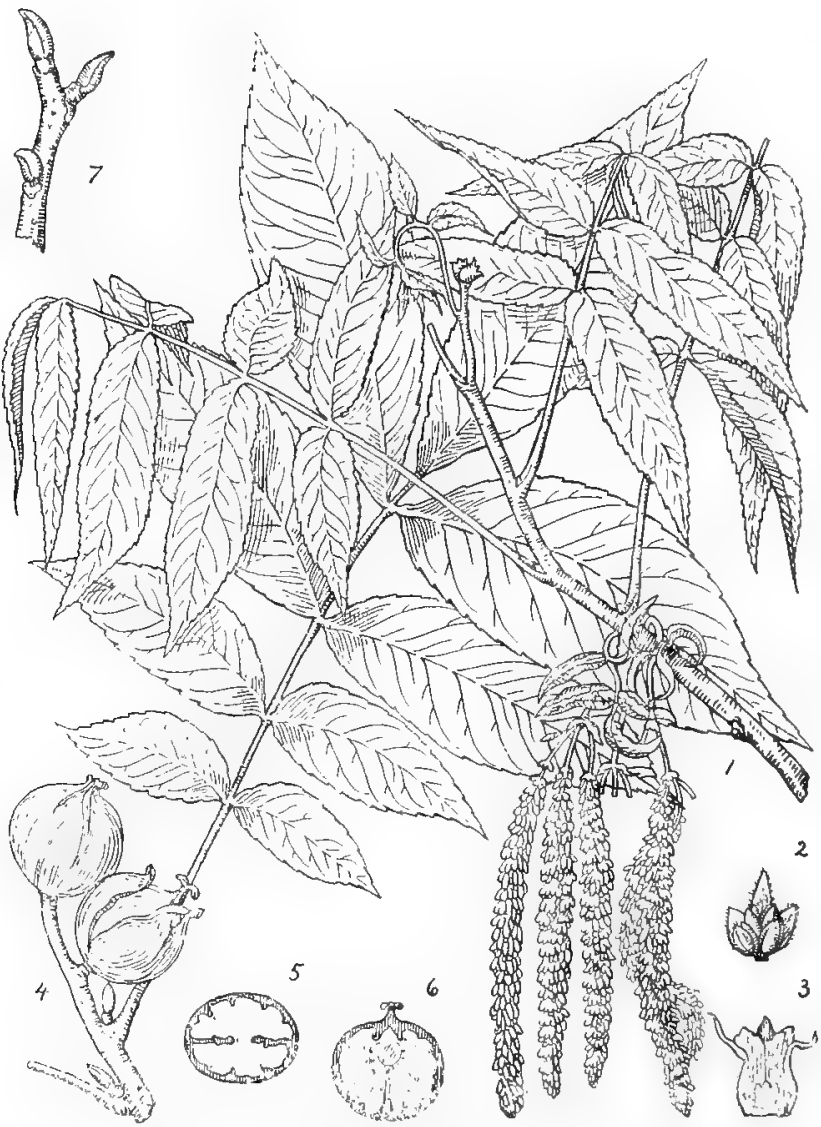

Plate 17. Hicoria minima. Bitternut Hickory.

I. Flowering branch, one-half natural size. 2. Staminate flower, enlarged. 3. l,ongitudinal section of pistillate flower, enlarged. 4. Fruiting branch, one-half natural size. 5. Cross section of nut, one-half natural size. 6. Longitudinal section of nut, one-half natural size. 7. Winter branchlet, one-half natural size. 
Hicoria minima. (curya (ma)a.) Bitternut Hickory. Swamp Hickory.

Leaves six to ten inches long; leaflets five to nine, sessile, lanceolate to oblong-lanceolate, taper-pointed, serrate; buds orange yellow in winter, resembling those of the Butternut, opening by valves, which fall away early. Fruit globular; shuck very thin; nut yellowish, thin-shelled, bitter. The bark does not shell off as in Shagbark Hickory. A slender tree of graceful habit, sometimes eighty feet high, but within our range much smaller. It is a more rapid grower than the other hickories.

Distribution.-From New England, Ontario and Minnesota south to Florida and Texas, in moist woods and near the borders of streams and swamps. In Minnesota frequent in the southern part of the state, extending through the Big Woods north to Mille Lacs county.

Propagation.-The same as for Shagbark Hickory.

Propertics of Hood.-Heavy, very hard, strong, tough and close grained, liable to check badly in drying; color dark brown, with thick light brown or nearly white sapwood. Specific gravity, 0.7552 ; weight of a cubic foot, 47.06 pounds.

Uses.-The Bitternut Hickory is a good ornamental tree, and quite hardy in proper locations in Minnesota. It is probably the most desirable of the hickories, either for ornamental use or for hoop poles in this section. The wood is inferior to that of the Shagbark Hickory, but is used for about the same purposes. It is said that in early days an oil pressed from the nuts was used for illuminating purposes. 


\section{SALICACEAE. WILLOW FAMILY.}

A large family of trees and shrubs, mostly inhabiting cold climates. Leaves alternate, simple, undivided, and furnished with stipules which are scale-like and deciduons, or leaf-like and persistent. Flowers, dioecious, both kinds in catkins, one under each bract or scale of the catkin, without calyx or corolla; in some cases the calyx is represented by a gland-like cup; ovary one or two-celled. Fruit a one or two-celled, two-valved pod, with numerous seeds attached to a parietal or basal placenta, ripening in early summer and furnished with long, silky down.

\section{Genus SALIX.}

Leaves generally narrow, long and pointed. Flowers appear before or with the leaves, in terminal or lateral, cylindrical, imbricated, generally erect catkins; two or more distinct or united stamens; stigmas two, short. Fruit a one-celled twovalved pod. Trees or shrubs with smooth round branches, usually found growing in moist land. A large and valuable genus of over 160 species, the greater number belonging to Europe and Asia. About sixty species belong to North America, A dwarf willow is found growing the farthest north of any shrub. Only two tree-like species are indigenous within our range, but there are several foreign kinds mentioned here that are of much value for cultivation in this climate.

Propagation.-The willows increase readily from cuttings, and are seldom grown in any other way. The cuttings grow readily at almost any season of the year, provided they are put in moist soil. Even in midsummer cuttings of firm wood a half inch or more in diameter will grow readily if planted in moist soil, but the best time to make cuttings is in the fall or spring, when wood of any age or size will root if properly planted. Some of the weeping varieties are grown by top-working in upright stocks.

Uscs. - The bark of the trees of all species of Salix with bitter bark yields salicylic acid, which is now used medicinally in the treatment of typhoid fever, gout and rheumatism. During the Civil War ground willow bark was used in the treatment of fevers in some of the Southern hospitals when quinine could not 
be obtained. The bark of some species is used for tanning leather. The slender tough twigs are used extensively for basket making and tying. They are often cultivated solely for this purpose. The wood of the Willow is not very valuable, but it is used for light fuel, for charcoal to be used in the manufacture of gunpowder and artists' charcoal, and that of some kinds for timber in a limited way, as hoops for kegs and barrels and for artificial limbs. Some kinds are also planted largely for holding the banks of streams and for windbreaks. For ornamental planting some kinds are used that are very pretty in flower and foliage, which quality, taken in connection with the ease with which they are propagated, their hardiness and the rapidity with which they grow, have made them largely used. Although most of the willows flourish best when they have abundant moisture at their roots, many of them will stand well on any land good enough for corn, and a few kinds, such as the White Willow, are among the hardiest kind we have for prairie planting.

Osier Willows is a term that is applied to a variety of willows which are grown for their twigs, which are used for basket making. The plantations made for this purpose are termed osier holts. The growing of osiers has not been carried on to any great extent in this country, but they are generally imported. At Syracuse, N. Y., and near a few other large cities here, it has reached a considerable degree of development. A large amount of these osiers are imported into this country each year, and an immense amount of willow basket material is used. The price paid for the rods, when of a proper length and in good condition, is about fifteen dollars a ton, green. The yield per acre around Syracuse, N. Y., is about four tons of green rods, but occasionally as high as eight tons has been obtained. Dried peeled rods are worth somewhere about sixty dollars per ton. In order to facilitate peeling, which in this case is termed stripping, the rods are steamed until the bark comes off easily. These are not as white, however, as those which are sap-peeled in the spring, but the latter are not as durable as steam-peeled rods.

The best soil for the growing of basket willows is a deep, sandy soil, drained yet moist. If water for irrigation can be commanded, so much the better, but the basket willows will prosper on even rather dry soil of good quality, but do not grow 
as fast as on moist soil. Avoid locations where stagnant water stands in summer. Among the best situations is along the rivers and brooks that pass through a level country, and on small islands which frequently are found in the midst of streams, or swales or hollows. If these places are occasionally quite wet in winter, it does not seem to injure seriously the basket willows.

In preparing the soil for this purpose care should be taken to make it very rich, and, if necessary, for best growth it should be heavily manured with stable manure, and as carefully prepared as if for a crop of corn. The best time for planting is in the late autumn, or very early in the spring, and the best cuttings are those about twelve inches long. Put these cuttings in so that their tops are even with the ground, but do not cover them with earth. Some growers prefer to set the cuttings about four inches apart in rows twenty inches apart for best results. This gives a thick, clase growth, which sufficiently shades the soil between the rows that weeds cannot grow there. If the plants should prove to be too thick, every alternate one can be grubbed out after the third year. This method will require about 65,000 cuttings to the acre. Other growers prefer to set twelve inches apart in rows three feet apart. This gives a chance to work between the rows with a horse, which is quite an advantage under some conditions. This method requires about i5,000 cuttings per acre.

On land that is wet late in autumn the willows are liable to grow too long, and not ripen their shoots, which is an important consideration in the growing of basket willows; since, if the shoots are not ripened at the time growth ceases, they are worthless for basket purposes, being soft and brittle. The rods should be cut the first year, even if of no value, for if the cutting is delayed until the second year, the plants will have branched, and will produce much less valuable material. The rods should be cut as near the surface of the ground as possible. They should then be tied in bundles about ten inches in dianeter, and, if it is intended to sap-peel them, these bundles should be placed in running water, standing upright, until the leaves or sprouts appear in the spring, when they should be ready to peel. This method of peeling is termed sap-peeling: When it is intended to remove the bark by steaming or boiling, the bundles may be set up anywhere until dry, when they may be stored in sacks or in 
covered sheds until wanted. Rods thus treated will be of a darker color than those peeled in the spring after the sap has started, owing to the fact that the wood is stained by the coloring matter in the bark, which is dissolved and taken up by the wood. These dark-colored rods, however, make the most valuable baskets. Willows should never be cut when the sap is flowing, as the material is poor, being too soft and turning black when peeled. Besides, they injure the plants by robbing them of their yearly supply of root nourishment. The cutting should always be done carefully, and in stuch a manner as not to split or mutilate the stocks. The peeling is done by pulling the rods through a springy wooden fork, shaped like a clothespin, but larger, and with blunt edges inside. This presses against the rod and loosens the bark in strands without injuring the wood. The rod is afterwards dried in the open air and put up in bundles of fifty pounds for the market.

Peeled rods keep much better than those left with the bark on, and this is said to be the most profitable way in which to market the product. The willow is generally a healthy plant, and rather free from insect enemies under ordinary conditions; but when grown in large groups of pure willows, it is occasionally attacked by rust and also by insects. The leaf-eating insects are easily destroyed by Paris green, used in the same way as is common for the destruction of the potato bug.

The Osier Willow, which has here proven most productive of the long, slender shoots so desirable for basket-making, is the Salix purpurea, and at the University Experiment Station this has frequently made a growth of six feet long in the season. It should be understood by anyone who undertakes this line of work that long, slender rods are desirable, and that one rod six feet long may be worth as much as several that are not over three or four feet long. Almost any willow may be used for making the common, coarse baskets, but for the better class of willow goods the special osier willows should be grown. The common White Willow and also the Golden Willow produce rods of fairly good quality.

\section{Wisconsin Weeping Willow.}

A willow known among horticulturists as the Wisconsin Weeping Willow (botanical name not known) has been grown 


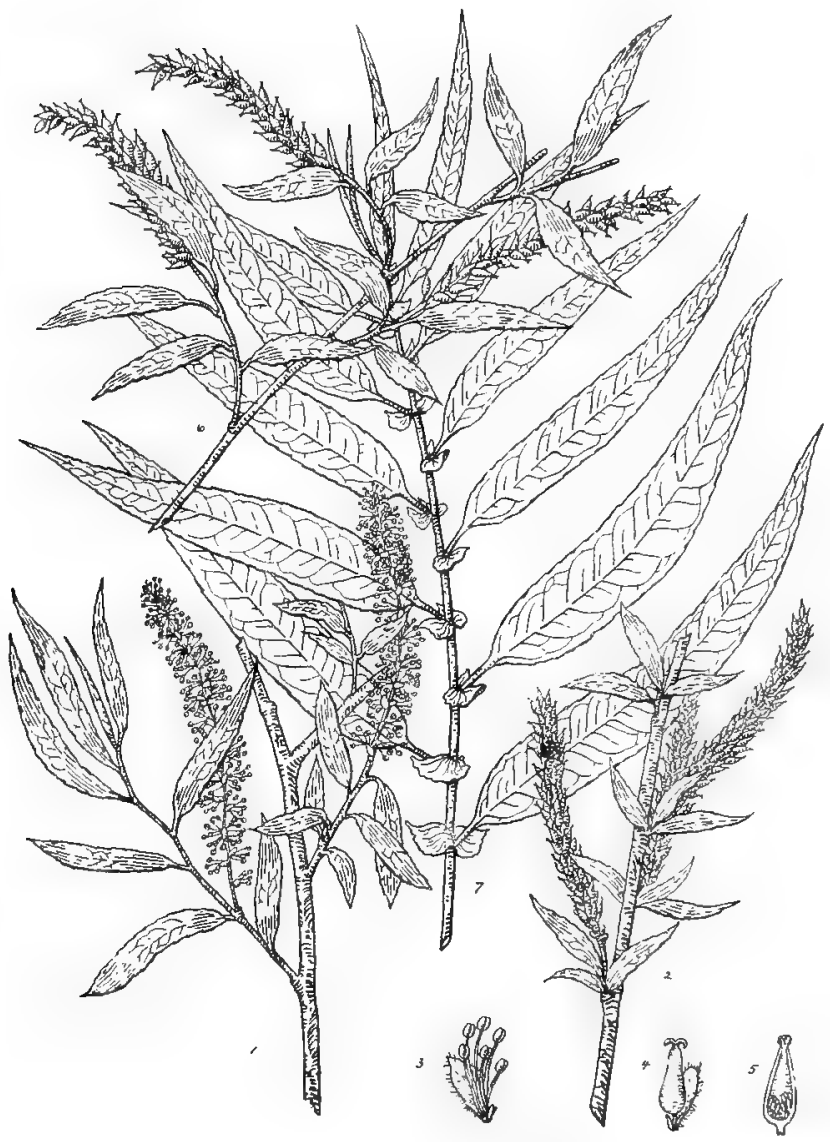

Plate 18. Salix nigra. Black Willow.

1. Flowering branch of staminate tree, one-half natural size. 2. Flowering branch of pistillate tree, one-half natural size. 3- Scale of staminate catkin, enlarged. 4. Scale of pistillate catkin, enlarged. 5 Longitudinal section of ovary, enlarged. 6. Fruilung branch, one-half natural size. 7. Sumpiner branch, one-half natural size. 
to a considerable extent here and is our best large Weeping Willow. It attains large size in favorable locations, but is occasionally killed back by severe winters.

\section{Salix nigra. Black Willow.}

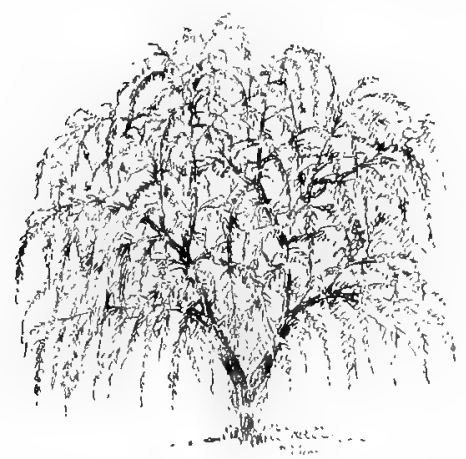

Figure 50. Wisconsin Weeping Willow.

Leaves vary greatly in size and outline on different trees, but are generally narrowly lanceolate, long pointed, serrulate, somewhat pubescent especially on the lower surface; when mature two and one-half to five inches long, bright green and glabrous above, somewhat paler and glabbrous beneath, and sometimes pubescent on the underside of midribs. Stipules persistent or soon falling away. Catkins appear with the leaves; stamens three to seven, distinct. Our largest native willow, forming a large tree, with dark brown or almost black rough flaky bark.

Distribution.-Along streams and lakes, New Brunswick to Eastern Dakota, south to Florida, Texas and Arizona.

Propagation.-By cuttings, but seedlings may often be gathered.

Properties of Wood.-Light, soft, weak, close grained, checks badly in drying; light reddish brown, with nearly white sapwood. Specific gravity, 0.4456; weight of a cubic foot, 27.77 pounds.

Uses.-The Black Willow is seldom used for ornamental or timber planting. The wood is used for fuel and the bark domestically in the treatment of fevers.

Salix amygdaloides. Almondleaf Willow. Peachleaf Willow.

Leaves lanceolate or ovate-lanceolate, long-pointed, three to five or more inches long, slightly pubescent when young, green above, pale and glaucous below with stout yellow or orange-col- 


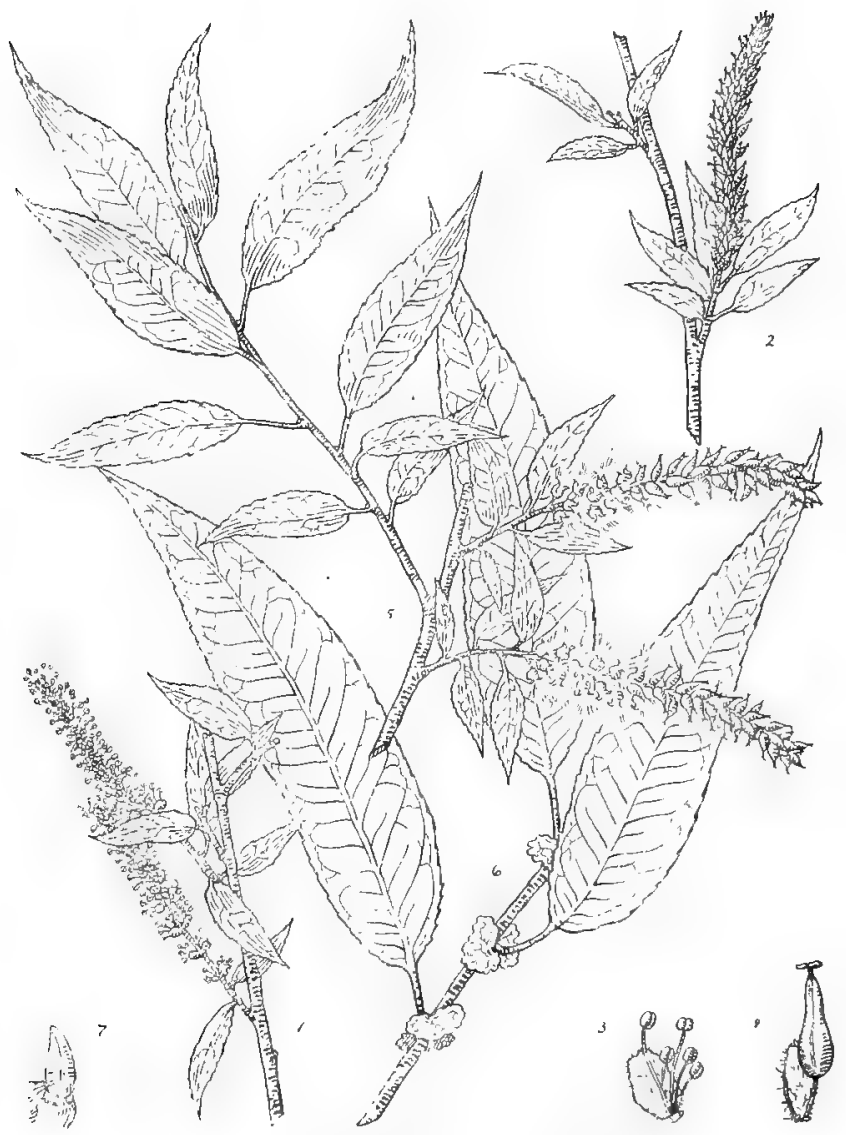

I'late I9. Salix amygdaloides, Almondleaf Willow.

I. Flowering branch of staminate tree, one half natural size. 2. Flowcring branch of pistillate tree, one-half natural size. 3. Staminate flower with scale, enlarged. 4. Pistillate flower with scale, enlarged. s. Fruiting branch, one-half natural size. 6. Summer branch, one-half natural size. 7. liud and leaf scar. 
ored midrib. Stiptles often one-half inch broad, on vigorous shoots, but scarcely appearing on the weaker branches. Catkins appear with the leaves; stamens five to nine, distinct. A small tree, occasionally seventy feet high.

Distribution.-Along lakes and streams. Quebec to the valley of the Upper Saskatchewan river and Oregon, south to Ohio, Missouri and Texas. Common in Minnesota.

Propagation-By cuttings. Seedlings can generally be gathered.

Properties of Wood.-Light, soft, weak, close grained, light brown with thick whitish sapwood. Specific gravity, 0.4509; weight of a cubic foot, 28. Io pounds.

Uses.-The Almondleaf Willow is not as desirable as several other willows for cultivation, but in suitable locations makes a very pretty tree. The wood is used for fuel.

\section{Salix alba. White Willow.}

Leaves lanceolate, taper pointed and tapering to the petiole, serrate with thickened teeth, silky on both sides when young, less so and pale or glatcous beneath when mature; stipules deciduous. Flowers appear in May, with the leaves at the ends of leafy lateral shoots of the season; stamens two. Fruit matures in June. Tree sometimes attains a height of eighty feet, with a trunk three or four feet in diameter, and ascending branches.

Distribution.-Native of Northern Europe and Asia, but was early brought to this country, and has become naturalized from the valley of the St. Lawrence to the Potomac. There are many varieties, and probably many hybrids of this with the American and European species. The form of the White Willow commonly used for windbreaks on our prairies has been considered by some as a hybrid between $S$. fragilis and $S$. alba, and by others as but a variety of $S$. alba. The pistillate tree is most commonly met with here.

Propagation.-It can be propagated easily from cuttings of large or small size. In growing this tree for windbreaks some planters prefer to use poles instead of common cuttings, laying them in furrows in the prepared soil, where they are all covered 


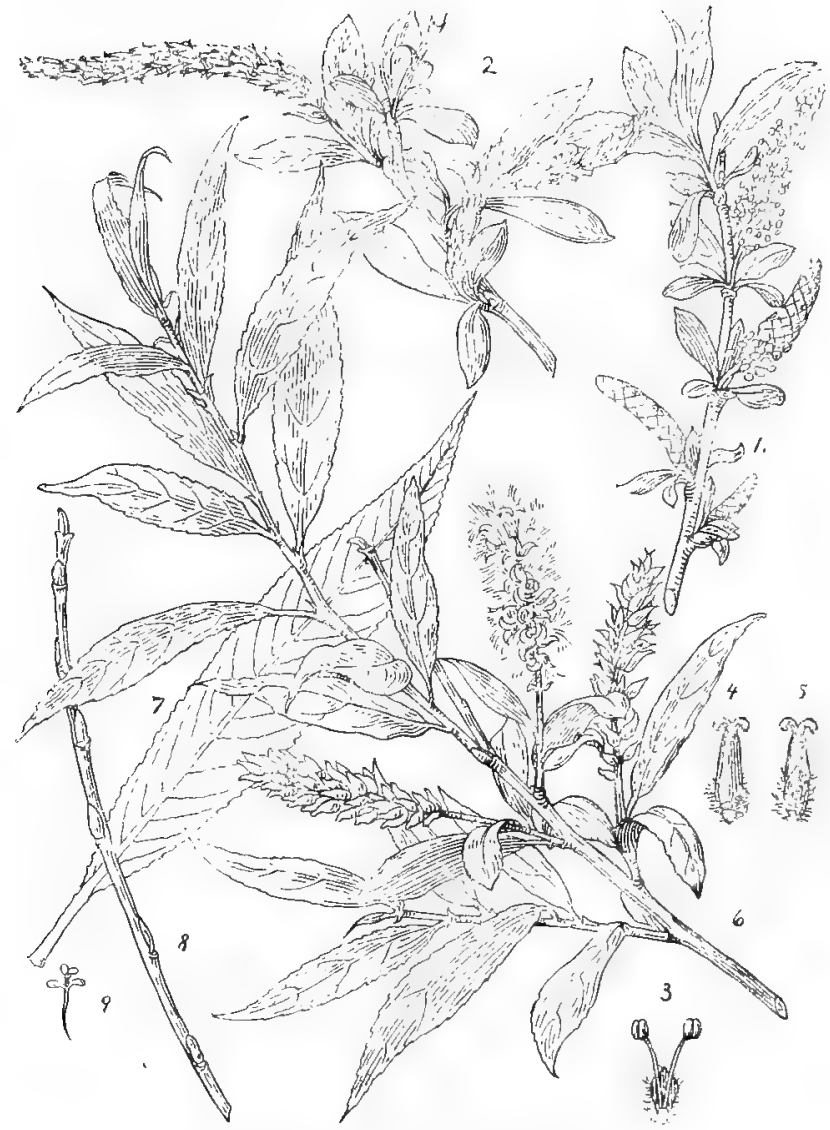

Plate 20. Salix alba. White Willow.

I. Flowering branch from staminate tree, one-half natural size. 2. Flowering branch from pistullate tree, one-half natural size, 3. Scale of staminate cathin, eularged. 4. Scale of pistllate catkin, front view, en. larged. 5. Scale of pistillate catkin, rear view, enlarged. 6. Fruiting tranch, one-half natural size. 7. Leaf, one-lialt natural size. 8. Winter branchlet, one-half natural size. 9. Seedling. 
except at intervals of about two feet, at which places they sprout and grow.

Propertics of IVood,-Soft, light, tough, strong and very flexible.

Uses.-The White Willow is one of the most valuable trees to use for windbreaks on our prairies. Wonderfully hardy even in dry locations. It sprouts vigorously from the stump and furnishes good straight poles of uniform size, which if cut in summer and the bark peeled off will last for a number of years exposed to the weather. When thoroughly dried they make fence posts that will last about six years, but generally are not durable. The fuel if dried under cover has greater value for summer use than is generally supposed. Some data collected by the Minnesota Experiment Station seem to show that the White Willow, on good land, may yield as much as five and one-half cords of firewood per acre per year. In Europe the wood is used for rafters of buildings, for the lining of carts used in hauling stone, in turnery, for baseball and cricket bats, and for any purpose where a very light, strong, tough wood is needed. The leaves are used as forage for cattle and the bark for tanning leather, for which purpose it is consiclered nearly as good as oak bark. A row of White Willow set about four feet apart with barbed wire put on then makes a very permanent and serviceable fence. Live willow posts or stakes that are used to support barbed wire soon root and become permanent trees in moist soil. The White Willow will not make a good low hedge, as it does not stand very close pruning.

Varieties.-The White Willow has given rise to a large number of varieties, among the best of which are the following:

\section{Salix alba vittellina. Common Golden Willow.}

A pretty tree at all seasons, but particularly so in winter and early spring, on account of its bright yellow bark; form like that of the species. This variety has been largely planted, but is now generally supplanted by the next, which is a better ornamental tree. This has become naturalized in this country, though it is probable that only the pistillate form is found in this section. 


\section{Salix alba vittellina (from Russia.) Russian Golden Willow.}

A very rapid growing, round, close-topped tree, with glossy deep green foliage, bright golden colored bark in winter, and

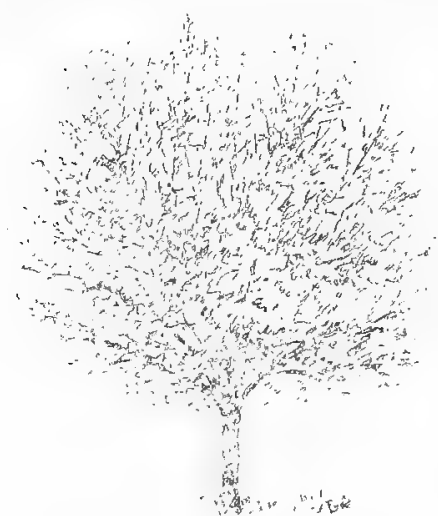

Figure 5I. Russian Golden Wil. low. A round-topped tree.

\section{Salix alba britzensis.}

A variety of the White Willow, with attractive reddish twigs in winter, pyramidal form and rapid growth. Valuable for variety in timber plantings, parks, etc.

Salix alba regalis. (Sulix regrits.) Royal Willow.

A distinct form of the White Willow forming a small tree or shrub; the foliage of which is covered with silky down, which gives it a silvery appearance. A very hardy tree, useiul for variety in ornamental planting. bright yellow, conspicuous, fragrant, staminate catkins, appearing with the leaves in the spring. One of the best quick-growing trees for this section, and very valuable for giving variety to lawn and timber plantings. Under favorable conditions a cutting of this has been known to make a tree ten inches through the trunk with a top that spread over thirty feet in eight years. The staminate form is perhaps the only one grown in this country.

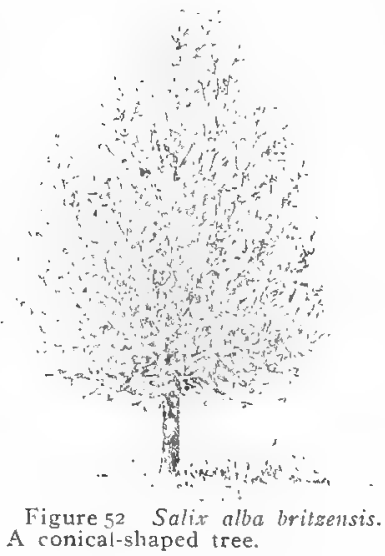

Figure 52 Saliz alba britzensis. A conical-shaped tree. 
Salix pentandra. (Salix laurifolia of horticulturists.) Laurelleaf Willow.

Leaves larger than those of any other of our cultivated willows, taper pointed, finely serrate with large stipules; upper surface of lcat dark green and shining as if var-

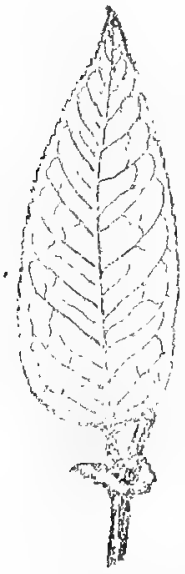

Figure 53. Leaf of Laurel leaf Wil. low, one-half nat. ural size. nishcd. Leaves are very thick, and so hard that the saw-fly larva are seldom found feeding on it. A vigorous grower when young, making a small, round, open topped tree; valuable for variety. The only objection to the extensive pianting of this tree here is a blight, which is occasionally injurious to it. On this account it should be used only in a small way. The form planted here bears pistillate flowers. Native of Europe. Propagated by cuttings.

\section{Salix 1ucida. Glossyleaf Willow.} Shining Willow.

Leaves three to five inches long and one to one and one-half inches wide, lanceolate, taper-pointed, dark green and glossy on the upper and paler on the lower surface with broad yellow midribs. Stipules one-eighth to one-quarter of an inch broad, remaining all summer. Catkins later than the leaves; stamens usually five, distinct. Occasionally a small tree, but within our range a shrub.

Distribution.-Newfoundland to Hudson Bay, westward to base of Rocky Mountains and south to Pennsylvania and Eastern Nebraska.

Propagation.-By cuttings and by seeds.

Uscs.-The Glossyleaf Willow is a pretty ornamental shrub on account of its lustrous green leaves and showy staminate Howers. Much resembles the Almondleaf Willow.

\section{Salix acutifolia.}

Leaves lanceolate-acuminate, dark green and shining above, pale glaucous below, crenate, those on strong shoots stipulate. 'Twigs yellowish green, older branches covered with a heavy purplish bloom. Catkins thick, stiff and very silky, appearing before 


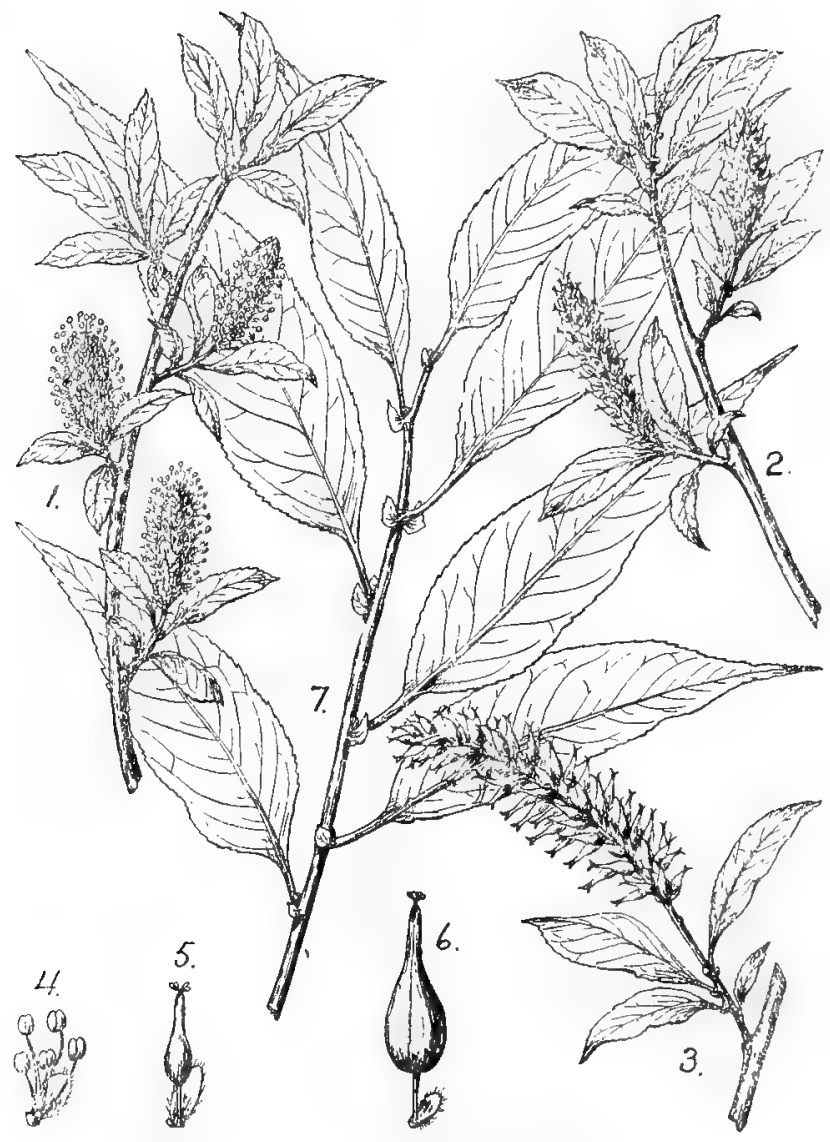

l'late zi. Salix hacida. Glossyleaf Willow.

I. Flowering branch of staminate tree, one-half natural size. 2. Flowcring branch of pistillate tree, one-half natural size. 3. Fruiting branch, one-half natural size. 4. Scale of statminate catkin, enlarged. 5. Scale of pistillate catkin, cnlarged. 6. Mature fruit, enlarged. 7. Summer branch, une-half natura! size. 
the leaves. A very hardy tree or shrub of graceful habit attaining a height of twenty feet. More difficult to propagate than most willows, and occasionally blights severely.

Salix purpurea pendula. (S. nufoleonis.) Napoleon Willow.

Leaves one and one-half to two inches long, linear, finely serrate, green and shining above, dull bluish green beneath; petioles short. Young twigs and petioles reddish. A spreading ' shrub, but when top-worked on an upright stock forms a very

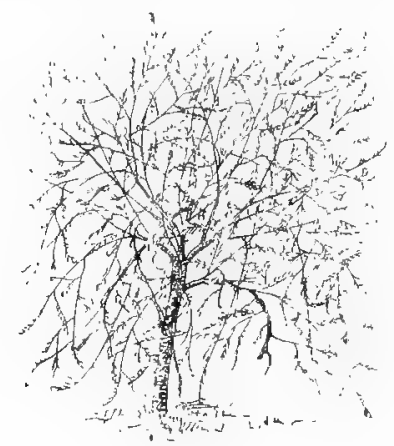

Figure 54. Napoleon Willow, top-worked on White Willow.

pretty tree, with spreading pendulous branches. Hardy at the Minnesota Experiment Station. Known among nurserymen as New American Willow, but often worked on too tender stocks.

\section{Genus POPULUS.}

Leaves alternate, broad, more or less heart shaped or ovate. Flowers dioecious. Individual trees bearing staminate and pistillate catkins, and also catkins having the two kinds of flowers mixed together occasionally occur. Flowers appear before the leaves in long, usually drooping, lateral, cylindrical catkins, the scales of which are furnished with a fringed margin; the calyx is represented by an oblique cup-shaped disk, with entire margin; stamens usually numerous; ovary short; stigmas long, twolobed; fruit described under family Salicacec, ripening before the 
full development of the leaves in May or June. A genus of about twenty species of soft wooded trees, mostly natives of cold climates, one-half of which are found in North America.

Populus tremuloides. Aspen. American Aspen. Quaking Asp. Poplar. Popple.

Leaves ovate or obicular, with a sharp, short apex, small, smooth on both sides; petiole long, flattened. Flowers in April before the leaves in hairy catkins. Fruit a small, two-valved capsule; seeds very small. Bark smooth, greenish white except on very old trees; twigs not angular. This is generally a small, short-lived tree, but occasionally it grows sixty or more feet high. The pendulous leaves tremble in the slightest breeze; the silver gray bark is attractive and the autumn color of the leaves is one of the purest golden yellows found among trees.

Distribution.-From Southern Labrador to southern shores of Hudson Bay, to the Mackenzie and Yukon rivers, south to Pennsylvania, Missouri, New Mexico and Lower California and through all mountain ranges of the West. One of the most widely distributed trees of North America. In Mimnesota it is found throughout the state, and is very common on cut-over timber lands, where it is generally the first tree to take possession of the land after the pine is cut off. It grows most luxuriantly along the borders of swamps and open forest glades. The seed is carried long distances by the wind.

Propagation.-By seeds, which grow frcely; but the seeds, however, are seldom sown in nurseries, as the limited demand for this species is easily supplicd by the seedlings which spring up along the lake shores and sand bars.

Properties of $\mathrm{II}^{\mathrm{T}}$ ood.-Light, soft, not strong, close grained, of cottony fiber, and soon decays in contact with the soil. It is of a light brown color, with thick, nearly whitc, sapwood. Specific gravity, 0.4032; weight of a cubic foot, 25.13 pounds.

Uses.-On account of the color of the bark and the autumn color of the leaves an occasional specinen of $\Lambda$ spen can be used to advantage to give variety to our tree plantings. Although it grows rapidly when young, it is of very slow growth when older. The wood is used for paper pulp, and occasionally for interior finishing and for turnery. It makes good light fuel if cured under cover. 


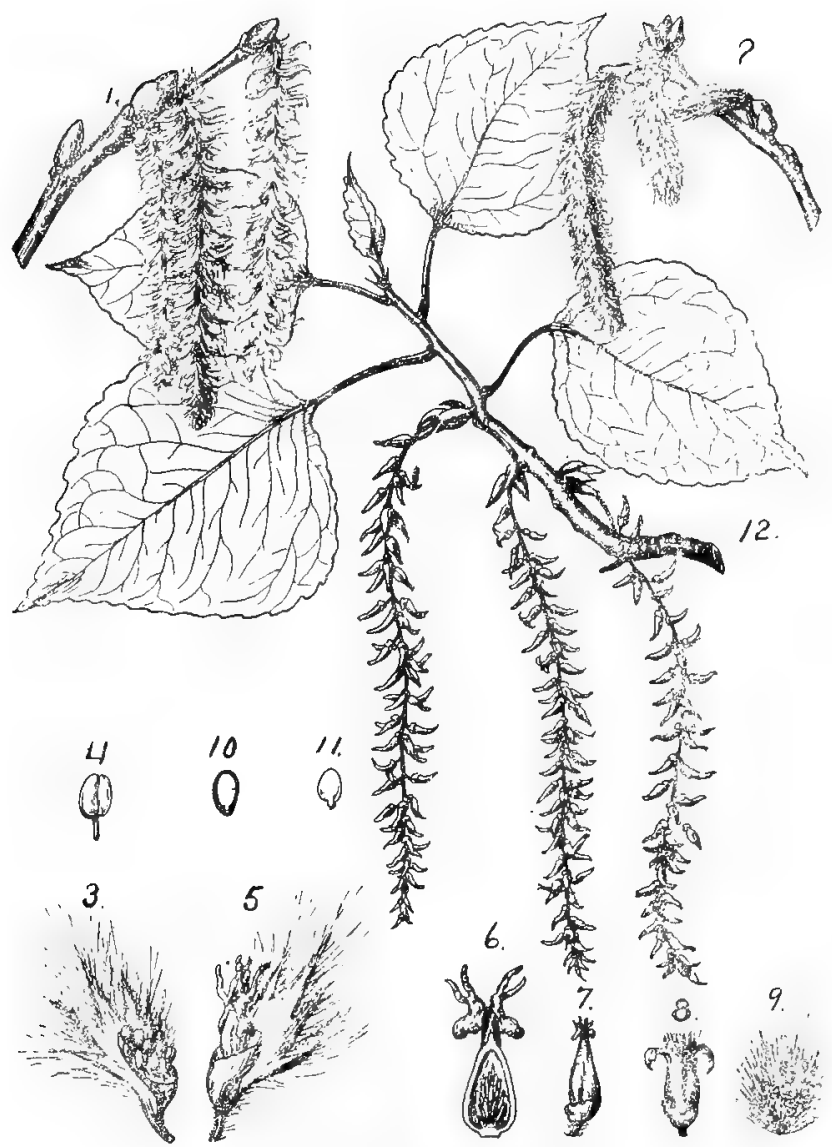

Plate 22. Populus tremuloidcs. Aspen.

1. Flowering branch of staminate tree, one-half natural size. 2. Flowering branch of pistillate tree, one-half natural size. 3. Scale of staminate catkin, enlarged. + . Stamen, enlarged. 5. Scale of pistrllate catkin, enlarged. 6. Longitudinal section of pistil. 7. Mature fruit, natural size. 8. Fruit, slowing mode of dehiscence, natural size. 9. Seed, enlarged. 10. Longitudinal section of seed, enlarged, Ir, Embryo, enlarged. I2. Fruiting branch, one-half natural size, 


\section{Populus grandidenta. Largetooth Aspen.}

Leaves roundish-ovate, with coarse unequal teeth, densely covered with silky wool beneath when young, smooth on both sides when old; petioles flattened, twigs not angled. Flowers in hairy catkins three to four inches long, the staminate catkins longer than the pistillate, stamens about twelve; seeds very small, dark brown. A medium-sized slender tree, with greenish gray bark rarely over seventy-five feet high and two feet in diameter; resembles the Aspen, and is sometimes confounded with it, but unlike the common Aspen it rapidly attains considerable size under cultivation.

Distribution.-From Nova Scotia west to Northern Minnesota and North Dakota, south ta North Carolina, Kentucky and Tennessee. In Minnesota throughout most of the state in forests, usually in rich moist sandy soil near swamps and streams.

Propagation.-By seeds and cuttings.

Properties of Wood-Light, soft, and close grained but not strong; light brown with thin, white sapwood. Specific gravity, 0.4632 ; weight of a cubic foot, 28.87 pounds.

Uses.-The Largetooth Aspen can sometimes be planted in timber belts to advantage. It makes good straight poles for various farm purposes and for framing; it is also used for wood pulp, and occasionally in turnery and for woodenware.

Varictics.-Populus grandidenta has given rise to several varieties with pendulous branches, which when grafted on straight stems of the species are used in ornamental planting and form the best weeping poplars.

\section{Populus balsamifera. Balm of Gilead. Tacamahac.}

Leaves ovate, lanceolate, acute or taper pointed, smooth on both sides; petioles not prominently flattened; buds in spring are large and abundantly covered and saturated with a fragrant aromatic varnish. Flowers appear in April or May; the staminate catkins two to three inches, and the pistillate four to six inches in length; stamens very numerous, purple. Seeds with a large cottony float. A large, upright tree, with narrow straight top, and nearly smooth gray bark, the largest of the sub-arctic trees. 


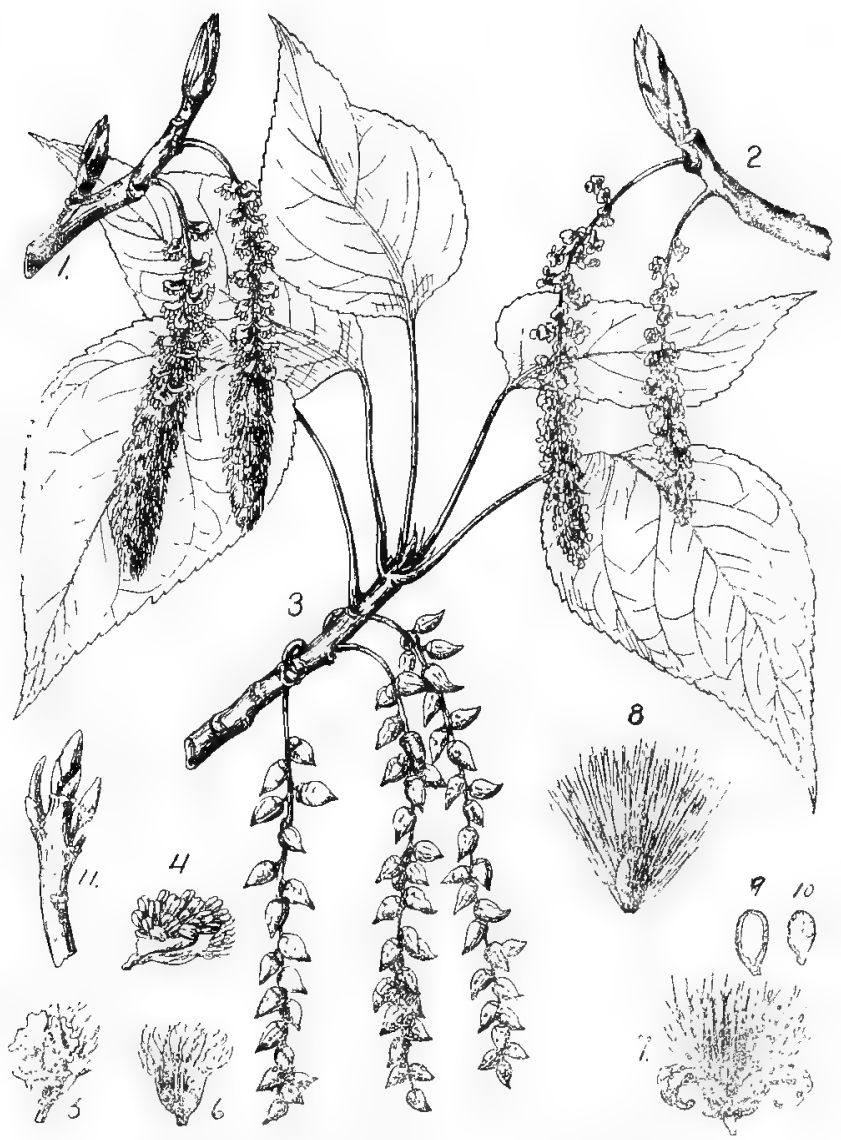

Plate 23. Populus balsamifera. Balm of Gilead.

I. Flowering branch of staminate tree, one-half natural size. 2. Fiow ering branch of pistillate tree, one-half natural size. 3. Fruiting branch, one-half natural size. 4. Scale of staminate catkin, enlarged. 5. Scale of pistillate catkin, enlarged. 6. Scale without flower, displayed, enlarged. 7. Mature fruit. 8. Seed, enlarged. 9. Longitudinal section of seed, enlarged. to. Embryo, enlarged. Ir, Winter branch showing buds, one-half natural size. 
Distribution, - Over the low bottom lands and swamp borders of the greater part of British America and the northern part of the United States. In Minnesota found throughout the northern part of the state.

Propagation.-By seeds and cuttings.

Properties of II'ood-Light, soft, not strong, close grained; light brown, with thick nearly white sapwood. Specific gravity, 0.3635 ; weight of a cubic foot, 22.65 pounds.

Uscs.-The Balm of Gilcad and its varieties are occasionally used for ornamental planting, but while they are of rapid growth and occasionally make good specimens, their open habit and liability to die in the top make them undesirable for extensive planting. The wood is excellent for paper pulp. The buds are used in liniments; their virtues probably being analagous to those of turpentine and the balsams.

Tarictics.-

\section{Populus balsamifera candicans. Hairy Balm of Gilead.}

This form has a wider leaf, longer and more resinous buds, more spreading branches, heavier wood, and is a more ornamental tree than the species. It is common in plantings in the Northeastern States and Eastern Canada.

\section{Populus ba1samifera intermedia.}

A European form, with close, upright habit and very thick, hard, oval leaves, which are whitened beneath. It is known to horticulturists as $P$. laurifolia and $P$. sibcrica pyramidalis.

\section{Populus balsamifera viminalis.}

A native of Northern Europe. The tree is of slender growth, with a slightly weeping habit when old. It has sharply angled twigs and willow-like leaves. Known to horticulturists as $P$. lindleyana, $P$. salicifolia, $P$. crispa, $P$. dudlcyi and $P$. pyramidalis suat'colcns.

\section{Populus balsamifera 1atifolia.}

A varicty including several Asiatic forms, with ovate leaves, cylindrical twigs and general habit of the Balsam Poplar. The 
forms of this are known to hortictulturists as $P$. Nolcsti and $P$. Hobsky.

\section{Populus angustifolia. Narrowleaf Cottonwood.}

Leaves lanceolate or ovate-lanceolate, narrow at base, green

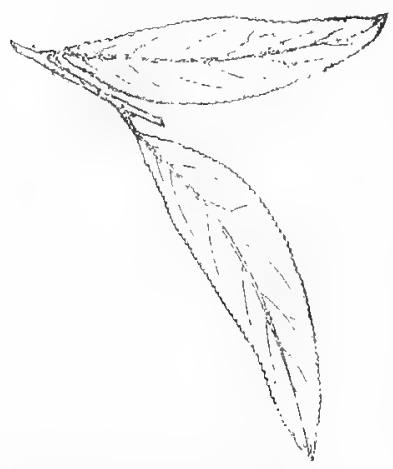

Figure 55. Leaves of Narrow. leaf Cottonwood, one-third nat. ural size. on both sides: branches rather slender with smooth bark. Catkins densely flowered, one and one-half to two inches long; stamens twelve to twenty; pistillate catkins lengthen as the fruit grows, and when the seeds are ipe the catkins are from two and one-half to four inches long. Tree much smaller than the common Cottonwood, it seldom being more than fifty feet high and fifteen inches in diameter, resembling a willow more than a poplar.

Distribution.-It is found along streams in Montana. Assiniboia,

Black Hills of South Dakota and Northwestern Nebraska to Arizona. It is the common Poplar of Southern Montana, Eastern Idaho, Wyoming, Utah and Northern Colorado.

Propagation.-By seeds and cuttings.

Propertics of $W^{r}$ ood.-Light, soft and weak; light brown, with thin, nearly white, sapwood. Specific gravity, 0.39I2; weight of a cubic foot, 24.38 pounds.

I'scs.-The Narrowleaf Cottonwood is used as a shade and street tree in towns of Colorado and Utah, for which purpose it docs very well if provided with water, and soon forms a conical shapely head. It is hardy in Minnesota, but has been planted here but a few years.

Populus deltoides. (P. monilifica.) Cottonwood. Carolina Poplar. Yellow Cottonwood.

Leaves large, deltoid or broadly ovate, usually abruptly acuminate, coarsely crenate; petioles laterally compressed. Twigs 
and smaller branches thick, smoother, but sharp angled or winged, at length becoming round. When the leaves unfold they are gummy and fragrant, with a balsamic odor, and covered more or less with white soft hairs; at maturity they are thick. leathery and green on both sides. Catkins pendulous; the staminate densely flowered and from three to four inches in length and a half inch in thickness; the pistillate sparsely flowered, thin stemmed and often a foot long before the ripening of the seeds. Stamens sixty or more to each flower. Seed oblong. one-twelfth of an inch in length, and surrounded by a tuft of long hairs, which aid in its distribution. Tree sometimes Ioo feet high, with trunk occasionally seven or eight feet in diameter.

Distribution.-From Quebec south to Florida and west to the base of the Rocky Mountains, from Alberta to New Mexico along banks of streams, where it often forms extensive groves. In Minnesota common in the southern part of the state, but rare farther north.

Propagation-By seeds and by cuttings. Seedlings can be obtained in large quantities on the sand bats along our rivers and on shores of receding lakes, and this is the chief source of supply. The opinion is common that secdlings are longer lived than plants from cuttings.

Propertics of Wood.-Light, soft, spongy and weak, although close grained; dark brown, with thick nearly white sapwood. Specific gravity, 0.3889; weight of a cubic foot, 24.24 pounds.

Uses.-The Cottonwood has been largely used in the Western States for timber and fuel. as a shade tree and for windbreaks. For all these purposes it is a very inferior tree, but on account of its abundance, rapid growth and hardiness it has almost necessarily been largely used in the pioneer work of settlement. As a timber tree it is inferior on account of its timber warping badly in drying and being extremely difficult to season. As a tree for shade and windbreaks it is not so valuable as the Green Ash, White Willow, White Elm or Boxelder; on the dry prairie it is subject to leaf rust, is short-lived, and fails to make a shade dense enough to keep the grass out of groves. The pistillate form is objectionable on account of the cottony floats with which it fills the air when shedding its seed. It has, however, done good service in our Western States, and may continue to be of 


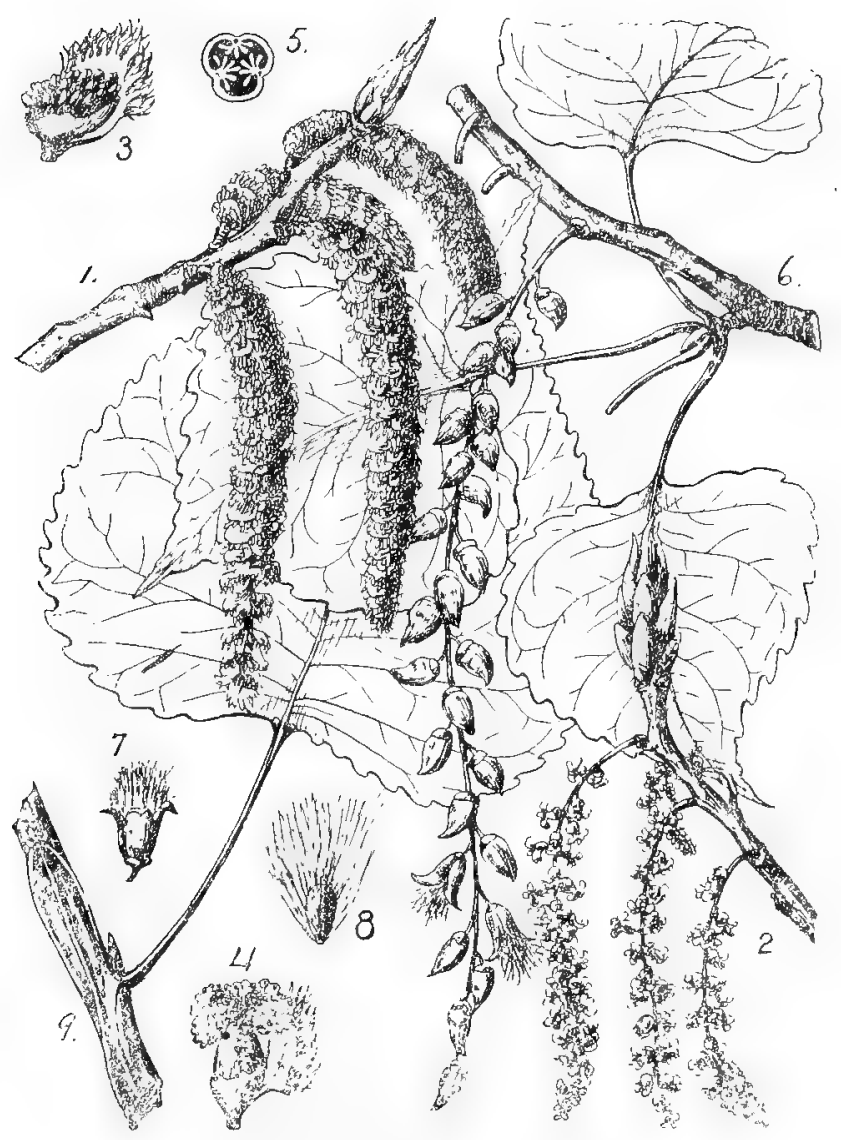

Plate 24. Populus deltoides. Cottonwood.

I. Hlowering branch of staminate tree, one-half natural size. 2. Flowering branch of pistillate tree, one-half natural size. 3. Scale of staminate catkin, enlarged. 4. Scale of pistillate catkin, enlarged. 5. Cross section of ovary, enlarged. 6. Fruiting branch, one-half natural size. 7. Mature fruit, 8. Seed, enlarged. 
service in first plantings, but our people had better plant longerlived and more desirable trees mixed in with it to replace it when it fails. Occasionally, however, the Cottonwood can be used to advantage where a cluick tree effect is wanted, for where it has plenty of water it will make a great stately tree in a very short time. If one wishes to plant Cottonwood and avoid the "cotton," which is so objectionable, cuttings from the staminate tree only should be used, as this form produces no cotton. The wood of the Cottonwood is used for cheap packing cases, trays and bowls, for paper pulp, excelsior and for fuel. For fuel and lumber the wood should be dried under cover, as it decays very quickly when exposed to moisture. Some figures collected at the Minnesota Experiment Station show that on good land Cottonwood may yield as much as seven cords per acre per year increase.

Yellow Cottonwood. In some sections along the Mississippi and Missouri rivers is found what is known as Yellow Cottonwood, which it is difficult or quite impossible to distinguish from the common or White Cottonwood by any of its external characters, but there is a very distinct difference in the wood. Some good authorities have thought this difference associated with the sex of the trees, but this is improbable, as the form seems localized.

What is known as Yellow Cottonwood lumber is highly esteened for turnery and various purposes for which Tulip Poplar (Liriodcndron tulipifera) is used, and is manufactured in large quantities. It has also been used for the siding of houses with good results. The characters of the wood of each are quite clearly given in a letter recently received from the "Three States Lumber Co." of Cairo, I1l, from which the following is taken:

"The Cottonwood belt extends along the Mississippi river below Cairo, and there is also considerable along the Missouri river. The Cottonwood in the Mississippi Valley consists mostly of Yellow Cottonwood. This generally grows on low moist land, and any Cottonwood that is found growing on land that is subject to overflow is gencrally the soft ycllow variety, known as Yellow Cottonwood. There is some White Cottonwood growing in the southern part of Illinois, on high, dry 
ground. It is not possible to distinguish one from the other by the leaves, as in such comparison there is no difference.

"Yellow Cottonwood grows very round at the bottom, and holds to size much better than White Cottonwood. It generally has a thick bark; what we term as a corrugated bark.

"White Cottonwood has a much thinner and softer bark. and is very apt to have a heavy spur root at the bottom. We mean by that it is liable to grow up somewhat flat-sided and ridged near the bottom of the trees. This is somewhat similar to the growth of oak.

"Yellow Cottonwood will saw up very smooth, is soft and tender, and must be handled very carefully after being manufactured into lumber in order to prevent the splitting of the boards or their ends. It will dress ont through a planer with a very smooth surface, and will break off square. It will also take a very nice polish after being surfaced.

"White Cottonwood is tough and stringy, is very hard on saws in manufacturing, and will sometimes bend almost double before it will break, and after breaking the ends will be rough.

"A White Cottonwood board put through a planer will not dress out smooth the entire surface, but there will be more or less spots that are fuzzy and rough, which is a serious objection to the consumer, as it will not take an even polish. A White Cottonwood board exposed to the sun will also warp and twist to a much greater extent than a Yellow Cottonwood board.

"Yellow Cottonwood Itmber is not strictly yellow, considering it from a color standpoint, nor is it strictly white. There is a tinge in the lumber which impresses you as different from a White Cottonwood board, which to the eye is very distinct."

I'aricties.--

Populus deltoides aurea. ( $P$. I Un Gertiz, Bailey.) Goldenleaf Cottonwood.

This variety of the Cottonwood is very desirable on account of the bright yellow leaves on the new growth in summer. It grows freely, and in Minnesota has proved as healthy as the species. It is valuable for occasional use to give variety to windbreaks, and is said to be more largely planted in Europe for park decoration than any other American tree. 


\section{Populus nigra. Black Poplar.}

Leaves broadly triangular, sometimes with tapering or rounded base, smaller, less deeply toothed and shorter in proportion to their width than those of the Cottonwood, which they resemble; leaf stock flattened. The tree has generally a pyramidal habit of growth and dark foliage. It is less lustrous than the Cottonwood, and grows more slowly. This is probably the tree known in some localities as Norway Poplar or Norway Cottonwood. What has been sent out under the name of Populus bctulifolia is probably a form of this species.

Distribution.-Europe and Asia. "It must now, however, be regarded as naturalized in this country, having become thoroughly established in many localities."

Propagation.-Almost entirely by cuttings in this country.

Properties of wood,-Light, soft, compact, not strong. Specific gravity of air-dried wood 0.45 .

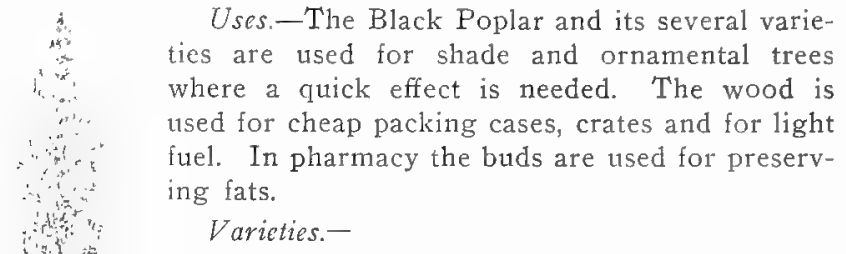

\section{Populus nigra italica. Lombardy Poplar.}

A common tree with upright branches, making a very straight columnar growth, and on this account very conspicuous. Leaves small and generally with a more tapering base than the species. This is one of the characteristic

Figure 56 Lombardy

Poplar. trees of Italy. Its common name is derived from Lombardy, one of the provinces of Italy. The tree is supposed to be a native of Persia and Asia Minor. Its peculiar form gives the landscape a crude look where it is much used. Single specimens, however, may be occasionally planted to advantage to give variety to shelter belts. It is hardy in moist soil, and on our average prairie soil makes a good growth while young, but soon becomes ragged in the top, and loses some of its branches and occasionally dies. When it becomes ragged in appearance 
it should be cut back, as it will then often renew itself. The tree is generally shortlived in this section. It does not afford shade enongh for a forest or shade tree, and does not make a good windbreak.

\section{Populus alba. White Poplar. Silverleaf.}

Leaves roundish, slightly heart-shaped, wary toothed or lobed; the under surface, woolly white, especially early in the season. Branches round, without angles; buds small. A large spreading tree of rapid growth, very much disposed to sucker from the root. It has given rise to many varieties, that differ from the species in form of tree and leaf and in other particulars.

Distribution.-Europe and Asia Minor; naturalized in the United States.

Propagation.-By cuttings and suckers.

Propcrties of wood.-White, soft, light, close grained and easily worked. Specific gravity of air-dried wood 0.48 .

Uses.-The White Poplar is seldom planted, as it is not so ornamental as some of the varieties. It is a very hardy tree, but is occasionally killed back in very trying locations. It is well adapted to planting in shelter belts where its suckering habit is not a drawback to its presence. The wood is adapted to inside finishing and to many of the purposes for which White Pine is used. "It is probable that we have no tree with valuable wood that will reach saw log size on our prairie soils as soon as this."

Varieties.-

Populus alba nivea. (P. argente , Koch.) Snowy Poplar.

This is the commonest form of the White Poplar in this country. It is known by the snow-white under surface of its foilage and the three to five-lobed maple-like leaf. It is sometimes wrongly called Silver Maple, from the resemblance of its foliage to that of a maple. The foliage is so very obtrusive that it is likely to be used too frequently in lawn plantings. It may, however, be used sparingly to good purpose to brighten up groups of trees and shrubbery which present too gloomy an aspect. It should seldom, if ever, be used as a street tree as masses of it seem to be out of harmony with every good thing in the landscape. In closely settled communities the down on the leaves often becomes filled with soot and gives the tree a dirty appearance. Hardy everywhere, and easily grown from cuttings. 


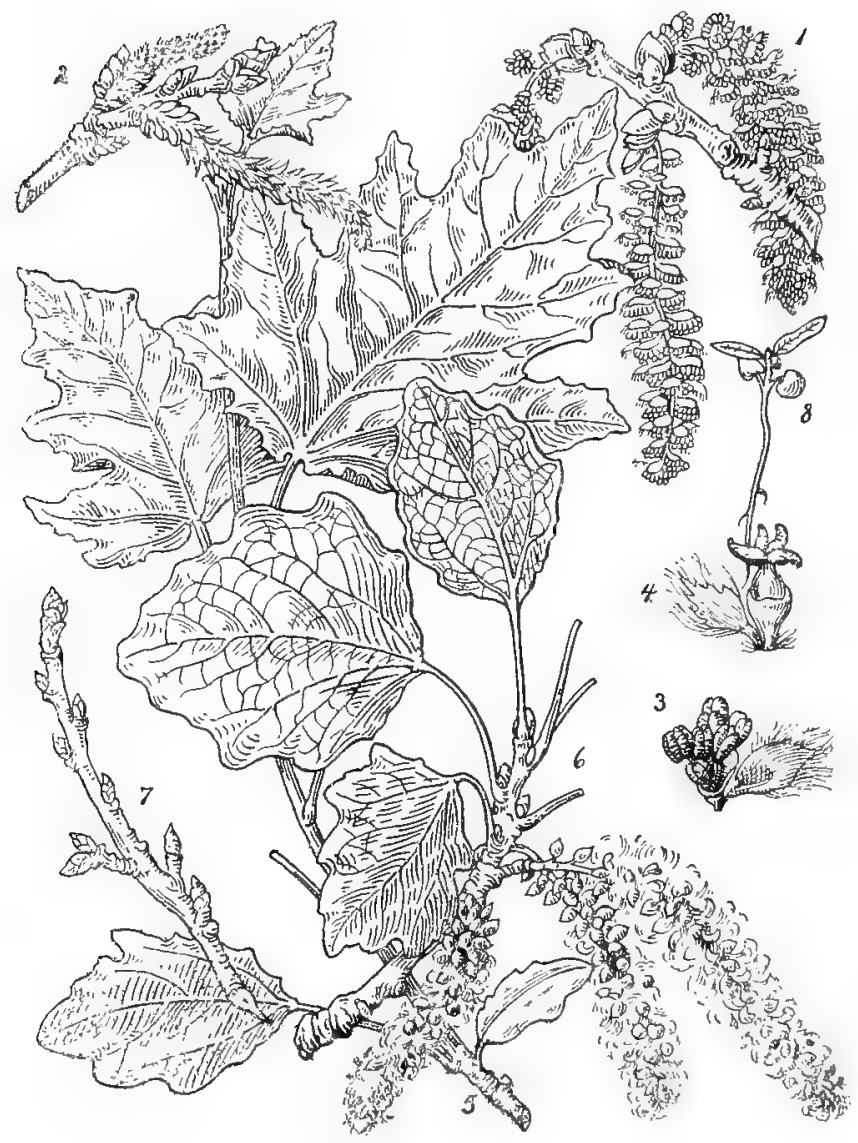

I'late 25. Populus alba. White Poplar.

1. Flowering branch from staminate tree, onc-half natural size. : I'lowering branch from pistillate tree, one half natural size, 3. Scale of ataminate catkin, unlitged. 4. Scalc of pistillate catkin, enlarged. 5. Sum mer branch, one-half natural size. o. lintiting branch, one-half natural size 7. Winter branchlet, one-half natural size. 8. Seedling. 


\section{Populus alba canescens. Silver Poplar.}

This differs from the above in having leaves broad or nearly circular in general outline, notched but not lobed, but like it in that the leaves and young shoots are downy.

\section{Populus alba bolleana. Bolle Poplat.}

A form of the White Poplar of the same narrow upright

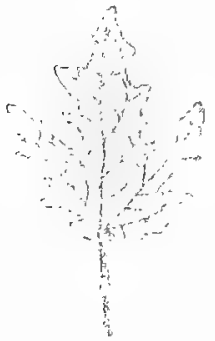

Figure 57. I,eaf of Bolle Poplar. One-third natural size. habit of growth as the Lombardy Poplar Leaves somewhat deeper lobed but with the same cottony covering. It differs from the common White Poplar in that it dnes not sucker from the root and is more difficult to propagate from cuttings, which require to be calloused before planting. It is striking in aspect, and should be used sparingly in ornamental planting.

Leaves on the old wood or slow growing twigs are very different from those on vigorous growing shoots. The former are broadly oval, with finely serrate margins and on cylindrical twigs. The strong shoots are decply angled or grooved, and the foliage on them is wavy in outline. The trees are sometimes confounded with the Cottonwood, from which they are very distinct, especially in the leaves, which are on shorter more rigid petioles. A large tree of rapid growth.

Distribution.-Introduced from Russia. Probably a native of northern Europe and Siberia.

Propagation.--Easily grown from cuttings.

Properties of wood.-Light, soft, easily worked and reported as being valuable for many of the purposes for which pine timber is commonly used.

Uscs.-The Certinensis Poplar has been tried largely in this section, and has proved to be a good, quick-growing tree for prairie planting. In some localities, however, it has been infested with a borer which has occasionally done much injury, 
and lecl to the impression that it is not so hardy as the Cottonwood. The foliage seems to resist the attacks of the leaf fungus better than the Cottonwood.

\section{BETULACEAE. BIRCH FAMILY.}

\section{Genus BETUL/A.}

Flowers monoecious, apetalous, appearing before or with the leaves: the staminate in long pendulous catkins; stamens two; the pistillate in erect cylindrical catkins; ovary naked, twocelled. Fruit a small nut, surrounded by a wing and covered by the enlarged scale of the catkin, ripening in autumn. Leaves alternate, simple, dentate or serrate. Trees or shrubs with watery juice. A large genus represented by many species. The bark contains a resinous balsamic oil sometimes used in tanning leather. In parts of this country and Canada the bark and leaves of various birches are esteemed as domestic remedies for diseases of the skin, for rheumatism and gout. An oil obtained from the inner bark by distillation is also used externally for the same purpose. The sweet sap of many species is used as a beverage, and is sometimes made into wine.

Propagation.-By seeds, which should be sown when gathered or stratified over winter and sown in the spring and the seedlings given some shade during the first season. The varieties are propagated by budding, grafting and inarching on the parent species.

Betula papyrifera. Paper Birch. Canoe Birch. White Birch.

Leaves ovate or heart-shaped, dark green on the upper side. The bark is reddish on the twigs under four or five years old and white on the older branches and trunk, and readily separated into papery shects. A good sized tree, frequently sixty or seventy feet high, with a trunk from two to three feet in diameter, or perhaps in severe locations dwarfted to a mere shrub.

Distribution.-Throughout Canada to Arctic Ocean ("Widest range of any Canadian tree"), south to northern Pennsylvania, 


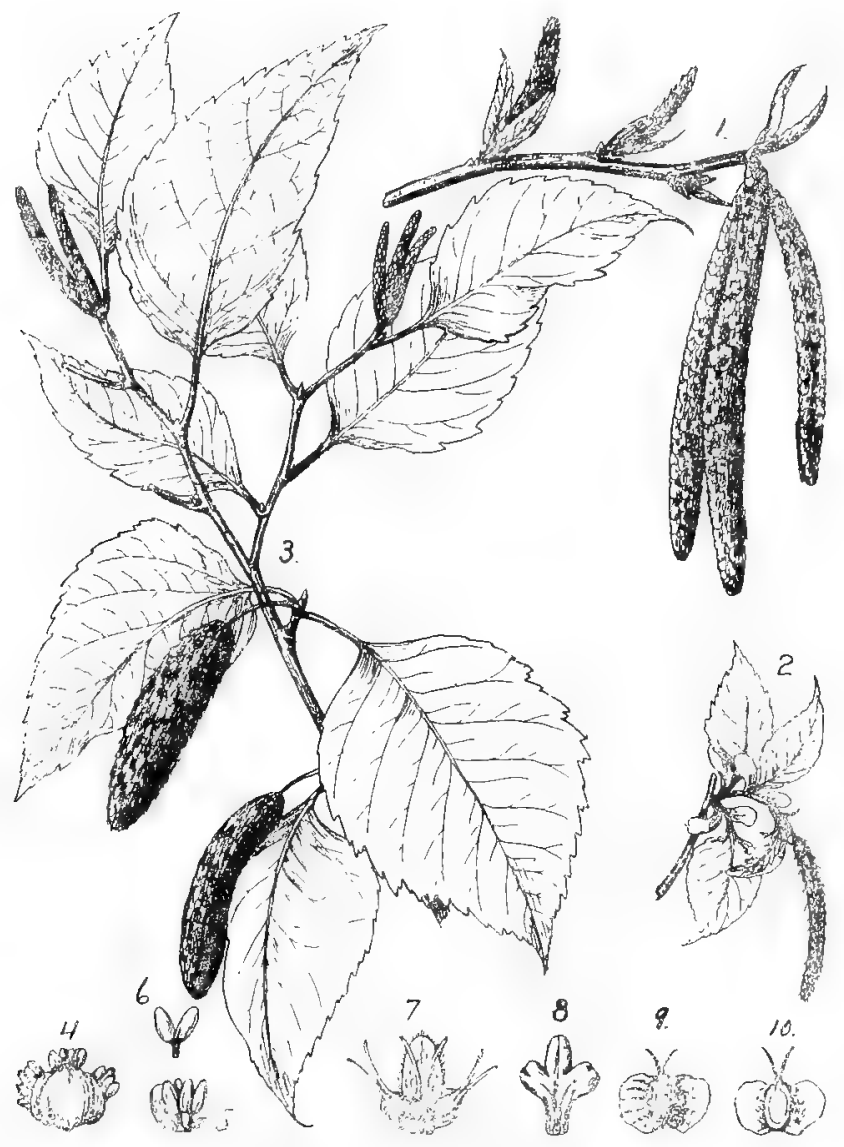

Plate 26. Betula papyrifera. Paper Birch.

1. Flowering branch, one-half natural size. 2. Lateral branch, showing unfolding leaves, stipules and pistillate catkins, one-half natural size. 3. Fruiting branch, one-half natural size. 4. Scale of slaminate catkin, rear view, enlarged. 5. Staminate flower, enlarged. 6. Stamen, enlarged. 7. Scale, bearing pistillate flowers. 8. Scale of fruiting catkin. 9. Nut, enlas ged. Io. Longitudinal section of fruit. 
central Michigan and northern Nebraska and northwestern Washington. In Minnesota generally common'in all but the southwestern part of the state.

Propagation.--See genus Betula.

Properties of wood.-Light, strong, hard, tough and very close grained, but not durable. It is light brown tinged with red, with thick nearly white sapwood. Specific gravity 0.5955; weight of a cubic foot 37.II pounds.

Uses.-The Paper Birch is a tree of good form and pretty habit. It is especially beautiful in the spring when the young leaves are unfolding, and in the winter is valuable for the contrast afforded by its white bark with other plants. It lends variety to windbreaks and lawn plantings. Prefers a moist soil, but does well on any retentive soil, and is perfectly hardy. The wood is largely used in the making of spools and bobbins, clothes pins, bread boards, rolling pins, wood screws, and shoe pegs, in the manufacture of wood pulp and for fuel. It is one of the very few woods that burn well when green. It decays quickly, and should always be cured under cover. The Indians of the north employ it for their sleds and paddles, the frames of their snow shoes and handles of their hatchets. Birch is also used for flooring, veneers, moldings, furniture. The knots and gnarled roots are turned into door knobs and fancy articles. The tough, resinous, durable bark of this tree is impervious to water, and readily separated into layers. It is used by the Indians for covering theit canoes and houses, and for making baskets, drinking cups, etc.

\section{Betula alba. European White Birch.}

Leaves small, somewhat triangular and tapering, very smooth and glossy. Stem and older branches chalky white; new growth with reddish or dark brown bark. It closely resembles the Paper Birch.

Distribution.-Native of northern Europe and Asia, and is becoming naturalized in localities in the United States.

Propagation.-See genus Bchlla.

Propertics of rood.-Fairly heavy, moderately hard, does not split well, not durable. Specific gravity, air dried, 0.64 .

Uses.-The European White Birch is used here for ornamental plantings, the same as the Paper Birch, though it is a 
smaller tree. In Russia the bark is utsed in the tanning of leather, for its preservative qualities and delightful odor. Many parts of the tree are used in pharmacy.

Varieties. - There is a large number of cultivated varieties of the European White Birch, among which the following is the most highly esteemed.

\section{Betula alba pendula laciniata. Cutleaf Weeping Birch.}

This is a very handsome tree, with fincly divided leaves and a drooping habit to the smaller branches. Desirable for lawn

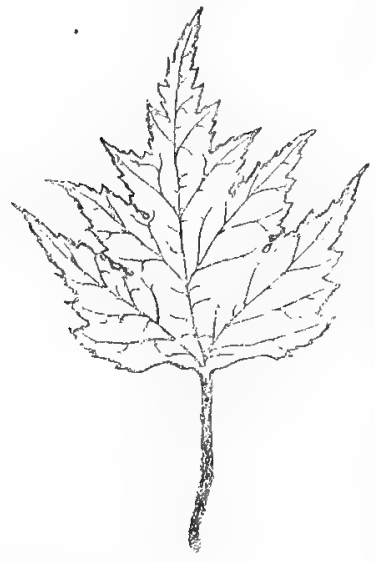

Figure 58. Leaf of Cut leaf Birch. One-half natural size. and park planting in retentive moist soil, but is very short-lived in dry locations.

\section{Betula nigra. River Birch.} Red Birch.

Leaves broadly ovate, acute or obtuse at apex, wedge-shaped at base, irregularly serrate or somewhat lobed; when mature dark green and glabrous above, pale and glabrous or tomentose beneath. Flowers open in early spring; staminate catkins mostly clustered in twos or threes, two and one-half to three and onethird inches long; pistillate catkins soft downy, oblong, cylindrical; catkins in fruit one to one and one-half inches long and about one-half inch in diameter; fruiting bracts tomentose, about equally lobed; not broadly ovate and wider than its wings, pubescent at its base; bark reddish brown. Sometimes a large tree, but very often made up of spreading stems, forming a low, bushy tree.

Distribution.-Massachusetts to Minnesota and south to Florida and Texas, where it attains its largest size. Generally found along river banks and in moist places.

Propagation.-By secds, which ripen in June, and should be sown at once, making plants eight to ten inches high by autumn. 
Propertics of wood-Light, rather hard, strong and close grained. It is light brown, with lighter colored sapwond. Specific gravity 0.5762 ; weight of a cubic font 35.91 pounds.

Uses.-The River Birch is seldom used as an ornamental trce, although it is very beautiful and does well in any good retentive soil. The wood is used for furniture, cabinet making, wooden shoes, ox yokes and in turnery.

\section{Betula lutea. Yellow Birch. Gray Birch.}

Lcaves ovate or oblong-ovate, wedge shaped or slightly heart shaped at the base. Bark of trunk yellowish gray and somewhat silvery, separating into thin layers and hanging loosely coiled up in rolls, giving old trunks a very ragged appearance. Fruiting catkins short, oblong. The inner bark, twigs and leaves spicy, aromatic. similar to wintergreen, but nuch less so than $B$. Innta. A large and very valuable timber tree.

Distribution.-From Newfoundland to the valley of the Rainy river, and south to North Carolina and Tennessee. In Minnesota common in woods in north half of the state and rare in the western and southwestern portion.

Propagation.-See genus Betula.

Properties of wood.-Heavy, very strong, hard and close grained, with a satiny surface that takes a fine polish; it is light brown tinged with red, with thin white sapwood. Specific gravity 0.6553 ; weight of a cubic foot 40.84 pounds.

Uses.-The wood of the Yellow Birch is one of the most valtuable of our northern woods, and is sometimes termed American Mahogany. It is largely used in the manufacture of fine furniture, the hubs of wheels, and for small wooden articles such as clothes pins, pill boxes, shoe pegs, tool handles, tripods, and also for keels for ships. As fuel it is much superior to Paper Birch. The bark is used to some extent for tanning purposes. The volatile oil used for imparting the flavor of Birch to candies, soda water, etc., is derived to some extent from this species though mostly from the Sweet Birch (B. lcnta.) It requires a cold, moist soil to develop its best form, and suffers severely from drouth. On this account it is not desirable as an ornamental tree or for prairie planting. 


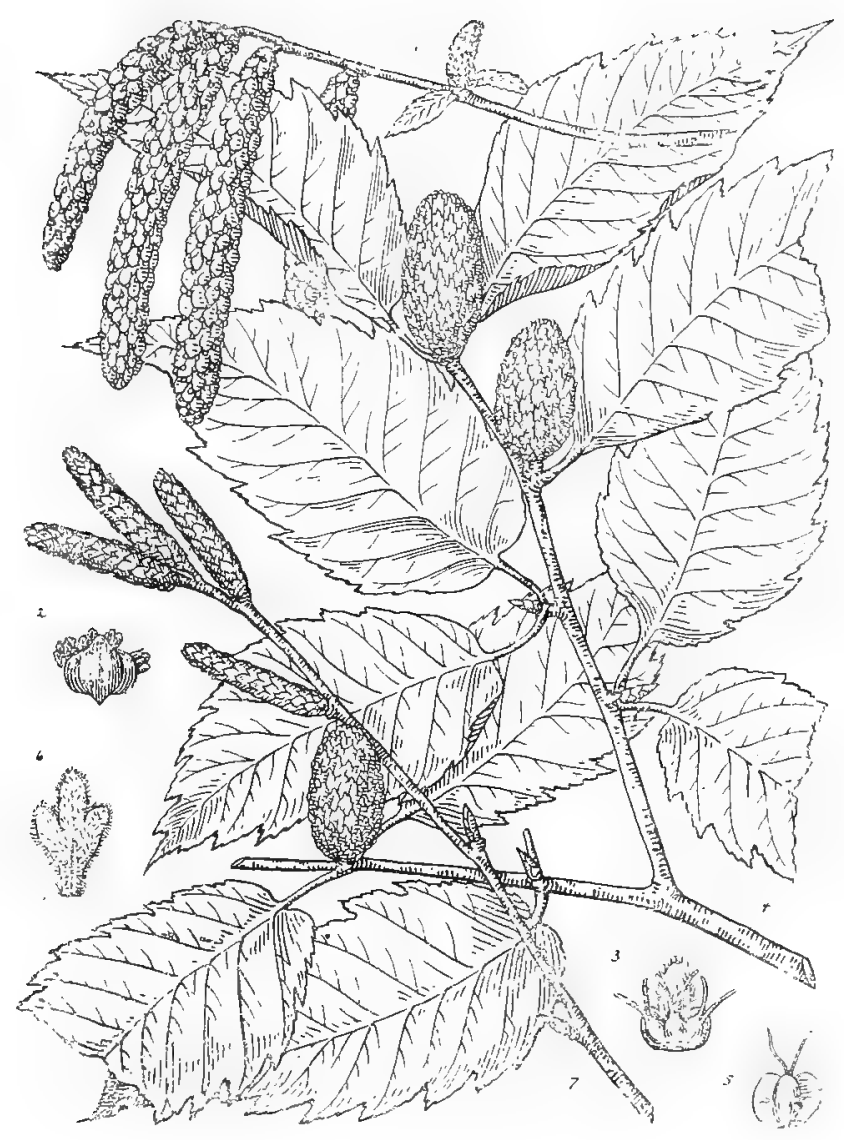

Plate 27. Betula hutca. Yellow Birch.

1. Flcwering branch, one-half natural size. 2. Staminate fower, enlarged. 3. Pistillate flower, enlarged. 4. Fruiting branch, one-half natural size. 5. Nut, enlarged. 6. Scale of iruiting catkin, enlarged. 7. Wnter branch, showing staminate catkin, one-half natural size. 


\section{Genus ALNUS.}

A genus comprising five species in the Northern States, two of which are in Minnesota. Flowers monoecious, both kinds in catkins pendulous when expanded. Apetalous, calyx usually four-parter. Fruit a winged or wingless minute flat nut. Flowers appearing before, with or after the leaves. The species here referred to is one of the smaller and least valuable of the genus. The Almus glutinosa of Europe makes a large timber tree, growing to the height of seventy feet, and Alnus oregona of the $\mathrm{Pa}$ cific slope sometimes attains a height of eighty feet and a diameter of three feet. The specius of Alnus produce soft, straightgrained wood which soon decays, but is of great durability when placed underground or in water. In some places it is largely grown for making charcoal, which is used for inferior kinds of gunpowder. Bowls and other domestic utensils are also made of its wood. The bark and cones are astringent, and are used in tanning leather and in medicine.

\section{Alnus incana. Speckled or Hoary Alder.}

Leaves oval or ovate, finely dentate, dark green above, pale or glaucous, with some pubescens beneath, veins prominent on lower surface. Catkins appearing much before the leaves; staminate catkins conspicuous in autumn and winter, one and one-half to three inches when unfolded; pistillate catkins about one-half inch long when expanded, but are protected in buds during winter. The fruit is a small cone, and opens in autumn and early winter, and generally remains on the tree until spring. The seed is flat, roundish, with a hard margin. A shrub or small tree eight to twenty-five feet high.

Distribution.-Newfoundland west to the Rocky Mountains and throughout Canada, south to Nebraska and Pennsylvania. Also in Europe and Asia. Generally found in moist places.

Propagation.-By seeds.

Properties of wood.-Light, soft, brittle, not strong.

Uses.-Seldom used in this country for any purpose, but the wood is undoubtedly of value for charcoal for the manufacture of inferior kinds of gunpowder. As a shrub for use in landscape gardening in wet places it is of some value. 


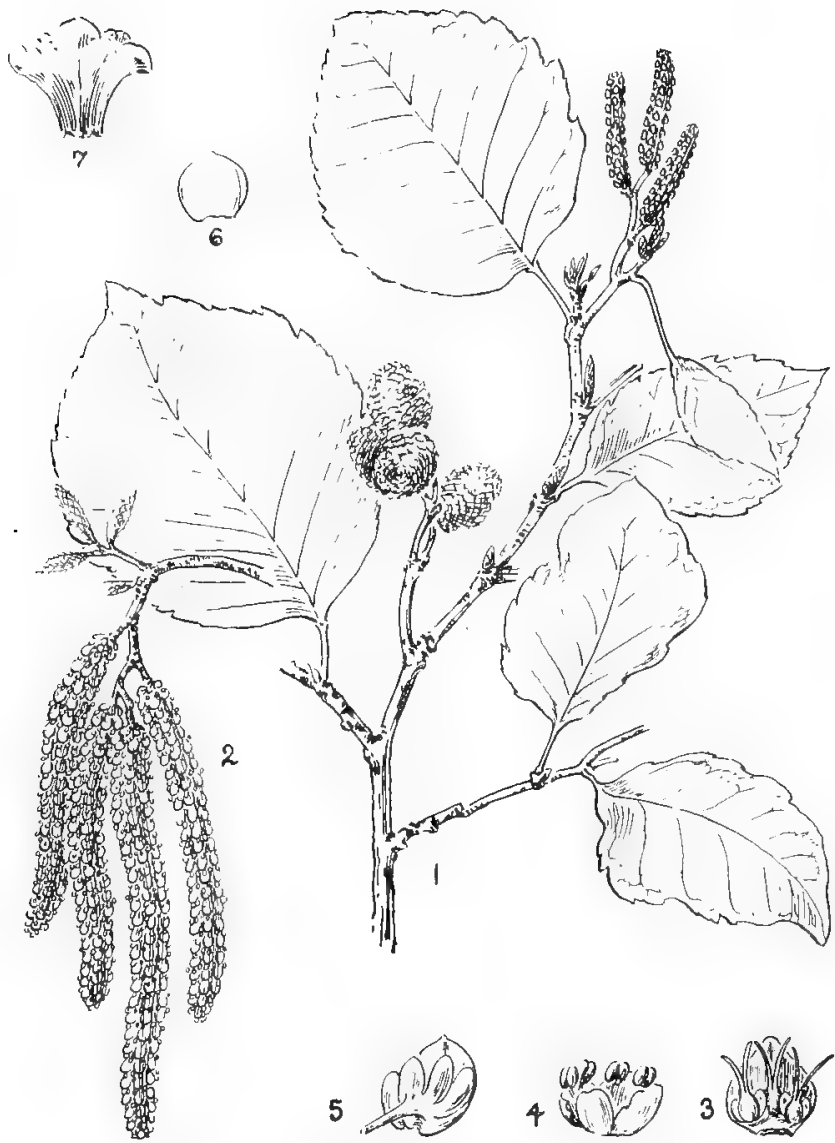

l'late 28. Aluus incana. Speckled or Hoary Alder.

1. A fruting mature branch, one-half tatural size. 2. A flowering brunch, one-halt natural size. 3. F'istillate flower and scale, front view, enlarged. 4* A staminate tower, enlarged. 5. Scale of a staminate catkin, rear view, enlarged. 6. A nut. 7 . Scalc of a cone. 


\section{Genus OSTRYA.}

Flowers monoecions, apetalous; the staminate naked in long pendulous catkins; the pistillate in erect loose catkins; ovary two-celled, inferior, surrounded by small deciduous bracts and each inclosed in a sac-like involucre which grows and forms a sort of cluster, like that of the common hop. Leaves altermate. Only one species comes within our range.

Ostrya virginiana. Hornbeam. Ironwood. Hop Hornbeam.

Leaves oblong-lanceolate, taper-pointed, very sharply and doubly serrate, green above and downy beneath. Flowers minute, appearing with the leaves. Seed in short imbricated catkin-like clusters, ripe in August but hanging on into late autumn; nut one-fourth to one-third of an inch long. Bark on old trees dark brown and furrowed, not smooth as in Carpinus. A handsome tree, generally small, but occasionally a foot or more in diameter.

Distribution.-From Cape Breton to northern Minnesota and Black Hills of Dakota and solth to northern Florida and eastern Texas. In Minnesota common throughout the timbered portions of the state except close to the shore of Lake Superior.

Propagation.-Generally grown from seeds, but may be grown from layers or grafts.

Propertics of zuood.-Heavy, very strong, hard and tough, exceedingly close grained, durable in contact with the soil and susceptible of a fine polish. It is light brown tinged with red, or ofter nearly white with thick pale sapwood. Specific gravity 0.8284 ; weight of a cubic foot 51.62 pounds.

Uscs.-The Hornbeam is a very beautiful, hardy tree, and is occasionally used for ornamental purposes, for umbrella sticks and canes, but on account of its rather slow growth it is not generally desirable for this purpose. The wood is used for fence posts, levers, mallets, handles of tools, and medicinally in homeopathic practice. 


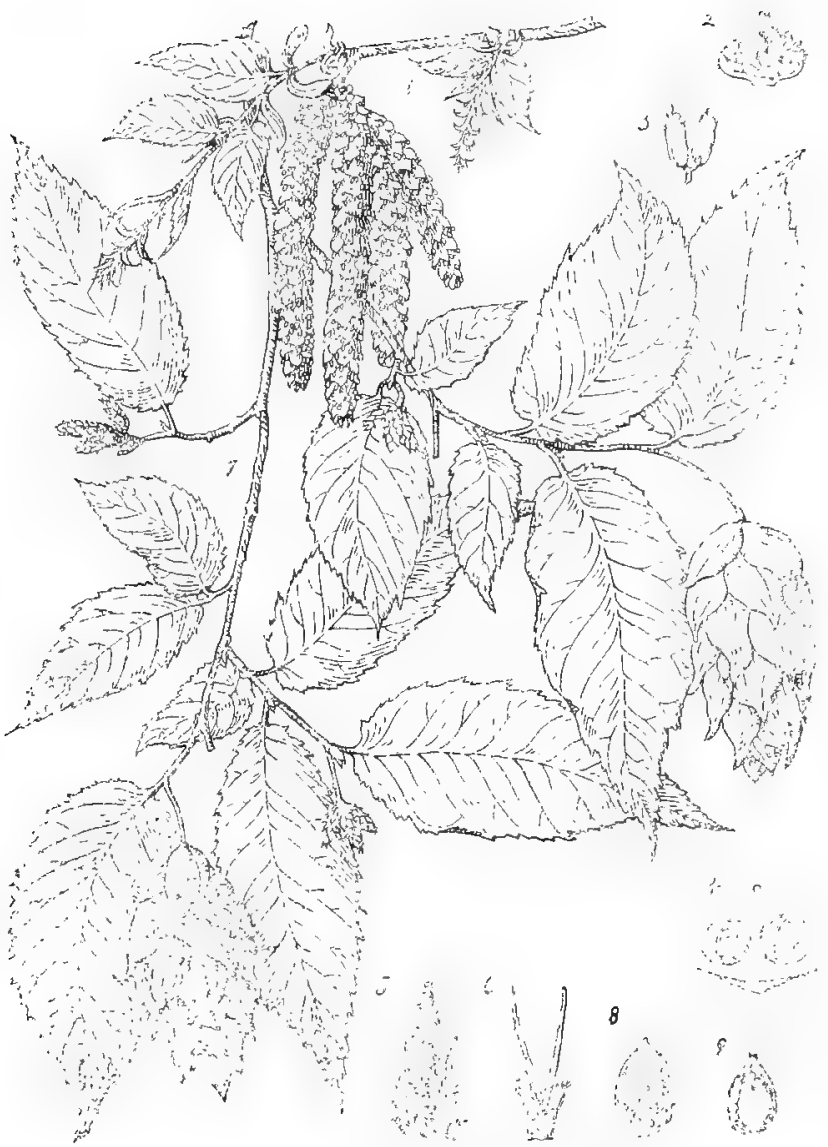

Plate 20. Ostrya itrgmana. II

I. [*lowerng branch, one-half natural size. z. Scale of staminate catkin, enlarged. 3. Stamen, enlarged. 4. Diagram of pistillate inflorescence. 5. Scale of pistillate cath, enlarged. 6. L'istillate flower enclused in bract and bractlets, enlarged. 7. Fruiting branch, one-half natural size. 8. Longitudinal section of truiting involucre, showing nut, one-half natural size. 9. Longitudinal section of nut, natural size. 


\section{Genus CARPINUS.}

Tall, slender trees or small shrubs. Ahnut twelve species in the northern hemisphere, only one of which is indigenous to North America.

Carpinus caroliniana. Blue Beech. Water Beech. Hornbeam.

Leaves ovate, oblong, sharply serrate, pale blue-green on upper surface and light yellow-green on the lower, smooth and thin, two and one-half to four inches long, resembling those of the common Beech. Flowers monoecious, appearing with the leaves; the staminate in rather dense catkins and the pistillate in small slender loose catkins with a three-lobed bracelet to each seed. Fruit in loose clusters at the ends of the new growth, with large three-lobed bracts to the involucre, ripening late in the autumn. The nut is one-sixth to one-third of an inch long. Shrubs or trees twenty or more feet high, with smooth, grayish bark and stems often deeply furrowed.

Distribution.-From southwestern Quebec westward to northern Minnesota and eastern Nebraska and south to Florida and Texas. Also found in southern Mexico and Central America. In Minnesota common throughout the south half of the state, along streams and around lakes.

Propagation-By seeds, which grow irregularly. The varieties may be grafted or budded on seedling stocks.

Propertics of wood.-Heavy, very strong, hard and close grained; light brown, with thick, nearly white sapwood. Specific gravity 0.7286 ; weight of a cubic foot $45.4 \mathrm{I}$ pounds.

Uses.-The graceful habit, dark blue-green foliage and beautiful autumn tints of the Blue Beech make it a desirable tree for parks and lawns on good soil in somewhat sheltered situations. The wood is so very tough that it was used by the early settlers in the northern states for brooms, ox-gads, withes, etc. The toughest wood of our northern forests. 


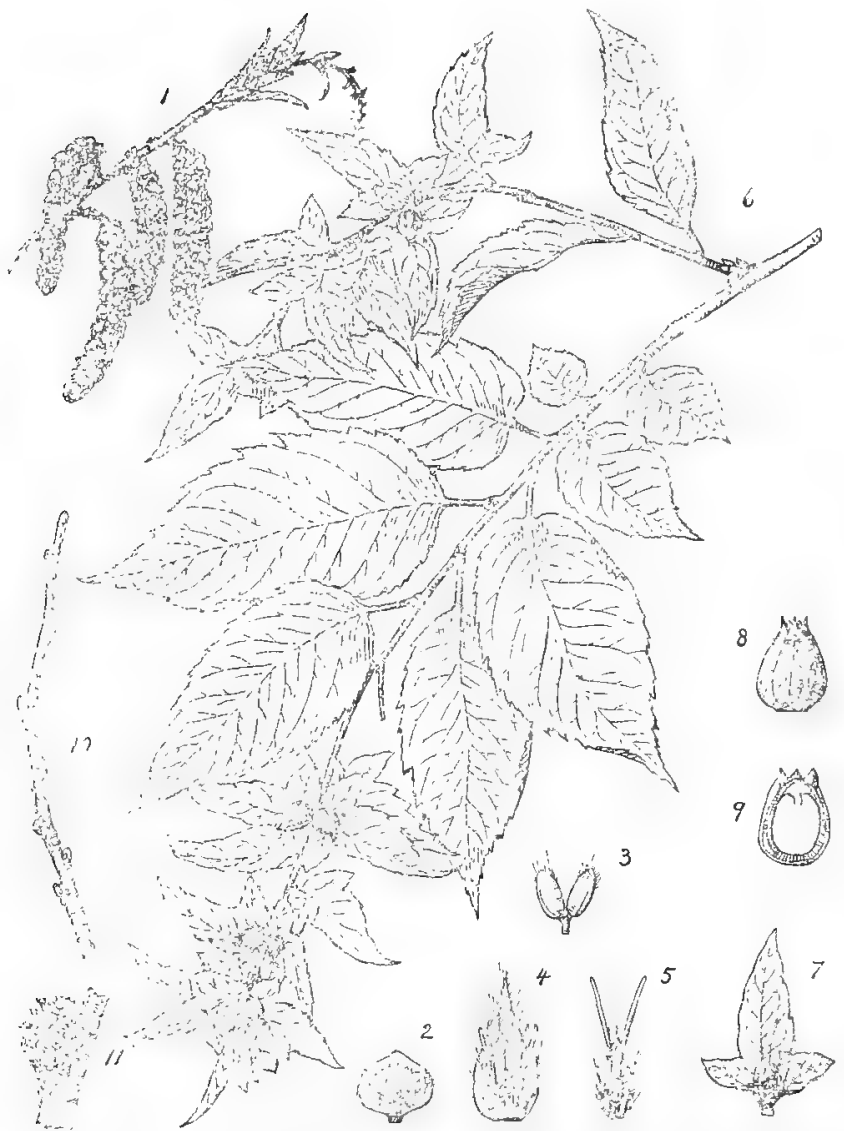

I'late 30. Carpinus caroilzana. Blue Beech.

I. Flowering branch, one-half natural size. 2. Scale of staminate cat. kin, enlarged. 3. Stamen, enlarged. 4. Scale of pistillate catkin, enlarged. 5. Pistillate flower with bract and bractlets, enlarged. 6. Fruiting branch, one-half natural size. 7 . Nut with involucre, one-half natural size. 8 . Nut, enlarged. 9. Longitudinal section of nut, enlarged. ro. Winter branch, one-half natural size. II. Staminate catkin in winter, enlarged. 


\section{FAGACEAE. OAK FAMILY.}

\section{Genus CASTANEA.}

Trecs or shrubs with watery juice and serrate straight reined leaves. Flowers monoccious, strong smelling, in axillary catkins near the ends of the branches, appearing after the leaves. The staminate flowers in erect or spreading yellowish cylindrical catkins; calyx mostly six-parted; stamens numerous, sometimes with abortive ovary; flaments slencler. The fertile Howers ustually two to five in an ovoid scaly prickly involucre at the base of the androgynous catkins; calyx with a six-lobed border crowning the mostly six-celled ovary and usually with four to twelve abortive stamens; ovules two in each cavity, but only one to each ovary usually maturing; styles corresponding in number with the cavities in the ovary, slender, exserted; stigmas small. Involucre of fertile flowers enlarging and becoming globose, mostly four-valved; in fruit a thick, very prickly bur inclosing from one to three ovoid nuts. Cotyledons very thick, cohering and remaining underground in germination.

\section{Castanea dentata. Chestnut.}

Leaves oblong lanceolate, pointed, acute at base, serrate with coarse pointed teeth; when mature smooth and grcen on both sides. Fruit sweet and edible, ripening in autumn. A large lorest tree with gray bark.

Distribution.-Maine and Ontario to Delaware, Michigan, Tennessee and Mississippi.

Propagation.-Most commonly by seed, which should be sown in autumn or stratified over winter and sown in the spring. The seed is very difficult to preserve in good condition for germination unless carcfully stratificd out of doors. When dried it soon loses its vitality and when stratified in the cellar is very liable to mould. The forcign sorts, of which there arc a number in cultivation, are mostly propagated by grafting on the species.

Propertics of rood.-Linht, solt, not strong, coarse grained, liable to check and warp in clrying, easily split, very dirable in 


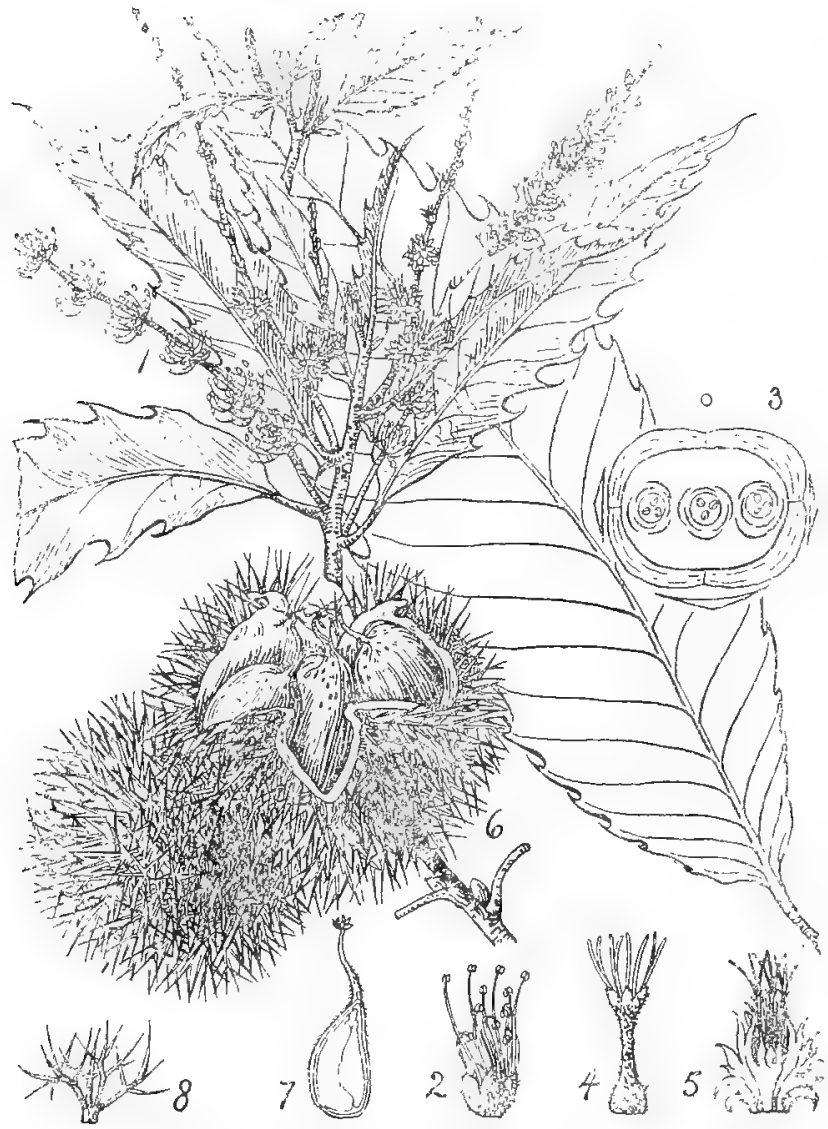

Plate 31. Casianca dentata. Chestnut.

I. Flowering branch, one-half natural size. 2. Staminate flower, en larged. 3. Diagram of pistillate flower cluster. 4. Pistillate flower, en. larged. 5. Longitudinal section of involucre of pistillate flowers. 6. Por tion of iruiting branch, one-half natural size. 7 . Longitudinal section of fruit, one half natural size, 8. Involucral spine, 9. End of young branchlet. 
contact with the soil, reddish brown, with thin, light colored sapwood. Specific gravity 0.4504 ; weight of a cubic foot 28.07 pounds.

Uses.-Within and near its range the Chestnut is an important and very fast-growing timber tree that readily renews itself from sprouts from the roots. As an ornamental tree it is highly esteemed wherever it is hardy. In this section it is not sufficiently hardy to warrant any extensive planting of it, but has held on well for twenty years in Houston county, where are found thrifty trees cight inches in dianeter and forty feet high at the home of Mr. J. S. Harris. In the forest plantation at the Minnesota Experiment Station the young trees are doing very well.

The wood is used in the manufacture of cheap furniture, school globes and object forms, tool handles, kegs, for interior finishing of houses, for railway ties, fence posts and rails. Its durability is due to the large amount of tannic acid which it contains. An extract of the wood is largely used in tanning.

\section{Genus QUERCUS.}

A very large genus of about 200 species, which are not always clearly defined. The fout here described are nearly distinct, but there are great variations in the species, and many undoubted hybrids. Flowers greenish or yellowish, monoecious; the staminate in slender naked catkins, each flower consisting of a four to seven-parted or lobed calyx and four to twelve stamens; the pistillate flowers scattered or somewhat clustered, each consisting of a nearly three-celled, six-ovuled, inferior ovary with a three-lobed stigma and inclosed by a scaly bud-like involucre, which becomes the hardened.cup (cupule) around the base of the fruit, which is a rounded onecelled nut or acorn. Cotyledons remain underground in germination. All our species flower in the spring and shed their acorns in the autumn of the same or following year. This genus is readily divided into the White Oak and the Black Oak classes.

The White Oak class is characterized by lcaves with rounded lobes, tecth that are never bristlc pointed; edible acorns maturing the first year, inner surface of shell glabrous; wood hard, close grained, durable; tree with deep permanent tap root. 
The Black Oak class is characterized by leaves having acute lobes and bristle-pointed teeth; acorns bitter, maturing the second year, inner surface of shell of acorn woolly; wood porous and brittle; roots spreading, seldom having clearly defined tap roots except when young.

Oak bark is used for tanning leather. The cork of commerce is the older bark of the Qucreus subcr of southern Europe. Galls caused by insects puncturing the young and tender shoots are produced on the branches of most oak trees, and are imported in large quantities from Asia Minor, China and elsewhere to be used in the manufacture of inks and dyes. The bark of most species is tonic and astringent, and as a decoction is sometimes cmployed as an external remedy.

Oak is in general use for ship and car building, general construction, canoes, carriages and wagons, furniture and finishing, school apparatus, billiard tables, cooperage, gunstocks, drawing instruments, pumps, cheese boxes, basket work, umbrella sticks and canes.

Propagation.-All the species grow readily from seeds which have been kept properly, but if allowed to get dry they are liable to lose their vitality. The seedlings have tap roots often three to four feet long when the top is not more than a foot high. On this account the trees are often very difficult and uncertain to transplant, but if the tap roots are cut off a foot from the surface of the grotnd when the trees are one year old they form side roots and then may be moved with a reasonable degree of certainty within the next few years before they have formed new tap roots.

\section{Quercus alba. White Oak.}

Leaves short petioled, oblong or obovate in outline, obliquely cut into three to nine oblong or linear and obtuse mostly entire lobes, smooth excepting when young, pale or glaucous underneath, bright green above, turning to a soft wine color in autumn. Fruit an edible acorn maturing the first year, hence borne on the shoot of the season, three-fourths to one inch long, oblong. often peduncled, not more than one-third covered by the hemispherical saucer-shaped naked cup which is rough or tubercled at maturity. A noble and picturesque tree sometimes attaining a height of 100 feet w.th a trunk six feet in diameter, but much smaller within our range. Its bark is rough, 


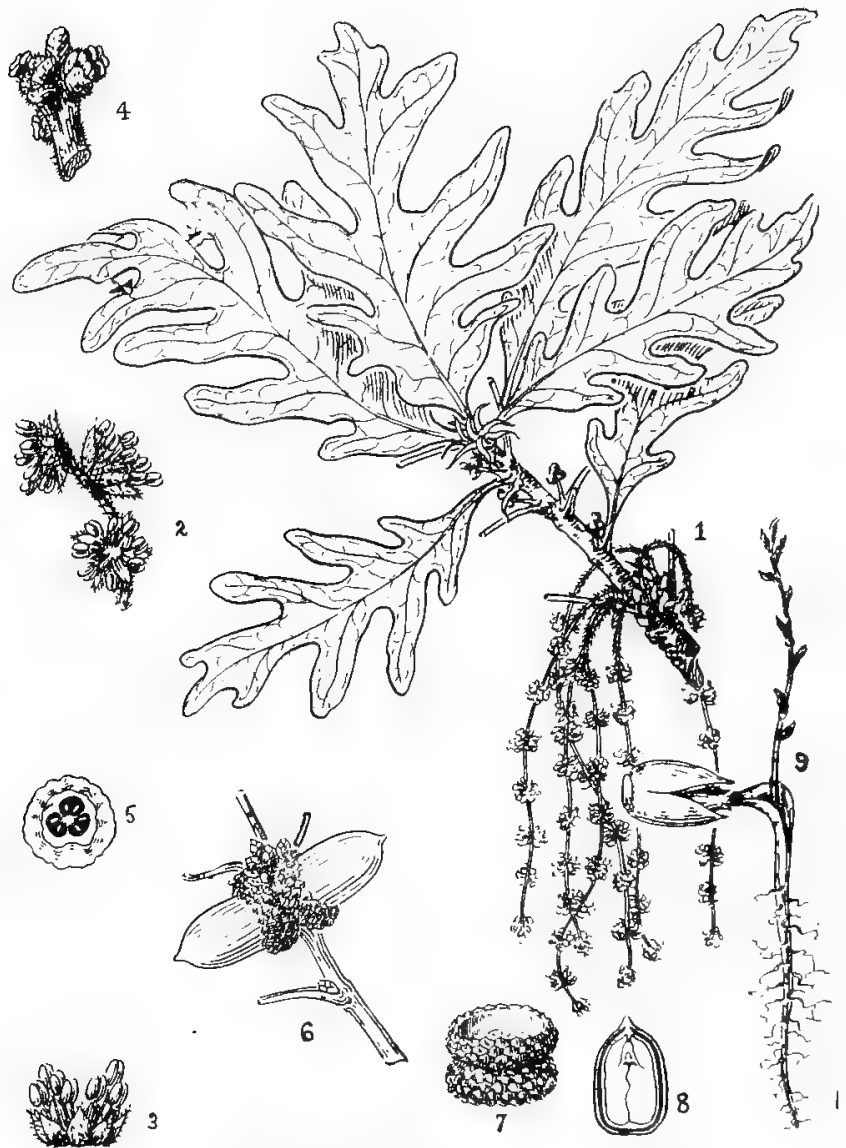

l'late 32. Qucrews alla. White Oak.

I. Flowcring branch, one-half natural size. 2. Portion of a staminate catkin, enlarged. 3. Staminate flower, cnlarged. 4. Cluster of pistillate flowers, enlarged. 5. Cross section of ovary, enlarged. 6. Fruiting branch, one-half natual size. 7. Cup, one-lialf natural size. 8. Longitudinal section of acurn, one-half natural size. 9. A germinated acorn, one-half natur. al size. 
with longitudinal fissures and of a whitish gray color, whence its name. It is also conspicuous from its holding many of its dead withered leaves until nearly spring, and in this respect it differs from the Bur Oak, to which it is closely allied but which sheds all its leaves in autumn.

Distribution.-From southern Maine westward through Ontario to southern and central Minnesota and eastern Kansas. south to Florida and Texas. In Minnesota frequent in the southeastern and central parts of the state.

Propagation.-The acorns of the White Oak naturally start into growth in the first of autumn, and often form roots several inches long by the time the ground freezes. In consequence of this there is but a short tine in which to sow them, and this should be done as soon as they can be gathered in autumn or if planted later great pains must be taken not to break the radicle which will probably have pushed out. The seeds require only ordinary care to secure a good stand if properly managed.

Properties of wood.-Strong, very heavy, hard, tough, close grained, durable in contact with soil although liable to check unless carefully seasoned; color light brown with thin light brown sapwood. Specific gravity 0.747 ; weight of a cubic foot 46.35 pounds.

Uscs.-The White Oak is highly esteemed as an ornamental tree on account of its sturdiness, longevity and magnificent spreading form, although it is seldom planted on account of its slow growth; one of our hardiest trees, although it will not endure as much drouth as the Bur Oak or White Elm. The wood is of great value on account of its adaptability to many purposes where a tough, strong, close grained wood is needed. It is largely used in ship building, in construction, in cooperage, for casks, barrels, kegs, tubs, pails and measures (large 'luantities being exported to Europe in the form of staves), in the manufacture of agricultural implements, carriages and baskets, for flooring and the interior finishing of houses, in furniture and cabinet making, tool handles and for railway ties, fence posts and fucl.

\section{Quercus p1atanoides. Swamp White Oak.}

Leaves obovate or oblong-obovate, coarsely sinuately toothed or sometimes lobed, dark green above and usually densely white-tomentose beneath, except on foliage that is much shaded. 


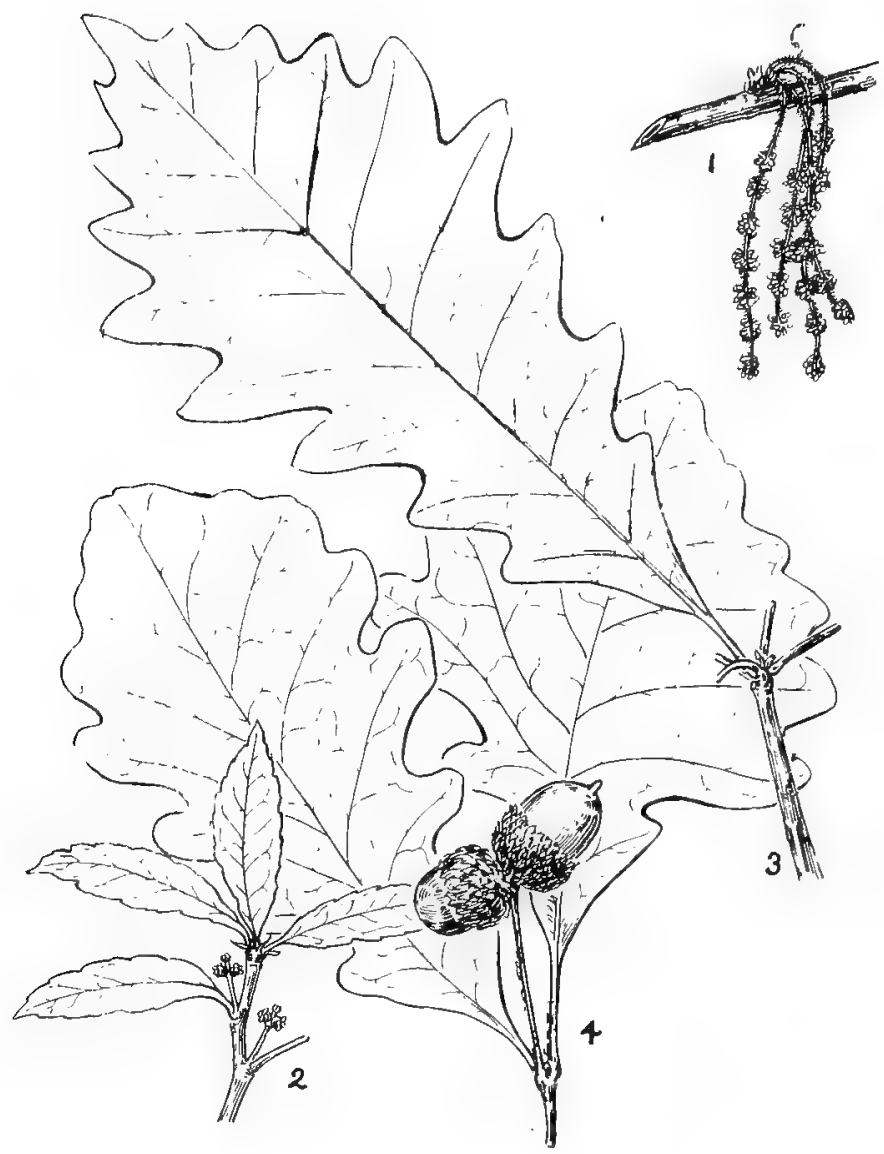

l'late 33. Qucreus platanoides. Swamp White Oak.

I. Staminate inflorescence, onc-half natural size, 2. Pistillate inflorescence and young branch, one-half natural size, 3. A leaf grown in the shade. 4. $\Lambda$ fruiting branch, reduced. 
Fruit usually in pairs and matures the first year; borne on slender erect peduncles from one and one-half to two and onehalf inches long. The rather deep cup incloses about one-third of the acorn, which is oblong-oval in form and about one inch long. Bark, gray, flaky, especially on young trees or branches. A large tree, attaining commonly a height of about seventy feet in this section, with a diameter of three or four feet. Easily recognized by the flaky bark of the young growth and the small dwarfed, twisted and generally pendulous branches, which often occur on the larger limbs and trunk.

Distribution.-From Maine to Minnesota and Missouri, and from Ontario south to northern Kentucky and Arkansas, where it is generally found along the borders of streams and swamps, . in moist, fertile soil.

Propagation.-By seed, as for white oak.

Properties of wood.-Heavy, hard, strong and tough; liable to check badly in seasoning. Color light brown, with sapwood of about the same shade. Durable in contact with the soil. Specific gravity 0.7662 ; weight of a cubic foot 47.75 .

Uses.-The Swamp White Oak is excellent for carriage building, cooperage, agricultural implements, railway ties, fence posts, cabinetmaking, interior finish of houses and for fuel.

Quercus macrocarpa. Bur Oak. Mossy-Cup Oak. Bur White Oak.

Leaves large, ovate or oblong, lyrate-pinnatifid or deeply sinuate-lobed or parted, the lobes sparingly toothed or entire, irregular, downy or pale beneath and bright green above, turning to a dull yellow before falling in autumn. Cup (cupule) deep, thick, woody, conspicuously imbricated with hard, thick pointed scales, the upper ones generally awned so as to make a mossy, fringed border, but this is occasionally lacking. Acorns ovoid, almost spherical, half or wholly inclosed by the cup. Bark rougher and darker colored than that of the White Oak. A large tree, varying greatly in form, sometimes growing Ioo feet high and six or seven feet through the trunk, but in this section seldom over seventy feet high and three feet through.

Distribution.-From New Brunswick and Nova Scotia westward to Manitoba, Montana and Kansas, and southwestward to 


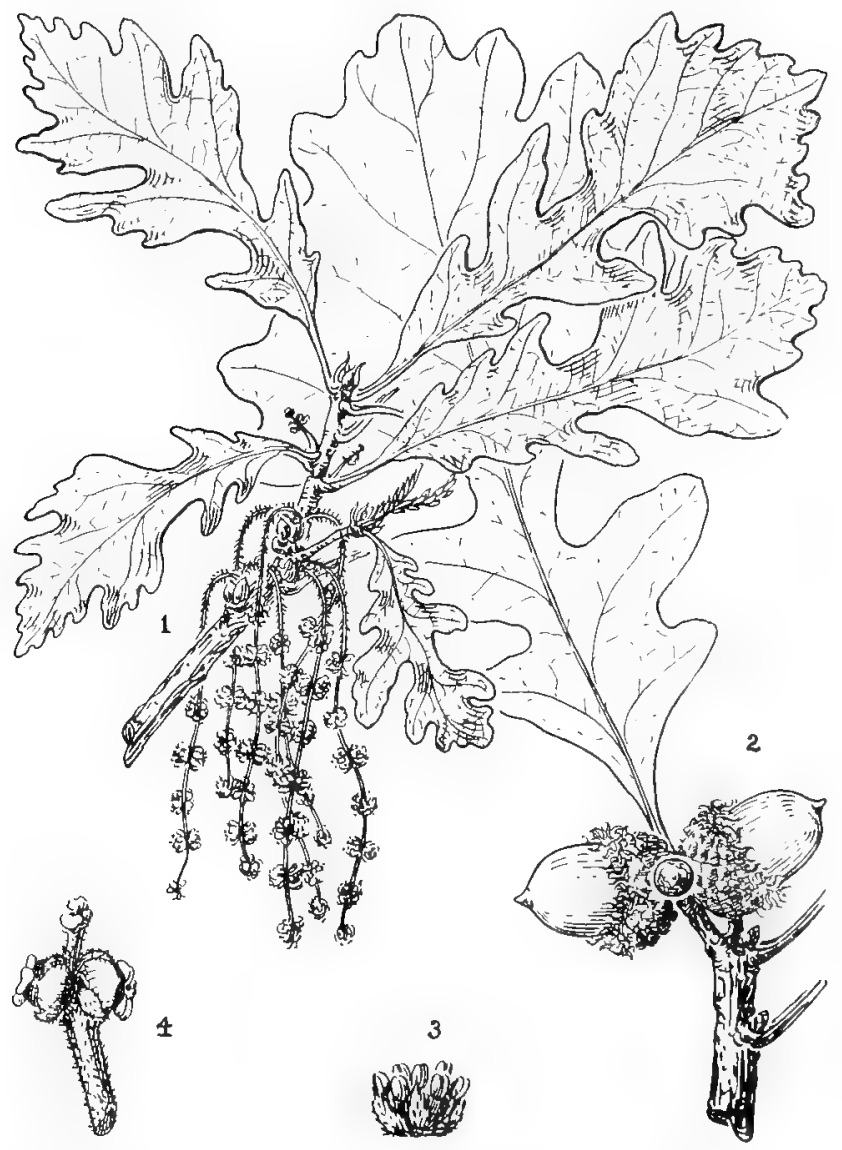

I'late 34. Qucrus macrocarpa. Bur Uak.

I. Flowering branch, one-half natural sizc, 2. Frtiting branch, onehalf natural size. 3. Staminate flower, cnlarged. 4. Pistillate inflores- 
Tennessee, Indian Territory and Texas. In Minnesota common or abundant in all except the extreme northeastern part.

Propagation.-Very easily grown from seeds planted in autumn. The seedlings in good prairie soil attain a height of about four feet in five years.

Proporties of zoood.-Heavy, hard, rather brittle, coarse grained and very durable in contact with the soil; color, rich brown with much lighter brown sapwood. Specific gravity 0.7453 ; weight of a cubic foot 46.45 pounds.

Uscs.-The Bur Oak is the most magnificent, most durable and longest lived tree for planting throughout this whole section. It is also one of the most valuable timber trees of North America. Although its wood is rather coarser grained and inferior in strength to that of the White Oak, with which it is commercially confounded, yet it is used for the same purposes.

\section{Quercus rubra. Red Oak.}

Leaves oblong-obovate to oblong, moderately sometimes deeply pinnatifid with rounded sinuses, seven to nine narrow lobes, these and the teeth being bristle pointed; mature leaves rather thin, turning dark red after fiost in autumn. Cup saucershaped or flat, with a narrow raised border of fine scales, sessile or on a very short stalk, very much shorter than the acorn. which is oblong-ovoid or turgid-ovoid, one inch or less in length, with a bitter kernel. Two years are required to ripen the nut, which is consequently found on the old wood below the leaves of the season. Bark smoother than that of most oaks. A tree seventy to eighty or more fect high, with a trunk three or four feet in diameter.

Distribution.-Fron Nova Scotia to the divide west of Lake Superior and to central Kansas, south 10 Georgia and Tennessee. In Minnesota found along the Mississippi river and occasionally in other parts, but is not very common anywhere in the state.

Propagation.-Easily grown from fall sown seeds.

Propertics of wood.-Heavy, hard, strong, coarse grained and liable to check badly in drying. Specific gravity $0.662 \mathrm{r}$; weight of a cubic foot, 41.25 pounds.

Uses.-The Red Oak has been used to a limited extent in this country and Europe as an ornamental tree, for which its stately 


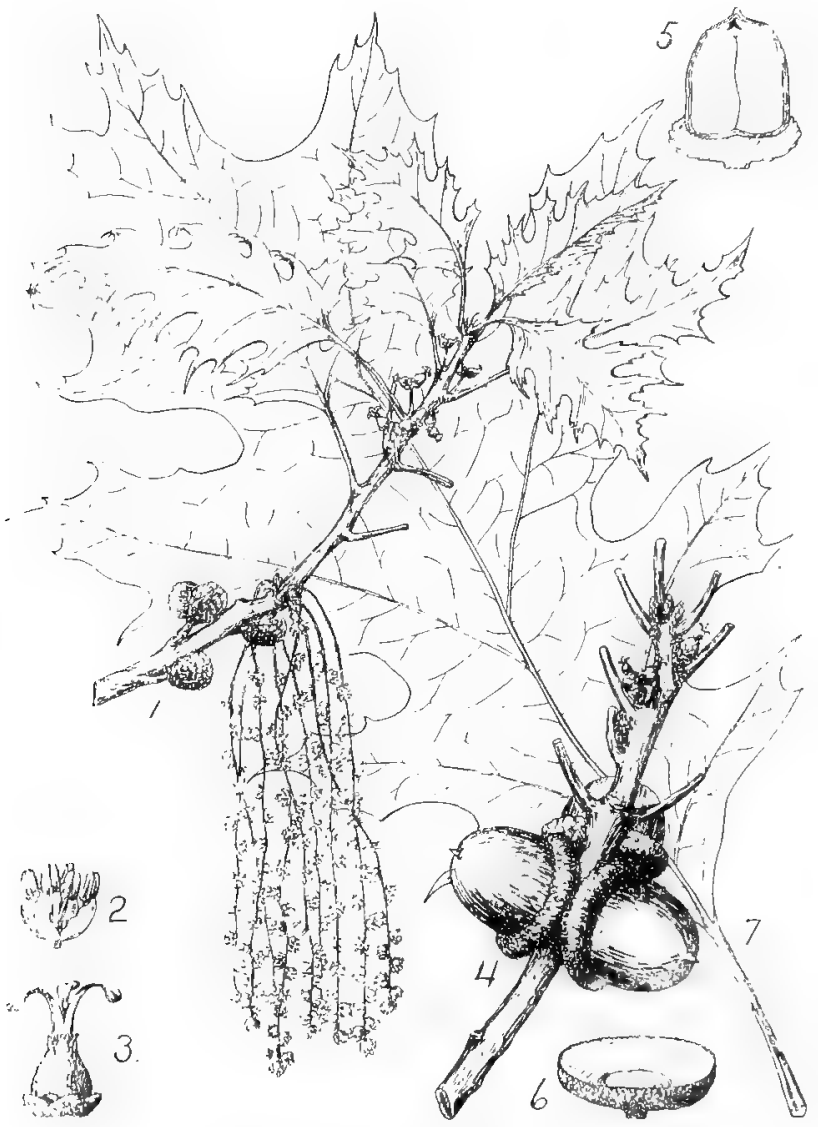

l'late 35. Unoreus rubra. Ral Uak.

I. Flowering branch showing inmature fruit of one year's growtl, onc. half natural si८்ֻ. 2. Stammate flower, enlarged. 3. Pistillate flower, enlarged. 4. liruining branch, one-halt natural size. 5. Longitudinal section of fruit, one-half natural size. 6. Cup, one-half natural size. 7. Mature lcaf, cne-half natural size. 
form, vigorous growth and fine autumn coloring make it especially desirable. No oak of the Northern States is more easily transplanted. The wood, which in trade is not distinguished from that of the Scarlet Oak, is used for interior finishing, furniture and in construction, and has a beatuiful grain for finishing. It is often used for fuel, but is generally though not nniversally considered much inferior to the White Oak for this purpose.

\section{Quercus coccinea. Scarlet Oak. Black Oak.}

Leaves oblong or obovate, decply pinnatifid with broad rounded sinuses and slender lobes divergent and divided at the apex into several teeth which are bristle-pointed. When the leaves unfold they are bright red and covered with pubescence, but towards maturity they become shining green and generally glabrous above, the lower side in this section often furnished with tufts of hair in the axils of the veins. The leaves turn a brilliant red or scarlet in autumn, remain on the trees in this section all winter and fall in the spring. The buds are often slightly pubescent, and are smaller and very different from the large tomentose buds of Quercus velutina. The fruit, which ripens in the autumn of the second year, is sessile, or on a stalk which is sometimes an inch long. It is oval or globular ovoid, with a bitter kernel. A common and often large tree in this section, where it is generally termed Black Oak, and is found on gravelly ridges and sandy land interspersed with Bur and Red Oak.

Distribution-From Maine to the District of Columbia and west to Minnesota and Nebraska.

Propagation.-By fall-sown seeds.

Propcrties of wood.-Heavy, hard, strong, coarse grained, light or reddish brown with thick darker colored sapwood. Specific gravity $0.7 \mathrm{c} 95$; weight of a cubic foot 42.20 pounds.

Uscs.-The Scarlet Oak is not planted to so great an extent as the Red Oak for ornamental purposes, but is fully as desirable because of its beautiful scarlet autumn coloring and rapid growth. The wood is largely used in the manufacture of furniture, for interior finishing and for fuel, and is not distinguishea commercially from that of Red Oak. 


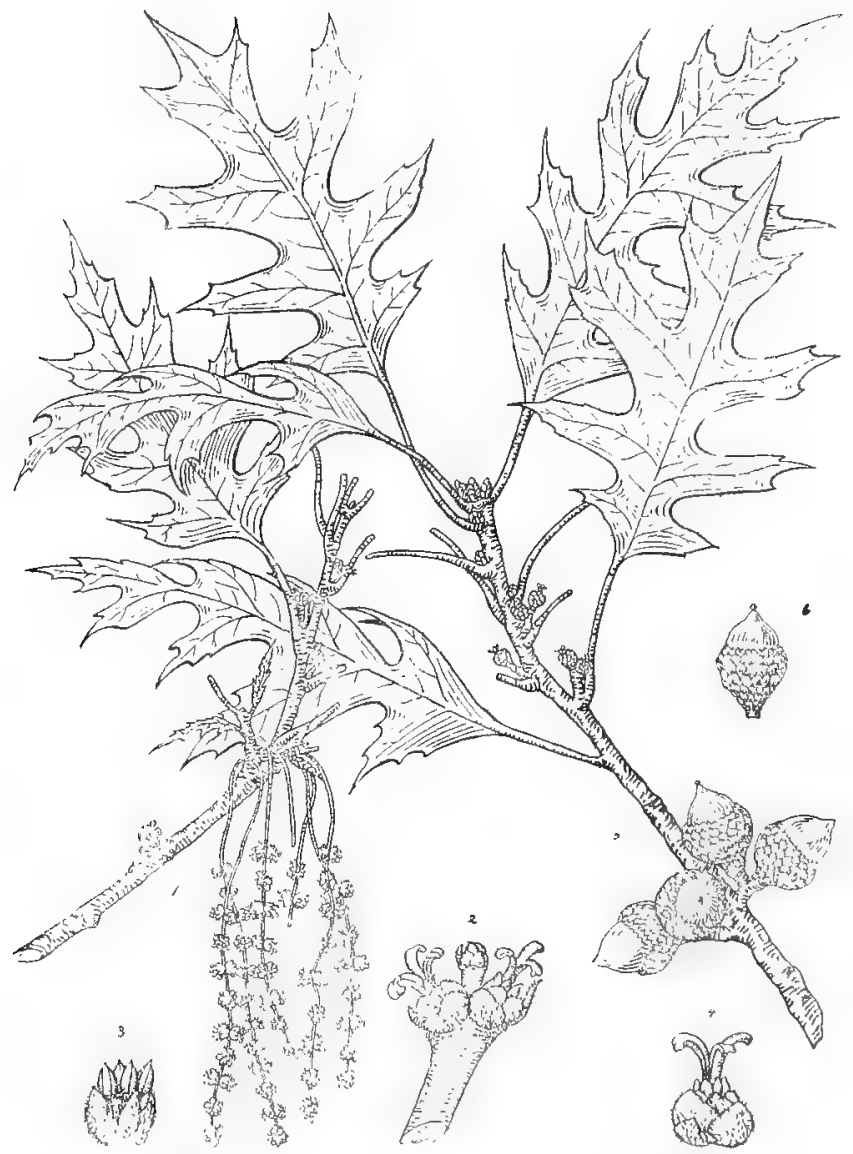

I'late 36. Sucreus coccinca. Scarlet Uak.

1. Iijuncrint brancl, onc-lalf natural sizc. 2. Pistillate flower cluster, cnlarged. 3. Staminate flower, enlarged. 4. Pistillate flower, enlarged. 5. liruiting branch, onc-lialf natural size, 6, Acorn, one-half natural size. 


\section{ULMACEAE. ELM FAMILY.}

\section{Genus ULMUS.}

Leaves simple, alternate, two-ranked, short petinled, straight veined, usually rather rough. Flowers appear before the leaves in our species; perfect or rarely polygamous, apetalous, greenish, in lateral clusters: calyx four to nine lobed; stamens four to nine with long slender filaments; ovary superior, one-celled or rately two-celled, flattened; styles two, short and diverging. Fruit a samara with a broad membranous margin, one-celled, one-seeded, ripens in early sunmer; seed all embryo. A genus of about fifteen widely distributed species, which are mostly large deciduous trees, three of which occur in our range. Most of the elms produce hard, tough wood, that is often difficult to split. The European species have given rise to many varieties differing from the parent species in many ways, but chiefly in habit of growth and color of foliage. A form of the European Scotch Elm (U. Montana) with pendulous habit, known in nurseries as Camperdown Weeping Elm, has done very well in a sonewhat protected location at the Minnesota Experiment Station, and bids fair to make a very ornamental specimen. The stock on which it is worked (probably $U$. campestris), however, has sunscalded. In China a white mucilaginous meal is made from the inner bark of the Elm, and is used as food by the mountaineers of the northern provinces and in the composition of incense sticks. The frtut is employed in medicine, and the bark and young frutits are eaten in periods of severe famine.

Propagation.-The species are grown from seeds and the varieties by layers, budding, and grafting. With the exception of the Slippery Elm (q. v.) the seeds should be sown as soon as gathered.

U1mus americana. White E1m. American Elm. Water Elm.

Leaves three to four inches long, obovate-oblong to oval, usually smooth on the upper and soft and velvety on the lower surface, coarsely and doubly serrate, taper-pointed, turning to a bright yellow before falling. Branches small, slender, ascending, at length spreading and pendulous; twigs and buds smooth, 


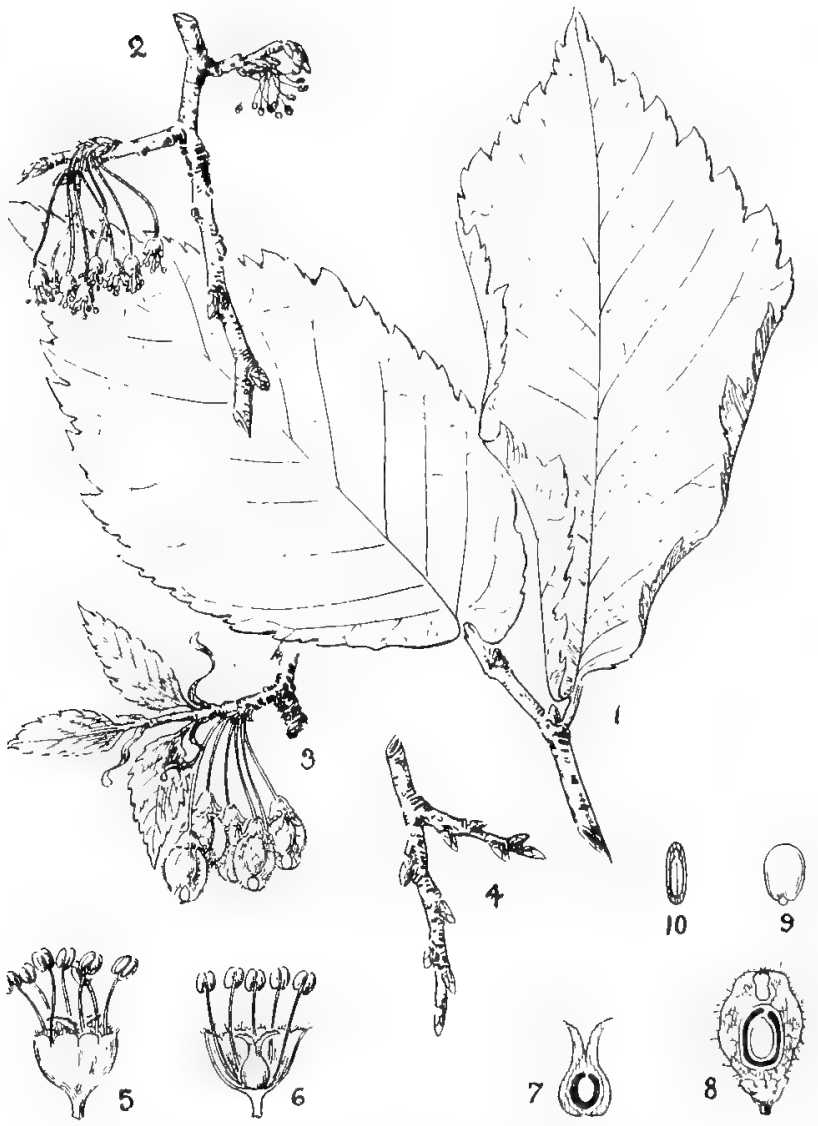

J'late 37. Ulmus americana. White Elm.

1. I'ortion of summer branch, one-half natural size. 2 . Irlowering branch, one-lialí natural sıze, 3. ir ruiting branch, one-half natural size. 4. Portion of winter branch, one-half natural size. 5- Hlower, cnlarged. 6. Longitudinal section of flower, enlarged. 7. Longitudinal section of pistillate flower, cnlarged. 8. Longitudinal section of fruit, natural size. 9. Embryo, cnlarged. Io. Longitudinal section of seed, natural size. 
not corky. Flowers appear in April, in dense clusters, with slender drooping pedicels. Firuit ripe in May, smooth except the edges, which are hairy, with incurved sharp points at the apex. A large common tree, sometimes 120 feet high and six feet or more in diameter. This tree varies greatly in habit; some specimens may be cutite upright in growth while others are very pendulous. One having the drooping habit, that was found in Illinois, is now offered by nurserymen.

Distribution.-From Newfoundland and along the northern shores of Lake Superior to the eastern base of Rocky Mounthins, south to Florida and Texas and west in the United States to the Black Hills of Dakota and western Kansas. In Minnesota common throughout the state.

Propagation.-Described under gents Ulmus. The seeds can often be swept up on roadways and pavements in large quantities.

Propertics of wood.-Very tough in young trees, light and moderately strong in old, difficult to split and rather coarse grained; color light brown, with lighter colored sapwood. Specific gravity 0.6506 ; weight of a cubic foot 40.55 pounds.

Uscs.-The White Elm has always been the favorite shade and ornamental tree in the Northern States, and is the best street and park tree for general planting in this section. It is also one of the hardiest trees for prairie planting, and will perhaps withstand as great extremes of temperature and moisture as any of our shade trees. It is a rapid and often straggling grower, and should have a little attention in the way of pruning when young to keep it in its best form. The wood is largely used in the manufacture of agricultural implements. for hubs of wagon wheels, for saddletrees, for flooring, in cooperage, for flour and meal barrels, cheese boxes, etc. The bark was used by the Indians when they could not procure birch bark in making their canoes and houses. In some parts of this country the tough inner bark was formerly twisted into ropes.

U1mus racemosa. Cork E1m. Rock Elm.

Leaves ovate-oblong or obovate, taper-pointed, smooth above, pubescent beneath, resembling those of the White Eilm, but less sharply serrate. Twigs and bud scales pubescent; 


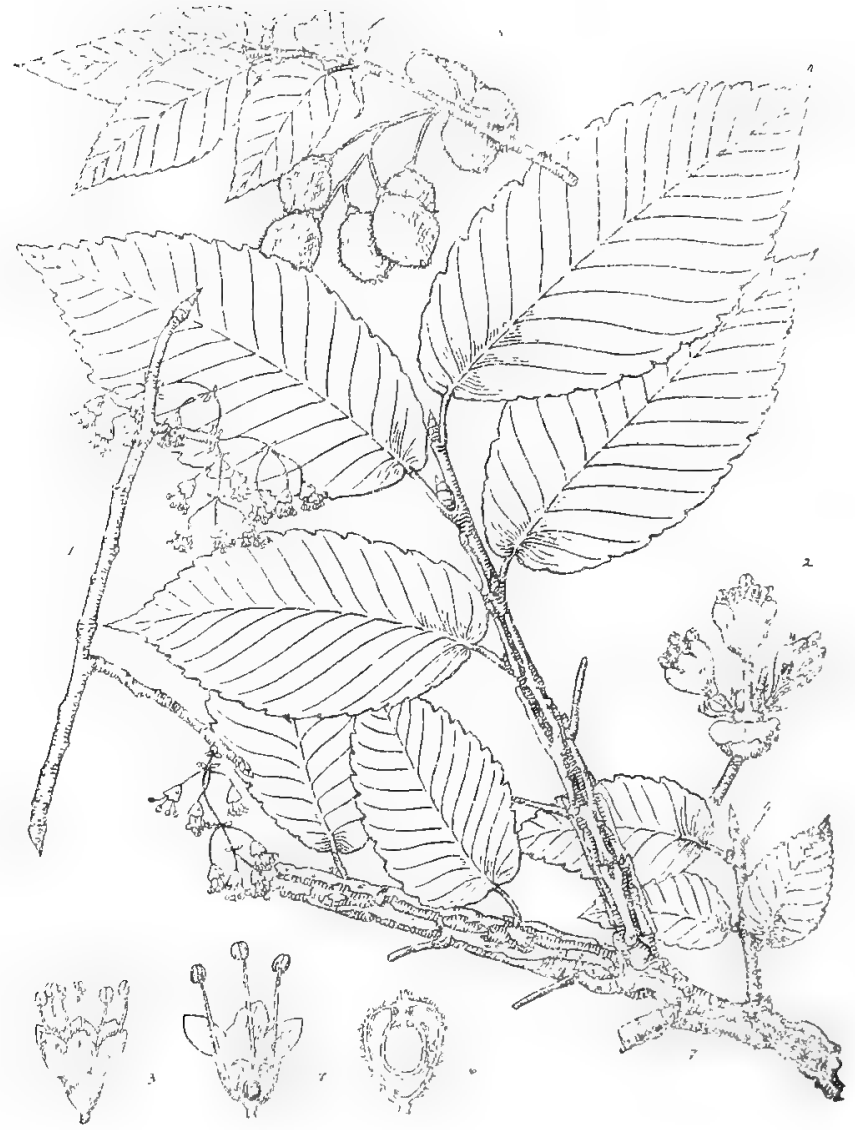

Plate 38. Ulmas faccmosa. Cork Elm.

I. Flowering liranch, one-half natural size. 2. Cluster of fowers subtended by bud scale, enlirgel. 3. Flower, enlarged. 4. Longiludinal section of flower, enlarged. 5. Iiruiting branch, one-half natural size, 6. I, ongitudinal section of fruit, two-thirls natural size. 7. Summer branch, one half natural size. 
branches generally with corky ridges or wings. Flowers in April, in open loose racemes with slender pedicels not in clusters. Frutit ripe in May, an ovate elliptical samara about threefourths of an inch long, pubescent, with margins thickly fringed, much like the fruit of the White Elm, but somewhat larger, Occasionally a tree eighty to one hu: .:ed feet high and three feet in diameter.

Distribution.-From Quebec, Ontario, Vermont and northern New York west to Minnesota and south to Missouri and Tennessee.

In Minnesota frequent in the eastern part and extending into the Minnesota Valley west at least to Montevideo, Chippewa county.

Propagation.-Described under genus Clmus.

Properties of wood.-Heavy, hard, very strong and tough, close grained, susceptible of receiving a high polish, very difficult to split. It is light brown, with yellowish or greenish white sapwood. Specific gravity 0.7265 ; weight of a cubic foot 45.63 pounds.

Uses.-As an ornamental tree the Cork Elm is occasionally used in place of the White Elm, and though a slower grower its great hardiness and sturdy form make it very desirable for park and street planting. It should be used more frequently than at present. The wood, having so many valuable qualities, is much sought for, and its extinction seems possible. It is largely used in the manufacture of large agricultural implements, like plows and threshing and mowing machines, for beams of stump pullers, bridge timbers, piles, wagon hubs, rims of bicycle wheels and ax handles. For the latter purpose it is superior to hickory. In fact, it is superior to most other woods wherever great strength, toughness, solidity, flexibility and durability are required.

\section{U1mus pubescens. (L. fularu) Slippery E1m. Red Elm. Moose Elm.}

Leaves ovate-oblong, doubly serrate, very rough above and slightly rough or soft downy beneath, often four to six inches long, taper-pointed, trough shaped, turning to a dull yellow before falling, fragrant while drying." Buds before expansion soft, downy, large; branclilets downy. Flowers in April, borne 


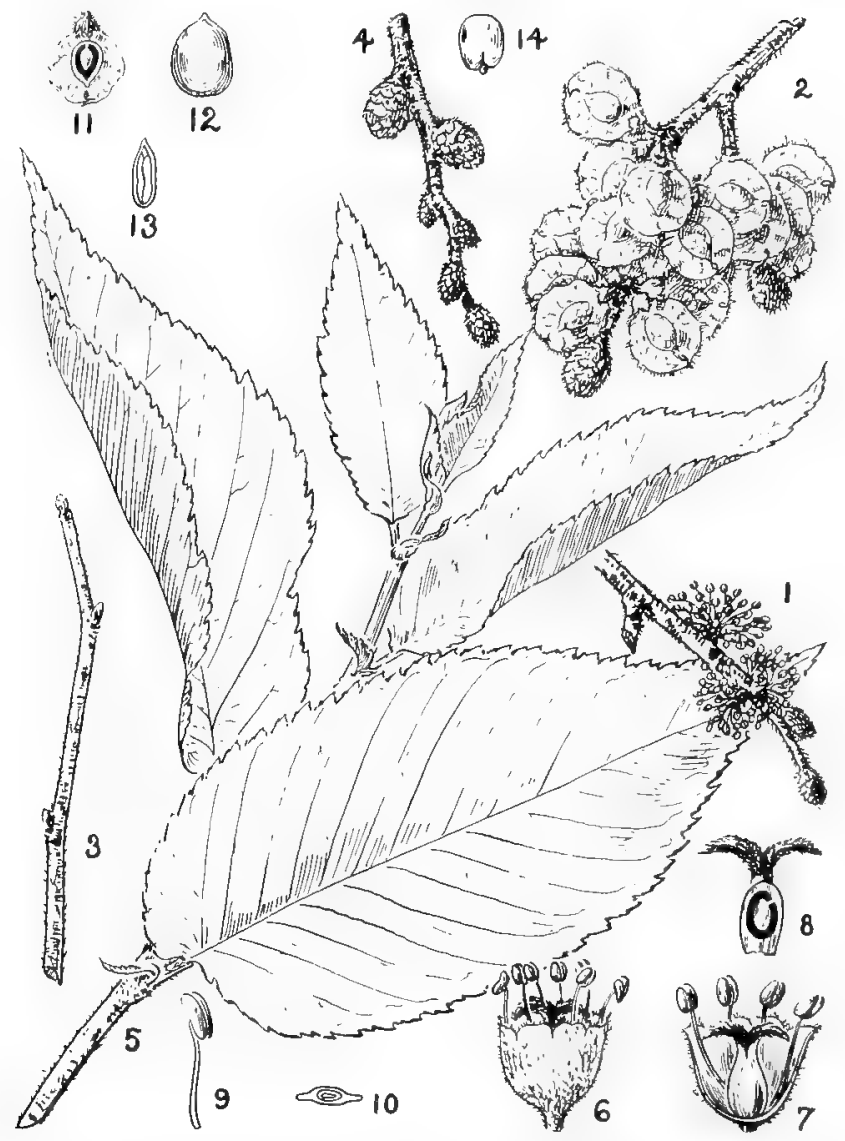

Plate 39. Ulmus pubescens. Slippcry Elm.

I. Flowering branch, onc-half natural size. 2. Fruiting branch, one-halt natural size. 3. A young winter bratuch with buds, one-half natural size. 4. Winter branch, showing flower buds beginning to enlarge, one-half natural size. 5. Summer branch, one-half natural size. 6. Flower, enlarged. 7. Jongitudinal section of flower, cnlarged. 8. Longitudinal section of pistil, cnlarged. 9. Stamen, enlarged. 10. Cross section of ovary, enlarged. I1. L.ongitudinal section of fruit, one-half natural size. 12. Seed, enlarged. $\pi_{3}$. Longitudinal section of seed, cnlarged, 14. Embryo, enlarged. 
on short pedicels. Fruit in May or June, nearly circular, about three-fourths inch long, only slightly if at all downy. Tree of medium size, forty to sixty feet high, with a trunk occasionally two feet in diameter.

Distribution.-From Quebec and Ontario west to North Dakota and south to Florida and Texas; less common than the White Elm. In Minnesota frequent throughout the state except far nothward.

Propagation.-By seeds kept stratified until the spring following the period of ripening. Unlike the other elms, the seeds will not grow the same season that they mature.

Propertics of wood.-Heavy, hatd, strong, very close grained, durable in contact with the soil, splits as freely and easily as that of young chestnut. It is dark brown, with thin, lightcolored sapwood. Specific gravity 0.6956; weight of a cubic foot 43.35 pounds.

Uses.-In cultivation the Slippery Elm is a shapely, fast growing tree, well adapted to this section; not of as pretty a form nor as hardy in dry locations as the White or Rock Elm, but more valuable in home timber lots. When planted as a street tree, the bark is likely to be stripped off by boys. The trees when planted closely together grow straight and tall and make excellent poles for farm use. When used for posts, they should be cut in summer and be peeled and dried before setting. When this is done they will last a long time. The wood 'is used for sleigh runners, the running gear of carriages, hubs of wheels, and in the manufacture of agricultural implements. It is tough when boiled or steamed, hence is one of the best woods for ribs of canoes and skiffs. The thick fragrant inner bark is soft, mucilaginous and slightly nutritious. It has been known to support life in case of scarcity of food. It is reported that during the last war with Great Britain the soldiers on the Canadian frontier found it a grateful and nutritious food for their horses in times of scarcity of forage. It is used in medicines for affections of the throat and lungs and for other troubles. 


\section{Genus CEITIS.}

Leaves alternate, simple, short petioled. Flowers monoeciously polygamous, appearing in the axils of the leaves of the season; the staminate in little clusters or racemes; the perfect flowers solitary or in pairs, peduncled; styles two. Fruit a globular drupe; embryo curved, nearly inclosing a little gelatinous albumen. Only one species in the Northern States of interest to us here.

Celtis occidentalis. Hackberry. Sugarberry. Nettle Tree.

Leaves quite various, but usually ovate to ovate-lancelate, sharply and coarsely serrate or sparingly so, taper-pointed, more or less rough above and unusually soft pubescent beneath, at least when young. Flowers appear in April and May, solitary, small, white, on rather long peduncles. Fruit a small, solitary, round, sweet edible drupe, reddish or yellowish, turning a dark purple when fully matured, remaining on tree into the winter; peduncle twice the length of the petioles. Generally a small, but sometimes a large tree over too feet high and two or three feet in diameter. The tree resembles the White Eilm, but the branches come out more at right angles and the bark is rougher and more closely divided than that of the White Elm.

Distribution.-From Montreal west to Lake of the Woods and North Dakota, and south to Filorida and eastern Texas. West of the Rocky Mountains it is rare, but occurs on banks of streams. It has been found in Idaho, Washington, Oregon. Nevada, Utah, Colorado and New Mexico, In Minnesota frequent in the southern half of the state, and not uncommon in the valley of the Red River even near the extreme northern limit of the state.

Propagation.-Easily grown from seeds, which should be sown as soon as ripe or stratified over winter and sown in the spring.

Properties of wood.-Heavy, rather soft, not strong, coarse grained, dark or light brown, with thick, light colored, often ycllowish, sapwood. Specific gravity 0.7287 ; weight of a cubic foot 45.4 I pounds.

Uses.-The Hackberry is of rapid growtly, and is one of the best trees for general park, lawn and prairie planting here. 


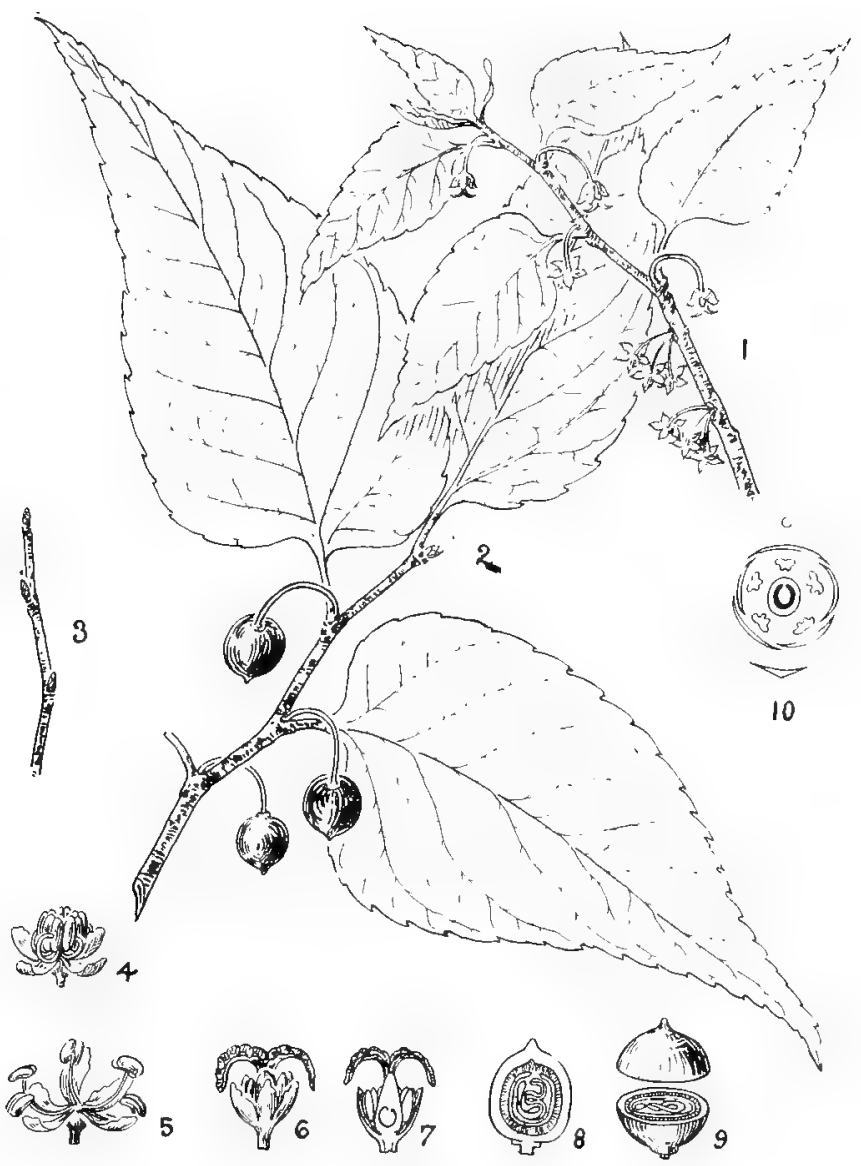

I'late 40. Celtis occidentalis. Hackberry.

I. Flowering branch, one-half natural size. 2. Frutiting branch, one. half natural size. 3. Winter twig, one-lialf natural size. 4. Staminate Hower before straightening of filaments, enlarged. 5. Stamnate flower, expanded, enlarged. 6. Perfect flower, enlarged. \%. Longitudinal section of perfect flower, enlarged, 8. Longitudinal section of fruit, natural size. 9. Trans. verse section of fruit, natural size. 1o. Diagram of flower. 
No deciduous tree presents a more graceful appearance in winter when the finely divided spray of the limbs, and the small size of the young growth make it very attractive. In this section it is preferred to the White Elm for a shade tree by some experienced planters. It endures drouth well, but is probably not as hardy in this way as the White Elm. It is also less liable to split in the crotches. The wood to some extent is used to take the place of elm, as in harness making.

\section{MORACEAE. MULBERRY FAMILY.}

The largest genus of this family is Ficus, which contains over 600 known species, including the cultivated fig (Ficus carica) and the Indiarubber Tree (Ficus elastica). The following genus contains about ten species, natives of the northern hemisphere.

\section{Genus MORUS.}

Trees or shrubs with milky sap and alternate; dentate and often lobed leaves. Flowers monoecions or dioecious (rarely polygamous) in axillary catkin-like spikes, the pistillate spikes ripening into succulent aggregated fruits. Calyx four-parted, in the pistillate flower becoming fleshy; stamens four; pistils one; stigma two.

\section{Morus rubra. Red Mulberry.}

Leaves ovate or ncarly orbicular in outline, acute or taperpointed, occasionally deeply lobed, glabrous above, persistently pubescent beneath, or when young almost tomentose. Flowers appear with the unfolding of the leaves. The fruit, which is at first bright red, when fully grown becomes dark purple or nearly black, and when fully ripe is sweet, juicy and pleasant to the taste. It ripens in summer, and is from one to one and one-fourth inches long. South, it forms a large tree, with brown rough bark, but within our range it is a small tree or mere shrub.

Distribution.-Vermont to Ontario, Michigan, and South Dakota and south to Florida and Texas. In Minnesota it reaches its northern limit in the southern part of the state. 
Propagation.-By secds or by cuttings.

Propertics of wood.-Light, soft, not strong, rather tough, coarse grained, and very durable in contact with the soil. Specific gravity 0.5808 ; weight of a cubic foot 36.75 pounds.

Uscs.-The Red Mulberry is sometimes used in the Middle and Southern States as an ornamental tree, where it forms a large spreading tree forty feet higin. It well deserves a place on lawns or in parks, but is not very hardy in Minnesota. The wood is valued for fence posts, and is used in cooperage; in the Southern States it is often used in boat building. The inner bark is fibrous, and was used by the Indians of the Southern States for making a coarse cloth; in early days this fiber. was used for cordage. The leaves have been largely experimented with as food for silk worms, but they are not so good for this purpose as those of the White Mulberry (Morus alba).

\section{Morus alba tartarica. Russian Mulberry.}

Leaves thin, smooth, glabrous and somewhat shining on both sides, heart-shaped, ovate or orbicular, generally deeply lobed and dentate. The same plant will often have leaves of several forms. Flowers appear with the leaves, generally dioecious or monoecious, but rarely polygamous. The fruit ripens early in July, and is white or purplish in color, and varies from threefourths to one and one-half inches in length. As commonly seen it is a low-growing, very bushy-topped, small tree with light gray bark and spreading branches.

Distribution.-Native of central Asia.

Propagation.-By seeds, cuttings, layers or graftage. The seeds, if sown as soon as gathered, will make plants about one foot high the first season.

Propertics of zoood.-Probably much the same as those of the Red Mulberry.

Uses.-The Russian Mulberry was introduced into the Western States by the Russian Mennonites, who esteem it very highly for its many good qualities, among which is the ease with which it is propagated, its rapid growth, the value of the leaves as food for silk worms, its fruit, ornamental appearance and the durability of the wood in contact with the soil. It is not perfectly hardy in this section, but generally holds on well as far north as St. Paul, although it generally kills back con- 


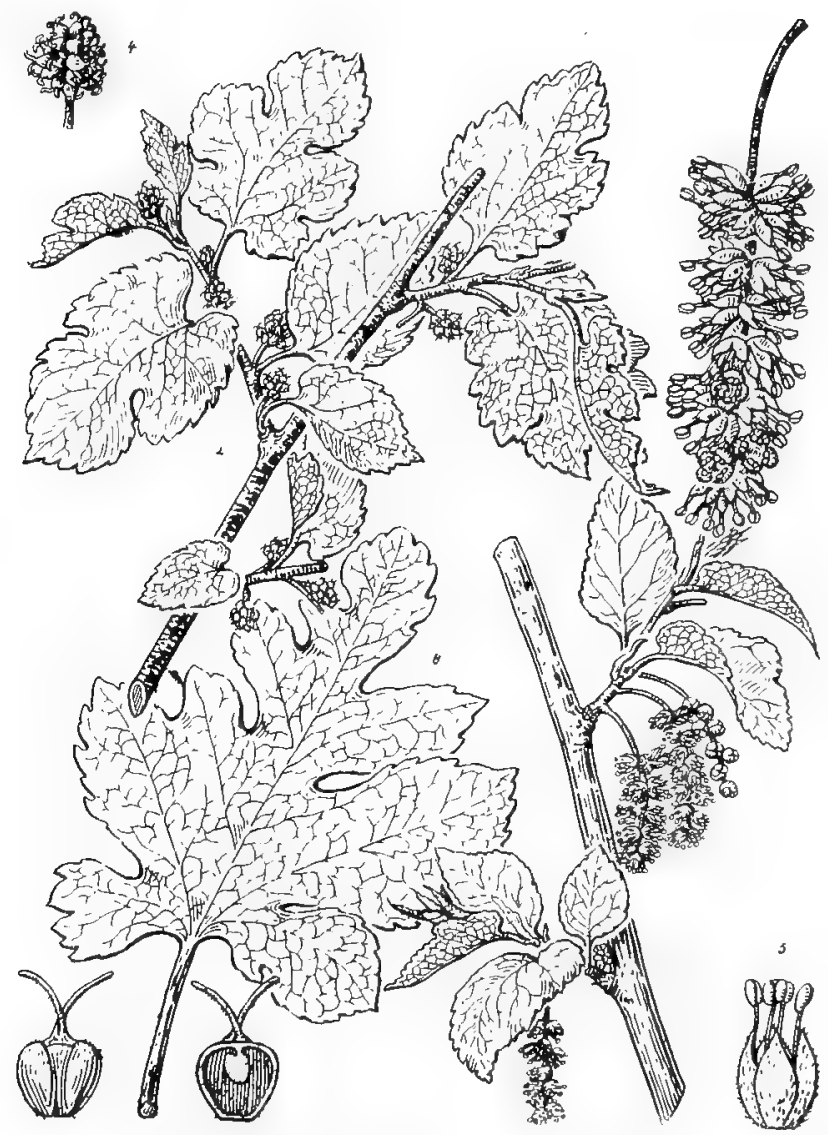

Plate 4I. Morus alba tartarica. Russian Mulberry.

I. IBranch bearing staminate flowers, one-half natural size, 2. Branch bearing pistillate flowers, one-half natural size. 3. Staminate flower-cluster, enlarged. 4. I'istillate flower-cluster, natural sizè, 5. Staminate flower, enlarged. 6. Pistillate flower, enlarged. 7. Longitudinal section of pistil, enlarged. 8. Full grown lobed leaf, one-half natural size. 
siderably for the first few years after planting. While it can be grown in tree form, it is much better adapted to being grown in this section in the form of a windbreak. It bears pruning well, and makes a very pretty hedge, but is not adapted to turning cattle, as it is unarmed. The fruit is insipid and generally small, but in almost every large lot of seedlings a few specimens will be found producing fruit of good size and fair quality. While the fruit is not marketable, it is often used domestically, and also furnishes a large amount of food for birds just when strawberries and raspberries are ripening, and is preferred by them to the more acid berries, hence affords some protection to these more important crops. Objections to its use in ornamental planting are its susceptibility to injury by late spring frosts, which blacken the new growth, and the early falling of the leaves in autumn. While its leaves are well adapted to feeding the silk worm, and have been successfutly used for this purpose in this section in a small way, yet the industry has not become profitable.

Varictics.-A variety known as Teas Weeping Mulberry has been partially tried at the Minnesota Experiment Station, and gives promise of proving sufficiently hardy for somewhat protected places. This variety is vigorous, naturally sprawls on the ground, and when worked on straight stems, its very pendulous branches make it a very conspicuous object. Foliage excellent.

\section{ROSACEAE. ROSE FAMILY.}

A large family of trees, shrubs and herbs, including many of our cultivated fruits and ornamental plants.

\section{Genus PYRUS.}

Leaves simple or pinnately compound, flowers white or rose colored, in corymbs, cymes or clusters, perfect, regular; stamens numerous; styles five (sometimes two or three); carpels of the same number, two-seeded. Seeds in cells that are made up of horny, parchment-like thin walls. Fruit a pome, 
Pyrus ioensis. Iowa Crab. Wild Crab. Western Crab.

Leaves simple, oblong or obovate-oval, variously notched and toothed: the lower surface as well as the leaf stalks, short pedicels and young growth densely white pubescent. Flowers rose-colored, fragrant, much like those of Pyrus coronaria, with which this species was formerly classed and is now sometimes referred to as a variety. Fruit round, somewhat flattened, dull green with small light dots, hard, bitter, keeps through the winter. A small tree.

Distribution.-Minnesota and Wisconsin, south to Kentucky and Indian Territory.

Propagation.-By seeds or by graftage. It docs not form a durable union wth Pyrus malus, although such unions may last several years.

Propcrites of wood.-Ileavy, close grained, not hard nor strong; brown to light red in color, with thick yellow sapwood. Specific gravity 0.7048 ; weight of a cubic foot 43.92 pounds.

Uses.-The Iowa Crab, with its large fragrant fowers, forms a very pretty small ornamental tree. The fruit is made into preserves and cider. When growing in its natural state the tree is hardy and is seldom injured by fire-blight, but seems to be very much subject to this disease when cultivated, especially after it has been transplanted.

\section{Pyrus americana. Mountain Ash. American Mountain Ash.}

Leaves odd-pinnate; leaflets eleven to seventeen, lanceolate, taper-pointed, bright green above, gencrally paler beneath. Flowers in large compound leafy cymes, appearing in May or June. Fruit usually three-celled, globose or slightly pearshaped, bright red with thin flesh, one-fourth inch in diameter, ripens in late autumn and remains on the tree all winter unless eaten by birds. A small tree with smooth bark seldom reaching a height of thirty feet, and often a mere shrub.

Distribution.-From Newfoundland to Manitoba and southwards through the more elevated portions of northeastern United States and the region of the Great Lakes. It reaches its greatest size north of Lake Superior and Lake Huron. In 


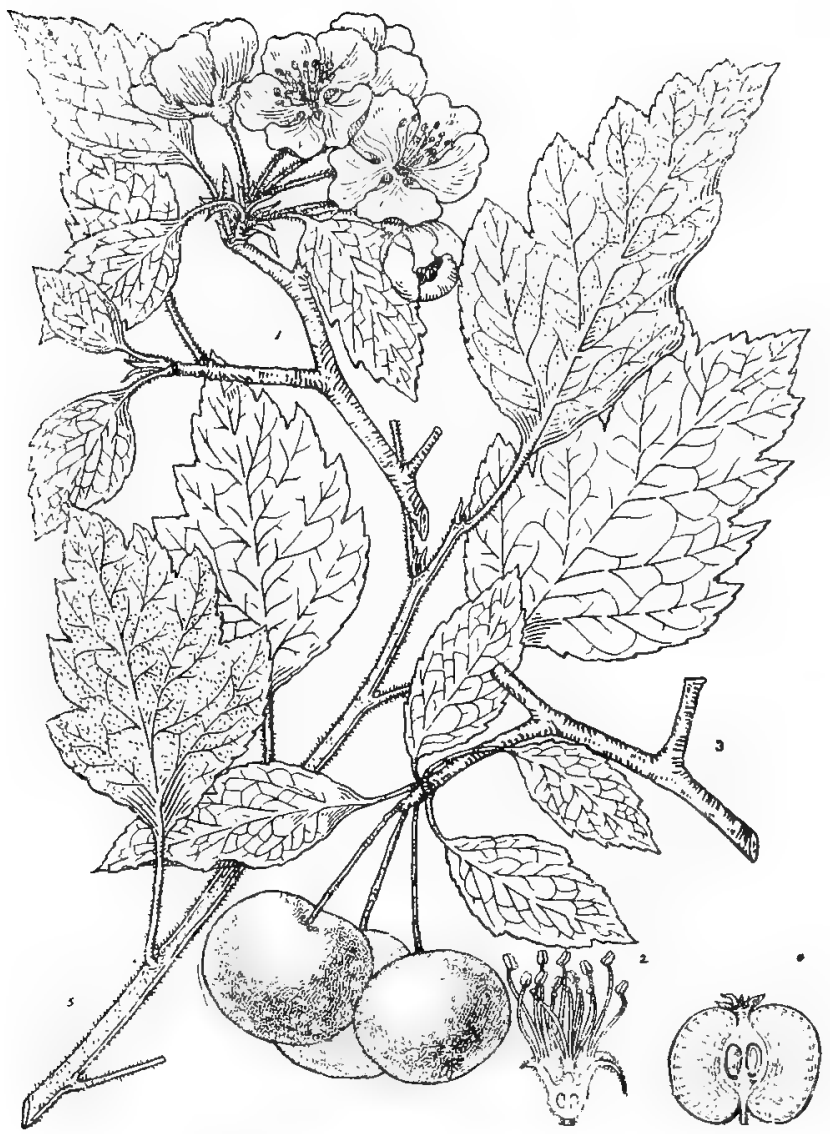

Plate 42. Pyrus ioensis. Iowa Crab.

I. Flowering branch, one-half natural size. z. Longitudinal section of flower with petals temoved, natural size. 3. Fruiting branch, one-half natural size. 4. Longitudinal section of fruit, one-half natural size. 5. Summer branch, one-half natural size. 
Minnesota common through the northern part of the state, extending south to Pine and Mille Lacs counties.

Propagation.-The species is grown from seeds and the varielies by budding and grafting. The seeds may be gathered during the autumn, stratified over winter and sown in the spring, but seeds thus treated will seldom start until the second season. A better way is to put the seeds ten inches deep in a hole, and cover with three inches of sand in the autumn. They should remain in such a place until a year trom the following spring, when the berries will be thoroughly rotted and the seeds may be sifted out from the pulp and sown. Thus treated, they come up the season of planting.

Properties of rood.-Soft, light and weak, pale brown with lighter colored sapwood. Specific gravity 0.545I; weight of a cubic foot 33.97 pounds.

U'ses.-The American Mountain Ash is used as an ornamental tree on account of its abundant bright colored fruit, but is not so pretty in this respect as the European or Elderleaf Mountain Ash. The trunk of the tree is liable to sunscald, and when planted in exposed places it should be encouraged to send up sprouts from the roots and from the lower parts of the trunk. Treated in this way it forms a large shrub of great value from an ornamental point of view, and is very hardy even in exceedingly severe locations. The fruit is astringent. It is used in some homeopathic and domestic remedies. The wood is sometimes used as a veneer in cabinet work.

\section{Pyrus sambucifolia. Elderleaf Mountain Ash.}

Leaves odd-pinnate; leaflets seven to fiftecn, oblong-ovate, mostly obtuse. Flowers appear in July, in small dense pubescent cymes. The fruit is globose, bright scarlet, and sometimes nearly a half inch in diameter. It is produced in dense red-branched clusters, and remains on the tree into the winter. A small tree that is often mistaken for Pyrus ancricana, from which it is best distinguished by its smaller cymes, its larger and later flowers and its more obtuse and broader leaflets.

Distribution.-It is found growing from southern Greenland to Labrador and northern New England, along the northern shores of the Great Lakes to Little Slave Lake, through the 


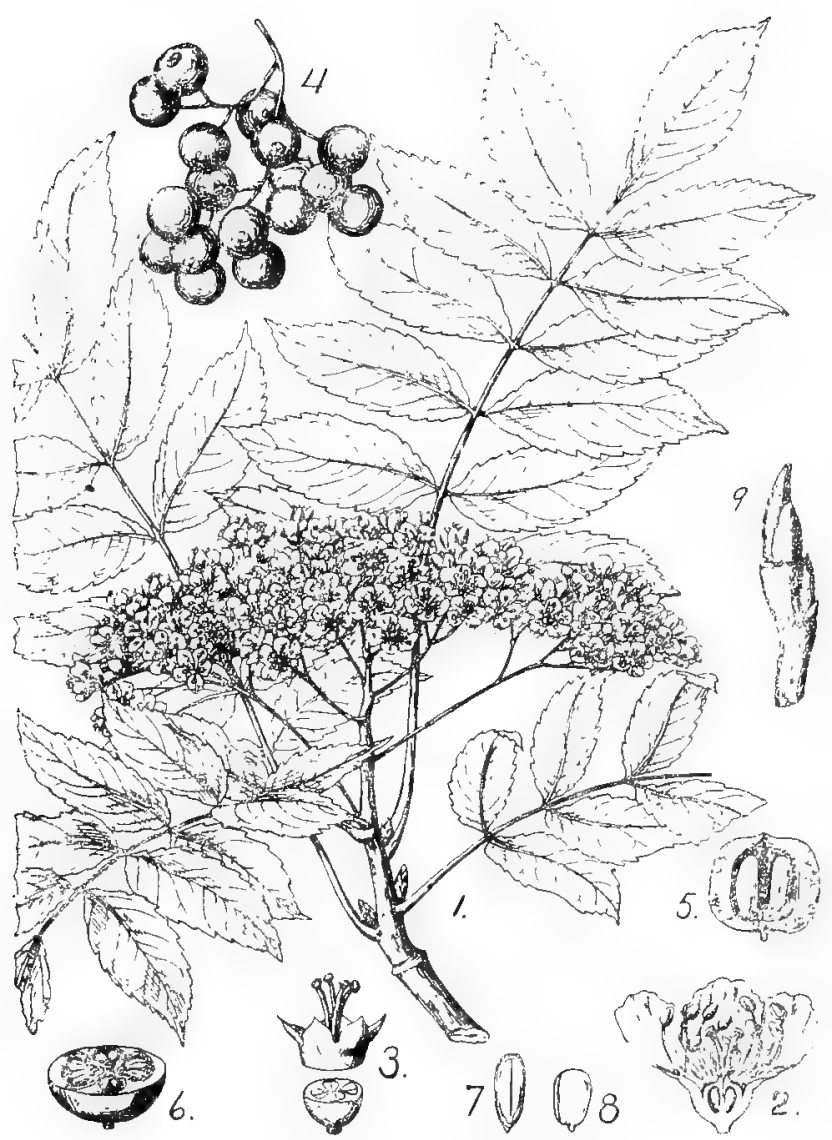

Plate 43. Pyrus sambucifolia. Eilderleaf Mountain Ash.

I. Flowering brancli, one-half natural size. 2. Longitudinal section of flower, enlarged. 3. Traverse sections of ovary, enlarged. 4. Cluster of fruit, one-half natural size. 5. Longitudinal section of fruit. 6. Cross section of fruit. 7. Longitudinal section of seed. 8. Embryo, magnified. 9. Winter buds, one-half natural size. 
Rocky Momntains to Alaska and northeastern Asia. In Minnesota it is common northward extending south to Lake Itasca and rarely found farther south.

Propagation.-Same as recommended for American Mountain Ash.

Propertics of wood.-Practically the same as American Mountain Ash.

Uses.-The large and brilliant fruit of the Eilderleaf Mountain Ash makes it the handsomest of all Mountain Ashes, and as it is very hardy it is a desirable lawn trec. Like all the Mountain Ashes it is likely to sunscald on the trunk when grown singly and the trunk left unprotected, and will do best if several sprouts are encouraged to grow from the trunk as rccommended for the American Mountain Ash.

\section{Pyrus aucuparia. European Mountain Ash.}

Leaves odd-pinnate, softer and more graceful than those of Pyrus amcricana; leaflets thirteen to fifteen, ovate, generally blunt pointed, lower surfaces and stalks downy, at length glabrous. Flowers in May or June followed by large red berries (one-half inch in diameter) which hold on into the winter. There are varieties with yellow and orange fruit. Tree of fair size, often thirty feet high, much more graceful than the American Mountain Ash.

Distribution.-Europe and Asia.

Propagation and propertics of awood.-About the same as the Amcrican Mountain Ash.

Uses.-The European Mountain Ash is a good, small orna-

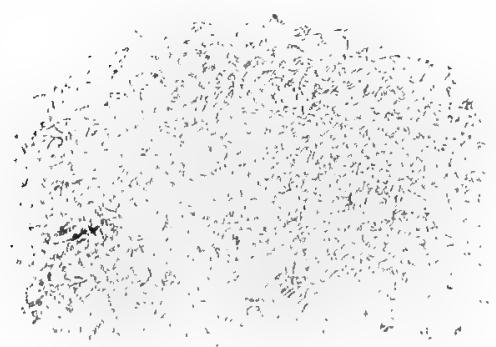

Figure 59. Weeping Motntain Ash. mental tree of graceful habit, conspicuous for its numerous large clusters of white flowers in May or June and for its bright red and orange fruit in autumn and winter. It is about as hardy as the American Mountain Ash, but of more rapid growth. It should be treated in the same way. 
Varicties.-There are several varieties, varying in habit of growth and color of fruit. The following are the ones most conmonly planted:

\section{Pyrus aucuparia pendula. Weeping Mountain Ash.}

A form with pendulous, graceful habit. It grows freely, is hardy and is interesting for variety. It is largely used as a lawn curiosity. Propagated by grafting onto the American or Furopean Mountain Ash.

\section{Pyrus hybrida. Oakleaf Mountain Ash.}

Leaves five to six inches long, lyrate pinnatifid, often pinnate at the base, irregularly and sharply serrate, dark green and glabrous above, pale and densely pubescent beneath. Flowers white, in large conspicuous clusters. Propagated by grafting onto the European or American species. This Mountain Ash forms a very pretty lawn or park tree of upright pyramidal habit, attaining a height of twenty or thirty feet. In hardiness it ranks with the European Mountain Ash. It is said to be a hybrid between Pyrus aria (Sweet Beam Tree) and Pyrus aucuparia.

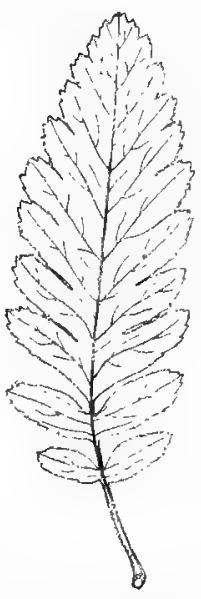

Figure 60, I, eaf of cakleaf Mountain Ash, one-third natural size.

\section{Genus AMELANCHIER.}

A small genus of trees and shrubs with alternate simple leaves, racemose white flowers and edible fruit.

Amelanchier canadensis. Serviceberry. Juneberry. Servicetree.

Leaves ovate or oval, pointed, finely serrate, reddish brown, with scattered white hairs when young, becoming dark green above and paler beneath at maturity; stipules early deciduous. Flowers appear after the leaves in spreading or drooping racemes; petals thin, pure white, about one-half inch long; calyx much shorter than petals. Fruit one-fourth to one-half inch in diameter; ripens in early summer, dark purple when 
fully ripe, sweet and edible. A tree sometimes reaching a height of fifty feet, but seldom over twenty-five feet, and often a mere shrub.

Distribution.-From Newfoundland westward along the northern shores of the Great Lakes to eastern Nebraska, and south to Florida and Louisiana.

Propagation. - The species by seeds and the varieties by suckcrs, layers and cuttings.

Properties of wood.-Heavy, very hard, close-grained, susceptible of a good polish; dark brown in color, with thick lighter-colored sapwood. Specific gravity 0.7838 ; weight of a cubic foot 48.85 pounds.

Uses.-The profusion of white flowers produced by the Serviceberry in early spring makes it a pretty ornamental tree or shrub at that time of the year. It may be planted to supply food for the birds or to produce fruit for home use. The wood is occasionally used for handles of tools or other small implements.

Varicties.-Amelanchicr canadcnsis varies considerably in the form of the leaves, size of flowers and fruit and in habit of growth. The following is the most distinct of these varieties.

\section{Amelanchier canadensis obovalis. Longleaf Service-} tree. Dwarf juneberry. Suscutanberry.

Leaves oblong or broadly elliptical, acute or rounded at the apex, remotely serrate or nearly entire below the middle, coated at first on the lower surface with thick white tomentum. Flowers smaller-than those of the species. A small bush or tree common in Quebec, Ontario and the Northeastern States, and in localities westward to the Mackenzie river, North Dakota. Minnesota and Missouri. A dwarf form of this, with large fruit, is cultivated to some extent through the Northern States. The Indians of Minnesota and Dakota gather the berries in rather large quantities and sell small quantities in some of the remote towns.

Amelanchier alnifolia. Western Serviceberry. Serviceberry.

Leaves broadly ovate, obtuse o1 rarely acute, coarsely dentate or serrate towards the apex. Flowers in erect rather dense 
racemes. Fruit dark blue or almost black, sweet and juicy. A shrub or small tree which in the eastern limits of its range is hardly distinguishable from some of the broad-leaved forms of Amelanchicr canadensis.

Distribution.-From the valley of the Yukon river south through the coast ranges to southern California and east to Michigan and Nebraska.

Propagation.-By seeds and suckers.

Properties of wood.-Very heavy, hard and close grained, light brown. Specific gravity 0.8262 ; weight of a cubic foot 5 I.55 pounds.

Uses.-The fruit as found in the wild state is gathered by the Indians and nsed by them for food.

\section{Genus CRAT 五GUS.}

Leaves alternate, simple, lobed or pinnatifid. Flowers mostly in terminal corymbs, regular, perfect, white or rarely rose colored. Fruit a fleshy, drupe-like pome, containing one to five hard one-seeded carpels, and having on its summit the persistent calyx lobes. Small trees or shrubs, armed with thorns. It is very difficult to identify accurately the species of this genus on account of their varying and conflicting characteristics. There are undoubtedly six or more species in Minnesota, and they are now being studied by specialists, but are not accurately defined.

Propagation.-The fruit should be stratified over winter before sowing the seeds, which seldom germinate until the second year.

\section{Cratægus punctata. Dotted Haw.}

Leaves wedge-obovate or ovate, midribs and principal veins prominent on lower surface. Petioles more or less winged. Flowers in broad corymbs, appearing about June Ist. Each flower has twenty stamens, which characteristic seems to be constant. Fruit dull red, one-half to one inch in length, flesh dry; ripens in late autumn. A tree twenty to thirty feet high, with branches that come out nearly at right angles, and often a broad flat top. Thorns on the older branches and trunks generally compound and gray in color. 

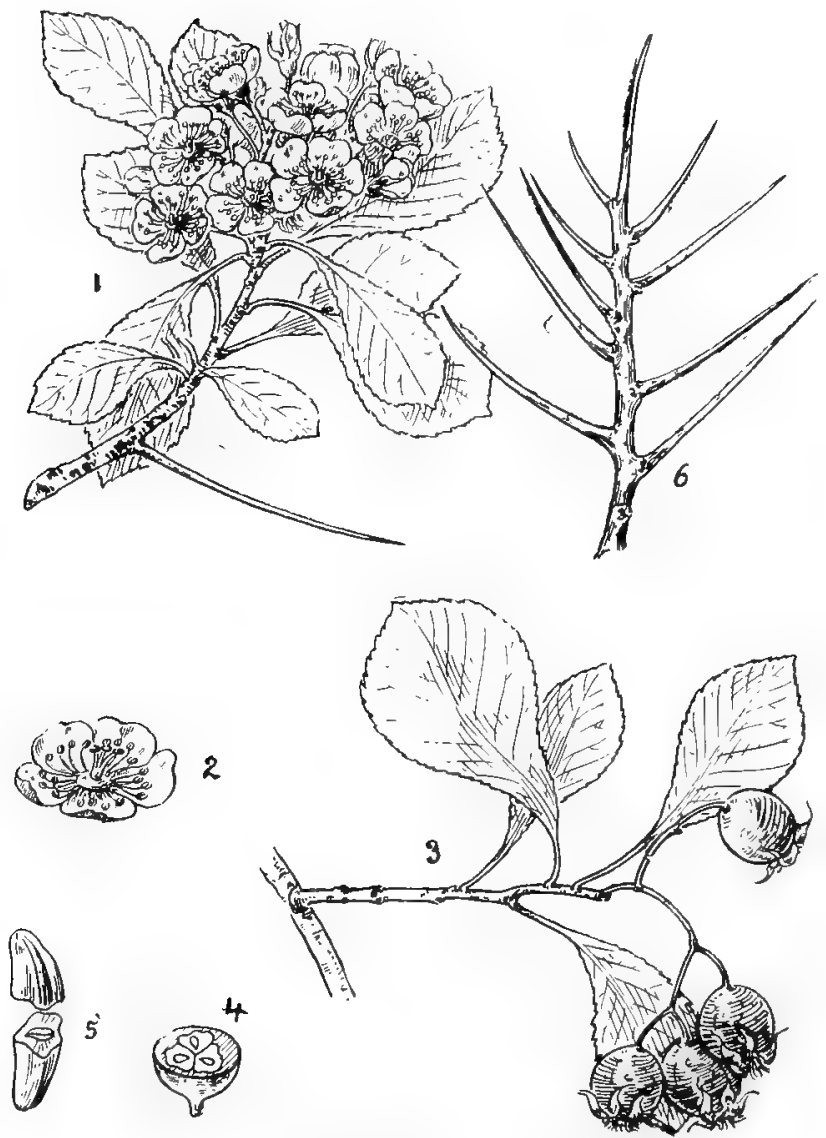

Plate 44. Cralacgits punclala. Dotted Haw.

I. A flowering branchi, 2, A flower, 3. A fruiting branch. 4. Crosssection of truit. 5. A nutlet divided transversely. 6. A characteristic thorny branch. 
Distribution.-At least quite common in the southern half of Minnesota.

Uses.-Valuable for hedges and as a lawn tree in good soil. The wood is heavy, hard and strong, and is often used for walking sticks and firewood.

\section{Genus PRUNUS.}

Shrubs or trees with alternate, simple leaves. Flowers with calyx that is deciduous after flowering; a single pistil with a superior ovary containing a pair of ovules and becoming a single drupe or stone fruit. This genus comprises some of our most valued fruits, such as the Plum, Peach. Cherry, Apricot and Nectarine, and ornamental plants such as the Double Flowering Almond. All the species here referred to are ornamental when in flower.

This genus seems to divide more or less into two groups, which are distinguished by the form of inflorescence, one group bearing its flowers in racemes and the other in umbels. It is of intercst to notice that it is difficult, if not quite impossible, to graft or bud trees of the different groups together, while within each group trees of the different species can be grafted quite readily.

\section{Prunus americana. Wild Plum.}

Leaves oval or slightly obovate. Flowers appear when the leaves are about one-half unfolded. Fruit large, colored with red and yellow, often with a heavy bloom; generally ascerb but frequently good; the parent of our cultivated sorts such as Rollingstone, Wolf, Forest Garden, De Soto, Cheney and others; ripens August to September. A small thorny tree, seldom over twenty feet high, and generally found growing in thickets. A form of this that flowers very early and has fruit with a thin pit is considered a variety or perhaps a separate species. ( $P$. nigra.) The Aitkin Plum comes under this head.

Distribution.-It is found from New York and New Jersey to Nebraska and the upper Missouri Valley south to northern Mexico and western Florida. In Minnesota throughout the state, in thickets along banks of streams.

Propagation.-Grown from the sceds, which should not be allowed to become hard and dry, but should be stratified if they 
are expected to grow the following spring. If planted in the autumn as soon as separated from the pulp about two-thirds of the seeds will grow the following spring and the remainder the second year. It may also be grown from sprouts and roots cuttings.

Propcrties of rood-Heavy, hard, close grained and strong It is dark brown in color, with a thin light-colored sapwond. and takes a good polish. Specific gravity 0.7313; weight of a culbic foot 46.95 pounds.

Uses.-The Wild Plum is pretty in flower and in fruit, and is a good hardy ornamental tree, as well as a good fruit tree. The fruit of the wild kinds is readily sold, and is much used for culinary purposes, and many of the cultivated kinds afford excellent table fruits. This is one of the best undershrubs that can be put in our prairie groves, where it affords protection to the soil from evaporation and at the same time yields desiralble though of course inferior fruit under such conditions.

Prunus pennsylvanica. Wild Red Cherry. Bird Cherry. Pigeon Cherry. Pin Cherry.

Leaves oblong-lanceolate, long pointed, finely and sharply serrate, with incurved teeth often tipped with minute glands, thin, shining, green and smooth on both sides. Fruit ripens in July or Angust, a very small, bright red drupe with thin sour flesh and smooth oblong stone that is ridged on the ventral margin. A small, handsome tree that seldom reaches a height of forty feet, and is often a mere shrub. It has smooth, reddish-brown, bark, which peels off in transverse strips around the tree.

Distribution.-Found in moist, rather rich soil from Newfoundland west to the eastern slopes of the Coast Range and south to northern Illinois and Pennsylvania; also in Nortl Carolina, Tennessee and Colorado. In Minnesota common throughout all but the southwestern part of the state, where is rarely occurs.

Propagation.-Grown from seeds, which should be stratified and sown in the spring or sown in attumm. They are distributed by robins, wax-wings and other birds that eat largely of the fruit. The Wild Red Cherry has thus become a very common trec in waste places, althongh not so common in our 


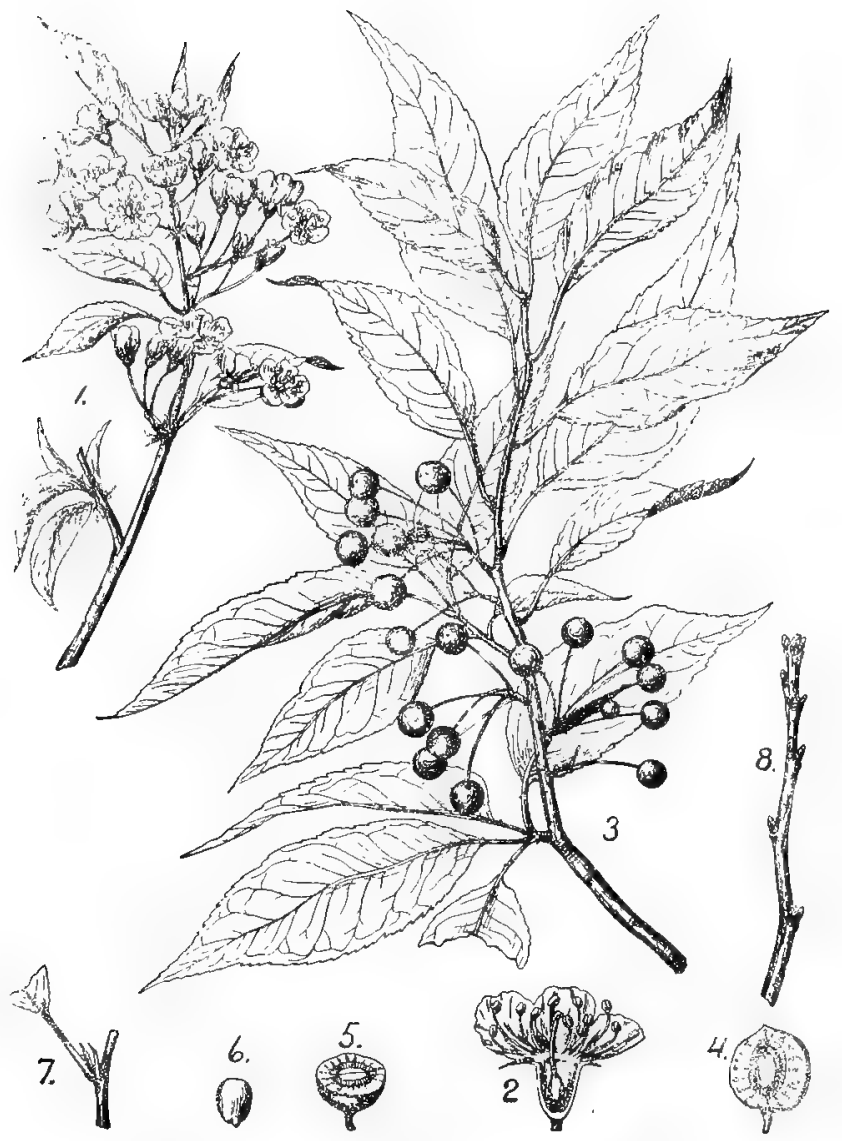

I'late 45. Prunus pennsylonica. Wild Red Cherry.

I. Flowering branch, one-half natural size. 2. Longittdinal section of flower. 3. Fruiting branch, one-half natural size. 4. Longitudinal section of fruit, slightly enlarged. 5. Cross section of fruit. 6. Embryo enlarged. 7. Axil of leaf showing stipules, one-half nattral size. 8. Winter branchlet, one-half natural size. 
section as castward, where it is one of the first trees to come in on old timber lands.

Propcrties of wood.-Light, soft, close grained, light brown in color, with thin yellow sapwood. Specific gravity 0.5023; a cubic foot weighs 3 r.3o pounds.

Uses.-The Wild Red Cherry is very hardy, grows rapidly under cultivation, and is well adapted to prairie planting. It is shapely and handsome, although a short lived tree. In the carly spring it is conspictious by reason of its great quantity of white flowers. It might be used for shade in timber plantings and for bird food. The fruit is used for domestic purposes and in the preparation of cough mixtures. Seedlings liave been used to a limited extent as a stock for the cultivated cherries.

Prunus serotina. Black Cherry. Wild Llack Cherry. Rum Cherry.

Lcaves oval oblong, or lanccolate-oblong taper-pointed, serrate, with two to four reddish glands on petiole. Flowers appear in June after the leaves are full grown, in long pendulous white racemes. Frutit somewhat larger than a pea, purplish black when ripe, smooth, one-seeded, rarely two-seeded, ripens in Angust or September in Minnesota. A large tree, sixty or more feet high, but generally much smaller at the limit of its range.

Distribution.-From Nova Scotia westward through the Canadian Provinces and Northern States to Dakota, and south to Texas and Florida. In Minnesota common throughout all but the extreme northern part of the state, in woods along shaded lake shores and banks.

Propagation.-The Black Cherry is grown from seeds which are produced in great abundance. They should be sown when gathered in the autumn, or stratified over winter and sown in the spring.

Properties of wood.-Light, strong and rather hard, with a close, straight grain and satiny surface susceptible of receiving a beautiful polish. It is light brown or red, with a thin layer of yellow sapwond, but grows darker on exposure to the air. Spe-cific gravity 0.5822 ; weight of a cubic foot 36.28 pounds. 


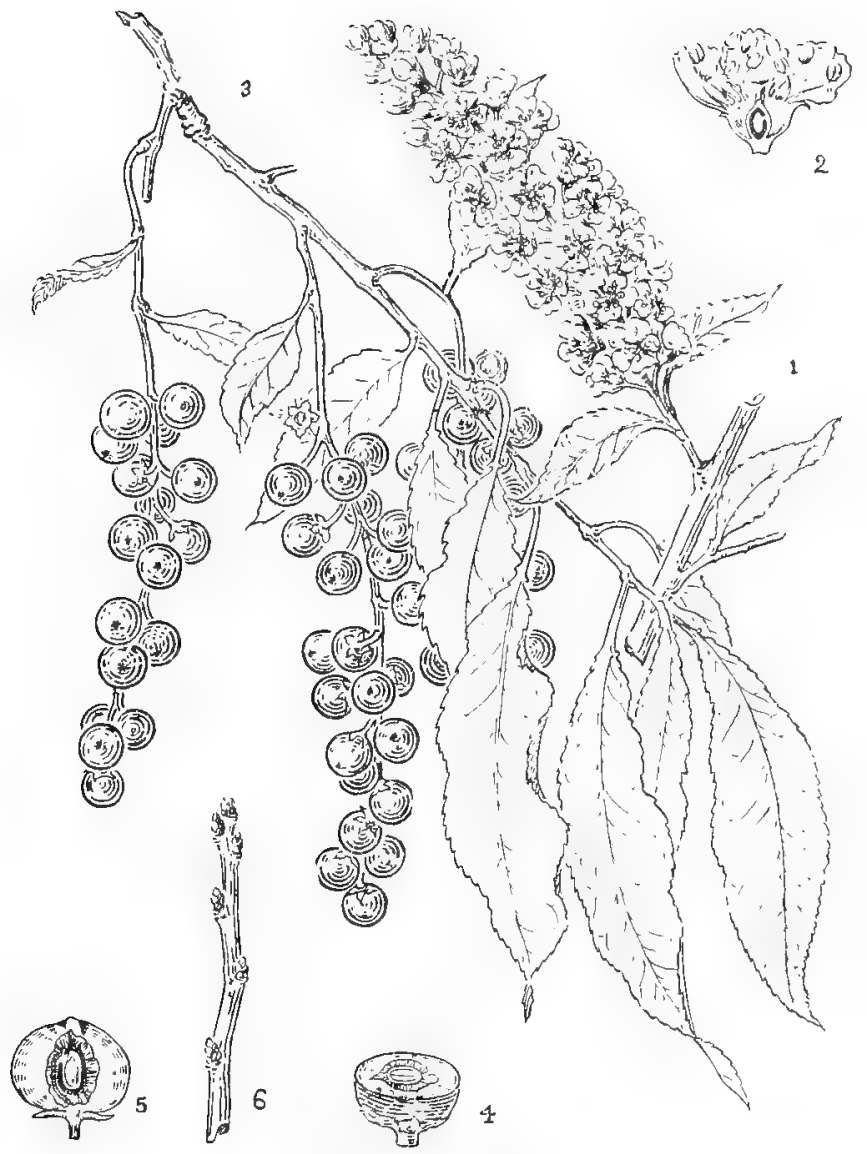

Plate 46. Prumus scrotina. Black Cherry.

I. Flowering branch, one-half natural size. 2. Longitudinal section of flower, enlarged. 3. Fruiting branch, onc-lialf natural size, 4. Cross section of fruit, natural size. 5. Longitudinal section of fruit, natural size. 6. Winter branchlet, one-half natural size. 
Uscs.-The Black Cherry has a pretty and often a stately form when growing single, and is very omamental when in flower and fruit. It is, however, liable to injuries from the tent caterpillar, which is very fond of its leaves. It can often be introduced to advantage into timber plantings in this section. and is an object of much intercst on account of its flowers and fruit. It is also a good timber tree. The fruit is often used in a small way for making cherry brandy and in flavoring alcoholic liquors. Medicinal properties are found in the bark, especially in that of the branches and roots, and are readily yielded to cold water, for owing to volatilization and chemical change boiling water must not be used. This extract contains hydrocyanic acid, and is employed for infusions, syrups and fluid extracts, which are used as tonics and sedatives in the treatment of pulmonary consumption and nervous debility. Cattle have been frequently poisoned by eating the wilted leaves. Children accasionally die from eating the kernels of the pits or by swallowing the fruit whole. Fresh leaves are considered harmless, as the poison is formed by chemical action in the leaves after being separated from the plant. The wood is valuable for cabinet making and fine interior finishing, and is in great demand, on account of its fine reddish brown color, for tripods, surveyors' rods and cases, and spirit levels. It is also used for printers' furniture and wood type, school apparatus, drawing instruments, gunstocks, crutches, toys and tool handles.

\section{Prunus virginiana. Choke Cherry.}

Leaves thin, broadly oval to oblong, usually abruptly pointed. Flowers in racemes (shorter and closer than in $P$. scrotina), appearing in June. Fruit ripens in summer, red, turning darls crimson, astringent when first colored, but later loses much of its astringency and becomes sweet and edible. A small tree with scented bark, rarely thirty feet high, and generally short and crooked. (In this section it is generally covered with the excrescences called Black Knot, which are caused by the fungus Plowrightia morbosa.)

Distribution.-From Labrador to British Columbia, north to within the Arctic Circle and south to Georgia, Texas and California. Very widely distributed. In Minnesota common throughout the state along banks of strcans and lakeshore. 


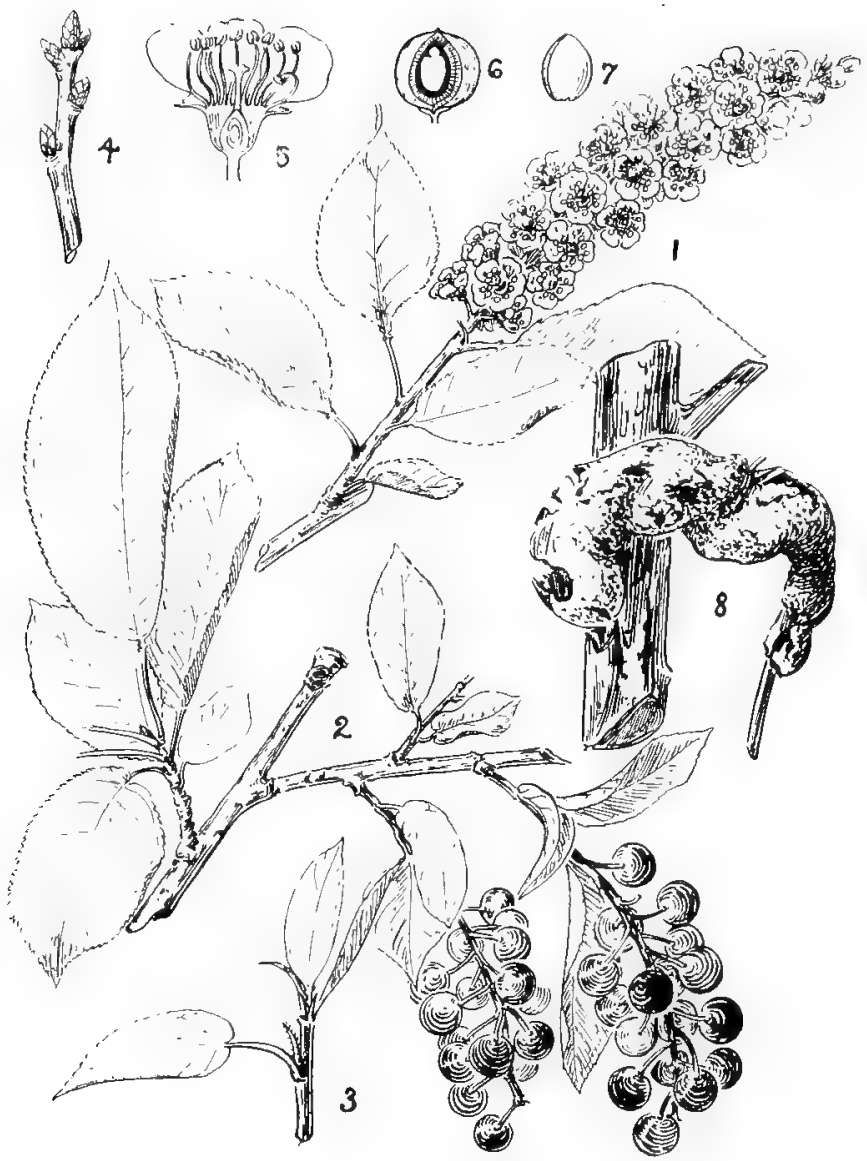

l'late 47. Prunus virginiana. Choke Cherry.

1. A flowering branch. 2. A fruitung branch. 3. Part of a leafy branch with stipules. 4. A winter branclilet, reduced. 5. Vertical section of flower, enlarged. 6. Vertical section of fruit, enlarged. 7. A stone, onelialf natural size, 8. Branch showing Black Knot, reduced. 
Propagation.-Grown from seeds, which should be stratified over winter and sown in the spring.

Propertics of rood--Heavy, hard and close grained, but not strong. It is light brown in color, with a thick light colored sapwood. The specific gravity $0.695 \mathrm{I}$; weight of a cubic foot 43.42 pounds.

Uses.-The Choke Cherry is a very handsome tree when covered with its abundant racemes of pure white flowers and also when in fruit, but generally it is so disfigured by Black Knot as to make it unsightly. The fruit is user in large quantities by the French Canadians and was formerly an important article of food among the northern Indians, and is now used to some extent in the Western States. In Minnesota and the Dakotas there is a form that is nuch superior to the common Choke Cherry, in that it has larger, less astringent fruit. Some authors make it a separate species (Prunus dcmissa), but Professor Sargent regards it as a variety whose variations are due to the drier climate of the mid-continental states.

\section{LEGUMINOSAE. PEA FAMILY.}

Distingtuished by the butterfy-shaped (occasionally regular) corolla, usually accompanied by ten monadelphous or diadelphus stamens (rarely distinct); fruit a legume; leaves alternate, compound with stipules.

A large and important family, comprising trees, shrubs and herbs. Some of our most important agricultural plants belong here, such as the pea, bean, clover, alfalfa, vetch, peanut, etc., and among shrubs the Siberian Pea Tree (Caragana), Cytisus, Bladder-senna (Colutea) and Wistaria. Important trees belonging here that are beyond our range are the Yellow-wood (Cladrastis), Sophora, Laburnum, Mesquit and Red Bud* (Cercis).

*Perhaps found in Southern Minnesota. 


\section{Genus GLEDITSIA.}

Gleditsia triacanthos. Honey Locust. Threethorn Acacia. Black Locust.

Leaves evenly once or twice pinnately compound; thorns very stout, from two to twelve inches in length, and usually sending out two thorns as branches; but in some sections, notably in Iowa, many trees may be found without thorns, and these are especially desirable for windbreaks. Flowers in June, polygamous, greenish and inconspicuous in small spike-like axillary racemes. Fruit a flat, lincar, dark-colored pod, often twelve inches long, which becomes much twisted as the seed ripens. This pod contains a pulp which is sweet at first, but after a few weeks ferments and becomes astringent. The seed ripens in autumn, and the pods fall off in late autumn or early winter. The twisted form of the pods assists in the distribution of the secd, as the pods do not open until some time after they fall, and may be rolled for long distances by the wind over the frozen ground or on the snow.

Distribution.-It inhabits rich woods and borders of streams from western New York, Pennsylvania and Georgia west to southern Ontario, eastern Nebraska, Louisiana and Texas.

Propagation.-The Honey Locust is easily grown from seeds which should be gathered in late autumn, early winter or as soon as the pods fall. The seecls must be scalded in the same manner as recommended for the Common Locust, or they may remain in the soil a year before growing.

Properties of wood.- Heavy, hard, strong and very durable in contact with the ground. It is coarse grained, of a red or bright reddish brown color, with thin, pale sapwood. Specific gravity 0.6740 ; weight of a cubic foot 42 pounds.

Uses.-The Honey Locust is a valuable tree for street and ornamental planting, for timber belts, windbreaks and for hedges wherever it is hardy. It has a graceful form, is a rapid grower, easy to transplant, very free from insect and fungous diseases, and not given to sprouting from the root. The wood is used for fence posts and rails, for the hubs of whecls and to some extent for construction. It also makes good fuel. This tree is not generally hardy in Minnesota, though it has stood very well in favorable locations in the southeastern portion of the state, and even at St. Paul has done fairly well where protected, 


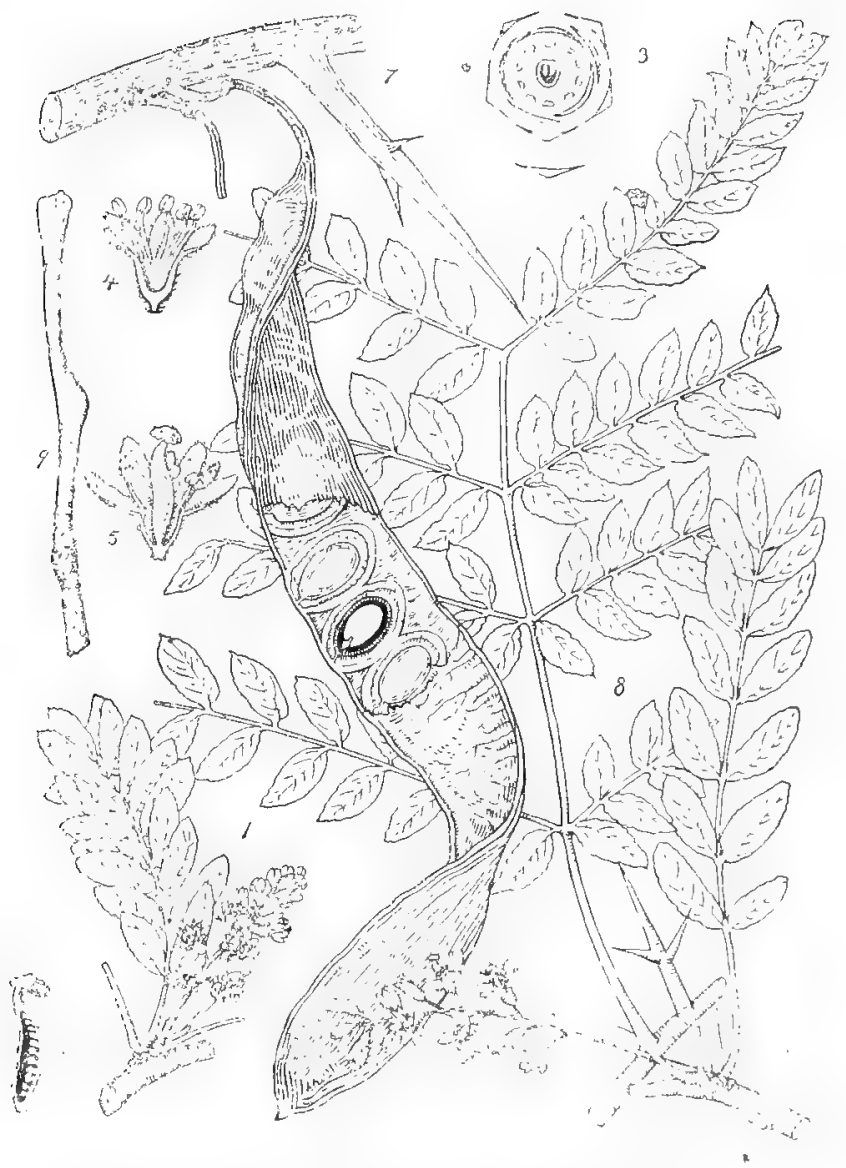

Plate 48. Gleditsia triacanthos. Honey Locust.

I. Flowering branch of staminate tree, one-half natural size. 2. Flowcring branch of vistillate tree, one-half natural size. 3. Uiagram of flower. 4. I.ongitudinal section of staminate flower, enlarged, 5, Longitudinal section of pistillate fower, enlarged. 6. Longitudinal section of ovary, enlarced. 7. A spine antl a single fruit showing seed, cross section of seed and embryo, one-half natural size, 8. Doubly pinnate leaf, one-half natural size, 9. Winter branchlet, one-half natural size. 
but is likely to kill back in severe winters, though the roots are very hardy and generally rencw the top the season following any winter injury. In Iowa and Missouri it forms a large tree, often three feet through the trunk. The one-ycar-old seedlings are rather tender the first winter, and should be dug and heelerl in or heavily mulched at the end of the first season, aftcr which they are rather hardy.

\section{Genus GYMNOCLADUS.}

\section{Gymnocladus dioicus. ( $i$. cundensis.) Coffeetree.} Kentucky Coffeetree.

Leaves very large, two to three fect long, twice pinnate, each partial leaf stalk bearing seven to thirteen ovate leaflets, the lowest pair with single leaflets. The leaflets stand verticaily. The color of the leaves is a bluish green. The flowers are dioecious or polygamous, whitish, borne in large racemes which are much longer on the fertile than on the sterile trees. Fruit a large flat pod, containing large seeds over one half inch in diameter, surrounded by a thick layer of dark colored sweet pulp. The fruit generally remains tnopened on the tree all winter. Flowers appear from May to July.

Distribution.-One of the rarest forest trees of North America, found growing from western New York and southern Ontario west to the Minnesota Valley, and eastern Nebraska and south between the Mississippi river and the Allegheny Mountains to Tennessee. In Minnesota it is found sparingly in southern and southeastern portions of the state north to near St. Paul and as far west as New Ulm.

Propagation.-Grown from root cuttings or from seeds, which should be scalded before being sown, as recommended for the seeds of Locust.

Properties of wood.-Heavy, not very hard, strong, coarse grained, likely to check in drying, but very durable in contact with the ground. It can be easily worked, and takes a good polish. It is rich brown in color, with thin rather lighter colored sapwood. Specific gravity 0.6937; weight of a cubic foot 43.21 pounds.

Uses.-The Coffectree is graceful and ornamental when in leaf, and in winter is interesting from its peculiar naked and 


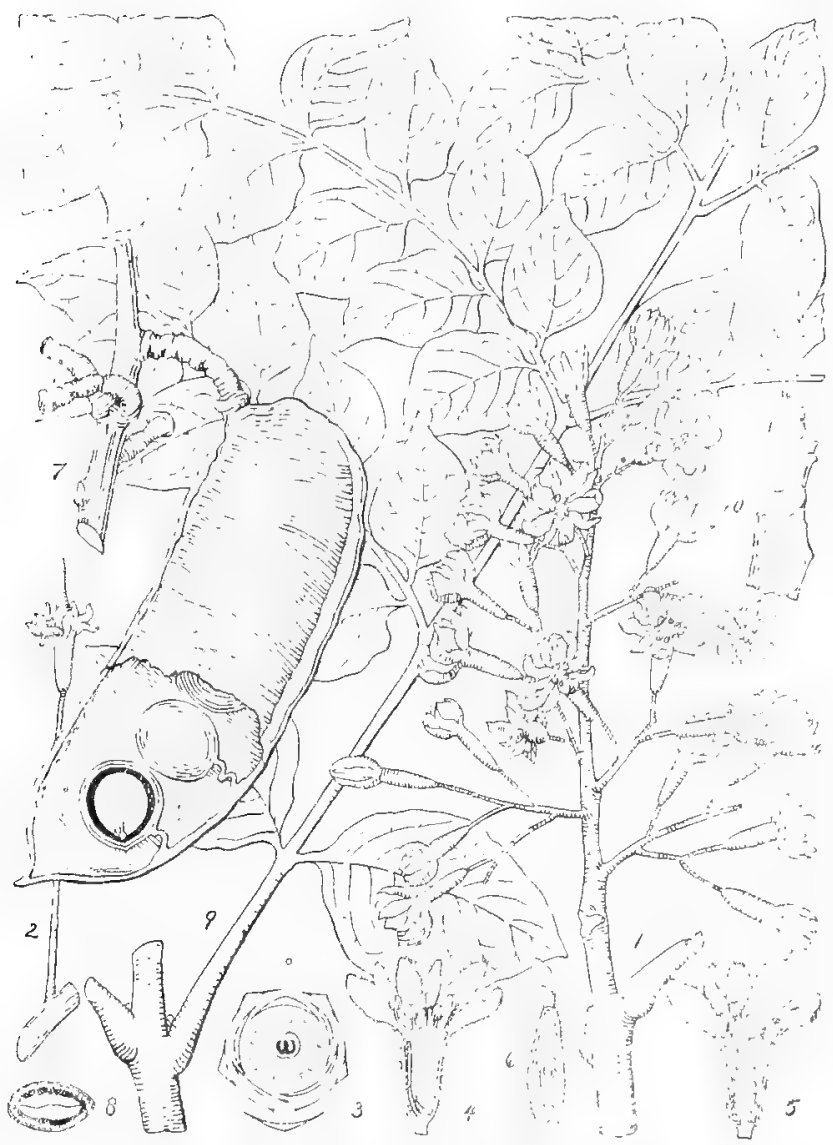

Plate 49. Gymnocladus dioicus. Coffeetree.

I. Inflorescence from staminate tree, onchalf natural size. 2. Pistil. late flower, one-half natural size. 3. Diagram of flower. 4. Longitudinal section of staminate flower, natural size. 5. Pistillate tluwer with a portion removed, 6. l'istil with section of ovary removed. 7 . Portion of branch bearing a single fruit showing seed and embryo, one-half natural sizc. 8. Cross section of seed, one-half natural size. 9. Portion of leaf, one. half natural sizc, 10. Portion of winter branch, one-half natural size. 
rlead appcarance. It is one of the latest trees to leaf out, and the now growth is strikingly pretty. The leaflets near the ends of the leaves are bright pink, while those that opened first are green or bronze colored. The young leaves in June are a rich brown color. It is very hardy, and is not particular about the soil in which it grows, but attains a large size only in rich, deep, moist soils. The wood is occasionally used in cabinet making and for fence posts, rails and in construction. As the name implies the seed has sometimes been used as a substitute for coffce. Its chief value is for ornament.

\section{Genus ROBINIA.}

Robinia pseudacacia. Locust. Yellow Locust. Black Locust. Common Locust. False Acacia.

Leaves alternate, pinnately compound, composed of from nine to seventeen leaflets. Flowers wlite, fragrant, in conspicutous pendulous racemes three to five inches long appearIng in latter part of May or early in June. Pods flat, four to five inches long, containing about six hard, small and rather flat sceds, which ripen in late autumn and often hang on the tree all winter. The light, handsome foliage of this tree constitutes one of its principal charms; the leaves open during the day and as night comes on close down as if for rest. The young growth is ustally furnished with strong recurved prickles, though trees can frequently be found that are entirely free from them, and it is this latter form that is used in some European cotntries as fodder for cattle. A siender forest tree, occasionally reaching the height of sixty or seventy feet and a diameter of two feet.

Distribution.-Southern Pennsylvania to Indiana, Iowa and southward. Under cultivation it has become widely distributed. In Minnesota it is found along the Mississippi river as far north as Minneapolis, and occasionally elsewhere in this state, sometimes forming trees fifty feet or more in height, but generally it is much smaller, and often forms mere thickets which are occasionally killed back in severe winters.

I'ropagation.-The Loctust is grown from seeds, which may be gathered in the pods, kept in any dry place, and planted in the spring. Just before planting the sceds should be scalded 


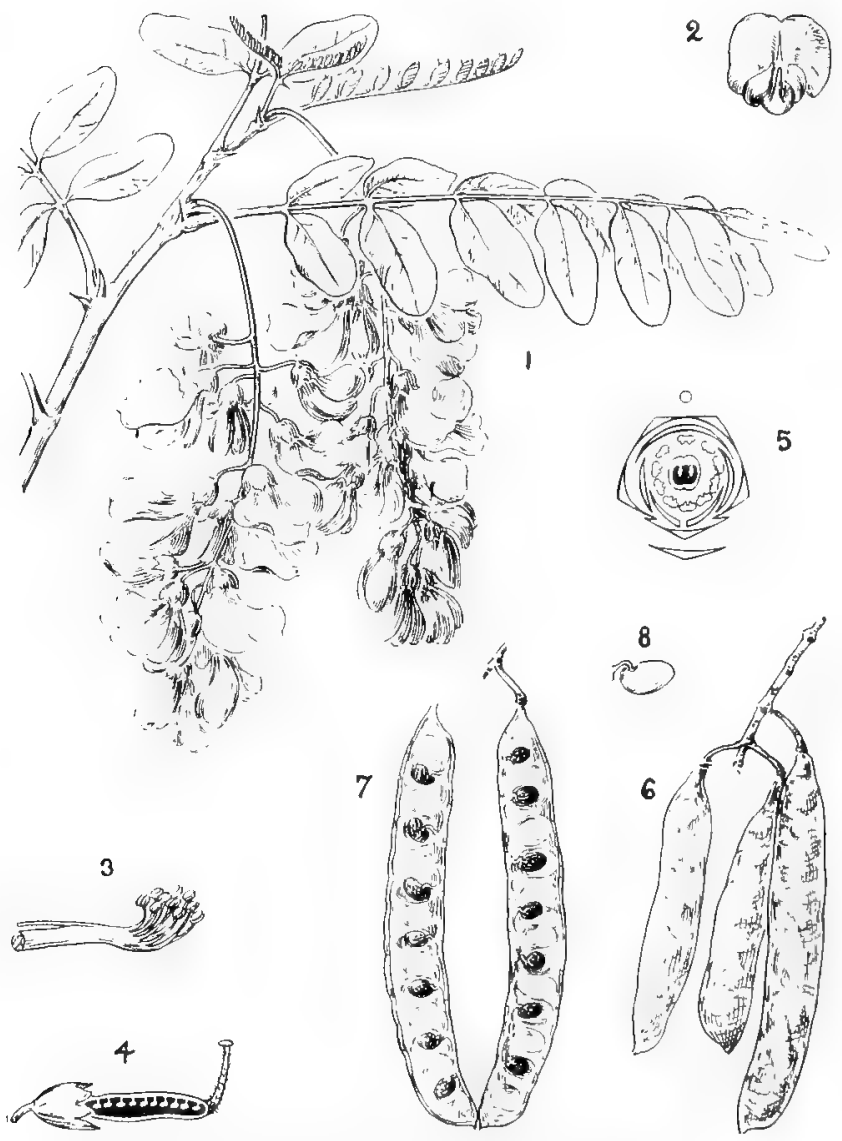

Plate 50. Robinia pscudacacia. Locust.

I. Flowering branch, one-half natural size. 2. Flower, front view, onehalf natural baze. 3. 'Tube of stamens. 4. Longitudinal section of pistil. 5. Diagram of the flower. 6. J.cgumes, onc-lialf natural size. 7. Pod open showing seed, one-half natural size, 8. A seed, one-half natural size. 
severely. This causes part of them to swell. Sift or pick these out and scald those remaining again. Continute this scalding and sifting until all have swelled. The seed can then be sown at once in well picpared soil, and will in good soil produce plants three or more feet high the first seasnn. They may alsn be grown from ront cuttings and from sprouts.

Properties of rood.-Heavy, exceedingly hard and strong, close grained and very durable in contact with the ground. It is brown or light green, with rery thin, pale yellow sapwood. The specific gravity is 0.7333 ; weight of a cubic foot 45.7 pounds.

Uses.-The Locust is too tender for general planting in Minnesota, but in favorable locations it makes a desirable lawn tree on account of its pretty foliage and white flowers. It can be sown in forest plantations, but is not generally desirable for sttch places on account of its sharp prickles, its tendency to sprout and its liability to being occasionally killed back, although it seldom kills out. This tree is subject to the attacks of borers. which generally spoil the value of the timber for manufacturing purposes. The wood is valuable for posts, ribs of vessels, tree nails, and anything which requires great strength. It is also excellent for fuel. It is a very popular tree in Europe, and is said to be more extensively cultivated there than any other American tree. The bark of the root is tonic, or in large doses purgative and emetic, and is used in homeopathic remedies. Three cases of poisoning in children who had eaten the root by mistake have been recorded.

\section{ACERACEAE, MAPLE FAMILY.}

it family composed of two genera, only one of which is represented in America.

\section{Genus ACER.}

A genus of about ico species of trees and shrubs, with watery often saccharine sap and opposite simple leaves. Flowers regular, generally poly ganous or dioccious and sometimes apetalous; ovary two-celled, having two ovules in each cell. Fruit a double samara. The bark is astringent, and yields coloring matter. 


\section{Acer saccharum. (. sacharinum) Sugar Map1e.}

Hard Maple. Rock Maple.

I, eaves large, three to five toothed, opposite, deep green above and paler green beneath. Flowers greenish yellow, in nearly sessile umbel-like corymbs, apetalous, appearing with the leaves in the spring. Fruit a double samara; wings rather broad; seed ripens in autumn. The foliage becomes very brilliantly colored in autumn.

Distribution.-A large and important tree in the Northern and Middle States, extending southward to Florida and Texas and from Newfoundland to North Dakota and northern Minnesota. Very abundant in eastern Minnesota, though seldom found in the western portions. It occurs at Lake Minnewaska, in Pope county, and at the head waters of the Redwood river in Lyon county, and as far west as Robert county, South Dakota, where it occurs in the coulies at the head waters of the Minnesota river.

Propagation.-The Sugar Maple is propagated by seeds, which should be gathered in autumn and sown at once or kept over winter, as recommended for the Ash, and sown in the spring.

Properties of zrood.-Very hard, heavy, compact and strong, with a fine satiny surface susceptible of taking a good polish. The perfectly seasoned sapwood is light colored, and the heartwood is light brown of various shades. Specific gravity 0.6916 ; weight of a cubic foot 43.08 pounds.

Uses.-The Sugar Maple is very hardy over most of Minnesota in rich, porous, moist soils, when grown in forests, and forms our best fuel wood. It does well as a street tree on suitable soil in the southeastern part of this state if the trunk is shaded. When not thus protected the trunk is liable to sun scald. In the northwestern and western portions it often winterkills badly in exposed locaiions, especially when young and beiore becoming well established, and for this reason is not well adapted to general planting.

The wood of the Sugar Maple is more valuable and more gencrally used than that of any other American Maple. It possesses a high fuel value, is largely used for interior finish of buildings, especially for floors, in the manulacture of furniture, agricultural inplements, school apparatus, musical instruments, gymnatiun gonds, drawing instruments, surveyors' rods, artists' 


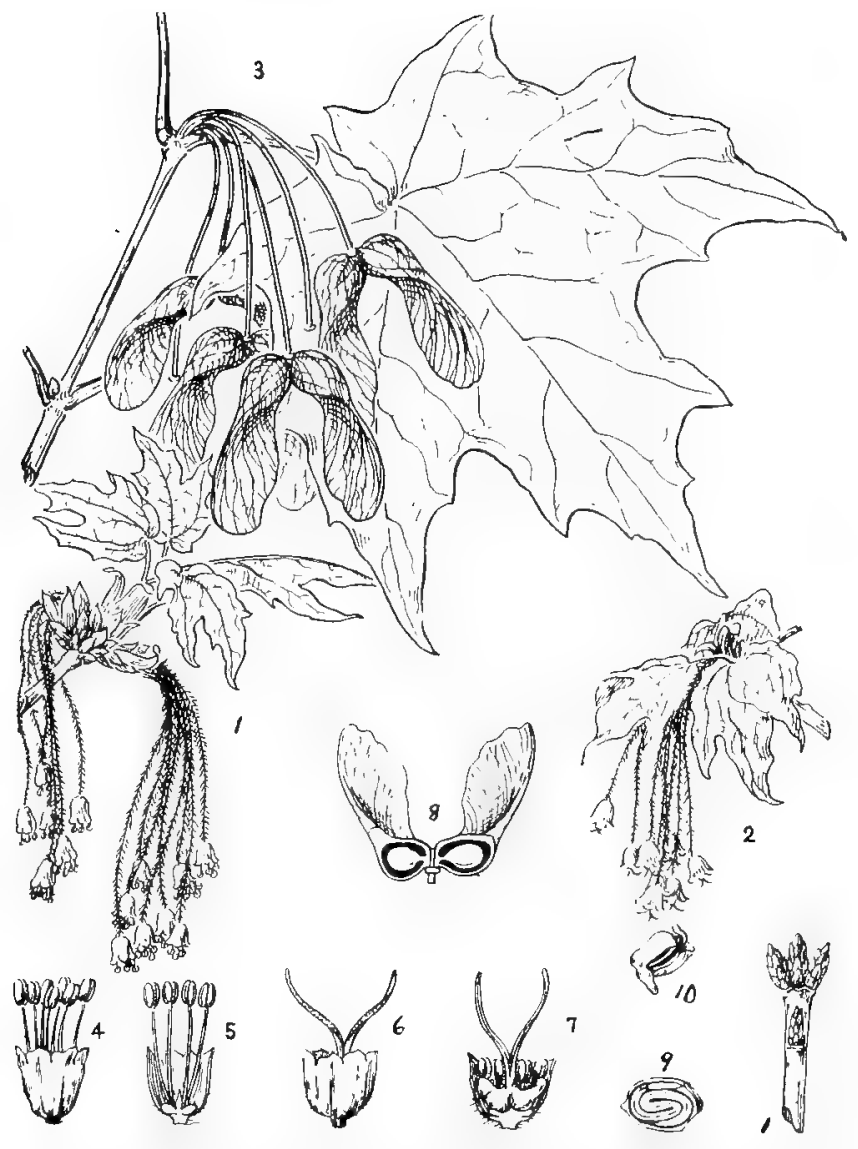

Plate 5r. Acer saccharm. Sugar Maple.

I. Pranch bearing stamınate flowers, one-half natural size, 2. Branch bearing pistıllate flowers, one-half natural size. 3. Fruiting branch, onehalf natural size. 4. Staminate flower, enlarged, 5. Longrtudinal section of staminate Hower, enlarged. 6. Pistillate flower, enlarged. 7. Longitudinal section of pistillate flower, enlarged. 8. Longitudinal section of fruit, one-half natural size. 9. Longitudinal section of seed, enlarged. Io. Embryo, enlarged. II. Winter branchlet, one-half natural size. 
goods, wood type, and engravers' wood, butter molds, croquet sets, crutches, umbrella sticks and canes, kegs, sugar hogsheads, churns, meastures, faucets, wood screws and gauges charcoal, in turnery for handles of tools and clothes pins, and in ship building for keels, etc. In the United States shoe lasts and pegs are made almost exclusively from this wood. Accidental forms in which the grain is beautifully curled and contorted, known as "curled maple" and "bird's-eye maple" are common, and highly prized for caluinet making. The ashes of the wood are rich in alkili, and yield large quantities of potash. The wood of the Minnesota and Wisconsin Sugar Maple is so very hard and uneven in grain that it has not been worked nuch into lumber, and the supply of Hard Maple lumber manufactured here is mostly imported from Michigan, where clear stock is more plentiful. Maple sugar is almost the exclusive product of this tree. It is made by evaporating the sap, which is procured by tapping the trees in early spring some weeks before the buds begin to swell. About three or four gallons of sap are usually required to make a pound of sugar. Two or three pounds of sugar per tree is the average yield, but large isolated trees will often yield very much more than this. When tapping is properly done it does not seriously impair the health of the tree.

\section{Acer platanoides. Norway Maple.}

Lcaves broad, smooth, thin, bright green on both sides, their five short taper-pointed lobes set with coarse taper-pointed teeth. Flowers numerous, with both sepals and petals distinct, yellowish, conspicuous, in erect corymbose clusters terminating the shoot of the season, or some from lateral buds appearing with the leaves. Fruit in drooping clusters, with large divergent wings spreading two and one-half to three and one-half inches, ripening in autumn. Buds blunt pointed and rather divergent; new growth often reddish; juice milky. Resembles the Sugar Maple in general appearance, but is easily distinguished from it. Its leaves hold green later than other maples, and turn a bright yellow in autumn. A round-headed tree attaining a height of from thirty to sixty leet.

Distribution.-Northern and central Furope and Asia.

Propagation.--By seeds for the species and by budding, grafting or layering for the varieties. 


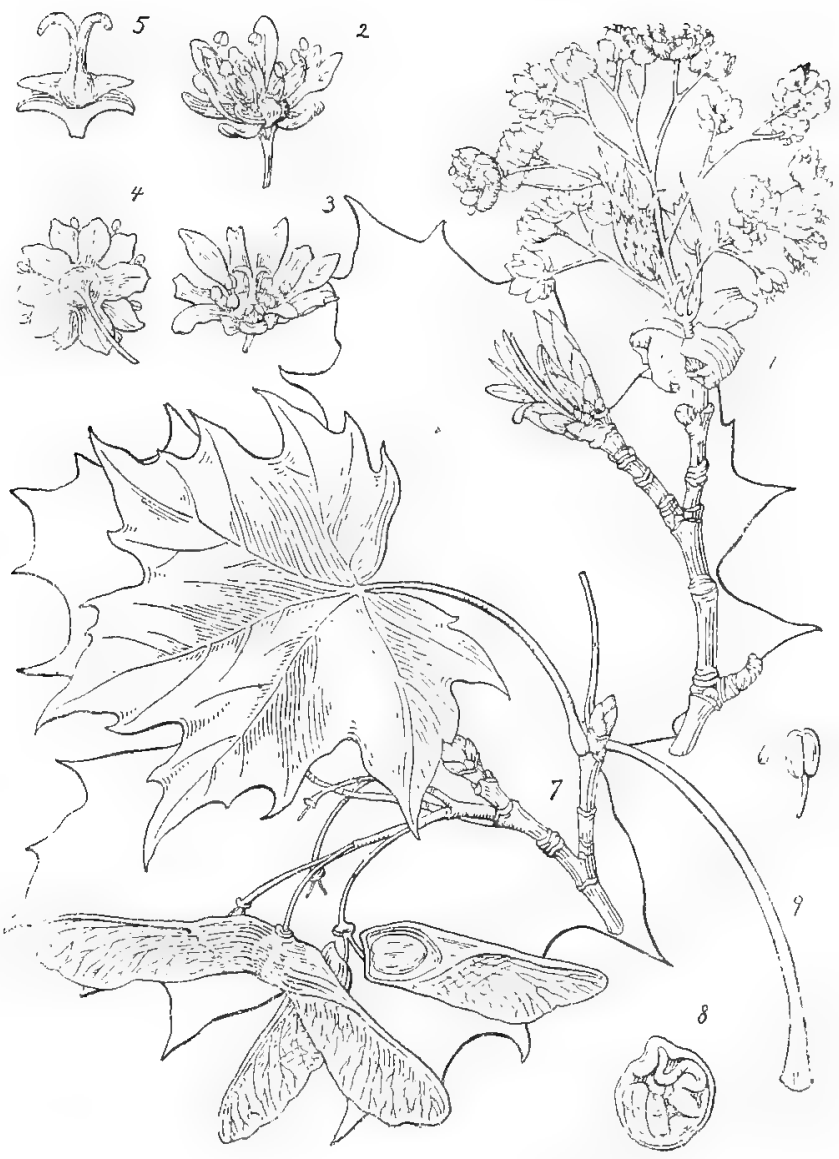

Plate 52. Acer platanoides. Norway Maple.

I. Flowering branch. one-half natural size. 2. Staminate flower. 3. Perfect flower. 1. Lnderside of flower. 5. Pistil on disk. 6. Stamen. enlarged. 7. Fruiting branch, one lalf natural size. 8. Longitudinal section of seed. 9. Leaf, one-half natural size. 
Properties of a ood.-Heavy, hard and durable under cover. Specific gravity, air dried, o.68.

Uses.-The Norway Maple has been much used as an ornamental tree in the Northeastern States, where it is long lived and often planted in preference to the Sugar Maple near the sea coast. In this section it has not been widely tried, but at the Minnesota Experiment Station it has never been seriously injured by the cold during the past twelve years, and has withstood drouth extremcly well. In the very dry summer of 1894 , Birch, Black Cherry and European Larch died out in large numbers in the forest plantation, while on similar land near by the Norway Maple grew vigorously, its leaves retaining their clark green color throughout the season. The wood of the Norway Maple is used by the joiner, wheelwright and carver for a variety of purposes.

Varictics.-There are many varieties of the Norway Maple, the most durable of which are the two following:

\section{Acer platanoides schwedlerii. Schwedler Maple.}

A bcautiful variety with new growth, bark and leaves of a bright purplish or crimson color which later changes to a purplish green. A valuable tree which has stood at the Minncsota Experiment Station for six years.

\section{Acer platanoides reitenbachi. Reitenbach Maple.}

An excellent and striking varicty with dark purple leaves, which hold their color throughout the season.

Acer saccharinum. (\%. dasycartum.) Silver Maple. Soft Maple. White Maple. Silverleaf Maple.

Leaves deeply palnately five-lobed, silvery white and smooth beneath but downy while young. Flowers greenish, apetalous, on short pedicles, in axillary clusters, appearing before the leaves; ovary and young fruit downy. Fruit with large divergent wings, smooth at maturity though downy when young, ripens in carly summer about the time the leaves are of full size. A large, quick growing tree, often ninety fect high, with more or less pendulous branches and light airy foliage, which grives it a graceful appearance. 


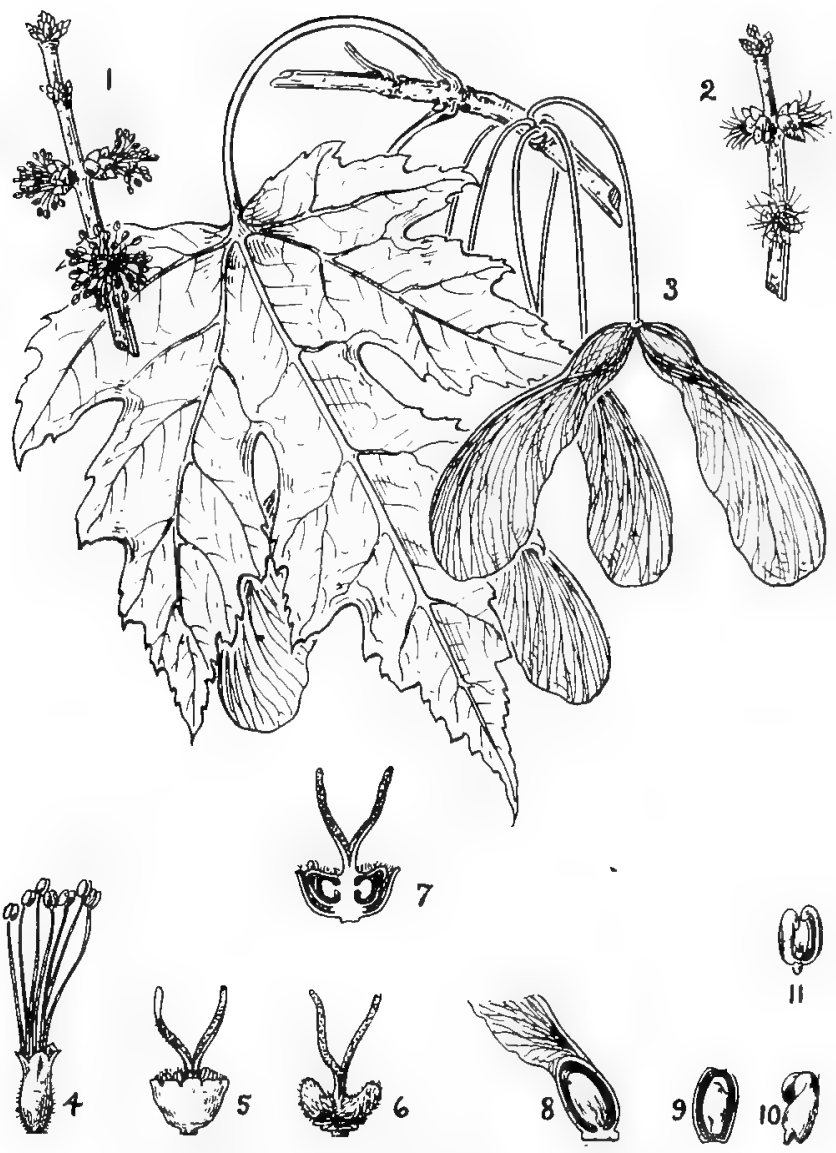

I'late 53. Acir saccharinum. Silver Maple.

I. Branch bearing staminate flowers, one-half natural size. 2. Branch bearing pistillate flowers, one-half natural size. 3. Eruiting branch, onehalf natural size. 4. Staminate flower, enlarged. 5. Pistillate flower, enlarged. 6. Pistil, enlarged. 7. Longitudinal section of pistillate flower, enlarged. 8. Longitudinal section of samara, one-half natural size. 9. Longitudinal section of seed, enlarged. 10, Embryo, enlarged. II. E,mbryo, displayed, enlarged. 
Distribution. - It is found in the north from the valley of the St. John river in New Brunswick to southern Ontario. It extends southward through the United States to western Florida and west to eastern Dakota and Nebraska. It is adapted to a wide variety of soils, and is especially abundant along rivers, often growing luxuriantly on sand bars and land that is inundated by spring freshets. A very common tree in southern and central Minnesota and north along the Mississippi valley.

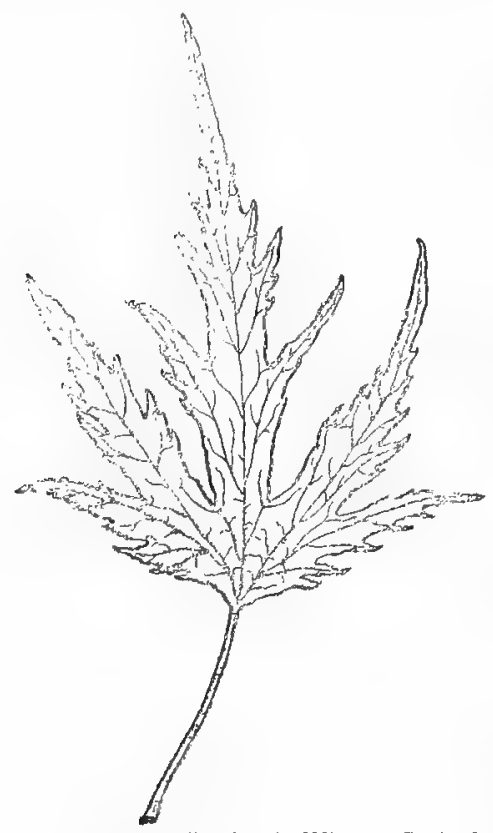

Figure 6r. Leaf of Wier"s Cutleaf Maple-one-lialf natural size.
Propagation.-By seeds, which drop off in early summer, and where they fall on moist soil they soon grow. They are very delicate, however, and cannot be kept in good condition many weeks after they are ripe. If sown at once in good moist soil they will often produce plants two feet or more high the first season, and the growth is also very rapid in subsequent years. The ornamental varieties are propagated by grafting or budding on the seedlings, and occasionally by layering.

Properties of wood. Light, hard (though not nearly so hard as Sugar Maple), rather brittle and easily worked. It is pale, faintly tinged with brown. The sapwood is light colored and thick. Specific gravity 0.5269 ; weight of a cubic font 32.84 pounds.

Uses.-The Silver Maple is exceedingly hardy and of very rapid growth, but suffers from a deficiency of moisture in the soil. It makes a very good street and lawn tree on retentive land, and is adapted to a wide variety of soils. The limbs are brittle, and the crotches of the tree are weak and likely to break in 
severe wind storms. This is most apparent where it grows on dry land, but if the trces are pruned occasionally they make very satisfactory shade trees, and are highly esteemed for this purpose in many sections of Minnesota. The Silver Maple is also successfully used for shelter belts. It sun scalds occasionally, though not commonly. The wood makes very good fuel, and is well adapted for interior finishing and flooring, and a form of it having a curly figure is used as veneering for elegant furniture and interior finishing. It is much used for shoe pegs. Maple sugar is sometimes made from the sap of this tree, but it is estimated that twice as much sap is necessary for a given quantity of sugar from this tree as from the Sugar Maple.

Varietics.-There are many varieties cultivated for ornamnetal planting, among the best of which is a form known as Wier's Cutleaf Maple, which has finely divided leaves and a very graceful pendent habit. It is about as hardy as the species, and is one of the most satisfactory small ornamental trees.

Acer rubrum. Red Maple. Scarlet Maple. Swamp Maple.

Lcaves palmately three to five-lobed, opposite. Flowers crimson scarlet, or sometimes yellowish, generally diccious; appearing in sessile lateral clusters before the leaves very early in the spring, often before the snow has disappeared. The fruit on prolonged drooping pedicles ripens in early summer, about the time the leaves are expanded, and then drops off. This is a slender tree, somewhat resembling the Silver Maple, but of much slower growth and more compact habit. It will finally attain as large size as the Silver Maple.

Distribution.-It is found naturally distributed over about the same area as the Silver Maple, but does not appear to be a common tree anywhere in Minnesota, and seems to be wholly absent in the western half of this state.

Propagation.-The Red Maple is propagated in the same manner as the Silver Maple.

Properties of wood.-Heavy, close grained, easily worked, and not very strong. It is light brown often tinged with red, with a smooth, satiny surface. The sapwood is thick, and lighter colored than the heartwood. Specific gravity 0.6178 ; weight of a cubic foot 38.5 pounds. 


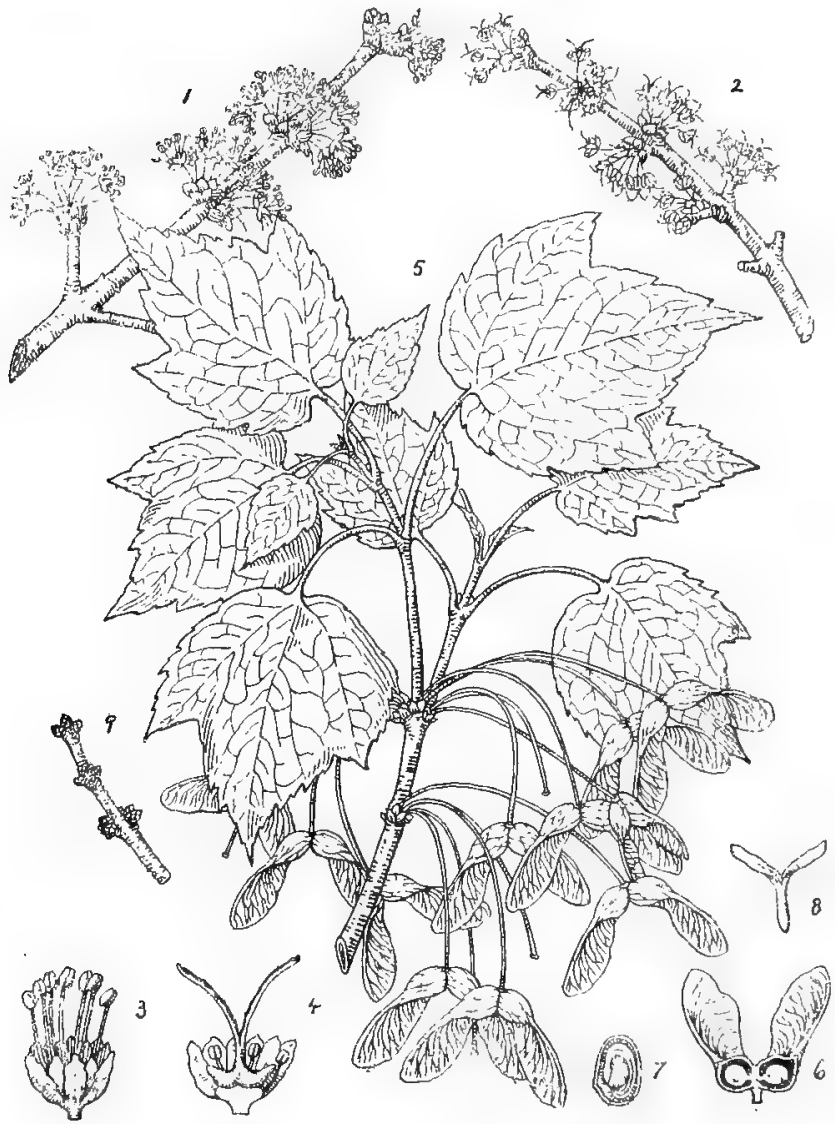

Plate 54, Acer rubrum. Red Maple.

I. Branch bearing staminate flowers, one-half natural size. 2. Branch bearing pistillate flowers, one-half natuial size. 3. Staminate flower, en. larged. 4. Yistillate flower, cnlarged, 5. liruiting branch, one-half nat ural size. 6. Longitudinal section ot iruit, one-halt natural size. 7. Longitudinal section of seed, enlarged. 8. Embryo, displayed, enlarged. 9. Winter branchlet, one-half natural size. 
Uscs.-On account of its slow growth the Red Maple is seldom used for planting, although very hardy. It is, however, very ornamental in the spring when loaded with its brilliant red fruit, which often appears while the branches are still destitute of leaves, and the gorgeons blaze of scarlet coloring of its leaves in autumn makes it a very conspicuous feature of the landscape at that season. It could often be employed to advantage in ornamental planting. The timber is a valuable fuel; it is used for floors, cabinet work, turnery, and in the manufacture of shovels, bowls and small wooden ware generally. The curly figure is sometimes found in this wood, and is sometimes used for choice veneering. The sap of the Red Maple is not so rich in sugar as that of the Sugar Maple, but produces a very good quality of maple sugar.

\section{Acer spicatum. Mountain Maple.}

Leaves three or slightly five-lobed, thin, downy on the lower surface, at maturity glabrous above. Flowers small, grecnish yellow, in upright dense, sometimes compound racenes, appearing after the leaves, the fertile towards the base and the sterile at the ends of the racemes; petals much longer than the sepals. Fruit with small erect or divergent wings. Within our range a low shrub, with slender erect branches; in the shade in moist woods the branches are often rather flexible, and it is probably on this account that it is given the name of Vine Maple in some parts of this section.

Distribution.-Valley of the St Lawrence to northern Minnesota and the Saskatchewan, southwards through the mountains to Georgia. Common in Minnesota south to Mille Lacs.

Propagation.-By seeds.

Properties of wood.-Light, soft, light brown with thick lighter colored sapwood. Specific gravity 0.5330; weight of a cubic foot 33.22 pounds.

Uses.-The Mountain Maple may occasionally be used to advantage in shrubbery in shady situations. The tree is so small that the wood is of no special economic importance. 
Acer pennsylvanicum. Striped Maple. Moosewood.

Leaves large, five to seven inches long, palmately threenerved, three-lobed at the apex, finely and doubly serrate. Flowers greenish, in slender drooping long-stenmed racemes; the sterile and fertile generally produced on different racemes on the same plant, appearing when the leaves are nearly full grown. Fruit with spreading wings, in long drooping racemes, ripens in antumn. An upright shrub in this section, seldom taking on a tree form.

Distribution.-Maine and Minnesota southwards to Virginia and Kentucky.

Propagation.-By seeds, as recommended for Ash.

Properties of rood.-Light, soft and close grained, light brown with thick lighter colored sapwood. Specific gravity 0.5299 ; weight of a cubic foot 33.02 pounds.

Uses.-The Striped Maple is used in New York and southwards for lawn planting, and may in this section be used for shrubberies. The brilliant foliage and bud scales in early spring, the graceful flowers and summer foliage, the brilliant autumn coloring of the leaves and the conspicuously striped markings of the bark make the Striped Maple an interesting and attractive feature of the landscape. Well worthy of a trial in shrubberies on retentive soil.

\section{Acer tartaricum. Tartarian Maple.}

I-eaves ovate or oblong, mostly undivided, incised-serrate, very bright colored in autumn; young branches tomentose. Flowers conspicuous, white, in erect clusters terminating the shoots of the season, appearing after the leaves. Fruit ripens in autumn. A small tree or shrub.

Distribution.-Europe and Asia.

Propagation.-By seeds, as recommended for Ash.

Uses.-Valuable for variety in ornamental planting. Very hardy at the Minnesota Experiment Station.

Varicties.-

\section{Acer tartaricum ginnala.}

This has mostly three-lobed leaves, which are longer than those of the species. 


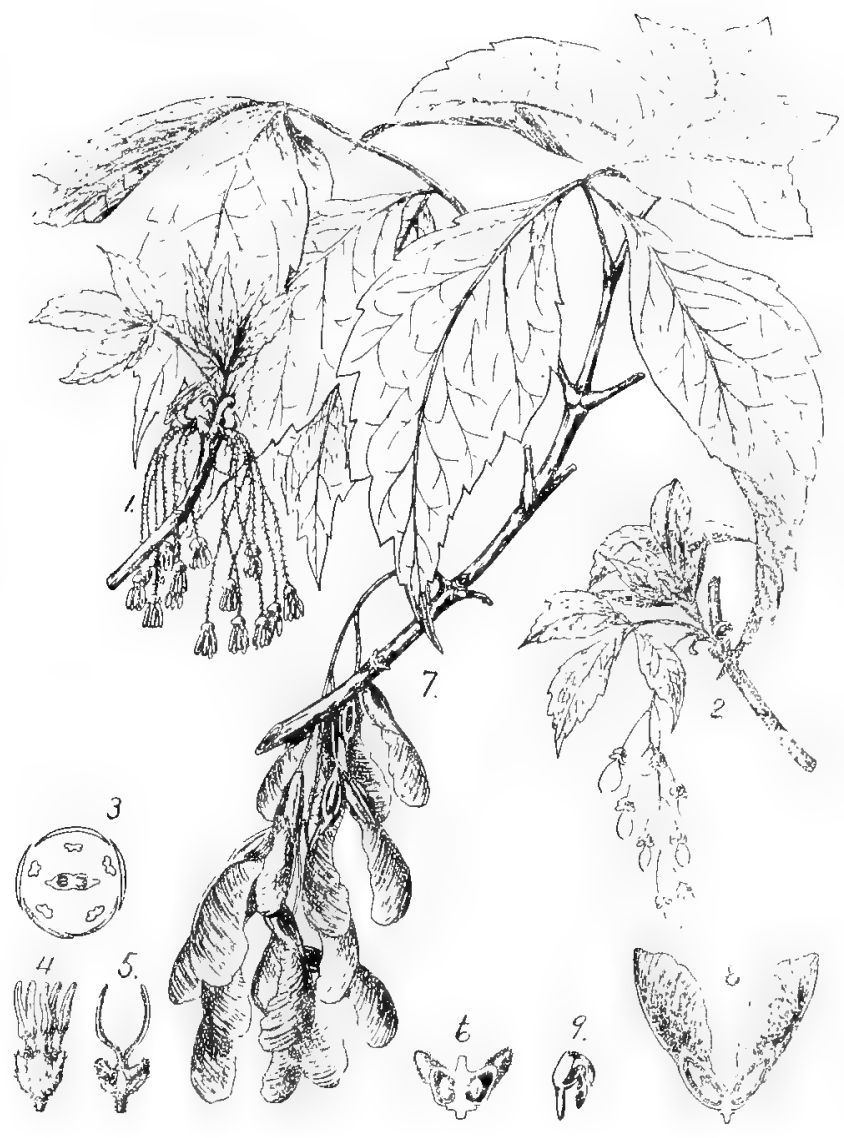

Plate 55. Acer negundo. Boxelder.

I. Flowering branch from staminate tree, one-half natural size. 2. Flowering branch from pistillate tree, one-lialf natural size. 3. Diagram of flower. 4. Staminate flower. 5. Pistillate flower. 6. Longitudinal section of ovary, enlarged. 7. Fruiting brancl, one-half natural size. 8. Longitudinal section of fruit, one-lialf natural size. 9. Embryo, enlarged, 
Acer negundo. (Negundo aceroides.) Boxelder. Ashleaf Maple.

Leaves opposite, pinnately compound with three to five leaflets. Flowers dioceious, apetalous small, grecnish, appearing just before or with the leaves. The seeds are oval in form, ripen in autumn, and hang on the trees until winter in this section. Many trees bear fruits that to outward appearance contain perfect seeds but which upon examination will be found to be empty seed vesscls.

Distribution.-One of the most widely distributed and hardiest trees of North America, ranging from the valley of the Saskatchewan to Florida and Texas and from Vermont to the eastern slopes of the Rocky Mountains. In the Minnesota river bottoms this tree grows seventy feet high and three feet in diameter, while in severe locations it becomes a low bushy tree.

Propagation.--By seeds sown as soon as ripe in the fall or stratified over winter and sown in the spring.

Propertics of wood.--Light, soft, close grained, but weak. It is creamy white, with thick, hardly distinguishable sapwood. Specific gravity 0.4328 ; weight of a cubic foot 26.97 pounds.

Uses.-The Boxelder is one of the hardiest of trees, and is highly estecmed for strect and lawn planting and for windbreaks in severe locations. It has, however, been too often planted where the White Eim or Green Ash should have been used. The wood makes good fucl; it is sometimes used for interior finishing, woodenware, paper pulp, etc. Maple sugar is sometimes made from this tree, though the sap is not so rich in sugar as the sap of the Singar Maple.

\section{HIPPOCASTANACEAE. BUCKEYE FAMILY.}

An order consisting of two genera, the following of which contains about fifteen species natives of America and Asid. None are native of Minnesota.

\section{Genus ASSUIUS.}

Leaves opposite, digitate, three to nine-foliate. Flowers in a terminal dense panicle, often polygamous, most of them with 
imperfect pistils, and only those near the base of the branches of the inflorescence perfect and fertile; calyx tubular, five-lobed, often oblique or swollen at the base; petals four or five; more or less unequal with claws; stamens five to eight; ovary threecelled with two ovules in each cell. Fruit a roundish leathery pod, three-celled and three-seeded or usually by suppression one or two-celled and one or two-sceded, the remnants of the abortive cells and seeds commonly visible in the ripened pods, seeds one to one and one-half inches broad, with a hard chestnut brown coat; embryo filling the seed; cotyledons very thick and fleshy. The large seeds of both species contain a large amount of starch, but present with it is a bitter principle, esculine, which renders them unfit for food for man, although they are sometimes fed to sheep, goats and swine. This bitter principle may be removed by repeated washings in pure water, and were it not for the cost of the operation the nuts could be made a valuable food for man.

Propagation.-Both species here described are easily propagated by seeds, which should generally be sown in autumn, for they soon lose their vitality; also, by layers made in spring or fall. The varieties may be grown by grafting.

\section{Aisculus hippocastanum. Horse Chestnut.}

Leaves made up of five to seven (generally seven) leaflets. Inflorescence large and conspicuous. Petals five, spreading, white, spotted with purple and yellow. A large tree, with round top, large sticky buds and very dense foliage.

Distribution.-Europe and Asia.

Propagation.-Described under genus.

Propertics of zvood.-Light, soft, easily worked, light-colored, not durable in contact with the soil.

Uses.-The Horse Chestnut is used in the Eastern and Central states as a shade trce. It is not sufficiently hardy for general planting in this state, and should never be used except in very favorable locations in southern Minnesota. The bark has been used in tanning and as a substitute for cinchona in the treatment of fevers and in homeopathic remedies. 


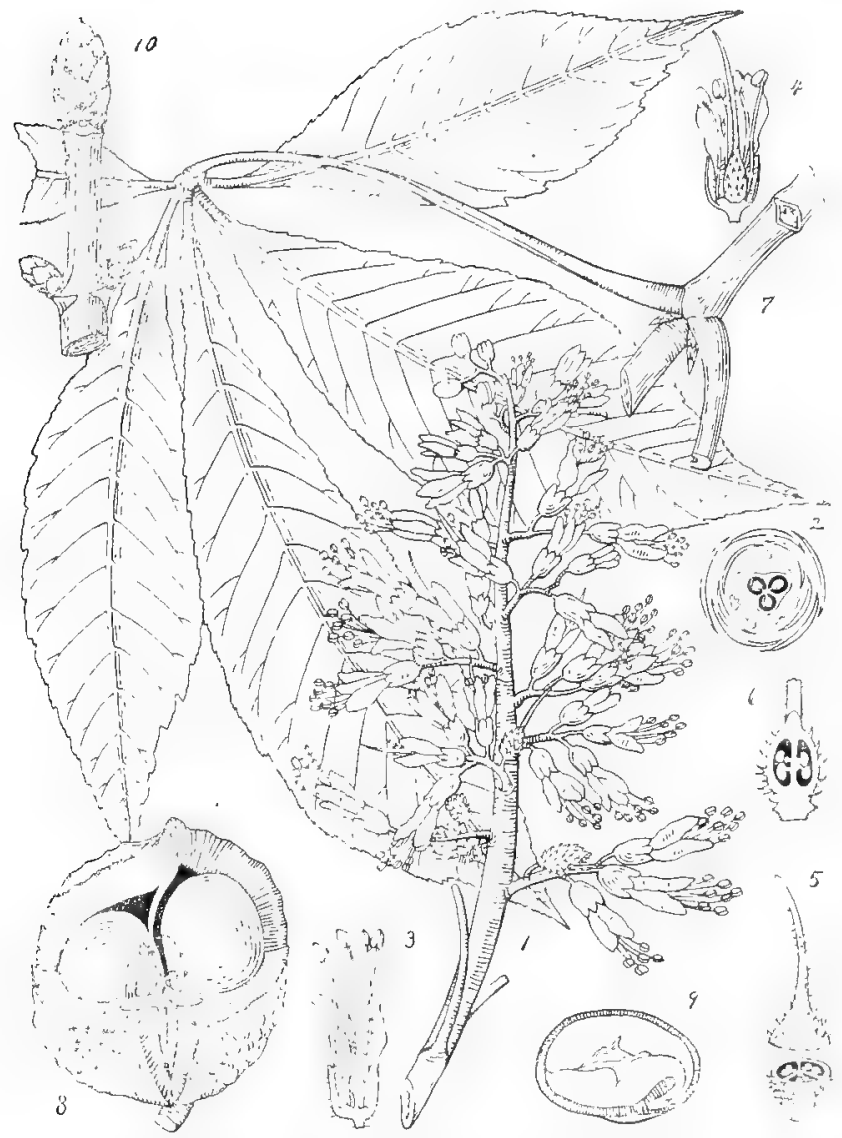

I'late 56. Isculus glabra. Ohio Buckeye.

I. Flowering branch, one-half natural size. 2, Diagram of flower. 3. I ongitudinal section of staminate $H_{0}$ ower, natural size. 4. Longitudinal section of pistillate flower, natural size. 5. Transverse sections of pistil, cnlarged. 6. Longitudinal section of ovary, enlarged. 7. P'ortion of summer branch, one-half natural size. 8. Wruit with portion removed, onelialf natural sizc, 9. Longitudinal scetion of seed, one-half natural size. io. Winter bud, one-half natural size. 


\section{Fisculus glabra. Ohio Buckeye. Fetid Buckeye.}

Leaves made up of five to seven (generally five) leaflets. Inflorescence appearing with the leaves, five to six inches long, not large and showy like the Horse Chestnut. Stamens usually seven, curved, longer than the pale yellow-green corolla; petals four, upright. Buds large, not sticky. Tree generally not more than thirty feet high.

Distribution.-Pennsylvania, south to northern Alabama and west to southern Iowa, central Kansas and Indian Territory.

Propagation.-Described under genus.

Properties of wood.-Light, soft, close grained but not strong, often blemished by dark lines of decay; nearly white with thin, darker colored sapwood. Specific gravity 0.4542 ; weight of a cubic foot 28.3I pounds.

Uses.-The Ohio Buckeye is much hardier than the Horse Chestnut, and stands fairly well in this section as far north as St. Paul, where there are some very good small specimens in the parks. It is of value to give variety to ornamental plantings. The wood is used in the manufacture of wooden ware, paper pulp and artificial limbs. For the latter purpose it is preferred to that of all other American trees.

\section{RHAMNACEAE. BUCKTHORN FAMILY.}

\section{Genus RHAMNUS.}

We have no native species of importance in this genus. $R$. catharticus, a foreign species, is so valuable as an ornamental shrub that it is here described.

Rhamnus catharticus. Buckthorn. English Buckthorn.

Leaves ovate, minutely serrate, opposite or nearly so. Flowers usually dioecious, small, greenish. Fruit a three to four sceded black berry, hanging on the branches all winter. A shrub or small tree with thorny branchlets.

Distribution.-Throughout northern Etrope, where it is native.

Propagation.-By seeds, which should be gathered in autumn, kept stratified over winter, and planted in the spring or by 


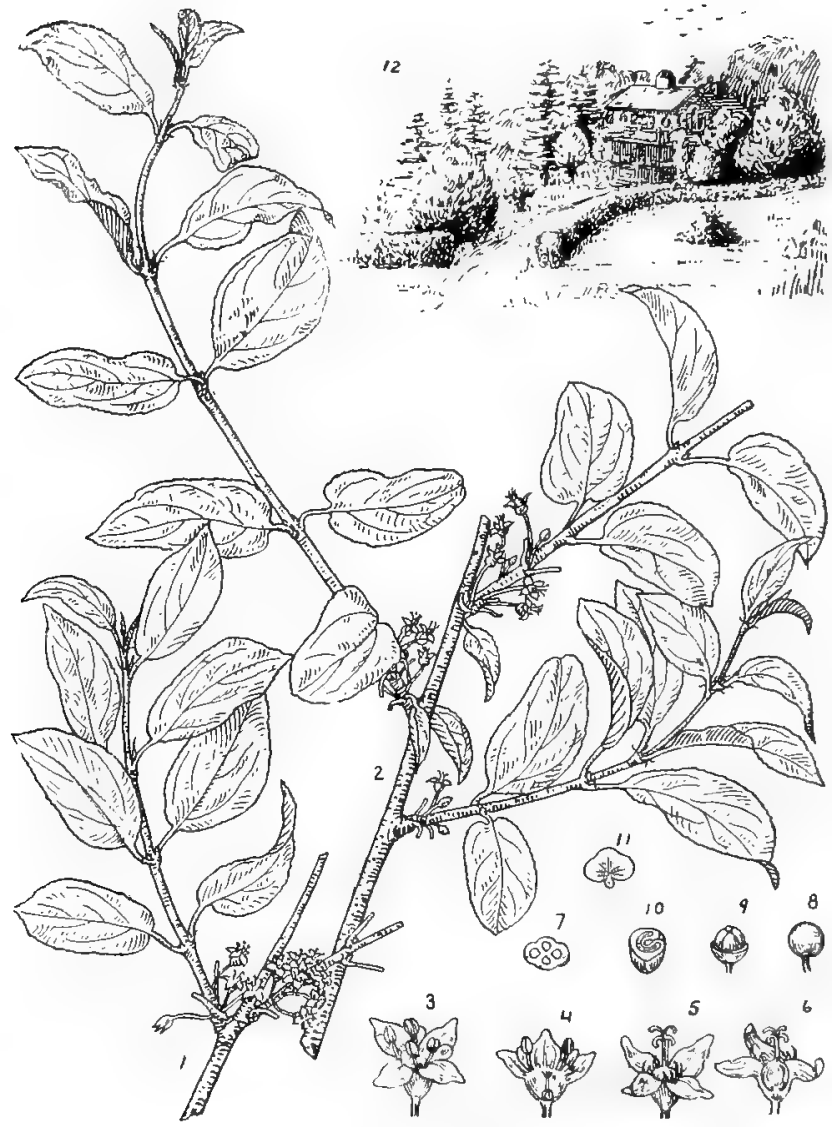

L'late 57. Rhammis callarticus. Buckthorn.

I. Elowering branch from staminate plant, one-half natural size. 2, Flowering brancis from pistillate plant, one-half natural size. 3. Staminate flower, cnlarged. 4. Longitudinal section of staminate flower, enlarged. 5. Pistillate flower, enlarged. 6. Longitudinal section of pistillate flower, enlarged. 7. Cross section of ovary. 8. Single fruit, one-half aatural size. 9. Single fruit with a part removed to show nutlets. 10. Cross section of sced. II. Embryo. 12. View of grounds showing the use of Buckthorn for a hedge. 
layers. If the fruit is allowed to hang on the bushes until spring in this section many of the seeds may be injured.

Uscs.-The Buckthorn is used largely for hedges, for which purpose it is one of the hardiest, thriftiest and cleanest plants that can be used in this section. It bears pruning well, and hedges of it can be made very ornamental. As single specimens it is desirable for park planting and for screens. The seeds and innerbark possess medicinal qualities.

\section{TILIACEAE. LINDEN FAMILY.}

A family of about thirty-five genera and 245 species, widely distributed in warm and tropical regions, a few in the temperate zone.

\section{Genus TII,A.}

A genus of about twelve species, only one of which is found in Minnesota. They are all handsome, valuable trees, with soft white wood.

Leaves alternate, more or less heart-shaped, often soft and downy. Flowers with five spatulate, oblong petals, cream colored, in small cymes or clusters, hanging on an axillary, slender peduncle, which is attached to a long, slender and thin leaf-like bract. Fruit a small globular nut, one-celled, one or two seeded, attached to the leaf-like bract and ripening in autumn. The flowers are fragrant, and yield a large quantity of clear, white, delicately flavored honey. The European Linden ( $T$. vulgaris) is mentioned here as being one of promising value for cultivation in this section.

Tilia americana. Basswood. American Linden. White Wood. Beetree.

Leaves large, alternate, nearly round or more or less heartshaped, commonly oblique at the base, serrate abruptly pointed, green on both sides and glabrous, or nearly so. Flowers yellowish-white, conspicuous, iragrant, appearing in June. Tree large, often attaining a height of seventy feet and a diameter of three feet. The bark of the trunk is furrowed, and its light 23 


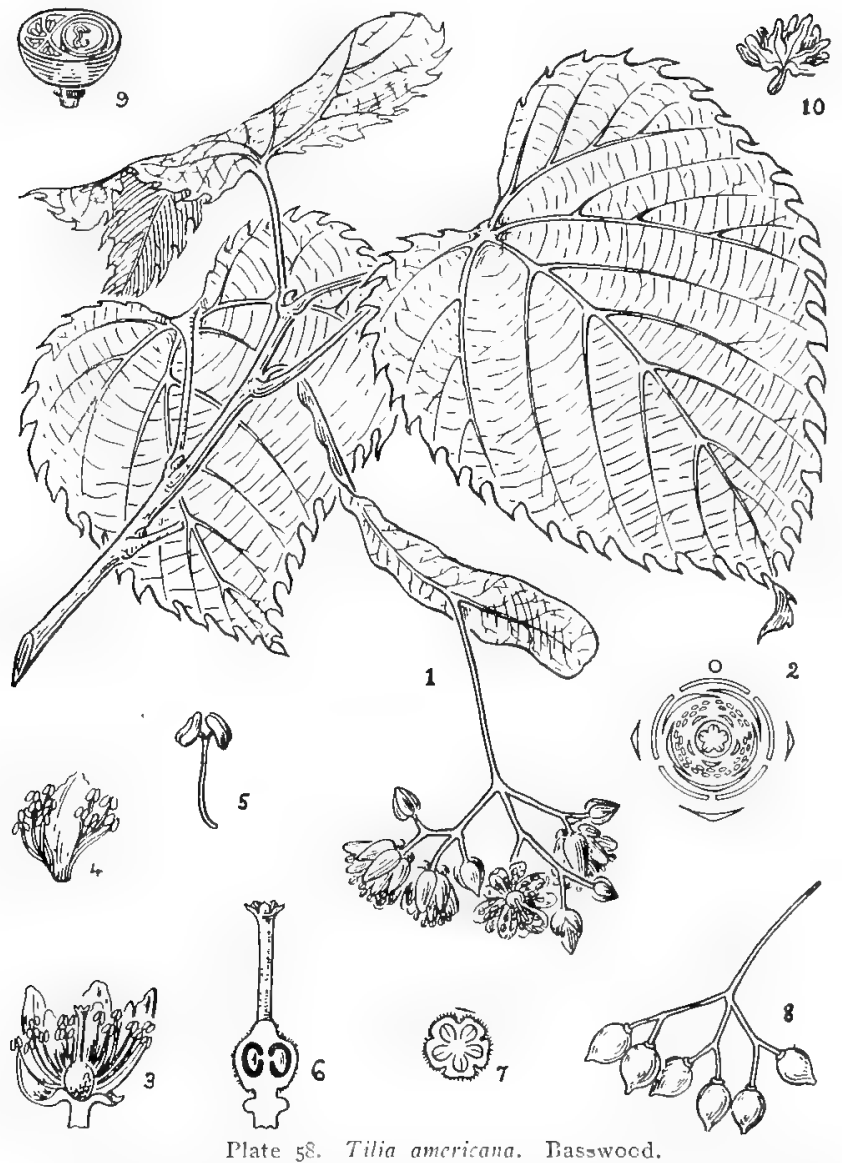

1. Flowering branch, one-halt natural size. 2, Diagram of flower. 3. A flower with two sepals and two petals removed. 4. A cluster of stamens with therr petaloid scale, enlarged. 5. A stamen, enlarged. 6. I'istil, showing longitudinal section of oviry, enlarged. 7 - Cross section of ovary, cnlarged. 8. Cluster of truit separated trom bract. 9. Cross section of fruit. 10. limbryo, showng 5-lobed cotyledons. 
brown surface is broken into small, thin scales. The bark on the young growth is light gray, and gradually becomes dark and finally brown. Very few varieties of this species are cultivated.

Distribution.-It is found from New Brunswick west to Assiniboia and south to Georgia and Texas. In Minnesota the Basswood is generally common throughout the state, and is very abundant in the Big Woods.

Propagation.-The Basswood is generally grown from the seeds, which even when stratified and exposed to frost the first winter will often fail to start until a year from the following spring. It may also be grown from layers, and from cuttings of the younger wood by using the solar pit. It sprouts readily from the stump if cut in winter, and renews itself very satisfactorily in this way. It may also be grafter.

Properties of a'ood.-Light, soit, tough, close grained, compact and easily worked. The sapwood is very thick, and when properly seasoned is nearly white in color; but generally it can hardly be distinguished from the light brown heartwood. It warps badly when exposed to weather, and rots quickly when in contact with moisture. The specific gravity is 0.4525 ; weight of a cubic foot 28.20 pounds.

Lscs.-The Basswood is a good street and lawn tree in suitable locations, taking on a very beautiful form, but is not nearly so much used for this purpose as it should be. It is very hardy, and resists drouth well, and is desirable in timber plantings in this section. Newly transplanted street trees of this species are liable to injury from sunscald in this section until they are well established and for this reason should have theit trunks protected from the sun for several years after they are set out.

The wood is largely sawed into lumber, and under the name of whitewood is used in the manufacture of cheap furniture, wooden ware, carriage boxes, etc., for interior finishing and a variety of other purposes such as churns and butter workers, cheese boxes, bee hives, measures, grape and fruit baskets, boxes, packing, tool handles, map rolls, toothpicks, musical instruments, penholders, step ladders, baseball bats and artificial limbs, and toys. It is also used for paper pulp, but makes an inferior quality of paper. The inner bark, known as bast, is occasionally made into coarse cordage and matting. The manufacture of these latter materials from European Linden has been 
conducted on a large scale in Europe, but has never attained any importance in the United States. The bast fiber is obtained by stripping the bark from the trees in the spring and soaking it until the nutucilage that binds the layers together is soaked out.

Tilia vulgaris. European Basswood. Eurnpean Linden

Native of northern Europe, forming a large tree. The wond of this specics is much like that of the American Basswood. The leaves, however, are smaller, and more regularly heart shaped. The tree is compact in habit, and has numerous short, rather slender reddish twigs. There are many varieties. This species has becn doing very well for about seven years in the forest plantation at the Minnesota Experiment Station, and scems to be of some value for this section. The varieties of the broad-leaved European Linden (T. Platyphyllos) have failed in this section.

\section{ELAEAGNACEAE. OLEASTER FAMILY.}

\section{Genus EI, 看AGNUS.}

Shrubs or trees, silvery-scurfy or stellate pubescent with entire leaves and perfect or polygamous flowers. The lower part $n \mathrm{f}$ the perianth of fertile flowers incloses the ovary, and ripens into a fleshy or mealy mass around the akene-like true fruit. The upper part is four-cleft and deciduous. Corolla none; stamens four, borne on the tube of the perianth.

\section{E1æagnus angustifolia. Russian Olive.}

Leaves narrowly lanceolate, two to three inches long, whitescuriy on lower side, stellate pubescent on the upper. Perianth whitish outside and yellowish inside.

Distribution.-Europe and Asia.

Propagation.-By secds, which grow readily, by layers and by attumn-made cuttings.

Uscs.-The Russian Olive is a very hardy small ornamental tree of very pretty habit, chiefly valued for the contrast it gives 

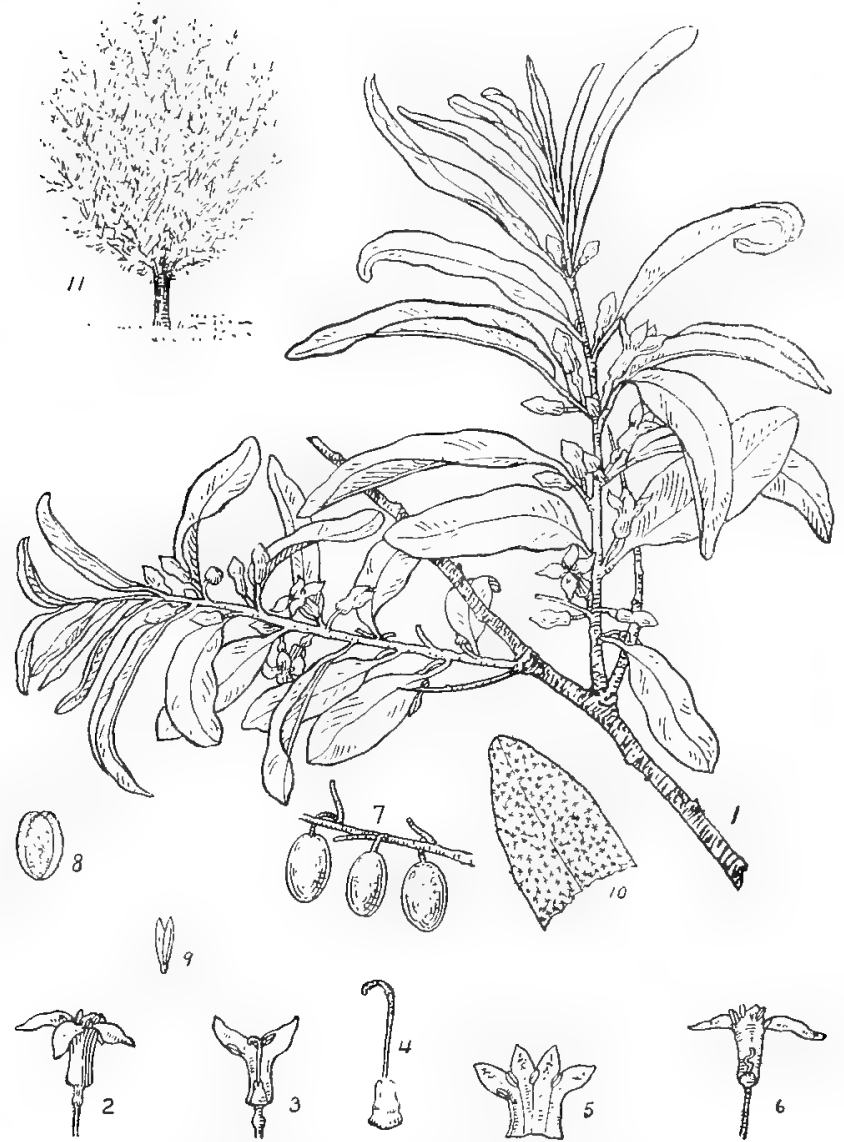

$y_{9}$
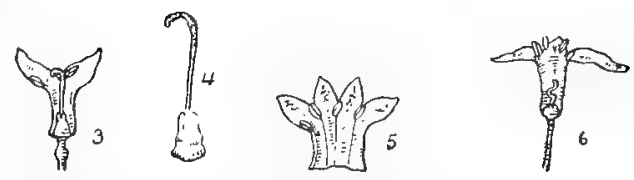

Plate 59. Elcagrus angustifolia. Russian Olive.

I. Flowering branch, natural sise. 2, Ierfect flower, enlarged. 3. Perfect flower with a part of corolla and stamens removed, enlarged. 4. Upper part of pistrl showing style and stigma, enlarged. 5. Corolla, displayed, enlarged. 6. Stamnate flower with a portion removed, showng rudimentary pistil, enlarged. 7. I'ortion of branch bearing fruit, natura size. 8. Longitudinal section of fruit, natural size. 9. Enbryo, displayed. Io. Portion of leaf showing stellate pubescence on upper surface. 11. Gen eral view of tree. 
to plantings. It has proved a very satisfactory tree in this section, and has endured drouth well at the Minnesota Experiment Station and at the Coteau Farm in Lyon county, Minnesota, and in South Dakota.

\section{OLEACEAE. OLIVE FAMILY.}

\section{Genus FRAXINUS.}

Leaves opposite, petioled, odd-pinnate with three to fifteen toothed or entire leaflets. Flowers small, diøecious or polygamous and apetalous in racemes or panicles from the axils of last year's leaves; stamens two; ovary two-celled. Fruit a flattened samara, winged at the apex, usually onc-seeded.

Propagation.-By seed, which may be sown as gathered in autumn, or which may be stratificd over winter and sown in in the spring. A good way to keep these seeds over winter is to place them on the surface of a garden walk; putting a box over them and cutting a trench around the box to keep the water away. They will not grow if kept too dry.

\section{Fraxinus americana. White Ash.}

Leaves with seven to nine leaflets, which are usually rounded at the base and generally entire in outline or very slightly serrate. Flowers diocions, appearing with or rather before the leaves. Fruit ripe in autumn, cylindrical and winged at one cnd and surrounded at the base by the persistent calyx. The bark on the young twigs is rather dark, nearly smooth and free from spots. A large and valuable tree, commonly confounded in this section with the Green Ash and the Red Ash. both of which, however, are smaller trees and much hardier, produce seed at an earlier age and in larger quantities, and altogether are better adapted to prairie planting than the White Ash.

Distribution.--From Nova Scotia west to northern Minnesota and eastern Nebraska and south to northern Florida and Texas. In Minnesota the White Ash appears to be a rare tree. In the western part of the state and in the Dakotas it is wholly replaced by Green Asli, or what secms to be a hopeless mixture of Green Ash and Red Ash. 


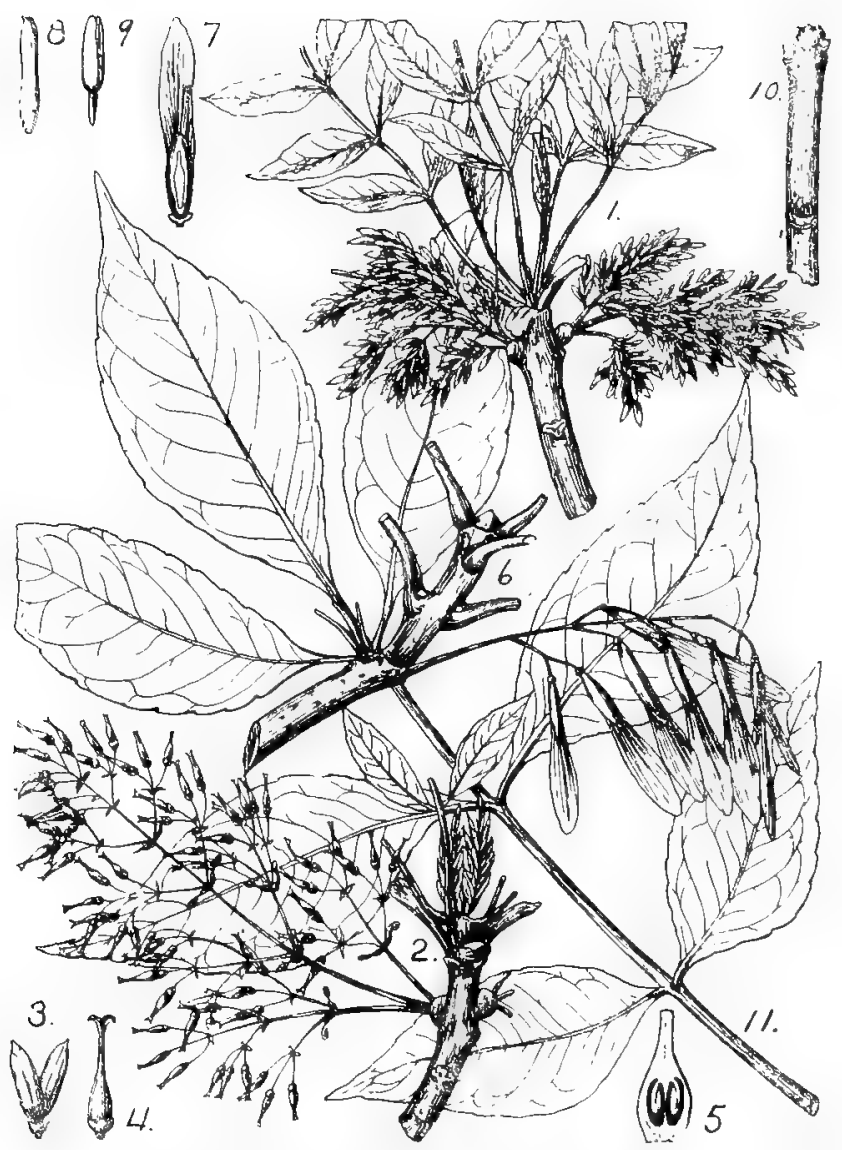

Plate 60. Fra.rinus amiricana. White Ash.

I. Flowering brancl of staminate tree, one-half natural size, 2. Flowering branch of pistillate 1ree, one-half natural size. 3. Staminate flower, enlarged. 4. Pistillate flower, enlarged. 5. Longitudinal section of ovary, enlarged. 6. Fruiting branch, one-lhalf natural size. 7. Longitudinal section of fruit, one-lialf natural size. 8. Seed, two-thirds natural size, 9. Embryo, natural size, Jo. Winter buds, one-late natural size, Ir. Leaf, one-half natural size, 
Propagation.--See genus.

Propcritics of wood.-Heavy, hard, strong, coarse grained and tough, although brittle when old; brown, with thick, lighter colored sapwood. Specific gravity 0.6543 ; weight of a cubic foot 40.77 pounds.

Uses.--The White Ash is a good ornamental tree in spite of its late foliage, and is desirable for timber belts in the milder portions of this section, but on the prairies does not grow as fast as the Green Ash. The wood is of less value when grown here than when grown in the Northeastern States. It is used in immense quantities in the manufacture of agricultural implements, carriages and furniture, for the interior finishing of buildings, and for any purpose where a light-colored, tough wood is needed. It is manufactured into baseball bats. lawn tennis racquets, polo mallets, tool handles, crutches, step ladders, tripods, churns, tubs and pails. The wood of what is termed second growth trees, i. e., those springing up after the original forest has been removed or from seed scattered in open fields. is usually superior in toughness to the first growth or large trees. The inner bark of the White Ash has some medicinal properties and is used in homeopathic practice.

\section{Fraxinus pennsylvanica. (F. fubescens.) Red Ash.}

Leaflets oblong-lanceolate to ovate, mostly coarsely serrate, velvety pubescent on their lower surface like the young shoots. Flowers dioecious; calyx present and persistent in the fruit. This tree is easily distinguished in the Eastern States, but in this section it merges into the Green Ash, and is often difficult to distinguish from it.

Distribution. - It has about the same range as the Green Ash, but is less common west of the Mississippi river.

Propagation.-See genus.

Properties of zvood.-Heavy, hard, rather strong and brittle and coarse grained; light brown, with thick lighter colored sapwood streaked with yellow. Specific gravity 0.62 I5; weight of a cubic foot 38.96 pounds.

Uses.-In this section the Red Ash is used for planting the same as Green Ash. The wood is often substituted for that of the White Ash, which is much more valuable. 


\section{Fraxinus lanceolata. (F. viridis.) Green Ash.}

The Green Ash closely resembles the Red Ash, from which it is distinguished in extreme forms by its glabrous leaves and branchlets and by its rather narrower and shorter and ustally more serrate leaves, which are lustrous and bright green on both surfaces. However, in western Minnesota and the Dakotas these two species run together, and are often indistinguishable. The flowers and fruit of the two species are alike, although many forms occur on each. Professor Sargent regards the Green Ash as a variety of the Red Ash.

"The bark on the preceding year's growth of the Green Asl, is noticeably lighter colored than that of the White Ash, and shows many more rather lighter spots or warts. The leaflets are usually strongly serrate. The leaves are bright dark green in color, although somewhat lighter below. The young growth of new wood is usually smooth and glabrous, while the mid veins of the leaves frequently show some pubescence on the lower side." (L. R. Moyer.)

Distribution.-From the shores of Lake Champlain west to the valley of the Saskatchewan and eastern range of the Rocky Mountains and south to Florida, Texas and Arizona. In Minnesota one of the most common trees along water courses in the western part of the state. It is probable that about all the Ash in western Minnesota and the Dakotas is Green Ash, or a hopeless mixture of it with Red Ash.

Propagation.-The Green Ash grows readily from seeds, as described under genus.

Propcrtics of a'ood.-Hard, strong, brittle and rather coarse grained; it is brown, with thicker, lighter colored sapwood. Specific gravity is 0.7117 ; weight of a cubic foot 44.35 pounds.

Uscs.-The Green Ash is one of the hardiest trees known, and is very valuable for windbreaks and ornamental plantings on the prairies of Minnesota and the Dakotas, and throughout this section should often talie the place of the Cottonwood. Its great hardiness against cold and drouth, its easy propagation from seed and its rapid growth make it especially fitted for general planting. The wood is used for the same purposes as White Ash, but is of inferior quality. 
Fraxinus nigra. (f. sambucifolia.) Black Ash. Swamp Ash. Hoop Ash.

Flowers dioecious or polygamous without calyx. Leaflets seven to eleven, oblong-lanceolate, taper-pointed; the lateral sessile. It naturally inhabits cold, wet swamps, and the low banks of streams and lakes. Gencrally a small, slender tree. The bruised foliage exhales the odor of Elder.

Distribution.-Cold swamps and low banks of streams from Newfotndland to Manitoba and south to Virginia and Arkansas. In Minnesota frccuent throughout the statc.

Propagation.-As described under genus, except that seeds of this are different from those of other native species in not growing the first season after planting, but must be kept stratified for one year.

Propertics of wood.-The Black Ash is heavy, rather soft, not strong, tough, coarse grained, durable in contact with the soil and easily separated into thin layers. It is dark brown, with thin light brown or often nearly white sapwood. The specific gravity is 0.63 I 8 ; weight of a cubic foot 39.37 pounds.

Uscs.-The Black Ash is of very little value for planting, but might sometimes be used to advantage in wet lands. It is a slow grower and short lived in our prairie soils. It is used extensively in the manufacture of furniture, for interior finishing, barrel, tub and pail hoops, baskets and chair seats. For this latter purpose the wood is split in as many layers as there are annual rings, which may be done very readily. There are peculiar excrescences popularly known as knots or "burls" that form on the Black Ash, and sometimes these grow as large as a bushel basket or larger. They are a sort of dwarfed branches. It has been found that when these "burls" are properly sawed they show a pretty curly grain, and make very desirable veneering for furniture and for interior finishing, and they are sought after for this purpose. However, in this section the "burls" seldom if ever grow to sufficient size to become of commercial inportance, 


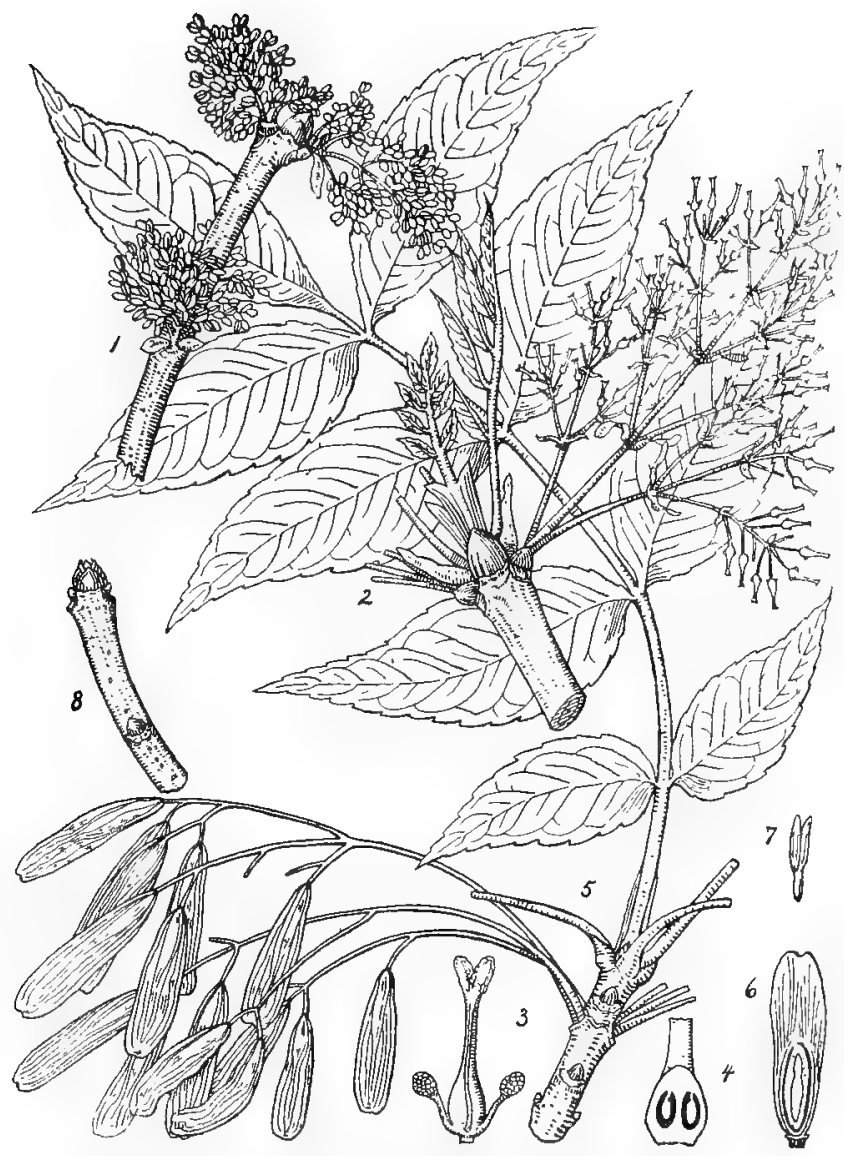

Plate 6r. Fraxinus nigra. Black Ash.

I. Flowering branch of staminate tree, one-half natural size. 2. Flowering branch of pistillate tree, one-half natural size. 3. P1stillate flower showing rudimentary stamens, enlarged. 4. Jongitudinal section of ovary, enlarged. 5. Fruiting branch, one-half natural size. 6. Longitudinal section of fruit, one-half natural size. 7. Embryo. 8. Winter branchlet, onehalf natural size, 


\section{BIGNONIACEAE. BIGNONIA FAMILY.}

\section{Genus CATALPA.}

A genus of four or five species of trees, natives of the West Indies, North America, Japan and China. Leaves simple, opposite or in whorls of three. Flowers in terminal panicles; calyx deeply two-lipped; corolla inflated, bell-shaped, the five. lobed border more or less two-lipped and wavy. Fruit a long slender hanging pod; seed, two-winged with silky fringe.

\section{Catalpa speciosa. Hardy Catalpa. Western Catalpa.}

Leaves large, opposite or in threes, heart-shaped at base, long-pointed, thick, firm, dark green above, falling after the first severe autumn frost. Flowers appear in June in large panicles, very conspicuous and pretty; corolla about two inches long, nearly white, faintly spotted, the lower lobes notched; calyx purple. Fruit nine to twenty inches long, about one-half inch in diameter at the middle and tapering towards both ends. It ripens in autumn, generally remains on the tree until spring, and then splits into two concave valves. The seed is light brown, about an inch long and one-third of an inch wide; the wings are rounded at the ends and terminate with a fringe of silky hairs. The ends of the branches die in winter without forming a terminal bud. A large and important tree in the forests within its range, where it attains a height of over Ioo feet and a diameter of three to four and one-half feet.

Distribution-Borders of streams and lakes and fertile and inundated bottom lands in southern Illinois and Indiana, western Kentucky and Tennessee, southeastern Missouri and northeastern Arkansas.

Propagation.-By seeds, and it is said by cuttings.

Properties of rvood.-Soft, light, not strong, coarse grained, very durable in contact with soil. Specific gravity 0.4165; weight of a cubic foot 25.96 pounds.

Uses.-The Hardy Catalpa is not a very hardy tree in this section, and probably most of the specimens of it growing north of central Iowa are more or less injured by our winters; but they often hold on well in favorablc locations as far north as St. Paul and Minneapolis, and form good small trees. They are 


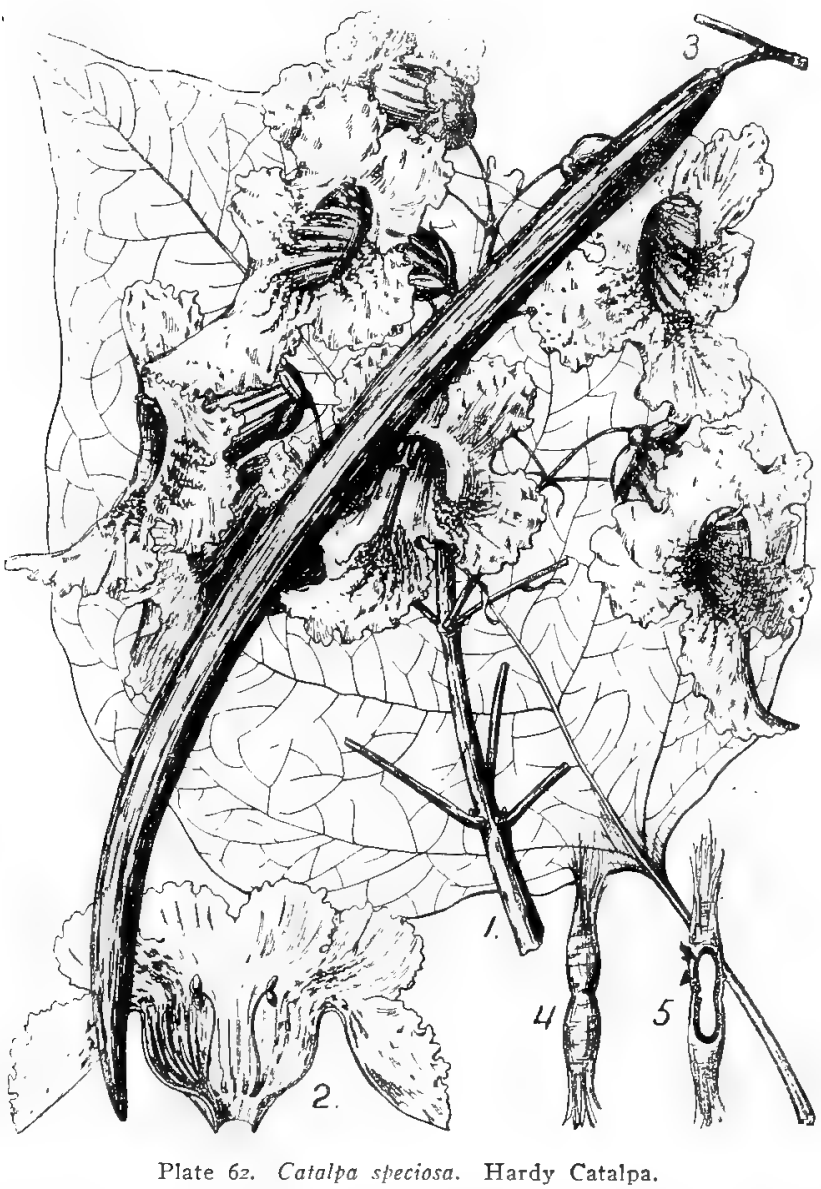

I. Panicle of flowers, one-half natural size. 2. Carolla, displayed, showing stamens, one-half natural size. 3. Single fruit, one-half natural size. 4. Seed, one-half natural size. 5. Longitudinal section of seed, onehalf natural size. 
occasionally killed to the ground, but generally renew themselves by sprouts from the roots. The Catalpa is, however, unfit for a street tree in Minnesota; but may often be used in protected locations in parks and lawns, where it is valuable for variety in foliage and for its beatiful flower clusters. It is of remarkably rapid growth when young and has been used in some of the most successful tree plantings that have been made in Kansas and southern lowa. The wood is used for railway ties, fence posts and rails, and occasionally for furniture and inside finish of houses.

The Hardy or Westen Catalpa was for a long time confounded with the Catalpa of the Eastern States (C. bignonioides), which is not nearly so hardy.

\section{CAPRIFOLIACEAE. HONEYSUCKLE FAMILY.}

A fanily of a few hundred species, including such well-known plants as the common Elder (Sambucus), the Snowberry (Symphoricarpus) and the Honeysuckle (Lonicera).

\section{Genus VIBURNUM.}

Small trees or shrubs with simple opposite leaves. Flowers perfect or neutral; calyx equally five-toothed, persistent; corolla five-lobed; stamens five; ovary inferior, one-celled. Fruit a dry or fleshy one-seeded drupe; seed flattened. This genus includes the well-known Snowball, which is a sterile form of the Highbush Cranberry (Viburnum opulus).

Viburnum lentago. Sheepberry. Black Haw. Nannyberry.

Leaves ovate-acuminate, petioles usually winged. Flowers perfect, in flat clusters from three to five inches across, slightly fragrant, appearing the latter part of May or first of June in this section; corolla crean-colored or nearly white, one-fourth inch across when open; filament thick; stigma broad. Fruit borne in drooping clusters, oval, about one-half inch long, 


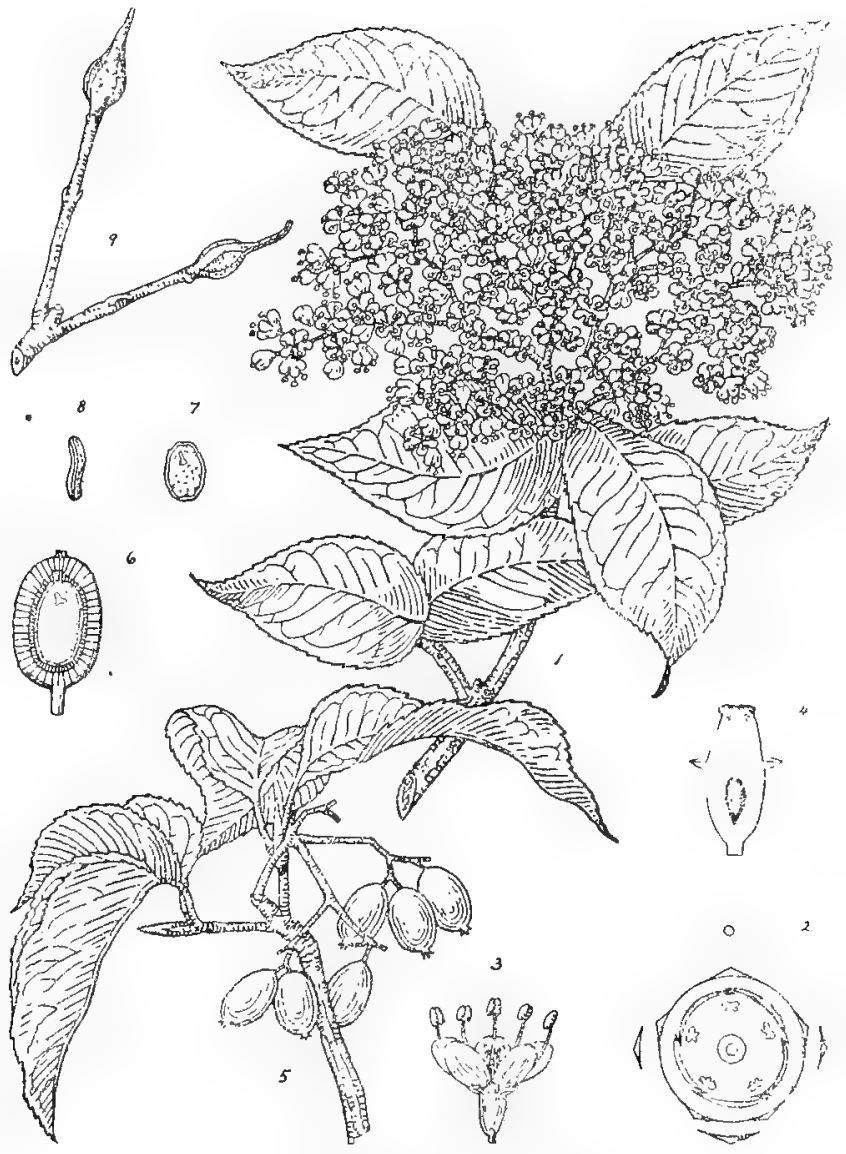

Plate 63. Viburnum lentago. Sheepberry.

I. Flowering branch, one-haif natural size. 2. Diagram of flower. 3 . Flower, enlarged. + Longitudinal section of flower, the corolla and stamens removed, enlarged. 5. Fruiting branch, one-half natural size. 6. Longitudinal section of fruit, natural size. 7. Longitudinal section of seed. 8. Side view of stone. 9. Winter branchlet, one-half natural size. 
sweet, juicy, black or dark blue, thick-skinned, covered with a glaucous bloom, ripens in September. Within our range a broad bush but occasionally a small tree.

Distribution.-Quebec to the Saskatchewan, and south to Georgia and Missouri. Ustially found in moist locations, especially along river and lake shores, but not uncommon in thickets.

Propagation.-By seed and by layers. The seeds should be. stratified over winter before planting and often remain in the soil a year before starting.

Propertics of wood.-Heavy, hard and close grained. Specific gravity 0.7303 ; weight of a cubic foot 45.5 I pounds.

Uses.-The Sheepberry is a good hardy ornamental shrub for park and lawn planting. It is esteemed for the abundance of its beautiful flowers, its vigorous growth, compact habit and its lustrous foliage, which takes on brilliant colors in autumn. 


\section{PART III.}

\section{A List of the Forest Trees of the United States.}





\section{A LIST OF THE MORE IMPORTANT TREES OF THE UNITED STATES.}

White Pine.

Red Pine

Pitch Pine

Jack Pine .

Longleaf Pine

Shortleaf Pine

Cuban Pine

Loblolly Pine

Spruce Pine.

Scrub Pine

Bull Pine

Rock Pine

Jeffrey Pine.

I,odgepole Pine

Monterey Pine.

Silver Pine

Sugat Pine
Pinus strobus

Pinus resinosa........

Pinus rigida

Pinus dizaricata .....

Pinus palustris.......

Pinus echinata

Pinus helerophylla ...

Pinus taeda

Pinusglabra

Pinus virginiana.....

Pinus ponderosa......

Pinusponderosa scopu-

loram.

Pinus jeffrevi.

Pinus murravana....

Pinus radiata ... .....

Pinus nonticola.

Pinus lamberliana
Minnesota and Iowa to the New England States and Georgia, Manitoba to Newfoundland.

Minuesota to New England and Penusylvania, Maniloba and Newfoundland.

New Brunswick to Georgia, Ontario and Kentucky.

Minnesota to New Brunswick, Hudson Bay, and northwest to Mackenzie River and the Rocky Mountains.

South Atlantic and Gulf coasts: Virginia to Teras.

New York to Florida, Illinois, Missouri and Texas.

Southern and southeastern coast regions: South Carolina to Florida and I,ouisiana. Southeastern and Gulf states: New Jersey to Texas and Arkansas to 'Tennessee.

South Carolina to Florida and Louisiana.

New York to South Carolina, Indiana and Alabama.

British Columbia to Mexico, Montana and Texas.

Rocky Mountains to Nebraska and Montana to Colorado.

California: eastern slopes of Sierra Nevadas and Oregon. Alaska to California, Montana and New Mexico.

South California coast.

British Columbia to California.

Western Facific slope: Oregoth to California. 
A LIST OF 'THE MORE IMPORTANT TREES OF 'THE UNITED S'IATES. - Conlinued.

\begin{tabular}{|c|c|c|}
\hline & \\
\hline I,imber Pine ........ & Pinus flexilis.......... & $\begin{array}{l}\text { Eastern slopes Rocky Moun- } \\
\text { tains: Alberta to Texas, and } \\
\text { Utah, Nevada, Arizona and } \\
\text { California. }\end{array}$ \\
\hline Foxtail Pine ........ & Pinus balfouriana... & California. \\
\hline Bristle-cone Pine...... & Pinus aristata......... & Colorado to California. \\
\hline Tamarack............ & Lavix laricuna ........ & $\begin{array}{l}\text { Minnesota to Illinois, New- } \\
\text { foundland and Labrador, } \\
\text { and northwest to Great Bear } \\
\text { Lake and Mackenzie River. }\end{array}$ \\
\hline Western Larch........ & Larix occidertalis..... & $\begin{array}{l}\text { Montana to Oregon and Brit- } \\
\text { ish Columbia. }\end{array}$ \\
\hline Black spruce......... & Picea maviana ....... & $\begin{array}{l}\text { Minnesota to North Carolina, } \\
\text { Hudson Bay, Mackenzie } \\
\text { River and Rocky Mountains. }\end{array}$ \\
\hline Red spruce .......... & Picea rubens .... . & $\begin{array}{l}\text { Nova Scotia to North Carolima } \\
\text { and Tennessee. }\end{array}$ \\
\hline White Spruce ........ & Picea canadensis...... & $\begin{array}{l}\text { Minnesota to Maine, Eabrador } \\
\text { and Hudson Bay, and Black } \\
\text { Hills to Moutana, British } \\
\text { Columbia and Alaska. }\end{array}$ \\
\hline Engelmann spruce... & Picea engelmanni..... & Arizona to British Columbia. \\
\hline Sitka Spruce .......... & Picea sitchensis..... . . & $\begin{array}{l}\text { Pacific coast: Alaska to Cali- } \\
\text { fornia. }\end{array}$ \\
\hline Hemlock .. & Tsuga canadensis.... & $\begin{array}{l}\text { Minnesota to Alleghany } \\
\text { Mountains and south to Ala- } \\
\text { bama; Nova Scotia and On- } \\
\text { tario. }\end{array}$ \\
\hline Western Hemlock & Tsuga heterophylla... & $\begin{array}{l}\text { Alaska to California and Mon- } \\
\text { tana. }\end{array}$ \\
\hline Douglas Spruce ....... & Pseudotsuga taxifolia & $\begin{array}{l}\text { British Columbia to California, } \\
\text { Mexico, Montana to Texas. }\end{array}$ \\
\hline Balsam Fir......... & Abies balsamea........ & $\begin{array}{l}\text { Minnesota and Iowa to New- } \\
\text { foundland, Virginia, I,ab- } \\
\text { rador, Hudson Bay and } \\
\text { northwest to Great Beat } \\
\text { Lake region and Rocky } \\
\text { Mountains. }\end{array}$ \\
\hline $\mathrm{I}_{4}$ owland Fir ........... & Abiesgrandis.... .... & $\begin{array}{l}\text { Montana to Vanconver Island } \\
\text { and California. }\end{array}$ \\
\hline White Fir .......... & Abies concolor......... & $\begin{array}{l}\text { Oregon to California, Colorado } \\
\text { and New Mexico. }\end{array}$ \\
\hline Amabilis Jit ........ & Abies amabilis... .... & Oregon to British Columbia. \\
\hline Noble Fir .......... & Abies mobills ......... & Washington to California. \\
\hline Ked Fir ........... & Abies magnifica . . . .... & $\begin{array}{l}\text { Califormia: Momnt Shasta and } \\
\text { western slope Sierra Nev- } \\
\text { adas. }\end{array}$ \\
\hline
\end{tabular}


A LIST OF THF MIORE IMPORTAN'T TREES OF THE UNITED STATES.-Continued.

\begin{tabular}{|c|c|}
\hline Bald Cypress..... & Taxodium distichum. \\
\hline IBig "1"ree .... & $\begin{array}{l}\text { Sequoia washingto- } \\
\qquad \text { niana } \ldots \ldots \ldots \ldots \ldots\end{array}$ \\
\hline $\begin{array}{l}\text { Redwood..... } . . \\
\text { Incense Cedar........ }\end{array}$ & $\begin{array}{l}\text { Seyuoia sempervilens. } \\
\text { Libocedrus decuriens.. }\end{array}$ \\
\hline Arborvitie ........ & Thuja occidcutalis.... \\
\hline Giant Arborvitic..... & Thuju plicala ......... \\
\hline White Cedar ......... & Chamacyparis thyoides \\
\hline Port Orford Cedar .... & $\begin{array}{c}\text { Chamacyparis laz'so- } \\
\text { niana } \ldots . . . \ldots \ldots . .\end{array}$ \\
\hline Red Juniper.......... & Juniperus virginiana \\
\hline Rocky M'nt'n Juniper & Juniperus scopulorum. \\
\hline
\end{tabular}

Pacific Yew ...........

Butternut

\begin{tabular}{|c|c|}
\hline lack Walnut........ & Juglans uigra \\
\hline Pecan & Hicoria pecan . . . . \\
\hline Bitternut.... & Hicoria mintma... \\
\hline Shagbark Hickory.... & Htcoria ozata .... \\
\hline Shellbark Hickory .... & Hicoria laciniosa. \\
\hline Mocker Nut... & Hicoria alba \\
\hline Pignut & Hicorta glabra ... \\
\hline & Populus tremuloide \\
\hline
\end{tabular}

Delaware to Florida, Texas and Missouri.

California: western slope Sierra Nevadas.

California coast ranges.

Oregon to Lower California and Nevada.

Minnesota to Lake Winnipeg, James Bay, Illinois, North Carolina, New Brunswick and Nova Scotia.

Alaska to California aud Mon. tana.

Coast region: Maine to Flor ida, and Mississippi.

Coast region: Oregon to California.

North Dakota to New Brunswick, Florida, Texas, Nebraska and Indian Ter.

Nehraska and Black Hills to Montana, British Columbia and Arizona.

California to British Columbia and Montana.

Minnesota and South Dakota to New Brunswick, Georgia and Arkansas.

Minnesota to Ontario and Massachusetts, Florida and Texas.

Iowa to Indiana, Alabama and Mexico.

Minnesota to Maine, Florida and Texas.

Same as Bitternut.

Iowa to New York, Pennsylvania, and Indian Ter.

Ontario to Florida, Missouri and 'lexas.

Maine to Florida, Nebraska and Texas.

Alaska to Labrador, Pennsylvania, Missouri and Mexico. 


\section{A LIS'1" OF 'THE MORE IMPORTAN'T TREES OF THE UNITED}

STATES.-Continued.

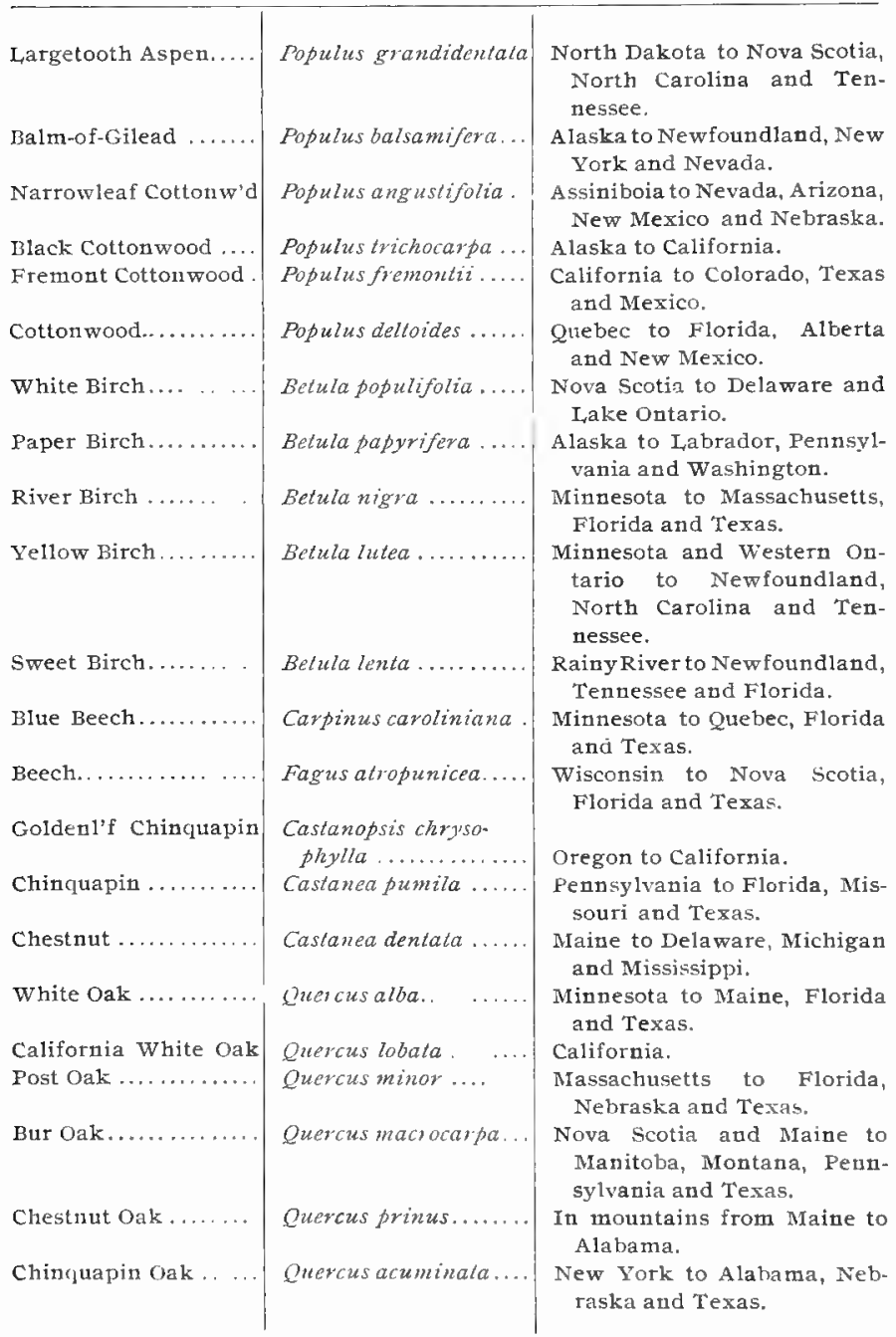


A LIST OF THE MORE IMPORTANT TREES OF THE UNITED STATES.-Continued.

\begin{tabular}{|c|c|}
\hline Swamp White Oak & Quercus platanordes... \\
\hline Cow Oak......... & Quercus michaaxii.... \\
\hline I,ive Oak............ & Quercus virginiana ... \\
\hline $\begin{array}{l}\text { Canyon Live Oak ..... } \\
\text { Red Oak ............. }\end{array}$ & $\begin{array}{l}\text { Quercus chiysolepis. } \\
\text { Quercus rubra....... }\end{array}$ \\
\hline Scarlet Oak. & Quercuscoccinea..... \\
\hline Yellow Oak ............ & Quercus velutina ...... \\
\hline Spanish Oak .......... & Quercus digitala. .. \\
\hline Pin Oak. .. & Quercus palustris.... \\
\hline Water Oak........... & Quercus nigra......... \\
\hline Tanbark Oak ... . & Quercus densiflora.... \\
\hline Cedar Elm $\ldots \ldots \ldots$. & Ulmus crassifolia ...... \\
\hline Slippery Elm .... & Uimus pübescens...... \\
\hline White Elm.......... & Uimusamericana..... \\
\hline $\operatorname{Cotk} \mathrm{Elm} \ldots \ldots \ldots$ & Ulmus racemosa... \\
\hline Wing Elm & tlmus alata........... \\
\hline Hackberry ....... & Celtis occidentalts...... \\
\hline Red Mulberry ........ & Morus rubra........... \\
\hline Osage Otange..... & Toxylon pomiferunt.. \\
\hline Magnolia............. & Magnolia fotida... ... \\
\hline Cucumber-tree ....... & Magnolia acuminata. \\
\hline
\end{tabular}

Maine to Georgia, Iowa and Arkansas.

Delaware to Florida, Texas and Missouri.

Shores from Virginia to Florida. Texas, Mexico, Central America and Cuta.

Oregon to Mexico.

Minuesota to Nova Scotia, Georgia and Kansas.

Minnesota to Maine, Nebraska, Tennessee and North Carolina.

Minnesota to Maine, Florida and Texas.

New Jersey to Florida, Illinois and Texas.

Wisconsin to Massachusetts, Virginia, Kausas and Indian Territory.

Delaware to Florida, Missouri and Texas.

Oregon to California.

Mississippi to Arkansas and Mexico.

North Dakota to Quebec, Florida and Texas.

Newfoundland to Rocky Mountains, Florida and Texas.

Minnesota to Quebec, New Hampsbire, Nebraska, Missouri and Tennessee.

Virginia to Florida, Missouti and rexas.

Quebec to Massachusetts, Florida, Texas, Washington and Nevada.

Massachusetts and vermont to Florida, Nebraska, South Dakota and Texas.

Arkansas to Texas.

North Carolina to Florida, Arkansas and Texas.

New York to Illinois, Alabama and Arkansas. 


\section{A LIST OF 'IHE MORE IMPORTAN'T 'IREES OI THE UNITID} SIIA'ES.-Continurd.

\begin{tabular}{|c|c|c|}
\hline & & \\
\hline Tulip-tree ........... & Liviodendrontulipifera & $\begin{array}{l}\text { Vermont and Rhode Island to } \\
\text { Florida, Mississippi, Mich- } \\
\text { igan and Atkansas. }\end{array}$ \\
\hline Sassafras .......... & Sassafras sassafras.... & $\begin{array}{l}\text { Massachusetts to Floricla, } \\
\text { Iowa and rexas. }\end{array}$ \\
\hline Sweet Gum.......... & $\begin{array}{l}\text { Liguidambar styra- } \\
\text { ciflua } \ldots \ldots \ldots \ldots \ldots\end{array}$ & $\begin{array}{l}\text { Connecticut to Florida, Mis- } \\
\text { souri and Texas. }\end{array}$ \\
\hline Sycamore ............ & Platanus occidentalis... & $\begin{array}{l}\text { Maine to Florida, Nebraska } \\
\text { aud 'lexas. }\end{array}$ \\
\hline Black Cherry ......... & Pranus selotina ....... & $\begin{array}{l}\text { Nurth Dakota to Nova Scotia, } \\
\text { Fjorida and 'l'exas. }\end{array}$ \\
\hline Honey Locust . . . . . . . . . & Gledilsia triacanthos... & $\begin{array}{l}\text { Minnesota to Pennsylvania } \\
\text { and New York, Georgia, } \\
\text { Nebraska and lexas. }\end{array}$ \\
\hline Coffectree .......... & Gymnocladus dioicus.. & $\begin{array}{l}\text { Minnesota to New York, Neb- } \\
\text { raska, Indiau Territory and } \\
\text { lennessee. }\end{array}$ \\
\hline Locust $\ldots \ldots \ldots \ldots \ldots$ & Robinia pseudacacza... & $\begin{array}{l}\text { Pennsylvania to Georgia, Min- } \\
\text { nesota, Arkansas and Indian } \\
\text { Territory. }\end{array}$ \\
\hline Anerican Holly .. & Ilex opaca $\ldots \ldots \ldots \ldots$ & $\begin{array}{l}\text { Massachusetts to Florida, In- } \\
\text { diana, Missouri and Texas. }\end{array}$ \\
\hline Oregon Maple ... . .. & Acer macropleyllum ... & Alaska to California \\
\hline Sugar Maple......... & Acer saccharum ....... & $\begin{array}{l}\text { North Dakota to Newfound- } \\
\text { land, Texas and Florida. }\end{array}$ \\
\hline Silver Maple ......... & Acersacchar inum & $\begin{array}{l}\text { Minnesota and south Dakota } \\
\text { to New Brunswick, Florida } \\
\text { and Indian "Ierritory. }\end{array}$ \\
\hline Red Maple.... ..... & Acer rubum......... & $\begin{array}{l}\text { Iake of the Woods to New } \\
\text { Brumswick, Florida and } \\
\text { Texas. }\end{array}$ \\
\hline Boxelder ........... & Acer negundo & $\begin{array}{l}\text { Vermont to Florida, Saskat- } \\
\text { chewan and Texas. }\end{array}$ \\
\hline Ohio Buckeye........ & Aesculus glabra...... & $\begin{array}{l}\text { Pennsylvania to Alabana, } \\
\text { Iow and Indian leerritory. }\end{array}$ \\
\hline Yellow Buckeye ...... & Aesculus octandra. & $\begin{array}{l}\text { Penusylvania to Aląlanua, } \\
\text { Iuwa and Texas. }\end{array}$ \\
\hline Basswood............. & Tilia americana. & $\begin{array}{l}\text { New Brunswick to Georgia, } \\
\text { Alabama, llexas, Assiniboia. }\end{array}$ \\
\hline White Basswood ..... & Tilia heterophylla..... & $\begin{array}{l}\text { Pennsylvauia to Florida, Illi- } \\
\text { nois and Alabama. }\end{array}$ \\
\hline Black Gum ............ & Nyssa sylvatra........ & $\begin{array}{l}\text { Maine to Florida, Michigan } \\
\text { and lexas. }\end{array}$ \\
\hline Cotton Gum ........... & Nyssa aqualica. . & $\begin{array}{l}\text { Virginia to Florida, Illinois } \\
\text { and Iexas. }\end{array}$ \\
\hline
\end{tabular}


A IIST OH THE MORH, IMPOR'SAN'T TREES OF 'THE UNITED S'TAT'ES.-Conlinued.

\begin{tabular}{|c|c|c|}
\hline Persimmon & Diospyros virginiana.. & Connecticut to Florida, Iowa \\
\hline Blue Ash. & $\begin{array}{l}\text { Fraxinus quadrangu- } \\
\text { lata.................. }\end{array}$ & $\begin{array}{l}\text { Minnesota to Michigan, Ar- } \\
\text { kansas and Alabana. }\end{array}$ \\
\hline Mlack Ash. . & Fraxinus nigra..... & $\begin{array}{l}\text { Manitoba to Newfoundland, } \\
\text { Arkansas and Virginia. }\end{array}$ \\
\hline White Ash. & fiaxinus americana.. & $\begin{array}{l}\text { Minnesota to Newfoundland, } \\
\text { Texas and Florida. }\end{array}$ \\
\hline Red Ash ... & $\begin{array}{l}\text { Fraxinus pennsylta- } \\
\text { nica. } \quad \ldots \ldots \ldots \ldots\end{array}$ & $\begin{array}{l}\text { North Dakota to New Bruns- } \\
\text { wick, Kansas, Alabama and } \\
\text { Florida. }\end{array}$ \\
\hline Green Ash............ & Fraxinus lanceolata... & $\begin{array}{l}\text { Vermont to Saskatchewan } \\
\text { River, Florida, Texas and } \\
\text { Arizona. }\end{array}$ \\
\hline $\begin{array}{l}\text { Oregon Ash........... } \\
\text { Catalpa } . . . \ldots \ldots \ldots\end{array}$ & $\begin{array}{l}\text { Fraxinus oregona } \\
\text { Catalpa catalpa... }\end{array}$ & $\begin{array}{l}\text { Washington to California. } \\
\text { Georgia, Florida, Alabama } \\
\text { and Mississippi. }\end{array}$ \\
\hline Hardy Catalpa & Calalpa speciosa. & $\begin{array}{l}\text { Indiana to Tennessee, Mis- } \\
\text { souri and Texas. }\end{array}$ \\
\hline
\end{tabular}




\section{GLOSSARY.}

Accretion. Growth or formation by external additions to the tree. Acorn. The fruit of an oak.

Acuminate. Taper-pointed or long-pointed. (e. g. leaves of Willow.)

Acute. Pointed. (e. g. leaves of Cork Elm.)

Albumen. Food stored up in seed with embryo; endosperm.

Alternate leaves. A single leaf at a node; not opposite. (e. g. Willow.)

Altimeter. An instrument for taking grades, level and heights.

Angle mirror. I Instruments for turning of angles in subdividing Angle prism. $\}$ land.

Annual. Yearly; a plant which reaches maturity and dies at the end of a single season. (e. g. Pea, Wheat.)

Annual ring. The layer of wood formed each year. (Page II.)

Anther. The pollen-containing sac; enlarged part of stamen.

Apetalous. Without corolla. (e. g. Soft Maple, Oak.)

Arboreous. Tree-like.

Assimilation. In plants, the production of organic matter from inorganic matter.

Axil. The angle formed by the junction of the leaf-blade, bract, petiole, pedicle or peduncle, with the branch or stalk from which it springs.

Back-firing. The burning, under control, of material in front of a fire to prevent its spreading.

Bark. A general term applied to all the tissues outside of the wood proper. (Fig. I.).

Basal. Attached to the base.

Basal area. The cross-sectional area of a tree near the ground, usually taken about four and one-hall feet above ground to avoid the excessive swelling of the root buttresses.

- Bast. The woody fibrous tissue of the inner bark. (Page 355.) 
Baummesser. An instrument for measuring the height of the trees, height and diameter at any part on the stem of a standing tree.

Berry. Botanically a fleshy fruit. (e. g. Grape, Currant.) Commonly applied to many kinds of fruits. (e. g. Strawberry, Mulberry.)

Blade of a leaf. The expanded portion; the wings.

Blight. The dying without apparent cause of the tenderer parts of plants.

Board-foot. The unit of board measure; equivalent to a board $\mathrm{I} 2$ in. $\mathrm{X} I 2$ in. $\mathrm{x} I$ in. One cubic foot is considered as equivalent to ten board feet, allowing for waste in working.

$B$. M. Abbreviation for board measure. (q. v.)

Board-measure. (B. M.) The system used by lumbermen in which the board-foot (q. v.) is the unit.

Bract. A much reduced leaf.

Broad-leaved trees. Applies to trees whose leaves have a broad flat surface, unlike the needle or awl-shaped leaves of the conifers.

Budding. The operation and process of inserting a bud with the intention that it shall grow.

Bud-division. A term including all methods of propagation except by seed. (e. g. Grafting, Layering, etc.)

Bud-variety. A strange variety or form appearing without obvious cause upon a plant or in cuttings or layers; a sport. A bud-variety springs from a bud in distinction from a seed-variety, which springs from a seed.

Callus. The new and protruding tissue which forms over a wound as over the end of a cutting.

Calyx. Outer circle of perianth, generally inconspicuous.

Cambium. In trees and shrubs, the layer of new growing tissue between the bark and wood.

Cants. A term used in mills to designate the pieces cut from the sides of a $\log$ and which are to be again cut into quartersawed lumber. It is sometimes also applied to the squared centerpiece of the log.

Carbon dioxide. A gas composed of one part of carbon to two parts of oxygen; carbonic acid gas.

Carpel. A simple pistil, or one of the divisions of a compound pistil. 
Catkin. A scaly spike-like dense flower cluster. (e. g. Willow, Birch.)

Coll. The anatomical unit of living tissues.

Chlorophyll. The green coloring matter of plants; leaf-green.

Ciliatc. Hairy on the margin.

Cleft leaf. Cut into lobes somewhat more than half the depth of wings. (e. g. Silver Maple.)

Compass. A magnetic needle used to determine directions in the woods.

Compound lcaf. One in which the blade or wings are composed of more than one part. (e. g. Ohio Buckeye, Mountain Ash.)

Cone. The flower or fruit of a conifer.

Conifer. A member of the Pine Family or Conifere.

Conifcrous. Cone-bearing.

Cooperage. The business of making wooden vessels, as casks, barrels, tubs.

Cordate. Heart-shaped.

Corolla. Inner series of the perianth; generally distinguished from the calyx by being of a color other than green.

Corymb. A flat-topped flower cluster, in which the outer flowers open first. (e. g. Mountain Ash.)

Cotyledon. One of the leaves of the embryo; a seed leaf.

Cross staff hcad. An instrument for turning off angles in surveying land, consisting of an octagonal brass box with slits in the faces for sighting through.

Crowded. Said of trees when so closely grown that the development of their lateral branches is intertered with. (Pagc I29.)

Crown of tree. See tree-crown.

Cuttage. The practice or process of multiplying plants by means of cuttings.

Cuttings. A piece of a leaf, branch, stem or root which when inserted in moist material is capable of sending out roots and forming a new plant; a slip. (Page 86.)

Cycle. One of the circles of a flower.

Cymes. A flower cluster in which the central flowers open first

Deciduous. Falling off; said of leaves that fall in autumn.

Dehiscent. Said of fruits that open at regular lines. 
Delinquent tax lands. Lands on which taxes have not been paid. They are offered for sale at stated times after public notice, and tracts which find no buyers revert to the state.

Dentatc. Toothed, with teeth pointing outward not forward.

Diadelphous. Said of stamens when united into two groups.

Dibbcr. A pointed instrument used for making holes.

Dicotyledon. One of the class of plants with two seed leaves.

Dicotyledonous. Having two cotyledons or seed leaves.

Digitate. See palmate.

Dioccious. Staminate and pistillate flowers borne on different plants.

Distillation product. The substance obtained by the decomposition of a compound.

Divided. Said of leaves when the wings are cut into divisions down to base or midrib.

Division. See bud-division.

Drupe. A fruit with hard pit (endocarp) and soft exterior (exocarp). (e. g. Plum, Cherry, Peach.)

Dry-rot. A kind of decay in wood. (Page 177.)

Dust-blanket. A layer of loose earth on the surface of the ground.

Embryo. The minature plant in the seed.

Erosion. Wearing away.

Evergreen. Holding leaves over winter until new leaves appear or longer.

Fanily. In botanical classification, a group of plants thrown together because of some natural common resemblances. Sometimes used synonymously with order.

Filamcut. The stalk of the stamen.

Firebreak. An opening, pioweã strip of land, or anything which prevents the spread of fires in forests or elsewhere. Hage 119.)

Fircfalls. Applied to arcas where the trees have fallen owing to their roots having been burned off.

Flower. A part of the plant especially modificd for the reproduction of the plant by seed.

Forcst. A dense growth of trees.

Forcst floor. The decayed leaves and twigs which cover the soil in forests. (Page 24.) 
Frost-hardy. Said of trees, the new growth of which is not easily killed by frost.

Frost-tender. Said of trees, the new growth of which is easily killed by frost.

Fruit. The seed-containing area derived from a single flower.

Fungi. Plural of fungus.

Fungous. Pertaining to fungi.

Fungus. A flowerless plant devoid of chlorophyll and drawing its nourishment from living organisms or decayed organic matter.

Gencra. Plural of genus.

Generic name. The name of the genus to which the plant belongs, and which with the name of the species forms the scientific name of the plant.

Genus. In botanical classification, a group of plants having several or many natural common resemblances; a division of a family.

Germination. The act or process by which a seed or spore gives rise to a new and independent plant.

Glabrous. Smooth, not pubescent.

Glauber salts. Sodium sulphate.

Glaucous. Covered with a fine white powder as that on a cabbage leaf.

Graftage. A system of propagation comprising all methods by which plants are grown on roots of other plants.

Grafting. The operation of inserting a cion in a plant.

Grafting Wax. A protective substance used in covering the junction of a graft with the stock, or for the covering of wounds. Bailey's formula for a reliable wax:-Resin, four parts (by weight); beeswax, two parts; tallow, one part. Melt together and pour into a pail of cold water. Then grease the hands and pull the wax until it is nearly white.

IIardy. Able to withstand a given climate.

Hccling-in. The operation and process of temporarily covering the roots of plants to preserve them until wanted for permanent planting. (Page 90.)

Hcight classcs. The arrangement of trees into classes according to height.

Hirb. A plant not woody. 
Hcrbaccous. Not woody; said of plants that die to the ground each year.

Horticulture. The art and science of raising fruits, kitchen garden vegetables, flowers and ornamental trees and shrubs.

Humus. Decomposed organic matter in the soil.

Hybrid. Plant derived from a cross between plants of different species.

Hybridizing. The operation or practice of crossing between species.

Hypogynous. Said of flowers when all parts are free. (e. g. Buckeye).

Hypsometer. An instrument for taking heights of trees.

Imbricatcd. Overlapped.

Inarching. The operation and process of uniting contiguous plants or branches while the parts are both attached to their own roots. (Page 90.)

Indehiscent. Not opening at regular lines; not dehiscent.

Indigenous. Native, i. e. growing naturally in a given region.

Inferior. Said of ovary when all the floral parts are attached above it. (e. g. Iowa Crab.)

Inflorescence. A flower cluster; mode of arrangement of flowers. Insecticide. A substance employed to destroy insects.

Inrolucre. A bract or series of bracts subtending a flower-cluster or fruit-cluster.

Irrcgular. Said of flowers when the separate parts of each cycle are not of the same size and shape. (e. g. Locust.)

Jacob staff. A pointed staff which may be pushed into the ground and on which instruments are mounted for taking observations.

Joinery. The art of framing the finishing work, making permanent wooden fittings and covering rough lumber.

Kerf. The cut made by the saw, or the width of such cut.

Lanccolate. Said of leaves when from four to six times as long as broad, the broadest part below the middle and tapering upward or both upward and downward. (e. g. Black Willow.)

Larva. (pl. larvae) The worm-like stage of insects.

Layer. A shoot which, while attached to the plant, takes root at one or more places and forms a new plant. (Page 8g.) 
Leaf-mould. Decayed leaves and other organic matter constituting the forest floor.

Leaftet. One of the wing divisions of a compound leaf.

Lcather board. A material made from wood pulp and which resembles leather in color and texture.

Legume. A simple pod opening by both ventral and dorsal sutures; fruit of pea family. (e. g. Locust.)

Leguminous. Pertaining to the family Leguminosae; said of plants bearing legumes.

Loam. Friable, mellow, rich soil containing much humus.

Lobe. A projection or division of a leaf not more than half the depth of the wing.

Lyrate. A pinnatifid leaf of an obovate or spatulate outline with the end lobe large and roundish and the lower lobes small, (e. g. Bur Oak.)

Manure. Plant food; any substance which promotes plant growth.

Monadelphous. Said of stamens when united by their filaments in one group.

Mono. Prefix meaning one.

Monoccious. Both staminate and pistillate flowers borne on the same plant. (e. g. Black Walnut.)

Mound-layering. (Page 89.)

Mulch. Any loose material that protects the soil from frost or evaporation.

Muskeg. A term commonly applied to sphagnum swamps by the Indians and woodsmen of northern Minnesota.

Narrow-leaved trees. Trees with needle or awl-shaped leaves, which expose no great surface to the light.

Nursery. A plot of ground set apart for the raising of plants that are to be transplanted elsewhere. An establishment for the raising of plants.

Obcordate. The reverse of corclate.

Oblanccolate. The reverse of lanceolate.

Oblong. About twice as long as broad with ncarly parallel sides. Obovate. The reverse of ovate.

Obtusc. Blunt, not acutc. (e. g. leaflets of Locust.)

Odd-pimale. Applied to pinnately componnd leaves having a terminal leaflet. (c. g. Ash.) 
Open grown. Said of trees when not grown sufficiently close to other trees to be influenced by them.

Ovary. The lower or enlarged part of the pistil bearing the oviles.

Ovate. About twice as long as broad and tapering from near the base to the apex. (e. g. leaves of Balm of Gilead.)

Ovoid. Egg-shaped.

Ovule. A rudimentary seed.

Palmate. Said of parts originating from a common point, as the veins, lobes or divisions of a leaf. (e. g. Leaflets of Ohio Buckeye.)

Panicle. A loose flower cluster. (e. g. White Ash, page 359.)

Papilionaceous. Butterfly-shaped, applied to flowers of the pea family. (e. g. Locust, page 334.)

Paraboloid. The figure of revolution formed by turning a parabola about its axis.

Parasite. A plant or animal that lives upon and obtains its food from other living plants or animals.

Parietal placenta. A placenta upon the wall of the ovary. (e. g. Coffeetree, page 332.)

Parted. Separated nearly to the base.

Pedicel. A stalk of a single flower of a flower cluster.

Peduncle. A stalk of a solitary flower or the common stalk of at flower cluster.

Pendulous. Hanging.

Penta. Prefix, meaning five.

Perennial. A plant living more than two years.

Perfect flower. One having both essential organs, i. e. and pistil. (e. g. lowa Crab, page 3r3.)

Perianth. The floral envelopes.

Pericarp. The ripened ovary; the seed vessel.

Persistcnt. Remaining beyond the period when such f art " $\because i 1$. erally fall.

Pctal. One of the divisions of a corolla.

Petiole. Leaf-stalk.

Pinnate. Parts arranged on opposite sides of a main axis. (e. g. Leaflets of Mountain Ash.)

Pinnatifid. Pinnately lobed or cleft. (e. g. leaves of Red Oak, page 296.) 
Pinnule. A secondary leafet in a pinnately decompound leaf. (e. g. Honey Locust.)

Pistil. The part of the flower bearing the ovules and which ripens into the fruit.

Pistillate. Bearing pistils but no fertile stamens. Often used synonymously with female.

Placenta. Place of attachment of ovules in an ovary.

Pollon. Small spores produced by the anthers for the fertilization of the ovules.

Pollination. The carrying of pollen from the anther to the stigna.

Polygamous. Perfect and unisexual flowers borne on the same plant.

Pone. Fruit represented by the Apple, Thorn, Quince, etc.

Propagation. The multiplication of plants.

Pruning. The removing of branches from a plant to improve its general appearance or to check or encourage growth.

Pubcscut. Covered with fine sho: thairs.

Quarter sawing. The sawing on the radius, but as it is not practicable to do this exactly, the $\log$ is first quartered and then sawed into boards, cutting them alternately from each face of the quarter of the log. Sawed in this way the grain of the wood does not show nearly so conspicuously and varied as in that tangentially sawed, but the grain is narrower, and the wood sawed in this way does not warp nearly so much as that tangentially sawed, and is much more expensive. (Page I68.)

Raceme. A simple inflorescence in which the flowers are on pedicels, and the lower open first. (e. g. Black Cherry, page 324.)

Ranging poles. Straight poles about eight feet long used by surveyors to indicate the direction of a line which is being measured or the position of points to be located.

Regular. Farts of each cycle of the perianth alike. (e. g. Bird Cherry.)

Root. A part of the plant which absorbs nourishment for the plant, or serves as a support. It may be underground or aerial.

Rcot-cutting. See cutting. (Page 86.) 
Rudimentary. Imperfectly developed or in an early state of development.

Samara. A winged fruit. (e. g. Maple.)

Saprophyte. A plant which lives upon and obtains its food from dead organic matter.

Sapwood. The outer or latest formed wood of a woody plant. (Page 12.)

Sawing. The two methods used in sawing are termed tangential sawing and quarter sawing, q. v.

Scion. The part inserted in the stock in the various processes of graftage.

Seed. The body containing the embryo plant; the ripened ovule.

Seedling. In nursery practice a young plant grown from seed and not having been transplanted.

Seeding tree. A tree, sufficiently mature, to produce fruit.

Seed variety. A variety that comes true from seed.

Sepal. One of the divisions of the calyx.

Serrate. Saw-toothed. (e. g. leaves of Balm of Gilead.)

Sessile. Without stalk.

Sheath. In pines, the case-like part surrounding the base of the needle cluster.

Shrub. A woody plant with no main stem or trunk; a bush.

Silver grain. Bands or plates of medullary rays exposed radially on longitudinal section.

Simplc. Composed of one part; not compound.

Sinuate. Strongly wavy.

Sinus. An indentation.

Solar-pit. (Page 89.)

Spatulate. Shaped like a spatula; broadly rounded at the apex; tapering toward the base.

Species. A division of a genus, the plants of which seem to be derived from an immediate common ancestor.

Species class. A group of trees of the same species made in forest survey.

Specific gravity. Weight compared with distilled water at 4 degrees Centigrade. Where used here with reference to wood it refers to absolutely dry wood unless otherwise noted.

Spike. A simple dense raceme-like inflorescence with flowers sessile or nearly so. 
Spore. A reproductive body, commonly applied to those borne by plants that do not produce seed. Analogous but not homologous to a seed.

Stamen. Pollen-bearing organ of a flower.

Staminate. Said of flowers bearing stamens, but no pistils. Often used synonymously with male.

Stem. The main axis or one of the main axes of a plant. It may be underground or aerial. Commonly used in place of petiole, pedicel and peduncle.

Stcrile. Not fertile; not able to reproduce.

Stigma. The part of the pistil upon which the pollen falls and germinates.

Stipule. A leaf appendage at the base of the blade or petiole; not always present. (e. g. Black Willow.)

Stock plants. Plants used to propagate from.

Stoma. (pl. Stomata) Breathing pores of leaves.

Stratification. A method of storing seeds with alternate layers of some other material, as sand or leaves. (Page 76.)

Strobilus or Strobile. A cone. (e. g. Pine, Lycopodium.)

Stumpagc. The standing timber.

Style. The stalk, if present, that joins the stigma to the ovary. Sucker. A shoot from an underground root or stem; often applied to an adventitious shoot above ground.

Sunscald. (Page II2.)

Superior. Applied to ovary when attached on a level or above the other parts of the flower. (e. g. Ohio Buckeye.)

Surveyor general. The officer whose duty it is to measure or to direct the measurement of logs and lumber.

Tangential sawing. The common way of cutting logs by which the boards on each side of the center board are sawed by a cut that is tangent to the annual rings. This method serves to bring out the grain of wood most conspicuously.

Tap-root. A central root running deep into the soil.

Tensile strength. The force which resists breaking or drawing asunder.

Tent-caterpillars. Caterpillars that build silky-like tents on trees and other plants.

Thorn. A hardened sharp-pointed branch.

Tomentose. Clothed with matted woolly hair.

Top-worked. Said of trees that are grafted or budded at some distance above the ground. 
Transit. A surveyor's instrument for measuring angles, etc.

Transpiration. The process by which water is taken up by the roots of plants and given off to the air through the leaves and branches.

Tree. A perennial woody plant with a single stem which from natural tendencies generally divides into two or more branches at some distance from the ground.

Tree-crown. That part of a tree that is branched, forming a head.

Tree-digger. Ordinarily a plow-like implement having a sharp knife-like blade that is drawn throngh the soil by a team and cuts the roots off the trees at a distance from the base of the tree-trunk. Where large quantities of trees are to be dug this is a most important implement. There are various kinds; one style cuts on both sides of the row at one time.

Tri. Prefix meaning three.

Triangulation. The method of survey by dividing into triangles. Tripod. A three-legged support for an instrument.

Turgid. Distended; applied to leaves and other parts when filled with water.

Umbel. An umbrella-like form of inflorescence. (e. g. flower clusters of Caraway. Parsnip.)

Unisexual. Bearing either male or female organs, not both. (e. g. flowers of Willows.)

Variety. A distinct and valuable variation from the original.

V'alve. One of the parts of a dehiscent pod.

l'alvate. Opening by valves.

Volume. Amount or mass of a tree or $\log$.

Water capital. The entire water of the earth.

Weed. A plant out of place, a generally troublesome plant, not of any appreciable economic value.

Whorl. Applied to leaves when arranged in a circle around the stem.

Wings of a lcaf. The expanded portion; the blade.

Windbrcak. A single tow or belt of trees, which serves as a protection from wind.

Wood. The hardened tissue of a stem. A forest.

Working plan. A pre-arrangement of the method of growing and harvesting a forest crop of a particular tract. 


\section{INDEX.}

Orders and families in SMALL CAPS; genera in heavy face; synonyuls in italics. Figures in parenthesis indicate illustrations.

NorE.-The trees embraced in the I,ist of the More Important Trees of the United States ate not indexed - see list page 369.

Abies, 22\%.

balsamea, (228), $22 \%$.

concolor, 229.

Acacia-False, 333 .

- Threethorn, 329.

Accretion, 139 .

Accretion borer, (151), 150.

ACERACE.E, 335.

Acer, 335.

Acer dasycarpum, 340 .

negundo, (347), 348 .

pentasylvanicum, 346 .

platanoides, (339), 338 .

platanoides reitenbachii, 340 .

platanoides schwedlerii, 340 .

rubrum, (344), 343 .

saccharinum, (341), 340 .

saccharinum, 336 .

saccharum, (337), 386.

spicatum, 345 .

tartaricum, 346.

tartaricum ginnale, 346 .

Act for prevention of forest fires in Mintiesota, 193.

Actual income, 187.

Aisculus, 348 .

glabra, (350), 351.

hippocastanum, 349 .

Agaricus melleus, (113), 112.

Alarm about destruction of forests, 184.

Alkali soils, Occurrence, 25.

Almondleaf willow, (252), 251.

Alder-Hoary, 280.

- Speckled, 280.

A1nus incal1a, (281), 280.

Altimeter, 168 .
Amelanchier, 317.

alnifolia, 318.

canadensis, 317 .

canadensis abovalis, 318 .

American Aspen, 260.

American Elm, 299.

American Larch, 214.

American Linden, 353.

American Mountain Ash, 312.

Angle mirror, 147.

Angle prism, 147 .

Annual rings, 11, 126.

Antiseptics, 180.

Arborvitæ, (281), 230.

- Douglas Golden, 233.

- Pyramidal, 233.

- Siberian, 232.

Areas of Circles, Table of, 136.

Ash--Black, (363), 361.

- Green, 361 .

- Hoop, 36\%.

- Mountain, 312.

- Elderleaf Mountain, (315), 314.

- Red, 360.

- Szuamp, 362.

- White, (359), 358.

Ashleaf Maple, 348.

Aspect, Effect on growth, 26.

Aspen, (261), 260.

Assimilation, 17.

Austrian Pine, (212), 211.

$A x$ and $S a w, 72$.

Balm of Gilead, (263), 262.

- Hairy, 264.

Balsam, 227.

Balsam Fir, (228), 227.

Bark, 12. 
Basa1 area, 134.

Basket Willows, 247.

Basswood, (354), 353 .

- European, 356.

Baummesser, 149.

Beech-Blue, (285), 284.

- Water, 284.

Beetiee, 353.

Betulacese, 274.

Betu1a, 274.

alba, 276.

alba pendula laciniata, $27 \%$.

lenta, 278.

lutea, (279), 2,8 .

nigra, 277.

papyrifera, $(275), 274$.

Bignoniacede, 364 .

Brgnonia family, 364.

Birch-Canoe, 274.

- Cutleaf Weeping, 276.

- European White, 276.

- Gray, 278.

- Paper, (275), 274.

- Red, 277.

- River, $27 \%$.

- Sucet, 278.

- White, 274 .

- Yellow, (279), 278.

Birch FamiLy, 274.

Bird Cherry, 322 .

Birds, Injuries from, 106.

Bitternut Hickory, (244), 24 ă.

Black Ash, (363), 362.

Black Cherry, (325), 322.

Black Haw, 366 .

Black Knot, 326.

Black Locust, 329, 333.

Black Oak, 297.

Black Pine, 211.

Black Poplar, 270.

Black Spruce, (219), 218.

Black Walnut, (239), 238.

Black Willow, (250), 251.

Blowing out of small seedlings, 56 .

Blue Beech, (211), 212.

Blue Spruce, 221.

B. M., 144.

Board Measure, 144.

Bolle Poplar, 273.

Borers, 105.

Boucherie process, 181.
Bounty for tree planting, 194.

Boxelder, (347), 348 .

Breed's Weeder, Use of, 49 .

Broken branches, 112.

Browsing of deer, 123.

BUCKEYE FAMILY, 348 .

Buckthorn, (350), 351 .

- English, 351.

BUCKTHORN FAMILY, 351.

Buds, 13.

Buildings on a Farm, Lncation of, (57), (58), 56.

Bull Pine, (208), 207.

Burnettizing, 182.

Bur Oak, (294), 293.

Bur White Oak, 293.

Butternut, (241), 240.

Calipers, 148.

Callousing, 89 .

Canoe Birch, 274.

Cants, 169.

Capital in wood, 186.

Capital stock, 187.

CAPRIFOLIACE.E, 366.

Carolina Poplar, 205.

Carpentry, 165.

Carpints, 284.

caroliniana, (285), 284.

Carya alba, 243.

amara, 245.

Castanea, 286.

dentata, (987), 286.

Catalpa, 364.

bignonioides, 366 .

speciosa, (365), 364 .

Cattle, Injuries from, 106.

Cedar-Red, 283.

- White, 230.

Ce1tis, 306 .

occidentalis, (307), 306.

Cerlinensis Poplar, 273.

Charring timber, 179.

Chemical pulp, 16\%.

Cherry-Bird. 322 .

- Black, (325), 324.

- Choke (327), 326.

- Pigeon, 322.

- Pin, 322.

- Rum, 324 .

- Wild Black, 324.

- Wild Red, (323), 322. 
Chestnut, (287), 286.

Chief fire warden, 198.

Chinook of the West, $3 \%$.

Chlotide of zinc, 182.

Choke Cherry, (327), 326 .

Circles, areas of, 136 .

Clear plantings, 51.

Climbers, 152.

Coal-tar, 179 .

Coatings for wood, 179.

Coffeetree, (832), 331.

Colorado Blue Spruce, 221.

Coloring matter of wood, 176 .

Color of wood, a test of durability, 176.

Common Locust, 333.

Commion Juniper, 28 o.

Common Golden Willow, 255.

Compass, 147.

Conifers, raising from seed, 80 .

Conservation, Elenents of, 39 .

Cooperage, 166.

Coppice, 68.

Cork Elm, 301.

Cotton batting, 123.

Cottonwood, (267), 265.

- Goldenleaf, 269.

- Narrowleaf, 265 .

- Seedlings, $7 \%$.

- Yield, 130.

Covering of tree seeds, 66 .

Crab-Iowa, (313), 312.

- Hild. 312.

- Western, 312.

Cratægus, $3(y)$.

puncata, $(320), 319$.

Creosote, 181.

Creosoting process, 181.

Crooked trees, 'Treatment of, 99.

Cross-cut sawing, 168.

Cross-sectiona1 area, 132 .

Cross staff head, 147.

Cubic feet in cord of firewood, 138.

Cubic feet, conversion into B. M., 188.

Cultivation, 55, 60 .

Curing wood, 178.

Curtis, Production of a hot wind, 46 .

Cutleaf Weeping Birch, 27\%.

Cutleaf Maple, 343 .

Cuttings, 86.

Bunch of willow, (87), 87,

Cultivation, 88 .
Cuttings, Form and size, 86.

Planting, 87 .

In solar pit, (89), 88 .

Source of, 86.

Time of planting, 88 .

Cutting of timber, 'rime, 176.

Damping off of conifers, 81 .

Dead oil, 181.

Deal wood, 209.

Decay in wood, 175.

Depth to cover seeds, 82.

Destruction of forests, 184.

Diameter accretion, 131.

Distillation of wood, $16 \%$.

Dissipation, Elements of, 33.

Distauce between trees, 50 .

Distance of trees from buildings, etc., 48.

Distribution of seeds, 16.

Distribution of water, 41.

Dominion Experiment Station in Assiniboia, 37.

Double Spruce, 218.

Douglas Golden Arborvitze, 233.

Douglas Fir, 2:5.

Douglas Spruce, (226), 225.

Drouth, injuries from, 111.

Dry rot in wood, $17 \%$.

Dry seeds, 78 .

Durability of fence posts, $1 \% 8$.

Durability of wood, 175 .

DreafJuneberry, 318.

Dwarf Juniper, (235), 235.

Duarf Mountain Pine, 211.

- Pine, 211.

Eastern slope, Fffect on growth, 26.

ELIEAGNACEIE, 456.

E1æagnus, 350 .

angustifolia, (357), 356 .

Elderleaf Mountain Ash, (315), 314.

Elm - American, 299.

- Cork, (302), 301.

- Moose, 303.

- Red. 303 .

- Rock, 301.

- Slippery, (304), 303.

- Haler, 299.

- White, (300), 299.

FLMT FAMILY, 299.

Eln 'Tree, Pruned, 103.

Engelmann Spruce, 221. 
English Buckthorn, 351.

Estimating standing timber, 143.

European Basswood, 356.

Furopean Larch, (215), 216.

European Linden, 3506.

European Mountain Ash, 316.

European White Birch, 276.

European systems of forest management, 188.

Evaporation from soil, 84 .

Evaporation in winter, 19.

Evergreen seed bed, 81 .

Evergteens, Sowing seed, 80.

Evergreens, Transplanting, 94 .

FAGACE $A \Sigma, 286$.

False Acacia, 333.

Farm machinery, 166.

Farm woodlot, 72 .

Fence Posts. Table of Dutability of, 178.

Fetid Buckeye, 351.

Fighting Fires, 120.

Files, 152.

Fir-Ba1sam, (2281, 227.

- Douglas, 22 .

- Red, 225

- Silver, 229.

- White, 229.

Firebreak on sand dune, 119.

Firebreaks, 118.

Fire-fall, 116.

Fire law in Minnesota, 193.

Fireproof wood, 182.

Fires in forests, 11:.

Causes, 117.

Crown, 114.

Prevention, 117.

Spring, 116.

Summer and atumn, 116.

Surface, 114, 115, 120.

Underground, 114, 120.

Fire wardens, 193.

Flowers, 15.

Foehn of Switzerland, 37.

Fogs and clouds, 49.

Food formation, 17.

Forest, The, 21.

Forest and pasture, 122.

Forest economics, 184.

Forest fires, 113.

Forest fires, Notable, $12 \mathrm{i}$.
Forest floor, 24, 11 อ.

Forest industries of Minnesota, 185.

Forest influences, 28.

on disposal of water supplies, 33 .

on fogs and clouds, 42.

on precipitation, 32.

on water supplies, 29.

on wind and hail storms, 42 .

Forest mensuration, 132.

Forest planting, 66 .

Forest problems in Minnesota, 153.

Forest protection, 104.

Forest-pulled trees, 92.

Forest regeneration and treatment, 60.

Forest reservations, and national park.s, 191.

Forest treatment, 60.

Forest trees of the United States, 269.

Forestry requires capital, 186.

Forest, Virgin, 60.

Forest weed, 70.

Forests, Wind-breaking power of, 35 .

Fraxinus, 358.

americana, (35̆9), 3588 .

lanceolata, 361 .

nigra, (363), 362 .

pennsylvanica, 360 .

pubescens, 360 .

sambucifotia, 362.

vividis, 361 .

Freezing and thawing, 107.

Frost cracks, 109.

Frost cracks in Sugar Maple, 110.

Frost. Injuries from, 108.

Frost-hardy trees, 108.

Frost-tender trees, 108.

Fruit, 16.

Fuel woods of Minnesota, 170 value of woods, 170 .

values, table of, 172 .

Futgi in wood, 175 .

Fungus, shelf, (175), 175.

Fungus diseases, 112, 175.

Gathering seeds, 75 .

Germination of seeds, 75 .

Girdling by mice, 105.

Glauber salts, 167.

Gleditsia, 328 .

triacanthos, (330), 329 .

Glossary, 378. 
Glossyleaf iwillow, (258), 257.

Golden Arborvila, 164.

Goldenleaf Cotton wood, 269.

Golden Willow-Common, 255.

- Russian, 256.

Gophers, 113.

Government supervision of forests in Germany, 190.

Grades of nursery stock, 98.

Graftage, 90.

Gray Birch, 278.

Gray Pine, 205.

Green Ash, 361.

Green Ash seedlings, Bunch of, 92 .

Grindstone, 152.

Group method, 64 .

Grove, 47 .

Growing stock of a forest, $13 \%$.

Growth of trees an index to value of land, 23.

Growth on muskegs, 23.

Gymnoc1adus, 391.

canadensis, 331 .

dioicus, (332), 331.

Hackberry, (307), 306.

Hack matack, 214.

Hail storms, Forest influences on, 42 .

Hairy Baltn of Gilead, 264.

Hand ax, 152.

Hard Maple, 386.

Hardy Catalpa, 364.

Haw, Dotted, (320), 319.

Heartwood, 12.

Coloration, 12.

Heaving out by frost, 10 .

Heavy-rooded Pine, 20\%.

Heeling-in, 97 .

Height accretion, 133.

Height classes, 137.

Heights of one-year-old seedlings, Table of, 83.

Hemlock, 224.

Hicoria, 242.

minima, (244), 245.

ovata, 243.

Hickory-Bitternut, (244), 245.

- shagbark, 243.

- Shellbark, 243.

- Swamp, 245.

Hinckley fire, 114, 122.

HipPOCASTANACEA, 348.
Honey Iocust, (330), 329.

HoNEYSUCKLE FAMILY, 366.

Hoop Ash, 362.

Hop Hornbeam, 282.

Hornbeam, (283) 282.

Hornbeam, 284.

Horse Chestnut, 349.

Hot winds, 45.

Hypsometer, (149-150), 148.

Impreguation of Beech wood, 180.

Improvement cuttings, 71 .

Improvement of land in forests, 42.

Improving the woodlot, 72.

Inarching, 90.

Income from forests, 187.

Income from game preserves, 189.

Increasing value of forests, 187 .

Influence of forests, 28.

Injury from late spring frosts, 108.

Injuries to trees, 104.

Insects, Injuries from, 104.

Instruments used in forest mensuration, 147-152.

Interception of rainfali, 33 .

Interception of water in forests, 33.

Intolerant, 2.2.

Investments in timber, 128.

Investments, Profits from, 128.

Iowa Crab, (313), 312.

Iron railroad ties, 180 .

Ironzeood, 282.

Jack Pine, (206), 205.

Jack Pine, Stand of, 137 .

Jacob staff, 149.

Joinery, 166.

JUGLANDACEAE, 237.

Juglans, 237.

cinerea, (241), 240.

nigra, (239), 238.

Junebery, 317.

- Drwarf, 318.

Juniper-Common, 235.

- Dwirf, (235), 235.

- Red, 166.

- Trailing, 235

Juniperus, 233.

communis, (235), 285.

virginiana, (284), 233.

Kentucky Coffeetree, 331.

Kerf, 146. 
King's experiments with windbreaks, $36,37$.

Kuisely's experiments on evaporation from trees in winter, 19.

Kyanizing process, 181.

Land broken by dragging logs, 33 .

Latch-American, 214.

- European, (215), 216.

Largetooth Aspen, 262.

Iarix, 213.

americana, 214.

europea, 215.

occidentalis, 372.

Jaricina, 214 .

I, ate spring frosts, 108.

Laurelleaf Willow, $25 \%$.

I,aw, Fire, in Minnesota, 193.

Irayers, 89.

Leather board, 167 .

Ieaves, 14 .

L,eaves on conifers, Time they remain on trees, 15.

LEGUMINOS.E, 328.

I.eve1, 147 .

Iice, 105 .

Iife history of mature tree, 126.

I,ight demanding trees, 21 .

Limber Pine, 202.

I,ime Whitewash, 179.

Linden-American, 353 .

- European, 3 ฮ̌6.

LINDEN FAMILY, 353.

Live fence posts, 160 .

I,og rule, 152 .

Location of buildings, 56 .

L,ocust, (334), 333.

- Black, 333.

- Comman, 383.

- Honey, (350), 329 .

- Yelloze, 333.

L,ombardy Poplar, 270.

Lumber industry in Minnesota, 185.

Maple-Ashleaf, 348.

- Cutleaf, 348.

- Hard, 336.

- Mountain, 345.

- Norway (339), 338.

- Red, (344), 343.

- Reitenbach, 340.

- Rock, 336.

- Scarlet, 343.
Maple-Schwedler, 340.

- Silver, (3t1), 340 .

- Silverleaf, 340

- Soft, 340.

- Striped, 346 .

- sugar, (3B5), 386.

- Swamp, 343.

- Tartarian, 346.

- White, 340.

- Wier's Cutleaf, 343.

MaPLE FAMILY, 335 .

Marking pins, 147.

Mass accretion, $139,140$.

Measurement of growing stock, 137 .

Measurement of logs and lumber, 144.

Measurement of single trees, 132 .

Mechanical condition of land in forests, 23.

Mechanical pulp, $16 \%$.

Men employed in lumbering indus-

tries, 185.

Methods of sawing, 168.

Mice, 105.

Mineral substances, 18.

Mining, 166.

Minnesota state forest reserves, 192.

Minnesota state forestry board, 193.

Miramichi fire, 121.

Mirror hypsometer, (150), 148.

Mixed plantings, 51.

Mixed plantings, List of trees for, 53.

Noose Elm, 303.

MToosewood, 346.

MoRACEA, 308.

Morus, 308.

alba tartarica, (310), 309 .

rubra, 308.

Mossy-Cup Oak, 298.

Mound planting, 68.

Mountain Ash, 312.

- American, 312.

- Eilderleaf, (315), 314.

- European, 316.

- Oakleaf, 317.

- Weeping, 317.

Mountain Maple, 345 .

Mountain Spruce, 221.

Mulberry-Red, 308.

- Russian, (310), 309.

- Tea's Weeping, 311.

MULBERRY FAMILY, 308. 
Mulching trees, 101.

Muskegs, Growth on, 23.

Nann verry, 366.

Napoleon Willow, 259.

Narrowleaf Cottonwood, 26 .

National parks, 191.

Negundo aceroides, 848.

Netlletree, 306.

Normal growing stock, 187.

Normal income, 187.

Northern Scrub-Pine, 205.

Northern slope, effect on growth, 26.

Norway Maple, (339), 338.

Norway Pine, 202.

Norway Pine crowded and opengrown, 129.

Norway Spruce, (223), 22:2.

Young growth in Germany, (190).

Notable forest fires, 121.

Miramichi, 121.

Peshtigo, 121.

Michigan, 121.

Hinckley, 122.

Nursery practice, 91.

Nursery, 91.

Soil and cultivation, 91.

Work and practice, 91.

Nursery stock, Grades of, 91.

Oak-Black, 289, 297.

- Bur (294), 293.

- Bur, White, 293.

- Mossy-Cup, 293.

- Red, (296), 295.

- Scarlet, (298), 297.

- White, (290), 289.

- Swamp, (292), 291.

OAK FAMILY, 286.

Oakleaf Mountain Ash, $31 \%$.

Odors of decaying wood, $17 \%$.

Ohio Buckeye, (350), 351 .

Oil paints, 179.

OLEACE.TE, 358.

OLEASTER FAMILY, 356 .

OLIVE FAMILY, 358.

Osier Willows, 247.

Ostrya, 28?.

virginiana, (283), 282.

Paper Birch, (275), 274.

Paper pulp, 167.

Paraboloid, 13\%.

Pasturing cattle in woodlands, 106.
PEA FAMILY, 328.

Peshtigo fire, 121.

Picea, 216.

$a l b a, 216$.

canadensis (217), 216.

engelmanni, 221.

excelsa, (223), 222.

young growth in Germany, (190).

mariana, (219), 218.

nigra, 218.

parryana, 221.

pungens, 221.

Peachleaf $U^{\prime i l l o z e}, 20 \overline{1}$.

Pigeon Cherry, 322.

Pin Cherry, 322.

PINACE A: 199.

Pine, 199.

- Austrian, (212), 211.

- Black, 211.

- Bull, 207.

- Dwarf, 211.

- Druarf Mountain, 211.

- Gray, 205.

- Heavy-Uooded, 207.

- Jack, (206), 205.

- I,imber, 202.

- Northern Scrub, 205.

- Norzay, 202.

- Red. (203), 202.

- Rock, (208), 207.

- Scotch, (210), 209.

- Western Yollow, 20\%.

- Western Whate, 202.

- Weymouth, 199.

- White, (200), 199.

Pine cuttings after being burned over, 67 .

PINE FAMILY, 199.

Pinus, 199.

banksiana, 205.

divaricata, (206), 205.

flexilis, 202.

laricio austriaca, (212), 211.

montana pumila, (213), 211.

mughus, 211.

ponderosa scopulorum, (208), 207.

resinosa, (203), 吕0?.

strobus, (200), 199.

sylvestris, $(210), 209$.

Pit, storing seeds in, 76 .

Plans for home grounds, 56 . 
Planting, Methods of, 54 .

Planting seedlings, Successive steps in, 96.

Planting to renew timber growth, 66. Plowrightia morbosa, 326 .

Plum, Wild, 321.

Pocket Gopher, 106.

Pocket Lens, 150.

Pollarding, 68.

Poplar-Aspen, (261), 260.

- Balm of Gilead, (263), 262.

- Black, 270.

- Bolle, 273.

- Certinensis, 273.

- Largetooth Aspen, 262.

— Iombardy, 270.

- Silverleaf, 271.

- Snowy, zrrl.

- White, (272), 270.

Poplar, 260.

Popple, 260.

Populus, 259.

alba, (27:), 270 .

alba bolleana, 273 .

alba canescens, 273.

alba nivea, 271 .

angustifolia, 265 .

argentea, 271.

balsamifera, (263), 262.

balsamifera candicans, 264 .

balsamifera intermedia, 264 .

balsamifera latitolia, 264 .

balsamifera viminalis, 264.

certinensis, 273.

crispa, 264.

deltoides, (2067), 265 .

deltoides aurea, 269 .

dudleyi, 264 .

grandidenta, 262.

laurifolia, 273.

lawrifolia, 264.

lindleyana, 264.

nigra, 270 .

nigra italica, 270.

nolesti, 265.

pyramidalis suaveolens, 264.

salicifolia, 264.

siberica pyramidalis, 264.

tremuloides, (261), 260 .

van gertii, 269 .

wobsky, 265 .
Possibilities of yield of our forest area, 185.

Prairie planting, 47.

Prairies, Why treeless, 43.

Pressler's tables of relative diameters, 141.

Price of fuel, 184.

Printing paper, $16 \%$.

Profits from timber, 128.

Propagation, 73.

by division, 73 .

Protection from windbreaks, 41 .

Protection to buildings, 48 .

Protection to crops by windbreaks, 48 .

Pruning, 97.

Directions for, 98.

of forest trees, 69 .

Purpose of, 97.

Time for, 98.

Prunus, 32t.

americana, $3: 1$.

demissa, 398 .

pennsylvanica, (323), 322.

nigra, 821.

serotina (325), 3:24.

virginiatla, (321), $3: 6$.

Pseudotsuga, 225. douglasii, 225 .

taxifolia, (226), 225.

Pyramidal Arborvite, 23:

Pyrus, 311.

americana, 312 .

aucuparia, $\mathbf{8 1 6}$.

aucuparia pendula, $31 \%$.

coronaria, 312 .

hybrida, 317 .

ioensis, (313), 312 .

sambucifolia, (315), 314.

Quaking Aspen, 260.

Quarter-sawing, 168.

Quercus, 288.

alba, (290), 289.

coccinea, (298), 297.

macrocarpa, (294), 298.

platanoides, (1992), 291.

rubra, (296), 295.

suber, 289.

velutina, $29 \%$.

Rabbits, Injuries from, 105.

Rainfa11, height of water table in the lanı, 44. 
Raising coniferous trees, 81 .

Rate of growth, 125, 139, 150.

Rate of increase in timber, 125.

Red Ash, 360.

Red Birch, 277.

Red Cedar, 283.

Red Cherry, 322.

Red Elm, 303.

Red Fir, 225.

Red Juniper, (234), 233.

Red Maple, (344), 343.

Red Mulberry, 308.

Red Oak, (296), 29 .

Red Pine, (203), 202.

Regeneration, 62.

by artificial seeding, 65 .

by natura1 seeding, 62,66 .

by planting cuttings, 68 .

by planting seedlings, 66 .

by sprouts and suckers, 68.

Reitenbach Maple, 840.

Relation between trees and soils, 23 .

Reseeding, Natural, 66 .

Rest period of plants, 19.

RHAMNACEA, 351 .

Rhamnus, 351 .

catharticus, (352), 351 .

Ripening of wood, 19.

River Birch, 277.

Robinia, 333 .

pseudacacia, (334), 333.

Rock Elm, 301.

Rock Maple, 386.

Rack Pine, 207.

Root growth, Extent of, 13.

Root formation, (Figure 2), 13.

Roots, 12.

Roots on a forest grown Elm, 98.

RosACEE, 311.

Rose FAMILY, 311 .

Rotation, 69.

Rot in wood, 175.

Royal Willow, 256.

Rum Cherry, 324.

Run-off of Water, 41.

Russell's experiment, Effect of wind on evaporation, 34 .

Russian-Mulberry, (310), 309.

- Olive, (857), 356 .

SALICACE $2,246$.
Salix, 246 .

acutifolia, 257.

alba, (254), 253.

alba britzensis, 256 .

alba regalis, 256 .

alba vittellina, (255), 256 .

amygdaloides, (252), 251.

laurifolia, 257.

lucida, (258), 257.

napoleonis, 259.

nigra, (250), 251.

pentandra, 25\%.

purpurea, 249.

pendula, 259.

regalis, 257.

Sample acre, 137.

Sample tree, 140.

Sand dunes, 123.

Sapwood, 12.

Savin, 233.

Saw, 72.

Sawing, Methods of, 168.

Sawflies, Injuries from, 104.

Scaling, 144.

Scarlet-Maple, 343 .

- Oak, (298), 297.

Schwedler Maple, 340 .

Scotch Fir, 207.

Scotch Pine, $20 \%$.

Scratcher, 152.

Scribner's Rule, 145.

Scrub Pine, Northern, 205.

Second growth, 20.

Seed, The, 16.

Evergreen, bed, 81.

Seeding of timber lands, 66 .

Seeding trees, 66 .

Seedlings, 92.

Green Ash, 92.

variations, 75 .

Height of one-year-old, 83.

Seeds, 13.

Amount to use, 82 .

Classified, 77 .

Coniferous tree, $7 \%, 79$.

Covering, 82.

Distribution of, 16.

Dry, 78 .

Fleshy covered, 78 .

Gathering, 7ó.

Germination of, 75 . 
Seeds, Leguminous tree, 79, 86 .

Nut, 79,86 .

Ripening in August, 78.

Ripeniug in spring and early summer, 77.

Sources of, 78 .

Sowing, 82 .

Stratification of, 76 .

Variations from, 75 .

Seed variations, 75 .

seed years, 63 .

Selection method, 63 .

Serviceberry, 817.

Servicetree-I, ongleaf, 318 . - Western, 318.

Servicetree, 317 .

Shade-enduring trees, 22.

Shagbark Hickory, 243.

Shapes of trees, 16.

Sheepberry, (367), 366.

Shellbark Fickory, 243.

Shelterbelt, 47.

Shelterbelts, Plans of, 57.

Shining Willow, 257.

Shipbullding, 166.

Siberian Arborvitæe, 932.

Silver Fir, 229.

Silver Grain, 168.

Silverleaf Maple, 340.

Silver Maple, (341), 340 .

Silverleaf Poplar, 271.

Silver Poplar, 273.

Silver Spruce, 221.

Size of trees, 54 .

Sleet storms, Injuries from, 108.

Sleet storm, Trees after, 109.

Slippery E/m, (304), 308.

Slope, Effect on growth, 26.

Snow crust, Injuries from, 110.

Snowy Poplar, 271.

Soft Maple, 340.

Soft Maple, pruned and unpruned, 102.

Soil conditions, 22.

Soil, Improvement of, in woodlands, 18.

Soils, Alkali, 25.

Soils, Washing of, 24 .

Solat pit, 89.

Sources of seeds, 73.

Southern slope, effect on growth, 26.
Sowing seed, 82.

Specific gravities, 'Table of, 170 .

Spring frosts, Injuries from, 108.

Spring growth of wood, 18.

Spruce--Black, (219), 218.

- Blate, 221.

- Colorado B1ue, 221.

- Double, 218.

- Douglas, (226), 225.

- Engelmann, 221.

-- Norway, (223), 222.

- Silver, 221.

- White, (217), 216.

- White, $22 \mathrm{~L}$.

State bounty for tree planting, 194.

Steel chain, 147.

Steel tape, 147.

Storing seeds, 78 .

Straightening streams with willows,

162.

Stratification, 76 .

Street trees, 92.

Distance apart, 100.

Kinds to plant, 100.

Mulching, 101.

Planting, 101.

Protection, 108.

Pruning, 102.

Setting, 101.

Success with, 100.

Watering, 102.

Strip method, 63 .

Subsoil, 24.

Succession of tree growth, 60 .

Sugarberry, 306.

Sulphite process, 180.

Sunscald, 112.

Small dead twigs a protection against, 70 .

Sunscalder Soft Maple and Basswood, (111), 111.

Surveyor general of logs and lumber, 144.

Suscutanberry, 318.

Sroamp Ash, 362.

Sruamp Hickory, 245.

Swamp Maple, 343.

Sweet Birch, 278 .

Tables-

Areas of circles, 136.

Diameter growth, 143. 


\section{Tables-}

Durability of fence posts, 175 .

Height growth, 83.

- Height of one-year-old seedlings, 83 . Length of time leaves of conifers ate persistent, 15.

Percentage of the logs, 146

Pressler's relative diameters, 141 .

Scribner's Rule, 145.

Specific gravities and fuel values, 170.

Transpiration, 17.

Tacamahac, 262.

Tallyboard, 147.

Tallyman, 147.

Tamarack, 214.

Tangential sawing, 168.

Tartarian Maple, 346.

Taxes on timber lands, 189.

Tendency to perpetuate qualities, 74 .

Tensile strength of wood compared with iron, 164.

Tent caterpillars, 104.

Thinning, 55,70 .

Threethorn Acacia, 329.

'Through and through sawing, 168.

Thuja, 230.

occidentalis, (231), 230.

occidentalis aurea, 233.

occidentalis fastigiata, 232.

occidentalis pyramidalis, 282 .

occidentalis wareana, 239 .

occidentalis sibirica, 232.

Tilia, 353 .

americana, (354), 353 .

platyphyllos, 356 .

vulgaris, 356 .

Tiliacere, 853 .

Timber famine, Possibility of a, in Minnesota, 184.

Timber lands, Management of, 186.

Timber lands, Taxes on, 189.

Toadstool root fungus, 112.

Tolerant, 22.

Trailing Juniper, 225.

Transit, 147 .

Transpiration, 17, 38.

Transplanting, 92 .

evergreens, 94 .

Time of, 94.

Transplants, 92.
Treatment of crooked trees, 99.

Tree, The, 11.

Tree claim, A good, (Figure 4), 52.

Iree growth, 17.

Trees grown from seeds, 73 .

Tree growt h affected by light condi tions, 21.

Influences of a, 28.

Tree planting, 17 .

Tree planting on prairies, 47.

Trtes for mixed plantings, List of, 53 .

Trees protect one another, 22.

Shape of, 16.

Triangulation, 132.

Tsuga, 224.

canadensis, 224.

ULMACE $2,299$.

U1mus, 299.

americana, (300), $2 \mathrm{c}$.

fulva, 30 s.

pubescens, (304), 303.

racemosa, (302), 301 .

Undergrowth in forests, 24.

Unproductive forest land, 188.

Uses of wood, 164.

Value of forest industries of Minnesota, 185.

Variations 1 rom seeds, 75 .

Viburnum, 366 .

lentago, (367), 366.

Virgin forest, (Figure 7), 61.

Volume of standing tree, 132.

Volume of standing timber, $13 \%$.

Volume of felled tree, 134.

Walnut, Black, (239), 238.

WALNUT FAMILY, 237.

Washing of soils, 24.

Waste in forests. 71 .

Water, Amount transpired, 38.

U'ater Beech, 284.

Water capital, Circulating, 30.

Water capita1, Fixed, 30.

Water discharged by Rhone, 30 .

Water, Distribution of, 31.

It ater EIM, 299.

Water last by trees in winter, Amount, 19.

Water supplies, Forest influences on, 29.

Water supply in soils, 22.

Water table in land, Height of, 44 
Weeping Birch, Cutleaf, $27 \%$.

Weeping Mountaill Ash, 317.

Western Catalpa, 364.

Western Crab, 312.

Western Larch, 372.

Western slope, Effect on growth, 27.

Western White Pine, 202.

Western Yellow Pine, 207.

Weymouth Pine, 199.

Whetstone, 152 .

White Ash, (359), 358.

White Birch, 274 .

White Cedar, 230.

White Elm, (3C0), 299.

White Fir, 229.

White Maple, 340 .

White Oak, (290), 289.

White Pine, (200), 199.

Crowded and then open grown, (127), 127.

Largest cut in Minnesota, 125.

Largest yield in Minnesota, 125.

Open grown, (128), 127.

White Western, 202.

White Poplar, (272), 2i1.

White Spruce, $(217), 216$.

White Spruce, 2:1.

Whitewash, 179.

White Willow, (254), 253.

White Wood, $35 ̄ 3$.

Why praities are treeless, 43.

Wier's Cutleaf Maple, 843.

Wild Black Cherry, 324.

U ila Crab, 312.

Wild Plum, 321.

Wild Red Cherry, (323), 322.

Willow-Almondleaf, (252), 251.

- Black, (250), 251.

- Common Golden, 255.

- Glossyleaf, $25 \%$.

- Laurelleaf, 257.

- Napoleon, 259.

- New American Weeping, 259.

- Osier, 247.
Willow-Peachleaf, 251.

- Royal, 256.

- Russian Golden, 256.

- Shining, 257.

-White, (254), 253.

- Wisconsin Weeping, (251), 249.

WILLOW FAMILY, 246 .

Willow for fuel, 130.

Willow, Rate of increase, 130.

Windbreaking power of forests, 35 .

Windbreaks of White Willow, 50 .

Windbreak, White Willow, Injured by saw.fly, 104.

Windbreaks, 47.

Height of, 49 .

Irocation of, 48 .

Protection to crops, 48.

Trees for, 49.

Wind injuries, 110 .

Winds, Hot, 37-45.

Wind storms, Forest infiuences on, 42.

Wintering acorns and other nuts, 76 .

Winter injuries, $10 \%$.

Wisconsin Weeping Willow, 249.

Wood and its uses, 164.

Wood, Durability of, 175.

Woodenware, 166.

Woodlot, 72.

Wood pulp and distillation products, $16 \pi$.

Wood structure, 168 .

Wood working industries of Minnesota, 185.

Working plan, 143.

Woody stem cross section, 11 .

Yearly round of life in a tree, 18.

Yellow Birch, (279), 278.

Yellow Cotion wood, 265.

- Locust, 333.

- Pine, Western, 202.

Young foliage eaten by stock, 106.

Young growth injured in logging, 69.

Zinc-tannin process, 182. 






(1) 24. Q6.

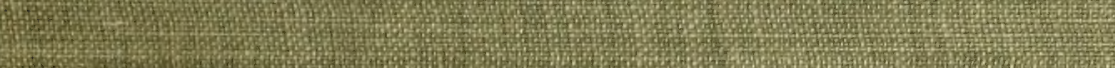
W. 2.

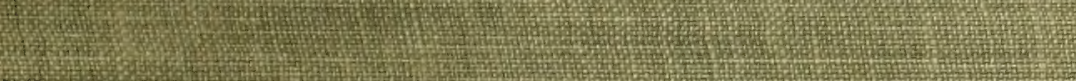
3. 10. W.1.20 (36) (1) 1.6. (1) (10.0. (5) H.

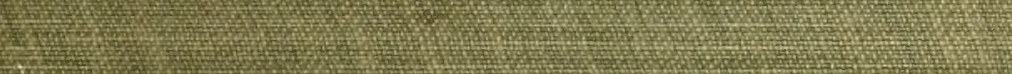

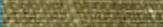
(1) (19) (3.) (x) (1)

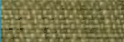
(17.0. (1)

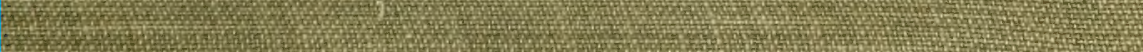
7. D. 3.1.5. 2. 